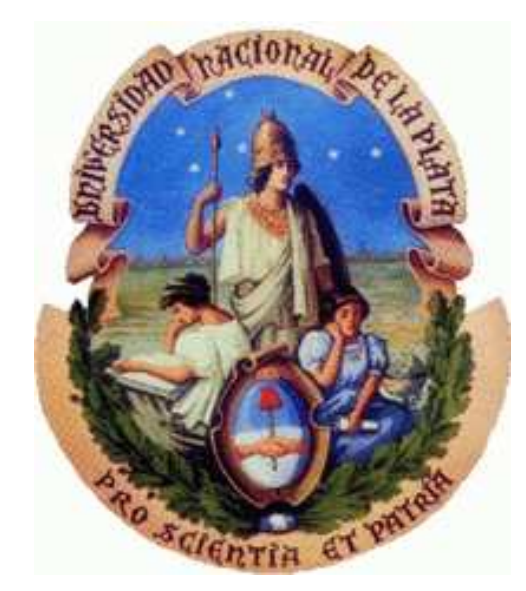

UNIVERSIDAD NACIONAL DE LA PLATA

Facultad de Ciencias Exactas

Departamento de Química

\title{
OBTENCIÓN TECNOLÓGICA DE MULLITA A PARTIR DE ARCILLAS Y CAOLINES REFRACTARIOS ARGENTINOS, Y ALÚMINA CALCINADA Ó ALÚMINAS HIDRATADAS.
}

\section{Tesis Doctoral}

Para optar por el grado de Doctora de la Facultad de Ciencias Exactas de La

Universidad Nacional de La Plata.

Ing. Angela X. Moreno Erazo

Director: Dr. Alberto N. Scian. 
A Dios,

A mis Papás

A mis Hermanos

A Sobrino y a mi Tía 


\section{AGRADECIMIENTOS}

En el transcurso de mi vida, siempre he conocido personas que contribuyen positivamente a mi formación profesional y como persona, algunas de ellas se irán, otras se quedarán para apoyarme, guiarme, y brindarme su buena energía, su amistad, y su amor, por esa razón quiero agradecer a las siguientes personas:

Primero que todo se lo debo a Dios y a la Virgen Santísima por darme fuerzas, sabiduría, y paz, para alcanzar este logro.

Agradezco a mi familia que es el motor de mi vida, en especial a mis padres Angel Moreno y Myriam Erazo que siempre han estado brindándome su amor, su energía y apoyo incondicional. A mis hermanos, mi sobrino y tía que siempre han estado presentes motivándome y colaborándome, en esta etapa que hoy culmina.

A mi Director, Dr. Alberto Scian por darme la oportunidad de pertenecer al CETMIC, por su confianza y por dedicar parte de su tiempo e intelecto, en brindarme sus orientaciones.

Al Dr. Jorge Rodríguez, por su valiosa amistad y por confiar siempre en mí.

A Lic. Susana Conconi, por su apoyo y su ayuda con Rietveld.

Al CONICET, por las becas y el apoyo financiero.

A todas las personas que hacen parte del CETMIC, por abrirme sus puertas y permitirme hacer uso de todos sus recursos tanto de laboratorio, como computacionales, bibliográficos y por su puesto su personal humano que contribuyó a que mi estadía fuera más grata. No quiero mencionar a nadie en especial, porque cada uno aporto un granito de arena para construir y adquirir este logro. De todo corazón gracias totales, los voy a recordar siempre y espero volverlos a ver. 
A la familia Mato Varano, por abrirme la puerta de su hogar y acogerme como una hija más, gracias a Antonia por ser mi madre Argentina, por sus regaños, enseñanzas y amor, a Pochito (QEPD), por enseñarme las principales bases de vivir lejos de mi tierra y a querer a este hermoso país. Los quiero tanto y siempre estarán en mis oraciones y en mi corazón.

Gracias amigos por apoyarme siempre, por tantos instantes de risa, rumba, y buenos momentos, por sus sabios consejos, por aguantarme mis altos y bajos estados de ánimo, por su amistad incondicional, durante el transcurso de esta etapa de mi vida, especialmente a Lorena, Fabián, Jesica S., Angélica, Andrés, Mally, Alejandra, Alexander, David, Jackeline y Fredy que estuvieron presentes apoyándome sin dejarme desfallecer. Gracias Lorena por ser mi amiga y hermana, por aguantarme tanto, por su compañía y apoyo incondicional. Gracias Fabián por tus concejos, compañía y apoyo.

Gracias a Emerita por estar siempre pendiente de mí y a Juan David por su amor, paciencia, confianza, por brindarme siempre toda su buena energía y por alegrar mis días.

Con cariño, 


\section{RESUMEN}

En el presente trabajo de investigación se busca mostrar la posibilidad de producir mullita de alta calidad en Argentina, utilizando materias primas nacionales y comodities internacionales con el objetivo de obtener un material confiable, de excelentes propiedades en el uso y con un costo razonable para ser incorporada en la producción de refractarios.

El estudio de la obtención tecnológica de mullita a partir de arcillas y caolines refractarios argentinos, y alúmina calcinada ó alúminas hidratadas, se realizó partiendo de los ensayos de caracterización de las materias primas utilizadas (arcillas, caolines, alúmina calcinada y un hidrato de alúmina), los cuales fueron analizados desde el punto de vista físico-químico, continuó con el estudio de las mezclas (arcilla/caolín con alúmina calcinada/hidratada) en proporciones de estequiometría $3 \mathrm{Al}_{2} \mathrm{O}_{3} \cdot 2 \mathrm{SiO}_{2}$ caracterizadas fisicoquímicamente. Posteriormente se realizó un seguimiento a las transformaciones físicoquímicas, termomecánicas y minerológicas llevadas a cabo durante su calcinación a alta temperatura y su estudio cinético.

Este último definió la temperatura y tiempo de calcinación a aplicar al proceso final. A posteriori se realizó el conformado de probetas por tres métodos, prensado (a tres presiones distintas), colado y extrusión. Se calcinaron probetas a la temperatura y tiempo definidas en la etapa anterior, caracterizándose fisicoquímica y termomecánicamente.

Se establecieron parámetros de semejanza entre las propiedades de las probetas obtenidas por colado ó extrudado, con aquellas provenientes de las prensadas a distintas presiones con el objeto de poseer herramientas científico técnicas en el caso de una producción industrial que permitan decidir un tipo de operación u otro según la disponibilidad de instalaciones de una empresa adoptante; siempre vinculado al tipo de propiedades finales deseadas.

Por último en base a los ensayos de caracterización realizados se seleccionó el material obtenido por extrudado, y se efectuó una pequeña producción de mullita a escala con la cual se elaboraron prototipos de refractarios mulliticos, comparándose sus propiedades mecánicas con otros elaborados de igual forma pero con materia prima importada (mullita comercial). 


\section{OBJETIVOS}

\section{OBJETIVO GENERAL}

$>$ El objetivo general de esta investigación es la obtención tecnológica de mullita sintética de alta gama utilizando mezclas de materias primas nacionales de disponibilidad industrial (arcillas y caolines), y de alúmina e hidratos de aluminio que son comodities internacionales obtenibles en el MERCOSUR (Brasil); además de determinar las mejores condiciones de conformado, temperatura y tiempo de calcinación.

\section{OBJETIVOS ESPECÍFICOS}

$>\quad$ Realizar la caracterización físico-químicas de arcillas y/o caolines de origen nacional (Argentina) provenientes de diferentes regiones y seleccionar las más aptas en calidad y disponibilidad para obtener mullita sintética $\left(3 \mathrm{Al}_{2} \mathrm{O}_{3} \cdot 2 \mathrm{SiO}_{2}\right)$. Caracterizar además dos fuentes de alúmina (una alúmina calcinada y un hidrato de aluminio) provenientes del MERCOSUR

$>\quad$ Confeccionar mezclas con estequiometria $3 \mathrm{Al}_{2} \mathrm{O}_{3} \cdot 2 \mathrm{SiO}_{2}$, combinando las mejores materias primas arcillosas de tipo caolinitico con las dos fuentes de alúmina y seleccionar las mejores mezclas para su posterior estudio.

$>\quad$ Evaluar el mejor método de cuantificación por difracción de rayos $\mathrm{X}$ de las fases cristalinas y amorfa presentes en la arcilla calcinada con mayor tenor de caolinita y en la mezcla de la misma con alúmina calcinada. Determinando por separado los porcentajes de mullita primaria, secundaria y neta, a diferentes temperaturas y tiempos de tratamiento.

Realizar un estudio cinético sobre la formación de mullita confeccionando curvas conversión - tiempo a distintas temperaturas y aplicar distintos modelos 
matemáticos al sistema para determinar los mecanismos ocurrentes en la reacción en estado sólido.

Realizar 4 mezclas combinando 2 arcillas y 2 alúminas pre-seleccionadas, las cuales serán sometidas a tres procesos distintos de conformado (prensado, colado y extrusión).

Determinar las propiedades fisicoquímicas y termomecánicas de las mullitas obtenidas de acuerdo a las distintas metodologías utilizadas en su síntesis de conformado (prensado a tres presiones, colado, extrudado), temperatura, tiempo y materias primas (arcilla y mezcla).

Comparar los resultados adquiridos en el ídem anterior y determinar a qué presión de prensado corresponderían las propiedades obtenidas por utilización de colado ó extrudado.

Seleccionar una mezcla Alúmina - Arcilla, con un tipo de conformado, una temperatura y un tiempo definido que posea las mejores propiedades como material refractario de potencial uso tecnológico, teniendo en cuenta disponibilidad y costo de las materias primas, además de métodos de conformado aplicable a grandes producciones.

Confeccionar y comparar las propiedades de dos hormigones refractarios de ultra-bajo cemento elaborados con granos de mullita, uno con mullita comercial y otro con la mullita experimental seleccionada (este estudio). 


\section{IV. ÍNDICE}

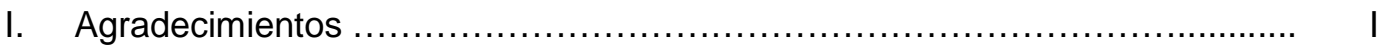

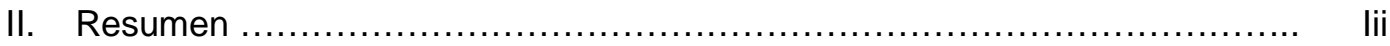

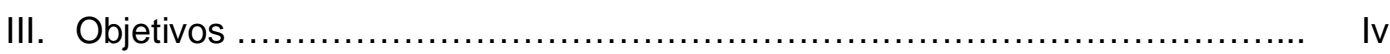

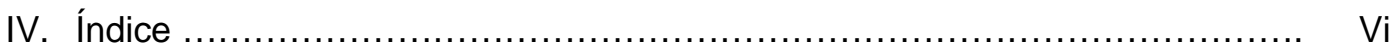

\section{CAPITULO 1}

INTRODUCCIÓN............................................................................. $\quad 1$

\section{CAPITULO 2}

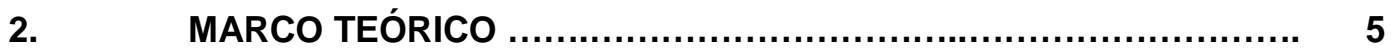

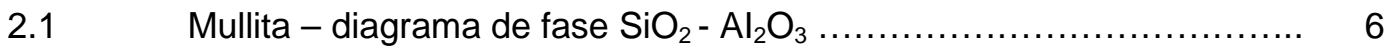

$2.2 \quad$ Propiedades de la mullita ......................................... 8

2.3 Métodos de preparación y/o usos de la mullita ........................... 12

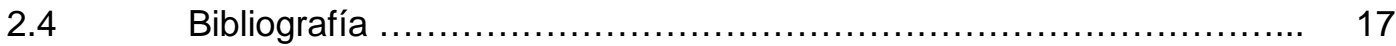

\section{CAPITULO 3}

3. TÉCNICAS DE CARACTERIZACIÓN........................................ 21

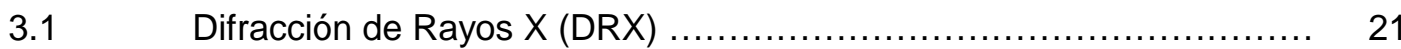

3.1.1 Identificación y/o cuantificación de fases cristalinas (análisis

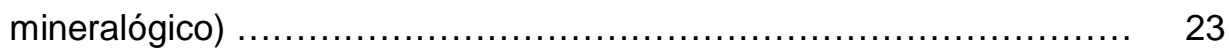

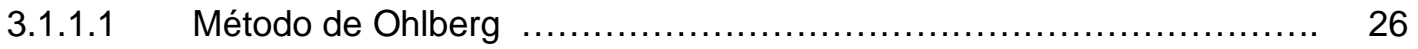

3.1.1.2 Modelo de Le Bail ............................................. 27

3.1.1.3 Método por comparación de área en el pico $\left(33.2^{\circ}\right.$ de $\left.2 \theta\right) \ldots \ldots \ldots \ldots \ldots . . . . .28$

3.2 Análisis Térmico Diferencial y Termogravimetrico (ATD/TG) ............ 29

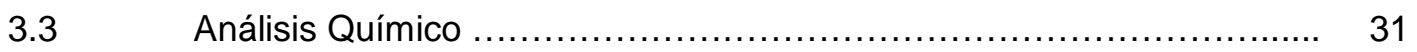

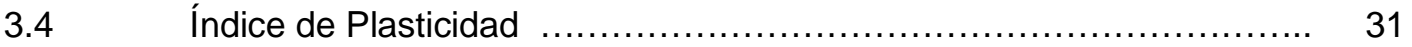




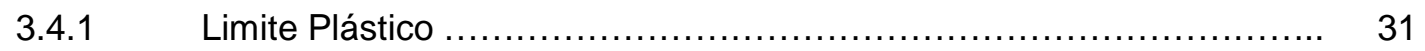

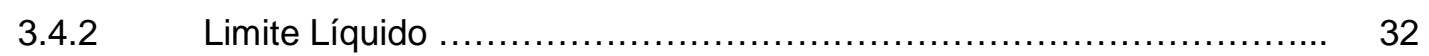

$3.5 \quad$ Cono Pirométrico Equivalente (CPE) .............................. 34

3.6 Volumen y Densidad Aparente en Agua, Porosidad Abierta y Densidad Aparente (Arquimedes) ............................................ 36

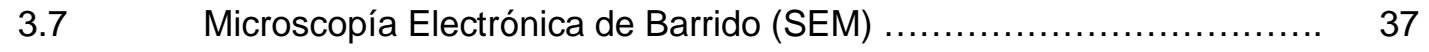

3.8 Dilatometría - Coeficiente medio de dilatación lineal ................... 40

3.9 Porosidad por Intrusión de Mercurio .................................. 41

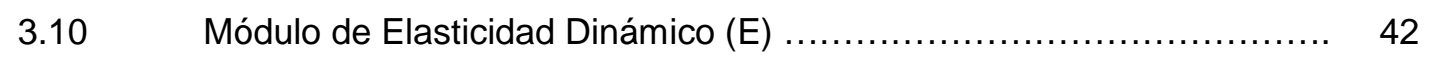

3.11 Resistencia a la Flexión en tres puntos (MOR) ......................... 43

3.12 Resistencia al Choque Térmico ................................... 45

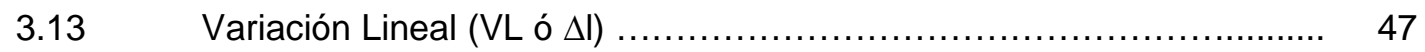

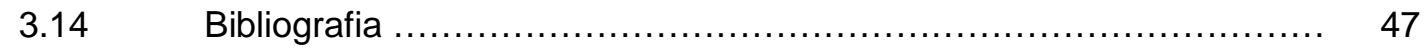

\section{CAPITULO 4}

4. CARACTERIZACIÓN Y SELECCIÓN DE MATERIAS PRIMAS ......... 52

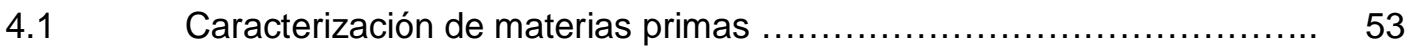

4.1.1 Arcilla/Caolin - Materias primas para la producción de mullita

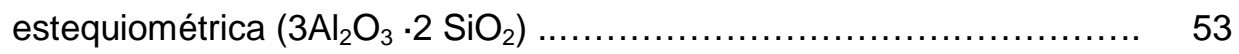

4.1.1.1 Análisis de Difracción de Rayos $X(\mathrm{DRX})$ para las materias primas arcillosas .......................................................... 54

4.1.1.2 Análisis de ATD / TG para las materias primas arcillosas ............... 56

4.1.1.3 Análisis Químico para las materias primas arcillosas ..................... 60

4.1.1.4 Análisis de índice de plasticidad, limite líquido y plástico, para las materias primas arcillosas ......................................... 61

4.1.1.5 Análisis de Cono Pirométrico Equivalente para las materias primas

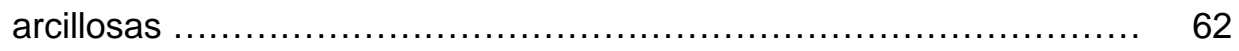

4.1.2 Alúminas - Materias primas para la producción de mullita

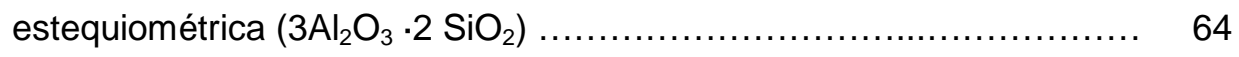

4.1.2.1 Análisis de DRX para las fuentes de alúmina .......................... 65

$4.2 \quad$ Mezclas Estequiometricas $3 \mathrm{Al}_{2} \mathrm{O}_{3} \cdot 2 \mathrm{SiO}_{2}$ (Arcilla - Alúmina) .............. 66

4.2.1 Análisis de DRX para las mezclas estequiométricas $3 \mathrm{Al}_{2} \mathrm{O}_{3} \cdot 2 \mathrm{SiO}_{2} \ldots \ldots \quad 67$

4.2.2 Análisis de las propiedades físicas y termomecánicas de las mezclas

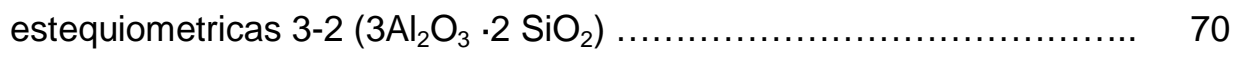


4.3 Selección final de las materias primas y formulación estequiométrica $3 \mathrm{Al}_{2} \mathrm{O}_{3} \cdot 2 \mathrm{SiO}_{2}$ (Arcilla - Alúmina) ................................ 73

Conclusiones Parciales ......................................... 74

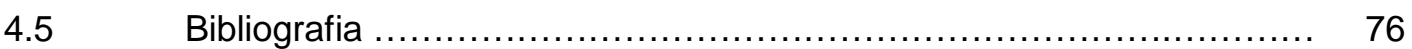

\section{CAPITULO 5}

5. GENERACION DE MULLITA PRIMARIA, NETA Y SECUNDARIA EN EL SISTEMA............................................................... 81

$5.1 \quad$ GENERACIÓN DE MULLITA PRIMARIA $\ldots \ldots \ldots \ldots \ldots \ldots \ldots \ldots \ldots \ldots \ldots \ldots \ldots \ldots \ldots \ldots$

5.1.1 Tratamiento térmico - Formación de mullita primaria (arcilla La Rioja)... 83

5.1.2 Difractogramas de arcilla La Rioja (mullita primaria) ..................... 83

5.1.3 Cuantificación del porcentaje de mullita primaria (arcilla La Rioja), por

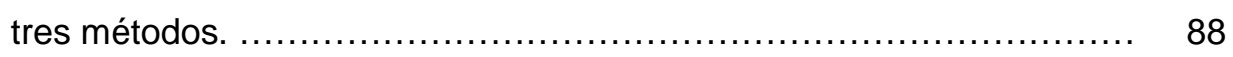

5.1.3.1 Método de Ohlberg - Cuantificación por Interpolación de fondos......... 89

5.1.3.2 Modelo de Le Bail - Arcilla (La Rioja) ..................................... 92

5.1.3.3 Método por comparación de área en el pico $\left(33.2^{\circ}\right.$ de $\left.2 \theta\right) \ldots \ldots \ldots \ldots \ldots . . . . . . .93$

5.1.4 Cuantificación de las fases presentes en la arcilla La Rioja, aplicando el método de Rietveld y el modelo de Le Bail ............................ 95

5.1.4.1 Resultados de la cuantificación de mullita primaria a $1300{ }^{\circ} \mathrm{C} \ldots \ldots \ldots \ldots . . . . .96$

5.1.4.2 Resultados de la cuantificación de mullita primaria a $1400^{\circ} \mathrm{C} \ldots \ldots \ldots . . . . .98$

5.1.4.3 Resultados de la cuantificación de mullita primaria a $1450{ }^{\circ} \mathrm{C} \ldots \ldots \ldots \ldots . . . .100$

5.1.4.4 Resultados de la cuantificación de mullita primaria a $1500{ }^{\circ} \mathrm{C} \ldots \ldots \ldots . . . .101$

5.1.4.5 Resultados de la cuantificación de mullita primaria a $1600{ }^{\circ} \mathrm{C} \ldots \ldots \ldots \ldots . . . .103$

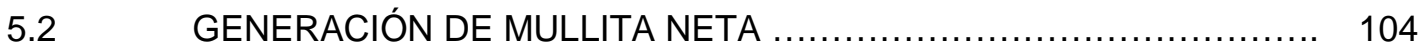

5.2.1 Tratamiento térmico - Formación de mullita neta (mezcla, Arcilla La Rioja más alúmina calcinada) ..................................... 104

5.2.2 Difractogramas de mezcla estequiométrica $3 \mathrm{Al}_{2} \mathrm{O}_{3} \cdot 2 \mathrm{SiO}_{2}$ (AriojAcal).. 105

5.2.3 Cuantificación del porcentaje de mullita neta (mezcla estequiometrica 3-2 de arcilla La Rioja más alúmina calcinada), por tres métodos ......... 109

5.2.3.1 Método de Ohlberg - Cuantificación por Interpolación de fondos mezcla estequiometrica 3-2 (AriojAcal) .............................. 110

5.2.3.2 Modelo de Le Bail - mezcla estequiometrica $3 \mathrm{Al}_{2} \mathrm{O}_{3} \cdot 2 \mathrm{SiO}_{2}$ (AriojAcal) 112

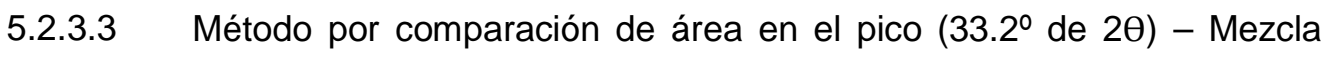
estequiométrica $3 \mathrm{Al}_{2} \mathrm{O}_{3} \cdot 2 \mathrm{SiO}_{2}($ arcilla - alúmina) $\ldots \ldots \ldots \ldots \ldots \ldots \ldots \ldots . \ldots \ldots$ 
5.2.4 Cuantificación de las fases presentes en la mezcla estequiométrica 32 (AriojAcal), aplicando el método de Rietveld y el modelo de Le Bail... 115

5.2.4.1 Resultados de la cuantificación de mullita neta a $1300{ }^{\circ} \mathrm{C} \ldots \ldots \ldots \ldots \ldots \ldots . . . . . .115$

5.2.4.2 Resultados de la cuantificación de mullita neta a $1400{ }^{\circ} \mathrm{C} \ldots \ldots \ldots \ldots \ldots . . . . . . .117$

5.2.4.3 Resultados de la cuantificación de mullita neta a $1450{ }^{\circ} \mathrm{C} \ldots \ldots \ldots \ldots \ldots . . . . . . .118$

5.2.4.4 Resultados de la cuantificación de mullita neta a $1500{ }^{\circ} \mathrm{C} \ldots \ldots \ldots \ldots \ldots . . . . . .120$

5.2.4.5 Resultados de la cuantificación de mullita neta a $1600{ }^{\circ} \mathrm{C} \ldots \ldots \ldots \ldots \ldots . . . . . . .121$

$5.3 \quad$ GENERACIÓN DE MULLITA SECUNDARIA ............................. 123

5.3.1 Tratamiento térmico - Formación de mullita secundaria (Mullita neta menos mullita primaria, calculada en base al valor obtenido con la arcilla La Rioja sola y su factor de dilución.) .............................. 123

$5.4 \quad$ Conclusiones Parciales ............................................ 127

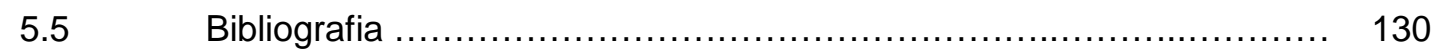

\section{CAPITULO 6}

6. ESTUDIO CINÉTICO - MODELAMIENTO MATEMÁTICO ............... 136

6.1 Curvas de conversión de mullita neta (AriojAcal) a diferentes temperaturas y tiempos ........................................ 137

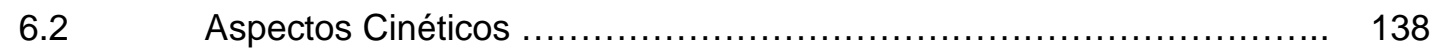

6.2.1 Modelos cinéticos - Control por procesos interfaciales ................ 139

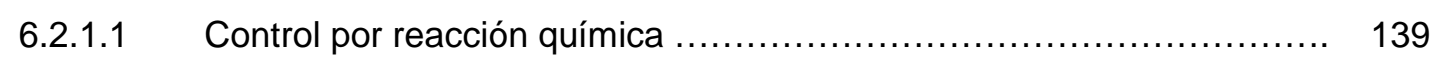

6.2.1.2 Control por nucleación y crecimiento cristalino ........................ 140

6.2.2 Modelos cinéticos - Control por procesos difusionales .................. 141

6.3 Aplicación de los modelos matemáticos a la mezcla estequiométrica $3 \mathrm{Al}_{2} \mathrm{O}_{3} \cdot 2 \mathrm{SiO}_{2}$ (AriojAcal) ...................................... 144

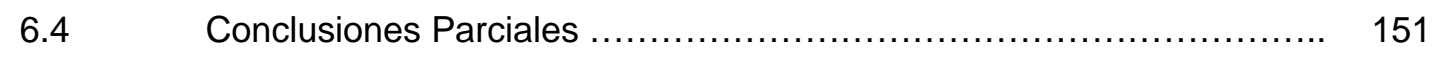

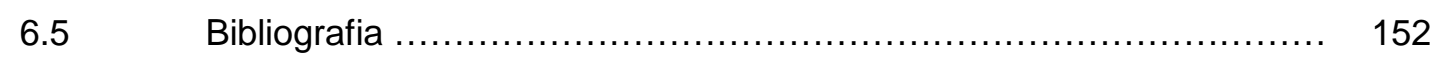

\section{CAPITULO 7}

7. CONFORMADO, TRATAMIENTO TÉRMICO Y CARACTERIZACIÓN DE MULLITA ESTEQUIOMETRICA 3-2 $\left(3 \mathrm{Al}_{2} \mathrm{O}_{3} \cdot 2 \mathrm{SiO}_{2}\right) \ldots \ldots \ldots \ldots \ldots \ldots$

7.1 Conformado por el método de prensado uniaxial ........................... 158

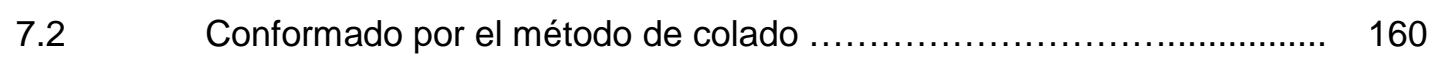


7.3 Conformado por el método de extrusión

7.4 Propiedades físicas y termomecánicas de mullita estequiométrica 3-2 $\left(3 \mathrm{Al}_{2} \mathrm{O}_{3} \cdot 2 \mathrm{SiO}_{2}\right)$ obtenida a partir de arcilla Tincar Súper más alúmina calcinada (AtinAcal) ó hidratada (AtinAhid), conformadas por los métodos de prensado, colado y extrudado.

7.4.1 Caracterización de la mezcla AtinAcal conformada por el método de prensado $(10,40$ y $100 \mathrm{MPa})$ y calcinadas a $1550 \stackrel{\circ}{\mathrm{C}}$ por 4 horas ...... 167

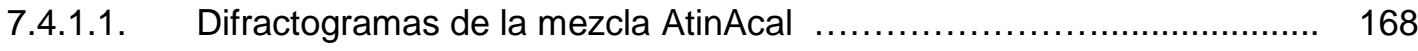

7.4.1.2. Propiedades físicas de la mezcla AtinAcal ................................ 169

7.4.1.3. Distribución de tamaño de poro por intrusión de mercurio de la mezcla AtinAcal

7.4.1.4. Microscopia electrónica de barrido de arcilla Tincar Súper y de la mezcla AtinAcal 173

7.4.1.4.1. Micrografía de la arcilla Tincar Súper (mullita primaria)

7.4.1.4.2. Micrografías de la mezcla AtinAcal [(mullita neta (primaria más secundaria)]

7.4.1.5. Propiedades termomecánicas de la mezcla AtinAcal

7.4.2. Caracterización física y termomecánica de la mezcla AtinAhid,

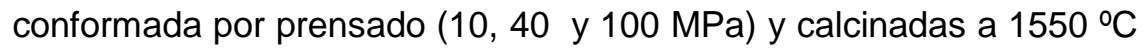
por 4 horas .

7.4.2.1. Difractogramas de la mezcla AtinAhid 181

7.4.2.2. Propiedades físicas de la mezcla AtinAhid 183

7.4.2.3 Distribución de tamaño de poro por intrusión de mercurio de la mezcla AtinAhid 185

7.4.2.4. Propiedades termomecánicas de la mezcla AtinAhid 187

7.4.3 Caracterización de la mezcla AtinAcal, conformada por el método de colado y calcinada a $1550{ }^{\circ} \mathrm{C}$ durante 4 horas. 190

7.4.3.1 Difractograma de la mezcla AtinAcal ...................................... 190

7.4.3.2 Propiedades físicas de la mezcla AtinAcal ........................... 191

7.4.3.3 Distribución de tamaño de poro por intrusión de mercurio de la mezcla AtinAcal.

7.4.3.4. Micrografías de la mezcla AtinAcal (mullita neta) ....................... 193

7.4.3.5. Propiedades termomecánicas de la mezcla AtinAcal .................... 195

7.4.4 Caracterización de la mezcla AtinAcal, conformada por el método de extrusión y calcinada a $1550 \stackrel{\circ}{\mathrm{C}}$ durante 4 horas ...................... 197

7.4.4.1 Difractograma de la mezcla AtinAcal ............................... 197 
7.4.4.2 Propiedades físicas de la mezcla AtinAcal

7.4.4.3 Distribución de tamaño de poro por intrusión de mercurio de la mezcla AtinAcal ......

7.4.4.4 Microscopia electrónica de barrido de la mezcla AtinAcal ................ 200

7.4.4.5 Propiedades termomecánicas de la mezcla AtinAcal ...................... 203

7.5 Propiedades físicas y termomecánicas de mullita estequiométrica 3-2 $\left(3 \mathrm{Al}_{2} \mathrm{O}_{3} \cdot 2 \mathrm{SiO}_{2}\right)$ obtenida a partir de arcilla La Rioja más alúmina calcinada (AriojAcal) ó hidratada (AriojAhid), conformadas por el método de prensado, colado y extrudado.

7.5.1 Caracterización de la mezcla AriojAcal, conformada por el método de prensado (10, 40 y $100 \mathrm{MPa})$ y calcinadas a $1550{ }^{\circ} \mathrm{C}$ durante 4 horas . 204

7.5.1.1 Difractogramas de la mezcla AriojAcal ..................................... 205

7.5.1.2 Propiedades físicas de la mezcla AriojAcal.............................. 206

7.5.1.3 Distribución de tamaño de poro por intrusión de mercurio de la mezcla AriojAcal .................................................................................

7.5.1.4 Microscopia electrónica de barrido de arcilla La Rioja y de la mezcla AriojAcal ..................................................................... 211

7.5.1.4.1 Micrografía de la arcilla La Rioja (mullita primaria) .......................... 211

7.5.1.4.2 Micrografías de la mezcla AriojAcal [mullita neta (primaria más secundaria)] 213

7.5.1.5 Propiedades termomecánicas de la mezcla AriojAcal ................... 216

7.5.2. Caracterización física y termomecánica de la AriojAhid y calcinadas a $1550{ }^{\circ} \mathrm{C}$ por 4 horas .................................................. 219

7.5.2.1. Difractogramas de la mezcla AriojAhid .................................. 219

7.5.2.2. Propiedades físicas de la mezcla AtinAhid ................................ 220

7.5.2.3 Distribución de tamaño de poro por intrusión de mercurio de la mezcla AriojAhid 223

7.5.2.4. Propiedades termomecánicas de la mezcla AriojAhid ..... 224

7.5.3 Caracterización de la mezcla AriojAcal, conformada por el método de colado y calcinada a $1550 \stackrel{\circ}{\mathrm{C}}$ durante 4 horas............................ 227

7.5.3.1 Difractograma de la mezcla AriojAcal ................................. 227

7.5.3.2 Propiedades físicas de la mezcla AriojAcal ............................ 228

7.5.3.3 Distribución de tamaño de poro por intrusión de mercurio de la mezcla AriojAcal 229

7.5.3.4. Micrografías de la mezcla AriojAcal (mullita neta) ....................... 230

7.5.3.5. Propiedades termomecánicas de la mezcla AriojAcal ................... 231 
7.5.4 Caracterización de la mezcla AriojAcal, conformada por el método de extrusión y calcinada a $1550{ }^{\circ} \mathrm{C}$ durante 4 horas ......................... 232

7.5.4.1 Difractograma de la mezcla AriojAcal ................................ 233

7.5.4.2 Propiedades físicas de la mezcla AriojAcal ............................... 234

7.5.4.3 Distribución de tamaño de poro por intrusión de mercurio de la mezcla AriojAcal .......................................................... 235

7.5.4.4 Microscopia electrónica de barrido de la mezcla AriojAcal ............... 236

7.5.4.5 Propiedades termomecánicas de la mezcla AriojAcal ................... 238

7.6 Caracterización por dilatometria de mullitas 3-2 obtenidas por distintos métodos de conformado de mezclas estequimetricas $3 \mathrm{Al}_{2} \mathrm{O}_{3} \cdot 2 \mathrm{SiO}_{2}$ de dos arcillas distintas más alúmina calcinada (AtinAcal y AriojAcal)...... 239

7.7 Conclusiones Parciales ......................................................... 242

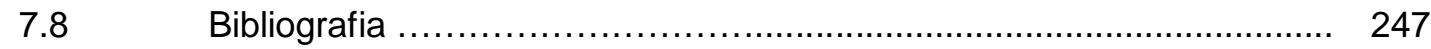

\section{CAPITULO 8}

8. ELABORACIÓN, CARACTERIZACIÓN Y COMPARACIÓN DE HORMIGONES REFRACTARIOS DE ULTRA BAJO CEMENTO UTILIZANDO COMO AGREGADOS GRANOS DE MULLITA (COMERCIAL Y EXPERIMENTAL)

8.1 Caracterización de una Mullita Comercial (MULCOA 70) ............... 258

8.1.1 Difractograma de la mullita comercial (Mulcoa 70) .................... 259

8.1.2. Propiedades físicas de la mullita comercial (Mulcoa 70) ................ 260

8.1.3 Micrografía de la mullita comercial (Mulcoa 70) ......................... 261

8.2 ELABORACIÓN DE DOS HORMIGONES REFRACTARIOS DE ULTRA BAJO CEMENTO, uno utilizando granos de mullita comercial (Mulcoa 70) y el otro con granos de mullita experimental (AtinAcal, $1550 \stackrel{\circ}{ } \mathrm{C}$ durante 4 horas)

8.2.2 Propiedades físicas de los hormigones refractarios de ultra bajo cemento (mullita comercial y experimental) .

8.2.3 Propiedades termomecánicas de los hormigones refractarios de ultra bajo cemento (mullita comercial y experimental) 267

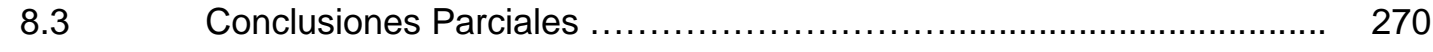

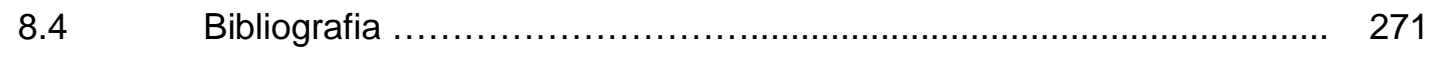




\section{CAPITULO 9}

CONCLUSIONES GENERALES

\section{APENDICE}

APENDICE I Tarjetas Cristalográficas de las Fases Cristalinas Presentes En Los Materiales Estudiados ..................................... 281

APENDICE II Índice de Siglas y Abreviaturas ................................ 285 


\section{CAPITULO 1 INTRODUCCIÓN}

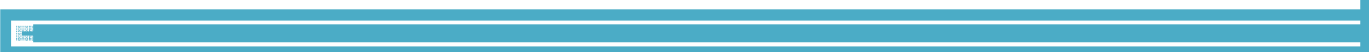

La mullita ha alcanzado una gran importancia como material cerámico tradicional así como también en el campo de los cerámicos avanzados, debido a sus favorables propiedades termomecánicas. Dicho material es un óxido cerámico silicoaluminoso el cual se puede presentar con varias relaciones $\mathrm{Al} / \mathrm{Si}$, ya que los óxidos de dichos elementos pueden formar soluciones sólidas en cierta región de su diagrama de fases: $\mathrm{Al}_{4+2 x} \mathrm{Si}_{2-2 x} \mathrm{O}_{10-x}$ con valores de $x$ entre 0.2 y 0.9 , aunque lo común es la ocurrencia del compuesto como $3 \mathrm{Al}_{2} \mathrm{O}_{3} \cdot 2 \mathrm{SiO}_{2}$ ó $2 \mathrm{Al}_{2} \mathrm{O}_{3} \cdot \mathrm{SiO}_{2}$ que corresponde a composiciones en masa de alúmina de $71,8 \%$ y $77,3 \%$ respectivamente.

La mayoría de los materiales refractarios silicoaluminosos poseen mullita en su composición aunque ésta no haya sido expresamente adicionada como tal en la formulación del material, sino formada por reacción de las materias primas durante el proceso de cocción de los mismos o cuando se encuentra en servicio; por esta razón el sistema $\mathrm{SiO}_{2}-\mathrm{Al}_{2} \mathrm{O}_{3}$ ha sido muy estudiado, tanto a partir de la ocurrencia en la cocción de arcillas y otros materiales silico aluminosos (rocas con mayor contenido de sílice que la mullita), como en la calcinación de bauxitas de distinta procedencia (rocas con menor contenido de sílice que la mullita). 
En la formación de Mullita y en general, de materiales refractarios, la microestructura depende de diversos factores, como: las características de las materias primas y su procesamiento, la naturaleza y concentración de las impurezas, la temperatura de calcinación y el tiempo de procesamiento, la atmósfera del horno, la presión de los gases durante la calcinación, la distribución de las fases mineralógicas en el sistema inicial, entre otros.

En la actualidad se han desarrollado nuevas tecnologías para la obtención de este material. Por ejemplo el desarrollado a partir del método sol-gel, la síntesis hidrotermal, la pirólisis, la combustión de polvos cerámicos y la síntesis a partir de hidrogeles son métodos afines de obtención de Mullita que tienen absoluta vigencia pero son costosos y para usos muy particulares, en tanto que en la producción de mullita sintética de alta pureza tanto sinterizada como electrofundida de uso masivo, la bibliografía es escasa o casi nula debido a que forma parte de los conocimientos de las empresas que las producen. Sin embargo, esta limitación ha propiciado a investigaciones y al desarrollo de procesos que utilicen materias primas regionales para lograr dicho objetivo. El desarrollo de nuevas tecnologías de síntesis ha permitido producir Mullita de alta pureza y homogeneidad, ubicándola en un lugar de privilegio para aplicaciones técnicas de alta temperatura y altas prestaciones termomécanicas requeridas por las nuevas cerámicas avanzadas.

La Mullita se caracteriza por tener excelentes propiedades, tales como: resistencia mecánica, altos módulos de ruptura, alta refractariedad y buena resistencia al choque térmico, resistencia a la abrasión mecánica y a la termoerosión (erosión por llama), resistencia al ataque de las escorias ácidas y básicas, metales fundidos y a la acción corrosiva de los gases, baja dilatación térmica a altas temperaturas, estabilidad química, estabilidad dimensional reflejada por su bajo coeficiente de expansión térmica, soportar altas temperaturas sin fundir o descomponerse y mediana conductividad térmica dentro de su clase. Su elevado punto de fusión - mayor que $1800{ }^{\circ} \mathrm{C}$, y sus buenas propiedades convirtieron a este material en el más versátil y noble en cuanto a usos para altas temperaturas dentro del sistema $\mathrm{SiO}_{2}-\mathrm{Al}_{2} \mathrm{O}_{3}$. Por lo tanto éste es el material refractario silicoaluminoso por excelencia que está presente en la mayoría de los materiales refractarios de uso tecnológico.

Teniendo en cuenta que los materiales refractarios constituyen un conjunto de productos intermedios indispensables, ya que sin ellos se detendría toda la actividad industrial en la que se dan condiciones de operación severas: ataque químico, tensiones mecánicas, 
etc. en las que, casi siempre se requiere la utilización de temperaturas elevadas, procesos como la cocción, la fusión, afinado de cualquier tipo de aleación, calcinación, clinkerización, así como otros, no pueden desarrollarse si los productos o los equipos de producción (Hornos) no están protegidos por materiales refractarios; estos por sus propiedades permiten controlar la emisión de calor ya sea resistiendo, conteniendo o aislando los cambios térmicos al tiempo que generan un ahorro de energía. Los principales sectores de aplicación de los materiales refractarios son la industria cerámica y del vidrio, siderúrgica, la industria del cemento, la petroquímica, metalurgia no ferrosa, y toda operación que requiera el manejo de altas temperaturas.

El método más conocido de preparación de mullita, es la descomposición térmica de la arcilla ó caolín a temperaturas superiores a los $1200^{\circ} \mathrm{C}$, pero en este caso junto a la mullita se genera sílice, la cual será amorfa o cristalina (cristobalita) según haya sido el origen de la arcilla ó caolín y el tratamiento térmico al que es sometido. Otros métodos son incorporando alúmina para alcanzar la estequiometría deseada, o también mezclando sílice con alúmina utilizando un tratamiento térmico apropiado. Aunque la mullita $\left(3 \mathrm{Al}_{2} \mathrm{O}_{3} \cdot 2 \mathrm{SiO}_{2}\right)$ ha sido estudiada durante años, constantemente se presentan nuevos retos para la obtención de este material variando sus materias primas y métodos de obtención, buscando así aprovechar los materiales encontrados en las diferentes regiones del mundo con las cuales se quieren obtener las mejores características y propiedades como son las descritas para la mullita de alta pureza.

Debido a la gran importancia y uso a nivel industrial, Argentina requiere importar Mullita porque no la produce en el país. Se intentó a principio de los 90 por parte de una empresa Argentina producir mullita con el apoyo técnico de investigadores del CETMIC (Centro de Tecnología de Recursos Minerales y Cerámica), pero en ese caso utilizando una bauxita brasilera como fuente de alúmina. Se llegó a obtener un material de mediana calidad dado el alto nivel de impurezas introducido mayoritariamente por la bauxita. Lamentablemente la crisis industrial en la que entró Argentina en esa década hizo que quebrara la empresa y el proyecto terminó.

Para producir mullita en Argentina, es necesario tener en cuenta que el país posee una cantidad y variedad de materiales silicoaluminosos como son las arcillas y/o caolines, pero Argentina no posee minerales bauxíticos ni produce alúmina por lo que debe importarse este comoditie (Brasil, China, USA, etc). Brasil, es nuestro socio del -3 - 
MERCOSUR, por lo que su disponibilidad está asegurada a precios de materia prima industrial internacional.

Ante esta problemática se decidió abordar en la investigación el desarrollo y factibilidad tecnológica para producir Mullita a partir de arcillas y caolines argentinos, los cuales serán mezclados con alúmina calcinada ó hidratos de aluminio, en proporciones de estequiometría tales que al ser calcinados a altas temperaturas se obtenga el material deseado. De igual forma se estudió la materia prima arcillosa (sola), con el fin de poder cuantificar y separar el porcentaje de mullita primaria procedente de la propia arcilla, y la mullita secundaria producida por la reacción entre alúmina calcinada y la sílice excedente de la arcilla al descomponerse térmicamente, modelizando cinéticamente el proceso de mullitización secundaria. Se abarca también la temática del procesamiento de las materias primas previo a la calcinación (prensado a distintas presiones, colado y extrusión), correlacionando las propiedades fisicoquímicas y termomecánicas obtenidas para establecer o no equivalencias entre los distintos procesos de preformado estudiados. 


\section{CAPITULO 2 MARCO TEORICO}

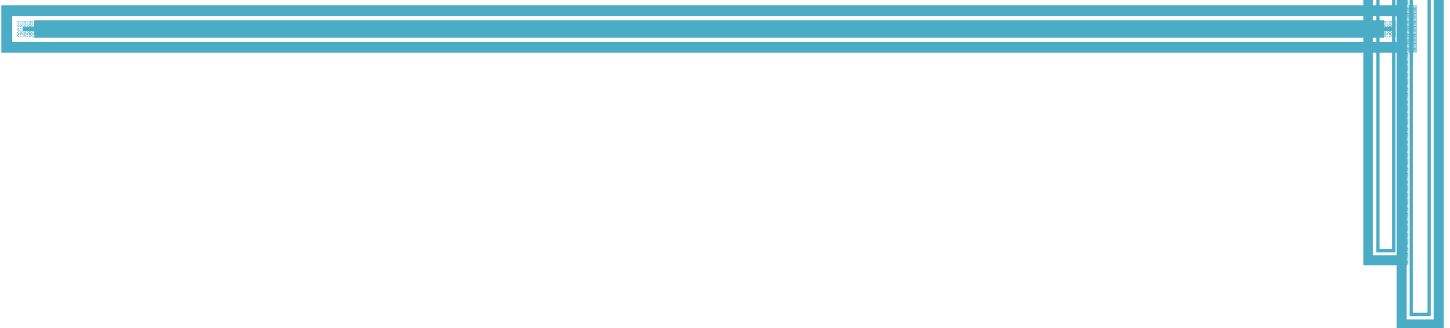

La mullita ha sido estudiada desde principios del siglo pasado después de que fue descubierta en la isla de Mull en Escocia, de ahí su nombre, en donde se ha formado en condiciones de presión y temperatura muy semejante a las que son necesarias para obtenerla artificialmente [Aksay et., 1981]. La mullita es parte de los compuestos denominados aluminosilicatos, [Tcheichvili y Butschkowskyi, 1975], considerándola como el silicoalúminato de mayor tenor de alúmina, seguido por el grupo de la Silimanita: Cianita, Silimanita y Andalucita, estos tres minerales tienen formas polimórficas del silicato de aluminio anhidro $\left(\mathrm{Al}_{2} \mathrm{SiO}_{5}\right)$ y se encuentran ampliamente en la naturaleza [Aksay et., 1981], aunque tienen igual composición química, y poseen diferente estructura, se forman mediante procesos de metamorfismo de las rocas sedimentarias con altos contenidos de alúmina a diferentes temperaturas y presiones, [Sainz et al.,1993; Tomba et al., 1994].

La mullita es la única fase cristalina estable en el sistema $\mathrm{SiO}_{2}-\mathrm{Al}_{2} \mathrm{O}_{3}$ a presión atmosférica normal y a altas temperaturas [Bowen y Greig, 1924; Sales y Alarcón], su composición química estequiométrica corresponde a $3 \mathrm{Al}_{2} \mathrm{O}_{3} \cdot 2 \mathrm{SiO}_{2}$ en casi la totalidad de 
los casos y cristaliza en el sistema ortorrómbico [Pask, 1989], presentando soluciones sólidas con contenidos de alúmina que varían según los diferentes autores.

A pesar de la cantidad de estudios realizados sobre la mullita, es aún tema de debate la naturaleza congruente o incongruente de su punto de fusión como la extensión de su rango de formación de soluciones sólidas [Pask, 1989; Chaudhuri, 1987].

Para aprovechar al máximo las condiciones de formación de la mullita en los productos cerámicos, y conocer las fases que presentan, es necesario conocer las reacciones que se forman en el sistema $\mathrm{SiO}_{2}-\mathrm{Al}_{2} \mathrm{O}_{3}$ al variar la temperatura, para ello existen varios estudios y análisis de diagramas de fases $\mathrm{SiO}_{2}-\mathrm{Al}_{2} \mathrm{O}_{3}$.

\subsection{MULLITA - DIAGRAMA DE FASE $\mathrm{SiO}_{2}-\mathrm{Al}_{2} \mathrm{O}_{3}$}

El primer diagrama $\mathrm{SiO}_{2}-\mathrm{Al}_{2} \mathrm{O}_{3}$ fue publicado por Bowen y Greig en 1924 donde la mullita se considera una fase estable [Bowen y Greig, 1924], indicando como punto de fusión de la cristobalita en $1725^{\circ} \mathrm{C}$; el de la $\alpha$-alúmina en $2040 \stackrel{\circ}{\circ}$ y el eutéctico a 1545

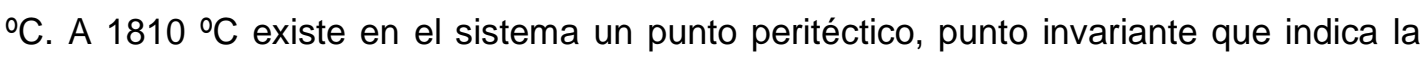
temperatura a la cual funde la fase mullita en fusión incongruente, dando lugar a corindón como nueva fase cristalina y a un líquido cuya composición no es inmediata entre la mullita y la alúmina sino que contiene $45 \%$ de $\mathrm{SiO}_{2}$ y $55 \%$ de $\mathrm{Al}_{2} \mathrm{O}_{3}$, lo cual equivale en peso a $23.4 \%$ de $\mathrm{SiO}_{2}$ y $76.6 \%$ de mullita de composición $3 \mathrm{Al}_{2} \mathrm{O}_{3} \cdot 2 \mathrm{SiO}_{2}$. El diagrama de Bowen y Greig fue aceptado en el mundo cerámico durante algún tiempo, pero trabajos posteriores modificaron ligeramente algunos puntos, donde la base principal de discusión es si la mullita funde congruentemente o incongruentemente [Bowen y Greig, 1924].

En 1953, Toropov y Galakhov publicaron un nuevo diagrama $\mathrm{SiO}_{2}-\mathrm{Al}_{2} \mathrm{O}_{3}$ donde llevaron a cabo la fusión de la mullita por calentamiento en vacío y establecieron un diagrama de fases del sistema $\mathrm{SiO}_{2}-\mathrm{Al}_{2} \mathrm{O}_{3}$ [Toropov y Galakhov, 1951], en el cual señalan un segundo punto eutéctico entre la mullita y el corindón, asegurando que la mullita funde congruentemente en el diagrama.

Aramaki y Roy en 1962 publican un nuevo diagrama mostrando los resultados de un extenso estudio en el sistema $\mathrm{SiO}_{2}-\mathrm{Al}_{2} \mathrm{O}_{3}$ [Aramaki y Roy, 1959; 1962]. Los autores parten de composiciones preparadas por mezcla de $\alpha-\mathrm{Al}_{2} \mathrm{O}_{3}$ y vidrio de sílice de alta 
pureza $(<0.2 \%$ de impurezas totales). A partir de los resultados obtenidos experimentalmente, determinan que la mullita funde congruentemente a $1850{ }^{\circ} \mathrm{C}$ y presenta un eutéctico con la alúmina localizada a $1840{ }^{\circ} \mathrm{C}$ y $78 \%$ en peso de $\mathrm{Al}_{2} \mathrm{O}_{3}$. Igualmente determinan que la mullita muestra un rango de solución sólida desde 71.8 al $74.3 \%$ en peso de $\mathrm{Al}_{2} \mathrm{O}_{3}$ [Aramaki y Roy, 1962; Berjeron y Risbud, 1994]. Dicha solución sólida se extiende hasta el $77.3 \%$ en peso de $\mathrm{Al}_{2} \mathrm{O}_{3}$ en condiciones metaestables. Es de resaltar que en sus experimentos a temperaturas hasta $1850{ }^{\circ} \mathrm{C}$, no encuentran el campo primario de la alúmina para composiciones con $71.8,74.5$ y $77.5 \%$ en peso de $\mathrm{Al}_{2} \mathrm{O}_{3}$, a pesar de que dicho óxido estaba presente en las mezclas de partida. Sin embargo, siempre encontraron presente una muy pequeña cantidad de vidrio, aun en composiciones con más del $71.8 \%$ en peso de $\mathrm{Al}_{2} \mathrm{O}_{3}$.

En 1975, Aksay y Pask extendieron el anterior estudio a temperaturas desde $1800{ }^{\circ} \mathrm{C}$ hasta 2000 C [Aksay y Pask, 1975], utilizando la m isma técnica experimental de pares de difusión [Davis y Pask,1972]. A partir de los datos obtenidos establecen un diagrama en condiciones de equilibrio que consideran estables con una línea de liquidus esencialmente igual a la de Bowen y Greig [Bowen y Greig, 1924]. En dicho diagrama la mullita presenta una fusión incongruente a la temperatura de $1828^{\circ} \mathrm{C}$, donde el líquido peritéctico en equilibrio con la alúmina coincide estrechamente con el valor dado por Bowen y Greig [Bowen y Greig, 1924]. Sin embargo, dichos autores [Aksay y Pask, 1975] no pudieron determinar la presencia de alúmina en equilibrio con un líquido, justificando esta ausencia de $\mathrm{Al}_{2} \mathrm{O}_{3}$ en las composiciones con relación de $\mathrm{Al}_{2} \mathrm{O}_{3} / \mathrm{SiO}_{2} \leq$ 3:2 es debido a la dificultad de nucleación de ésta en los vidrios de silicatos en los que no está inicialmente presente la $\mathrm{Al}_{2} \mathrm{O}_{3}$ y por la similitud entre las estructuras de los fundidos con elevado contenido de alúmina y de la mullita. Los experimentos que ponen de manifiesto que la mullita funde congruentemente han sido establecidos en condiciones de metaestabilidad [Aksay y Pask, 1975; Berjeron y Risbud, 1994].

Posteriormente en 1987, Klug, Prochazka y Doremus [Klug et al., 1987] abordan nuevamente el problema de la mullita estudiando la zona alta en alúmina de la región comprendida entre el 72 y el $76 \%$ en peso de $\mathrm{Al}_{2} \mathrm{O}_{3}$. Estos autores establecen la zona alta en alúmina del diagrama $\mathrm{SiO}_{2}-\mathrm{Al}_{2} \mathrm{O}_{3}$ a partir de los datos obtenidos. La mullita funde incongruentemente a $1890{ }^{\circ} \mathrm{C}$ con un peritéctic o entre 76.5 y $77 \%$ en peso de $\mathrm{Al}_{2} \mathrm{O}_{3}$. Poniendo de manifiesto que no encuentran dificultades para la nucleación de 
$\mathrm{Al}_{2} \mathrm{O}_{3}$ en composiciones con más del $75 \%$ en peso de ésta y a temperaturas por encima del punto invariante.

En el presente trabajo se utilizó el diagrama de fase de Aramki y Roy, donde el punto de fusión y formación de la fase mullíta se determinó como una recta en el diagrama $\mathrm{SiO}_{2}$ $\mathrm{Al}_{2} \mathrm{O}_{3}$ [Aramaki y Roy, 1962], figura 2.1.

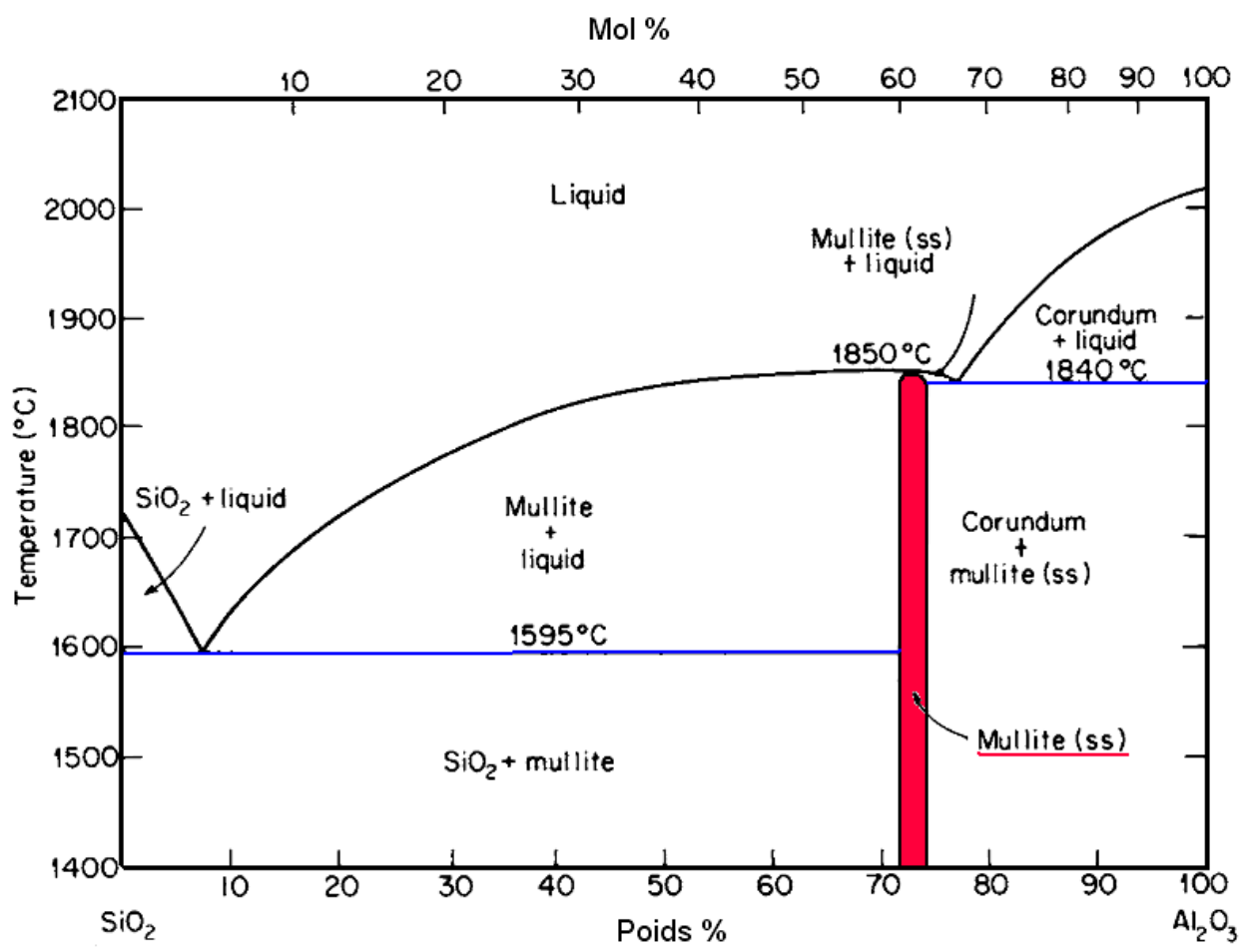

Figura 2.1. Diagrama de fases $\mathrm{SiO}_{2}-\mathrm{Al}_{2} \mathrm{O}_{3}$ [Aramaki y Roy, 1962].

\section{2}

PROPIEDADES DE LA MULLITA

La mullita se caracteriza por presentar buenas propiedades termomecánicas tales como: baja dilatación a altas temperaturas, estabilidad química, resistencia mecánica, resistencia al choque térmico que se relaciona con su coeficiente de dilatación y la forma de agujas entrecruzadas que adopta la mullita, resistencia a la abrasión mecánica y a la erosión por la llama, resistencia al ataque de las escorias y metales fundidos y a la acción corrosiva de los gases [Jain, 1998; Schneider, 1994]. La microestructura y 
microtextura de la mullita y en general de materiales refractarios, dependerá de factores tales como las características de las materias primas, la naturaleza y concentración de las impurezas, la temperatura de calcinación, el tiempo de procesamiento, la atmósfera del horno, la presión durante la calcinación y la distribución de las fases en el sistema inicial; también dependerá de los tratamientos que dicho sistema reciba hasta adquirir su estado final en forma de piezas, entre ellos: el tratamiento mecánico de molienda, el mezclado de los componentes y las condiciones del tratamiento térmico durante la cocción. [Jovani et al., 1979].

En la tabla 2.1 se presentan algunos valores de las propiedades características de la mullita. La simetría ortorrómbica y la estructura atómica, son probablemente las causas por las cuales la mullita presenta comúnmente una cristalización de forma acicular. Estas conductas estructurales parecen no estar relacionados con la composición en el rango 3:2 a 2:1, pero en cambio aparentan estar relacionados con el método utilizado en la producción [Skoog y Moore, 1988; Tcheichvili y.Butschkowskyi, 1975].

En la figura 2.2 se muestran micrografías (MEB) de mullita natural densa, donde se observan los granos aciculares [Ismail, 1987; Schneider, 2008].

Tabla 2.1. Propiedades generales de la Mullita [German, 1996; Schneider, 2008].

\begin{tabular}{|c|c|}
\hline MATERIAL & MULLITA \\
\hline Composición & $3 \mathrm{Al}_{2} \mathrm{O}_{3} \cdot 2 \mathrm{SiO}_{2}$ \\
\hline Sistema cristalino & Ortorrómbico \\
\hline Temperatura de fusión $\left({ }^{\circ} \mathrm{C}\right)$ & 1850 \\
\hline Densidad teórica $\left(\mathrm{g} / \mathrm{cm}^{3}\right)$ & 3.17 \\
\hline Peso atómico (g/mol) & 425.9 \\
\hline Coeficiente de expansión térmica $\left(\times 10^{-6} \mathrm{C}^{-1}\right)$ & $\sim 5.2$ \\
\hline 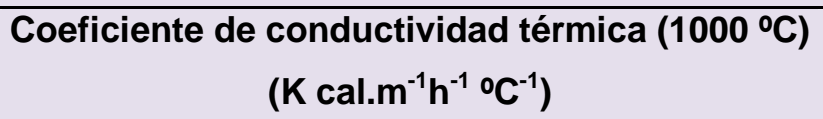 & 9 \\
\hline Resistencia a la compresión (MPa) & $\sim 200$ \\
\hline \% Elongación a falla & 0 \\
\hline
\end{tabular}




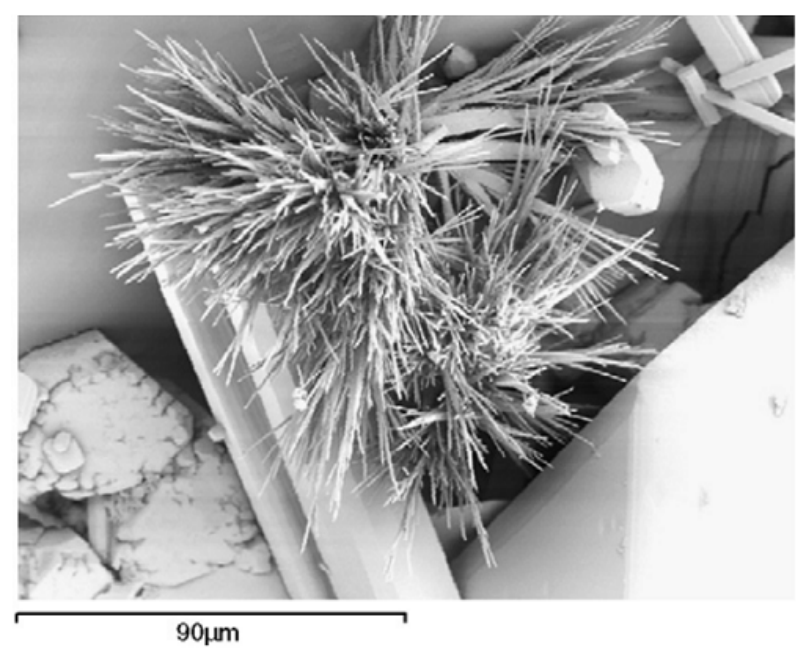

(a)
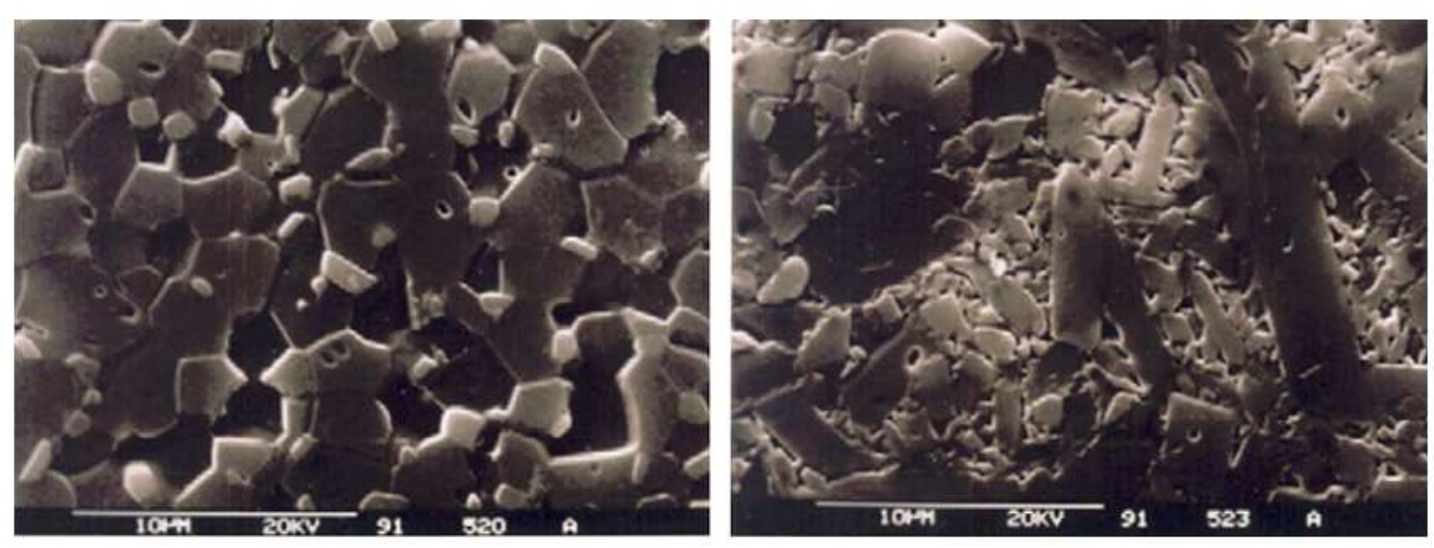

(b)

Figura 2.2. (a) Micrografía electrónica de una mullita natural encontrada en piedras volcánicas, (b) microestructura de un refractario a base de Mullita. [Rendtorf, 2009; Schneider, 2008].

La mullita es utilizada en diferentes aplicaciones, desde la cerámica tradicional, hasta la cerámica avanzada; se caracteriza por tener excelentes propiedades mecánicas como son: altos módulos de ruptura y resistencia a la compresión tanto en frío como en caliente, estabilidad química, estabilidad térmica, resistencia al choque térmico reflejada por su relativamente bajo coeficiente de expansión térmica, entre otros, [Aksay et al., 1991; Schneider et al., 2008].

La importancia de la elaboración de mullita y su aplicabilidad en materiales cerámicos y refractarios, está documentada por el gran número de publicaciones que aparecieron en los últimos años en la plataforma de búsqueda científica Science direct y Scopus 
[www.sciencedirect.com., www.scopus.com], la figura 2.3 evidencia lo anteriormente mencionado.

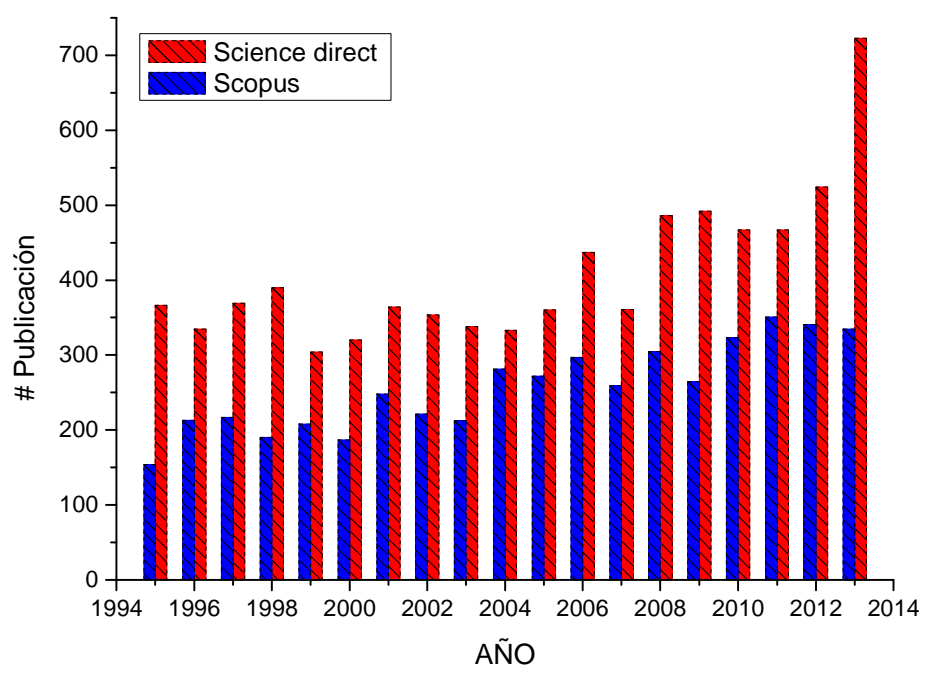

Figura 2.3. Número de publicaciones y reviews con Mullita como palabra clave. Science direct y Scopus.

La sinterización de la mullita por procesos en estado sólido o líquido han sido llamados sinterización de mullita y fusión de mullita, respectivamente, dependiendo de la temperatura de tratamiento térmico de los compuestos de sílice $\left(\mathrm{SiO}_{2}\right)$ y alúmina $\left(\mathrm{Al}_{2} \mathrm{O}_{3}\right)$. El término mullita sinterizada se refiere al calentamiento a una temperatura cercana al punto de fusión para cristalizar y densificar la mullita, en general tienden a tener relaciones estequiométricas $3-2\left(3 \mathrm{Al}_{2} \mathrm{O}_{3} \cdot 2 \mathrm{SiO}_{2}\right)$. Cuando se habla de mullita fundida se refiere a la preparación de mezclas de alúmina y sílice, las cuales se llevan hasta temperaturas por encima del punto de fusión seguido por un enfriamiento para cristalizar la mullita. Las mullitas obtenidas usando rutas que utilizan soluciones sol-gel son llamadas comúnmente mullitas químicas, ellas se sintetizan por una reacción química, pirolisis y posterior mullitización. La pureza, homogeneidad, temperatura de cristalización, densificación y propiedades de la mullita son dependientes del método de síntesis [Schneider y Komarneni, 2005].

La industria de los materiales refractarios ha experimentado una extraordinaria evolución en los últimos 40 años, como consecuencia de las nuevas y cada vez más exigentes especificaciones impuestas por la industria consumidora. Esto quiere decir no solo un control estricto de las materias primas y una mejora en los procesos de fabricación, sino 
también en el aporte científico de técnicas que, utilizadas tanto en la metalografía como en la físico-química de materiales, han permitido el uso de los diagramas de equilibrio de fases de óxidos potencialmente utilizables como refractarios por su elevado punto de fusión $\left(\mathrm{Al}_{2} \mathrm{O}_{3}, \mathrm{CaO}, \mathrm{SiO}_{2}, \mathrm{MgO}\right.$, etc.), y por lo tanto mejorar el conocimiento de la influencia de las impurezas presentes, a la temperatura y condiciones reales de trabajo de cada tipo de material. [De Aza et al., 2002; Verdeja et al.,2008].

La materia prima fundamental para elaborar materiales refractarios de alta alúmina es la mullita, debido a que es un material refractario capaz de resistir condiciones a altas temperaturas sin alterar sus propiedades físico-químicas, durante un período de tiempo económicamente rentable en dependencia del equipo térmico donde se le dará explotación. Las condiciones del medio no incluyen únicamente el efecto de las altas temperaturas, sino también la resistencia al ataque por fundidos, al choque térmico y, en general, todos aquellos usos a los que vaya a estar sometido el material en servicio. [De Aza et al., 2002; Mazdiyasni y Brown, 1972].

\subsection{MÉTODOS DE PREPARACIÓN Y/O USOS DE LA MULLITA}

Los métodos más conocidos de preparación de mullita se han basado en la descomposición térmica de la caolinita ó de materiales similares con complementos de $\mathrm{Al}_{2} \mathrm{O}_{3}$, y en la fusión a una temperatura aproximada de $1850^{\circ} \mathrm{C}$ empleando mezclas de $\mathrm{Al}_{2} \mathrm{O}_{3}$ puro y $\mathrm{SiO}_{2}$ puro (usualmente con exceso de $\mathrm{Al}_{2} \mathrm{O}_{3}$ ) [Skoog y More, 1988; Villar et al., 2004]. En la actualidad se han desarrollado nuevas tecnologías para la obtención de este material, por ejemplo la síntesis hidrotermal, la combustión de polvos cerámicos, la pirólisis, y la síntesis a partir de hidrogeles [Ribero et al., 2007; 2009], los cuales son métodos afines de obtención de Mullita que tienen absoluta vigencia [Mazdiyasni y Brown, 1972; Basu et al., 2006], pero muy costosos para producir en gran escala.

El desarrollo de nuevas tecnologías de síntesis ha permitido producir Mullita de alta pureza y homogeneidad, ubicándola en un lugar de privilegio para aplicaciones técnicas de alta temperatura requeridas por las nuevas cerámicas avanzadas.

La mullita preparada por procesos de estado sólido implica aluminosilicatos naturales, tales como minerales caoliníticos, el grupo sillimanita (sillimanita, andalucita, cianita) y muchos tipos de óxidos, hidróxidos, sales inorgánicas y orgánicas de metales como la 
alúmina y precursores de sílice. Actualmente y con vista a la producción de refractarios, dos son las vías utilizadas; una por electrofusión de sílice y alúmina provenientes de distintas fuentes dosificadas convenientemente y la otra por sinterización reactiva a partir de mezclas de arcillas caoliníticas y alúmina o bauxitas.

Algunos parámetros como la temperatura de sinterización, la presión aplicada, el tamaño promedio de la partícula y la atmósfera gaseosa pueden ser controlados con suficiente exactitud. Otras como las características de las muestras y el empaquetamiento de las partículas son muy difíciles de controlar pero tienen un efecto significativo en la sinterización [Rahaman, 2003].

Un trabajo realizado por Sainz y otros colaboradores muestran los estudios microestructurales de una reacción obtenida por sinterización de mezclas de caolinita y $\alpha$-alúmina tratadas térmicamente entre un rango de $1150-1700^{\circ} \mathrm{C}$, explicando que los cristales de mullita bimodal corresponden a la nucleación de mullita secundaria, y que la mullita primaria comienza a los $1300^{\circ} \mathrm{C}$. Trabajando a temperaturas más bajas no se observó formación de mullita, [Sainz et al., 1997]. A temperaturas ente 1300 a $1500{ }^{\circ} \mathrm{C}$ se refleja el crecimiento de los cristales, y a temperaturas mayores de $1550^{\circ} \mathrm{C}$ se muestra que la mullita primaria y secundaria crecen simultáneamente. A los $1700{ }^{\circ} \mathrm{C}$ se presenta un crecimiento importante del tamaño de los cristales, esta evolución es característica para el crecimiento de la mullita a altas temperaturas en presencia de una fase liquida permanente.

Un estudio realizado por Carmen Cáceres muestra que se pueden lograr condiciones operativas para que la reacción de formación de mullita no se encuentre controlada por la etapa difusional del proceso, estudió el mecanismo y la cinética de la reacción de formación de mullita a partir de bauxita y de mezclas bauxita - arcilla utilizando materiales finamente divididos, pero solo hasta $1400^{\circ} \mathrm{C}$. [Cáceres., 1977].

Para el caso de la bauxita mostró por Difracción de Rayos $\mathrm{X}$ la ausencia de mullita a temperaturas de 1000 y $1100{ }^{\circ} \mathrm{C}$ en un rango de tiempo que oscilaba entre 1 a 60 minutos, mostrando que solo a $1400{ }^{\circ} \mathrm{C}$ se encontró formulación de soluciones sólidas, se estimó que esto no incidiría en forma apreciable sobre el mecanismo y cinética de la reacción. En cambio en la mezcla se observó que a $1200 \stackrel{\circ}{\circ}$ la mullita formada se debe fundamentalmente a la transformación de la caolinita proveniente de la caolinita presente en la bauxita y a la caolinita de la arcilla. El mecanismo controlante es la nucleación y crecimiento de los núcleos. 
La mullita formada a 1250, 1300 y $1400 \stackrel{\circ}{C}$ es debida además a la reacción entre la sílice liberada de la descomposición de la caolinita, con la alúmina de la bauxita. La velocidad de la reacción está determinada por los procesos interfaciales en estado inicial de la reacción. Es posible entonces alcanzar altos valores de conversión a mullita y además que la reacción esté controlada por los procesos interfaciales, si se opera con materiales finamente divididos y periodos de calcinación cortos a $1400 \stackrel{\circ}{\mathrm{C}}$.

Un estudio sobre la mullitización y el comportamiento de la caolinita, expresa que la forma hexagonal de las partículas permanece a una temperatura mayor a la deshidratación de la caolinita, indicando la presencia de algún tipo diferente de estructura residual del anhídrido del caolín. Comeforo [Comeforo et al., 1948] en este trabajo concluye que dos estados de reacción representan el comportamiento de la caolinita frente a un tratamiento térmico; primero el agua de composición presente en el cristal como grupo hidroxilo es removida con la formación de un único componente no cristalino al cual se le conoce como metacaolín o pre-mullita nombre que está plenamente justificado; segundo, el componente no cristalino ya mencionado colapsa en un núcleo cristalino de mullita donde son libres de exhibir un crecimiento normal en una extensa o una intensa quema. [D.J. Duval et al., 2008].

El articulo presentado por W.E Lee y otros colaboradores muestran la formación de mullita en arcillas y sistemas cerámicos vítreos basados en arcillas, donde los cristales de mullita crecen en un líquido viscoso de aluminosilicatos, existiendo en las arcillas muy puras la mullita primaria y en arcillas que contienen una gran cantidad de fundentes alcalinos se forma la mullita secundaria acicular si existe alúmina libre [Lee et al., 2008]. La mullita obtenida se localiza en la matriz de vidrio producido por la fusión de los aluminosilicatos, estos líquidos, formados por la presencia de los álcalis y óxidos de hierro, hacen que adquieran mayor fluidez y fomenten el crecimiento de cristales.

El trabajo realizado por C.Y. Chen muestra la preparación de mullita y mullita - alúmina por reacción de sinterización de caolinita y alúmina a temperaturas superiores a 1000 ${ }^{\circ} \mathrm{C}$, encontrando que la mullita primaria aparece a alrededor de los $1200{ }^{\circ} \mathrm{C}$, y que las partículas de alúmina son inertes a esta temperatura. La alúmina empieza a reaccionar con la sílice en fase vítrea proveniente de la descomposición de la caolinita para formar mullita secundaria por encima de los $1300^{\circ} \mathrm{C}$, por lo tanto la temperatura de sinterización del caolín más alúmina tiene que ser mucho mayor a esta, observándose también que la adición de alúmina reduce el tamaño de los granos de mullita. La 
resistencia y la dureza de la mullita resultante aumentan con el incremento del contenido de alúmina, sin embargo, las propiedades mecánicas de los compuestos mullita y mullita - alúmina son inferiores a los de alúmina por sus diferencias estructurales y su menor densidad. [Chen et., 2000].

En el artículo de Schneider y Majdic presentan un estudio de los mecanismos cinéticos de las transformaciones de la andalucita desde $1250{ }^{\circ} \mathrm{C}$ hasta $150{ }^{\circ} \mathrm{C}$ existiendo una temperatura crítica a $1380{ }^{\circ} \mathrm{C}$ en el análisis de la formación de mullita. Trabajaron estructuras con cristales de $\mathrm{SiO}_{2}$ (cristobalita) - $\alpha-\mathrm{Al}_{2} \mathrm{O}_{3} \mathrm{SiO}_{2}$ y sílice amorfa - $\alpha-\mathrm{Al}_{2} \mathrm{O}_{3}$, los cuales presentaron dos mecanismos distintos de sinterización a temperaturas menores a $1500{ }^{\circ} \mathrm{C}$, donde el primer sistema densifica a través de la sinterización de flujo semiviscoso, mientras que el segundo sistema se identifica por la reacción de estado sólido lo que crea una velocidad más baja de nucleación y un largo periodo de incubación para la formación de la mullita, lo cual es bastante bueno cuando se trabaja con mecanismos de sinterización visco-fluida [Schneider y Majdic, 1979], concluyendo que se debe trabajar a temperaturas mayores para obtener mullita en el segundo sistema, observado esto también por Saruhan [Mesa, 2011; Saruhan et al., 1996].

Ganesh elaboró un trabajo utilizando la técnica de prensado uniaxial para preparar agregados densos de mullita con varios contenidos de alúmina (47- 70 \%) a partir de polvo seco (algunos tipos de arcillas, arena de sillimanita y un hidróxido de aluminio con alta pureza), los cuales se trataron térmicamente en un rango de temperatura de 1450 $1725^{\circ} \mathrm{C}$. Las mullitas obtenidas de la arena sillima nítica presentaron granos equiaxiales, mientras que las obtenidas a partir de la arcilla mostraron granos alargados. [Ganesh y Ferreira 2009].

Ganesh también mostró una etapa de pre-mullitización a través de un proceso llamado de doble etapa, que consiste en llevar inicialmente los materiales a una temperatura entre $1250{ }^{\circ} \mathrm{C}$ y $1300^{\circ} \mathrm{C}$, dando así una formación in icial de mullita y luego se trata térmicamente a las temperatura mencionadas anteriormente (1450 a $1725^{\circ} \mathrm{C}$ ). Con este método se encontraron mejores propiedades de sinterizado en términos de porosidad aparente, densidad, la capacidad de absorción de agua y mayor contenido de mullita en comparación con los obtenidos sin el proceso doble capa. 
Las mezclas de caolinitas e hidróxidos de aluminio (gibbsita y bohemita) fueron estudiadas por Temuujin, observando que al realizar una molienda intensiva sobre la mezcla se generaba una aceleración en las reacciones térmicas, encontrando que el efecto mecanoquímico acelera la formación de mullita. Moliendo las mezclas de caolinita - bohemita se producen precursores de mullita los cuales son más homogéneos que otras mezclas en donde la caolinita había sido deshidratada, sin embargo es mejor en la mezcla de caolinita - gibbsita que en caolinita - bohemita bajo las mismas condiciones, [Temuujin et al., 2000].

En cuanto al problema de analizar cuantitativamente fases presentes en silicoaluminosos, la cuantificación de una fase vítrea formada en un sistema que contiene $\mathrm{Al}_{2} \mathrm{O}_{3}-\mathrm{SiO}_{2}-\mathrm{ZrO}_{2}$ (AZS) ha sido estudiada por Conconi presentando y comparando los resultados de la cuantificación de la fase no cristalina de un material AZS comercial por tres métodos distintos basados en la difracción de rayos X. El primer método consiste en la interpolación de la línea de base del difractograma entre las correspondientes a sílice amorfa y a cuarzo cristalino (método de Ohlberg). Los otros dos se basan en la aplicación del método de Rietveld. Uno con agregado de cuarzo $\left(\mathrm{SiO}_{2}\right)$ como patrón interno bien cristalizado y el otro incorporando al refinamiento la fase vítrea con un modelo estructural que incluye ensanchamiento por defectos del tamaño cristalino (modelo de Le Bail). Concluyendo que el método de Ohlberg, a pesar de su simplicidad puede ser utilizado sólo en muestras que no presenten líneas de difracción en la zona de medida del fondo y sólo aporta información sobre el contenido de fase no cristalina sin cuantificar el resto de las fases, [Conconi et al., 2011]. Por último, si bien en la cuantificación de fases no cristalina de materiales tipo AZS se pueden obtener resultados similares con ambas metodologías basadas en el método de Rietveld, el modelo de Le Bail es recomendable porque no es necesario contaminar la muestra con un estándar interno y podría ser incorporado fácilmente a un análisis y es el que terminó adaptado.

En los sucesivos capítulos se aportará más información bibliográfica específica relacionada con los mismos.

Considerando lo expuesto en este marco teórico, que en Argentina existen buenos yacimientos de material caolinítico y que la disponibilidad actual de alúmina con cierta reactividad en escala industrial en este país se circunscribe a alúmina calcinada e hidratada (ésta en menor escala), es por eso que se decidió realizar este trabajo 
seleccionando dos arcillas caoliníticas y estas dos fuentes de alúmina, para la síntesis de mullita de uso tecnológico.

\subsection{BIBLIOGRAFÍA}

Aksay I.A., Dabbs D.M., Sarikaya M.., Mullite for structural, electronic, and optical applications, Journal of the American Ceramics Society. 74 (10), pp. 2343-2358 (1991).

$>\quad$ Aksay I.A., Pask J.A., Stable and metastable equilibria in the system $\mathrm{SiO}_{2}-\mathrm{Al}_{2} \mathrm{O}_{3}$. Journal of the American Ceramics Society. 58, pp 11-12; 507-512 (1975).

$>\quad$ Aramaki, S., Roy R., Revised Equilibrium diagram for the system $\mathrm{Al}_{2} \mathrm{O}_{3}-\mathrm{SiO}_{2}$, Nature. 184, pp. 631-632 (1959).

$>\quad$ Aramaki, S., Roy R., Revised Phase Diagram for the System $\mathrm{Al}_{2} \mathrm{O}_{3}-\mathrm{SiO}_{2}$, Journal of the American Ceramics Society. 45, pp. 229-242(1962).

$>\quad$ Basu A.K., Mitra A., Ghatak S., Synthesis of a powder in the form of hydroxyhydrogel for reaction sintering of BN-millite composite, Ceramics International. 32, pp. 213-219 (2006).

$>\quad$ Berjeron C.G., Risbud S.H., Introduction to phase equilibria in ceramics, The American Ceramic Society. pp. $43-44$ (1994).

$>$ Bowen M.L., Greig J.W., The system $\mathrm{Al}_{2} \mathrm{O}_{3}-\mathrm{SiO}_{2}$, Journal of the American Ceramics Society. 7, pp. 238-254 (1924).

$>\quad$ Cáceres Carmen V., Pereira E., Formación de mullita por procesos no difusionales en el sistema bauxita - arcilla caolinítica, I estudio cinético, Rev. Latinoam. Ing. Quim. Apl. 7, pp. 119-133 (1977).

$>\quad$ Chaudhuri S.P., Ceramics International. 13, 177-181 (1987).

$>\quad$ Chen C.Y., Lan G.S., Tuan W.H., Preparation of mullite by the reaction sintering of kaolinite and alúmina, Journal of the European Ceramics Society. 20, pp. 25192525 (2000).

$>$ Comeforo J.E., Fischer R.B., et al. Mullitization of kaolinite. Journal of the American Ceramic Society. 31(9), pp. 254-259 (1948). 
$>\quad$ Conconi M.S., Rendtorff N.M., Aglietti E.F., Evaluation of non crystalline phase in AZS refractories by XRD methods, New Journal of Glass and Ceramics. 1, pp. 2833 (2011).

$>\quad$ Davis, R. F. and Pask J. A. Diffusion and reaction studies in the system $\mathrm{Al}_{2} \mathrm{O}_{3}$ $\mathrm{SiO}_{2}$, Journal of the American Ceramics Society. 55, pp. 525-531 (1972).

$>\quad$ De Aza A.H., Moset M., Pena P., Materiales de $\mathrm{Al}_{2} \mathrm{O}_{3}-\mathrm{MgAl}_{2} \mathrm{O}_{4}-\mathrm{CaAl}_{12} \mathrm{O}_{19}-$ $\mathrm{Ca}_{2} \mathrm{Mg}_{2} \mathrm{Al}_{28} \mathrm{O}_{46}$ obtenidos mediante un proceso de sinterización reactiva entre $\mathrm{Al}_{2} \mathrm{O}_{3}$ y $\mathrm{CaMg}\left(\mathrm{CO}_{3}\right)_{2}$. Boletín de la Sociedad Española de Cerámica y Vidrio. 41 (4), pp. 361-366 (2002).

$>\quad$ Duval David J., Risbud Subhash H., Shackelford James F., Ceramic and glass materials. Structure, properties and processing. Mullite, pp 27-39 (2008).

> Ganesh I., Ferreira J.M.F., Influence of raw material type and of the overall chemical composition on phase formation and sintered microstructure of mullite aggregates, Ceramics International. 35(5), pp.2007-2015 (2009).

> Ismail M.G.M.U., Nakai Z., Somiya S., Microstructure and mechanical propierties of mullite prepared by Sol-Gel method, Journal of the American Ceramics Society. 70, C7-C8 (1987).

$>\quad$ Jain D.C., Mullite, The American Ceramic Society Bullletin. pp. 109-110 (1998).

> Jovani M., Alonso J.J., Manglano J.J., Estudio por microscopía electrónica de barrido (S.E.M.) de pastas cerámicas refractarias y de la mullita en ellas formada, Boletín de la Sociedad Española de Cerámica y Vidrio. 18, pp. 85-92 (1979).

$>\quad$ Klug F.J., Prochazka S., Doremus R.H., Alúmina - silica phase diagram in the mullite región, Journal of the American Ceramic Society. 70, pp 750-759 (1987).

$>\quad$ Lee W.E., Souza G.P., et al., Mullite formation in clays and clay-derived vitreous ceramics, Journal of the European Ceramic Society. 28(2), pp. 465-471(2008).

> Mazdiyasni K.S., Brown L.M., Synthesis and mechanical properties of stoichiometric aluminum silicate (Mullite), Journal of the American Ceramic Society. 55 (11), pp. 548-552 (1972).

$>\quad$ Mesa Toro Carlos Mario., Estudio de la producción de agregados mullíticos para la industria refractaria, Tesis doctoral, Universidad Nacional de Colombia, Medellin, Colombia, pp. 26-31 (2011).

> Pask J.A., Proceedings of the 1st International Work-Shop on Mullite, Pub., Japón 
pp. 1-13 (1989).

Dahaman M.N., Ceramic processing and sintering, Taylor \& Francis group, LLC. (2003).

Rendtorff N.M., Materiales cerámicos del sistema Mullita Zirconia Zircón; propiedades mecánicas, de fractura y comportamiento frente al choque térmico, Tesis doctoral, Universidad Nacional de La Plata, Argentina, pp 27 (2009).

> Ribero D., Restrepo R., et al., Disminución de la temperatura en la síntesis de un material cerámico altamente refractario (mullita) a partir de hidroxihidrogeles, Dyna Revista Facultad Nacional, minas. Medellín - Colombia. 74 (153), pp 85100 (2007).

$>\quad$ Ribero D., Restrepo R., et al., Highly refractory mullite obtained through the route of hydroxyhydrogels, Journal of materials processing technology 209 (2), pp. 986990 (2009).

Sainz M.A., Tomba A.G., Camerucci M.A., Caballero A., Obtención de Mullita de elevada pureza a partir de materias primas naturales. Minerales del grupo de la Silimanita. II Jornada de Ciencia de los Materiales Voll., pp. 517 - 520 (1993).

> Sainz, M.A., Serrano F.J., et al., Microstructural evolution and growth of crystallite size of mullite during thermal transformation of kyanite, Journal of the European Ceramic Society. 17(11), pp. 1277-1284 (1997).

> Sales M., Alarcón J., Evolución estructural de geles de mullita, Boletín de la Sociedad Española de Cerámica y Vidrio. 33, pp. 273-278 (1994).

$>\quad$ Saruhan B., Albers W., et al., Reaction and sintering mechanisms of mullite in the systems cristobalite / [alpha]- $\mathrm{Al}_{2} \mathrm{O}_{3}$ and amorphous $\mathrm{SiO}_{2} /$ [alpha]- $-\mathrm{Al}_{2} \mathrm{O}_{3}$, Journal of the European Ceramic Society. 16 (10), pp. 1075-1081(1996).

$>\quad$ Schneider H., Komarneni S., Mullite, WILEY-VCH. (2005).

$>\quad$ Schneider H., Majdic A., Kinetics and mechanism of the solid - state high temperature transformation of Andalusite $\left(\mathrm{Al}_{2} \mathrm{SiO}_{5}\right)$ Into $3 / 2$ - Mullite $\left(3 \mathrm{Al}_{2} \mathrm{O}_{3}\right.$ $\left.2 \mathrm{SiO}_{2}\right)$ and Silica $\left(\mathrm{SiO}_{2}\right)$, Ceramurgia International 5(1), pp. 31-36 (1979).

> Schneider H., Okada K., Pask J.A., Mullite and mullite ceramics, John Wiley and Sons, Chichester,. pp. 1-251 (1994).

$>$ Schneider H., Schreuer J., et al., Structure and properties of mullite - A review, -19 - 
Journal of the European Ceramic Society. 28(2), pp. 329-344 (2008).

> Skoog A.J., Moore R.E., Refractory of the past for the future: Mullite, and Its use as a bonding phase, Ceramic Bulletin. 67, pp.1180-1184 (1988).

> Tcheichvili L., Butschkowskyi M., Un aporte al problema de la mullita, Boletín de la Sociedad Española de Cerámica y Vidrio. 14(1), pp. 9-22 (1975).

$>\quad$ Temuujin J., MacKenzie K.J.D., et al., Phase evolution in mechanically treated mixtures of kaolinite and alúmina hydrates (gibbsite and boehmite), Journal of the European Ceramic Society. 20(4), pp. 413-421 (2000).

> Tomba A.G., Camerucci M.A., Cavalieri A.L., Porto López J.M., Caballero A., Sainz M.A., Purificación de Mullita obtenida a partir de Silimanita, 8th Cimtec. World Ceramics Congreso. Florence. (1994).

$>\quad$ Toropov N.A., Galakhov F.Y., New data on the system $\mathrm{Al}_{2} \mathrm{O}_{3}-\mathrm{SiO}_{2}$. Dokl. Akad. Nauk. SSSR. 78, pp. 299-302 (1951).

$>\quad$ Verdeja L.F., Sancho J.P., Ballester A., Materiales refractarios y cerámicos, Ed. Síntesis, Madrid, pp. 19-22; 156-176 (2008).

> Villar M.P., Gago - Duport L., Garcia R., Comportamiento de mullitas a alta temperatura: Estudio mediante Difracción de Rayos X, Boletín de la Sociedad Española de Cerámica y Vidrio. 43, pp. 135-137 (2004). 


\section{CAPITULO 3}

\section{TÉCNICAS DE CARACTERIZACIÓN}

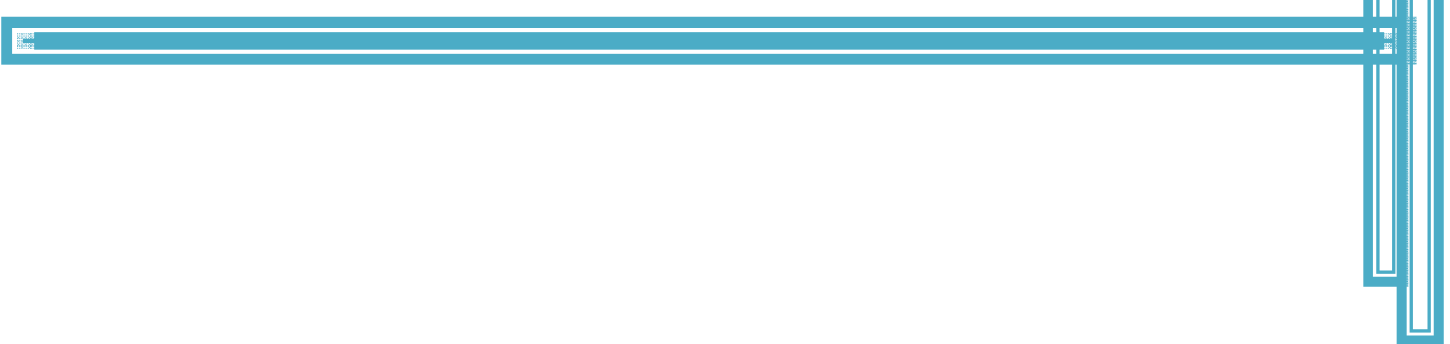

La caracterización de los materiales abarca desde su estructura microscópica hasta sus propiedades útiles como materiales, la composición y estructura química, el tamaño y forma macroscopica, la morfología en estado sólido, plasticidad de las materias primas (valor importante para el proceso de conformado de las piezas, ya sea por prensado, extrusión ó colado), el comportamiento frente a tratamientos térmicos, etc. Las técnicas descritas en este capítulo estarán especialmente orientadas a mostrar las fortalezas de las mismas para su uso de acuerdo a la problemática a resolver.

\subsection{DIFRACCIÓN DE RAYOS X (DRX)}

El análisis por Difracción de Rayos $X$ es una técnica analítica no destructiva ampliamente aplicada para la caracterización de materiales cristalinos, tales como los metales, cerámicos, polímeros, intermetálicos, minerales u otros compuestos orgánicos e inorgánicos. El método consiste en la difracción de un haz monocromático de rayos $\mathrm{X}$ incidente sobre una muestra midiendo la intensidad de haz que ha sido difractado en 
función del ángulo de incidencia del mismo de acuerdo a la ley de Bragg (Ec. 3.1), [Jenkins y Snyder, 1996; Klug y Alexander, 1974].

$$
n \lambda=2 d \sin \theta
$$

Ec. 3.1

Donde " $\lambda$ " es la longitud de onda del rayo, "d" es la distancia entre planos cristalinos de la sustancia y " $\theta$ " es el ángulo de incidencia.

Los planos formados por los átomos en la estructura cristalina que permiten determinar el sistema cristalino al que pertenece el material estudiado, así como los parámetros de su red cristalina permiten identificar las fases que componen cualquier material en estudio, siempre que estas no sean amorfas.

Los rayos $X$ son un tipo de radiación electromagnética con longitud de onda de $\sim 1 \AA$ que se encuentran en el espectro de radiación entre los rayos gama y ultravioleta. Los rayos $X$ se originan cuando partículas de alta energía, por ejemplo electrones acelerados a través de un potencial de aproximadamente $30 \mathrm{KV}$, colisionan con un blanco metálico. Los electrones son retardados, o parados, por la colisión produciendo transiciones electrónicas de los electrones más internos de los orbitales atómicos del blanco metálico. La relajación del sistema produce una radiación electromagnética de baja longitud de onda (alta energía) que puede ser utilizada en diferentes campos científicos y/o tecnológicos [Shmueli, 2007 Skoog y Leary, 1994].

Cuando el haz de rayos $X$ incide sobre un material cristalino, la interacción de esta radiación con los centros dispersores, y núcleos del material, genera patrones de interferencia, tanto destructiva como constructiva, debido a que la distancia entre los centros dispersores en el material tiene el mismo orden de magnitud, de angströms, que la longitud de onda del haz incidente (Figura 3.1), [Birkholz, 2006; Skoog y Leary, 1994]. 


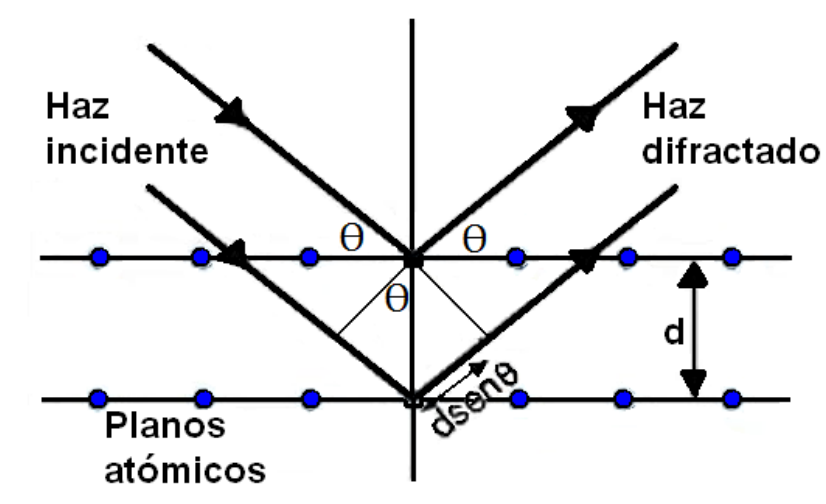

Figura 3.1. Esquema de la ley de Bragg (Ec. 3.1). [Bragg, 1913; Cullity, 1978].

La posición angular en que aparecen las interferencias constructivas definirá según la ley de Bragg los espaciados entre los planos de las redes cristalinas presentes, mientras que la cantidad volumétrica presente de cada especie se verá reflejada en la intensidad del pico de difracción visualizado en el espectro, el cual es proporcional al área bajo la curva del mismo [Bish y Reynolds, 1989; Moore y Reynolds. 1997; Rahaman, 1995].

La técnica de Difracción de Rayos X utilizada en el presente trabajo corresponde a muestras en polvo, para todas las materias primas (arcilla/caolín - alúmina calcinada/hidratada) y los materiales conformados (mezcla arcilla-alúmina). Se prepararon pulverizando las mismas en un molino Herzog HSM100 hasta un tamaño menor a malla 200, la molida se realizó en tiempos menores a 5 segundos por lo que no se vió afectadá su cristalinidad. Las determinaciones de los espectros de difracción se llevaron cabo en un difractómetro Philips 3020 modelo PW 10, empleando la radiación $\mathrm{Cu}-\mathrm{Ka}(\lambda=1.54 \mathrm{~A}$ ) y filtro de $\mathrm{Ni}$, operando con una potencia de $35 \mathrm{kV}$ y una intensidad de corriente de $40 \mathrm{~mA}$. El barrido se realizó en todos los casos en pasos de $0.02^{\circ}$ (20) y 1 segundo por paso, en el intervalo de $2 \theta$ desde $5^{\circ}$ a $70^{\circ}$.

\subsubsection{Identificación y/o cuantificación de fases cristalinas (análisis mineralógico)}

La identificación de una fase cristalina se basa en el hecho de que cada sustancia en estado cristalino tiene un diagrama de rayos $\mathrm{X}$ que le es característico. La determinación de las fases cristalinas presentes en todas las muestras en estudio, desde la materia 
prima de partida hasta su producto final se realizaron comparando los difractogramas experimentales con los patrones de difracción registrados en las bases de datos existentes, que permitieron llevar a cabo la identificación de las fases cristalinas en cada muestra. Para este estudio se utilizaron las tarjetas PDF (Powder Difraction Files), las tarjetas utilizadas fueron las de; cuarzo, caolinita, oxido de aluminio ( $\alpha$-Alúmina), gibbsita, cristobalita y mullita (ver apéndice I).

Existen varios programas que poseen estas bases de datos cristalográficas ICSD (Inorganic Crystal Structure Database) con 166.000 compuestos [http://www.fizkarlsruhe.de/icsd.html] y la PDF-2 de la ICDD (International Centre for Diffraction Data) con 265.127 compuestos [http://www.icdd.com/products/pdf2.htm]. Para la identificación de las fases cristalinas se cuenta con los programas Match y el X'Pert High Score Plus.

Para realizar la cuantificación de las fases cristalinas de los difractogramas obtenidos en en el estudio térmico se utilizó el método de Rietveld (Fullprof), con el cual se pueden cuantificar las fases cristalinas presentes. [Bish y Howard, 1988; Bish y Post 1993; O'Connor y Raven, 1988]. Los programas disponibles de forma libre para realizar la cuantificación de muestras son: el método Rietveld (Fullprof), del Dr. J. Rodríguez Carvajal, del Instituto Laue-Langevin, Saclay (Francia) [Rodríguez, 1990; 2001], DBWS del grupo del profesor R. A. Young, del Instituto Tecnológico de Georgia, Atlanta (USA) [Young, 1993; Izumi y Momma, 2007], RIETAN de F. Izumi, Instituto Nacional de Investigaciones en Materiales Inorgánicos (Japón) [Izumi et., 2007], entre otros.

En 1969 Rietveld [Rietveld, 1969], desarrolló un método para refinar estructuras cristalinas usando datos de difracción de neutrones. Actualmente, su uso se ha extendido a la realización de análisis estructurales, determinación de defectos cristalinos, medición de parámetros reticulares y análisis cuantitativo en difractometría de polvos por rayos $X$.

El método consiste en ajustar, punto a punto, las intensidades experimentales ( $\mathrm{y}^{\mathrm{ibs}}$ ) correspondientes a todo el espectro, con las calculadas ( $\mathrm{yi}^{\mathrm{i}}{ }^{\mathrm{cal}}$ ) en base a un determinado modelo de estructura cristalina, efectos ópticos de difracción, factores instrumentales y otras características de la muestra. Los parámetros incluidos en el modelo utilizado son refinados hasta obtener el mejor ajuste de cuadrados mínimos de los miles de yi pertenecientes al difractograma. La cantidad minimizada es el residual $R_{y}$, cuya definición se muestra en la ecuación 3.2. 


$$
R_{y}=\sum_{i} w_{i}\left(y_{i}^{o b s}-y_{i}^{c a l}\right)^{2}
$$

Con el peso estadístico $w i=1 /$ yibs

La sumatoria es sobre todos los puntos del diagrama de rayos $\mathrm{X}$, con las intensidades calculadas según la ecuación 3.3 .

$$
y_{i}^{c a l}=\sum_{p} S_{p} \sum_{K} L_{K}\left|F_{K}\right|^{2} \varphi\left(2 \theta_{i}-2 \theta_{K}\right) P_{K} A+y_{b i}
$$

Donde $S_{p}$ es el factor de escala de la fase $\mathrm{p}, \mathrm{K}$ representa los índices de Miller para una reflexión de Bragg, $L_{K}$ contiene los factores de Lorentz, Polarización y multiplicidad, $\theta_{K}$ es la función del perfil de la reflexión, $P_{K}$ es la función de orientación preferencial, $A$ es un factor de absorción, $F_{K}$ es el factor de estructura de la K-ésima reflexión de Bragg e $y_{b i}$ es la intensidad del fondo en el punto i.

El análisis cuantitativo se realiza a partir de los factores de escala refinados para cada fase $\left(\mathrm{S}_{\mathrm{i}}\right)$ de acuerdo con la ecuación 3.4 .

$$
W_{i}=\frac{S_{i}(Z M V)_{i} / \tau_{i}}{\sum_{p} S_{p}(Z M V)_{p} / \tau_{p}}
$$

Donde; $\mathrm{W}_{\mathrm{i}}$ es la fracción en peso de la fase $\mathrm{i}$, la suma se extiende sobre todas las fases presentes y $S_{i}, Z_{i}, M_{i}, V_{i}$ y $T_{i}$ son el factor de estructura, el número de moléculas por celda unidad, el peso molecular, el volumen de la celda y el factor de corrección por absorción másica de las partículas para la fase i, respectivamente.

Como ya se mencionó, para poder realizar el análisis de Rietveld debe conocerse la estructura cristalina para cada fase presente en la muestra. Por lo tanto, en sí mismo, no permite incluir fases amorfas o no cristalinas. Sin embargo, diversos autores han 
implementado la cuantificación de estas fases utilizando el refinamiento de Rietveld en forma eficaz, en este trabajo se estudió el método de Ohlberg y el de Le Bail.

\subsubsection{Método de Ohlberg:}

En el campo de los materiales, el uso de la técnica de difracción de rayos $\mathrm{X}$ para la cuantificación de la fracción no cristalina o amorfa, es un permanente desafío que ha sido estudiado y abordado de diversas maneras.

Ohlberg [Ohlberg, 1962] desarrolló un método para la determinación del porcentaje de cristalinidad $(\mathrm{C} \%)$ en vidrios parcialmente desvitrificados, por interpolación de la línea de base del difractograma entre las correspondientes a sílice amorfa y a cuarzo cristalino:

$$
C \%=100 \frac{\left(I_{\text {vid }}-I_{m}\right)}{\left(I_{\text {vid }}-I_{\text {cris }}\right)}
$$

donde $I_{\text {vid }}, I_{m}$ y $I_{\text {cris }}$ son la intensidades del fondo en 22.5ำ correspondientes a una muestra $100 \%$ vítrea, la muestra parcialmente cristalina y una muestra patrón $100 \%$ cristalina respectivamente.

La ecuación es utilizada comúnmente en la determinación de cristalinidad en materiales vitrocerámicos [Morimoto, 2006; Willams et., 1967].

Ohlberg comprobó su validez en mezclas patrón de vidrio de sílice (fused silica) y cuarzo cristalino asignándole a este último $100 \%$ de cristalinidad, por lo cual sería válido suponer que a partir de esa ecuación puede obtenerse el porcentaje de fase amorfa o no cristalina. Se aplicó la ecuación de Ohlberg redefinida para el porcentaje de fase Amorfa (\%Am) [Ohlberg y Strickler 1962]:

$$
\% A m=100\left[1-\frac{\left(I_{\text {vid }}-I_{m}\right)}{\left(I_{\text {vid }}-I_{\text {cris }}\right)}\right]=100 \frac{\left(I_{m}-I_{\text {cris }}\right)}{\left(I_{\text {vid }}-I_{\text {cris }}\right)}
$$


Para caracterizar la fase amorfa, se utilizó dióxido de Silicio (Carlo Erba RPE) como fase vítrea $\left(I_{\text {vid }}\right)$ y cuarzo como fase cristalina $\left(I_{\text {cris }}\right)$, aplicando el método de Ohlberg para refinar la fase vítrea pura en el método de Rietveld.

\subsubsection{Modelo de Le Bail:}

El modelo de Le Bail es un método utilizado para la descomposición del patrón de difracción en intensidades integradas, ya que en los métodos policristalinos existe una superposición de los picos de difracción que corresponden a diferentes familias de planos cuyas distancias interplanares son iguales o aproximadamente iguales [Le Bail, 1995].

De esta manera, los métodos de descomposición del patrón son usados generalmente cuando no se tiene el conocimiento de la estructura del material, por lo que ésta técnica es ampliamente usada para obtener la intensidad de las reflexiones estimadas como un precursor de la solución estructural [Ward y French, 2006].

El problema es abordado determinando el área de los máximos de difracción considerando que este es proporcional al cuadrado de la magnitud del factor de estructura $\left(\left.|F h k|\right|^{2}\right)$. Para datos experimentales provenientes de materiales cuya estructura es desconocida, la proposición inicial corresponderá entonces a un conjunto de reflexiones que determine los parámetros de celda y el grupo espacial, considerando inicialmente que todas las intensidades integradas son iguales [Young, 1993]. De esta forma y a través de un proceso iterativo mediante el método de mínimos cuadrados se hace un ajuste de perfil que consiste en refinar los parámetros de celda, de perfil del pico y de asimetría con el objetivo de ajustar el perfil calculado al experimental y obtener los factores de estructura. Éste método se encuentra implementado en el programa FullProf [Rodríguez, 2001]

Finalmente, se aplicó el análisis por el método de Rietveld, incorporando al refinamiento la fase vítrea como un material nanocristalino con un modelo estructural que incluye ensanchamiento por defectos del tamaño cristalino (modelo de Le Bail).

En el caso de la fase vítrea con el modelo de Le Bail, se refinó únicamente el factor de estructura. Para las demás fases se refinaron el factor de escala, los parámetros de celda, y los parámetros que describen el perfil. El fondo del difractograma se calculó a 
partir de la interpolación entre pares de valores ( $2 \theta$ e intensidad). En el refinamiento, estas intensidades se mantuvieron fijas entre $5^{\circ}$ y $45^{\circ}$, donde se presentaba la banda del amorfo. En el resto del difractograma, las intensidades del fondo fueron refinadas.

De los tres métodos de refinamiento estudiados en éste capítulo, esté fue el adpptado finalmente por su mayor precisión.

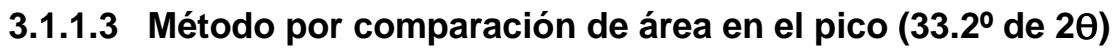

La difracción de polvo es un método de análisis estructural que permite identificar los minerales por su estructura cristalina. No se trata pues de un método analítico químico, pero, como veremos, permite indirectamente estimar la composición de la muestra analizada con una buena aproximación del contenido en elementos mayoritarios. Por otra parte la intensidad de cada pico es directamente proporcional a la cantidad de este elemento en la muestra. Por tanto, puede utilizarse este método para determinar la composición mineralógica de un volumen de muestra [Bragg, 1913; Nyburg, 1954].

En un difractograma multifásico existe la posibilidad de cuantificar el porcentaje de cada fase cristalina presente en la mezcla: en efecto, la sustancia más abundante producirá intensidades de difracción mayores y el área relativa de los picos de difracción permite obtener la cantidad de cada fase. Deben tenerse en cuenta las limitaciones de los métodos basados en intensidades de los picos [Field, 1941; Klug y Alexander, 1974; Rodríguez, 1990; 2001], tales como;

$>$ Debe conseguirse la fase pura o de composición conocida.

$>$ Deben hacerse los barridos en exactamente las mismas condiciones (equipo, portamuesta, voltaje, amperaje, masa, etc).

$>$ Las intensidades individuales de los picos se ven afectadas por fenómenos como:

- Picos superpuestos. Si no es posible, utilizar métodos matemáticos de deconvolución para resolver los picos.

- Orientación preferencial.

- Microabsorción.

Como ya se ha venido mencionando, un análisis cuantitativo de fases cristalinas se fundamenta en el hecho de que las intensidades de las reflexiones de una fase cristalina 
contenida en una muestra dependen de la concentración relativa de dicha fase en la muestra. La relación entre la intensidad y la concentración no es lineal, debido a efectos de absorción. Para obtener el porcentaje de cada fase presente en una muestra (sola ó mezcla) se comparan con las intensidades de los diagramas de control de una composición conocida.

Cuando se utilizó este método, se realizó la cuantificación de tenor de mullita por comparación de las áreas del pico centrado en $33,2^{\circ}$ de $2 \theta$ con el área medida para una mullita sinterizada sintética comercial (Mulcoa 72) de alta calidad (91\% mullita cristalina), utilizando el programa FullProf, para una arcilla caolinita y su mezcla estequiométrica $3 \mathrm{Al}_{2} \mathrm{O}_{3} \cdot \mathrm{SiO}_{2}$ (arcilla - alúmina). Se midió la fase mullita en el pico $33.20^{\circ}$ de $2 \theta$, ya que no se superponían con otras fases como alúmina, cristobalita y cuarzo.

\subsection{ANÁLISIS TÉRMICO DIFERENCIAL Y TERMOGRAVIMETRICO (ATD/TG)}

La termogravimetría (TG) es una técnica utilizada para medir el cambio de peso de una muestra en función de la temperatura. Una poca cantidad de muestra, del orden de los miligramos, es calentada a velocidad constante en el rango de 1 a $20^{\circ} \mathrm{C} \cdot \mathrm{min}^{-1}$. Inicialmente la muestra tiene un peso constante $W_{i}$ pero cuando comienza a descomponerse, a una temperatura $T_{f}$, adquiere un valor $W_{f}$. Bajo estas condiciones de calentamiento, la descomposición tiene lugar usualmente sobre un rango de temperatura de $T_{i}$ a $T_{f}$, figura 3.2. [Smothers y Chiang, 1958; West, 1984] 


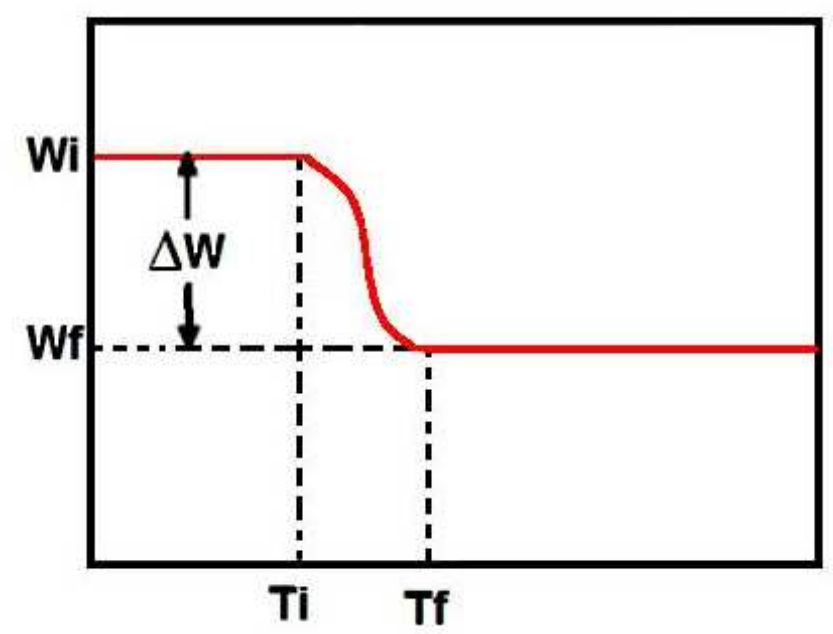

Figura 3.2. Termograma esquemático para una reacción de descomposición de un solo paso [Mackenzie, 1957].

El Análisis Térmico Diferencial (ATD), es una técnica en la cual la temperatura de la muestra de interés se compara con la temperatura de un material inerte (referencia) mientras se realiza un cambio de temperatura a velocidad programada. Las temperaturas de la muestra y de la referencia son las mismas hasta que algún evento térmico asociado con un $\Delta \mathrm{H}$ (entalpía de reacción) ocurre en la primera, tal como la fusión, la descomposición, o el cambio en la estructura del cristal. En este caso dichos eventos pueden disminuir (cambio endotérmico) o aumentar la temperatura (cambio exotérmico) de la muestra, con respecto a la temperatura de referencia. El análisis térmico diferencial permite conocer a qué temperatura ocurren los cambios dentro de la muestra en estudio cuando es sometida a un tratamiento térmico y la intensidad relativa de los mismos, entre otras informaciones. El análisis térmico se emplea para estudiar reacciones en estado sólido, descomposiciones térmicas, transiciones de fase para determinar diagramas de fase, etc. [Mackenzie, 1957; 1970].

Las materias primas arcillosas se analizaron mediante las técnicas de Análisis Térmico Diferencial (DTA) y Análisis Termogravimétrico (TG) para apreciar los cambios que ocurrían dentro de las mismas con la temperatura. Para el desarrollo de este trabajo se usó un equipo NETZSCH 409/c, a una velocidad de calentamiento de $10{ }^{\circ} \mathrm{C} \cdot \mathrm{min}^{-1}$, hasta $1400^{\circ} \mathrm{C}$. 


\subsection{ANÁLISIS QUÍMICO}

El análisis químico de cualquier material es una técnica insustituible en la caracterización del mismo, pues permite determinar la composición química del material en estudio, la presencia o no de impurezas e inferir la influencia que dicha composición puede tener en el comportamiento del mismo [Spiers et., 1983].

Los análisis químicos de las materias primas se tomaron de las fichas técnicas suministradas por los proveedores de las mismas. Pero luego para las materias primas arcillosas de tipo caolinita seleccionadas para el conformado final de las piezas (prensado, colado y extrusión) se realizaron los análisis por Espectroscopia de Emisión Atómica por Plasma Inductivamente Acoplado (ICP-AES) [Xiandeng y Bradley; 2000], observándose en esos casos ligeras diferencias, las cuales son normales en rocas naturales como las arcillas caoliníticas.

\section{4 ÍNDICE DE PLASTICIDAD}

Para determinar el Índice de Plasticidad (IP) de una muestra se debe conocer el Límite Líquido (LL) y el Plástico (LP) de la misma y la diferencia de estos da este valor del IP. Las normas que describen los métodos de ensayo son la IRAM 10501 y 10502 respectivamente.

\subsubsection{Límite Plástico}

El ensayo se realiza tomando aproximadamente $20 \mathrm{~g}$ de muestra malla pasante 40 , se coloca en una cápsula, se añade agua poco a poco, se mezcla con una espátula hasta obtener una masa plástica y uniforme. Luego del amasado se toma una porción, se hace rodar sobre una superficie lisa, dándole forma de pequeños cilindros, los cuales deben presentar fisuras o signos de desmenuzamiento al llegar a $3 \mathrm{~mm}$ de diámetro. Si al llegar a $3 \mathrm{~mm}$ de diámetro no se logra lo anterior por mantener el estado plástico se reúnen los trozos y se amasan nuevamente, tantas veces como sea necesario hasta que se cumpla con la condición requerida (sucesivos mezclados, amasados y trabajó de rodado eliminan gradualmente agua del sistema), [IRAM 10 502]. 
Logrando lo anterior, se colocan los cilindros en un pesafiltro tarado, tapándolo inmediatamente para evitar evaporación. Se pesa, se deduce el valor de Gh (peso de la masa húmeda), luego se coloca en una estufa a $105 \stackrel{\circ}{\circ}$ hasta peso constante, deduciendo el valor de Gs (peso de la masa seca). El límite plástico se expresa en porcentaje y se calcula:

$$
L P=\frac{G h-G s}{G s} \times 100
$$

Deben realizarse tres determinaciones tomando la media aritmética de los resultados obtenidos, para así disminuir los errores de interpretación o de medición.

\subsubsection{Límite Líquido}

Se toman aproximadamente $50 \mathrm{~g}$ de muestra malla pasante 40 , se coloca en una cápsula, se añade agua poco a poco, se mezcla con una espátula hasta obtener una masa plástica y uniforme. Luego de amasado se toma una porción, se coloca en la cuchara del aparato de Casa Grande (marca Cosacov), y con la ayuda de una espátula se modela una superficie lisa que sea horizontal cuando la cuchara esté apoyada y cuyo espesor, en el centro sea de aproximadamente $10 \mathrm{~mm}$. Con el acanalador se practica un surco en la muestra, evitando despegarla de la cuchara, de manera que su plano de simetría coincida con el del aparato [IRAM 10 501], ver figura 3.3.

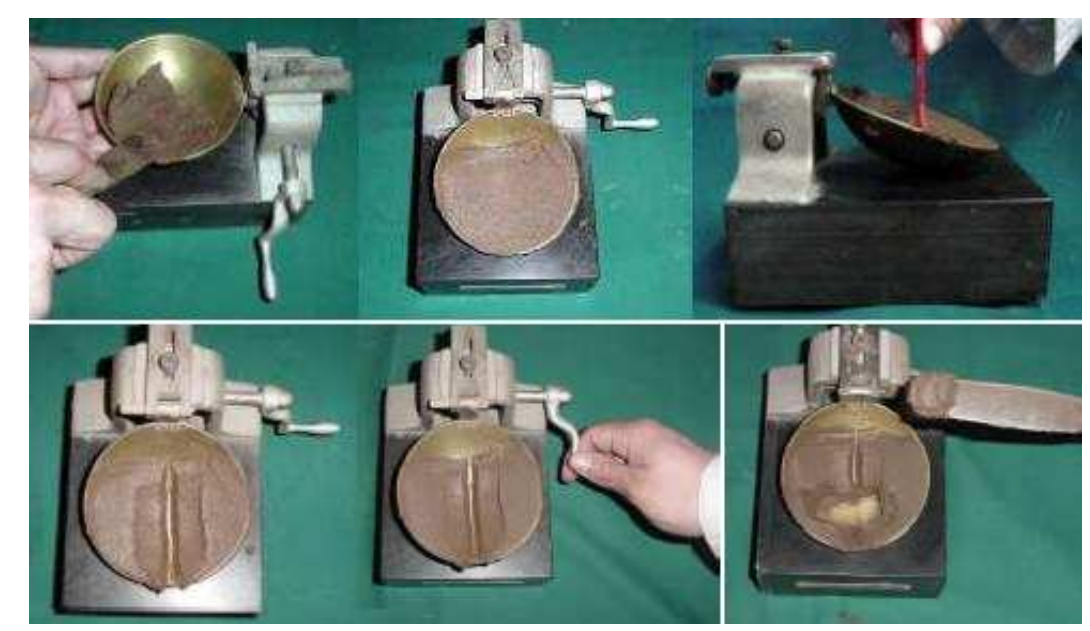

Figura 3.3. Etapas para la determinación del límite líquido mediante el aparato de Casagrande. 
Posteriormente se gira la manivela del aparato dándole dos vueltas por segundo y contándose los golpes así generados hasta que los dos bordes de la muestra se juntan en el fondo del surco en una longitud de aproximadamente $12 \mathrm{~mm}$ como consecuencia de la fluencia de la pasta. El número de golpes debe ser tal que se requieran entre 20 y 30 golpes para la unión de los bordes de la muestra.

Del lugar donde se juntan los bordes de la muestra se toma una porción de $20 \mathrm{~mm}$ de largo y ancho con la espátula y se coloca en un pesafiltro tarado tapándolo inmediatamente para evitar evaporación. Se pesa, se deduce el valor de Gh, luego se coloca en la estufa a $105 \stackrel{\circ}{\mathrm{C}}$ hasta peso constante, deduciéndose el valor de Gs. El límite líquido se expresa en porcentajes y se calcula:

$$
L L=\frac{G h-G s}{G s} \times 100 \times\left(\frac{N}{25}\right)^{0.12}
$$

Donde $\mathrm{N}=$ el número de golpes requeridos para la unión de los bordes inferiores de la muestra dejando $12 \mathrm{~mm}$ sin unir. En la tabla 3.1 figuran los valores de $(\mathrm{N} / 25)^{0.12}$ correspondientes a $\mathrm{N}$ entre 20 y 30 golpes.

El índice de plasticidad (IP) expresado en porcentaje, se calcula por medio de la siguiente fórmula:

$$
I P=L L-L P
$$

Tabla 3.1. Valores de $(\mathrm{N} / 25)^{0.12}$ correspondientes a $\mathrm{N}$ entre 20 y 30 golpes. Aparato Casagrande [IRAM 10 501].

\begin{tabular}{|c|c|c|c|}
\hline $\mathbf{N}$ & $(\mathbf{N} / 25)^{0.12}$ & $\mathbf{N}$ & $(\mathbf{N} / 25)^{0.12}$ \\
\hline $\mathbf{2 0}$ & 0.974 & 26 & 1.005 \\
\hline $\mathbf{2 1}$ & 0.979 & 27 & 1.009 \\
\hline $\mathbf{2 2}$ & 0.985 & 28 & 1.014 \\
\hline $\mathbf{2 3}$ & 0.990 & 29 & 1.08 \\
\hline $\mathbf{2 4}$ & 0.995 & 30 & 1.022 \\
\hline $\mathbf{2 5}$ & 1.000 & & \\
\hline
\end{tabular}


Los valores del límite líquido, plástico e índice de plasticidad, fueron de vital importancia para el conformado de las probetas elaboradas en este trabajo, debido a que con esa información se pudo predecir la cantidad de agua necesaria para el conformado de las probetas, ya sea por el método de prensado, extrudado y colado. Estos ensayos se realizaron sobre las materias primas arcillosas y a las mezclas estequiométricas $3 \mathrm{Al}_{2} \mathrm{O}_{3}$ $2 \mathrm{SiO}_{2}$ (arcilla - alúmina) que se utilizaron para el desarrollo de este trabajo. Los resultados que se mostrarán son el promedio de tres pruebas realizadas para cada muestra.

\subsection{CONO PIROMÉTRICO EQUIVALENTE (CPE)}

Existe diversidad de materiales refractarios, que se diferencian uno del otro en su composición - estructura, y por ende no exhiben un punto de fusión uniforme. El cono pirométrico equivalente es una medida de la refractariedad de un material cerámico.

Un cono pirométrico normal (de referencia) es una pieza moldeada en forma de pirámide trunca de base triangular, de dimensiones y composición normalizadas, que se identifica con un número característico. La punta troncocónica toca la plaqueta de soporte cuando se la somete a un calentamiento en un horno a una determinada temperatura, y el cono pirométrico equivalente de un material (de estudio) es un cono elaborado con la muestra problema cuya punta toca la plaqueta de soporte al mismo tiempo que el cono de referencia normalizado, asignándosele a la muestra en estudio el mismo número que el normalizado (de referencia) correspondientemente a la norma IRAM 12507. Ver tabla 3.2, cada número tiene asociado una temperatura que es aquella donde la punta del cono toca la base de la placa donde se apoya. 
Tabla 3.2. Temperatura equivalente al cono pirométrico (de acuerdo con la serie de conos Orton U.S.A.). [IRAM 12507].

\begin{tabular}{|c|c|c|c|c|c|}
\hline $\begin{array}{c}\text { Cono IRAM } \\
\#\end{array}$ & $\begin{array}{c}\text { Temperatura } \\
\left({ }^{\circ} \mathrm{C}\right)\end{array}$ & $\begin{array}{c}\text { Cono IRAM } \\
\#\end{array}$ & $\begin{array}{c}\text { Temperatura } \\
\left({ }^{\circ} \mathrm{C}\right)\end{array}$ & $\begin{array}{c}\text { Cono IRAM } \\
\#\end{array}$ & $\begin{array}{c}\text { Temperatura } \\
\left({ }^{\circ} \mathrm{C}\right)\end{array}$ \\
\hline $\mathbf{1 2}$ & 1337 & 26 & 1621 & 34 & 1763 \\
\hline $\mathbf{1 3}$ & 1349 & 27 & 1640 & 35 & 1785 \\
\hline $\mathbf{1 4}$ & 1398 & 28 & 1646 & 36 & 1804 \\
\hline $\mathbf{1 5}$ & 1430 & 29 & 1659 & 37 & 1820 \\
\hline $\mathbf{1 6}$ & 1491 & 30 & 1665 & 38 & 1835 \\
\hline $\mathbf{1 7}$ & 1512 & 31 & 1683 & 39 & 1865 \\
\hline $\mathbf{1 8}$ & 1522 & $311 / 2$ & 1699 & 40 & 1885 \\
\hline $\mathbf{1 9}$ & 1541 & 32 & 1717 & 41 & 1970 \\
\hline $\mathbf{2 0}$ & 1564 & $321 / 2$ & 1724 & 42 & 2015 \\
\hline $\mathbf{2 3}$ & 1605 & 33 & 1743 & - & - \\
\hline
\end{tabular}

Para efectuar la determinación del CPE en las muestras estudiadas en este trabajo de tesis (arcilla/caolín y mezcla estequiométrica $3 \mathrm{Al}_{2} \mathrm{O}_{3} \cdot \mathrm{SiO}_{2}$ ) se utilizó un horno apropiado según norma, (figura 3.4).
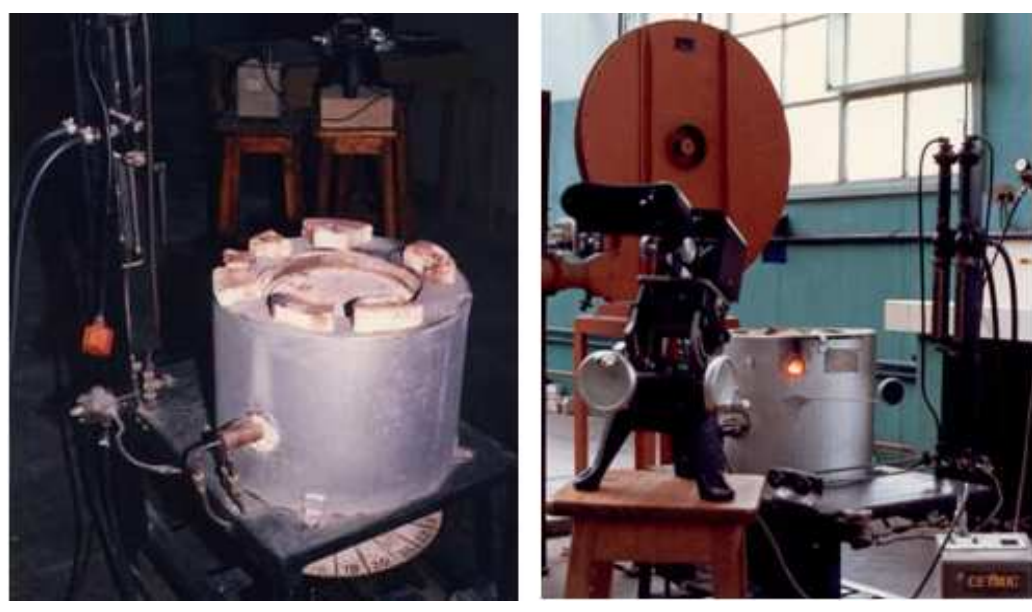


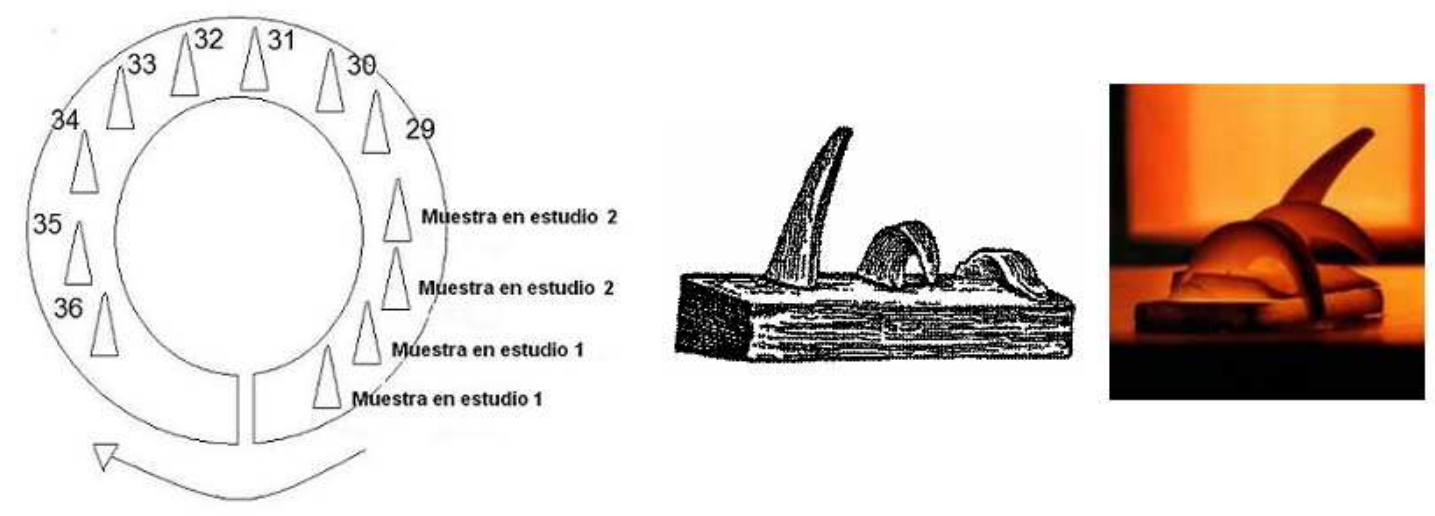

Figura 3.4. Ensayo de cono pirométrico (CPE).

Una serie de conos de referencia con temperaturas de caída regulares se calientan en el mismo horno con los conos de prueba fabricados con el material de la muestra, de manera que es posible realizar una determinación de temperatura comparativa precisa del punto de reblandecimiento del material.

\section{6}

VOLUMEN Y DENSIDAD APARENTE EN AGUA, POROSIDAD ABIERTA Y DENSIDAD APARENTE (ARQUIMEDES).

Los resultados de volumen aparente en agua, porosidad porcentual, densidad y densidad aparente en agua de los materiales sinterizados en este trabajo (mullita) se determinaron aplicando el método de Arquímedes de inmersión en agua [ASTM C20].

El ensayo consiste en medir el peso de la probeta seca $\left(P_{s e c}\right)$, el peso de la misma luego de hervirla durante dos horas en agua destilada e inmersa en agua $\left(P_{\text {sat }}\right)$ y finalmente el peso de la probeta saturado en agua en donde toda su porosidad abierta es ocupada por agua $\left(\mathrm{P}_{\text {sum }}\right)$.

Se midieron los tres parámetros mencionados a cada una de las probetas, obteniéndose con ellos los siguientes datos:

- Volumen aparente (global del material):

$$
\text { Volumen Aparente }=V_{a p}=\frac{P_{\text {sat }}-P_{\text {sum }}}{\delta_{l}}
$$


$\delta_{l}=$ Densidad del líquido $\left(\right.$ agua $\left.=1 \mathrm{gr} / \mathrm{cm}^{3}\right)$ :

- La porosidad abierta es el cociente entre el volumen de los poros abiertos y el volumen del material.

$$
\text { Porosidad } \%=\frac{\frac{P_{\text {sat }}-P_{\text {sec }}}{\delta_{l}}}{V_{a p}} \times 100
$$

- Densidad del material

$$
\text { Densidad }=\frac{P_{s e c}}{V_{a p}}=\delta
$$

- Densidad aparente en agua, es la del sólido incluyendo el poro cerrado:

$$
\text { Densidad aparente en agua }=\delta_{a p}=\frac{P_{s e c}}{\frac{P_{s e c}-P_{s u m}}{\delta_{l}}}
$$

Esta densidad define la densidad del material sólido, incluyendo como volumen total del sólido a los poros cerrados.

Los resultados que se mostrarán para cada materia prima arcillosa y mezcla estequiométrica $3 \mathrm{Al}_{2} \mathrm{O}_{3} \cdot 2 \mathrm{SiO}_{2}$ (alúmina - arcilla) son el promedio de los resultados de 10 probetas con la misma composición.

\subsection{MICROSCOPÍA ELECTRÓNICA DE BARRIDO (SEM).}

El microscopio electrónico de barrido (SEM, del inglés Scanning Electron Microscopy), figura 3.5, permite obtener información sobre la morfología a nivel de superficie del material a evaluar. 


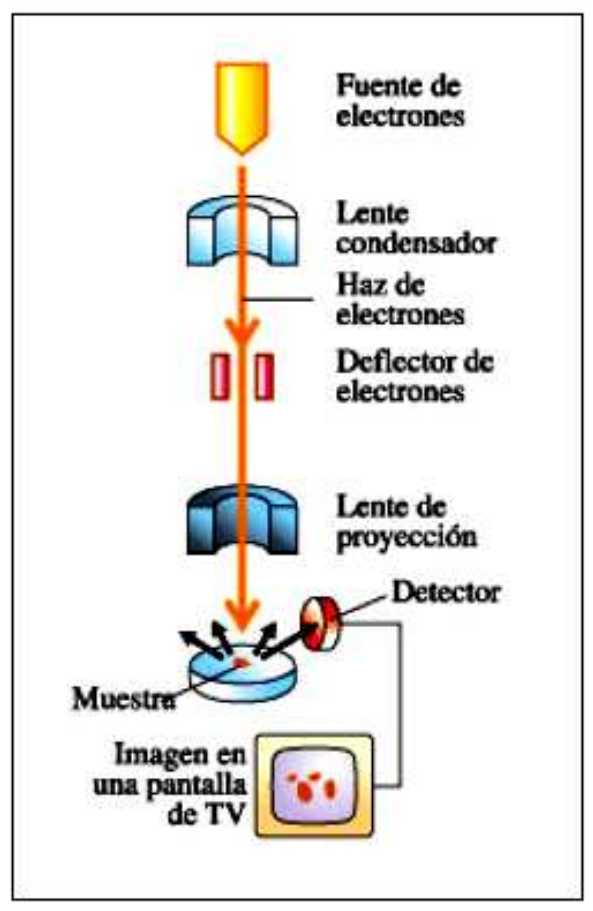

Figura 3.5. Esquema del microscopio electrónico de barrido (SEM).

El principio del funcionamiento del microscopio se basa en la generación de electrones por efecto termo-iónico, a partir de un filamento de tungsteno. Estos son acelerados con potenciales cerca de los 1-30 kV, los cuales se hacen pasar por un conjunto de elementos como lentes magnéticas, condensadores y objetivos, con la finalidad de colimar el haz de electrones sobre la muestra.

Cuando el haz de electrones interactúa con la muestra, se generan varias emisiones, tales como electrones secundarios, electrones retrodispersados y rayos- $\mathrm{X}$, los cuales dependen tanto de las características del espécimen en estudio como de la energía del haz colimado. Estas emisiones son capturadas por un detector, que produce un determinado voltaje de mayor o menor intensidad en función del número de electrones que son capturados. De esta forma es posible obtener una imagen en claros y oscuros de la superficie de una muestra, pues los electrones que provienen de zonas altas (más superficiales) llegan directamente al detector, mientras que algunos electrones de las zonas bajas (más profundas), pueden quedar atrapados. [Agar et., 1974; Goldstein et., 2003; Hammond, 1997].

En análisis por SEM es un estudio importante para el desarrollo de los materiales cerámicos, debido a que la microestructura de un material esta constituida por fases 
cristalinas, poros, fase vítrea, bordes de grano, etc. Todas estas características afectan tanto las propiedades como los comportamientos del material. Estos aspectos microestructurales dependerán de elementos tales como la naturaleza química y cristaloquímica de las materias primas y del procesamiento del material.

Para realizar el análisis de SEM en el presente trabajo de tesis, se procedió a tratar las muestras de la siguiente forma:

- Las probetas fueron montadas en resina fenólica de alta densidad, en una inclusora marca Prazis - modelo MP2.

- Se pulieron en forma manual, empleando en primera etapa polvos de carburo de silicio de distinta granulometría (malla 120, 220, 500 y 1000) durante por lo menos 5 minutos cada uno, de manera descendente en el tamaño, por vía húmeda (agua), realizando ultrasonido entre cada pulido de manera de evitar contaminación de la muestra.

- En una segunda etapa el pulido se realizó con pastas diamantadas, con diferentes diámetros $(15 \mu \mathrm{m}, 5 \mu \mathrm{m}, 3 \mu \mathrm{m}, 1 \mu \mathrm{m}$ y $1 / 4 \mu \mathrm{m})$, puliéndolas de manera descendente, por vía húmeda (kerosene) sobre telas marca Buehler, durante aproximadamente 5 minutos o el tiempo suficiente para borrar las huellas del paso anterior, realizando ultrasonido entre cada pulido.

Se compararon las micrografías de las probetas pulidas con las mismas luego de un tratamiento del tipo "etching" químico, con el cual se revelaron los bordes de grano de las microestructuras a través de un tratamiento con ácido fluorhídrico (HF) al 5\%, durante 10 minutos. [Elssner et., 1999].

Generalmente se usaron varios grados de aumentos debido a las microestructuras presentadas por los materiales de estudio, encontrándose entre 32 y $8000 x$. En todos los casos se depositó una capa conductora de oro. El equipo que se utilizó en el presente trabajo fue un Microscopio Electrónico de Barrido FEI, modelo Quanta 200. 


\subsection{DILATOMETRÍA - Coeficiente medio de dilatación lineal}

Esta técnica permite registrar en forma continua la variación de longitud (contracción o expansión) de una muestra conformada como probeta cilíndrica o prismática, la cual es sometida a calentamiento o enfriamiento en condiciones controladas. De esta forma puede definirse un coeficiente medio de expansión térmica lineal:

$$
\alpha_{\Delta \ell}=\frac{\Delta \ell}{\ell_{o} \Delta T}
$$

dónde:

$\Delta \ell=$ variación de longitud $\left(\ell_{f}-\ell_{0}\right)$

$\ell_{0}=$ longitud inicial

$\Delta T=$ variación de temperatura $\left(T_{f}-T_{0}\right)$

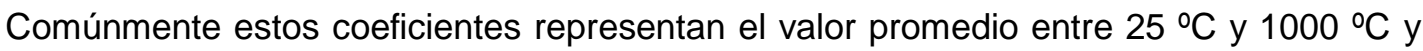
se expresan en unidades de ${ }^{\circ} \mathrm{C}^{-1}$.

Las probetas utilizadas fueron de tamaño de $0.8 \times 0.8 \times 50 \mathrm{~mm}^{3}$, con sus caras extremas pulidas, planas y paralelas, estas probetas fueron sinterizadas a temperatura de $1550{ }^{\circ} \mathrm{C}$ a $5{ }^{\circ} \mathrm{C}$ por minuto, durante 4 horas, previo al análisis dilatómetro. En material estable permite medir el coeficiente de dilatación lineal a partir de dos puntos determinados de la curva graficada en la Dilatometría.

Se utilizó un dilatómetro Netzsch (figura 3.6) con velocidad de calentamiento de 5 ํㅡ por minuto, desde temperatura ambiente hasta $1100{ }^{\circ} \mathrm{C}$, siguiendo la norma ASTM-E228; DIN 51045-1/5.

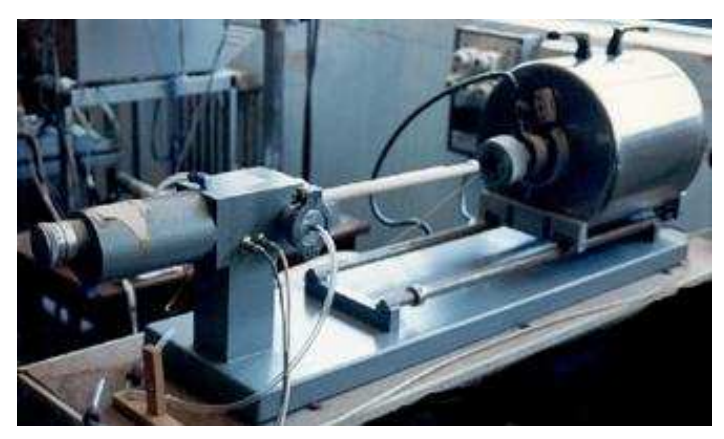

Figura 3.6. Equipo para análisis dilatométrico. 
La teoría de la medida de porosidad por intrusión de mercurio se basa en el principio físico de que un líquido no reactivo y no humectante, no va a penetrar en los poros abiertos de un material hasta que la presión que se aplica sea suficiente para forzar su entrada venciendo las fuerzas de tensión superficial.

A medida que la presión aplicada aumenta, el mercurio es introducido en poros cada vez más estrechos. Este método permite determinar el volumen de poros y la distribución de tamaños de poros, siendo adecuado para materiales mesoporosos y aplicable a poros mayores a 3,6 nm. Esta técnica solo considera poros abiertos, es decir, accesibles al mercurio en el que está sumergido el material.

Para obtener la curva de distribución de poros en función del radio aparente de los mismos se emplea la ecuación de Washburn [Washburn, 1921].

$$
r=\frac{-2 \sigma \cos \theta}{P}
$$

$\mathrm{r}=$ radio del poro $(\mathrm{nm})$.

$\mathrm{P}=$ presión aplicada $\left(\mathrm{Kg} / \mathrm{cm}^{2}\right)$.

$\Theta$ = ángulo de contacto sólido líquido.

$\sigma=$ tensión superficial del mercurio (dinas/cm)

La ecuación de Washburn correlaciona el radio de poro en forma inversa a la presión ejercida. A medida que la presión aumenta, el mercurio va introduciéndose en los poros cada vez más pequeños. Sin embargo la penetración nunca es perfecta, ya que se necesitaría una presión infinita para llenar todos los poros completamente y esta condición provocaría alteraciones en la estructura de los poros en la muestra. Por lo tanto, por intrusión de mercurio y con el instrumento disponible se pueden determinar radios de poros entre $3,7 \mu \mathrm{m}$ y $16 \mathrm{~A}^{\circ}$ en un equipo Thermo Scientific, Pascal 440 series, lo cual permite trabajar a presiones que no afectan a la estructura porosa (en general se aplica presión en un rango de hasta $4000 \mathrm{Kg} / \mathrm{cm}^{2}$ ).

Esta técnica se utilizó para el estudio de las propiedades texturales de mullita obtenida a partir de mezcla estequiométrica $3 \mathrm{Al}_{2} \mathrm{O}_{3} \cdot 2 \mathrm{SiO}_{2}$ elaborada por tres métodos distintos de conformado. 


\subsection{MÓDULO DE ELASTICIDAD DINÁMICO (E)}

La medida de módulo de elasticidad dinámico (E), es un ensayo no destructivo y se basa en la relación bien fundamentada que existe entre la frecuencia de vibración de cada material y sus propiedades elásticas además de su geometría y densidad.

Este ensayo se midió en un equipo marca GrindoSonic, Modelo MK5 "Industrial" (http://www.grindosonic.com) según lineamientos de la norma ASTM C1198-01.

El esquema del sistema de medida para la evaluación de E, se muestra en la figura 3.7 donde las barras a ensayar se apoyan sobre soportes perpendiculares a una distancia de 0.224 de la longitud de la misma (que actuarán como nodos de las ondas propagadas), a continuación la barra es golpeada en el centro con un pequeño martillo generando una onda vibratoria a lo largo del material. La frecuencia de la misma es medida con un sensor (micrófono), para luego ser transmitida como una señal eléctrica.

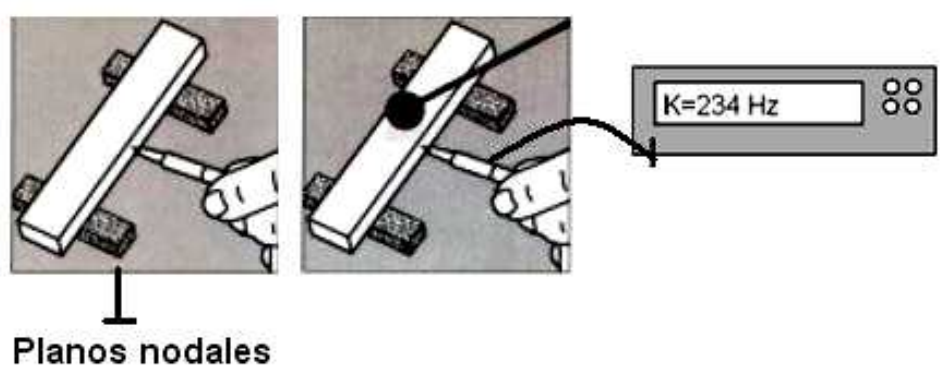

Figura 3.7. Esquema del sistema utilizado en el método de excitación por impulso para la evaluación del módulo de elasticidad dinámico $(E)$ en una probeta prismática.

A partir del peso y dimensiones de la probeta, el coeficiente de Poisson $(\mu=0.3)$ y la frecuencia de la onda, se calcula el módulo elástico dinámico, dado por la siguiente ecuación:

$$
E=0.9465\left(\frac{m f_{f}^{2}}{w}\right) *\left(\frac{L^{3}}{e^{3}}\right) * T_{1}
$$

Dónde:

$E=$ módulo de Young.

$\mathrm{m}=$ masa de la barra.

$w=$ ancho de la barra.

$\mathrm{L}=$ longitud de la barra. 
$e=$ espesor de la barra.

$f_{f}=$ frecuencia fundamental en $\mathrm{Hz}$.

$T_{1}=$ factor de corrección.

El factor de corrección $T_{1}$ viene dado por la siguiente ecuación:

$$
T_{1}=1+6.585\left(1+0.2023 \mu+2.173 \mu^{2}\right)(e / L)^{2}-0.868(e / L)^{4}-\left[\frac{8.340\left(1+0.2023 \mu+2.173 \mu^{2}\right)(e / L)^{4}}{1.000+6.338\left(1+0.1408 \mu+1.536 \mu^{2}\right)(e / L)^{2}}\right]
$$

Si la relación entre la longitud y el espesor de la barra es suficientemente grande (L/e>20) la expresión de la ecuación anterior se simplifica a la siguiente ecuación:

$$
T_{1}=\left[1.000+6.585\left(\frac{e}{L}\right)^{2}\right]
$$

De la misma manera hay algoritmos para otras geometrías simples, como los discos, placas cuadradas o anillos.

Los valores de módulo de elasticidad dinámico se expresaron en GPa. La evaluación de E fue realizada sobre 10 probetas para cada material estudiado, y los resultados que se mostrarán son el promedio de los valores obtenidos.

\subsection{RESISTENCIA A LA FLEXIÓN EN TRES PUNTOS (MOR)}

La resistencia a la flexión ó Módulo de Rotura a la Flexión o MOR, es uno de los parámetros más difundidos para caracterizar la resistencia mecánica de materiales cerámicos. El módulo de rotura se define como la tensión máxima que un espécimen de prueba puede soportar en una prueba de flexión de 3 ó 4 puntos hasta que se rompe, expresado en $\mathrm{N} / \mathrm{mm}^{2}$ o MPa.

Para realizar el ensayo de MOR, las probetas prismáticas se pusieron sobre dos apoyos separados aproximadamente el 80 por ciento de la longitud, ya que el ensayo realizado en esta tesis fue de resistencia a la rotura por flexión en tres puntos, ver figura 3.8. La 
carga se aplicó lentamente en el centro de la distancia entre los apoyos, con una velocidad de desplazamiento de $1.1 \mathrm{~mm} / \mathrm{min}$, hasta la rotura de la probeta.

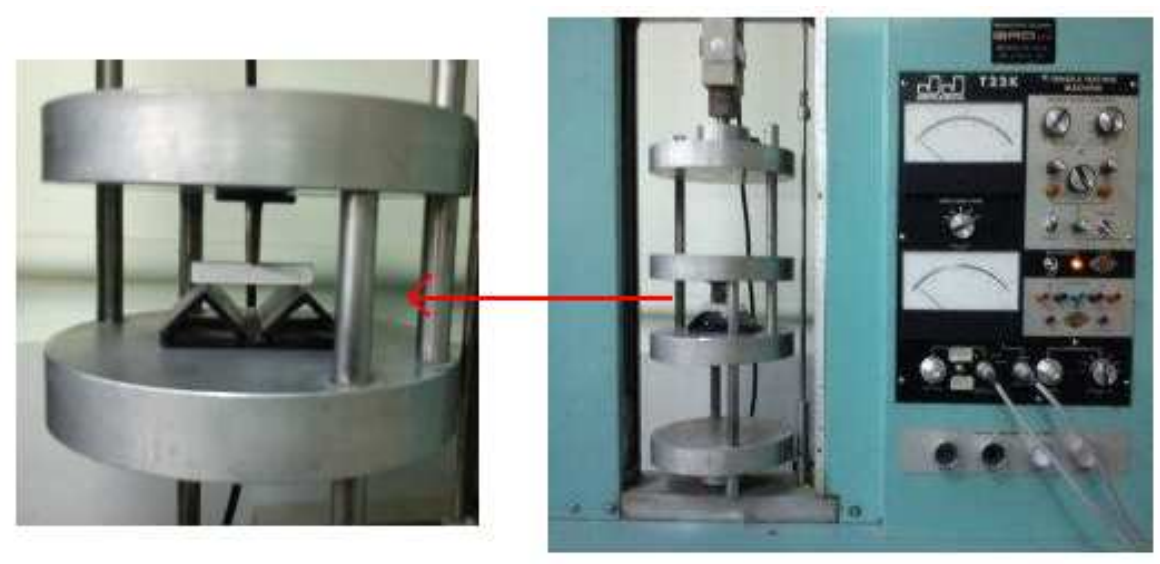

Figura 3.8. Ensayo de Módulo de Rotura (MOR) por flexión en tres puntos.

Con el valor de la carga de rotura, se pudo encontrar el valor de la resistencia mecánica $\sigma_{\mathrm{f}}$ mediante la siguiente ecuación:

$$
\sigma_{f}=\frac{3 Q l}{2 b d^{2}}
$$

Dónde:

$\sigma_{f}=$ resistencia a la flexión $(\mathrm{MPa})$

$Q=$ carga final de rotura (Newton)

I = número de luz de apoyo (longitud del apoyo).

$\mathrm{b}=$ ancho de la probeta.

$d=$ espesor de la probeta.

En este estudio, las medidas de resistencia a la flexión de los materiales estudiados fueron realizadas en una máquina de ensayos mecánicos, marca JJ instruments T22K modificada siguiendo los lineamientos de la norma ASTM C1161-02.

Cada valor de MOR expresado es el promedio de los valores obtenidos de por lo menos 6 probetas nominalmente idénticas para cada material. 


\subsection{RESISTENCIA AL CHOQUE TÉRMICO}

Algunos materiales, como el vidrio o los cerámicos refractarios, pueden sufrir roturas por choque térmico cuando aparece un gradiente de temperatura en el material. El astillamiento o rotura debida al choque térmico es un fenómeno que aparece asociado con cambios bruscos de temperatura, especialmente en materiales frágiles como vidrios y cerámicas. Un cambio brusco de temperatura, por ejemplo, un enfriamiento, provoca que las partes exteriores del material reduzcan su temperatura más rápidamente que el interior, produciendo tensiones mecánicas que si superan la resistencia del material terminan en la rotura parcial o total del mismo. [ASTM C1525].

Indudablemente el deterioro del material estará ligado a las condiciones de ensayo, geometría de la probeta y a la resistencia al choque térmico del material. Es por eso que la evaluación de la tercera será posible y comparativa si es que las primeras se mantienen invariantes.

Recientemente se han desarrollado varios estudios sobre el comportamiento frente al choque térmico de los más diversos materiales debido a que no existe un ensayo simple y universal para estudiar el comportamiento frente al choque térmico de materiales cerámicos-refractarios y que además sea extrapolable a las diferentes condiciones de trabajo del material, sus dimensiones, su geometría y ciclos de temperatura al que es sometido. En cualquier ensayo planteado, los resultados estarán fuertemente ligados a la geometría de la pieza y ciclos térmicos aplicados [Aksel y Warren, 2003].

El método de "quenching" consiste en calentar las probetas a alta temperatura y enfriarlas rápidamente hasta temperatura ambiente por inmersión en agua, alcohol, aceites, etc. determinando alguna propiedad antes y después del tratamiento térmico. Comúnmente se recurre a propiedades físicas características de la probeta: la resistencia mecánica a la rotura por flexión en tres o cuatro puntos, la velocidad del sonido, el módulo de elasticidad, la observación del daño microestructural, etc. Además, no sólo se puede estudiar el efecto de la severidad del tratamiento sino que se puede observar la evolución del daño con la repetición de los tratamientos [Rendtorff, 2009].

En este trabajo se realizó el ensayo tipo quenching en agua a temperatura ambiente: las piezas en forma prismática (elaboradas por el método de prensado, colado y extrudado) previamente calcinadas (a 1550 y $1600{ }^{\circ} \mathrm{C}$ ) con dimensiones de $\sim 5.0 \times 0.8 \times 0.8 \mathrm{~cm}^{3}$, se calentaron en un horno eléctrico hasta la temperatura de $1000^{\circ} \mathrm{C}$, manteniéndolas a esta -45 - 
temperatura durante 20 minutos. Con una pinza metálica (de a una por vez) las probetas fueron sumergidas rápidamente en un baño de agua a temperatura ambiente (figura 3.9). Luego de 5 minutos en el agua las probetas fueron retiradas y secadas en estufa a $110^{\circ} \mathrm{C}$.

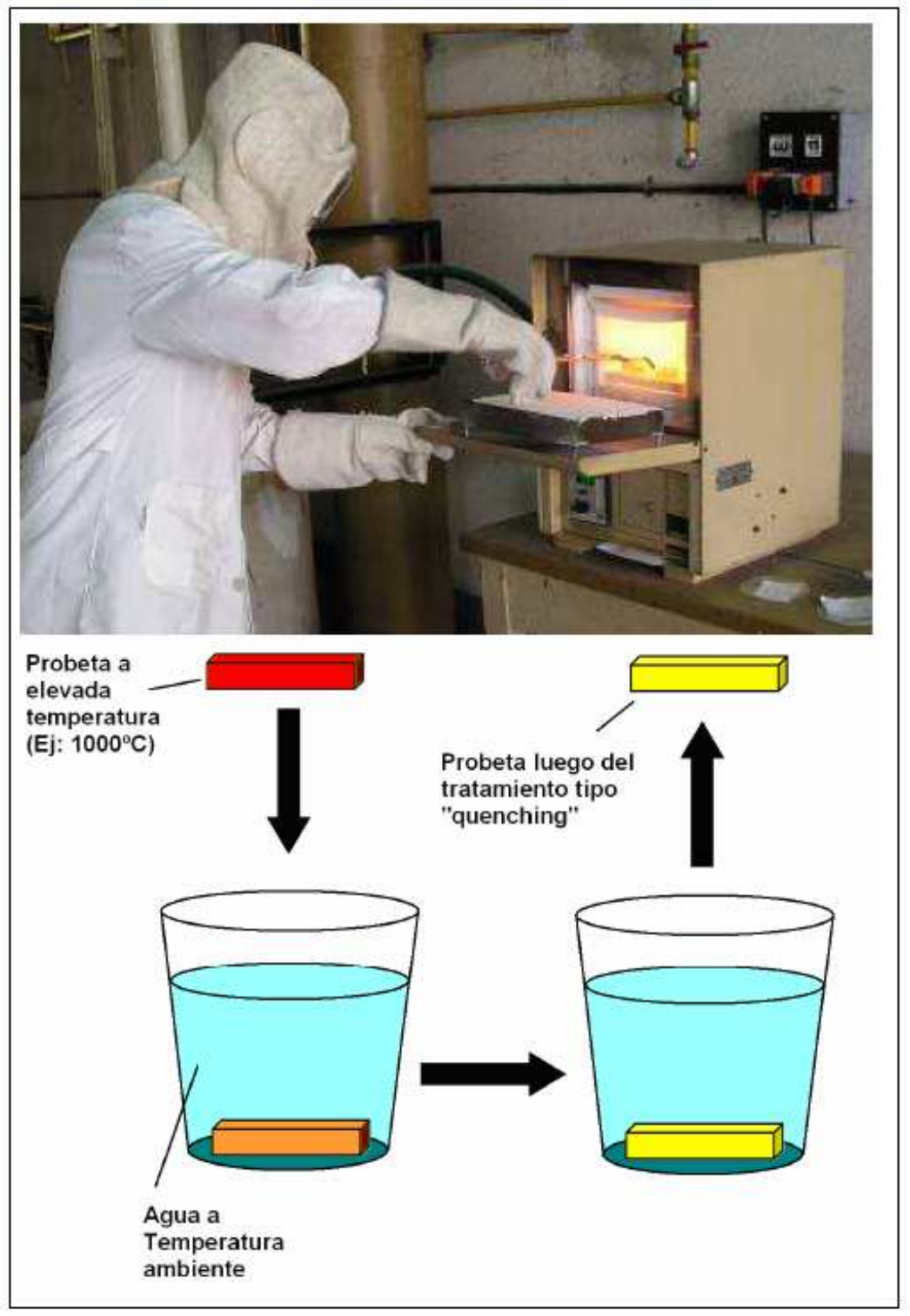

Figura 3.9. Ensayo de choque térmico (quenching). [Rendtorff, 2009].

Por último, la degradación o daño de la microestructura del material fue evaluada mediante la medida del módulo de elasticidad dinámico por el método de excitación por impulso (E2) y módulo de rotura a la flexión (MOR 2) descripto anteriormente, si es que 
la probeta no colapsó por la severidad del choque. La cantidad de agua en el baño debe ser suficiente como para que la diferencia de temperatura de la misma luego de un "quenching" fuera despreciable.

\subsection{VARIACIÓN LINEAL (VL ó $\Delta$ l)}

Por medio de este ensayo se determina la expansión o contracción lineal de un refractario luego de someterlo a la temperatura requerida, o sea se refiere al cambio en las dimensiones de las probetas después de dicho tratamiento térmico con respecto a las dimensiones de las probetas antes del tratamiento térmico. Se expresa en porcentaje, de la siguiente manera:

$$
\Delta l=\frac{\ell_{f}-\ell_{o}}{\ell_{o}} * 100
$$

dónde:

$\Delta \mathrm{l}=$ variación lineal.

$\ell_{\mathrm{f}}=$ longitud final

$\ell_{0}=$ longitud inicial

Las medidas de $\Delta \mathrm{l}$ se tomaron con un calibre sobre la dimensión más larga de las probetas elaboradas, siguiendo las normas IRAM 12516 y 12541. Cada valor presentado es el promedio de los valores obtenidos de por lo menos 10 probetas.

\subsection{BIBLIOGRAFIA}

> Agar A.W., Alderson R.J.H., Chescoe D., Principles and practice of Electron Microscope Operation. Practical Methods in Electron Microscopy, North Holland 2 (1974).

$>\quad$ Aksel C., Warren P.D., Thermal shock parameters [R, R"' and R"'"'] of magnesia - spinel composites, Journal of the European Ceramic Society. 23, pp. 301-308 
(2003).

> ASTM C1525 - 04 Standard Test Method for Determination of Thermal Shock Resistance for Advanced Ceramics by Water Quenching.

> ASTM C20., Standard Test Methods for Apparent Porosity, Water Absorption, Apparent Specific Gravity, and Bulk Density of Burned refectory Brick and Shapes by Boiling Water. (2005)

> Birkholz M., Thin film Analysis by X-ray Sacttering, Wiley- Vch Verlag GmbH \& Co, Germany. (2006).

$>$ Bish D.L., y Howard S.J., Quantitative phase analysis using the Rietveld method. Journal of Applied Crystallography. 21, pp. 86-91 (1988).

$>$ Bish D.L., y Post J.E., Quantitative mineralogical analysis using the Rietveld fullpattern fitting method. American Mineralogist. 78, pp. 932-940 (1993).

> Bish D.L., y Reynolds R.C., Sample preparation for X-ray diffraction, in: modern powder. Diffraction, Reviews in Mineralogy, 20. Mineralogical Society of America, Washington, D.C. pp. 73-99 (1989).

$>$ Bleicher L., Sasaki J. M., y Santos C.O.P. J. Development of a graphical interface for the Rietveld refinement program DBWS. Journal of Applied Crystallography. 33, pp 1189 (2000).

$>$ Bragg W.L., The Diffraction of short electromagnetic waves by a crystal, Proc. Cambridge Phil. Soc., 17, pp. $43-57$ (1913).

$>$ Cullity B. D., Elements of X - Ray difraction, Reading, Massachusetrs Addison Wesley. pp. 84 (1978).

$>$ Elssner G., Hoven H., Kiessler G., Wellner P., Ceramic and ceremic composites: Materialographic preparation. Elservier science, New York, pp. 40-41 (1999).

$>$ Field J. E., X-Ray Study of Proportion of Crystalline and Amorphous Components in Stretched Rubber, Journal of Applied Physics. 12 (1), pp. 23-24(1941).

$>\quad$ Goldstein J., Newbury D.E., Joy D.C., Lyman C.E., Echlin P., Lifshin E., Sawyer L.C., Michael J.R., Scanning Electron Microscopy and X-ray Microanalysis, 3rd edition, Springer. pp. 271-296 (2003).

$>$ Goppel J. M., y Arlman J.J., On the degree of Crystallinity in Natural Rubber: IV, the degree of Crystallization in Frozen Raw Rubber and Stretched Vulcanized Rubber, Applied Science Research. (5 - 6), A1, pp. 462 - 74 (1946). 
$>$ GrindoSonic, Modelo MK5 “Industrial” [http://www.grindosonic.com]

$>$ Hammond, C., The basics of crystallography and diffraction, 3rd edition, Oxford University Press, USA, pp. 243-256 (1997).

$>\quad$ ICSD (Inorganic Crystal Structure Database) [http://www.fizkarlsruhe.de/icsd.html]

$>\quad$ Izumi F., y Momma K., Three-Dimensional Visualization in Powder Diffraction. Solid State Phenomena. 130, pp. 15-20 (2007).

$>$ J. Rodríguez-Carvajal, "Recent Developments of the Program Fullprof," Newsletter in Commission on Powder Diffraction (IUCr). Newsletter 26, pp.12-19 (2001).

$>\quad$ Jenkins R., Snyder R. L., Introduction to X- ray powder diffractometry, Jhon Wiley \& Soncs. Inc. (1996).

$>\quad$ Klug H.P., y Alexander L.E., X-ray diffraction procedures for polycrystalline and amorphous materials. John Wiley \& Sons, New York., pp. 716 (1974).

$>\quad$ Le Bail A., Modelling the silica glass structure by the Rietveld method. Journal of Non-Crystalline Solids 183, pp. 39-42 (1995).

$>$ Mackenzie R. C., The diferential termal investigation of clays. Min. Soc. of London., pp. 124 (1957).

> Mackenzie R.C., Differential Thermal Analysis, Academic Press. London and New York (Academic Press). 1, pp. $393-414$ (1970).

$>$ Moore D.M. y Reynolds R.C., X-ray Diffraction and the identification and analysis of clay minerals, 2nd edition, Oxford University Press, New York. (1997).

$>$ Morimoto S., Phase separation and crystallization in the system $\mathrm{SiO}_{2}-\mathrm{Al}_{2} \mathrm{O}_{3}-$ $\mathrm{P}_{2} \mathrm{O}_{5}-\mathrm{B}_{2} \mathrm{O}_{3}-\mathrm{Na}_{2} \mathrm{O}$ glasses. Journal of Non-Crystalline Solids 352, pp. $756-760$ (2006).

> Norma ASTM C1161-02., Standard Test Method for Flexural Strength of Advanced Ceramics at Ambient Temperature.

> Norma ASTM C1198-01., Standard Test Method for Dynamic Young's Modulus, Shear Modulus, and Poisson's Ratio for Advanced Ceramics by Sonic Resonance.

$>$ Norma ASTM C1259., Method for Dynamic Young's Modulus, Shear Modulus, -49 - 
and Poisson's Ratio for Advanced Ceramics by Impulse Excitation of Vibration.

$>\quad$ Norma ASTM-E228., Coefficient of Linear Thermal Expansion.

$>\quad$ Norma DIN 51045-1/5., Determination of the thermal expansion of solid.

> Norma IRAM 10 501., Métodos de determinación del límite líquido y del índice de fluidez. Instituto Argentino de Racionalización de materiales. (1968).

> Norma IRAM 10 502., Métodos de determinación del límite plástico e índice de plasticidad. Instituto Argentino de Racionalización de materiales. (1968).

$>$ Norma IRAM 10 507. Cono pirométrico equivalente. Instituto Argentino de Racionalización de materiales. (1971).

> Norma IRAM 12516., Método de determinación de la variación lineal permanente por recalentamiento. Instituto Argentino de Racionalización de materiales.

$>\quad$ Norma IRAM 12541., Método de determinación de la variación lineal permanente por calentamiento de hormigones refractarios. Instituto Argentino de Racionalización de materiales.

$>\quad$ Nyburg S. C., X-Ray Determination of Crystallinity in Deformed Natural Rubber, British Journal of Applied Physics. 5 (9), pp. 321-21 (1954).

> O'Connor B.H., y Raven M.D., Application of the Rietveld refinement procedure in assaying powder mixtures. Powder Diffraction. 3, pp. 2-6 (1988).

$>$ Ohlberg S.M., Strickler D.W., Determination of Percent Crystallinity of Partial Devitrified Glass by X-Ray Diffraction. Journal American Ceramic Society. 45, pp.170-171 (1962).

> PDF-2 (Powder Difraction Files) de la ICDD (International Centre for Diffraction Data) con 265.127 compuestos [http://www.icdd.com/products/pdf2.htm]

> Rahaman M.N., Ceramic processing and sintering, taylor \& francis group, 2ed., pp. 163 (1995).

> Rendtorff N.M., Materiales cerámicos del sistema Mullita Zirconia Zircón; propiedades mecánicas, de fractura y comportamiento frente al choque térmico, Tesis doctoral, Universidad Nacional de La Plata, Argentina, pp 27 (2009).

> Rietveld H. M., A profile refinement method for nuclear and magnetic structures, Journal of Applied Crystallography. 2, pp. 65-71 (1969).

$>$ Rodriguez - Caravajal "FULLPROF, a Program for Rietveld Refinement and 
Pattern Matching Analysis", Abstracts of the Satellite Meeting on Powder Difraction of XV Congres of the IUCr, Toulouse, France, pp. 127 (1990).

$>$ Shmueli U., Theories and Ttchinques of crystal structure determination. IUCr, Oxford Science Publications. pp. 269 (2007).

$>\quad$ Skoog D., Leary J., Análisis Instrumental, Ed McGraw-Hill., pp 297-339; 418-449; 600-601(1994).

$>$ Smothers W.J., y Chiang Yao., Differential termal analysis: Theory and practice. Ohem. Publ. Co., (1958).

$>$ Spiers, Dudas, y Hodgins., Simultaneous multielement analysis of clays by inductively coupled plasma-atomic emission spectroscopy using suspension aspiration Clays and Clay Minerals. 31 (5), pp. 397-100 (1983).

$>\quad$ Ward C.R., y French D., Determination of glass content and estimation of glass composition in fly ash using quantitative X-ray diffractometry. Fuel 85, pp. 22682277 (2006).

> Washburn E. W., The Dynamics of Capillary Flow, Physical Review 17, pp. 273 (1921).

$>$ West, A.R., Solid State chemistry and its Applications. John Wiley \& Sons, pp. 639-47 (1984).

$>\quad$ Willams J.P., Carrier G. B, Holland H. J., y Farncomb F.J., The determination of the CrystallineContent of Glass-Ceramics.Journal of Materials Science 2, pp. 513520 (1967).

$>\quad$ Xiandeng Hou y Bradley T. Jones., Inductively Coupled Plasma/Optical Emission Spectrometry In Encyclopedia of Analytical Chemistry R.A. Meyers (Ed.). John Wiley \& Sons Ltd, Chichester., pp. 9468-9485 (2000).

$>\quad$ Young R. A., The Rietveld Method. International Union of Crystallography, Oxford Science Publications, (1993). 


\section{CAPITULO 4}

\section{CARACTERIZACIÓN Y SELECCIÓN DE MATERIAS PRIMAS}

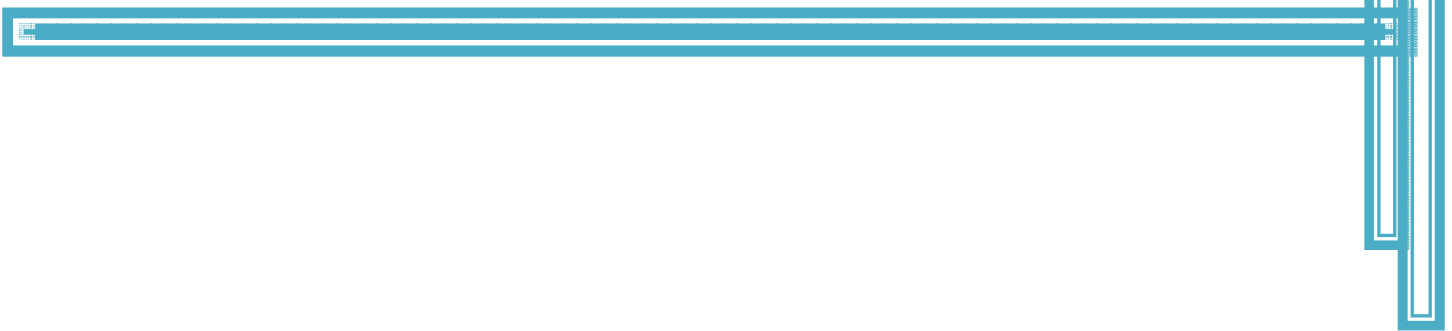

El estudio preliminar de la obtención tecnológica de mullita a partir de arcillas y/o caolines refractarios argentinos, con alúmina calcinada ó alúmina hidratada, se realizaron a partir de varios ensayos de caracterización sobre dichas materias primas, los cuales fueron analizados desde el punto de vista físico-químico, con el fin de encontrar las mejores materias primas arcillosas para el desarrollo y factibilidad tecnológica para producir mullita; caracterizándose también las dos fuentes de alúmina. Posteriormente se procedió a realizar mezclas (arcilla/caolín con alúmina calcinada/hidratada) en proporciones de estequiometría $3 \mathrm{Al}_{2} \mathrm{O}_{3} \cdot 2 \mathrm{SiO}_{2}$ tales que al ser calcinadas a altas temperaturas se obtenga el material deseado (mullita de alta gama), caracterizándolas fisicoquímicamente. En este capítulo se definieron las mejores mezclas estequiométricas para continuar el estudio. 


\subsection{CARACTERIZACIÓN DE MATERIAS PRIMAS}

\subsubsection{ARCILLA/CAOLIN - Materias primas para la producción de mullita estequiométrica $\left(3 \mathrm{Al}_{2} \mathrm{O}_{3} \cdot 2 \mathrm{SiO}_{2}\right)$}

La bondad de una arcilla caolinítica para la producción de mullita sintética depende de diversas características: análisis químico y mineralógico, contracción al secado y calcinación, plasticidad (sobre todo si el proceso de conformado es por prensado ó extrusión), entre otras. [Barba et al., 1997; Berteli y Marsaioli, 2005; Kingery. et al., 1976; Worral, 1968]

Para realizar la caracterización fisicoquímica de las materias primas arcillosas procedentes de diferentes partes de Argentina, se procedió a secarlas con el fin de eliminar humedad de las mismas colocándolas en una estufa a una temperatura de 110 oC durante 24 horas.

Como las materias primas arcillosas (arcillas/caolines) fueron provistas en diferentes granulometrías (unas finas y otras en forma de piedra), se procedió a triturarlas de acuerdo a la granulometría de cada una ellas, con molinos (mandíbula y martillo) para las más gruesas y para las más finas con un mortero de ágata, con el fin de obtener el tamaño de partícula requerida para cada ensayo. Para la elaboración de las mezclas (arcilla - alúmina) se utilizó la materia prima arcillosa a un tamaño de partícula pasante malla \# 200, solo el caolín C-80 se utilizó pasante malla \# 325.

Para la caracterización de las materias primas arcillosas se utilizaron varias técnicas tales como; Difracción de Rayos X (DRX), termogravimetria (TG), Análisis térmico diferencial (ATD), análisis químico, índice de plasticidad y Cono Pirométrico Equivalente (CPE). Se evaluaron las siguientes arcillas: Tincar Súper, La Rioja, caolín C-80 (fino y triturado o molido hasta pasante malla \# 200), caolín Sur del Rio y Patagonia (fino y triturado o molido hasta pasante malla \# 200). 


\subsubsection{Análisis de Difracción de Rayos $X$ (DRX) para las materias primas arcillosas}

Con el fin de conocer las fases cristalinas presentes en las materias primas arcillosas se utilizó la técnica de Difracción de Rayos X, los difractogramas obtenidos se muestran en la figuras 4.1 .

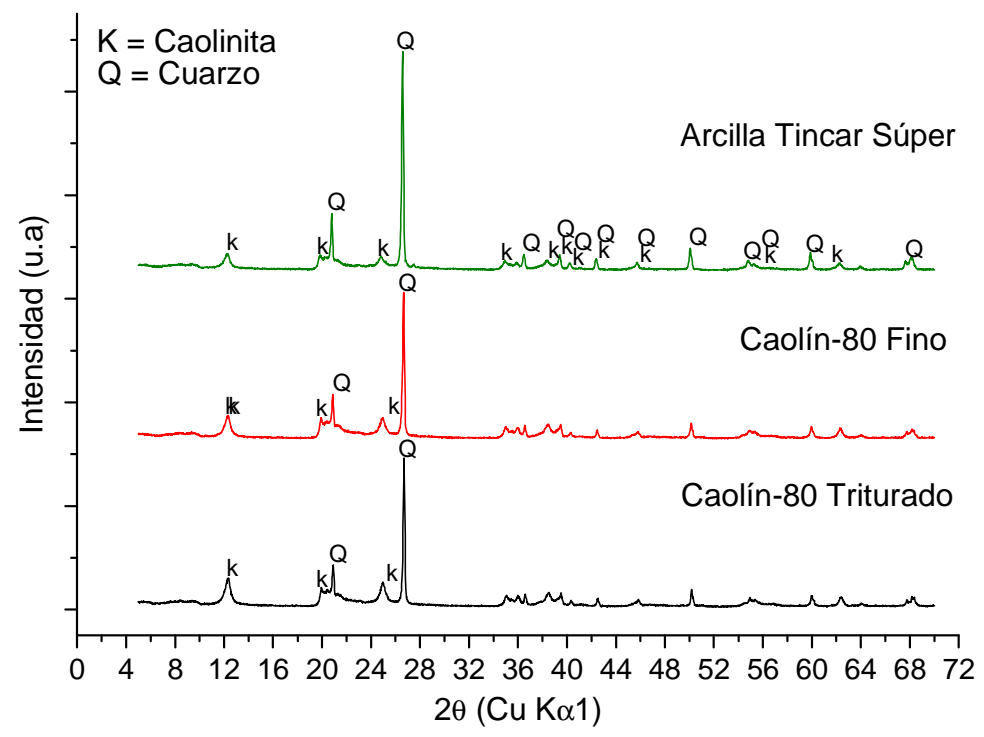

(a)

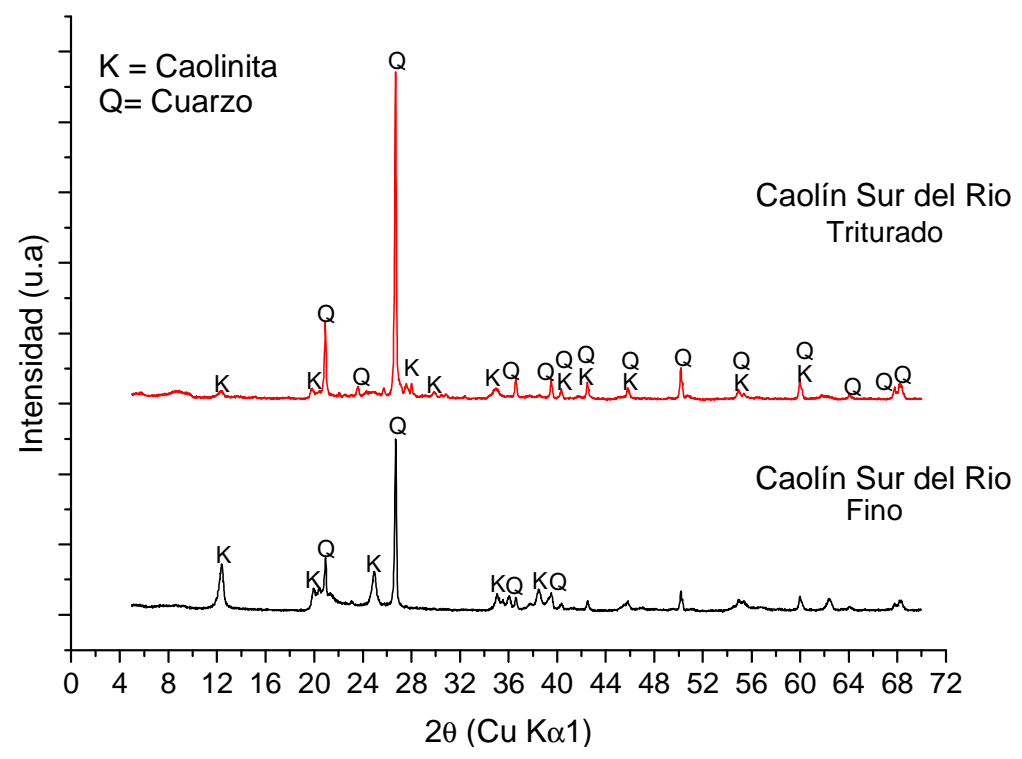

(b) 


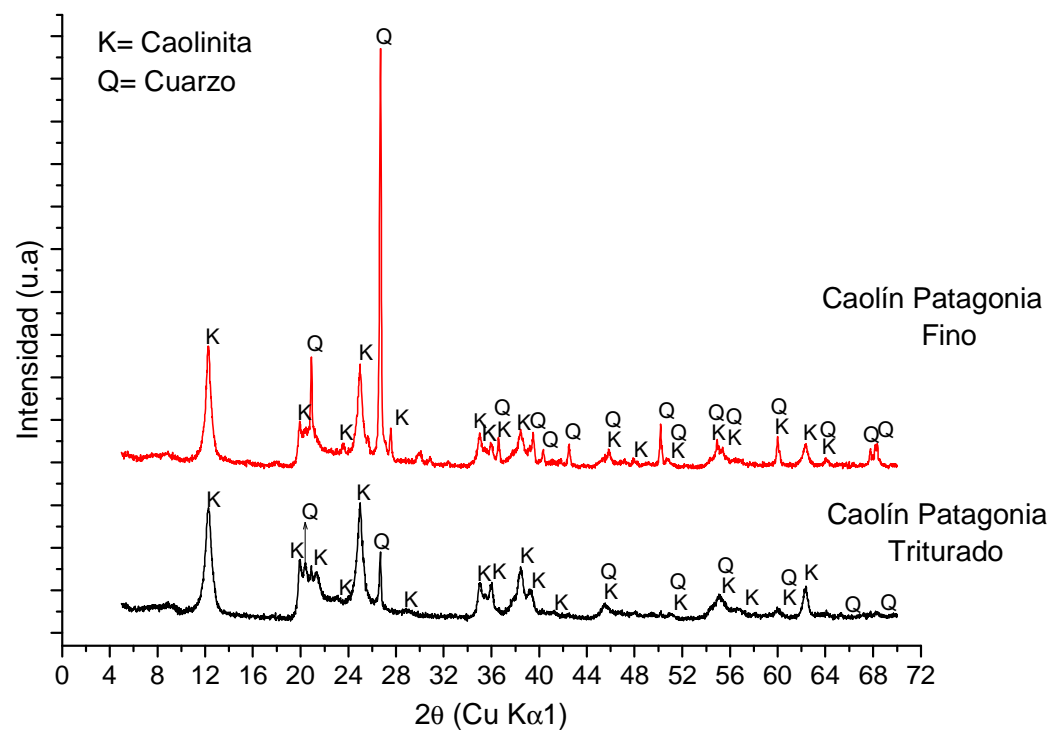

(c)

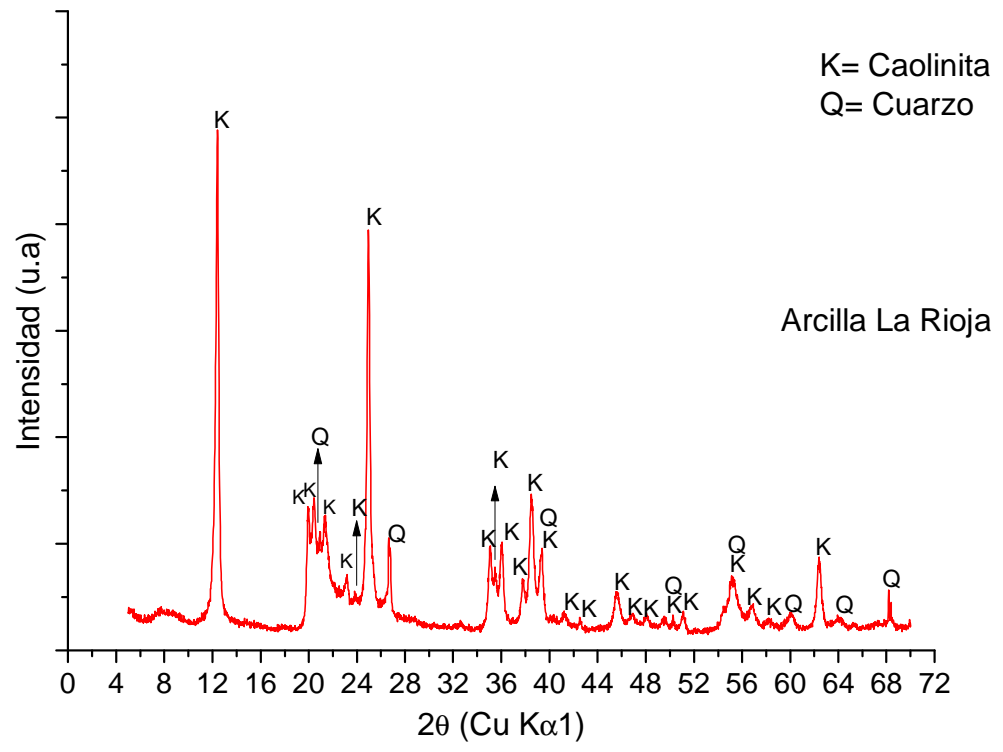

(d)

Figura 4.1. Difractogramas de las materias primas arcillosas. (a) Arcilla Tincar Súper, Caolín C-80 fino y triturado, (b) Arcilla Sur del Rio fino y triturado, (c) Caolín Patagonia fino y triturado, (d) Arcilla La Rioja. 
En la figura 4.1 se puede observar que en todos los difractogramas son evidentes dos minerales característicos de las materias primas arcillosas de tipo caolinitico, cuarzo y caolinita, variando la intensidad de sus picos característicos de acuerdo a la naturaleza de cada materia prima y por ende la cantidad relativa de estos dos minerales. [Andreis, 2006; Hammond, 1997; Moore y Reynolds, 2002; Moore y Reynolds, 2002; Viswabaskaran et al., 2003].

En la figura 4.1(a) (Arcilla Tincar Súper, caolín C-80 fino y triturado) se puede ver que el pico más representativo es el cuarzo $\left(26.6^{\circ} \mathrm{de} 2 \theta\right)$, con poca intensidad en los picos de caolinita, la arcilla Tincar presentó mayor intensidad de cuarzo en comparación a las otras dos, respecto al caolín C-80 fino y triturado se observaron pequeños vestigos de mineral tipo illítico, también se apreció claramente que la granulometría poco o casi nada influye en sus fases cristalinas.

La figura 4.1(b) (Caolín Sur del Rio fino y triturado) presenta los difractogramas del caolín Sur del Rio con diferente granulometría (triturado y fino), observándose que el pico más representativo es el del cuarzo, con mayor intensidad para el caolín triturado que para el fino, notándose también en ambos casos la presencia de caolinita, presentando mayor intensidad en el caolín sur del rio fino con respecto al triturado.

Para los difractogramas de la figura 4.1(c) (Caolín Patagonia fino y triturado) se observó que el caolín Patagonia fino mostró el pico mayor de cuarzo con gran intensidad, notándose también una menor intensidad de los picos de caolinita con respecto al cuarzo, en cambio el caolín Patagonia triturado presentó en términos relativos una mayor presencia de caolinita con poca presencia de cuarzo.

En la figura 4.1(d) (Arcilla la Rioja) se observó que el pico con mayor intensidad corresponde a la caolinita, también se pudo ver que existe poca presencia o casi nula de la fase cuarzo.

\subsubsection{Análisis de ATD / TG para las materias primas arcillosas}

Para conocer el comportamiento térmico de las materias primas arcillosas y obtener información cuantitativa sobre tenores de caolinita se realizaron las caracterizaciones por termogravimetría (TG) y Análisis térmico diferencial (ATD), los diagramas correspondientes se pueden ver en la figura 4.2, habiéndose seleccionado para el caolín C-80, Sur del Rio y Patagonia las clases: fino, fino y triturado respectivamente debido a su mayor intensidad de picos de caolinita observados por DRX. 


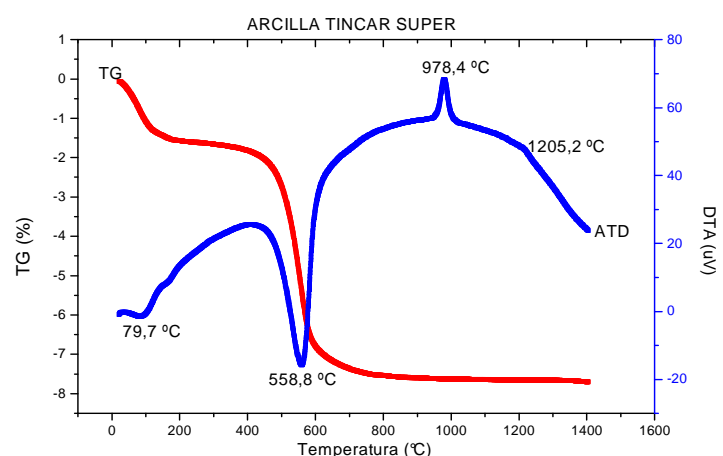

(a)

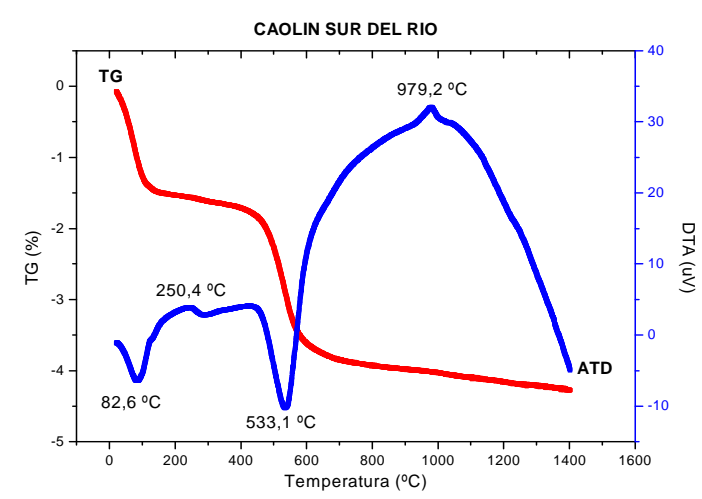

(c)

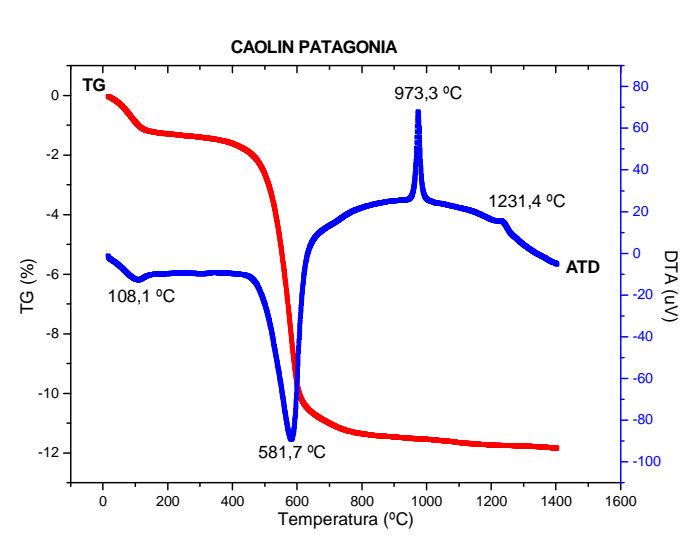

(e)

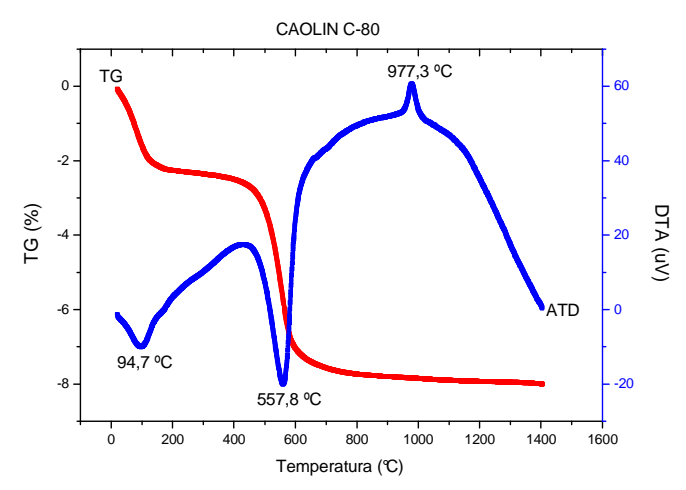

(b)

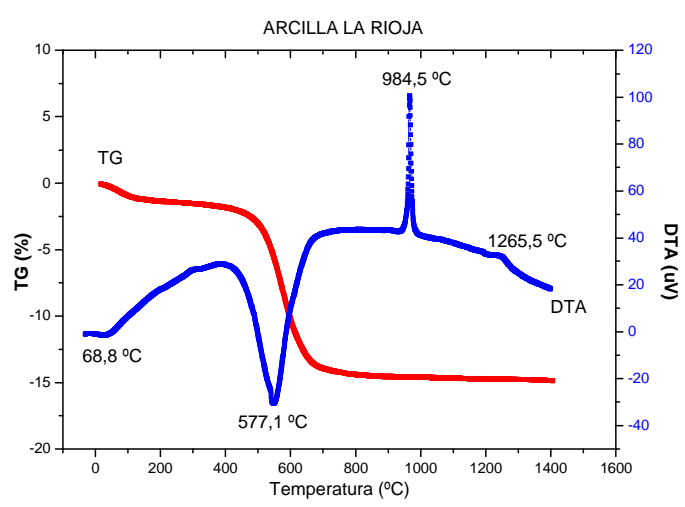

(d)

Figura 4.2. Diagramas de ATD/TG de: (a) Arcilla Tincar Súper; (b) Caolín C-80 (fino); (c) Caolín Sur del Rio (fino); (d) Arcilla La Rioja; (e) Caolín Patagonia (triturado).

En la figura 4.2(a), se observa la curva termogravimétrica (TG) de la arcilla Tincar Súper, mostrando dos pérdidas de masa, una de $1.5 \%$ entre 21 - $200{ }^{\circ} \mathrm{C}$ debido a la pérdida de 
agua absorbida; la otra se presentó entre 200 - $800{ }^{\circ} \mathrm{C}$ mostrando $6.1 \%$ de pérdida la cual está asociada a la deshidroxilación del caolín. Por otro lado el Análisis Térmico Diferencial (ATD) presentó cuatro efectos térmicos; el primero endotérmico en $79.7 \stackrel{\circ}{\circ}$ debido a la pérdida de agua absorbida sobre las partículas finas y de agua interlaminar, el segundo pico endotérmico a $558.8 \stackrel{\circ}{\circ} \mathrm{C}$ que pertenece a la deshidroxilación de la caolinita y al cambio de fases de $\alpha$ a $\beta$ reversible del cuarzo (este último no observado por ser de muy baja intensidad y superpuesto al de deshidroxilación), el tercero pico exotérmico a $978.4{ }^{\circ} \mathrm{C}$ que corresponde a la formación de espinela, y el cuarto un pequeño pico exotérmico a $1205.2{ }^{\circ} \mathrm{C}$ que está asociado a la formación de cristobalita y a la nucleación de la mullita. [Bich. et al., 2009; Saikia, et al., 2003].

En la figura 4.2(b) se observó que el Caolín C-80 (fino) sufre dos pérdidas de masa (curva TG), una de $2.2 \%$ entre 20 - $200{ }^{\circ} \mathrm{C}$ que pertenece a la pérdida de agua absorbida y la otra entre $200-800 \stackrel{\circ}{-}$ que concierne a $5.7 \%$ que se debe a la deshidroxilación de la caolinita. En la misma figura, la curva de ATD muestra tres efectos térmicos; el primero en $94.7^{\circ} \mathrm{C}$ efecto endotérmico que corresponde a la pérdida de agua absorbida entre las partículas finas y de agua interlaminar, el segundo a 557.8 ○C efecto endotérmico que está asociado a la deshidroxilación de la caolinita y al cambio de fases de cuarzo $\alpha$ a $\beta$ (superpuesto al de deshidroxilación), su tercer efecto térmico (exotérmico) a $977.3{ }^{\circ} \mathrm{C}$ corresponde a la formación de espinela. [Johnson et al., 1982; Sonuparlak et al., 1987].

En la figura 4.2(c), se observa la curva termogravimétrica del caolín Sur del Rio (fino) mostrando dos pérdidas de masa, una entre $21-200{ }^{\circ} \mathrm{C}$ de $1.4 \%$ correspondiente a la pérdida de $\mathrm{H}_{2} \mathrm{O}$ absorbida, la otra pérdida entre $200-800^{\circ} \mathrm{C}$ de $2.6 \%$ debido a la deshidroxilación de la caolinita. La curva de análisis térmico diferencial del caolín Sur del Rio, mostró cuadro efectos térmicos, el primero en $82.6{ }^{\circ} \mathrm{C}$ efecto endotérmico que pertenece a la pérdida de agua absorbida entre las partículas finas y agua interlaminar, el segundo en $250.4^{\circ} \mathrm{C}$ que corresponde a un pico endotérmico que representa la descomposición de ciertas impurezas presentes en el mineral, el tercer pico se presenta en $533.1 \stackrel{\circ}{\circ}$, efecto endotérmico que está asociado a la deshidroxilación de la caolinita y al cambio de fase del cuarzo $\alpha$ a $\beta$, y el cuarto a $979.2{ }^{\circ} \mathrm{C}$ efecto exotérmico que pertenece a la formación de espinela. [Kuo-Chung et al.,1994; Vieira, 2008].

Para la arcilla La Rioja, figura 4.2(d), la curva de termogravimetría presentó dos pérdidas de masa, una de $2.18 \%$ entre $20-200{ }^{\circ} \mathrm{C}$ equivalent e a la pérdida de agua absorbida, y la otra entre $200-800{ }^{\complement} \mathrm{C}$ de $13.5 \%$ correspondie nte a la deshidroxilación del caolín. El análisis térmico diferencial mostró cuatro efectos térmicos, el primer pico endotérmico en $68,8^{\circ} \mathrm{C}$ que representa la pérdida de agua absorb ida entre las partículas finas y agua 
interlaminar, el segundo pico endotérmico en $577.2{ }^{\circ} \mathrm{C}$ que está asociado a la deshidroxilación de la caoliníta y al cambio de fase del cuarzo $\alpha$ a $\beta$ ya mencionada, el tercer efecto térmico (exotérmico) se mostró en $977.3 \stackrel{\circ}{\circ} \mathrm{C}$ que corresponde a la formación de espinela, y el cuarto pico a $1243.4{ }^{\circ} \mathrm{C}$ que pertenece a la formación de cristobalita y a la nucleación de la mullita. [Mackenzie, 1972; Viswabaskaran et al., 2003].

En la figura 4.2(e) se observa al caolín Patagonia (triturado), donde sufre dos pérdidas de masa (curva TG), una entre $20-200{ }^{\circ} \mathrm{C}$ que equiv ale a $1.2 \%$ y está asociado a la pérdida de agua absorbida, la segunda de $10.4 \%$ entre $200-800^{\circ} \mathrm{C}$ que pertenece a la deshidroxilación de la caolinita. La curva de Análisis Térmico Diferencial presentó cuatro efectos térmicos; el primer pico endotérmico a $108.1^{\circ} \mathrm{C}$ corresponde a la pérdida de agua absorbida entre las partículas finas y de agua interlaminar, el segundo pico endotérmico a $581.7^{\complement} \mathrm{C}$ debido a la deshidroxilación de la caolinita y al cambio de fases de $\alpha$ a $\beta$ del cuarzo, el tercer pico exotérmico a $973.3^{\circ} \mathrm{C}$ que corresponde a la formación de espinela y el cuarto un pico exotérmico a $1231.4{ }^{\circ} \mathrm{C}$ que está asociado a la formación de cristobalita y a la nucleación de la mullita. [Brindley y Nakahira, 1959; Domínguez et al., 2008].

El porcentaje de caolinita de cada materia prima arcillosa se calculó en base a los TG (pérdida entre $200-800^{\circ} \mathrm{C}$ ) de acuerdo a la formulación estequiométrica de la caolinita, ver tabla 4.1.

Tabla 4.1. Porcentaje de caolinita de las arcillas ó caolines.

\begin{tabular}{|c|c|}
\hline MATERIA PRIMA ARCILLOSA & \% CAOLINITA \\
\hline Arcilla Tincar Súper & 43.8 \\
\hline Caolín C-80 & 41.1 \\
\hline Arcilla Sur del Rio & 18.6 \\
\hline Arcilla La Rioja & 96.7 \\
\hline Caolín Patagonia & 74.5 \\
\hline
\end{tabular}


En la tabla 4.1, se puede observar que la arcilla La Rioja presentó el más alto porcentaje de caolinita (96.7\%) y la arcilla Sur del Rio el menor valor (18.6\%), en comparación a las demás.

\subsubsection{Análisis Químico para las materias primas arcillosas}

La composición química preliminar de las materias primas arcillosas se tomó de las fichas técnicas suministradas por proveedores comerciales. Es importante resaltar que todas las arcillas analizadas contienen un alto porcentaje de sílice y alúmina, lo que las hace favorables para la elaboración estequiométrica de mullita de alta gama y un tenor de impurezas acorde a arcillas caoliníticas naturales. Ver tabla 4.2.

Tabla 4.2. Análisis químico por fichas técnicas suministradas por los proveedores de las materias primas arcillosas.

\begin{tabular}{|c|c|c|c|c|c|}
\cline { 2 - 6 } \multicolumn{1}{c|}{} & Caolín C-80 & $\begin{array}{c}\text { Caolín Sur } \\
\text { del Rio }\end{array}$ & $\begin{array}{c}\text { Caolín } \\
\text { Patagonia }\end{array}$ & $\begin{array}{c}\text { Arcilla Tincar } \\
\text { Súper }\end{array}$ & $\begin{array}{c}\text { Arcilla La } \\
\text { Rioja }\end{array}$ \\
\hline $\mathrm{SiO}_{2}$ & 57.10 & 58.70 & 60.80 & 64.40 & 44.57 \\
\hline $\mathbf{A l}_{2} \mathbf{O}_{3}$ & 31.00 & 28.60 & 27.24 & 24.20 & 39.60 \\
\hline $\mathrm{Na}_{2} \mathbf{O}$ & N. det. & 0.40 & 0.23 & 0.06 & 0.07 \\
\hline $\mathrm{K}_{2} \mathbf{O}$ & 0.60 & 0.90 & 1.06 & 0.53 & 0.39 \\
\hline $\mathbf{C a O}$ & N. det. & 0.40 & 0.29 & 0.42 & 0.05 \\
\hline $\mathrm{Fe}_{2} \mathbf{O}_{3}$ & 0.40 & 0.40 & 1.61 & 0.60 & 0.46 \\
\hline $\mathbf{M g O}^{*}$ & N. det. & N. det. & 0.54 & 0.18 & 0.11 \\
\hline $\mathrm{TiO}_{2}$ & 0.13 & 0.30 & 0.37 & 0.49 & 0.60 \\
\hline $\mathbf{P x C}^{*}$ & 10.80 & 10.30 & 7.87 & 9.12 & 14.15 \\
\hline
\end{tabular}

${ }^{*}$ N. det. $=$ No determinado

En la tabla 4.2, se puede ver el análisis químico de las arcillas y caolines argentinas estudiadas en este capítulo, observándose que todas contienen sílice y alúmina en proporciones elevadas, que son características de arcillas silicoaluminosas de base caolinítica, lo que las hace favorables para la elaboración de mullita, ya que otro tipo de arcillas silicoaluminosas que no son de base caolinita (ejemplo esmectitas), poseen un bajo potencial para la formación de mullita primaria (mullita generada por la propia arcilla) y requerirían por lo tanto mayores cantidades de alúmina para mullitizar 
completamente por tratamiento térmico. [Aparicio y Galán, 1999; Domínguez et al., 2008; Grimshaw, 1971].

Cabe aclarar que se observó una inconsistencia entre el análisis químico suministrado por el proveedor con el tenor de caolinita calculado a partir de la pérdida de masa (agua de estructura) observada en el ATD-TG en el caolín Patagonia.

Respecto al porcentaje de $\mathrm{SiO}_{2}$ la arcilla Tincar Súper presentó un valor mayor y la arcilla La Rioja una cantidad menor con respecto a las demás. Para el porcentaje de $\mathrm{Al}_{2} \mathrm{O}_{3}$ la arcilla Tincar mostró el menor valor en comparación a las otras, y la arcilla La Rioja presentó un mayor porcentaje con relación a las demás.

El caolín Patagonia y Sur del Rio mostraron en suma los mayores porcentajes de impuerezas, sobre todo de $\mathrm{Na}_{2} \mathrm{O}$ y $\mathrm{K}_{2} \mathrm{O}$, los cuales no son muy favorables para la elaboración de mullita de alta gama, debido a que contribuirían a bajar el punto de fusión, produciendo mayor fase vítrea y por tanto bajas propiedades mecánicas en el producto final, aunque por otro lado ayudaría al sinterizado. [Johnson, 1982].

Del análisis anterior se pudo descartar el uso del Caolín Patagonia y Sur del Rio para la continuación del estudio ya que por lo antedicho no serían favorables para la elaboración de materiales refractarios como en este caso de mullita de alta calidad. Por lo tanto las arcillas con las que se prosiguió trabajando en el análisis fisicoquímico fueron: caolín C-80, arcilla Tincar Súper y La Rioja.

\subsubsection{Análisis de índice de plasticidad, límite líquido y plástico, para las materias primas arcillosas}

Este análisis es importante para el conformado de las piezas, sobre todo cuando se utilizan en procesos de extrusión, compactación por prensado, o colado.

El límite plástico es la mínima cantidad de agua (en porcentaje sobre base seca) necesaria para que la mezcla adquiera comportamiento plástico. El límite liquido es la mínima cantidad de agua (en porcentaje sobre base seca) que debe agregarse para que la mezcla adquiera consistencia fluida al aplicársele un esfuerzo mecánico como el producido por el equipo de Casagrande. El índice de plasticidad (IP) es la diferencia entre el límite líquido y el límite plástico. Se determinó el IP de las arcillas seleccionadas (3) siguiendo la norma IRAM 10 502, los datos obtenidos se muestran en la tabla 4.3 
Tabla 4.3. Índice de plasticidad, límite líquido y plástico de arcillas y/o caolines.

\begin{tabular}{|c|c|c|c|}
\hline MUESTRAS & $\begin{array}{c}\text { Límite } \\
\text { Liquido }\end{array}$ & $\begin{array}{c}\text { Límite } \\
\text { Plástico }\end{array}$ & $\begin{array}{c}\text { Índice de } \\
\text { Plasticidad }\end{array}$ \\
\hline Caolín C-80 & 46.2 & 38.8 & 7.4 \\
\hline Arcilla Tincar Súper & 32.2 & 25.2 & 8.0 \\
\hline Arcilla La Rioja & 23.1 & 19.3 & 3.8 \\
\hline
\end{tabular}

La determinación del índice de plasticidad involucra la medición del límite plástico y del límite líquido. Los valores de agua adicionada entre ambos límites muestran el rango de agua sobre el que se podría trabajar en un conformado por extrusión; y para el caso de colado el límite liquido es el valor de porcentaje de agua a partir del cual se podría trabajar en conformado por colado. Para el conformado por prensado se utilizan en general porcentajes de agua menores al límite plástico. [Berna et al., 2003; Mackenzie, 1972; Modesto y Bernardin, 2008; Muñoz et al., 2007; Worral, 1986].

Por otro lado los valores del índice de plasticidad muestran la estrechez o amplitud del rango de agua donde el material s puede tener comportamiento plástico.

La tabla 4.3, muestra que el índice de plasticidad es menor para la arcilla La Rioja y mayor para la arcilla Tincar Súper, en comparación con el caolín C-80.

\subsubsection{Análisis de Cono Pirométrico Equivalente para las materias primas arcillosas}

También se realizó el ensayo de Cono Pirométrico Equivalente (C.P.E) para las tres arcillas seleccionadas, siguiendo la norma IRAM 12507.

Para determinar el valor de CPE se prepararon 2 conos para cada materia prima arcillosa (Caolín C-80, Arcilla Tincar Súper y La Rioja) y se compararon con conos de referencia número $29,30,31,32,33,34,35$, y 36, donde cada número está asociado a una temperatura de ablandamiento, la cual corresponde a aquella donde la punta del cono toca la plaqueta de soporte, tal como se muestra en la figura 4.3. 

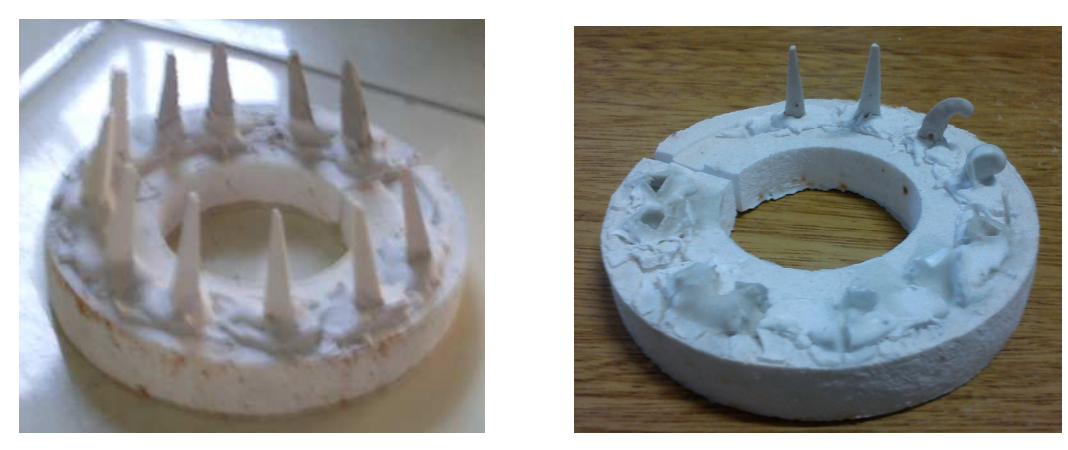

Figura 4.3. Placas del ensayo de Cono Pirométrico Equivalente (CPE), antes y después del ensayo,

Los valores obtenidos en el ensayo de CPE de las materias primas arcillosas se muestran en la tabla 4.4, donde se puede observar el valor del número de cono pirométrico equivalente correspondiente a cada arcilla, junto con su temperatura asociada.

Tabla 4.4. Valores de Cono Pirométrico Equivalente (CPE) de las materias primas arcillosas.

\begin{tabular}{|c|c|c|}
\hline MUESTRA & CPE (\#) & TEMPERATURA ( $\left.{ }^{\circ} \mathrm{C}\right)$ \\
\hline Caolín C-80 & 29 & 1659 \\
\hline Arcilla Tincar Súper & 32 & 1717 \\
\hline Arcilla La Rioja & 34 & 1763 \\
\hline
\end{tabular}

Los resultados de la tabla 4.4 muestran que la arcilla La Rioja presentó mayor refractariedad debido a un menor tenor de impurezas y una mayor cantidad de caolinita en su composición (observado en TG), en cambio el caolín C-80 presentó menor refractariedad con respecto a la arcilla Tincar Súper. [Ford, 1967]. 


\subsubsection{ALÚMINAS - Materias primas para la producción de mullita estequiométrica $\left(3 \mathrm{Al}_{2} \mathrm{O}_{3} \cdot 2 \mathrm{SiO}_{2}\right)$}

La alúmina es óxido de aluminio $\left(\mathrm{Al}_{2} \mathrm{O}_{3}\right)$ que junto con la sílice a altas temperaturas, se convierte en la materia prima más importante para la elaboración de diversos materiales silicoaluminosos entre ellos la mullita.

El óxido de aluminio existe en la naturaleza en forma de corindón, pero en escasa cantidad. La alúmina $\mathrm{Al}_{2} \mathrm{O}_{3}$ se halla también en forma de óxidos hidratados que son los componentes de la Bauxita y de la laterita (ésta consta principalmente de hidróxidos alumónico y férrico, sílice y menores proporciones de otros óxidos). La industria emplea el proceso Bayer para producir alúmina, a partir de la bauxita, de la siguiente manera:

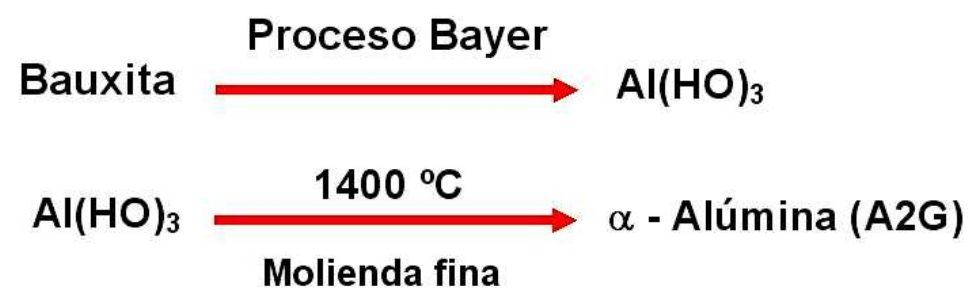

Las dos fuentes de alúmina utilizadas en este trabajo fueron: $\mathrm{Al}(\mathrm{HO})_{3}$, y $\alpha$-alúmina.

Argentina no posee minerales bauxíticos ni produce alúmina por lo que debe importarse este commodity (Brasil, China, USA, etc). Brasil es nuestro socio del MERCOSUR, por lo que su disponibilidad está asegurada, y utilizando materiales silicoaluminosos como son las arcillas y/o caolines argentinos, se podría producir mullita en el país.

Para el desarrollo de este trabajo se seleccionaron dos tipos de alúminas comerciales, una alúmina hidratada y la otra alúmina calcinada. Se realizó la caracterización fisicoquímica de estas fuentes de alúmina por Difracción de Rayos X. El análisis químico fue tomado de las fichas técnicas suministradas por las empresas que los producen; además para la alúmina hidratada se determinó la pérdida por calcinación para establecer su tenor de alúmina en base deshidratada. A más de $600{ }^{\circ} \mathrm{C}$ la alúmina hidratada ya perdió totalmente su agua de estructura. 


\subsubsection{Análisis de DRX para las fuentes de alúmina}

Para conocer las fases cristalinas presentes de las fuentes de alúmina (hidratada y calcinada) se realizó $\mathrm{DRX}$, donde los difractogramas obtenidos de las alúminas se muestran en la figura 4.4 .

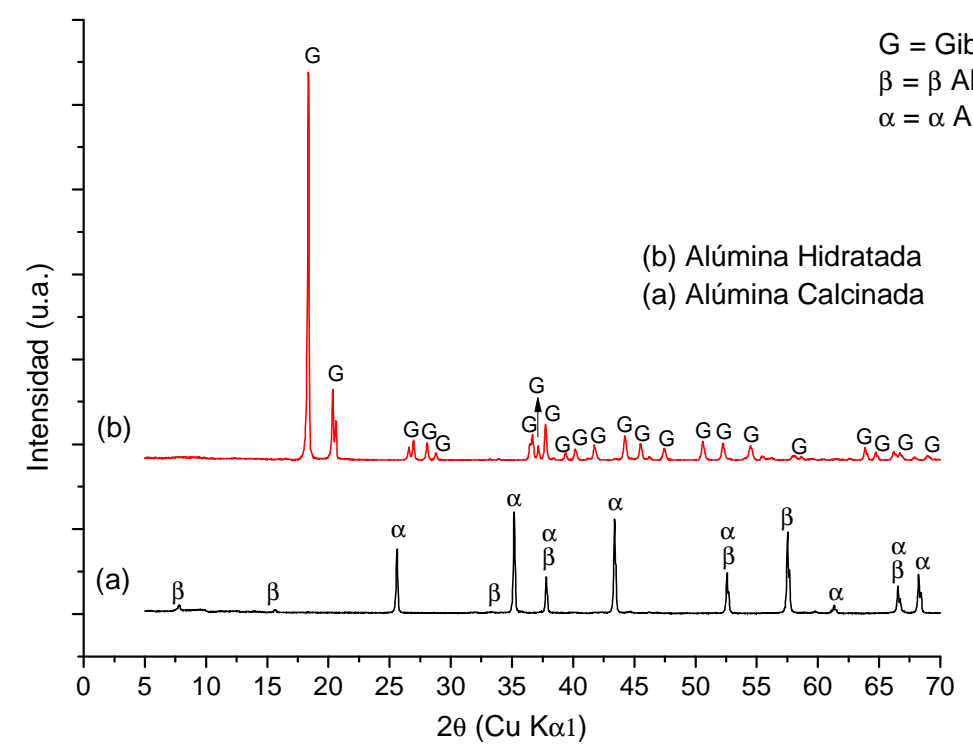

Figura 4.4. Difractogramas de las fuentes de alúmina. a) Alúmina Calcinada, (b) Alúmina Hidratada.

El difractograma que corresponde a la alúmina calcinada, figura 4.4(a), presentó fases cristalinas mayoritarias de $\alpha \mathrm{Al}_{2} \mathrm{O}_{3}$ con vestigios de $\beta$-alúmina $\left(\mathrm{Na}_{2} \mathrm{O} .11 \mathrm{Al}_{2} \mathrm{O}_{3}\right)$. En la misma figura se puede ver que la alúmina hidratada (figura 4.4(b), mostró cómo fase mayoritaria la Gibbsita $\left(\mathrm{Al}(\mathrm{OH})_{3}\right)$ más algunos picos sin identificar probablemente de pseudo- monohidratos.

La $\beta$-alúmina proviene del proceso Bayer ya que en el mismo se utiliza $\mathrm{NaOH}$ para extraer el aluminio de la bauxita, el cual no se puede extraer totalmente a bajo costo.

El análisis químico de las fuentes de alúmina se tomó de las fichas técnicas suministradas por proveedores comerciales. Las alúminas utilizadas en este trabajo de investigación son: alúmina calcinada (Almatis $\mathrm{A} 2 \mathrm{G}$ ), $99.5 \%$ de $\mathrm{Al}_{2} \mathrm{O}_{3}$ con tamaño de partícula medio de $5 \mu \mathrm{m}$; y alúmina hidratada $67.3 \%$ de $\mathrm{Al}_{2} \mathrm{O}$, con granulometría malla pasante $50(300 \mu \mathrm{m})$. 
Para la alúmina hidratada se realizó el ensayo de pérdida de calcinación encontrando un valor de $32.7 \%$ no muy lejano al valor teórico de la gibbsita (34.6\%).

\subsection{MEZCLAS ESTEQUIOMÉTRICAS $3 \mathrm{Al}_{2} \mathrm{O}_{3} \cdot 2 \mathrm{SiO}_{2}$ (ARCILLA - ALÚMINA)}

De acuerdo al análisis anterior donde se caracterizaron y definieron las mejores materias primas arcillosas (Caolín C-80, arcilla Tincar Súper y La Rioja) y las fuentes de alúmina (calcinada e hidratada), se procedió a efectuar una etapa exploratoria realizando mezclas (cada una de las arcillas con dos fuentes de alúmina), en proporciones de estequiometría 3-2 $\left(3 \mathrm{Al}_{2} \mathrm{O}_{3} \cdot 2 \mathrm{SiO}_{2}\right)$ Ver figura 4.5.
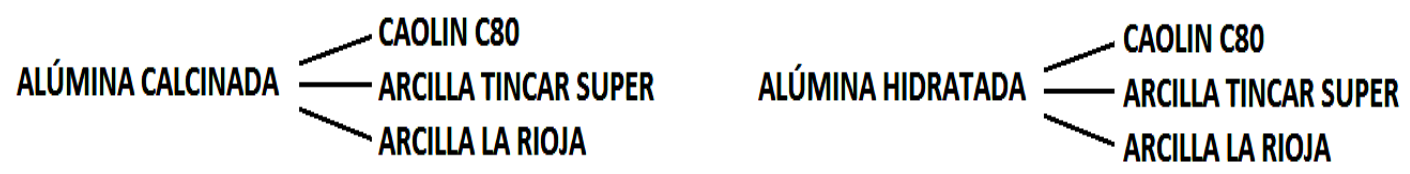

Figura 4.5. Diagrama de elaboración de mezclas.

En la tabla 4.5 se muestran las cantidades de alúmina calcinada o alúmina hidratada necesarias por cada $100 \mathrm{gr}$ de cada caso de arcilla con el fin de obtener mullita 3-2 al ser calcinadas a conversión total. Los cálculos estequiométricos se realizaron en base a los valores de porcentaje de $\mathrm{Al}_{2} \mathrm{O}_{3}$ y $\mathrm{SiO}_{2}$ de cada una de las arcillas y alúminas utilizadas. [Brindley y Nakahira, 1959; Liu et al., 1994; Sahnoune et al., 2008; Saruhan et al., 1996; Viswabaskaran et al., 2004]

Se procedió a realizar las mezclas (6 en total), ver tabla 4.5 en una mezcladora tipo Hobart. Posteriormente se compactaron las mismas por prensado a $40 \mathrm{MPa}$ con una humedad de $\sim 12,4 \%$ utilizando un compuesto orgánico como ayudante de prensado. Se prepararon por esta vía probetas prismáticas de aproximadamente $\sim 5.0 \times 0.8 \times 0.8$ $\mathrm{cm}^{3}$, éstas fueron secadas a $110^{\circ} \mathrm{C}$ y luego calcinadas a $1600^{\circ} \mathrm{C}$ durante 3 horas con una velocidad de calentamiento de 5ํㅜ por minuto en un horno eléctrico. 
Tabla 4.5. Porcentajes de la formulación de mezclas (arcilla - alúmina), con su respectiva nomenclatura.

\begin{tabular}{|c|c|c|c|c|c|}
\hline NOMENCLATURA & $\begin{array}{c}\text { Caolín } \\
\text { C-80 } \\
(\mathrm{gr})\end{array}$ & $\begin{array}{c}\text { Arcilla } \\
\text { Tincar } \\
\text { Súper } \\
(\mathrm{gr})\end{array}$ & $\begin{array}{c}\text { Arcilla } \\
\text { La Rioja } \\
(\mathrm{gr})\end{array}$ & $\begin{array}{c}\text { Alúmina } \\
\text { Calcinada } \\
\text { al 99.5\% } \\
(\mathrm{gr})\end{array}$ & $\begin{array}{c}\text { Alúmina } \\
\text { Hidratada } \\
\text { al 67.3\% } \\
(\mathrm{gr})\end{array}$ \\
\hline Cc80Acal & 100 & --- & --- & 115.2 & --- \\
\hline Cc80Ahid & 100 & --- & --- & --- & 170.3 \\
\hline AtinAcal & --- & 100 & --- & 140.7 & --- \\
\hline AtinAhid & --- & 100 & --- & --- & 208.0 \\
\hline AriojAcal & --- & --- & 100 & 74.4 & --- \\
\hline AriojAhid & --- & --- & 100 & --- & 110.0 \\
\hline
\end{tabular}

Las probetas elaboradas fueron caracterizadas por Difracción de Rayos X, porosidad y densidad por el método de Arquímedes, variación lineal respecto al conformado, módulo de rotura a la flexión (MOR1) y resistencia al choque térmico (MOR2), el cuál consistió en colocar las probetas a una temperatura de 1000 ㅇ en forma instantánea, manteniéndolas durante 20 minutos a esa temperatura para luego enfriarlas bruscamente en agua, comparando luego los módulos de rotura a la flexión antes y después del choque.

\subsubsection{Análisis de DRX para las mezclas estequiométricas $3 \mathrm{Al}_{2} \mathrm{O}_{3} \cdot 2 \mathrm{SiO}_{2}$.}

Para conocer las fases cristalinas presentes en las mezclas tratadas a $1600^{\circ} \mathrm{C}$ durante 3 horas se utilizó Difracción de Rayos X (DRX), cuyos difractogramas se observan en la figura 4.6. 


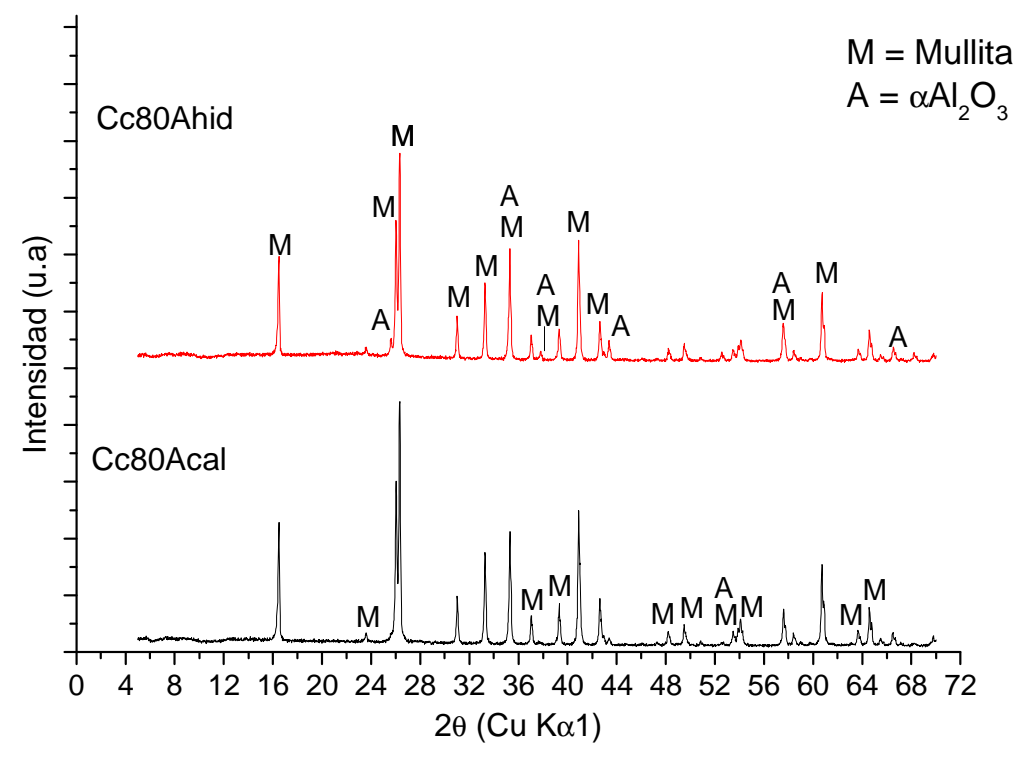

(a)

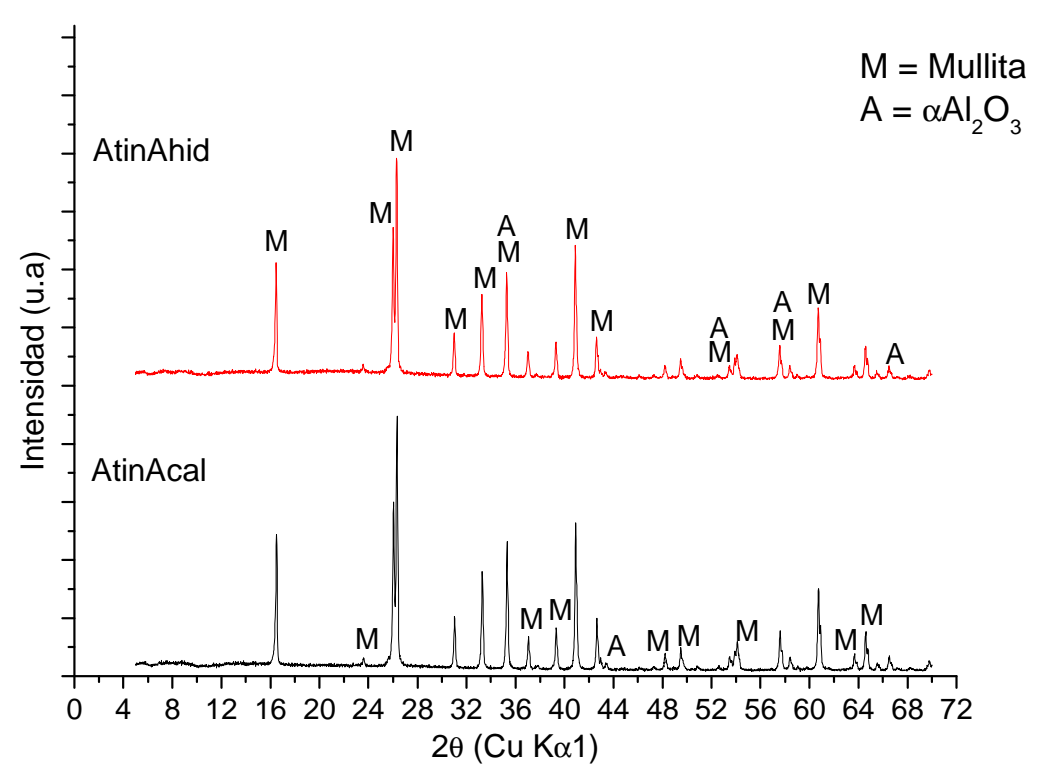

(b) 


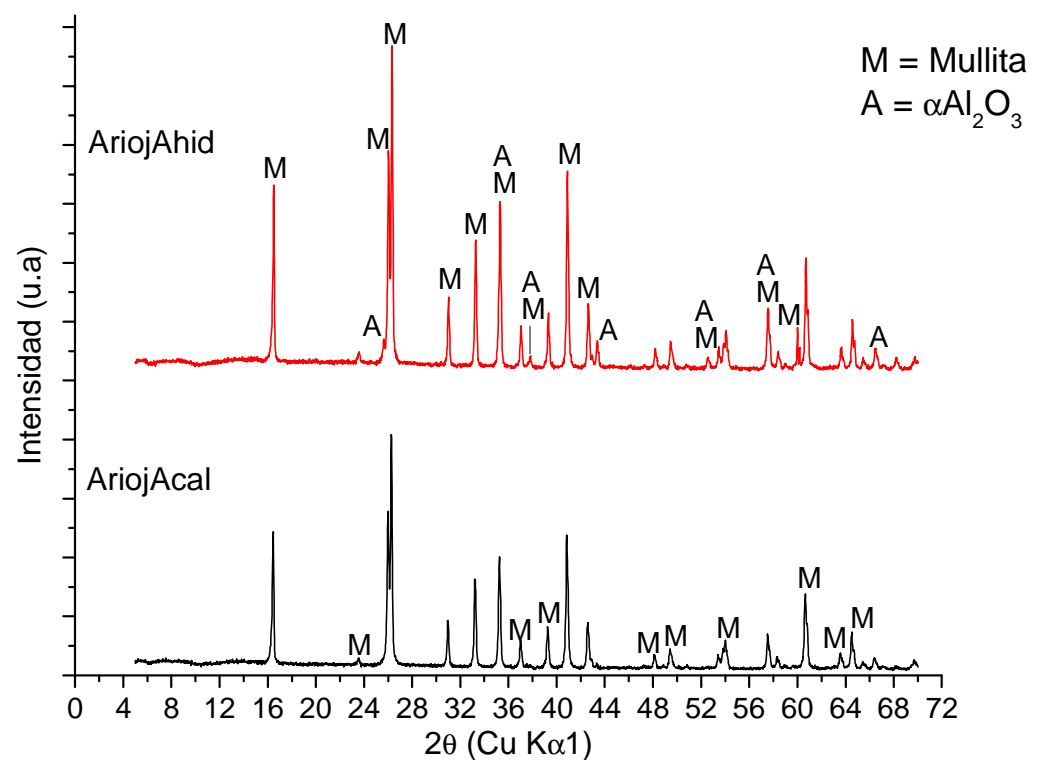

(c)

Figura 4.6. Difractogramas de las mezclas; (a) Caolín C-80 con alúmina calcinada (C80Acal) y con alúmina hidratada (C80-Ahid), (b) Arcilla Tincar Súper con alúmina calcinada (AtinAcal) y con alúmina hidratada (AtinAhid), (c) Arcilla la Rioja con alúmina calcinada (AriojAcal) y con alúmina hidratada (AriojAhid). Calcinadas a $1600^{\circ} \mathrm{C}$ durante 3 horas.

Al analizar los difractogramas de la figura 4.6, en sus escalas originales se observó que las arcillas Tincar Súper y La Rioja generaron más cantidad de mullita que el caolín C-80 independientemente del tipo de alúmina utilizada. Respecto a los fondos de los difractogramas que mostrarían el tenor de fases amorfas o vítreas, se observó mayor tenor de fase vítrea en las que se utilizó alúmina hidratada que la de alúmina calcinada, esto coincide con el hecho de haber observado menor tenor de mullita. También se observó que los tenores residuales de alúmina fueron bajos y parejos para todas las mezclas con alúmina calcinada y para las mezclas con alúmina hidratada mostró una cantidad ligeramente mayor. Observando los difractogramas desde el punto de vista cristalográfico y de presencia de impurezas, todas las mezclas mostraron un elevado tenor de mullita (PDF 15-0776) con vestigios de $\alpha \mathrm{Al}_{2} \mathrm{O}_{3}$ y poca presencia de fase vítrea. [Juettner T., et al., 2007; Liu et al.,1994; Mazdiyasni y Brown, 1972; Moore y Prasad, 1955; Pankratz et al., 1963] 


\subsubsection{Análisis de las propiedades físicas y termomecánicas de las mezclas estequiométricas 3-2 $\left(3 \mathrm{Al}_{2} \mathrm{O}_{3} \cdot 2 \mathrm{SiO}_{2}\right)$.}

Posteriormente se procedió a evaluar las propiedades fisicoquímicas y termomecánicas de las mezclas elaboradas con estequiometría 3-2 y calcinadas a $1600 \stackrel{\circ}{\circ}$ por 3 horas, los resultados se observan en la tabla 4.6.

Tabla 4.6. Propiedades fisicoquímicas y mecánicas de las probetas a $1600{ }^{\circ} \mathrm{C}$ por 3 horas.

\begin{tabular}{|l|c|c|c|c|c|c|}
\hline MUESTRA & $\begin{array}{c}\text { VARIACIÓN } \\
\text { LINEAL } \\
\text { respecto al } \\
\text { conformado } \\
\text { del material } \\
\text { seco } \\
\left(110^{\circ}\right) \\
(\%)\end{array}$ & $\begin{array}{c}\text { DENSIDAD } \\
\text { (Arquimedes) } \\
\mathrm{g} / \mathrm{cm}^{3}\end{array}$ & $\begin{array}{c}\text { POROSIDAD } \\
(\%)\end{array}$ & $\begin{array}{c}\text { MÓDULO } \\
\text { DE } \\
\text { ROTURA } \\
\text { "MOR1" } \\
(\mathrm{MPa})\end{array}$ & $\begin{array}{c}\text { MÓDULO } \\
\text { DE } \\
\text { ROTURA } \\
\text { "MOR2" } \\
(\text { MPa })\end{array}$ & $\begin{array}{c}\text { \% } \\
\text { RETENCIÓN } \\
(\text { (MOR2/MOR1) } \\
* 100)\end{array}$ \\
\hline Cc80Acal & -0.7 & 2.1 & 27.9 & 76.9 & 4.1 & 5.3 \\
\hline Cc80Ahid & -13.1 & 2.3 & 26.5 & 65.5 & 10.6 & 16.2 \\
\hline AtinAcal & -0.2 & 2.0 & 30.3 & 60.4 & 4.2 & 7.0 \\
\hline AtinAhid & -10.5 & 2.2 & 25.3 & 55.5 & 7.4 & 13.3 \\
\hline AriojAcal & -3.8 & 2.2 & 28.9 & 102.9 & 7.2 & 7.0 \\
\hline AriojAhid & -11.2 & 2.3 & 24.1 & 18.8 & 7.4 & 39.4 \\
\hline
\end{tabular}

Analizando la tabla 4.6 se observa, que los resultados de la variación lineal por calcinación a $1600^{\circ} \mathrm{C}$ durante 3 horas con velocidad de calentamiento de $5^{\circ} \mathrm{C} / \mathrm{min}$ mostró una mayor contracción para las mezclas con alúmina hidratada $\left(\mathrm{Al}(\mathrm{OH})_{3}\right)$ con respecto al conformado del material seco a $110^{\circ} \mathrm{C}$ p ara cualquier par (arcilla - alúmina calcinada o arcilla - alúmina hidratada) Este fenómeno concuerda con que al ser las partículas de $\mathrm{Al}(\mathrm{OH})_{3}$ de tamaño mayor a las de alúmina calcinada, al perder el agua de hidratación y comenzar a reaccionar de afuera hacia adentro con la sílice que la rodea (sílice remanente proveniente de la mullitización primaria de la arcilla) se acentúa la contracción por sinterización ya que la resistencia que opone a la expansión por mullitización la alúmina recién deshidratada es baja.

Respecto a los resultados de densidad se observa un valor mayor para las muestras provenientes de alúmina hidratada, comparadas con su par de alúmina calcinada. El fenómeno tiene la misma interpretación que la explicada anteriormente, ya que al tener 
igual estequiometría total, al existir mayor contracción a pesar de no haber reaccionado totalmente, las muestras con alúmina hidratada mostraron una mayor densidad.

Para los valores de porosidad y comparándolos de a pares (arcilla/caolín con alúmina calcinada/hidratada) se observa una mayor porosidad en las probetas con $\mathrm{Al}_{2} \mathrm{O}_{3}$ calcinada.

Esto se puede interpretar suponiendo que la alúmina hidratada al perder su agua de hidratación a $550{ }^{\circ} \mathrm{C}$ generó partículas de alúminas de transición muy reactivas pero endebles mecánicamente, por lo que como ya se explicó anteriormente al comenzar a reaccionar a alta temperatura $\left(1600{ }^{\circ} \mathrm{C}\right.$ cercano al punto de fusión de la $\mathrm{SiO}_{2}$ ) con la sílice que los recubre, generaron un sistema parecido a una esfera cuyo exterior es $\mathrm{SiO}_{2}$ - $\mathrm{Al}_{2} \mathrm{O}_{3}$ rica en sílice y de menos punto de fusión que en el interior que sería alúmina porosa. La capa exterior es la principal responsable de la sinterización y contracción del sistema, dejando en su interior alúmina porosa aislada del exterior y formando poros cerrados no compatibles con el método de evaluación utilizado (Arquímedes), que mide solo la porosidad abierta, figura 4.7.

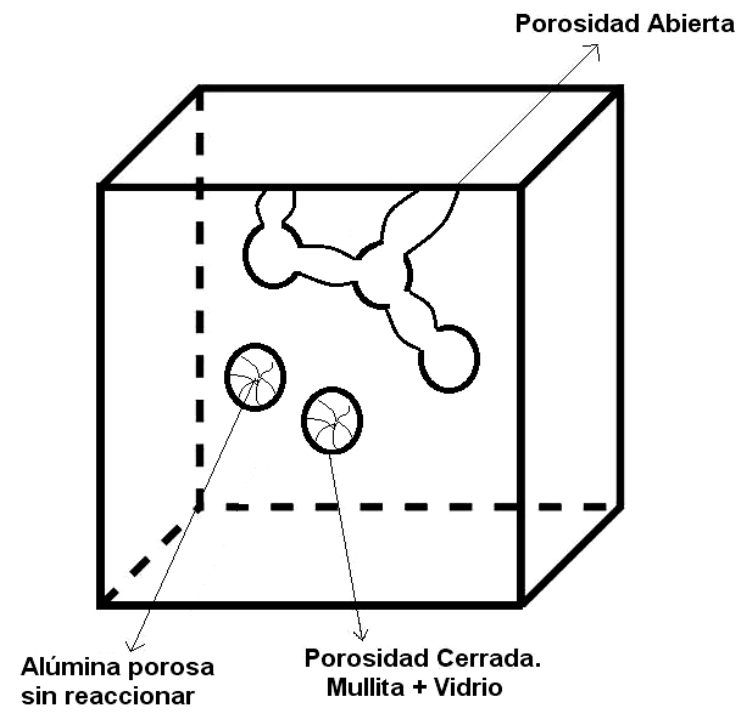

Figura 4.7. Esquema de poros abiertos y cerrados, generados por la sinterización.

Entonces la cantidad de poros cerrados generados por la alúmina hidratada será mayor que los posibles generados por pequeñas partículas sólidas como lo son las de alúmina calcinada. Por lo tanto la porosidad abierta en los tres casos (alúmina con: caolín C-80 o 
arcilla Tincar Súper o arcilla La Rioja) es mayor con alúmina calcinada que con alúmina hidratada.

En los resultados de Módulo de Rotura a la flexión en tres puntos de las probetas no sometidas al choque térmico (MOR 1) se observó en todos los pares mayor valor de resistencia en las probetas con alúmina calcinada respecto a las probetas con alúmina hidratada. Los valores son explicados a través de que los de alúmina hidratada contienen núcleos cerrados no conectados con el exterior donde en su interior hay un sistema poroso de alúmina no totalmente sinterizado y por ende de baja resistencia mecánica (figura 4.7). Eso hace que una fractura inducida por una velocidad de avance constante de la guillotina en el ensayo a tres puntos (como el realizado) se propague muy fácilmente dentro de dichos núcleos sin prácticamente ofrecer resistencia (probetas más débiles mecánicamente). [Cultrone, 2004; Hemantha y Satapathy, 2008; Sandoval del Rio y Gonzalez, 1986; 1984].

Respecto al Módulo de Rotura a la flexión en tres puntos, luego de un choque térmico (MOR 2), el sistema se comporta en forma inversa al punto anterior (MOR1). O sea que presentaron mayor resistencia a la flexión las probetas con alúminas hidratadas. Este hecho responde a que la violencia del choque térmico aplicado induce grandes tensiones en la pieza, que pueden ser o no absorbidas por la misma de acuerdo a los posibles puntos o zonas de disipación de la energía de fractura.

En el caso de las piezas con alúmina hidratada, los poros cerrados conteniendo alúmina porosa, sirven como centros de absorción y neutralización de esa energía de fractura, impidiendo la propagación de la misma en mayor intensidad que para las piezas confeccionadas con alúmina calcinada, lo antedicho se refleja en el porcentaje de retención que se calcula de la siguiente forma:

$$
\% \text { Retención }=\left[\left(\frac{M O R 2}{M O R 1}\right) * 100\right]
$$

Observándose menor porcentaje de retención para las mezclas con alúmina calcinada, independiente de la arcilla utilizada. 


\section{SELECCIÓN FINAL DE LAS MATERIAS PRIMAS Y FORMULACIÓN} ESTEQUIOMÉTRICA $3 \mathrm{Al}_{2} \mathrm{O}_{3} \cdot 2 \mathrm{SiO}_{2}$ (Arcilla - Alúmina)

De acuerdo a los análisis anteriores en donde se caracterizaron las mejores materias primas arcillosas (Caolín C-80, arcilla Tincar Súper y La Rioja) y se formularon mezclas estequiométricas 3-2 con las dos fuentes de alúmina mencionadas (calcinada e hidratada), se descartó para la continuación de este trabajo de tesis el caolín C-80, debido a que poseía la menor refractariedad y menor resistencia al choque térmico con alúmina calcinada en comparación a las otras dos (arcilla Tincar Súper y La Rioja). Por otro lado la arcilla Tincar Súper es la arcilla refractaria de mayor disponibilidad comercial en el país y la arcilla La Rioja la de mejor refractariedad.

A las arcillas que continuarán el estudio se les realizó un análisis químico por Espectroscopia de Emisión Atómica por Plasma Inductivamente Acoplado (ICP-AES), en la tabla 4.7, se muestran los resultados obtenidos para la arcilla Tincar Súper y La Rioja, para así tener datos precisos al momento de formular las mezclas.

Tabla 4.7. Análisis químico por ICP-AES, para las materias primas arcillosas (arcilla Tincar Súper y La Rioja).

\begin{tabular}{|c|c|c|}
\cline { 2 - 3 } \multicolumn{1}{c|}{} & $\begin{array}{c}\text { Arcilla Tincar Súper } \\
\text { (Atincar) }\end{array}$ & $\begin{array}{c}\text { Arcilla La Rioja } \\
\text { (Arioja) }\end{array}$ \\
\hline $\mathrm{SiO}_{2}$ & 65.70 & 45.90 \\
\hline $\mathrm{Al}_{2} \mathrm{O}_{3}$ & 21.10 & 37.00 \\
\hline $\mathrm{Na}_{2} \mathrm{O}$ & 0.07 & 0.06 \\
\hline $\mathrm{K}_{2} \mathrm{O}$ & 0.68 & 0.40 \\
\hline $\mathrm{CaO}$ & 0.26 & 0.08 \\
\hline $\mathrm{Fe}_{2} \mathrm{O}_{3}$ & 0.85 & 0.77 \\
\hline $\mathrm{MgO}^{\mathrm{TgO}}{ }_{2}$ & 0.22 & 0.12 \\
\hline Otros & 0.43 & 0.99 \\
\hline PxC & 2.92 & 1.38 \\
\hline & 7.77 & 13.30 \\
\hline
\end{tabular}

En la tabla 4.7, se puede ver el análisis químico de las arcillas y caolines argentinas que continuaron en estudio, observándose que todas contienen sílice y alúmina en proporciones elevadas, lo que las hace favorables para la elaboración de mullita. 
Se procedió a realizar mezclas (cada una de las arcillas con dos fuentes de alúmina), en proporciones de estequiometría $3 \mathrm{Al}_{2} \mathrm{O}_{3} \cdot 2 \mathrm{SiO}_{2}$. En la tabla 4.8 se muestran las cantidades de alúmina calcinada ó alúmina hidratada necesarias por cada $100 \mathrm{gr}$ de cada caso de arcilla con el fin de obtener mullita 3-2 al ser calcinadas a conversión total. Los cálculos estequiométricos se realizaron en base a los valores de porcentaje de $\mathrm{Al}_{2} \mathrm{O}_{3}$ y $\mathrm{SiO}_{2}$ de cada una de las arcillas y alúminas utilizadas indicadas en la tabla 4.7.

Tabla 4.8. Porcentajes de la formulación de mezclas (finales) estequiométricas 3-2 (arcilla - alúmina), con su respectiva nomenclatura

\begin{tabular}{|c|c|c|c|c|}
\hline Nomenclatura & $\begin{array}{c}\text { Arcilla Tincar } \\
\text { Súper } \\
(\mathrm{gr})\end{array}$ & $\begin{array}{c}\text { Arcilla La } \\
\text { Rioja } \\
(\mathrm{gr})\end{array}$ & $\begin{array}{c}\text { Alúmina } \\
\text { Calcinada al } \\
99.5 \% \\
(\mathrm{gr})\end{array}$ & $\begin{array}{c}\text { Alúmina } \\
\text { Hidratada al } \\
67.3 \% \\
(\mathrm{gr})\end{array}$ \\
\hline AtinAcal & 100 & --- & 147.15 & --- \\
\hline AtinAhid & 100 & --- & --- & 217.56 \\
\hline AriojAcal & --- & 100 & 80.44 & --- \\
\hline AriojAhid & --- & 100 & --- & 118.93 \\
\hline
\end{tabular}

Se realizaron 4 mezclas, ver tabla 4.8 en una mezcladora tipo Hobart, para garantizar una buena homogenización de las dos materias primas (arcilla-alúmina).

\subsection{CONCLUSIONES PARCIALES}

Se analizaron cinco materias primas arcillosas nacionales (arcillas/caolines), con diferente granulometría (fina y otra en forma de piedra), procedentes de diferente origen geológico y provenientes de diferentes regiones del país (Patagonia y NOA).

Se observó por Difracción de Rayos $X$ la presencia de dos minerales mayoritarios característicos presentes en las materias primas arcillosas de tipo caolinítico, cuarzo y caolinita, variando la intensidad de sus picos característicos de acuerdo a la naturaleza de cada materia prima y por ende la cantidad relativa de estos dos minerales. 
El porcentaje de caolinita de cada materia prima arcillosa se calculó en base a los TG (pérdida entre $200-800^{\circ} \mathrm{C}$ ) de acuerdo a la formulación estequiométrica de la caolinita, donde se puede ver que la arcilla La Rioja presentó el más alto porcentaje de caolinita (96.7\%) y la arcilla Sur del Rio menor valor (18.6\%).

$>\quad$ El análisis químico corrobora que las arcillas y caolines argentinas contienen sílice y alúmina en proporciones elevadas, que son características de arcillas silicoaluminosas de base caolinítica, lo que las hace favorables para la elaboración de mullita.

$>\quad$ El caolín Patagonia y Sur del Rio mostraron en suma los mayores porcentajes de impurezas, sobre todo de $\mathrm{Na}_{2} \mathrm{O}$ y $\mathrm{K}_{2} \mathrm{O}$, los cuales no son muy favorables para la elaboración de mullita de alta gama, por lo tanto se descartaron para continuar este estudio.

Las materias primas arcillosas que se eligieron para continuar el estudio fueron: Caolín C-80, arcilla Tincar Súper y La Rioja, ya que poseían de mediano a alto tenor de caolinita y bajo tenor de impurezas.

Se encontró que el índice de plasticidad es menor para la arcilla La Rioja y mayor para la arcilla Tincar Súper, en comparación con el caolín C-80.

> Se observó según análisis de Cono Pirométrico Equivalente que la arcilla La Rioja presentó mayor refractariedad debido a su menor tenor de impurezas, en cambio para el caolín C-80 presentó menor refractariedad con respecto a la arcilla Tincar Súper.

Se efectuó una etapa exploratoria realizando 6 mezclas (cada una de las arcillas con dos fuentes de alúmina) con estequiometría $3 \mathrm{Al}_{2} \mathrm{O}_{3} \cdot 2 \mathrm{SiO}_{2}$, con las materias primas arcillosas seleccionadas (Caolín C-80, arcilla Tincar Súper y La Rioja) y las fuentes de alúmina (calcinada e hidratada). Se conformaron probetas para cada mezcla por prensado a $40 \mathrm{MPa}$ y se calcinaron a $1600^{\circ} \mathrm{C}$ durante 3 horas. 
Todas las mezclas mencionadas anteriormente presentaron alta presencia de mullita tal como se observó por DRX, aunque en los difractogramas originales se observó que las mezclas con arcilla Tincar Súper y La Rioja generaron más cantidad de mullita que el caolín C-80 independientemente del tipo de alúmina utilizada, notándose también un mayor tenor de fase vítrea en las que se utilizó alúmina hidratada que la de alúmina calcinada.

Dentro de las mullitas obtenidas las realizadas con alúmina calcinada dieron en general mayor porosidad y menor variación dimensional respecto a las dimensiones del material sin calcinar $\left(110^{\circ} \mathrm{C}\right)$.

$>\quad$ Se observaron en todos los pares (arcilla - alúmina) un mayor valor de Módulo de Rotura a la flexión en tres puntos (MOR1) en las probetas con alúmina calcinada respecto a las probetas con alúmina hidratada, mientras que el Módulo de Rotura a la flexión, luego de un choque térmico (MOR 2), presentaron mayor resistencia las probetas con alúminas hidratadas y también mayor porcentaje de retención del mismo.

$>\quad$ Se descartó para la continuación de este trabajo el caolín C-80, debido a que poseía la menor refractariedad y menor resistencia al choque térmico con alúmina calcinada en comparación a las otras dos (arcilla Tincar Súper y La Rioja). Por otro lado la arcilla Tincar Súper es la arcilla refractaria de mayor disponibilidad comercial en el país y la arcilla La Rioja la de mejor refractariedad.

\section{BIBLIOGRAFIA}

Andreis R.R., Diagénesis y arcillas intersiciales en las unidades neopaleozoicas del grupo Paganzo - La Rioja. Revista de la Asociación Geológica Argentina. 61, pp. 364-369 (2006).

$>$ Aparicio P., y Galan E., Mineralogical interference on kaolinite crystallinity index measurements. Clays and Clay Minerals. 47, pp. 12-27 (1999).

$>\quad$ Barba A., Beltrán V., Feliu C., Gracia J., Gines F., Sánchez E. y Sanz V., Materias primas para la fabricación de soportes de baldosas cerámicas. Instituto de 
Tecnología Cerámica, Castellón - España, (1997).

$>$ Bernal I., Cabezas H., Espitia C., Mojica J., y Quintero J., Análisis próximo de arcillas para cerámica. Revista. Académica Colombiana de Ciencias exactas y naturales. 27, pp. 569-578 (2003).

$>\quad$ Berteli M.N., y Marsaioli Jr., Evaluation of short cut pasta air dehydration assisted by microwaves as compared to the conventional drying process. Journal of Food Engineering. 68, pp. 175-183 (2005).

$>$ Bich Ch., Ambroise J., Péra J., Influence of degree of dehydroxylation on the pozzolanic activity of metakaolin. Applied Clay Science. 44, pp. 194-200 (2009).

> Brindley G.M., Nakahira M., The kaolinite-mullite reaction series I-III. J. Am.Ceram. Soc. 42 (7), pp. 311-324 (1959).

$>\quad$ Cultrone G., Sebastián E., Elert K., De La Torre M. J., Cazalla O., RodriguezNavarro, C. Influence of mineralogy and firing temperature on the porosity of bricks, Journal of the European Ceramic Society. 24, pp. 547-564 (2004).

$>$ Domínguez E., Iglesias C., Dondi M., The geology and mineralogy of a range of kaolins from the Santa Cruz and Chubut Provinces, Patagonia (Argentina). Applied Clay Science. 40, pp. 124-142 (2008).

$>\quad$ Domínguez E., Iglesias C., Dondi M., The geology and mineralogy of a range of kaolins from the Santa Cruz and Chubut Provinces, Patagonia (Argentina). Applied Clay Science. 40, pp. 124-142 (2008).

$>\quad$ Ford W.F. The effect of heat in ceramics. Mclaren and Sons, London. (1967).

$>$ Grimshaw Rex W., The Chemistry and Physics of Clays and Other Ceramic Materials. Published by Ernest Benn, London, (1971).

$>$ Hammond C., The basics of crystallography and diffraction, 3rd edition, Oxford University Press, USA, pp. 243-256 (1997).

$>$ Hemantha kumariw P.N., Satapathy L.N., A Comparison of the Effects of Microwave Versus Conventional Drying on the Mechanical Properties Distribution of Dried Green Porcelains, International Journal of Applied Ceramic Technology. 5 (1), pp. 94-100 (2008).

$>\quad$ Johnson M., Pask. J.A., Moya J.S., Influence of impurities on high-temperature reactions of kaolinite. J. Am. Ceram. Soc. 65 (1), pp. 31 (1982). 
> Johnson S.M., Pask J.A., y Moya J.S., Influence of Impurities on HighTemperature Reactions of Kaolinite. J. Am. Cerum. Soc., 65 (1), pp. 31-35 (1982).

> Juettner Thomas., Moertel Heinrich., Svinka V., Svinka R., Structure of kaolinealúmina based foam ceramics for high temperature applications. Journal of the European Ceramic Society. 27 (2-3), pp. 1435-1441 (2007).

$>$ Kingery W.D., Bowen H.K., Uhlmann D.R., Introduction to ceramics, second edition. John Wiley \& Sons, Inc, Publ., New York. 1976.

$>\quad$ Klug H.P., y Alexander L.E., X-ray diffraction procedures for polycrystalline and amorphous materials. John Wiley \& Sons, New York., pp. 716 (1974).

$>$ Kuo-Chung Liu., Gareth Thornas., Caballero Angel., Moya Jose S, y De Aza Salvador., Time-Temperature-Transformation Curves for Kaolinite- - $\alpha$ Alúmina. Journal of the American Ceramic Society - Liu et al. 77 (6), pp. $1545-1552$ (1994).

$>\quad$ Liu K.C., Zhomas G., Caballero A., Moya J.S., S. De Aza. Mullite formation in kaolinite- $\mathrm{Al}_{2} \mathrm{O}_{3}$. Acta Metall. Mater., 42 (2), pp. 489-495 (1994).

> Liu Kuo-Chung., Gareth Thornas., Caballero Angel., Moya Jose S, y De Aza Salvador., Time-Temperature-Transformation Curves for Kaolinite- - $\alpha$ Alúmina. Journal of the American Ceramic Society. 77 (6), pp. 1545 -1552 (1994).

> Mackenzie R.C., Differential Thermal Analysis, Applications. Academic Press, London and New York. 2 (1972).

> Mazdiyasni K.S., Brown L.M., Sintesis and mechanical properties of stoichiometric aluminum silicate (mullite). Journal of the American Ceramic Society. 55 (11), pp. 548-552 (1972).

$>$ Modesto C., Bernardin A.M. Determination of clay plasticity. Indentation method versus Pfefferkorn method, Applied Clay Science. 40, pp. 15-19 (2008).

$>\quad$ Moore D., Reynolds R., X-ray Diffraction and the identification and analysis of clay minerals. Oxford University, USA. (2002).

$>$ Moore H., y Prasad M.R., The effects of various mineralizing agents in promoting recrystallizations in mixtures of clay an alúmina during firing. J. Soc. Glass techonol., 39 (10), pp. 314-330 (1955).

> Muñoz R.A., Muñoz J.A., Mancilla P., Rodríguez J.E., Caracterización fisicoquímica de arcillas del municipio de Guapi - costa pacífica Caucana 
(Colombia). Revista. Académica Colombiana de Ciencias exactas y naturales. 31 (121), pp. 537- 544 (2007).

> Norma IRAM 10 502., Métodos de determinación del límite plástico e índice de plasticidad. Instituto Argentino de Racionalización de materiales. (1968).

$>$ Norma IRAM 10 507. Cono pirométrico equivalente. Instituto Argentino de Racionalización de materiales. (1971).

> Pankratz L.B., Weller W.W., y Kelley K., Low - Low-temperature heat capacity and high-temperature heat content of mullite U.S. Dept. of the Interior. Bureau of Mines, Rep. Inyest., 6287, pp. 7 (1963).

$>\quad$ Sahnoune F., Chegaar M., Saheb N., Goeuriot P., Valdivieso F., Algerian kaolinite used for mullite formation, Applied Clay Science. 38, pp. 304- 310 (2008).

> Saikia N.J., Bharali D.J., Sengupta P., Bordoloi D., Goswamee R.L., . Saikia P.C, Borthakur P.C. Characterization, beneficiation and utilization of a kaolinite clay from Assam, India, Applied Clay Science. 24, pp. 93-103 (2003).

> Sandoval del Rio F., y Gonzalez Peña J.M., Influencia de las características físicas de caolines en las propiedades de porcelana de alta alúmina. Boletín de la Sociedad Española de Cerámica y Vidrio 23 (3), pp. 187 (1984).

$>\quad$ Sandoval del Rio F., y Gonzalez Peña J.M., La arcilla ilítica en la obtención de porcelanas de alta resistencia mecánica. II. Materiales en cuya composición interviene el caolín de puentedeume (La Coruña), Boletín de la Sociedad Española de Cerámica y Vidrio. 25 (4), pp. 249-255 (1986).

$>$ Saruhan B., Albers W., Schneider H., Kaysser W.A., Reaction and sintering mechanisms of mullite in the systems cristobalite/alpha- $\mathrm{Al}_{2} \mathrm{O}_{3}$ and amorphous $\mathrm{SiO}_{2} /$ alpha- $\mathrm{Al}_{2} \mathrm{O}_{3}$. Journal of the European Ceramic Society. 16 (10), pp. 10751081 (1996).

> Sonuparlak B., Sarikaya M., y. Aksay I.A., Spinel Phase Formation during the $980^{\circ} \mathrm{C}$ Exothermic Reaction in the Kaolinite-to-Mulli te Reaction Series. Journal of the American Ceramics Society. 70 (11), pp. 837-42 (1987).

$>$ Vieira C.M.F., Sánchez R., y Monteiro S.N., Characteristics of clays and properties of building ceramics in the state of Rio de Janeiro, Brazil. Construction 
and Building Materials. 22, pp. 781-787 (2008).

> Viswabaskaran V., Gnanam F.D., Balasubramanian M., Mullitisation behaviour of calcined clay-alúmina mixtures. Ceramics International 29 (5), pp. 561-571 (2003).

$>\quad$ Viswabaskaran, V., Gnanam F.D., Balasubramanian M., Mullite from clay-reactive alúmina for insulating substrate application. Applied Clay Science 25, pp. 29-35 (2004).

$>$ Worral E., Clays: their nature, origin and general properties. Transatlantic Arts, Estados Unidos. (1968).

$>\quad$ Worral W.E., Clay and ceramic raw materials. Elsevier applied science publishers. London., pp. 147 -166 (1986). 


\section{CAPITULO 5 SECUNDARIA EN EL SISTEMA}

GENERACION DE MULLITA PRIMARIA, NETA Y

En el presente capítulo se desarrolla la caracterización y cuantificación de mullita obtenida a partir de una arcilla refractaria (mullita primaria) y de mullita obtenida por una mezcla estequiométrica 3-2 de la arcilla mencionada con alúmina calcinada (mullita neta), estudiando la evolución de las fases presentes de acuerdo a su temperatura y tiempo de tratamiento.

Para este estudio se tomó la mejor materia prima arcillosa estudiada en al capítulo anterior (arcilla La Rioja), la que presentó mayor porcentaje de caolinita y menos impurezas; con relación a la fuente de alúmina se escogió la alúmina calcinada en comparación con la alúmina hidratada, debido a que presentaba un menor tamaño de partícula y no poseía agua de estructura lo que generaba menor porosidad a temperaturas intermedias.

Posteriormente la arcilla La Rioja y alúmina calcinada fueron mezcladas en proporciones estequiométricas $3 \mathrm{Al}_{2} \mathrm{O}_{3} \cdot 2 \mathrm{SiO}_{2}$ (AriojAcal), como se mostró en el capítulo anterior (tabla 4.8), con el fin de determinar la mullita neta generada en el sistema. 
Para realizar el estudio cinético, se elaboraron probetas de arcilla La Rioja (Arioja, sola) y mezcla (AriojAcal) prensadas unixialmente a $100 \mathrm{MPa}$, se utilizó esta presión debido a que las partículas estarían en mayor contacto una de la otra, mayor densidad en verde y así disminuir los problemas difusionales que se podrían presentar en el estudio debidos a la mayor porosidad generada al prensar a menor presión.

Las probetas elaboradas fueron luego sometidas a tratamiento térmico a diferentes tiempos y temperaturas, con el objetivo de evaluar el porcentaje total de mullita a dichas temperaturas y tiempos, y además poder analizar por separado dentro de los porcentajes observados la mullita primaria procedente de la propia arcilla (Arioja), de la secundaria producida por la reacción entre la alúmina calcinada y la sílice liberada por la arcilla al descomponerse térmicamente (mullita Neta producida en la mezcla menos mullita primaria generada por la arcilla sola multiplicándola por el factor de dilución correspondiente $(0,5187))$. [Sanchez, 1996; Schneider et al., 1994; 2008].

Los tratamientos térmicos consistieron en calcinaciones a diferentes temperaturas las cuales fueron; $1300,1400,1450,1500$ y $1600^{\circ} \mathrm{C}$, y a distintos tiempos de permanencia dependiendo ellos de la temperatura de trabajo. Se introdujeron las muestras crudas en forma directa (probeta de $\sim 1.25 \times 0.80 \times 0.80 \mathrm{~cm}^{3}$ ) en un horno tubular, dejándolas a cada una de ellas el tiempo prefijado hasta que se retiraron del mismo. Para evitar el posible estallido de las probetas al introducirlas en el horno en forma directa a cada temperatura de estudio, se precalentaron las mismas hasta $800{ }^{\circ} \mathrm{C}$ con 1 hora de permanencia, de esta manera se permitió una salida apropiada del vapor de agua procedente de la descomposición de la arcilla. [Brindley y Nakahira, 1959; Tcheichvili y Butschkowskyi, 1975]. La permanencia previa a $800 \stackrel{\circ}{\circ}$ durante 1 hora no afecta la conversión a mullita que se desea evaluar.

Las probetas extraídas del horno fueron caracterizadas y analizadas por Difracción de Rayos X, cuantificando sus fases cristalinas por el método de Rietveld (Fullprof) [Rietveld, 1969; Rodríguez, 1990; 2001], con el fin de obtener las curvas conversión de mullita vs tiempo necesarias para la aplicación de los diferentes modelos matemáticos que podrían modelizar la cinética de los procesos en estudio. 


\subsection{GENERACIÓN DE MULLITA PRIMARIA}

\subsubsection{Tratamiento térmico - Formación de mullita primaria (arcilla La Rioja)}

Los tratamientos térmicos de las probetas prensadas a $100 \mathrm{MPa}$ de la arcilla La Rioja (Arioja) y luego sometidas a tratamiento de $800 \stackrel{\circ}{\circ}$ por 1 hora, fueron calcinadas a diferentes temperaturas y tiempos, los cuales son descriptos en la siguiente tabla 5.1.

Tabla 5.1. Arcilla La Rioja (Arioja) tratada a diferentes temperaturas y tiempos

\begin{tabular}{|c|c|c|c|c|c|c|c|c|c|c|c|c|}
\hline $\begin{array}{c}\text { TEMPERATURAS } \\
\left({ }^{\circ} \mathrm{C}\right)\end{array}$ & \multicolumn{10}{|c|}{ TIEMPO (Horas) } \\
\hline $\mathbf{1 3 0 0}$ & - & - & 1 & 2 & & 4 & - & 6 & - & 8 & 10 & 12 \\
\hline $\mathbf{1 4 0 0}$ & - & 0.5 & - & 2 & - & 4 & - & 6 & 7 & 8 & 10 & - \\
\hline $\mathbf{1 4 5 0}$ & - & 0.5 & & 2 & - & 4 & - & 6 & - & 8 & 10 & - \\
\hline $\mathbf{1 5 0 0}$ & 0.25 & 0.5 & 1 & 2 & 3 & - & 5 & 6 & 7 & - & - & - \\
\hline $\mathbf{1 6 0 0}$ & 0.25 & 0.50 & 1 & 2 & 3 & - & 5 & - & - & - & - & \\
\hline
\end{tabular}

En la tabla 5.1, se observa que a bajas temperaturas se usaron tiempos finales más largos para lograr la mayor conversión de mullita posible, procediéndose en forma inversa a medida que se aumentaba la temperatura ya que las conversiones en estos casos eran mayores a menores tiempos de tratamiento.

\subsubsection{Difractogramas de arcilla La Rioja (mullita primaria)}

Todas las probetas extraídas del horno fueron analizadas y caracterizadas por Difracción de Rayos X, los difractogramas obtenidos se muestran en la figura 5.1. 


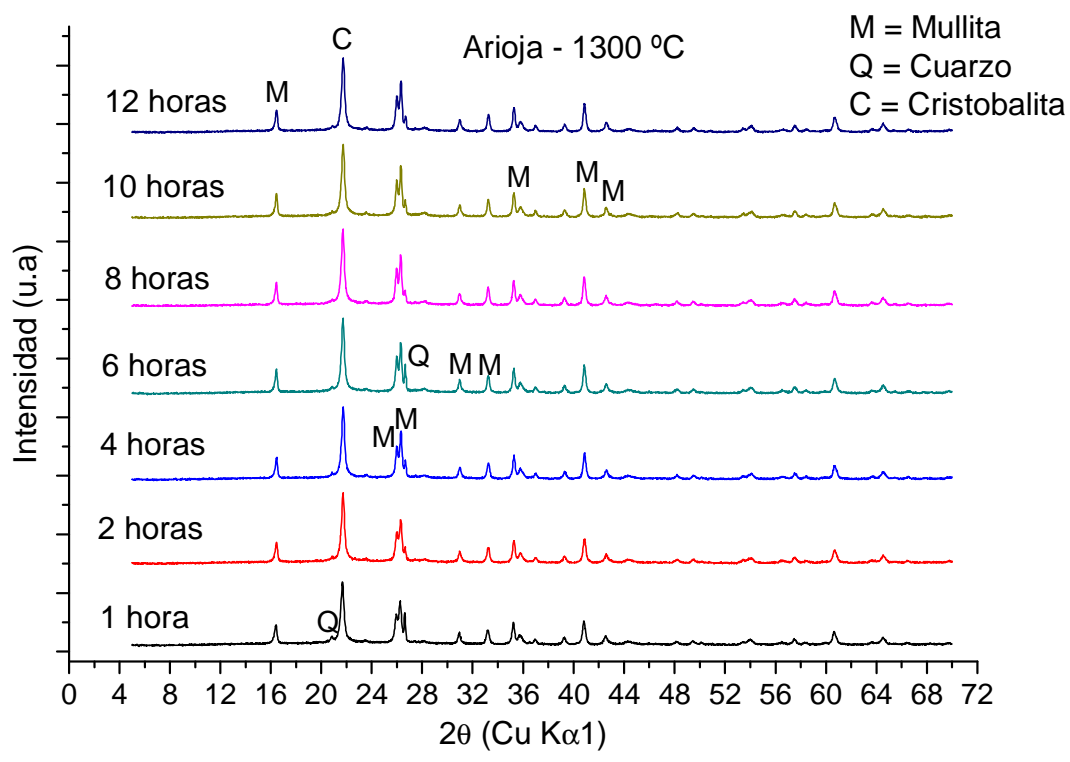

(a)

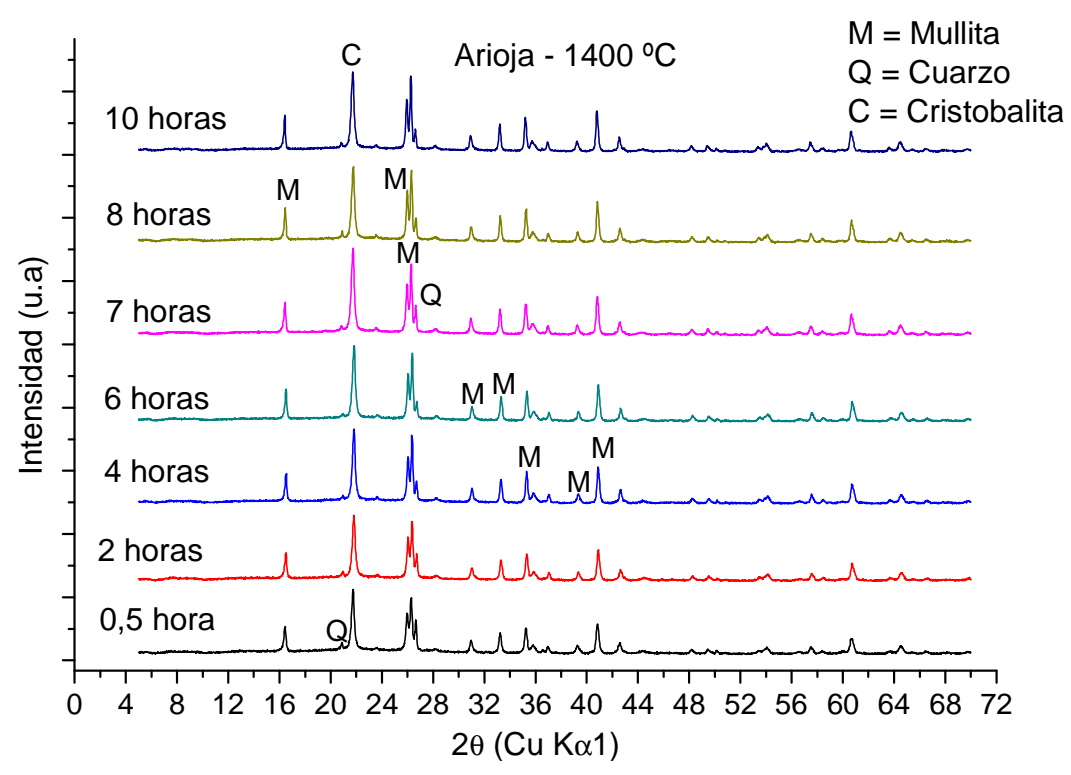

(b) 


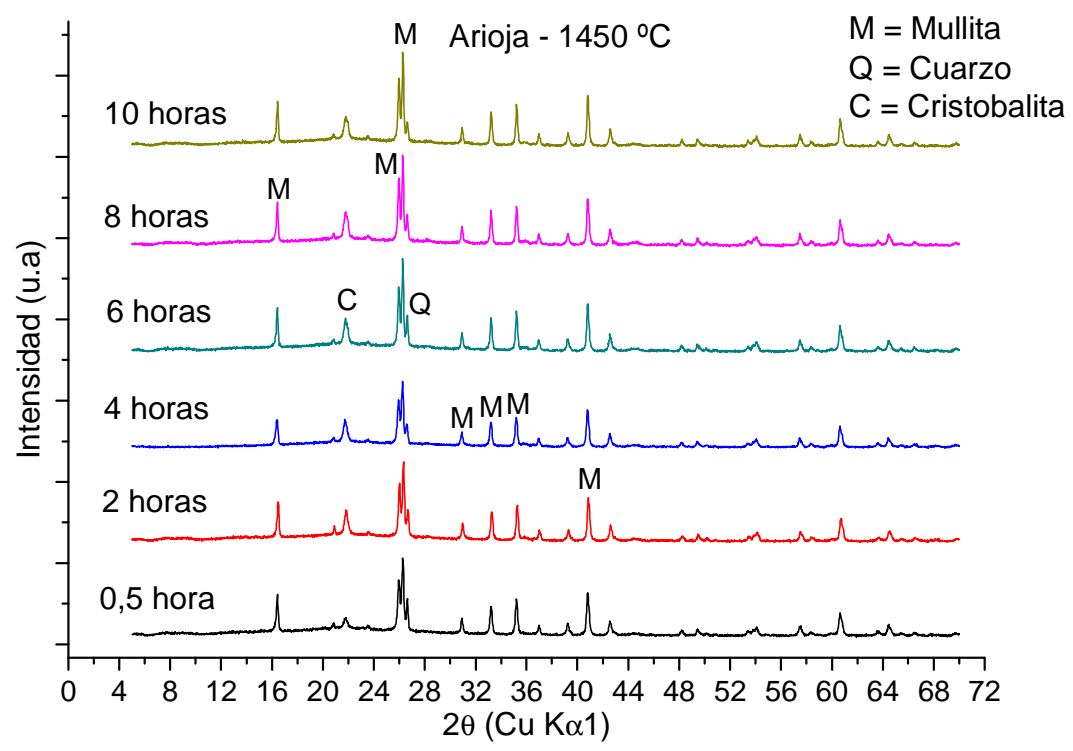

(c)

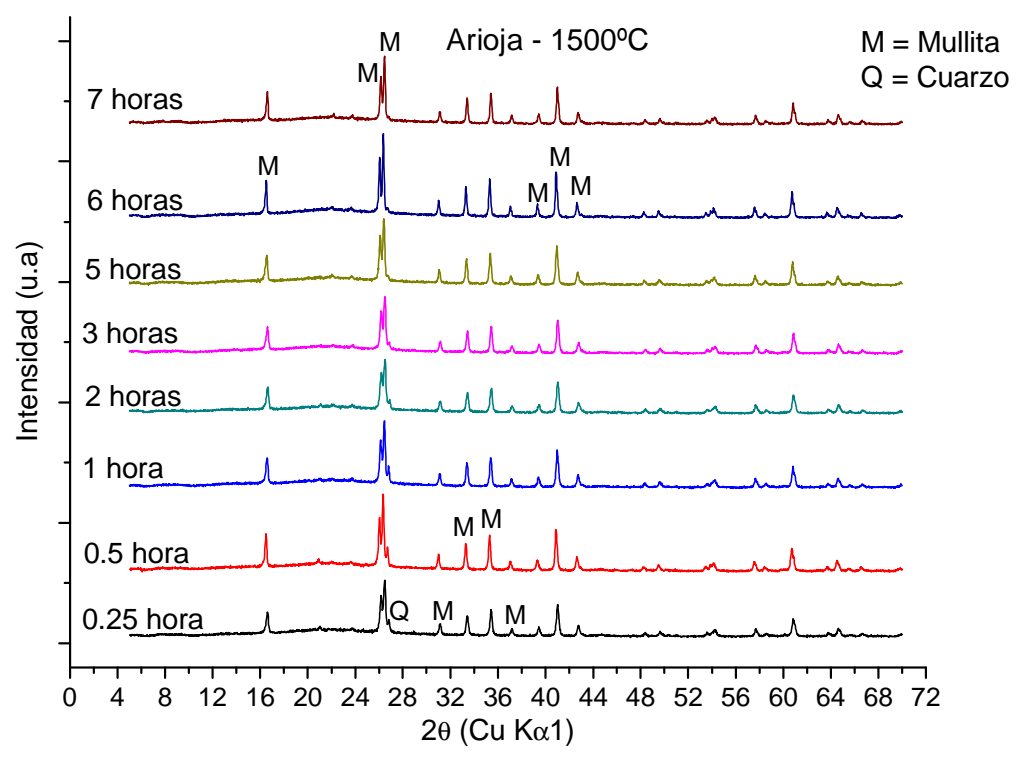

(d) 


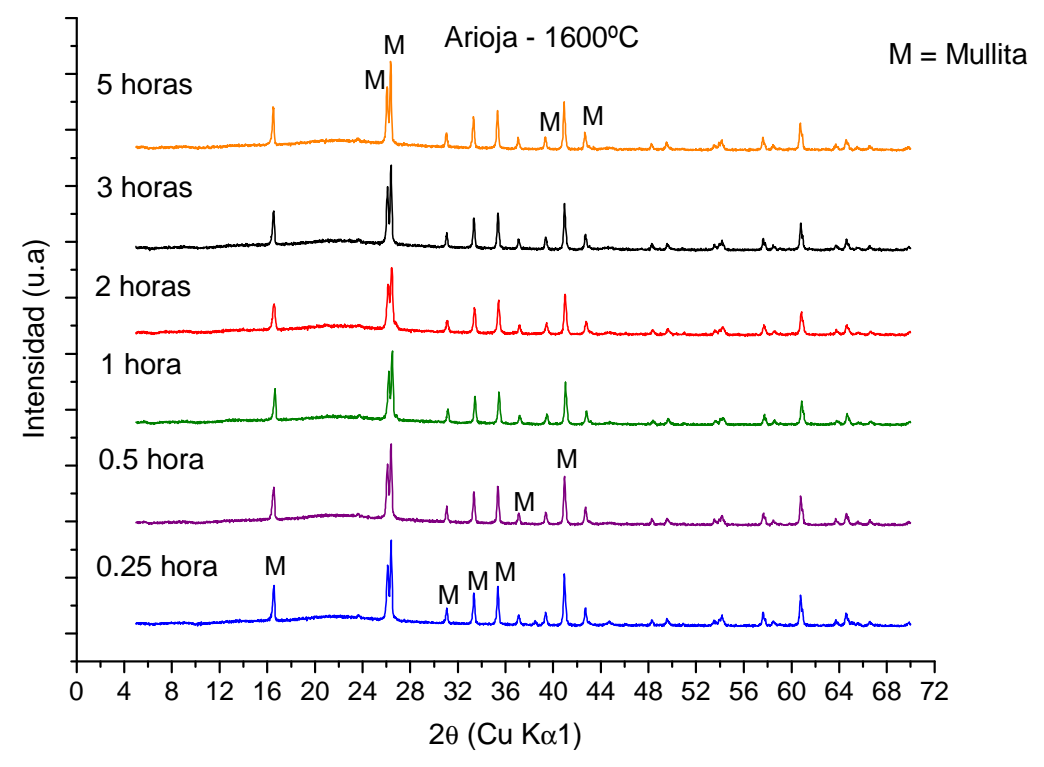

(e)

Figura 5.1. Difractogramas de la arcilla La Rioja (Arioja) tratada a diferentes temperaturas y tiempos; (a) $1300^{\circ} \mathrm{C}$, (b) $1400^{\circ} \mathrm{C}$, (c) $1450 \stackrel{\circ}{\mathrm{C}}$, (d) $1500^{\circ} \mathrm{C}$ y (e) $1600^{\circ} \mathrm{C}$.

Se puede observar en todos los difractogramas de la figura 5.1 que las intensidades de las fases cristalinas presentes en la arcilla La Rioja varían de acuerdo a la temperatura y tiempo de reacción principalmente en los primeros tiempos de tratamiento, encontrándose fases de mullita (mullita primaria), cuarzo y cristobalita, notándose también un elevado fondo en todos los difractogramas visualizándose mayoritariamente como una banda en la zona de $22^{\circ}$ de $2 \theta$, esto debido a la fase vítrea generada en el sistema. Klug y Alexander, 1974; Sahnoune et al., 2008].

Recordando que la descomposición de una arcilla caolinítica que posee cuarzo al ser tratada térmicamente, presenta las siguientes transformaciones:
$\mathrm{Al}_{2} \mathrm{O}_{3} \cdot 2 \mathrm{SiO}_{2} \cdot 2 \mathrm{H}_{2} \mathrm{O}$
(Caolinita)

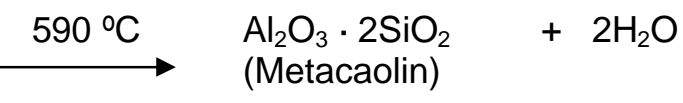
$3\left(\mathrm{Al}_{2} \mathrm{O}_{3} \cdot 2 \mathrm{SiO}_{2}\right)$
$\stackrel{>1100 \stackrel{\circ}{\longrightarrow}}{\longrightarrow} \underset{(\text { Mullita Primaria) }}{3 \mathrm{Al}_{2} \mathrm{O}_{3} \cdot 2 \mathrm{SiO}_{2}}+4 \mathrm{SiO}_{2}{ }^{*}$
${ }^{*} \mathrm{SiO}_{2}$

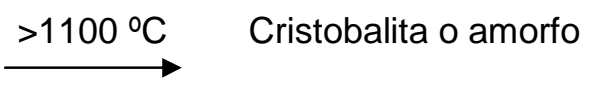
$4 \mathrm{SiO}_{2}+6 \mathrm{Al}_{2} \mathrm{O}_{3}$
(extra)
$\stackrel{>1200 \stackrel{\circ}{\longrightarrow}}{\longrightarrow} \begin{aligned} & 2\left(3 \mathrm{Al}_{2} \mathrm{O}_{3} \cdot 2 \mathrm{SiO}_{2}\right) \\ & (\text { Mullita Secundaria) }\end{aligned}$ 
La formación de cristobalita dependerá de la arcilla de origen, del tamaño de partícula del cuarzo, de la temperatura, tiempo y velocidad de calentamiento. Según sea las condiciones realizadas y velocidad de enfriamiento podría quedar también en forma de fase amorfa, además las arcillas caoliníticas poseen en general otras impurezas $\left(\mathrm{Fe}_{2} \mathrm{O}_{3}\right.$, $\mathrm{TiO}_{2}, \mathrm{Na}_{2} \mathrm{O}$, etc) que puede ocurrir una estabilización de sistema amorfo (vidrios a altas temperaturas).

La figura 5.1(a), muestra los difractogramas de la arcilla La Rioja tratada a $1300{ }^{\circ} \mathrm{C}$ a diferentes tiempos de tratamiento, encontrándose que la cristobalita presenta mayor intensidad con respecto a la mullita, notándose también la presencia de cuarzo, donde los picos de mullita se van definiendo a medida que aumenta el tiempo de tratamiento y para el cuarzo van disminuyendo su intensidad.

Para los difractogramas de la figura 5.1(b) (arcilla La Rioja tratada a $1400{ }^{\circ} \mathrm{C}$ a diferentes tiempos de reacción) se observó que las intensidades de la cristobalita y la mullita son casi similares y van aumentando los mismos a medida que crece el tiempo de reacción, hallándose también la presencia de cuarzo que va disminuyendo a medida que aumenta el tiempo de tratamiento; en cambio para la mullita los picos se muestran más definidos.

La figura 5.1(c), muestra los difractogramas de la arcilla La Rioja tratada a $1450{ }^{\circ} \mathrm{C}$ a diferentes tiempos de tratamientos, observándose que el pico con mayor intensidad corresponde a la mullita, posteriormente cristobalita y cuarzo, notándose pequeños crecimientos de intensidad para la cristobalita con respecto al tiempo, en cambio para el cuarzo van disminuyendo las intensidades.

Para los difracotgramas de la figura 5.1(d) (arcilla La Rioja tratada a 1500 ㅇ a diferentes tiempos de reacción) se observó que, independientemente del tiempo la fase cristalina principal es la mullita, posteriormente cuarzo en muy baja proporción y un porcentaje alto de fase vítrea. Debido a las características de la arcilla utilizada (casi totalmente caolinita), los productos de reacción son mullita y sílice mayoritariamente, esta última se mostró en el diagrama como sílice amorfa (no cristalizo en cristobalita como lo visto a temperaturas menores), mostrando un elevado fondo en todo el diagrama, pero que alcanza su máxima expresión en la banda centrada en $21,80^{\circ}$ de $2 \theta$ (posición en donde se encontraría el pico de máxima intensidad de la sílice, variedad cristobalita). 
En la figura 5.1(e) (arcilla La Rioja a $1600{ }^{\circ} \mathrm{C}$ a diferentes tiempos de tratamiento), se puede observar que la fase cristalina mayoritaria es la mullita (primaria), independientemente de la temperatura y tiempo de reacción y que dadas las características de la arcilla utilizada, prácticamente el producto de reacción restante es sílice. Esta última se manifestó en el diagrama como sílice amorfa, observándose un elevado fondo en todo el diagrama, adquiriendo su máxima expresión en la banda centrada en $21,80^{\circ}$ de $2 \theta$ (posición en donde se encontraría el pico de máxima intensidad de la sílice, variedad cristobalita). La observación de esta serie de difractogramas solo muestra visualmente la presencia de mullita como fase cristalina y además la presencia de fase vítrea o amorfa manifestada por una amplia banda centrada en $21,80^{\circ}$ de $2 \theta$.

\subsubsection{Cuantificación del porcentaje de mullita primaria (arcilla La Rioja), por tres métodos.}

Para realizar la cuantificación de cada difractograma, por el método de Rietveld, primero se debe conocer la estructura cristalina de cada fase presente en las muestras. Por lo tanto, en sí mismo, no permite incluir fases amorfas o no cristalinas, sin embargo, diversos autores han implementado la cuantificación de estas fases utilizando el refinamiento de Rietveld en forma eficaz [Rietveld, 1969]. En este capítulo para cuantificar las fases amorfas se estudió el método de Ohlberg y el de Le Bail.

Como ya se mencionó en el capítulo 3, el refinamiento Rietveld comienza por el planteamiento de una estructura modelo para la fase cristalina a investigar y la simulación por computadora del patrón de difracción de los polvos. Cuando se ha comprobado que el patrón modelado se parece cualitativamente al experimental, se desarrolla un cuidadoso proceso de variaciones sistemáticas en las características de la muestra y del experimento, llevando a cabo un proceso iterativo por mínimos cuadrados, hasta que se satisface un criterio de convergencia con los valores de las intensidades experimentales y el modelo teórico, sin perder de vista el sentido físico de la estructura observado en los valores de las distancias y ángulos de enlace, factores térmicos, ocupación, etc. [Lutterotti et al., 1998].

En el presente capítulo se presentan y comparan los resultados de la cuantificación de mullita por tres métodos distintos basados en la Difracción de Rayos X, y para dos de estos métodos se estudió la cantidad de fases cristalinas y no cristalina presentes en los 
difractogramas anteriormente mencionados (arcilla La Rioja tratada térmicamente diferentes temperaturas y tiempos, tal como se describió en la tabla 5.1.), con el fin de conocer su conversión a mullita primaria generada por la arcilla para cada caso.

Se cuantificaron las fases cristalinas presentes y el contenido de fase amorfa por dos de los métodos. En el primer método, se utilizó la cuantificación por el método de Rietveld (Fullprof) [Rietveld, 1969; Rodríguez, 2001] para las fases cristalinas, mientras que la fase amorfa se determinó por la interpolación de fondos (método de Ohlberg) entre una sílice cristalina (cuarzo) y una amorfa (sílice volátil) [Conconi et al., 2011; Ohlberg y Strickler 1962]; y en el segundo, se introdujo la fase vítrea como una sílice con excesivos defectos por tamaño cristalino (modelo de Le Bail) [Conconi et al., 2011; Le Bail, 1995].

En el tercer método solo se cuantificó el tenor de mullita por comparación de las áreas del pico centrado en $33.2^{\circ}$ de $2 \theta$ (CuKa1) con el área medida para una mullita sinterizada sintética comercial de alta calidad ( $91 \%$ mullita cristalina y $9 \%$ fase amorfa). Los resultados arrojados por los tres métodos fueron contrastados contra el valor máximo de mullita $(59.40 \%)$ que podría producir la arcilla en estudio (La Rioja) de acuerdo a su composición química en $\mathrm{SiO}_{2}$ y $\mathrm{Al}_{2} \mathrm{O}_{3}$.

Para realizar el análisis cuantitativo por los tres métodos y compararlos, se escogió la arcilla La Rioja tratada a $1600{ }^{\circ} \mathrm{C}$ a diferentes tie mpos de tratamiento, debido a que a estas condiciones la arcilla presentaría su máxima conversión a mullita (primaria).

\subsubsection{Método de Ohlberg - Cuantificación por Interpolación de fondos.}

Hay que tener en cuenta que el análisis de los difractogramas y la determinación de las fases cristalinas presentes en cada muestra son de vital importancia para poder ejecutar el refinamiento de Rietveld, debido a que si existiera alguna fase no cristalina no incluida en el refinamiento, el contenido del estándar interno calculado sería sobreestimado. Para empezar la cuantificación de las muestras (Arcilla La Rioja tratada a diferentes temperaturas y tiempos) primero se caracterizaron las fases cristalinas presentes para luego ser evaluadas cuantitativamente empleando el método de Rietveld (Fullprof) que como se vio permite realizar refinamientos de estructuras, cálculos de parámetros cristalinos y determinaciones cuantitativas. 
Los difractogramas obtenidos en el estudio térmico de la arcilla La Rioja fueron cuantificados para las fases cristalinas mullita, cuarzo, y cristobalita, sin tener en cuenta su fase amorfa. Para encontrar el porcentaje de esta fase amorfa o vítrea, se utilizó el método de Ohlberg [Ohlberg y Strickler 1962] que permite la determinación del porcentaje de cristalinidad y por ende el porcentaje de fase vítrea en vidrios parcialmente desvitrificados, por interpolación de la línea de base del difractograma entre las correspondientes a sílice amorfa y a cuarzo cristalino.

Para ello se utilizó dióxido de Silicio (Carlo Erba RPE) como fase vítrea o amorfa y cuarzo como fase cristalina, por lo cual sería válido suponer que a partir de la ecuación de Ohlberg (Ec. 3.5) se puede obtener el porcentaje de fase amorfa o no cristalina. El porcentaje de material amorfo o no cristalino se encontró midiendo las intensidades del fondo en $22.5^{\circ}$ de $2 \theta$, correspondientes a la muestra vítrea (sílice amorfa), a la cristalina (cuarzo) y a la de estudio (Arioja) que es parcialmente cristalina. La figura 5.2 representa el esquema del método de Ohlberg utilizando en el programa Fullprof, para la arcilla La Rioja tratada térmicamente a $1600 \stackrel{\circ}{\mathrm{C}}$ por 5 horas con una rampa de calentamiento de 5 ${ }^{\circ} \mathrm{C}$ por minuto.

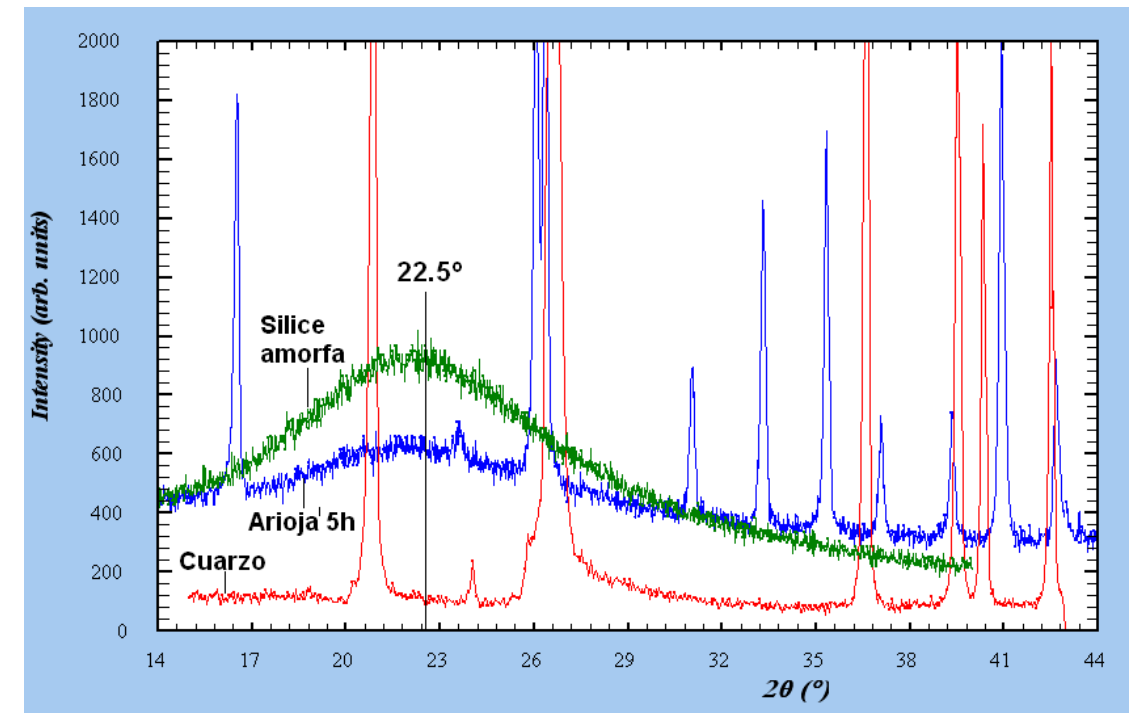

Figura 5.2. Difractogramas de cuarzo, sílice amorfa y arcilla La Rioja (Arioja) tratada a $1600{ }^{\circ} \mathrm{C}$ por 5 horas. Método de de Ohlberg.

La figura 5.2 muestra la interpolación de los difractogramas de la sílice amorfa, el cuarzo y la arcilla La Rioja tratada a $1600 \stackrel{\circ}{C}$ por 5 horas, observándose claramente la cantidad de fase amorfa presente en esta, manifestando una gran importancia en la intensidad 
del fondo en $22.5^{\circ}$ de $2 \theta$, tomándose los valores en ese punto para ser aplicados a la ecuación de Ohlberg [Ohlberg y Strickler 1962].

Teniendo ya los porcentajes de las las fases cristalinas (\% de mullita, \% de cuarzo, y \% de cristobalita), obtenidas por el método de Rietveld y por el método de Ohlberg (Interpolación de fondos) su porcentaje amorfo, se pudieron calcular todos los porcentajes de las fases presentes en todos los difractogramas mencionadas anteriormente. En la tabla 5.2 se observan los porcentajes de las fases obtenidas de la arcilla La Rioja tratada térmicamente a $1600^{\circ} \mathrm{C}$ a diferentes tiempos de tratamiento.

Tabla 5.2. Resultados de los porcentajes de las fases presentes en la arcilla La Rioja tratada a $1600 \stackrel{\circ}{\mathrm{C}}$ a diferentes tiempos, obtenidos por el método de Ohlberg.

\begin{tabular}{|c|c|c|c|c|}
\hline $\begin{array}{c}\text { Tiempo } \\
\text { (Horas) }\end{array}$ & $\begin{array}{c}\text { \% Mullita } \\
\text { (Primaria) }\end{array}$ & $\begin{array}{c}\% \\
\text { Cuarzo }\end{array}$ & $\begin{array}{c}\% \\
\text { Cristobalita }\end{array}$ & $\begin{array}{c}\% \\
\text { Fase amorfa }\end{array}$ \\
\hline $\mathbf{0 . 2 5}$ & 41.6 & 0.3 & --- & 58.1 \\
\hline $\mathbf{0 . 5 0}$ & 35.8 & 0.1 & --- & 64.1 \\
\hline $\mathbf{1}$ & 43.7 & 1.1 & --- & 55.2 \\
\hline $\mathbf{2}$ & 40.0 & 1.3 & --- & 58.7 \\
\hline $\mathbf{3}$ & 36.1 & 0.1 & --- & 63.8 \\
\hline $\mathbf{5}$ & 36.0 & 0.1 & --- & 63.9 \\
\hline
\end{tabular}

En la tabla 5.2 se observan los porcentajes de las fases de mullita, cuarzo y porcentaje amorfo, notándose un mayor porcentaje de mullita primaria a 1 hora respecto al porcentaje obtenido a los 15 minutos ( 0.25 hora). Se percibe una oscilación de su porcentaje a diferentes tiempos, que se podrían interpretar como que la fase vítrea formada redisuelve algo de mullita y cuando satura la vuelve a precipitar (disolución precipitación). No se detectó cristobalita en estas condiciones de tratamiento. [Lee et al., 1995; Moore y Reynolds, 1997; Zevin y Viaene, 1990].

Estos valores son bajos en comparación al porcentaje de mullita máxima $(59,40 \%)$

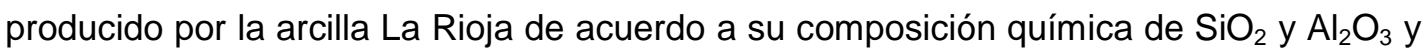
teniendo en cuenta la alta temperatura y tiempos de tratamiento. Este mismo comportamiento se presentó para las demás temperaturas y tiempos estudiados (ver tabla 5.1). 


\subsubsection{Modelo de Le Bail - Arcilla (La Rioja)}

Otro método para cuantificar las fases cristalinas teniendo en cuenta la fase amorfa generada en el sistema, utilizando el método de Rietveld es aplicando el modelo de Le Bail que consiste en introducir dentro del programa una fase vítrea de sílice con excesivos defectos por tamaño cristalino (sílice volátil amorfa). [Bish y Howard, 1988; Le Bail, 1995].

En el caso de la fase vítrea con el modelo de Le Bail, se refinó únicamente el factor de estructura. Para las demás fases se refinaron el factor de estructura, los parámetros de celda, y los parámetros que describen el modelo. [Le Bail, 1995; Schneider et al., 1993]. Para el refinamiento las intensidades del fondo se mantuvieron fijas entre $5^{\circ}$ y $45^{\circ}$, donde se presenta la banda del amorfo.

En el resto del difractograma, las intensidades del fondo fueron refinadas.

En la figura 5.3 se presenta el esquema del refinamiento mediante el método de Rietveld utilizando el modelo de Le Bail para la arcilla La Rioja tratada térmicamente a $1600{ }^{\circ} \mathrm{C}$ por 5 horas. Las líneas de difracción corresponden a las fases: mullita, cuarzo y sílice amorfa respectivamente.

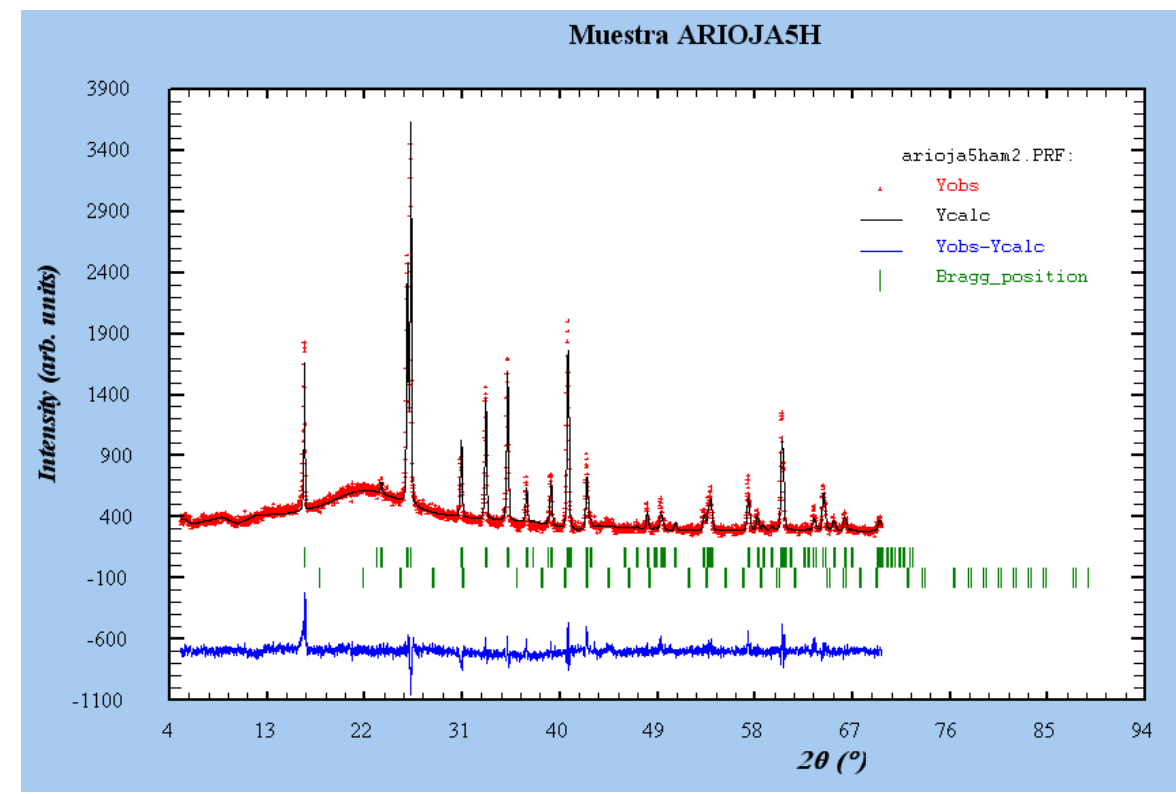

Figura 5.3. Difractograma de la arcilla La Rioja (Arioja) tratada a $1600 \stackrel{\circ}{\mathrm{C}}$ por 5 horas, con las líneas de difracción correspondientes a las fases de mullita, cuarzo y sílice amorfa. Modelo de Le Bail. 
Los porcentajes de las fases cristalinas (mullita, cuarzo y cristobalita) por el método de Rietveld y su fase amorfa aplicando el modelo de La Bail, se presentan en la tabla 5.3.

Tabla 5.3. Resultados de los porcentajes de las fases presentes en la arcilla La Rioja (Arioja) tratada a $1600{ }^{\circ} \mathrm{C}$ a diferentes tiempos, obtenidos por el método de Le Bail.

\begin{tabular}{|c|c|c|c|c|}
\hline $\begin{array}{c}\text { Tiempo } \\
\text { (Horas) }\end{array}$ & $\begin{array}{c}\text { \% Mullita } \\
\text { (Primaria) }\end{array}$ & $\begin{array}{c}\% \\
\text { Cuarzo }\end{array}$ & $\begin{array}{c}\% \\
\text { Cristobalita }\end{array}$ & $\begin{array}{c}\% \\
\text { Fase amorfa }\end{array}$ \\
\hline $\mathbf{0 . 2 5}$ & 65.0 & 1.0 & --- & 34.0 \\
\hline $\mathbf{0 . 5 0}$ & 61.3 & --- & --- & 38.7 \\
\hline $\mathbf{1}$ & 62.8 & 0.8 & --- & 36.4 \\
\hline $\mathbf{2}$ & 61.6 & 1.8 & --- & 36.6 \\
\hline $\mathbf{3}$ & 64.4 & --- & --- & 35.6 \\
\hline $\mathbf{5}$ & 61.6 & --- & --- & 38.4 \\
\hline
\end{tabular}

En la tabla 5.3 se observan los porcentajes de las fases de mullita (primaria), cuarzo, sílice amorfa y la ausencia de cristobalita cómo fase cristalina presente, notándose que todos los valores de mullita superan el valor máximo teórico que podría producir la arcilla La Rioja $(59,40 \%)$ de acuerdo a su composición química de $\mathrm{SiO}_{2}$ y $\mathrm{Al}_{2} \mathrm{O}_{3}$ aunque estos valores estarían dentro del margen error originado por el método de cuantificación y por la cantidad de fase amorfa generada en el sistema. Este mismo comportamiento se presentó para las demás temperaturas y tiempos estudiados (ver tabla 5.1).

\subsubsection{Método por comparación de área en el pico (33.2ํㅡㄹ $2 \theta)$}

El tercer método estudiado en este capítulo, consistió en realizar solo la cuantificación del tenor de mullita por comparación de las áreas del pico centrado en $33,2^{\circ}$ de $2 \theta$ con el área medida para una mullita sinterizada sintética comercial (M-72) de alta calidad (91\% mullita cristalina y $9 \%$ fase amorfa), utilizando el programa FullProf, ver figura 5.4. 


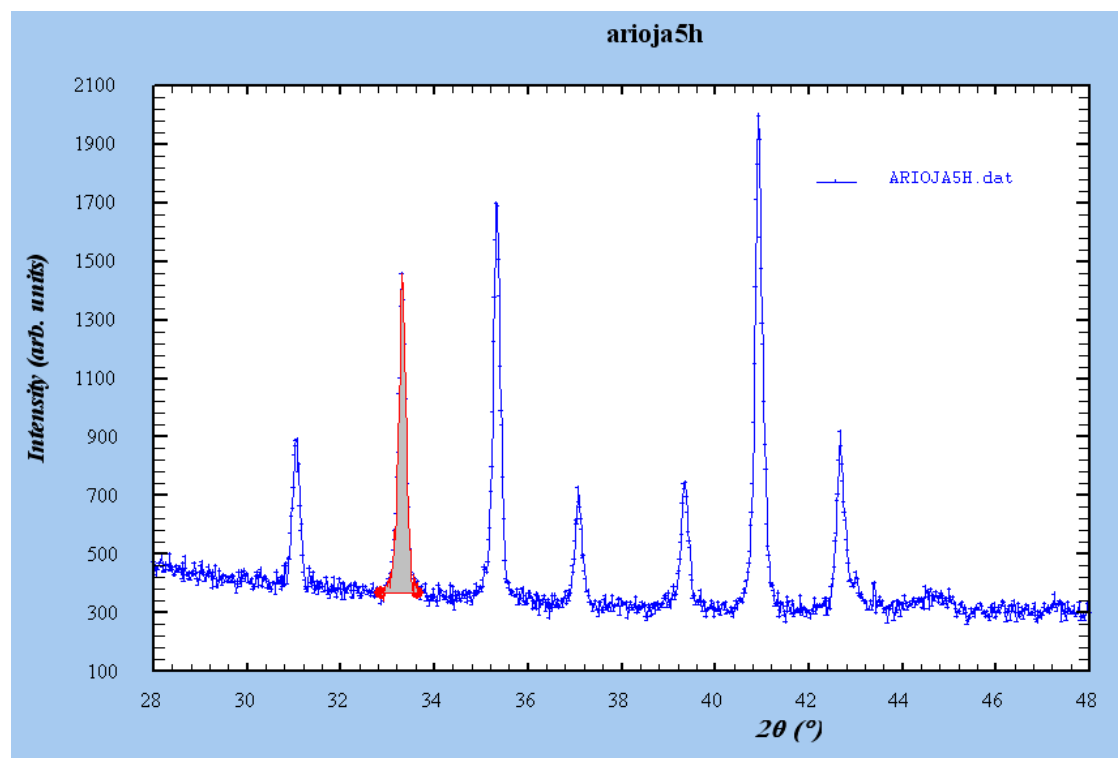

Figura 5.4. Difractograma de la arcilla La Rioja tratada a $1600 \stackrel{\circ}{\mathrm{C}}$ por 5 horas, midiendo el áreas del pico centrado en $33,2^{\circ}$ de $2 \theta$ (Cu K $\alpha 1$ ).

Los resultados de la cuantificación de mullita (primaria) de los difractogramas de la arcilla La Rioja tratada a $1600{ }^{\circ} \mathrm{C}$ a diferentes tiempos, por el método de comparación de áreas en el pico centrado en 33,2 de $2 \theta$, se observan en la tabla 5.4 .

Tabla 5.4. Resultados de la cuantificación de la arcilla La Rioja tratada a $1600 \stackrel{\circ}{\mathrm{C}}$ a diferentes tiempos, por comparación de áreas en el pico centrado en $33,2^{\circ}$ de $2 \theta$ (CuKa1).

\begin{tabular}{|c|c|}
\hline $\begin{array}{c}\text { Tiempo } \\
\text { (Horas) }\end{array}$ & $\begin{array}{c}\text { \% Mullita } \\
\text { (Primaria) }\end{array}$ \\
\hline $\mathbf{0 . 2 5}$ & 38.5 \\
\hline $\mathbf{0 . 5 0}$ & 44.9 \\
\hline $\mathbf{1}$ & 33.2 \\
\hline $\mathbf{2}$ & 35.7 \\
\hline $\mathbf{3}$ & 49.8 \\
\hline $\mathbf{5}$ & 36.7 \\
\hline
\end{tabular}

En la tabla 5.4 se observa que la mullita (primaria) alcanzó su máxima conversión a las 3 horas, para luego decaer a 5 horas, esto se podría interpretar como que la fase amorfa formada (observados en DRX) redisuelve algo de mullita y cuando satura la vuelve a 
precipitar, [Cáceres y Pereira, 1977; Srodon, 2006], mostrando valores bajos de mullita primaria en comparación a la máxima mullita generada por arcilla en el sistema.

\subsubsection{Cuantificación de las fases presentes en la arcilla La Rioja, aplicando el método de Rietveld y el modelo de Le Bail}

De los resultados obtenidos en la cuantificación de la mullita primara (producida por la arcilla La Rioja) por los tres métodos anteriormente mencionados y analizados, y dada la cantidad de fase amorfa generada por la sílice sin reaccionar, observada por DRX, se concluyó que la técnica de Rietveld con el modelo de Le Bail es aplicable para materiales con alto porcentaje de fase amorfa (como los materiales en estudio). Aplicando el método de Ohlberg se obtuvieron valores de mullita muy inferiores al valor máximo de mullita (59.40 \%) que podría producir la arcilla en estudio (La Rioja) de acuerdo a su composición química en $\mathrm{SiO}_{2}$ y $\mathrm{Al}_{2} \mathrm{O}_{3}$, lo mismo sucedió para el análisis del área bajo el pico centrado en $33.2^{\circ}$ de $2 \theta$ (CuKa1).

Si bien se adoptó la técnica de Rietveld con el método de Le Bail para la fase amorfa, se debe mencionar que el error del método de cuantificación está en el orden del $6 \%$ en cada fase y que éste se incrementa en términos totales al incrementarse el tenor de material amorfo (vítreo) como ocurre en el caso de la arcilla calcinada sola (Arioja).

Se observará que cuando se analice la mezcla arcilla - alúmina (AriojAcal), donde existe una disminución sustancial de amorfo, el error disminuye también sustancialmente. Por otro lado, también es importante mencionar que los cálculos de máximo porcentaje teórico de mullita a obtener por conversión total de la alúmina en la arcilla La Rioja $(59,4 \%)$ fueron realizados en base a los resultados del análisis químico realizado por ICP - AES (tabla 4.7), sobre una alícuota de $20 \mathrm{gr}$ cuarteado de un lote de $30 \mathrm{Kg}$ de mineral. [Vandecasteele y Block; 1993]. Los datos de dicha tabla también fueron utilizados para el cálculo de la mezcla estequiométrica 3-2 (AriojAcal).

Es sabido que las rocas naturales, como en este caso, son susceptibles de poseer alteraciones composicionales que puedan variar dentro de ciertos límites aun con tomas de muestras realizadas meticulosamente, [Bernal et al., 2003], por lo que también pueden ser fuente de error en cuanto al valor máximo de mullita a obtener teóricamente. 
Como ejemplo citaremos que si se hubiera adoptado el análisis químico de la ficha técnica histórica (proveedor) de dicha arcilla (tabla 4.2), el máximo teórico de porcentaje de mullita producida seria del $(64,2)$.

Las oscilaciones observadas podrían tener su influencia en las cuantificaciones realizadas, cuando son utilizadas en los modelos cinéticos, sin embargo la información utilizada en los modelos mostró buenos ajustes de los mismos, por lo que a pesar de esto el sistema es confiable.

Las muestras de arcilla La Rioja (Arioja) tratadas a diferentes temperaturas y tiempos se describen en la tabla 5.1, casi todas presentaron un margen de error un poco mayor a lo esperado dado a la gran cantidad de fase amorfa y a los inconvenientes presentados por los procesos de disolución - precipitación generadas en el sistema.

Los resultados obtenidos en el análisis cuantitativo para la Arioja por el método Rietveld aplicando el modelo de Le Bail se muestran en las tablas 5.3, 5.5, 5.6, 5.7, y 5.8. La cantidad de mullita primaria generada por la arcilla La Rioja tratada a diferentes temperaturas y tiempos, se graficaron como curvas del porcentaje de mullita vs tiempo (ver figuras $5.5,5.6,5.7,5.8$ y 5.9 ).

\subsubsection{Resultados de la cuantificación de mullita primaria a $1300 \stackrel{\circ}{C}$}

Los valores adquiridos en el análisis cuantitativo de la muestra Arioja tratada térmicamente a $1300^{\circ} \mathrm{C}$ a diferentes tiempos se muestran en la tabla 5.5 , indicando los porcentajes de mullita primaria, cuarzo, cristobalita y fase amorfa con respecto al tiempo. [Cáceres y Pereira, 1977; De la Torre et al., 2001; Taylor y Rui, 1992].

En la tabla 5.5, se puede observar que la mullita primaria y la cristobalita van aumentando en función del tiempo, mientras el cuarzo y la fase amorfa van disminuyendo, si bien se presentan pequeñas oscilaciones en el sistema, lo que indicaría que existe un proceso de solubilización - precipitación entre el $\mathrm{SiO}_{2}$ y $\mathrm{Al}_{2} \mathrm{O}_{3}$. [Srodon, 2006; Zevin y Viaene, 1990]. 
Tabla 5.5. Resultados de los porcentajes de las fases presentes en la arcilla La Rioja

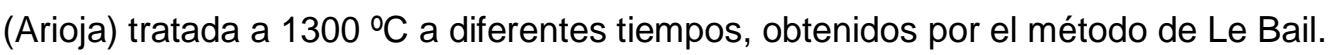

\begin{tabular}{|c|c|c|c|c|}
\hline $\begin{array}{c}\text { Tiempo } \\
\text { (Horas) }\end{array}$ & $\begin{array}{c}\text { \% Mullita } \\
\text { (Primaria) }\end{array}$ & $\begin{array}{c}\% \\
\text { Cuarzo }\end{array}$ & $\begin{array}{c}\% \\
\text { Cristobalita }\end{array}$ & $\begin{array}{c}\% \\
\text { Fase } \\
\text { amorfa }\end{array}$ \\
\hline $\mathbf{1}$ & 56.8 & 5.3 & 16.2 & 21.7 \\
\hline $\mathbf{2}$ & 60.0 & 2.4 & 17.1 & 20.5 \\
\hline $\mathbf{4}$ & 62.5 & 2.4 & 20.0 & 15.1 \\
\hline $\mathbf{6}$ & 61.4 & 3.3 & 19.7 & 15.6 \\
\hline $\mathbf{8}$ & 61.3 & 2.2 & 20.4 & 16.1 \\
\hline $\mathbf{1 0}$ & 63.1 & 2.3 & 20.6 & 14.0 \\
\hline $\mathbf{1 2}$ & 63.2 & 2.3 & 20.8 & 13.7 \\
\hline
\end{tabular}

El análisis cuantitativo de los porcentajes de mullita primaria con relación al tiempo para la arcilla La Rioja tratada térmicamente a $1300{ }^{\circ} \mathrm{C}$ a diferentes tiempos de permanecia se pueden ver en la figura 5.5 .

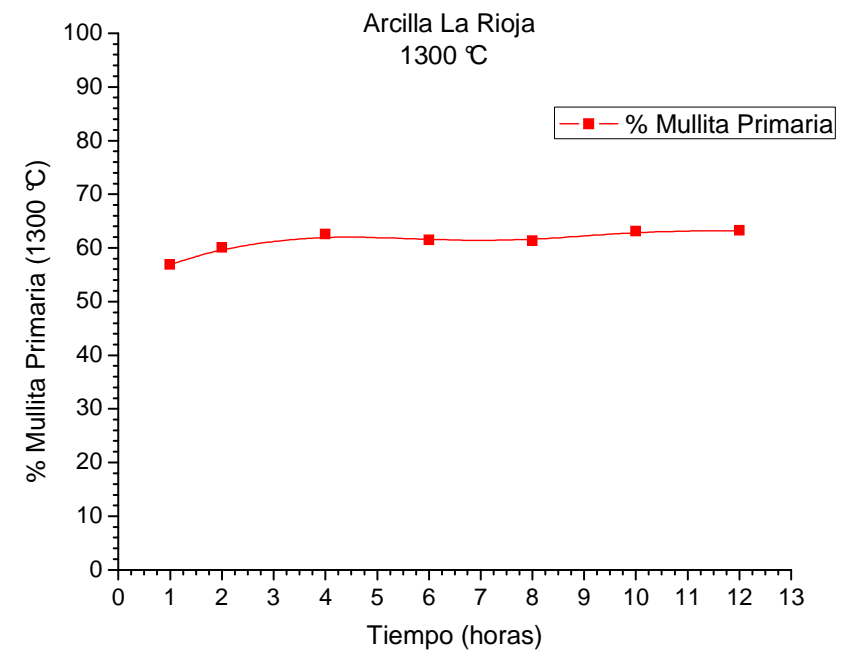

Figura 5.5 Porcentaje de mullita primaria con respecto al tiempo, para la arcilla La Rioja a $1300 \stackrel{\circ}{\circ}$.

Se observa en la figura 5.5 que a partir de las dos horas el sistema ha superado el valor máximo de conversión de mullita (59.4\%), sin embargo todos estos valores estarían dentro del margen de error permitido en el proceso de cuantificación. Las oscilaciones 
presentes se deben a que el sistema comienza a presentar fenómenos de solubilización - precipitación entre la fase amorfa y la cristalina (mullita primaria). [Cáceres y Pereira, 1977; Zevin y Viaene, 1990].

A su vez la temperatura no es suficientemente alta (lejos del punto de fusión de la sílice $1723^{\circ} \mathrm{C}$ ) [Aramaki y Roy, 1962] como para formar una fase semi-fluida donde ocurre mayoritariamente este fenómeno, por lo que el mismo estaría ocurriendo por fenómenos de transporte difusionales en sólidos y/o fase gaseosa. Los cambios debidos al fenómeno mencionado son lentos y no se manifiestan como muy visibles en la curva (oscilación de baja amplitud). La figura 5.5 muestra un porcentaje de mullita estable de alrededor del $62.5 \%$. De todas formas a tiempos mayores a 10 horas se observa una alta conversión a mullita.

\subsubsection{Resultados de la cuantificación de mullita primaria a $1400 \stackrel{\circ}{C}$}

Se realizó la cuantificación de todas las fases presentes (\%mullita, \% cuarzo, \% cristobalita y $\%$ fase amorfa) en la muestra Arioja que fue tratada a $1400{ }^{\circ} \mathrm{C}$ a diferentes tiempos, por el método y modelo mencionado anteriormente, los resultados se pueden ver en la tabla 5.6 .

Tabla 5.6. Resultados de los porcentajes de las fases presentes en la arcilla La Rioja (Arioja) tratada a $1400 \stackrel{\circ}{ } \mathrm{C}$ a diferentes tiempos, obtenidos por el método de Le Bail.

\begin{tabular}{|c|c|c|c|c|}
\hline $\begin{array}{c}\text { Tiempo } \\
\text { (Horas) }\end{array}$ & $\begin{array}{c}\text { \% Mullita } \\
\text { (Primaria) }\end{array}$ & $\begin{array}{c}\% \\
\text { Cuarzo }\end{array}$ & $\begin{array}{c}\% \\
\text { Cristobalita }\end{array}$ & $\begin{array}{c}\% \\
\text { Fase amorfa }\end{array}$ \\
\hline $\mathbf{0 . 5}$ & 68.2 & 6.0 & 8.9 & 16.9 \\
\hline $\mathbf{2}$ & 65.5 & 5.1 & 16.9 & 12.5 \\
\hline $\mathbf{4}$ & 65.7 & 3.9 & 17.6 & 12.9 \\
\hline $\mathbf{6}$ & 66.1 & 3.7 & 18.6 & 11.6 \\
\hline $\mathbf{7}$ & 64.4 & 4.5 & 19.7 & 11.4 \\
\hline $\mathbf{8}$ & 65.1 & 4.3 & 17.6 & 13.0 \\
\hline $\mathbf{1 0}$ & 65.5 & 3.5 & 17.9 & 13.1 \\
\hline
\end{tabular}

En la tabla 5.6 se observan los resultados de los porcentajes de cada fase presentes en la muestra Arioja tratada a $1400^{\circ} \mathrm{C}$, notándose que a la media hora el porcentaje de mullita primaria alcanzó su máxima conversión, presentándose también oscilaciones 
como las observadas en la temperatura anterior. Todos los valores adquiridos de mullita primaria estarían dentro del error permitido.

Si se comparan los resultados obtenidos a la media hora con los de 10 horas, se pueden ver que las fases de cuarzo y fase vítrea presentaron una disminución en los porcentajes, en cambio la cristobalita exhibió un aumento más del doble.

Los valores adquiridos de mullita primaria, en la muestra Arioja calcinada a $1400{ }^{\circ} \mathrm{C}$ a diferentes tiempos, fueron graficados, ver figura 5.6, donde se indica los porcentajes de mullita primaria con relación al tiempo.

La figura 5.6 muestra una inestabilidad del sistema, manifestándose en forma visual oscilaciones en los porcentajes de mullita en función del tiempo con cierta deriva, debido como ya se mencionó a los fenómenos de solubilización - precipitación de mullita con la fase amorfa rica en sílice, [Bish y Howard, 1988]. En este caso la temperatura de 1400 ○C es más cercana que la anterior al punto de fusión de la sílice pura.

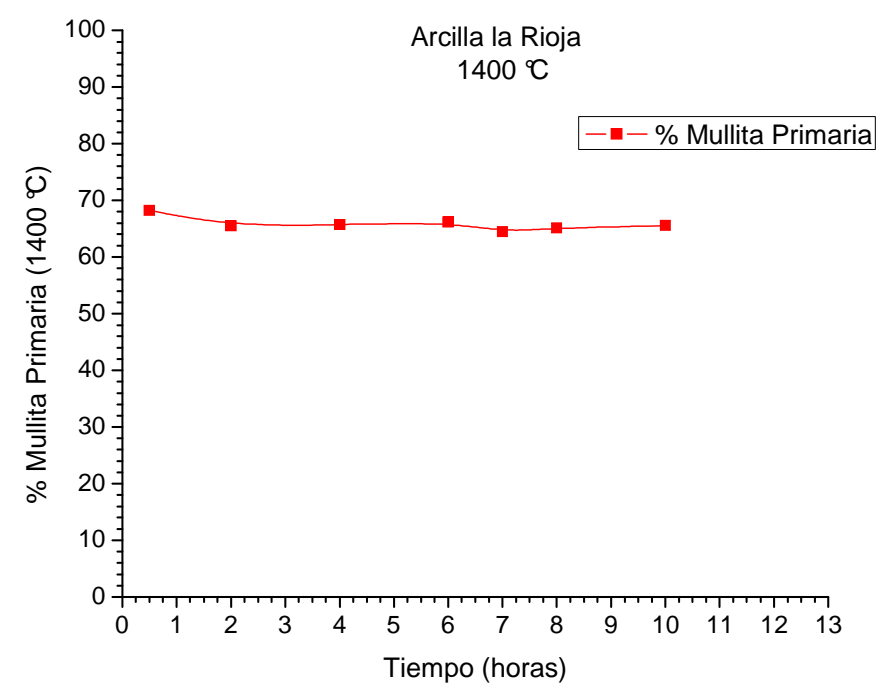

Figura 5.6 Porcentaje de mullita primaria con respecto al tiempo, para la arcilla La Rioja a $1400 \stackrel{\circ}{\circ}$. 


\subsubsection{Resultados de la cuantificación de mullita primaria a $1450 \stackrel{\circ}{C}$}

Los resultados obtenidos en la cuantificación por el método de Rietveld (Fullprof) aplicando el modelo de Le Bail para la muestra Arioja (arciilla La Rioja) tratada térmicamente a $1450^{\circ} \mathrm{C}$ a diferentes tiempos, se pueden ver en la tabla 5.7 .

La tabla 5.7 muestra los resultados de las fases presentes en la Arioja calcinada a la temperatura que se indicó a diferentes tiempos, notándose que el valor máximo de mullita primaria se encuentra a las 10 horas, mientras la fase amorfa va disminuyendo a medida que aumenta el tiempo de tratamiento, evidenciando la reacción del sistema $\mathrm{SiO}_{2}-\mathrm{Al}_{2} \mathrm{O}_{3}$. [Onike et al., 1986].

Tabla 5.7. Resultados de los porcentajes de las fases presentes en la arcilla La Rioja (Arioja) tratada a $1450 \stackrel{\circ}{ } \mathrm{C}$ a diferentes tiempos, obtenidos por el método de Le Bail.

\begin{tabular}{|c|c|c|c|c|}
\hline $\begin{array}{c}\text { Tiempo } \\
\text { (Horas) }\end{array}$ & $\begin{array}{c}\text { \% Mullita } \\
\text { (Primaria) }\end{array}$ & $\begin{array}{c}\% \\
\text { Cuarzo }\end{array}$ & $\begin{array}{c}\% \\
\text { Cristobalita }\end{array}$ & $\begin{array}{c}\% \\
\text { Fase amorfa }\end{array}$ \\
\hline $\mathbf{0 . 5}$ & 66.7 & 4.5 & 2.9 & 25.9 \\
\hline $\mathbf{2}$ & 66.2 & 5.0 & 5.9 & 22.9 \\
\hline $\mathbf{4}$ & 66.2 & 4.8 & 6.1 & 22.9 \\
\hline $\mathbf{6}$ & 65.6 & 4.2 & 6.4 & 23.8 \\
\hline $\mathbf{8}$ & 66.9 & 3.4 & 6.8 & 22.9 \\
\hline $\mathbf{1 0}$ & 68.5 & 2.8 & 5.7 & 23.0 \\
\hline
\end{tabular}

Los resultados del porcentaje de mullita primaria generada a $1450{ }^{\circ} \mathrm{C}$ a diferentes tiempos, fueron graficados elaborando la curva de conversión tiempo, tal como se muestra en la figura 5.7 .

A esta temperatura se observa el mismo fenómeno anterior pero al estar el sistema más sinterizado la difusión requerida para el proceso de solubilizacion - cristalización es más lenta (existe menor porosidad para la difusión en fase de vapor), y por eso presenta una mayor estabilidad de porcentaje de mullita en función del tiempo (curva más plana). 


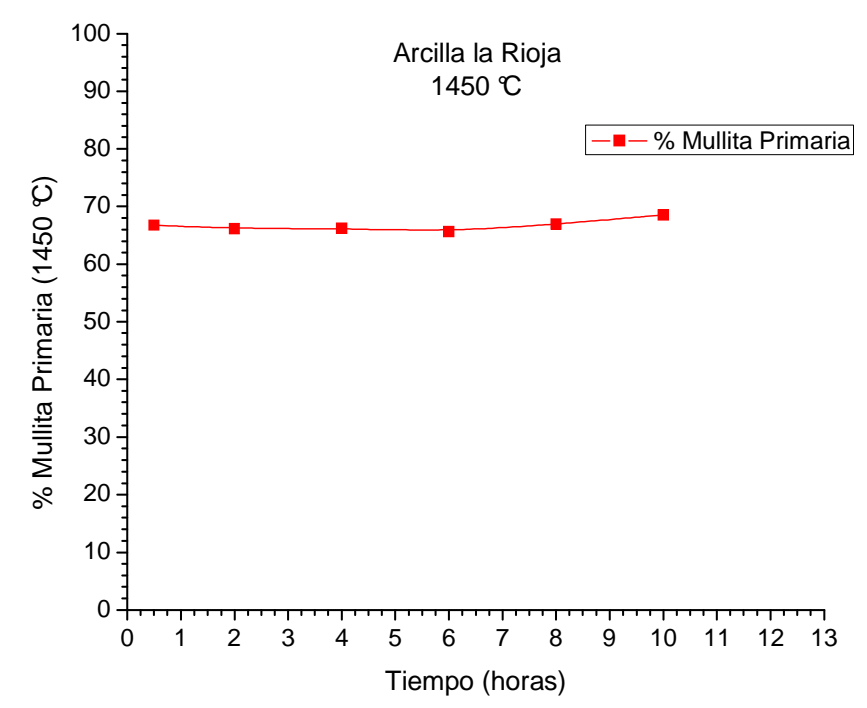

Figura 5.7 Porcentaje de mullita primaria con respecto al tiempo, para la arcilla La Rioja a $1450 \stackrel{\circ}{\circ}$.

\subsubsection{Resultados de la cuantificación de mullita primaria a $1500 \stackrel{\circ}{C}$}

Los valores adquiridos en el análisis cuantitativo de la muestra Arioja tratada térmicamente a $1500^{\circ} \mathrm{C}$ a diferentes tiempos se observan en la tabla 5.8 , indicando los porcentajes de mullita primaria, cuarzo, cristobalita y fase amorfa con respecto al tiempo.

Tabla 5.8. Resultados de los porcentajes de las fases presentes en la arcilla La Rioja (Arioja) tratada a $1500{ }^{\circ} \mathrm{C}$ a diferentes tiempos, obtenidos por el método de Le Bail.

\begin{tabular}{|c|c|c|c|c|}
\hline $\begin{array}{c}\text { Tiempo } \\
\text { (Horas) }\end{array}$ & $\begin{array}{c}\text { \% Mullita } \\
\text { (Primaria) }\end{array}$ & $\begin{array}{c}\% \\
\text { Cuarzo }\end{array}$ & $\begin{array}{c}\% \\
\text { Cristobalita }\end{array}$ & $\begin{array}{c}\% \\
\text { Fase amorfa }\end{array}$ \\
\hline $\mathbf{0 . 2 5}$ & 62.7 & 2.4 & 0.1 & 34.8 \\
\hline $\mathbf{0 . 5}$ & 65.7 & 3.1 & 0.2 & 31.0 \\
\hline $\mathbf{1}$ & 66.1 & 2.7 & 0.2 & 31.0 \\
\hline $\mathbf{2}$ & 68.4 & 1.6 & 0.3 & 29.7 \\
\hline $\mathbf{3}$ & 66.0 & 1.9 & 0.3 & 31.8 \\
\hline $\mathbf{5}$ & 67.4 & 1.0 & 0.5 & 31.1 \\
\hline $\mathbf{6}$ & 64.8 & 0.7 & 0.5 & 34.0 \\
\hline $\mathbf{7}$ & 67.7 & 0.5 & 0.4 & 31.4 \\
\hline
\end{tabular}


Se observa en la tabla 5.8 un franco descenso de los tenores de cuarzo y cristobalita (a partir de las 6 horas) con respecto al tiempo correspondiente a la reacción del sistema para producir mullita primaria, pero con un correspondiente aumento de la fase amorfa respecto a los valores obtenidos a $1400^{\circ} \mathrm{C}$ (tabla 5.6 ).

Se obtuvo una máxima conversión de mullita primaria a las 2 horas, mostrando posteriormente oscilaciones que corresponden a fenómenos de solubilización precipitación.

Comparando los resultados obtenidos de la arcilla La Rioja sinterizada a $1500 \stackrel{\circ}{C}$ con la de $1450 \stackrel{\circ}{C}$ (tabla 5.7), se pudo percibir que existió una gran disminución de las fases de cuarzo y cristobalita.

Los resultados obtenidos en el análisis cuantitativo de mullita para la arcilla la Rioja tratada térmicamente a $1500 \stackrel{\circ}{\circ}$ a diferentes tiempos de permanencia se observan en la figura 5.8, indicando los porcentajes de mullita primaria con respecto al tiempo.

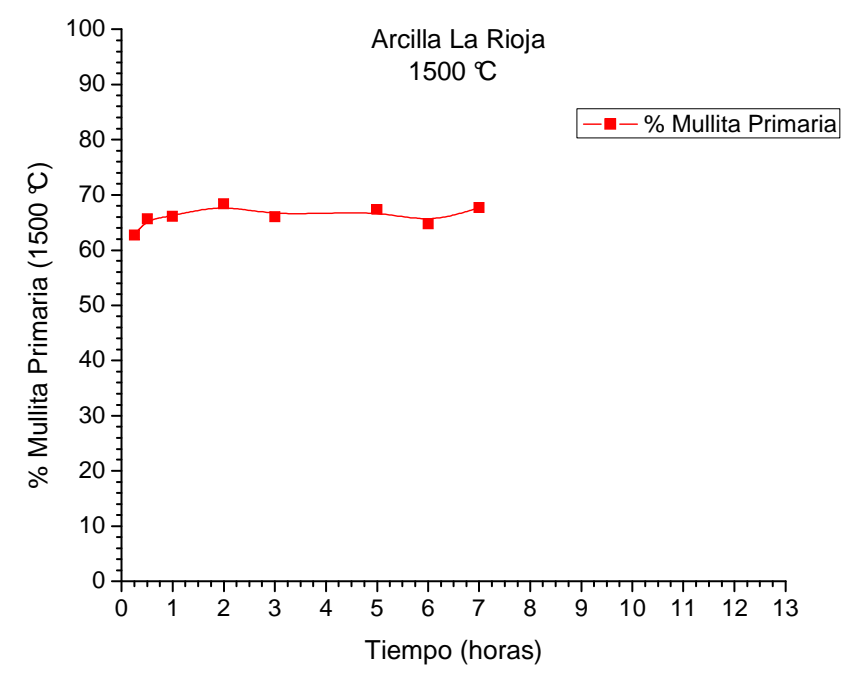

Figura 5.8 Porcentaje de mullita con respecto al tiempo, para la arcilla la Rioja a 1500 $\stackrel{\circ}{ } \mathrm{C}$.

A esta temperatura, la curva está cada vez más cerca del punto de fusión de la sílice. Se observa una mayor oscilación en función del tiempo con respecto a la de 1450 C. Esto último debido a una menor viscosidad de la fase amorfa por el incremento de la temperatura, siendo que la mayor cantidad de fase amorfa observada contribuye a este fenómeno, el cual debe sumarse como ya se mencionó al transporte de masa en fase sólida y/o gaseosa, justificándose la oscilación mencionada. 


\subsubsection{Resultados de la cuantificación de mullita primaria a $1600 \stackrel{\circ}{C}$}

Los valores adquiridos en la cuantificación de las fases presentes en la arcilla La Rioja (Arioja) calcinada a $1600 \stackrel{\circ}{\circ}$ a diferentes tiempos, se muestran en la tabla 5.3 , se tomaron los porcentajes de mullita primaria generada para realizar una curva de conversión tiempo, tal como se observa en la figura 5.9.

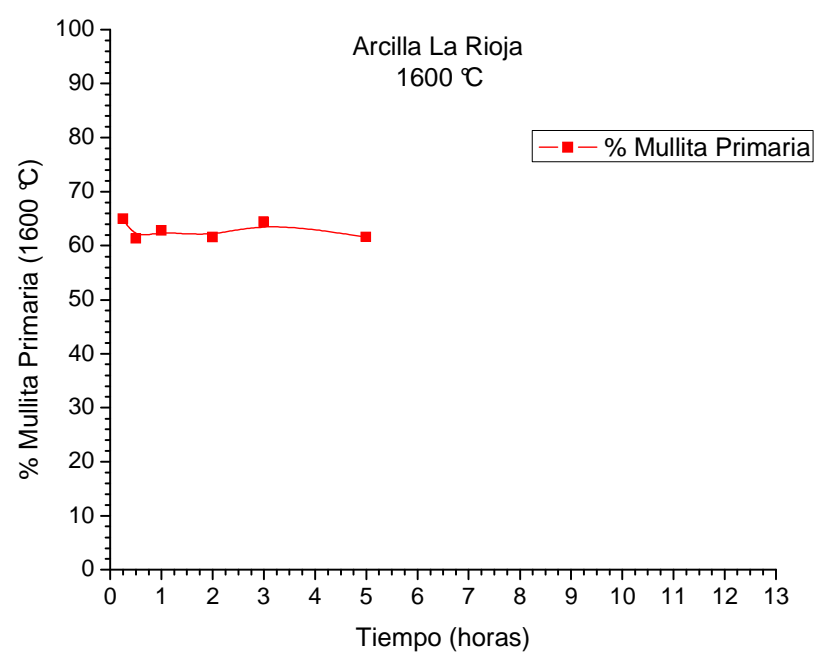

Figura 5.9 Porcentaje de mullita con respecto al tiempo, para la arcilla La Rioja a $1600^{\circ} \mathrm{C}$.

La matriz vítrea a esta temperatura es aún más fluida que la anterior (menor viscosidad) lo que promueve y aumenta los fenómenos de difusión para el proceso de solubilización - cristalización, mostrando una mayor oscilación de los contenidos de mullita en función del tiempo. [Liu et al.,1991; Onike et al., 1986; Young, 1993].

El valor medio observado de mullita primaria se dio aproximadamente a las 2 horas aunque a mayor temperatura la solubilildad de la mullita en la fase vítrea se ve incrementada, como ocurre en general en la mayoría de los sistemas.

Por otro lado observando el diagrama de sílice - alúmina (figura 2.1) se ve que al aumentar ligeramente el tenor de alúmina frente a la sílice el punto de fusión del sistema va bajando y aumentando el tenor de líquido frente al sólido en la matriz amorfa, reforzando este concepto lo sostenido acerca de la fludificación del sistema. 


\subsection{GENERACIÓN DE MULLITA NETA}

\subsubsection{Tratamiento térmico - Formación de mullita neta (mezcla, Arcilla La Rioja más alúmina calcinada)}

En esta sección, se presenta la caracterización y cuantificación de la mullita (Neta o total) obtenida a partir de una arcilla caolinítica (La Rioja) y alúmina calcinada, las cuales fueron mezcladas en proporciones estequiométricas $3 \mathrm{Al}_{2} \mathrm{O}_{3} \cdot 2 \mathrm{SiO}_{2}$ (AriojAcal), prensadas uniaxialmente a $100 \mathrm{MPa}$, tal como se describió anterioriormente, y luego sometidas a un pretratamiento de $800 \stackrel{\circ}{\circ}$ por 1 hora, recordando que la permanencia previa a esta temperatura no afecta la conversión a mullita que se desea evaluar, posteriormente se calcinaron a diferentes temperaturas y tiempos con el objeto de evaluar el porcentaje de mullita neta, producido por la mezcla (AriojAcal), ver tabla 5.9. La caracterización de los materiales obtenidos fue realizada por Difracción de Rayos $\mathrm{X}$, obteniendo las fases cristalinas presentes en cada uno de los casos y cuantificando el tenor de mullita neta. La cuantificación de estos tenores se realizó con los mismos tres métodos mencionados en la sección anterior, comparando el tenor de mullita neta, con el valor de una mullita sinterizada sintética comercial de alta calidad ( $91 \%$ mullita cristalina y $9 \%$ fase amorfa).

Tabla 5.9. Temperaturas y tiempos de calcinación para la mezcla estequiométrica 3-2 (arcilla La Rioja más alúmina calcinada).

\begin{tabular}{|c|c|c|c|c|c|c|c|c|c|c|c|c|}
\hline $\begin{array}{c}\text { TEMPERATURAS } \\
\left({ }^{\circ} \mathrm{C}\right)\end{array}$ & \multicolumn{10}{|c|}{ TIEMPO (Horas) } \\
\hline $\mathbf{1 3 0 0}$ & - & - & 1 & 2 & & 4 & - & 6 & - & 8 & 10 & 12 \\
\hline $\mathbf{1 4 0 0}$ & - & 0.5 & - & 2 & - & 4 & 5 & 6 & & 8 & 10 & - \\
\hline $\mathbf{1 4 5 0}$ & - & 0.5 & & 2 & - & 4 & 5 & 6 & - & 8 & 10 & - \\
\hline $\mathbf{1 5 0 0}$ & 0.25 & 0.5 & 1 & 2 & 3 & - & 5 & 6 & 7 & - & - & - \\
\hline $\mathbf{1 6 0 0}$ & 0.25 & 0.5 & 1 & 2 & 3 & - & 5 & - & - & - & - & \\
\hline
\end{tabular}

La tabla 5.9 muestra todas las temperaturas y tiempos estudiados en esta sección para la mezcla estequiométrica 3-2 de arcilla La Rioja más alúmina calcinada (AriojAcal), observándose que a bajas temperaturas se usaron tiempos finales más largos para así lograr una mayor conversión de mullita (neta), procediéndose en forma inversa a medida que se aumenta la temperatura ya que las conversiones en estos casos eran mayores. En este caso cuando se realicen las comparaciones entre mullita primaria generada solo por la arcilla La Rioja contra la mullita neta generada por la mezcla 3-2 (mullita primaria 
más secundaria), a los valores de porcentaje obtenidos en la sección anterior (mullita primaria sola) hay que multiplicarlos por el factor de dilución $(0,5187)$ el cual corresponde a la relación que tiene en cuenta la alúmina adicionada para formarse la mezcla estequiométrica. [Field, 1941; Mazdiyasni y Brown, 1972; [Tcheichvili y Butschkowskyi, 1975; Von Dreele, 1997].

\subsubsection{Difractogramas de mezcla estequiométrica $3 \mathrm{Al}_{2} \mathrm{O}_{3} \cdot 2 \mathrm{SiO}_{2}$ (AriojAcal)}

Los difractogramas correspondientes a la muestra AriojAcal tratada a cada temperatura y tiempos descriptos anteriormente se muestran en la en la figura 5.10.

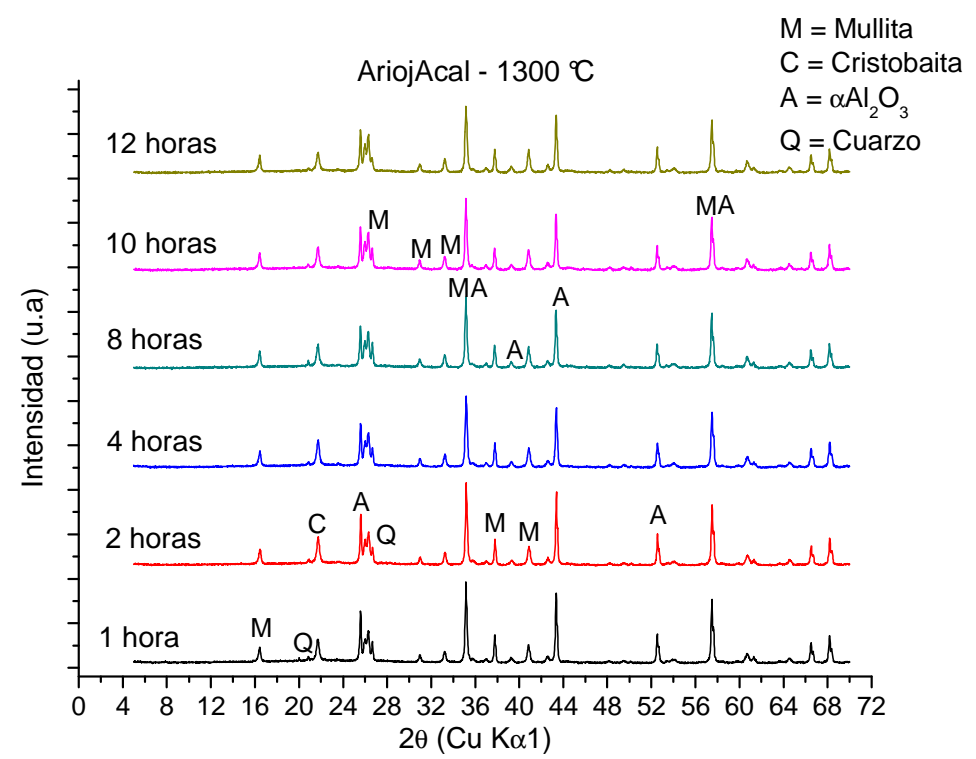

(a) 


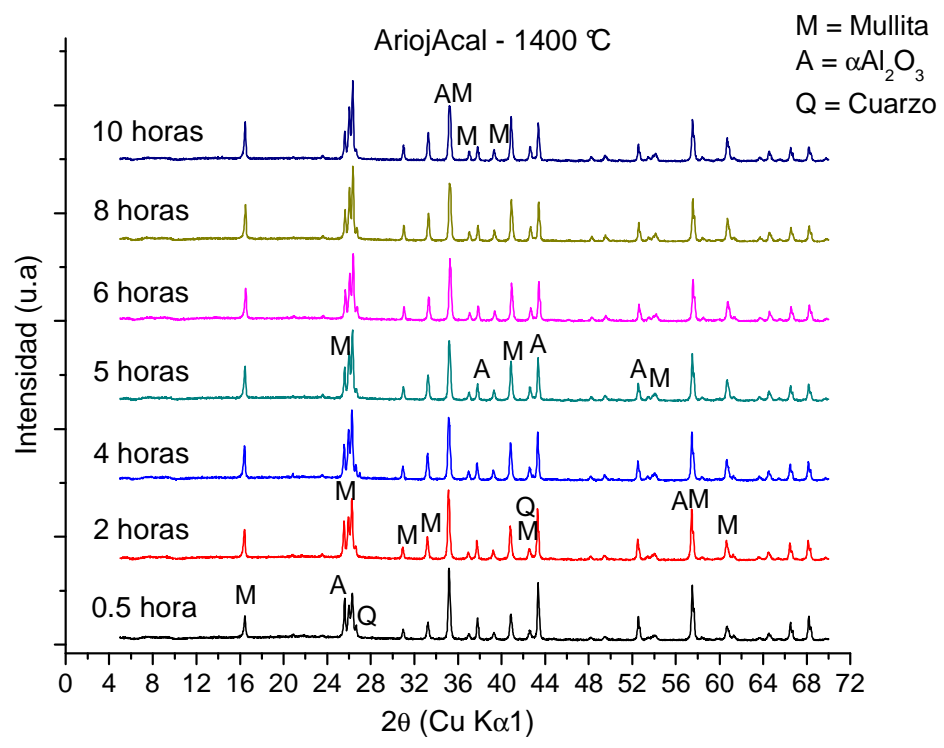

(b)

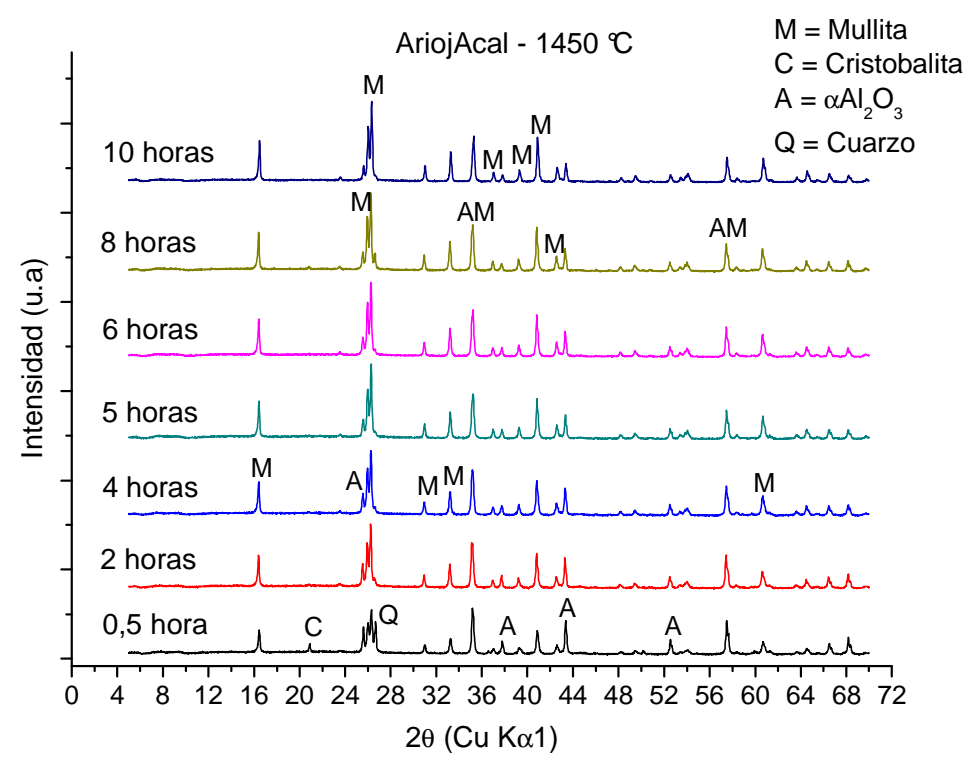

(c) 


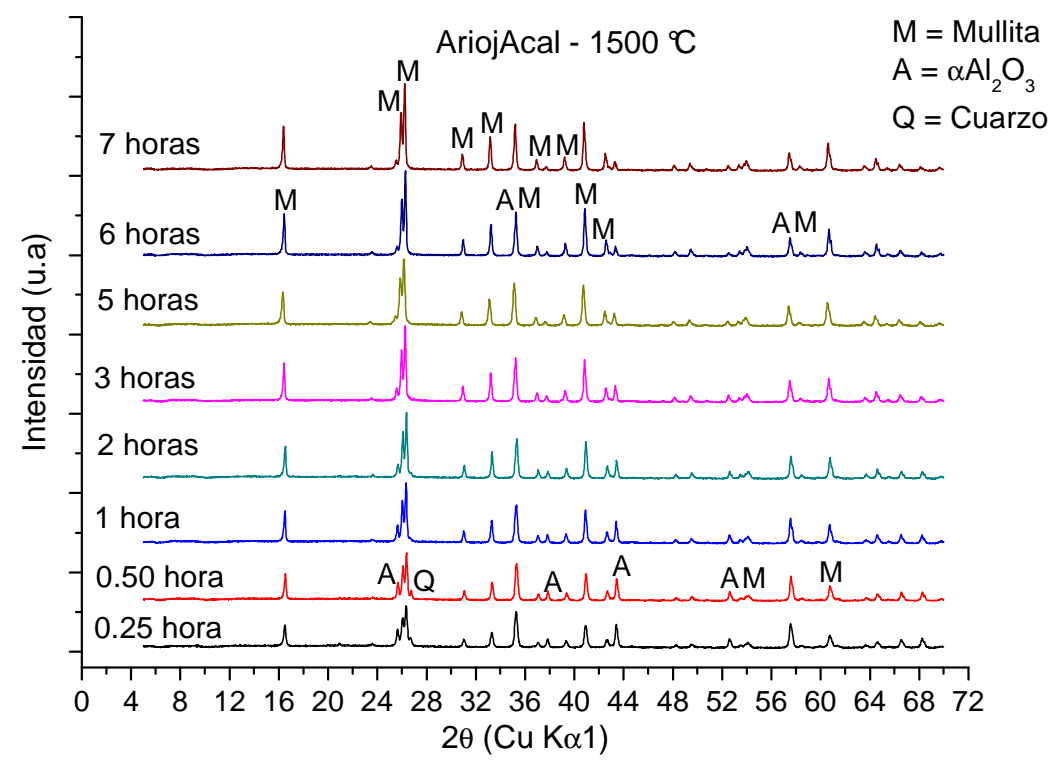

(d)

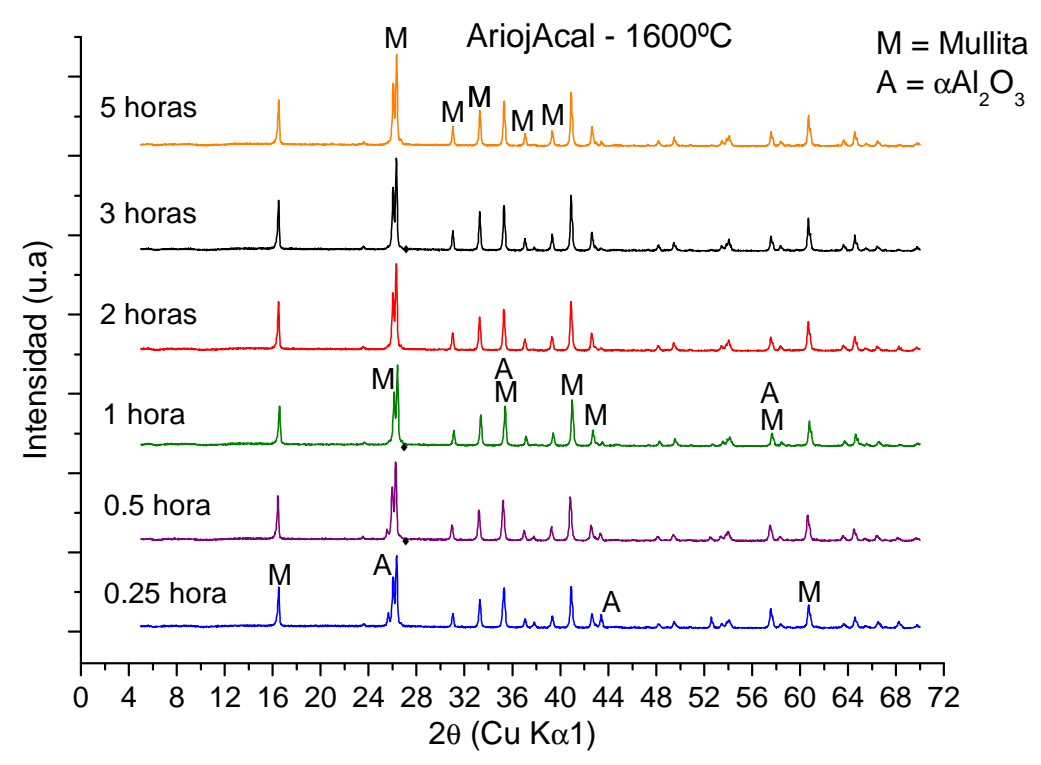

(e)

Figura 5.10. Difractogramas de la mezcla estequiométrica 3-2 (AriojAcal) tratada a

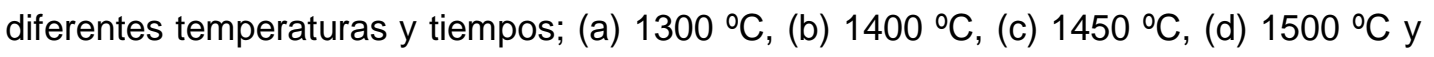
(e) $1600^{\circ} \mathrm{C}$. 
La figura 5.10, muestra los difractogramas de la mezcla estequiométrica 3-2 (Arcilla La Rioja más alúmina calcinada "AriojAcal") tratada térmicamente a diferentes temperaturas y tiempos, evidenciándose en todos los difractogramas la presencia de la fase mullita (neta) variando su intensidad de acuerdo a las temperaturas y tiempos de reacción, también se observa la presencia de otras fases cristalinas como; cristobalita, alúmina y cuarzo que van variando o desapareciendo de acuerdo a las condiciones de reacción (temperatura - tiempo). [Bragg, 1913; Cullity, 1978; Klug y Alexander, 1974; Liu et al., 1994; Schneider et al., 1994; 2008].

En los difractogramas de la figura 5.10(a) (AriojAcal calcinada a $1300{ }^{\circ} \mathrm{C}$ a diferentes tiempos de tratamiento) además de mullita se encontraron otras fases cristalinas como: $\alpha$-alúmina con alta intensidad, mostrando una pequeña disminución en el pico $43,36^{\circ}$ de $2 \theta$ a partir de las 4 horas de tratamiento. Respecto a la fase mullita ésta presentó un leve aumento en el pico principal (26,26 de $2 \theta$ ) a partir de las 4 horas, existiendo también la presencia de cristobalita donde la intensidad disminuye un poco a medida que aumenta el tiempo de reacción, lo contrario pasa para el cuarzo.

La figura 5.10(b), muestra los difractogramas de la mezcla AriojAcal tratada térmicamente $1400 \stackrel{\circ}{\circ}$ a diferentes tiempos, observándose que los picos correspondientes a la mullita (neta) y $\alpha$-alúmina a los 30 minutos ( 0.5 horas) poseen alturas casi similares, a partir de las 2 horas se evidencia un crecimiento de la fase mullita y para $\alpha-\mathrm{Al}_{2} \mathrm{O}_{3}$ una disminución con respecto al aumento del tiempo de tratamiento; para la fase de cuarzo mostró una disminución en su intensidad, a esta temperatura no se observó presencia de cristobalita.

En la figura $5.10(\mathrm{c})$, (AriojAcal calcinada a $1450 \stackrel{\circ}{\circ} \mathrm{C}$ tratada a diferentes tiempos), se puede observar que la fase mullita (neta) presenta un crecimiento en su intensidad a medida que aumenta el tiempo de reacción, lo contrario sucedió para las intensidades de $\alpha$-alúmina y cuarzo; también se puedo apreciar que a los 30 minutos ( 0.5 horas) apareció un pequeño pico que corresponde a la fase cristobalita.

La figura 5.10(d), muestra los difractogramas de la mezcla AriojAcal calcinada a $1500{ }^{\circ} \mathrm{C}$ a diferentes tiempos de tratamiento, notándose como fase cristalina principal la mullita (neta), presentando un crecimiento a medida que aumenta el tiempo de reacción, también se evidencian las fases de $\alpha-\mathrm{Al}_{2} \mathrm{O}_{3}$ y cuarzo presentando una disminución respecto al tiempo, y para este último una desaparición a partir de la primera hora.

Para la serie de los difractogramas de la figura 5.10(e) (AriojAcal tratada térmicamente a $1600 \stackrel{\circ}{\circ}$ a diferentes tiempos), se observa como fase cristalina principal a la mullita (neta), y una muy pequeña cantidad de alúmina cristalina como $\alpha-\mathrm{Al}_{2} \mathrm{O}_{3}$. Luego de la 
primera hora la reacción ha progresado en forma casi total, observándose que la desaparición de la fase a-Alúmina es casi completa. La presencia de esta pequeña cantidad de alúmina a todos los tiempos de tratamiento estaría indicando, si presuponemos una mezcla estequiométrica para formar mullita, que existe una cantidad de fase vítrea (amorfa) muy rica en sílice que aún le falta reaccionar con la alúmina presente para terminar la conversión total del sistema.

\subsubsection{Cuantificación del porcentaje de mullita neta (mezcla estequiométrica 3-2 de arcilla La Rioja más alúmina calcinada), por tres métodos.}

La cuantificación de las fases para una mezcla estequiométrica $3 \mathrm{Al}_{2} \mathrm{O}_{3} \cdot 2 \mathrm{SiO}_{2}$ (arcilla La Rioja más alúmina calcinada) tratada a diferentes temperaturas y tiempos (tabla 5.9), se realizó también por los tres métodos mencionados en la sección anterior (5.1.3 arcilla La Rioja). En el primer método, se utilizó la cuantificación por el método de Rietveld (Fullprof) para las fases cristalinas, [Rietveld, 1969; Rodríguez, 1990; 2001], mientras que la fase amorfa se determinó por la interpolación de fondos (método de Ohlberg) entre una sílice cristalina (cuarzo) y una amorfa (sílice volátil) [Conconi et al., 2011; Ohlberg y Strickler 1962]; y en el segundo, se introdujo la fase vítrea como una sílice con excesivos defectos por tamaño cristalino (modelo de Le Bail) [Conconi et al., 2011; Le Bail, 1995].

En el tercer método solo se cuantificó el tenor de mullita por comparación de las áreas del pico centrado en $33.2^{\circ}$ de $2 \theta$ (CuKa1) con el área medida para una mullita sinterizada sintética comercial de alta calidad ( $91 \%$ mullita cristalina).

Los resultados arrojados por los tres métodos fueron contrastados contra el valor máximo de una mullita sinterizada sintética comercial (M-72) de ata calidad ( $91 \%$ mullita cristalina y $9 \%$ fase amorfa).

El objeto de encontrar los porcentajes de mullita neta generada por la muestra AriojAcal tratada a diferentes temperaturas y tiempos (tabla 5.9) fue poder generar las curvas de conversión tiempo para a posteriori hallar el porcentaje de mullita secundaria presente cada caso, realizando la resta de la mullita neta (AriojAcal) con la mullita primaria (Arioja) diluida en un sistema con $\mathrm{Al}_{2} \mathrm{O}_{3}$, y así poder conocer el progreso de la reacción existente entre la alúmina y la fase amorfa silícea proveniente de la arcilla. [Juettner $\mathrm{T}$., et al., 2007; Onike et al., 1986; Saalfeld y Guse, 1981; [Skoog y Moore, 1988; Testa y Pereira, 1971a; 1971b]. 
Para realizar la cuantificación por los tres métodos, se escogió como referencia para la selección la mezcla estequiométrica $3 \mathrm{Al}_{2} \mathrm{O}_{3} \cdot 2 \mathrm{SiO}_{2}$ (arcilla La Rioja más alúmina calcinada) ( tabla 4.8) tratada a $1600{ }^{\circ} \mathrm{C}$ a diferen tes tiempos de tratamiento, debido a que en estas condiciones la mezcla AriojAcal a tiempo mayor (5 horas) presentaría su máxima conversión a mullita (neta).

\subsubsection{Método de Ohlberg - Cuantificación por Interpolación de fondos - mezcla estequiométrica 3-2 (AriojAcal)}

Los difractogramas obtenidos a partir de mezcla con estequiometría $3 \mathrm{Al}_{2} \mathrm{O}_{3} \quad \cdot 2 \mathrm{SiO}_{2}$ (arcilla La Rioja más alúmina calcinada) tratadas a diferentes temperaturas y tiempos (tabla 5.9), fueron caracterizadas por PDF (Powder Difraction File), y cuantificadas las fases cristalinas utilizando el método Rietveld (porcentaje de mullita, cuarzo, $\alpha$-alúmina y cristobalita). Para conocer el porcentaje de fase amorfa se utilizó el método de Ohlberg, que consistió en medir las intensidades del fondo en $22,5^{\circ}$ de $2 \theta$, para una muestra vítrea (sílice amorfa), una cristalina (cuarzo) y la muestra en estudio, en este ejemplo (AriojAcal a $1600^{\circ} \mathrm{C}$ por 5 horas), en la figura 5.11 se observa la interpolación de fondos de las 3 muestras.

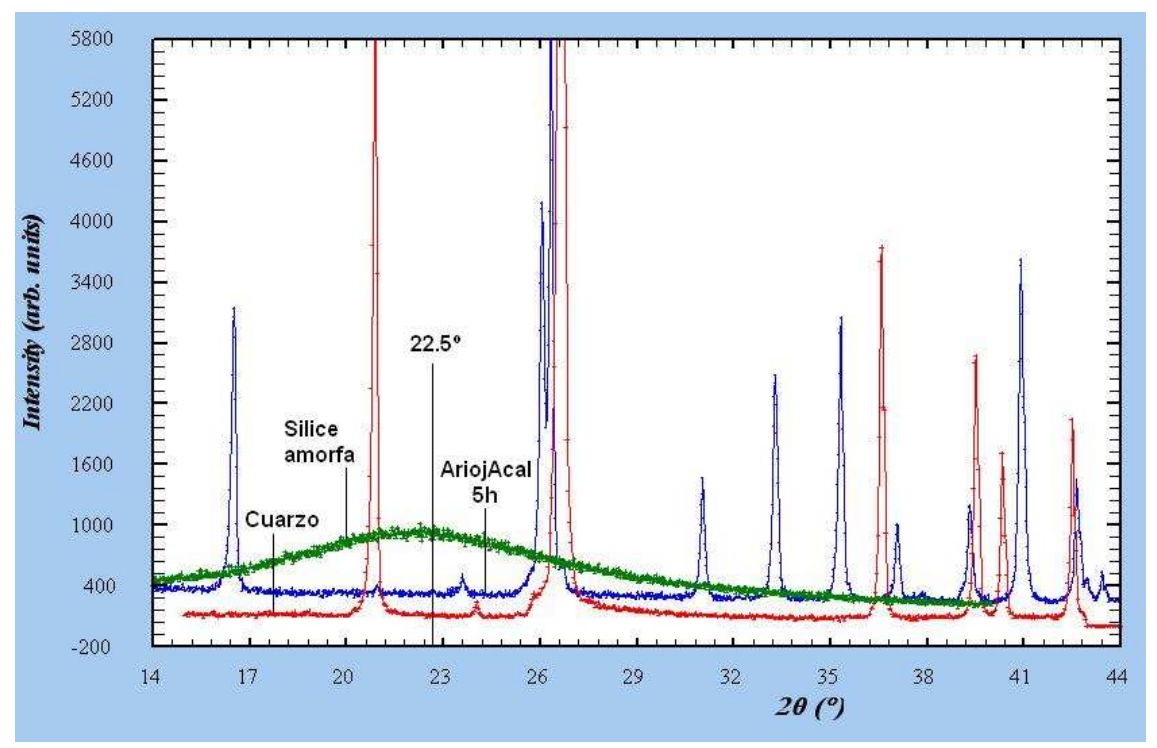

Figura 5.11. Difractogramas de cuarzo, sílice amorfa y mezcla estequiométrica 3-2 (arcilla la Rioja más alúmina calcinada) tratada a $1600 \stackrel{\circ}{\circ}$ por 5 horas. Método de Ohlberg. 
La figura 5.11, muestra la interpolación de los difractogramas de sílice amorfa, cuarzo y la mezcla estequiométrica 3-2 (AriojAcal) calcinada a $1600 \stackrel{\circ}{\mathrm{C}}$ durante 5 horas, mostrando una menor cantidad de fase amorfa en comparación a la generada por la arcilla sola (La Rioja), mostrada en la figura 5.2.

Del análisis realizado por el método de Rietveld se obtuvieron los porcentajes de las fases cristalinas (mullita, cuarzo, alfa alúmina y cristobalita) y por el método de Ohlberg el porcentaje de fase amorfa. En la tabla 5.10 se puede ver todas las fases presentes en la muestra AriojAcal calcinada a $1600 \stackrel{\circ}{\mathrm{C}}$ a diferentes tiempos de tratamiento.

En la tabla 5.10, se puede ver que los porcentajes de mullita neta son bajos en comparación al valor máximo de una mullita sintética comercial de alta calidad $(91 \%$ de mullita) y al valor máximo de mullita que podría generar un sistema de mezcla estequiométrica 3-2 con arcilla refractaria más alúmina, que al ser tratadas térmicamente producen mullita $\left(3 \mathrm{Al}_{2} \mathrm{O}_{3} \cdot 2 \mathrm{SiO}_{2}\right)$, [Cáceres y Pereira, 1977; Shigeo y Rustum, 1962; Taylor y Norrish, 1966]. Todas las fases de la muestra AriojAcal calcinada a $1600 \stackrel{\circ}{\circ}$ presentaron oscilaciones de sus porcentajes, esto debido a que la fase amorfa generada redisuelve algo de mullita y cuando satura la vuelve a precipitar.

Tabla 5.10. Resultados de la cuantificación de las fases presentes en la mezcla estequiométrica 3-2 (arcilla La Rioja más alúmina calcinada) tratada a $1600{ }^{\circ} \mathrm{C}$. Método de Ohlberg.

\begin{tabular}{|c|c|c|c|c|c|}
\hline $\begin{array}{c}\text { Tiempo } \\
\text { (Horas) }\end{array}$ & $\begin{array}{c}\% \text { Mullita } \\
\text { (Neta) }\end{array}$ & $\begin{array}{c}\% \\
\alpha-\text { Alúmina }\end{array}$ & $\begin{array}{c}\% \\
\text { Cuarzo }\end{array}$ & $\begin{array}{c}\% \\
\text { Cristobalita }\end{array}$ & $\begin{array}{c}\% \\
\text { Fase Amorfa }\end{array}$ \\
\hline $\mathbf{0 . 2 5}$ & 56.1 & 12.3 & 0.1 & --- & 31.5 \\
\hline $\mathbf{0 . 5 0}$ & 64.5 & 6.3 & 0.1 & --- & 29.1 \\
\hline $\mathbf{1}$ & 71.8 & 3.7 & 0.1 & --- & 24.4 \\
\hline $\mathbf{2}$ & 70.4 & 2.8 & 0.4 & --- & 26.4 \\
\hline $\mathbf{3}$ & 68.2 & 4.3 & 0.2 & --- & 27.3 \\
\hline $\mathbf{5}$ & 64.2 & 3.7 & 0.5 & --- & 31.6 \\
\hline
\end{tabular}




\subsubsection{Modelo de Le Bail - mezcla estequiométrica $3 \mathrm{Al}_{2} \mathrm{O}_{3} \cdot 2 \mathrm{SiO}_{2}$ (AriojAcal)}

Otro método de cuantificación es usando el método de Rietveld para las fases cristalinas y para la fase amorfa aplicando el modelo de Le Bail, tal como se explicó en la sección anterior, el cual consistió en introducir dentro del programa una fase vítrea de sílice con excesivos defectos por tamaño cristalino, [Bish y Howard, 1988; Le Bail, 1995].

La figura 5.12 interpreta el bosquejo del refinamiento por el método de Rietveld utilizando el modelo de Le Bail para la mezcla estequiométrica 3-2 (arcilla La Rioja más alúmina calcinada) calcinada a 1600 ํ C durante 5 horas. Las líneas de difracción corresponden a las fases de mullita (neta), alfa alúmina, cuarzo y sílice amorfa respectivamente.

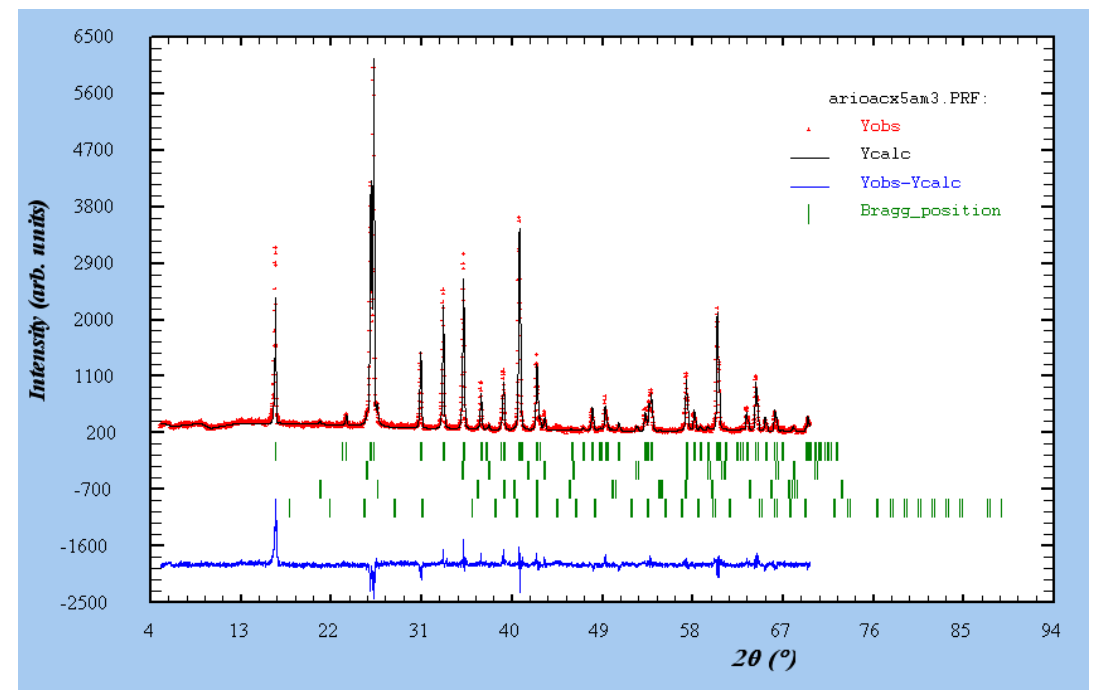

Figura 5.12. Difractograma de la mezcla estequiométrica 3-2 (arcilla La Rioja más alúmina calcinada) tratada a $1600 \stackrel{\circ}{ } \mathrm{C}$ por 5 horas, mostrando las líneas de difracción correspondientes a las fases de mullita, alfa alúmina, cuarzo y sílice amorfa. Modelo de Le Bail.

Los resultados obtenidos en la cuantificación por el método de Rietveld aplicando el modelo de Le Bail, se muestran en la tabla 5.11. 
Tabla 5.11. Porcentajes de las fases presentes en la mezcla estequiométrica 3-2 (AriojAcal) tratada térmicamente a $1600^{\circ} \mathrm{C}$, a diferentes tiempos. Modelo de Le Bail.

\begin{tabular}{|c|c|c|c|c|c|}
\hline $\begin{array}{c}\text { Tiempo } \\
\text { (Horas) }\end{array}$ & $\begin{array}{c}\% \text { Mullita } \\
\text { (Neta) }\end{array}$ & $\begin{array}{c}\% \\
\text { o- Alúmina }\end{array}$ & $\begin{array}{c}\% \\
\text { Cuarzo }\end{array}$ & $\begin{array}{c}\% \\
\text { Cristobalita }\end{array}$ & $\begin{array}{c}\% \\
\text { Fase Amorfa }\end{array}$ \\
\hline $\mathbf{0 . 2 5}$ & 80.9 & 14.9 & 0.4 & --- & 3.8 \\
\hline $\mathbf{0 . 5 0}$ & 86.7 & 7.9 & 0.1 & --- & 5.3 \\
\hline $\mathbf{1}$ & 91.3 & 3.5 & 0.2 & --- & 5.0 \\
\hline $\mathbf{2}$ & 92.8 & 2.8 & 0.5 & --- & 3.9 \\
\hline $\mathbf{3}$ & 91.9 & 4.1 & 0.2 & --- & 3.8 \\
\hline $\mathbf{5}$ & 91.5 & 3.8 & 1.3 & --- & 3.4 \\
\hline
\end{tabular}

En la tabla 5.11 se observa que a altos tiempos y habiendo alcanzado porcentajes estables de mullita neta $\sim 92 \%$ a temperatura de 2 horas, aún queda fase amorfa y alúmina sin convertir, con una pequeña cantidad de cuarzo. En este caso no se observan oscilaciones importantes en el porcentaje de mullita neta como las vistas en el caso de la arcilla La Rioja (mullita primaria), debido al consumo de la fase vítrea por parte de la alúmina calcinada, lo que limitó los procesos de solución - cristalización de la mullita en el vidrio. [Lee et al., 1995; Nurishi y Pask, 1982; Srodon, 2006].

\subsubsection{Método por comparación de área en el pico $\left(33.2^{\circ}\right.$ de $\left.2 \theta\right)$ - Mezcla estequiométrica $3 \mathrm{Al}_{2} \mathrm{O}_{3} \cdot 2 \mathrm{SiO}_{2}$ (arcilla - alúmina)}

El último método de cuantificación estudiado en esta sección consistió en cuantificar solo la fase mullita (neta) por comparación de áreas en el pico centrado en 33.2 de $2 \theta$ con el área medida para una mullita sinterizada sintética comercial (M-72) de ata calidad (91\% mullita cristalina), utilizando el programa FullProf, tal como se observa en la figura 5.13. 


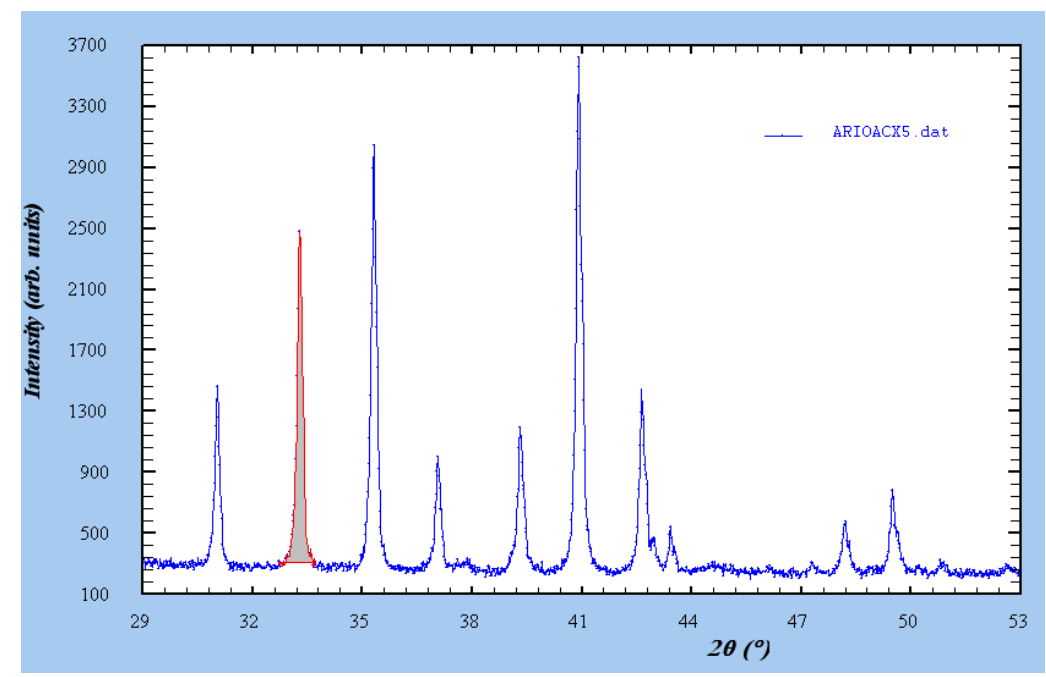

Figura 5.13. Difractograma de la mezcla estequiométrica 3-2 (arcilla La Rioja más alúmina calcinada) tratada a $1600 \stackrel{\circ}{\circ}$ por 5 horas, midiendo el áreas del pico centrado en $33.2^{\circ}$ de $2 \theta$.

Los resultados de la cuantificación del tenor de mullita neta obtenidos por el método de comparación de áreas para la muestra AriojAcal calcinada a $1600{ }^{\circ} \mathrm{C}$ a diferentes tiempos se muestran en la tabla 5.12.

Tabla 5.12. Resultados de la cuantificación de la mezcla estequiométrica 3-2 (AriojAcal) tratada a $1600{ }^{\circ} \mathrm{C}$ a diferentes tiempos, por comparación de áreas en el pico centrado en $33.2^{\circ}$ de $2 \theta$ (CuKa1).

\begin{tabular}{|c|c|}
\hline $\begin{array}{c}\text { TIEMPO } \\
\text { (Horas) }\end{array}$ & $\begin{array}{c}\text { \% MULLITA } \\
\text { (Neta) }\end{array}$ \\
\hline $\mathbf{0 . 2 5}$ & 96.3 \\
\hline $\mathbf{0 . 5 0}$ & 99.7 \\
\hline $\mathbf{1}$ & 78.6 \\
\hline $\mathbf{2}$ & 97.3 \\
\hline $\mathbf{3}$ & 75.6 \\
\hline $\mathbf{5}$ & 116.3 \\
\hline
\end{tabular}

En la tabla 5.12 se puede observar los porcentajes de mullita neta obtenidos para la muestra AriojAcal tratada térmicamente a $1600{ }^{\circ} \mathrm{C}$ a diferentes tiempos, presentando valores que sobrepasan al valor máximo teórico posible generado para un sistema arcilla refractaria - alúmina tratada térmicamente para producir mullita $\left(3 \mathrm{Al}_{2} \mathrm{O}_{3} \cdot \mathrm{SiO}_{2}\right)$, y al 
valor de una mullita sinterizada sintética comercial $(\mathrm{M}-72)$ de ata calidad que tiene un 91\% mullita cristalina.

\subsubsection{Cuantificación de las fases presentes en la mezcla estequiométrica 3-2 (AriojAcal), aplicando el método de Rietveld y el modelo de Le Bail}

Del análisis de los resultados obtenidos por los tres métodos de cuantificación para la mullita neta generada por la mezcla estequiométrica 3-2 (arcilla La Rioja más alúmina calcinada "AriojAcal"), se escogió el que arrojó mejores resultados en comparación con una mullita sinterizada sintética comercial (M-72) de ata calidad (91\% mullita cristalina). El que presentó mejores valores fue el método de Rietveld (Fullprof) para las fases cristalinas, y para la fase amorfa aplicando el modelo de Le Bail, siendo que además coincidió con el mejor método utilizado para la arcilla La Rioja sola pudiéndose compatibilizar a posteriori los cálculos para obtener los valores de mullita secundaria.

\subsubsection{Resultados de la cuantificación de mullita neta a $1300^{\circ} \mathrm{C}$}

Se realizó la cuantificación de todas las fases presentes (\%mullita, \% alfa alúmina, \% cuarzo, \% cristobalita y \% fase amorfa) en la muestra AriojAcal que fue tratada a diferentes temperaturas y tiempos (tabla 5.9), por el método y modelo mencionado anteriormente. En la tabla 5.13 se observan los resultados de los porcentajes de cada fase para la muestra AriojAcal tratada térmicamente a $1300^{\circ} \mathrm{C}$ a diferentes tiempos.

La tabla 5.13 muestra que los tenores de cuarzo y cristobalita se mantuvieron estables dentro del margen de error que es del $\pm 8 \%$ del método de cuantificación, notándose también como se va consumiendo la alúmina en función del tiempo para formar mullita secundaria.

Los valores de porcentajes de fase amorfa (rica en sílice) también se mantuvieron estables cuando deberían haber bajado ligeramente al ser consumidos por la alúmina reaccionante, pero en este caso el error del método para esta determinación no permite visualizar pequeñas diferencias de fase amorfa. 
Tabla 5.13. Porcentajes de las fases presentes en la muestra AriojAcal tratada térmicamente a $1300^{\circ} \mathrm{C}$, a diferentes tiempos.

\begin{tabular}{|c|c|c|c|c|c|}
\hline $\begin{array}{c}\text { Tiempo } \\
\text { (Horas) }\end{array}$ & $\begin{array}{c}\% \text { Mullita } \\
\text { (Neta) }\end{array}$ & $\begin{array}{c}\% \\
\alpha \text {-Alúmina }\end{array}$ & $\begin{array}{c}\% \\
\text { Cuarzo }\end{array}$ & $\begin{array}{c}\% \\
\text { Cristobalita }\end{array}$ & $\begin{array}{c}\% \\
\text { Fase } \\
\text { Amorfa }\end{array}$ \\
\hline $\mathbf{1}$ & 35.2 & 46.5 & 2.00 & 4.6 & 11.7 \\
\hline $\mathbf{2}$ & 37.4 & 45.2 & 1.8 & 5.3 & 10.3 \\
\hline $\mathbf{4}$ & 38.7 & 43.6 & 2.0 & 5.3 & 10.4 \\
\hline $\mathbf{6}$ & 39.8 & 42.5 & 2.1 & 4.5 & 11.1 \\
\hline $\mathbf{8}$ & 40.1 & 42.0 & 2.7 & 4.4 & 10.8 \\
\hline $\mathbf{1 0}$ & 42.1 & 39.9 & 2.3 & 4.3 & 11.4 \\
\hline $\mathbf{1 2}$ & 41.6 & 41.1 & 1.9 & 3.8 & 11.6 \\
\hline
\end{tabular}

Los porcentajes adquiridos de mullita neta, en la muestra AriojAcal calcinada a $1300{ }^{\circ} \mathrm{C}$ a diferentes tiempos, fueron graficados obteniendo las curvas de conversión tiempo, ver figura 5.14, donde se indica los porcentajes de mullita neta con relación al tiempo.

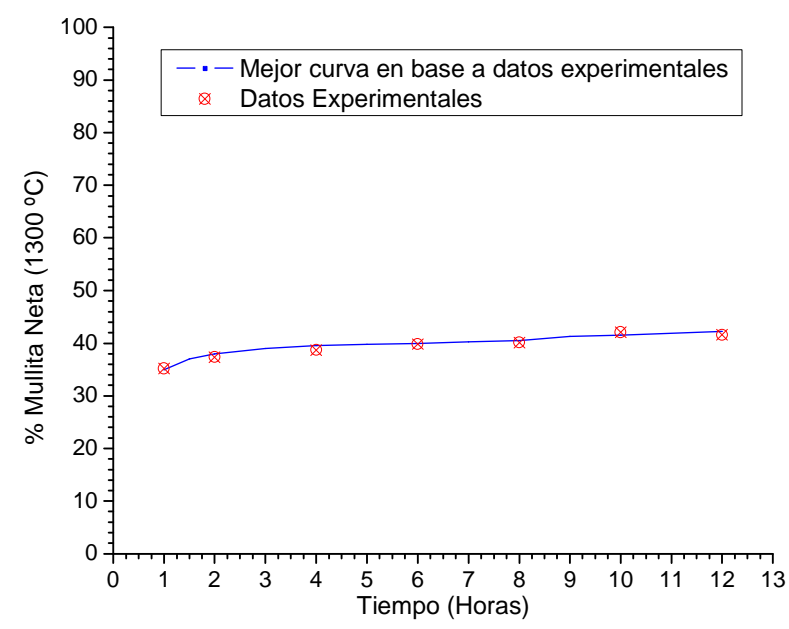

Figura 5.14. Porcentajes de mullita neta con respecto al tiempo, para la muestra, AriojAcal calcinada a $1300^{\circ} \mathrm{C}$.

En la figura 5.14, no se observan oscilaciones a tiempos menores a 2 horas, debido a la presencia de alúmina calcinada que en primera instancia diluye dichos elementos y amortigua las oscilaciones, al formarse una fase vítrea de mayor viscosidad. [Cáceres y Pereira, 1977; Liu et al.,1991; Takayuki y Kiyoshi, 1992]. 
Se observa un ligero crecimiento en el tenor de mullita en función del tiempo alcanzando un máximo de $\sim 42 \%$. Este valor es algo superior al mencionado para la arcilla La Rioja con su correspondiente factor de dilución, pero en este caso el leve crecimiento con el tiempo mostraría que la mullita secundaria que se forma es incipiente, ya que como se vio a esta temperatura, la mullitización primaria ya está casi completa a las 3 horas de tratamiento, como se verá en la tabla $5.17_{2}$ donde se especifican los valores comparativos de mullita primaria (valor anterior con su factor de dilusión), neta y secundaria (por diferencia) en este sistema de mezcla para todas las temperaturas y tiempos.

\subsubsection{Resultados de la cuantificación de mullita neta a $1400^{\circ} \mathrm{C}$}

Los resultados obtenidos en la cuantificación por el método de Rietveld (Fullprof) aplicando el modelo de Le Bail para la mezcla estequiométrica $3 \mathrm{Al}_{2} \mathrm{O}_{3} \cdot 2 \mathrm{SiO}_{2}$ (AriojAcal) tratada térmicamente a $1400{ }^{\circ} \mathrm{C}$ a diferentes tiempos, se pueden ver en la tabla 5.14.

Tabla 5.14. Porcentajes de las fases presentes en la muestra AriojAcal tratada térmicamente a $1400^{\circ} \mathrm{C}$, a diferentes tiempos.

\begin{tabular}{|c|c|c|c|c|c|}
\hline $\begin{array}{c}\text { Tiempo } \\
\text { (Horas) }\end{array}$ & $\begin{array}{c}\% \text { Mullita } \\
\text { (Neta) }\end{array}$ & $\begin{array}{c}\% \\
\alpha-\text { Alúmina }\end{array}$ & $\begin{array}{c}\% \\
\text { Cuarzo }\end{array}$ & $\begin{array}{c}\% \\
\text { Cristobalita }\end{array}$ & $\begin{array}{c}\% \\
\text { Fase Amorfa }\end{array}$ \\
\hline $\mathbf{0 . 5 0}$ & 45.3 & 43.5 & 2.1 & 0.7 & 8.4 \\
\hline $\mathbf{2}$ & 55.7 & 33.7 & 1.8 & 0.3 & 8.5 \\
\hline $\mathbf{4}$ & 59.0 & 32.5 & 1.6 & 0.2 & 6.7 \\
\hline $\mathbf{5}$ & 61.1 & 30.0 & 1.1 & 0.1 & 7.7 \\
\hline $\mathbf{6}$ & 64.9 & 29.1 & 1.9 & 0.3 & 3.8 \\
\hline $\mathbf{8}$ & 63.7 & 28.1 & 1.3 & --- & 6.9 \\
\hline $\mathbf{1 0}$ & 66.2 & 26.7 & 1.1 & 0.2 & 5.8 \\
\hline
\end{tabular}

Se observa en la tabla 5.14 un franco descenso de los tenores de alúmina, cuarzo, cristobalita y fase amorfa que son los responsables de la mullitización secundaria (reacción entre la sílice sobrante con la alúmina calcinada), [Chung, 1974a; 1974b]. Obteniendo su máxima conversión de mullita neta a las 10 horas. 
Los resultados del porcentaje de mullita neta generada a $1400{ }^{\circ} \mathrm{C}$ a diferentes tiempos, fueron graficados elaborando la curva de conversión tiempo, tal como se muestra en la figura 5.15 .

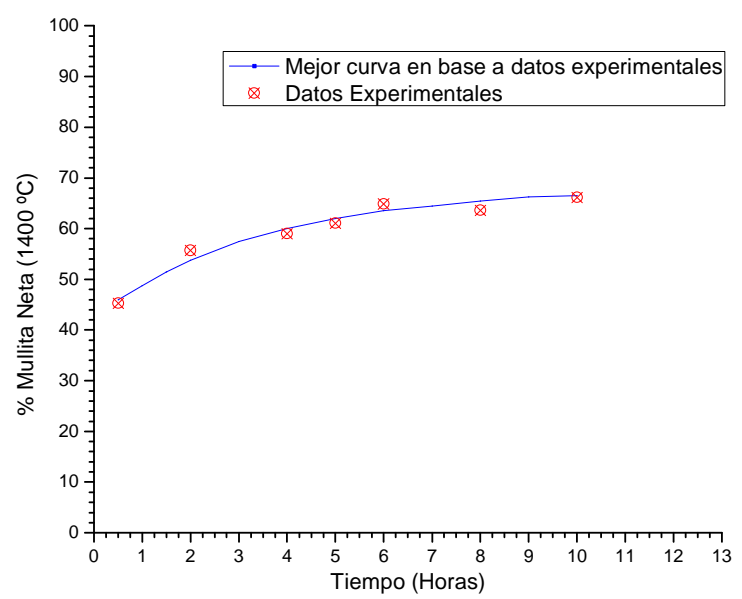

Figura 5.15. Porcentajes de mullita neta con respecto al tiempo, para la muestra AriojAcal calcinada a $1400^{\circ} \mathrm{C}$.

Se observa en la curva un crecimiento importante de mullita hasta las 4 horas observándose luego un crecimiento de tipo asintótico.

\subsubsection{Resultados de la cuantificación de mullita neta a $1450{ }^{\circ} \mathrm{C}$}

Los valores adquiridos en el análisis cuantitativo de la muestra AriojAcal tratada térmicamente a $1450^{\circ} \mathrm{C}$ a diferentes tiempos se observan en la tabla 5.15 , indicando los porcentajes de mullita neta, $\alpha$-alúmina, cuarzo, cristobalita y fase amorfa con respecto al tiempo.

En la tabla 5.15 también se notó un franco descenso en función del tiempo en las fases de $\alpha-\mathrm{Al}_{2} \mathrm{O}_{3}$, cuarzo y fase amorfa, observándose la total desaparición de la fase cristobalita.

Esto último es debido a que la misma se produjo durante la mullitización primaria (no la poseía el mineral de La Rioja) y por lo tanto estaría en forma de muy pequeños cristales, lo que lo haría de alta reactividad o para reaccionar con la alúmina o para ser redisuelta en la fase amorfa a alta temperatura, [Fischer et al., 1996; Rohan et al., 2004]. A las 10 horas de tratamiento se obtuvo un tenor de mullita de $\sim 80 \%$. 
Tabla 5.15. Porcentajes de las fases presentes en la muestra AriojAcal tratada térmicamente a $1450 \stackrel{\circ}{\mathrm{C}}$, a diferentes tiempos.

\begin{tabular}{|c|c|c|c|c|c|}
\hline $\begin{array}{c}\text { Tiempo } \\
\text { (Horas) }\end{array}$ & $\begin{array}{c}\% \text { Mullita } \\
(\text { Neta })\end{array}$ & $\begin{array}{c}\% \\
\alpha-\text { Alúmina }\end{array}$ & $\begin{array}{c}\% \\
\text { Cuarzo }\end{array}$ & $\begin{array}{c}\% \\
\text { Cristobalita }\end{array}$ & $\begin{array}{c}\% \\
\text { Fase } \\
\text { Amorfa }\end{array}$ \\
\hline $\mathbf{0 . 5 0}$ & 53.6 & 32.2 & 6.3 & 0.3 & 7.6 \\
\hline $\mathbf{2}$ & 68.0 & 24.9 & 1.4 & --- & 5.7 \\
\hline $\mathbf{4}$ & 68.2 & 24.5 & 1.1 & --- & 6.2 \\
\hline $\mathbf{5}$ & 73.2 & 20.9 & 0.7 & --- & 5.2 \\
\hline $\mathbf{6}$ & 75.0 & 19.1 & 0.7 & --- & 5.2 \\
\hline $\mathbf{8}$ & 74.5 & 18.0 & 2.3 & --- & 5.2 \\
\hline $\mathbf{1 0}$ & 80.3 & 16.4 & 0.6 & --- & 2.7 \\
\hline
\end{tabular}

La curva obtenida a partir de los tenores de mullita neta con relación al tiempo para una mezcla estequiométrica 3-2 (arcilla La Rioja más alúmina calcinada) tratada térmicamente a $1450 \stackrel{\circ}{\mathrm{C}}$ a diferentes tiempos se pueden ver en la figura 5.16.

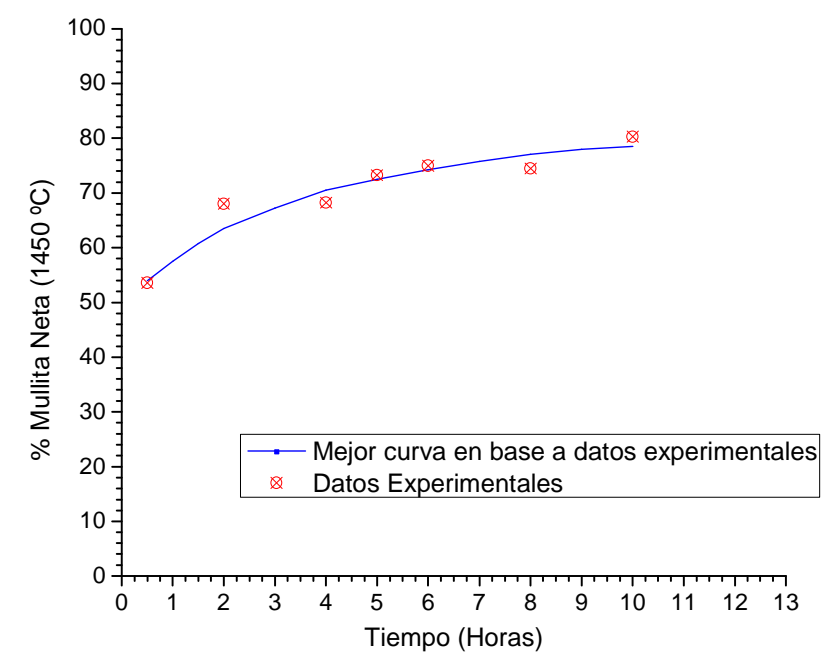

Figura 5.16 Porcentajes de mullita neta con respecto al tiempo, para la muestra AriojAcal, calcinada a $1450 \stackrel{\circ}{\circ}$.

En la figura 5.16, se repiten los fenómenos descriptos en la temperatura anterior, con la diferencia de que en este caso ya a los 30 minutos ( 0.50 hora) existe mullitización neta ( $54 \%$ mullita respecto a $\sim 42 \%$ máxima a $1300 \stackrel{\circ}{\circ}$ ). 


\subsubsection{Resultados de la cuantificación de mullita neta a $1500 \stackrel{\circ}{C}$}

Los porcentajes de las fases obtenidas en la cuantificación por el método de Rietveld y aplicando el modelo de Le Bail para la mezcla estequiométrica 3-2 (arcilla La Rioja más alúmina calcinada) tratada térmicamente a $1500^{\circ} \mathrm{C}$ a diferentes tiempos, se pueden ver en la tabla 5.16.

En la tabla 5.16, se observó el mismo fenómeno que el descripto a la temperatura anterior, la conversión fue mucho mayor, ocurriendo la desaparición del cuarzo, luego de las 3 horas de tratamiento. El máximo porcentaje de mullita neta obtenida a las 7 horas fue de $\sim 88 \%$, este valor se aproxima al porcentaje de mullita comercial europea sintética de alta pureza de uso industrial ( $91 \%$ de mullita).

Tabla 5.16. Porcentajes de las fases presentes en la mezcla estequiométrica 3-2 (AriojAcal) tratada térmicamente a $1500^{\circ} \mathrm{C}$, a diferentes tiempos.

\begin{tabular}{|c|c|c|c|c|c|}
\hline $\begin{array}{c}\text { Tiempo } \\
\text { (Horas) }\end{array}$ & $\begin{array}{c}\% \text { Mullita } \\
\text { (Neta) }\end{array}$ & $\begin{array}{c}\% \\
\alpha-A l u ́ m i n a\end{array}$ & $\begin{array}{c}\% \\
\text { Cuarzo }\end{array}$ & $\begin{array}{c}\% \\
\text { Cristobalita }\end{array}$ & $\begin{array}{c}\% \\
\text { Fase } \\
\text { Amorfa }\end{array}$ \\
\hline $\mathbf{0 . 2 5}$ & 60.2 & 32.0 & 2.3 & --- & 5.5 \\
\hline $\mathbf{0 . 5 0}$ & 66.1 & 27.7 & 1.5 & --- & 4.7 \\
\hline $\mathbf{1}$ & 70.7 & 23.4 & 0.6 & --- & 5.3 \\
\hline $\mathbf{2}$ & 77.8 & 17.3 & 0.7 & --- & 4.2 \\
\hline $\mathbf{3}$ & 80.5 & 15.1 & 0.4 & --- & 4.0 \\
\hline $\mathbf{5}$ & 83.9 & 11.9 & --- & --- & 4.2 \\
\hline $\mathbf{6}$ & 86.8 & 8.9 & --- & --- & 4.3 \\
\hline $\mathbf{7 h}$ & 88.4 & 8.4 & --- & --- & 3.2 \\
\hline
\end{tabular}

Los resultados del porcentaje de mullita neta generada a $1500 \stackrel{\circ}{\mathrm{C}}$ a diferentes tiempos, fueron graficados elaborando la curva de conversión tiempo, tal como se muestra en la figura 5.17. 


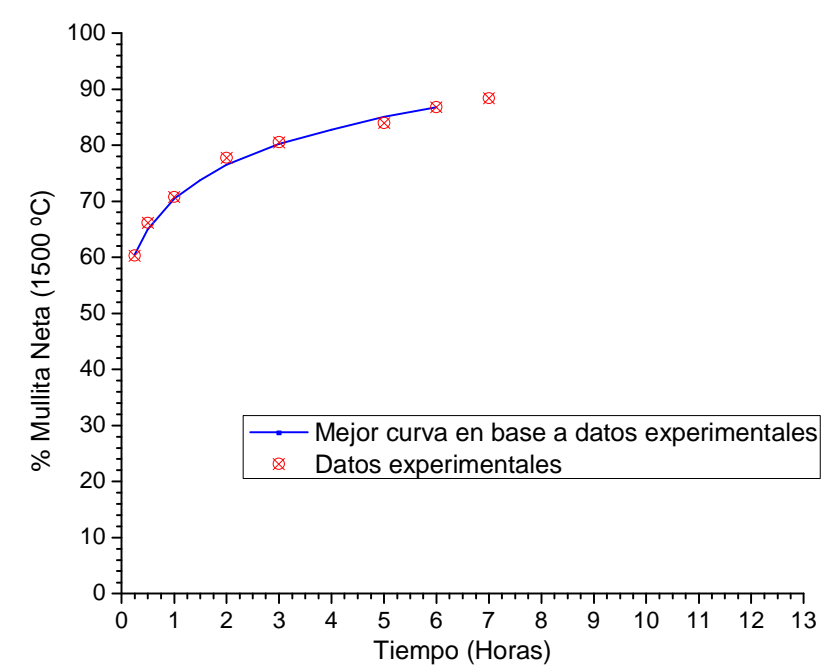

Figura 5.17 Porcentajes de mullita neta con respecto al tiempo, para la muestra AriojAcal a $1500^{\circ} \mathrm{C}$.

En la figura 5.17 se muestra un sistema mucho más estable (sin oscilaciones) que el de la arcilla sola (La Rioja), debido a que la sílice amorfa producida por la arcilla es tomada por la alúmina calcinada para formar mullita secundaria, no permitiendo la formación de grandes cantidades de fase vítrea. Estos valores son la suma del proceso de mullitización primaria generada por la arcilla más la mullita secundaria proveniente de la reacción entre la alúmina y la fase amorfa silícea proveniente de la arcilla. [Norton, 1949; Saruhan et al., 1996].

\subsubsection{Resultados de la cuantificación de mullita neta a $1600 \stackrel{\circ}{C}$}

Los valores adquiridos en la cuantificación de las fases presentes en la mezcla estequiométrica 3-2 (AriojAcal) calcinada a $1600 \stackrel{\circ}{\circ}$ a diferentes tiempos, se muestran en la tabla 5.11, los resultados obtenidos presentaron el mismo comportamiento que la temperatura anterior $\left(150{ }^{\circ} \mathrm{C}\right)$ pero alcanzándose en éste los valores asintóticos a la primera hora de tratamiento. De la tabla 5.11 se tomaron los porcentajes de mullita neta generada para realizar una curva de conversión tiempo, tal como se observa en la figura 5.18 . 


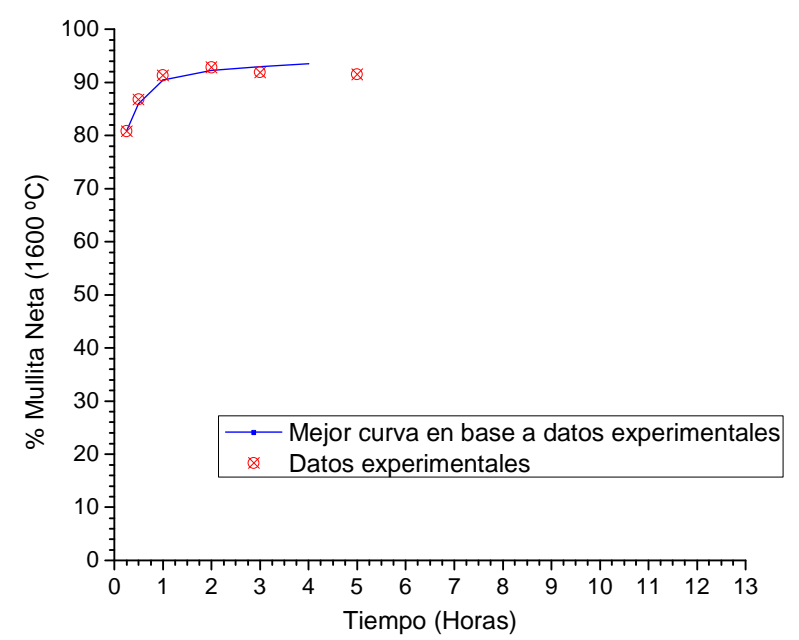

Figura 5.18 Porcentajes de mullita neta con respecto al tiempo, para la muestra AriojAcal a $1600 \stackrel{\circ}{\circ}$

En la figura 5.18, se puede observar que ya a los 30 minutos ( 0.50 hora) la conversión alcanzada es casi igual a la máxima obtenida a temperatura de $1500^{\circ} \mathrm{C}$. Esta curva es la suma del proceso de mullitización primaria generada por la arcilla más la mullita secundaria proveniente de la reacción entre la alúmina y la fase amorfa silicea proveniente de la arcilla. [Di Girolamo et al., 2010; McGEE y Dodd, 1961; O'Connor y Raven, 1988].

Se observa que el proceso de crecimiento del porcentaje de mullita neta a esta temperatura concluye prácticamente a la hora, manteniéndose luego una conversión aproximada del $\sim 92 \%$ de mullita con una presencia de aproximadamente $\sim 8 \%$ entre fase amorfa y otras menores. Estos valores finales son prácticamente similares a los de una mullita comercial europea sintética de alta pureza de uso industrial (91\% de mullita). 


\subsection{GENERACIÓN DE MULLITA SECUNDARIA}

\subsubsection{Tratamiento térmico - Formación de mullita secundaria (Mullita neta menos mullita primaria, calculada en base al valor obtenido con la arcilla La Rioja sola y su factor de dilución.)}

Del estudio cuantitativo de la arcilla La Rioja (mullita primaria) y de la mezcla estequiométrica 3-2 $\left(3 \mathrm{Al}_{2} \mathrm{O}_{3} \cdot 2 \mathrm{SiO}_{2}\right)$ de arcilla La Rioja más alúmina calcinada (mullita neta) tratadas térmicamente a diferentes temperaturas y tiempos, se pudo calcular el porcentaje de mullita secundaria para cada uno de estos casos, restando al porcentaje de mullita neta el porcentaje de mullita primaria obtenida por cuantificación de arcilla sola multiplicándola por el factor de dilución correspondiente $(0,5187)$, los resultados obtenidos se muestran en las tablas $5.17,5.18,5.19,5.20$ y 5.21 .

Tabla 5.17. Porcentajes de mullita neta, mullita primaria diluida en un sistema $\mathrm{Al}_{2} \mathrm{O}_{3}, \mathrm{y}$ mullita secundaria, a temperatura de $1300 \stackrel{\circ}{C}$ y diferentes tiempos.

\begin{tabular}{|c|c|c|c|}
\hline $\begin{array}{c}\text { Tiempo } \\
\text { (Hora) }\end{array}$ & \% Mullita Neta & $\begin{array}{c}\text { \% Mullita Primaria - } \\
\text { en un sistema } \\
\text { diluido con } \mathrm{Al}_{2} \mathrm{O}_{3}\end{array}$ & $\begin{array}{c}\text { \% Mullita } \\
\text { Secundaria }\end{array}$ \\
\hline $\mathbf{1}$ & 35.2 & 29.5 & 5.7 \\
\hline $\mathbf{2}$ & 37.4 & 31.1 & 6.2 \\
\hline $\mathbf{4}$ & 38.7 & 32.4 & 6.2 \\
\hline $\mathbf{6}$ & 39.8 & 31.9 & 8.3 \\
\hline $\mathbf{8}$ & 40.1 & 31.8 & 9.3 \\
\hline $\mathbf{1 0}$ & 42.1 & 32.8 & 8.8 \\
\hline $\mathbf{1 2}$ & 41.6 & 32.8 & 8.0 \\
\hline
\end{tabular}


Tabla 5.18. Porcentajes de mullita neta, mullita primaria diluida en un sistema $\mathrm{Al}_{2} \mathrm{O}_{3}, \mathrm{y}$ mullita secundaria, a temperatura de $1400 \stackrel{\circ}{C}$ y diferentes tiempos.

\begin{tabular}{|c|c|c|c|}
\hline $\begin{array}{c}\text { Tiempo } \\
\text { (Hora) }\end{array}$ & \% Mullita Neta & $\begin{array}{c}\text { \% Mullita Primaria - } \\
\text { en un sistema } \\
\text { diluido con } \mathrm{Al}_{2} \mathrm{O}_{3}\end{array}$ & $\begin{array}{c}\text { \% Mullita } \\
\text { Secundaria }\end{array}$ \\
\hline $\mathbf{0 . 5}$ & 45.3 & 35.4 & 9.9 \\
\hline $\mathbf{2}$ & 55.7 & 34.0 & 21.8 \\
\hline $\mathbf{4}$ & 59.0 & 34.1 & 30.6 \\
\hline $\mathbf{6}$ & 64.9 & 34.3 & 29.9 \\
\hline $\mathbf{8}$ & 63.6 & 33.8 & 32.2 \\
\hline $\mathbf{1 0}$ & 66.2 & 34.0 & \\
\hline
\end{tabular}

Tabla 5.19. Porcentajes de mullita neta, mullita primaria diluida en un sistema $\mathrm{Al}_{2} \mathrm{O}_{3}, \mathrm{y}$ mullita secundaria, a temperatura de $1450 \stackrel{\circ}{C}$ y diferentes tiempos.

\begin{tabular}{|c|c|c|c|}
\hline $\begin{array}{c}\text { Tiempo } \\
\text { (Hora) }\end{array}$ & \% Mullita Neta & $\begin{array}{c}\text { \% Mullita Primaria - } \\
\text { en un sistema } \\
\text { diluido con } \mathrm{Al}_{2} \mathrm{O}_{3}\end{array}$ & $\begin{array}{c}\text { \% Mullita } \\
\text { Secundaria }\end{array}$ \\
\hline $\mathbf{0 . 5}$ & 53.6 & 34.6 & 19.0 \\
\hline $\mathbf{2}$ & 68.0 & 34.3 & 33.7 \\
\hline $\mathbf{4}$ & 68.2 & 34.4 & 33.9 \\
\hline $\mathbf{6}$ & 75.0 & 34.1 & 39.8 \\
\hline $\mathbf{8}$ & 74.5 & 34.7 & 44.7 \\
\hline $\mathbf{1 0}$ & 80.3 & 35.5 & \\
\hline
\end{tabular}


Tabla 5.20 Porcentajes de mullita neta, mullita primaria diluida en un sistema $\mathrm{Al}_{2} \mathrm{O}_{3}, \mathrm{y}$ mullita secundaria, a temperatura de $1500 \stackrel{\circ}{\circ}$ y diferentes tiempos.

\begin{tabular}{|c|c|c|c|}
\hline $\begin{array}{c}\text { Tiempo } \\
\text { (Hora) }\end{array}$ & \% Mullita Neta & $\begin{array}{c}\text { \% Mullita Primaria - } \\
\text { en un sistema } \\
\text { diluido con } \mathrm{Al}_{2} \mathrm{O}_{3}\end{array}$ & $\begin{array}{c}\text { \% Mullita } \\
\text { Secundaria }\end{array}$ \\
\hline $\mathbf{0 . 2 5}$ & 60.1 & 32.5 & 27.6 \\
\hline $\mathbf{0 . 5 0}$ & 66.1 & 34.1 & 32.1 \\
\hline $\mathbf{1}$ & 70.7 & 34.3 & 36.4 \\
\hline $\mathbf{2}$ & 77.78 & 35.5 & 42.3 \\
\hline $\mathbf{3}$ & 80.5 & 34.3 & 46.3 \\
\hline $\mathbf{5}$ & 83.9 & 34.9 & 53.2 \\
\hline $\mathbf{6}$ & 86.78 & 33.6 & 53.2 \\
\hline $\mathbf{7}$ & 88.4 & 35.1 & 49.0 \\
\hline
\end{tabular}

Tabla 5.21 Porcentajes de mullita neta, mullita primaria diluida en un sistema $\mathrm{Al}_{2} \mathrm{O}_{3}$, y mullita secundaria, a temperatura de $1600 \stackrel{\circ}{C}$ y diferentes tiempos.

\begin{tabular}{|c|c|c|c|}
\hline $\begin{array}{c}\text { Tiempo } \\
\text { (Hora) }\end{array}$ & \% Mullita Neta & $\begin{array}{c}\text { \% Mullita Primaria - } \\
\text { en un sistema } \\
\text { diluido con } \mathrm{Al}_{2} \mathrm{O}_{3}\end{array}$ & $\begin{array}{c}\text { \% Mullita } \\
\text { Secundaria }\end{array}$ \\
\hline $\mathbf{0 . 2 5}$ & 80.9 & 33.7 & 47.1 \\
\hline $\mathbf{0 . 5 0}$ & 86.8 & 31.8 & 55.0 \\
\hline $\mathbf{1}$ & 91.3 & 32.6 & 58.8 \\
\hline $\mathbf{2}$ & 92.8 & 31.9 & 58.9 \\
\hline $\mathbf{3}$ & 91.9 & 33.4 & 59.5 \\
\hline $\mathbf{5}$ & 91.5 & 32.0 & 58.5 \\
\hline
\end{tabular}

Su puede observar en las tablas 5.17 hasta la 5.21 que el porcentaje de mullita primaria (arcilla La Rioja) en un sistema diluido con $\mathrm{Al}_{2} \mathrm{O}_{3}$ (alúmina calcinada), presenta oscilaciones en función del tiempo, debido como ya se mencionó a los fenómenos de solubilización - precipitación de mullita observada para La Rioja sola en la fase amorfa rica en sílice. [Elssner et al., 1999; Hall, 1941; McGEE y Dodd, 1961; Pole y Taylor, 1935; Saruhan et al., 1996]. 
Encontrar los porcentajes de mullita secundaria es importante en este capítulo, ya que se podría conocer que mecanismo de mullitización predomina en la mullita neta en cada temperatura y tiempo, si es la mullita primaria (diluida en el sistema mezcla) o la secundaria, para ello se efectuaron curvas de porcentaje de mullita secundaria con respecto al tiempo, ver figura 5.19 .

Los resultados obtenidos de mullita secundaria presentes en la figura 5.19, presentaron en todas las curvas a excepción de la temperatura de $1500 \stackrel{\circ}{\circ}$, unas pequeñas oscilaciones en sus porcentajes cerca de su máximo tiempo de tratamiento, aunque estos valores estarían dentro del margen error originado por el método de cuantificación y por la cantidad de fase amorfa generada en el sistema de arcilla sola (La Rioja).

El porcentaje máximo de mullita secundaria a $130{ }^{\circ} \mathrm{C}$ se dio a las 10 horas, y para las temperaturas de 1400,1450 y $1500 \stackrel{\circ}{\circ}$ se dieron aproximadamente entre las 6 a 10 horas, y para la curva que representa el tratamiento a $1600{ }^{\circ} \mathrm{C}$ mostró su máxima conversión a las 2 horas, observándose que a medida que se aumenta la temperatura la conversión máxima de mullita se da a tiempos más cortos.

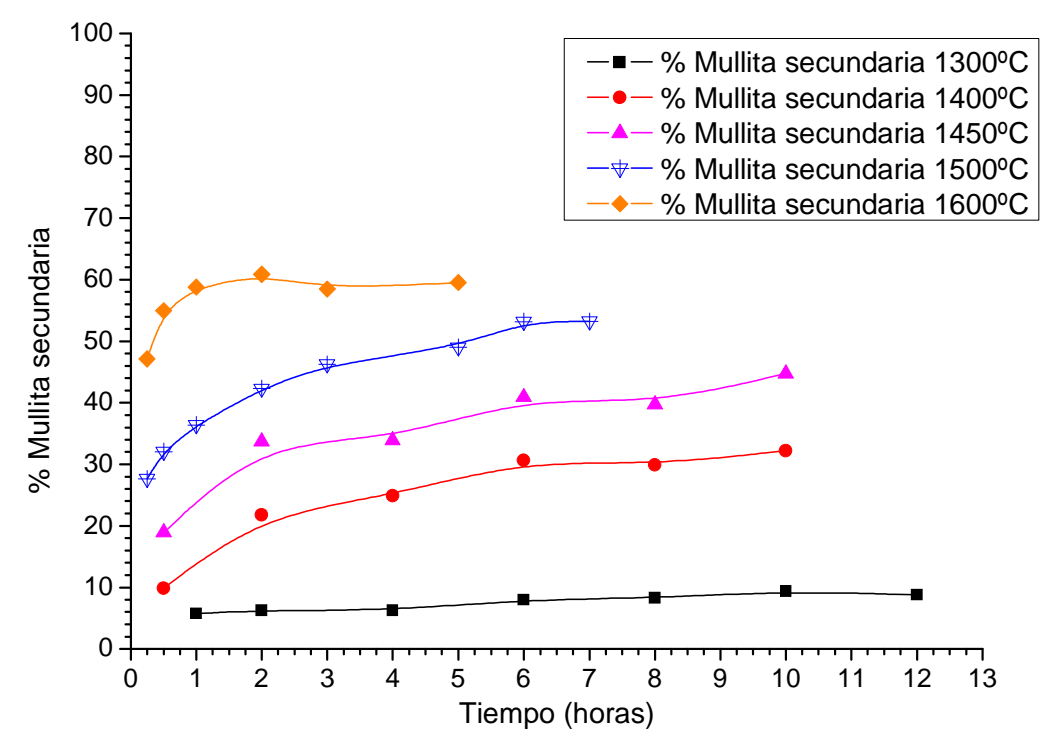

Figura 5.19. Porcentajes de mullita Secundaria para la muestra AriojAcal tratada a diferentes temperaturas y tiempo de reacción (Mullita Neta - Mullita Primaria).

La mullitización primaria en un sistema diluido con $\mathrm{Al}_{2} \mathrm{O}_{3}$ predomina sobre la mullita

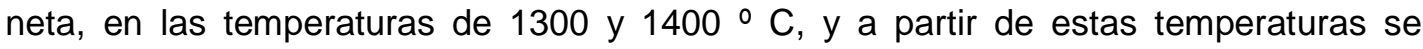
empieza a ver en términos relativos una disminución de mullita primaria, para empezar a predominar la mullitización secundaria, como en el caso de $1600 \stackrel{\circ}{\circ}$. 


\subsection{CONCLUSIONES PARCIALES}

Se elaboraron probetas prensadas unixialmente a $100 \mathrm{MPa}$ de arcilla La Rioja sola (Arioja) y mezcla estequiométrica $3 \mathrm{Al}_{2} \mathrm{O}_{3} \cdot 2 \mathrm{SiO}_{2}$ (AriojAcal), estas se trataron térmicamente a diferentes temperaturas las cuales fueron; 1300, 1400, 1450, 1500 y $1600{ }^{\circ} \mathrm{C}$, y a distintos tiempos de permanencia dependiendo ellos de la temperatura de trabajo.

$>\quad$ Se observó por Difracción de Rayos $X$ que las intensidades de las fases cristalinas presentes en la arcilla La Rioja varían de acuerdo a la temperatura y tiempo de reacción principalmente en los primeros tiempos de tratamiento, encontrándose fases de mullita (primaria), cuarzo y cristobalita, notándose también un elevado fondo en todos los difractogramas visualizándose mayoritariamente como una banda en la zona de $22^{\circ} \mathrm{d}$ e $2 \theta$, esto debido a la fase vítrea generada en el sistema. La mezcla AriojAcal presentó el mismo comportamiento mencionado pero con menos fase amorfa, encontrándose fases cristalinas como: mullita (neta), cristobalita, alúmina y cuarzo que van variando ó desapareciendo de acuerdo a las condiciones de reacción (temperatura tiempo).

El estudio de los métodos de cuantificación de fases se realizaron sobre la arcilla La Rioja y la mezcla estequiométrica 3-2 conformada por arcilla La Rioja más alúmina calcinada (AriojAcal) tratadas a $1600{ }^{\circ} \mathrm{C}$ a diferentes tiempos de tratamiento, debido a que a estas condiciones la arcilla y la mezcla presentarían su máxima conversión a mullita (primaria y neta respectivamente). Comparando los resultados de mullita primaria con el porcentaje de mullita máxima $(59,40 \%)$ producido por la arcilla La Rioja de acuerdo a su composición química de $\mathrm{SiO}_{2}$ y $\mathrm{Al}_{2} \mathrm{O}_{3}$, y la mullita neta se comparó con el valor de una mullita sinterizada sintética comercial (M-72) de alta calidad (91\% mullita cristalina y $9 \%$ fase amorfa).

De los resultados obtenidos en la cuantificación de mullita primaria y neta (producida por la arcilla La Rioja y mezcla AriojAcal) por los tres métodos estudiados y dada la cantidad de fase amorfa generada por la sílice sin reaccionar (observada por DRX), se concluyó que la técnica de Rietveld con el 
modelo de Le Bail es aplicable para materiales con alto porcentaje de fase amorfa (como los materiales en estudio).

Los otros dos métodos estudiados para la cuantificación de la fase amorfa fueron, el método de Ohlberg y el método por comparación de área en el pico $33.2^{\circ}$ de $2 \theta$ (CuKa1), encontrándose que en el método de Ohlberg aplicado a la arcilla La Rioja se lograron valores de mullita primaria muy inferiores al porcentaje máximo de mullita $(59.40 \%)$ y en la mezcla AriojAcal se hallaron valores bajos de mullita neta con respecto al valor de una mullita comercial de alta calidad ( $91 \%$ mullita cristalina). Aplicando el método del área bajo el pico centrado en $33.2^{\circ}$ se observó que la arcilla La Rioja presentó el mismo comportamiento y la mezcla AriojAcal se comportó de forma contraria a lo mencionado anteriormente.

Se evaluó el porcentaje total de mullita a dichas temperaturas y tiempos, y se le restaron los porcentajes de mullita primaria procedente de la propia arcilla (Arioja), obteniéndose la mullita secundaria producida por la reacción entre la alúmina calcinada y la sílice liberada por la arcilla al descomponerse térmicamente (mullita Neta producida en la mezcla menos mullita primaria generada por la arcilla sola multiplicándola por el factor de dilución correspondiente (0.5187)).

La cuantificación de las fases cristalinas y amorfa de la arcilla La Rioja a diferentes temperaturas y tiempos, mostraron que casi todos los resultados han superado el valor máximo de conversión de mullita (59.4\%), sin embargo todos estos valores estarían dentro del margen de error permitido en el proceso de cuantificación por el método de Rietveld y aplicando el modelo de Le Bail. Es conocido que cuando la fase amorfa está presente en gran cantidad el error es mayor como el observado. Es el caso de la arcilla sola (Arioja), pues en el caso de la mezcla con alúmina (AriojAcal) no ocurre esta diferencia. Además el método de Rietveld posee un $8 \%$ de error, al que habría que sumarle el de Le Bail el cual se desconoce.

- La cuantificación de la arcilla La Rioja tratada térmicamente a $1300 \stackrel{\circ}{\circ}$ mostró que las fases de mullita (primaria) y cristobalita van aumentando en función del tiempo, mientras el cuarzo y la fase amorfa van disminuyendo, las oscilaciones 
que se presentaron en estas fases se debieron a que el sistema comienza a presentar fenómenos de solubilización - precipitación entre la fase amorfa y la cristalina (mullita primaria), notándose que a las dos horas el porcentaje de mullita primaria alcanzó su máxima conversión.

- A la temperatura de $1400 \stackrel{\circ}{\mathrm{C}}$ se presentó el mismo comportamiento anterior, pero su máxima conversión la alcanzó a la media hora. A $1450 \stackrel{\circ}{\mathrm{C}}$ se observó el mismo fenómeno mencionado pero al estar el sistema más sinterizado la difusión requerida para el proceso de solubilizacion - cristalización es más lenta y por eso presenta una mayor estabilidad de porcentaje de mullita en función del tiempo.

- A $1500^{\circ} \mathrm{C}$ se observó un franco descenso de los tenores de cuarzo, cristobalita y fase amorfa con respecto al tiempo correspondiente a la reacción del sistema para producir mullita primaria, mostrando después de las 2 horas oscilaciones que corresponden a fenómenos de solubilización - precipitación.

- Se estimó en la cuantificación a $1600{ }^{\circ} \mathrm{C}$ que la matriz vítrea es aún más fluida que la anterior (menor viscosidad) lo que promueve y aumenta los fenómenos de difusión para el proceso de solubilización - cristalización, mostrando una mayor oscilación de los contenidos de mullita en función del tiempo.

En la cuantificación de las fases cristalinas y amorfa de la mezcla estequiométrica 3-2 (AriojAcal) utilizando el método de Rietveld y el modelo de Le Bail se observó que el sistema es mucho más estable (sin oscilaciones) que el de la arcilla sola (La Rioja), debido a que la sílice amorfa producida por la arcilla es tomada por la alúmina calcinada para formar mullita secundaria, no permitiendo la formación de grandes cantidades de fase vítrea. Las siguientes apreciaciones se manifestaron en la cuantificación:

- En la cuantificación de fases a $1300{ }^{\circ} \mathrm{C}$, se observó que los tenores de cuarzo y cristobalita se mantuvieron estables, notándose también como se va consumiendo la alúmina en función del tiempo para formar mullita secundaria.

- A temperatura de $1400 \stackrel{\circ}{\circ}$, se observó un franco descenso de los tenores de alúmina, cuarzo, cristobalita y fase amorfa que son los responsables de la 
mullitización secundaria. A $1450 \stackrel{\circ}{\circ}$, se percibió el mismo comportamiento anterior, sin embargo la fase cristobalita desapareció totalmente.

- Se manifestó en la cuantificación de fases a $1500 \stackrel{\circ}{\circ} \mathrm{C}$, la desaparición del cuarzo, luego de las 3 horas de tratamiento. A $1600^{\circ} \mathrm{C}$, se observó que el porcentaje de mullita neta concluyó prácticamente a la hora, manteniéndose luego una conversión aproximada del $\sim 92 \%$. Aunque se alcanzaron porcentajes estables de mullita neta ( $92 \%)$ aún quedó fase amorfa y alúmina sin convertir, con una pequeña cantidad de cuarzo.

La mullitización primaria en un sistema diluido con $\mathrm{Al}_{2} \mathrm{O}_{3}$ predomina sobre la mullita neta, en las temperaturas de 1300 y $1400 \stackrel{\circ}{\circ}$, y a partir de estas temperaturas empieza a ver una disminución relativa del tenor de mullita primaria frente a la secundaria.

$>\quad$ El porcentaje máximo de mullita secundaria a $1300^{\circ} \mathrm{C}$ se dió a las 10 horas, y para las temperaturas de 1400, 1450 y $1500 \stackrel{\circ}{\mathrm{C}}$ se dieron aproximadamente entre las 10 a 6 horas, y para la curva que representa el tratamiento a $1600{ }^{\circ} \mathrm{C}$ mostró su máxima conversión a las 2 horas, observándose lógicamente que a medida que se aumenta la temperatura, la conversión máxima de mullita se da a tiempos más cortos.

\subsection{BIBLIOGRAFIA}

Aramaki, S., Roy R., Revised Phase Diagram for the System $\mathrm{Al}_{2} \mathrm{O}_{3}-\mathrm{SiO}_{2}$, Journal of the American Ceramics Society. 45, pp. 229-242 (1962).

> Bernal I., Cabezas H., Espitia C., Mojica J., y Quintero J., Análisis próximo de arcillas para cerámica. Rev. Acad.Colomb. Cienc. 2, pp. 569-578 (2003).

$>\quad$ Bish D.L., y Howar S.D., Quantitative Phase Analysis Using the Rietveld Method, Journal of Applied Crystallography. 21 (2), pp. 86-91 (1988).

$>\quad$ Bish D.L., y Howard S.J., Quantitative phase analysis using the Rietveld method. Journal of Applied Crystallography. 21, pp. 86-91 (1988).

> Bragg W.L., The Diffraction of short electromagnetic waves by a crystal, Proc. 
Cambridge Phil. Soc. 17, pp. 43-57 (1913).

> Brindley G.M., Nakahira M., The kaolinite-mullite reaction series I-III. Journal of the American Ceramics Society. 42 (7) pp. 311-324 (1959).

> Cáceres Carmen V., Pereira E., Formación de mullita por procesos no difusionales en el sistema bauxita - arcilla caolinítica, I estudio cinético, Rev. Latinoam. Ing. Quim. Apl. 7, pp. 119-133 (1977).

> Chung F.H., Quantitative interpretation of X-ray diffraction patterns of mixtures I. Matrix-flushing method for quantitative multicomponent analysis. Journal of Applied Crystallography. 7, pp. 519-525 (1974a).

$>\quad$ Chung F.H., Quantitative interpretation of X-ray diffraction patterns of mixtures II. Adiabatic principle of $X$-ray diffraction analysis of mixtures. Journal of Applied Crystallography. 7, pp. 526-531 (1974b).

$>\quad$ Conconi M.S., Rendtorff N.M., Aglietti E.F., Evaluation of non crystalline phase in AZS refractories by XRD methods, New Journal of Glass and Ceramics. 1, pp. 28-33 (2011).

$>\quad$ De la Torre A.G., Bruque S., Aranda M.A.G., Rietveld quantitative amorphous content analysis. Journal of Applied Crystallographic. 34, pp. 196-202 (2001).

> Di Girolamo Giovanni., Blasi Caterina., Pilloni Luciano., Schioppa Monica., Microstructural and thermal properties of plasma sprayed mullite coatings. Ceramics Internationa. 36(4), pp. 1389-1395 (2010).

> Elssner G., Hoven H., Kiessler G., Wellner P., Ceramics and Ceramic composites: Materialographic preparation, Elsevier, pp. 33-39 (1999).

$>$ Field J.E., X-Ray Study of Proportion of Crystalline and Amorphous Components in Stretched Rubber, Journal of Applied Physics., 12 (1), pp. 23-24 (1941).

$>\quad$ Fischer R.X., Schneider H., Voll D., Formation of aluminum rich 9:1 mullite and its transformation to low alúmina mullite upon heating. Journal of the European Ceramic Society. 16, pp. 109-113 (1996).

> Hall J.L., Secondary Expansion of High-Alúmina Refractories, Journal of the American Ceramics Society. 24 (11), pp. 349-56 (1941).

$>\quad$ Juettner Thomas., Moertel Heinrich., Svinka V., Svinka R., Structure of kaoline - 
alúmina based foam ceramics for high temperature applications. Journal of the European Ceramic Society. 27, pp. 1435-1441 (2007).

$>\quad$ Klug H.P., y Alexander L.E., X-ray diffraction procedures for polycrystalline and amorphous materials. John Wiley \& Sons, New York., pp. 716 (1974).

> Le Bail A., Modelling the silica glass structure by the Rietveld method. Journal of Non-Crystalline Solids., 183, pp. 39-42 (1995).

> Lee K.N., Miller R.A., y Jacobson N.S., New generation of plasma - sprayed mullite coatings on silicon carbide. Journal of the American Ceramic Society. 78 (3), pp. 705-710 (1995).

> Liu Kuo-Chung., Gareth Thornas., Caballero Angel., Moya Jose S, y De Aza Salvador., Microstructure and Microanalysis of Mullite Processed by Reaction Sintering of Kaolinite - Alúmina Mixtures: in Ceramics Today-Tomorrow's Ceramics. Edited by P. Vincenzini. Elsevier Science Publishers, London, U.K., pp. 177-86 (1991).

$>\quad$ Liu Kuo-Chung., Gareth Thornas., Caballero Angel., Moya Jose S, y De Aza Salvador., Time-Temperature-Transformation Curves for Kaolinite-- $\alpha$ Alúmina. Journal of the American Ceramic Society. 77 (6), pp. 1545 -1552 (1994).

> Lutterotti L., Ceccato R., Dal Maschio R., y Pagani, E., Quantitative analysis of silicate glass in ceramic materials by theRietveld method. Materials Science Forum. Vol 278-281 (1), pp. 87-92 (1998).

> Mazdiyasni K.S., Brown L.M., Sintesis and mechanical properties of stoichiometric aluminum silicate (mullite). Journal of the American Ceramic Society. 55 (11), pp. 548-552 (1972).

> McGEE Thomas y Dodd M., Mechanism of secondary expansión of high alúmina refractaries containing calcined bauxite. Journal of the American Ceramic Society. 44 (6), pp. 277-283 (1961).

> Moore D.M. y Reynolds R.C., X-ray Diffraction and the identification and analysis of clay minerals, 2nd edition, Oxford University Press, New York. (1997).

> Norton F. H., Refractories, McGraw-Hill Book Co., Inc., New York, Ceram. Abstr. pp. $492-93$ (1949).

$>\quad$ Nurishi Y., y Pask J.A., Sintering of $\alpha-\mathrm{Al}_{2} \mathrm{O}_{3}$, - Amorphous Silica Compacts. 
Ceramic International. 8 (2), pp. 57-59 (1982).

> O'Connor B.H., y Raven M.D., Application of the Rietveld refinement procedure in assaying powder mixtures. Powder Diffraction. 3, pp. 2-6 (1988).

$>\quad$ Ohlberg S.M., Strickler D.W., Determination of Percent Crystallinity of Partial Devitrified Glass by X-Ray Diffraction. Journal American Ceramic Society. 45, pp.170-171 (1962).

> Onike F., Martin G.D., y Dunham A.C., Time-Temperature-Transforrnation Curves for Kaolinite, Mater. Sci. Forum. 7, pp.73-82 (1986).

> Pole G.R., y Taylor N.W., Kinetics of Solid-Phase Reactions of Certain Carbonates with Mullite, Silica, and Alúmina, Journal of the American Ceramics Society. 18 (11), pp. 325-337 (1935).

> Rietveld H. M., A profile refinement method for nuclear and magnetic structures, Journal of Applied Crystallography. 2, pp. 65-71 (1969).

> Rodriguez - Caravajal., FULLPROF, a Program for Rietveld Refinement and Pattern Matching Analysis, Abstracts of the Satellite Meeting on Powder Difraction of XV Congres of the IUCr, Toulouse, France, pp. 127 (1990).

> Rodríguez - Carvajal J., Recent Developments of the Program Fullprof, Newsletter in Commission on Powder Diffraction (IUCr). Newsletter 26, pp.12-19 (2001).

$>$ Rohan P., Neufuss K., Matejicek J., Dubský J., Prchlík L., Holzgartner C., Thermal and mechanical properties of cordierite, mullite and steatite produced by plasma spraying. Ceramics International. 30 (4), pp. 597-603 (2004).

$>$ Saalfeld $\mathrm{H}$., y Guse W., Structure refinement of 3:2-mullite $\left(3 \mathrm{Al}_{2} \mathrm{O}_{3} \cdot 2 \mathrm{SiO}_{2}\right)$. Journal of Mineralogy and Geochemistry. 4, pp. 145-150 (1981).

> Sahnoune F., Chegaar M., Saheb N., Goeuriot P., Valdivieso F., Algerian kaolinite used for mullite formation, Applied Clay Science. 38, pp. 304-310 (2008).

> Sanchez Conde C., La mullita y su identificación en materiales cerámicos. Boletín de la Sociedad Española de Cerámica y Vidrio. 5 (1), pp. 79-106 (1996).

> Saruhan B., Albers W., Schneider H., Kaysser W.A., Reaction and sintering mechanisms of mullite in the systems cristobalite/alpha- $\mathrm{Al}_{2} \mathrm{O}_{3}$ and amorphous 
$\mathrm{SiO}_{2} /$ alpha- $\mathrm{Al}_{2} \mathrm{O}_{3}$. Journal of the European Ceramic Society. 16 (10), pp. 10751081 (1996).

> Schneider H., Fischer R. X. y Voll D., Mullite with lattice constants a > b. Journal of the American Ceramics Society. 76, pp.1879-1881 (1993).

> Schneider H., Okada K., Pask J.A., Mullite and Mullite Ceramics. John Wiley \& Sons, Chichester., pp. 266 (1994).

> Schneider H., Schreuer J., Hildmann, B., Structure and properties of mullite-A review. Journal of the European Ceramic Society. 28 (2), pp 329-344 (2008).

> Shigeo Aramaki., y Rustum Roy., Revised Phase Diagram for the System $\mathrm{Al}_{2} \mathrm{O}_{3}$ $2 \mathrm{SiO}_{2}$, Journal of the American Ceramics Society. 45 (5), pp. 229-42 (1962).

$>\quad$ Skoog, A.J., Moore, R.E., Refractory of the past for the future: mullite, and its use as a bonding phase. American Ceramic Society Bulletin. 67 (7), pp. 11801184 (1988).

$>\quad$ Srodon J., Identification and quantitative analysis of clay minerals. Handbook of clay Science, F. Bergaya, B.K.G. Theng, and G. Lagaly, Developments in Clay Science. Elsevier, Amsterdam. 1, pp. 765 -787 (2006).

> Takayuki Ban., y Kiyoshi Okada., Structure Refinement of Mullite by the Rietveld Method and a New Method for Estimation of Chemical Composition. Journal of the American Ceramic Society. 75 (1), pp. 227-230 (1992).

> Taylor J.C., Rui Z., Simultaneous use of observed and calculated standard profiles in quantitative XRD analysis of minerals by the multiphase Rietveld method: The determination of pseudorutile in mineral sands products. Powder Diffraction, 7 (3), pp. 152-161 (1992).

> Taylor R.M., y Norrish K., The measurement of orientation distribution and its application to quantitative X-ray diffraction analysis. Clay Minerals. 6, pp. 127142 (1966).

> Tcheichvili L., Butschkowskyi M., Un aporte al problema de la mullita. Boletín de la Sociedad Española de Cerámica y Vidrio. 14 (1), pp. 9-22 (1975).

> Testa R.H., y Pereira E., Reacciones de mullitización en el sistema bauxita arcilla. Rev. Lati. Am. Ing. Quim. y Quim. Apl 1, pp. 45-55 (1971a).

> Testa R.H., Pereira E., y Quiroz R.W., Mullitization des bauxites. Materials Science and Engineering. 7, pp. 134-140 (1971b). 
$>$ Vandecasteele C., Block C.B., In Modern Methods for Trace Element Determination, Wiley \& Sons, Chichester., pp. 138-167 (1993).

> Von Dreele R.B., Quantitative texture analysis by Rietveld refinement. Journal ofA pplied Crystallography. 30, pp. 517-525 (1997).

> Young R.A., The Rietveld Method. International Union Crystallography, Oxford University Press, New York., pp.298 (1993).

> Zevin L. y Viaene W., Impact of clay particle orientation on quantitative clay diffractometry, Clay Minerals. 25, pp. 401-418 (1990). 


\section{CAPITULO 6}

\section{ESTUDIO CINÉTICO - MODELAMIENTO MATEMÁTICO}

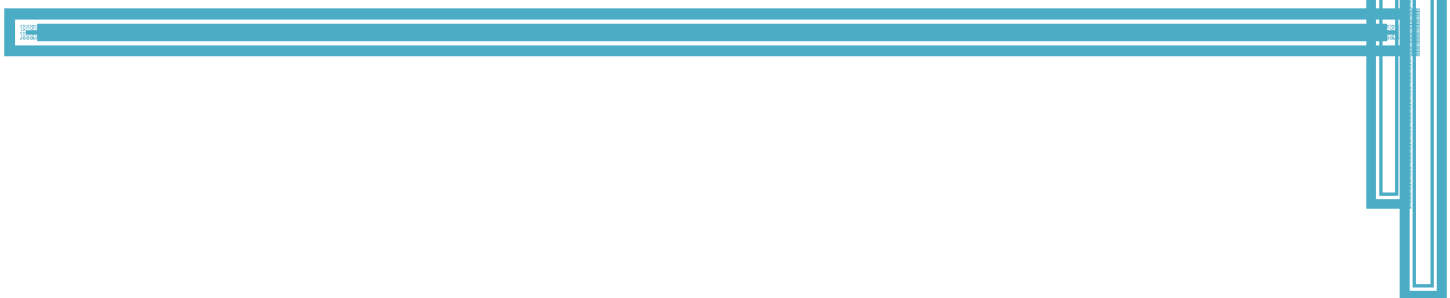

En el presente capítulo se desarrollará un estudio cinético para conocer los mecanismos que controlan la velocidad de reacción (etapas lentas), y de este modo se podría saber que acción se debería tomar, por ejemplo acelerar una reacción o retrasarla.

Para llevar a cabo este estudio cinético fue necesario realizar curvas conversión a mullita vs tiempo a diferentes temperaturas, siendo el análisis de éstas muy valioso al momento de decidir el par de valores (temperatura, tiempo) que se emplearán en un sistema productivo para obtener la mejor ecuación costo beneficio.

Se utilizó una arcilla de La Rioja (Arioja), debido a que es la mejor arcilla caolinítica de Argentina ( $\sim 96.7 \%$ de caolinita) trabajada en esta tesis, lo que generaría en el estudio cinético solo dos formas de mullitización; la primaria generada istrínsecamente por la misma caolinita al calcinarla, liberando además sílice, y la secundaria formada por la reacción de la sílice liberada con la alúmina adicionada (AriojAcal). Si se hubiera realizado una mezcla estequiométrica $3-2\left(3 \mathrm{Al}_{2} \mathrm{O}_{3} \cdot 2 \mathrm{SiO}_{2}\right)$ utilizado otra arcilla por ejemplo que contuviera mucho cuarzo, existiría otra formación de mullita por reacción entre el cuarzo y la alúmina adicionada y así otros ejemplos.

No se evaluará n los mecanismos de cinética de reacción para la arcilla sola (La Rioja) ya que existen trabajos previos [Cáceres y Pereira, 1977] donde la mullitización 
secundaria fue realizada con bauxita en lugar de alúmina de alta pureza, siendo que además dicho estudio fue realizado solo hasta $1300{ }^{\circ} \mathrm{C}$ y a tiempos relativamente cortos, lo que abarcaría mayoritariamente a la producción de mullita primaria y parte de la secundaria.

El presente estudio cinético proyectó la continuación de la evolución de mullitización a partir de dichas temperaturas, ya que a $1300^{\circ} \mathrm{C}$ dur ante las primeras 3 horas ya se generó toda la mullita primaria según lo observado en los difractogramas de la figura 5.1(a), [Rosenstock, 1973], por lo que el análisis encarado consiste prácticamente en la producción de mullita total y secundaria.

Las condiciones de trabajo para obtener los valores experimentales (conversión mullita tiempo) se mostraron en la tabla 5.9 donde se especifican todas las temperaturas utilizadas y los tiempos de permanencia de la mezcla estequiométrica 3-2 (arcilla La Rioja más alúmina calcinada (AriojAcal)).

La técnica utilizada para el estudio cinético, en cuanto a la introducción de muestras en el horno, ya fue explicada en el capítulo anterior, siendo que la extracción de las mismas se realizó en forma instantánea ni bien cumplido el tiempo de tratamiento para "congelar" la reacción, obteniéndose así sistemas a baja temperatura tal cual estaban a alta temperatura.

\subsection{CURVAS DE CONVERSIÓN DE MULLITA NETA (AriojAcal) A DIFERENTES TEMPERATURAS Y TIEMPOS.}

Con los datos del análisis cuantitativo por Difracción de Rayos X usando el método de Rietveld aplicando el modelo de Le Bail publicados en el capítulo anterior (figuras 5.14 a 5.18) [Le Bail, 1995; Rietveld, 1969], se construyeron gráficas de conversión ( $\alpha$ ) vs tiempo mostrándose en la figura 6.1. 


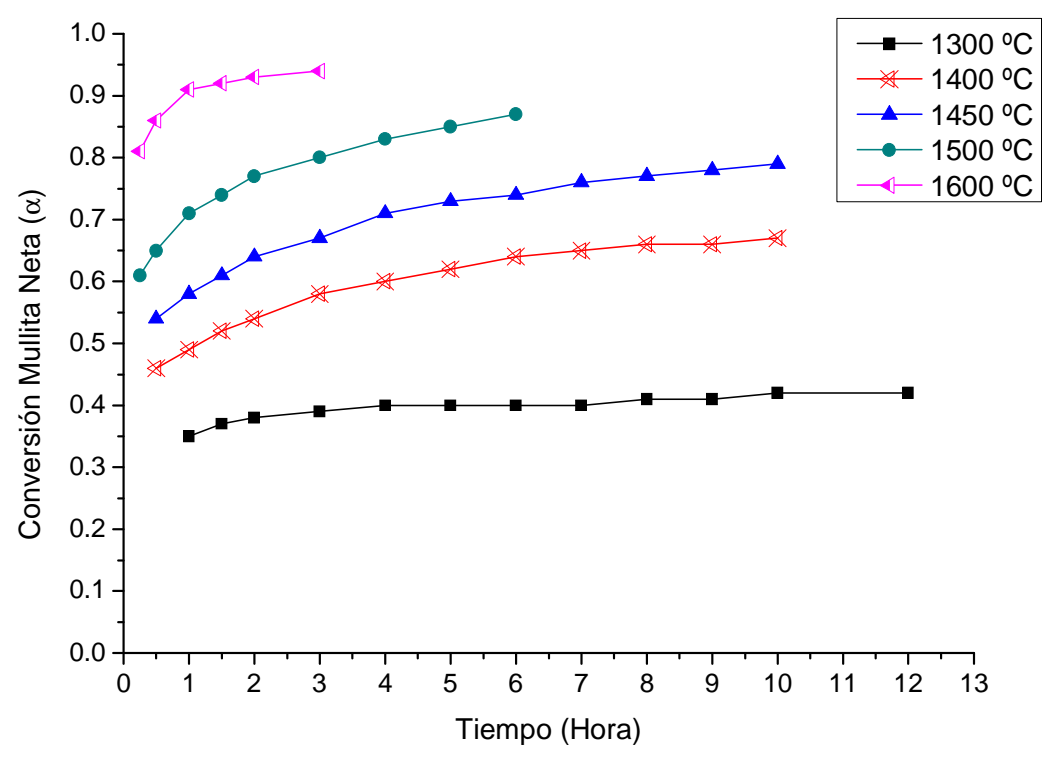

Figura 6.1. Curvas de conversión de mullita neta vs tiempo a diferentes temperaturas para la muestra AriojAcal.

De las curvas de la figura 6.1, se extrajeron los valores de conversión para cada temperatura y tiempo, para ser utilizados en las ecuaciones de los distintos modelos cinéticos estudiados. En algunos casos se han observado desviaciones (puntos que no respondían al mismo) en situaciones de muy bajas conversiones, otras veces de muy altas conversiones, en dichos casos esos puntos no fueron considerados, dado que los modelos cinéticos funcionan realmente en valores de conversión no extremos.

Con los datos obtenidos se probaron los siguientes modelos cinéticos: para controles por procesos interfaciales (reacción química y, nucleación y crecimiento) y para el control por procesos difusionales (Ecuaciones de Jander, de Kroger y Ziegler, de Zhuravlev, Lesokhim y Tempelman, de Ginstling y Brounshtein y ecuación de Dunwald y Wagner)

\subsection{ASPECTOS CINÉTICOS}

Las reacciones que ocurren en estado sólido no siempre se presentan de una forma uniforme y definida en cuanto a mecanismos cinéticos se refiere, es por eso que en estas reacciones se pueden distinguir varias etapas consecutivas cuyos límites de 
iniciación y terminación no son precisos ni definidos. Desde la perspectiva estrictamente cinética se puede decir que las reacciones en estado sólido se asocian a dos procesos globales sin solución de continuidad, los interfaciales y difusionales.

\subsubsection{Modelos cinéticos - Control por procesos interfaciales}

Dentro del proceso interfacial se encuentran la reacción química, nucleación y crecimiento. [Kingery et al., 1976; Sharp et al., 1996]

\subsubsection{Control por reacción química}

Este proceso será controlado por la reacción química que se llevará a cabo en la interfase, siendo las velocidades de las demás etapas superiores a ésta. Se han desarrollado para este caso modelos que cumplan los siguientes requisitos:

> La velocidad total del proceso está controlada por las reacciones que ocurren en la interfase.

$>$ La velocidad de reacción es proporcional al área de la interfase entre los reactivos que no han reaccionado.

$>$ La nucleación de producto es instantánea, de forma que cada partícula es cubierta por una película de productos.

Para un cilindro que reacciona desde la periferia hacia adentro, se cumple:

$$
k t=\frac{U}{r} t=1-(1-\alpha)^{\frac{1}{2}}
$$

Para una esfera que reacciona desde la superficie hacia el centro, la ecuación que describe el proceso es:

$$
k t=\frac{U}{r} t=1-(1-\alpha)^{\frac{1}{3}}
$$


dónde:

$$
\propto=\text { conversión }=\frac{\text { Cantidad de producto a tiempo " } t "}{\text { Cantidad de producto a tiempo inicial }}
$$

$\mathrm{t}=$ tiempo

$\mathrm{U}=$ constante de velocidad

$r=$ radio inicial

En las ecuaciónes (6.1) y (6.2), U/r se puede agrupar como una constante global de la velocidad de reacción $(k)$, esta constante es inversamente proporcional al radio de las partículas, por lo que los sistemas controlados por reacción química serán más veloces, más reactivos, cuanto menor sea el tamaño de partícula.

\subsubsection{Control por nucleación y crecimiento cristalino}

Nucleación y crecimiento cristalino involucra la nucleación de las moléculas de producto hasta constituir núcleos de tamaño crítico, y crecimiento de dichos núcleos hasta construir una capa interfacial continua del producto.

Cuando una fase se forma por nucleación y crecimiento, ésta comienza constituyendo una región pequeña del espacio, y cuando dichas partículas alcanzan un dado tamaño el incremento de energía superficial es despreciable frente al descenso de energía volumétrica y entonces el cambio de energía libre que acompaña el proceso pasa de positivo a negativo, haciendo que el proceso sea espontáneo. La transformación mencionada involucra: a) la energía libre de formación de la nueva región (incluyendo la tensión superficial), y b) la velocidad de transporte de átomos a la interfase.

Avrami [Avrami, 1939; 1941] y Erofe'ev [Erofeev, 1946], desarrollaron modelos de nucleación suponiendo que la nueva fase se forma a partir de gérmenes potenciales que ya existen en la fase inicial y cuyo número puede ser alterado por tratamiento previo, concluyendo en las siguientes ecuaciones:

$$
\begin{aligned}
& -\operatorname{In}(1-\alpha)^{\frac{1}{2}}=k t \\
& -\operatorname{In}(1-\alpha)^{\frac{1}{3}}=k t
\end{aligned}
$$


Dependiendo el exponente $1 / 2$ ó $1 / 3$ de si la nucleación se desarrolla en dos o tres dimensiones respectivamente, y donde las variables $\alpha, \mathrm{k}$ y t poseen el mismo significado que el descripto anteriormente.

Hulbert [Hulbert, 1969] basándose en los trabajos de Avrami y Erofe`ev [Avrami, 1939; 1940; Erofeev, 1946], y haciendo una extensión de las ideas de Christian [Christian, 1965a; 1965b] referentes a modelos de crecimiento de núcleos para transformaciones de fase en interacciones sólido - sólido, dedujo una ecuación con parámetros que caracterizan a los núcleos en cuanto a forma y velocidad de crecimiento, siendo la misma de la forma:

$$
\operatorname{In} \frac{1}{1-\alpha}=(k t)^{m}
$$

Donde m: parámetro que es función del mecanismo de reacción dentro del grupo de mecanismo de nucleación y crecimiento, de la composición de las fases reactivos y productos, y de la granulometría de los núcleos.

Cuando una reacción en estado sólido responde en su cinética a control por nucleación y crecimiento y puede ser representada por la ecuación (6.5), una graficación de $\ln \{\ln [1 /(1-\alpha)]\}$ vs In $t$ debería dar una línea recta con pendiente "m" y ordenada al origen "m In k".

\subsubsection{Modelos cinéticos - Control por procesos difusionales}

Estos modelos son aplicables cuando la velocidad global del proceso está controlada por la difusión de los reactivos a través de la capa del producto.

Considerando la aplicación de la ley parabólica a un sistema en reacción con control difusional, Jander [Jander, 1927] aplicó la ley parabólica para el caso de reacciones entre polvos compactos, estando su modelo sustentado en los siguientes postulados:

$>$ La reacción es de tipo aditivo, o sea $A+B \rightarrow C$ 
> La nucleación que precede al proceso difusional ocurre a una temperatura inferior a la necesaria para que comience el segundo proceso, de modo que existe una capa definida de producto cuando la difusión comienza.

$>$ La reacción química en la interfase es considerablemente más rápida que el proceso de transporte difusional.

$>$ El producto no es miscible con ninguno de los reactivos.

$>$ Las partículas de reactivo A son esferas de radio uniforme, y están completamente rodeadas por las partículas (mucho más pequeñas) de reactivo B.

> La relación del volumen de la capa de producto formado, con respecto al volumen de los reactivos consumidos es igual a la unidad.

$>$ El incremento en espesor de la capa de producto sigue la ley parabólica.

$>$ El valor del coeficiente de difusión de las especies transportadas es independiente del tiempo.

$>$ La actividad de los reactivos, se mantiene constante a ambos lados de la interfase de reacción.

Su modelo matemático quedó expresado en la siguiente ecuación:

$$
k_{j} t=\frac{2 k D t}{r^{2}}=\left[1-(1-\alpha)^{\frac{1}{3}}\right]^{2}
$$

dónde:

$\mathrm{k}_{\mathrm{j}}=$ constante global del proceso de Jander.

$\mathrm{D}=$ coeficiente de difusión medio de las especies transportadas.

$\mathrm{k}=$ constante puntual o local.

En este caso, en un proceso isotérmico donde se cumple el modelo al graficar $f(\alpha)$ vs $t$ debería obtenerse una línea recta que pasa por el origen y cuya pendiente seria $\mathrm{k}_{\mathrm{j}}$. Jander demostró también que la constante de velocidad de reacción $\mathrm{k}_{\mathrm{j}}$, cumple con la ecuación de Arrhenius:

$$
k_{j}=A e^{-E / R T}
$$

donde:

$\mathrm{A}=$ una constante del sistema. 
$\mathrm{T}=$ temperatura absoluta.

$\mathrm{R}=$ constante universal de los gases.

$\mathrm{E}=$ energía de activación del proceso.

Kroger y Ziegler [Kroger y Ziegler, 1953; 1954] desarrollaron un modelo basado en la hipótesis de Jander pero considerando que el coeficiente de difusión de las especies transportadas era inversamente proporcional al tiempo, llegando a:

$$
k_{K Z} \operatorname{Int}=\left(\frac{2 k}{r^{2}}\right) \operatorname{In} t=\left[1-(1-\alpha)^{\frac{1}{3}}\right]^{2}
$$

Zhuravlev, Lesokhim y Tempelman [Zhuravlev et al., 1948] modificaron la relación de Jander y consideraron que la actividad de las sustancias reaccionantes es proporcional a la fracción de material no reaccionado (1- $\alpha)$, concluyendo en la siguiente ecuación:

$$
k_{z L T} t=\left\lfloor\left(\frac{1}{1-\alpha}\right)^{\frac{1}{3}}-1\right\rfloor^{2}
$$

Ginstling y Brounshtein [Ginstling y Brounshtein, 1950] desarrollaron un modelo basado en la hipótesis de Jander pero excluyendo la ley parabólica, ya que consideraron que la superficie de reacción no se mantiene constante para partículas esféricas de reactivo que se va consumiendo. La ecuación a la que arribaron fue:

$$
k_{G B} t=\frac{2 k D t}{r^{2}}=1-\left(\frac{2}{3} \alpha\right)-(1-\alpha)^{\frac{2}{3}}
$$

Dunwald y Wagner [Dunwald, 1934] desarrollaron una ecuación para analizar reacciones en estado sólido basándose en la solución de la segunda ley de Fick para la difusión de un gas en un sólido semi-infinito, pero fueron Serin y Ellikson [Serin y Ellickson, 1941] quienes expresaron la ecuación en términos de conversión.

$$
k_{D W}=\frac{\pi^{2} D t}{r^{2}}=\operatorname{In}\left(\frac{6}{\pi^{2}(1-\alpha)}\right)
$$


Si bien todos los modelos citados consideran la reacción de partículas esféricas y de radio uniforme, muchas reacciones sólido- sólido se ajustan a los mismos.

Como ya se mencionó un modelo cinético es una expresión matemática que vincula la conversión con el tiempo y la constante global de velocidad de reacción, y cuando los datos experimentales cumplen con la ecuación matemática propuesta por un modelo, se dice que ese modelo responde a dicha realidad.

\subsection{APLICACIÓN DE LOS MODELOS MATEMÁtICOS A LA MEZCLA ESTEQUIOMÉTRICA $3 \mathrm{Al}_{2} \mathrm{O}_{3} \cdot 2 \mathrm{SiO}_{2}$ (AriojAcal)}

De las curvas conversión tiempo (figura 6.1), se tomaron los valores para las distintas temperaturas estudiadas y se probaron los diferentes modelos cinéticos: control químico; nucleación y crecimiento (Hulbert) y procesos difusionales (Jander, Kroger -Ziegler, Zhuravlev -Lesokhim - Tempelman, Ginstling - Brounshtein y Dunwald Wagner). Según el modelo elegido para su evaluación se representan dichos pares de valores de la forma:

$$
f(\alpha) \text { vs } t \quad o ́ \quad \ln (\ln 1 / 1-\alpha) v s \ln t \quad o ́ \quad f(\alpha) v s \ln t
$$

Los modelos que representarán el comportamiento del sistema para una o varias temperaturas son aquellos en los cuales la graficación de los pares de valores mencionados muestra rectas cuya pendiente es $\mathrm{k}$ (constante global de velocidad) salvo en el caso del modelo de Hulbert donde " $k$ " se obtiene de la ordenada del origen al graficar In (In 1/1- $\alpha$ ) vs In $t$, y "m" de la pendiente.

Evaluados los modelos antes presentados ajustaron a rectas casi todas las temperaturas, excepto la de $1300^{\circ} \mathrm{C}$ a los modelos de Hulbert (nucleación y crecimiento) [Hulbert, 1969] y Zhuravlev, Lesokhim y Tempelman (control difusional) [Zhuravlev et al., 1948].

Se vio que los datos experimentales obtenidos a $1300^{\circ} \mathrm{C}$ no responden a los mecanismos que ajustaron y a ningún otro de los analizados y evidentemente existe otro mecanismo desconocido o un solapamiento de más de uno o es la transición entre el final de la mullitización primaria y el principio de la secundaria, [Rosenstock, 1973; Testa y Pereira, 1971]. El mecanismo de control por reacción química a esa temperatura tampoco linealizó (la linealización se realizó por regresión lineal), figura 6.2. 

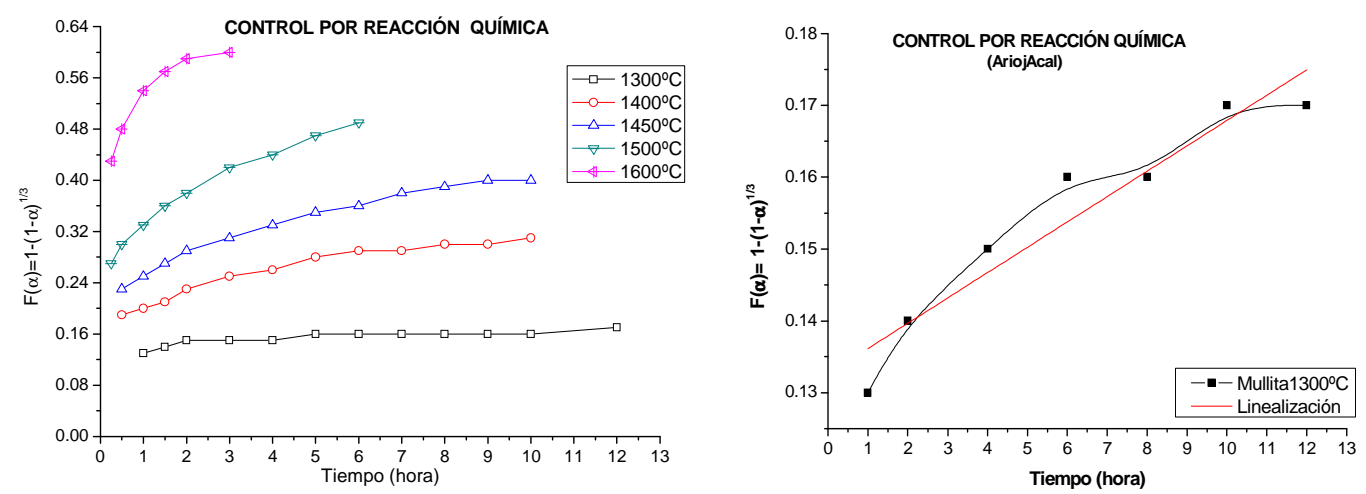

Figura 6.2. Modelamiento matemático, por reacción química para la mezcla AriojAcal.

Las figuras 6.3 y 6.4 representan la aplicación de los datos experimentales conversión tiempo al modelo de Hulbert, y al modelo de Zhuravlev, Lesokhim y Tempelman, respectivamente.

Se puede observar en las figuras 6.3(a) y 6.4(a), que los modelos seleccionados no ajustaron a los valores obtenidos a $1300^{\circ} \mathrm{C}$. Por lo tanto no se consideró esta temperatura para incluirla en la evaluación cinética de modelados matemáticos.

Las desviaciones del modelo difusional en cuanto a que las rectas no pasan exactamente por el origen cuando el modelo matemático lo exige es debido a que en todos los sistemas experimentales hay variables que no son consideradas en la matemática de los modelos pues corresponden a todo lo concerniente a la "historia" del material en estudio: naturaleza y características de las materias primas utilizadas; procedimiento; conformado, y tipo de tratamiento térmico. Todos ellos pueden contribuir en mayor o menor medida al desplazamiento mencionado. 


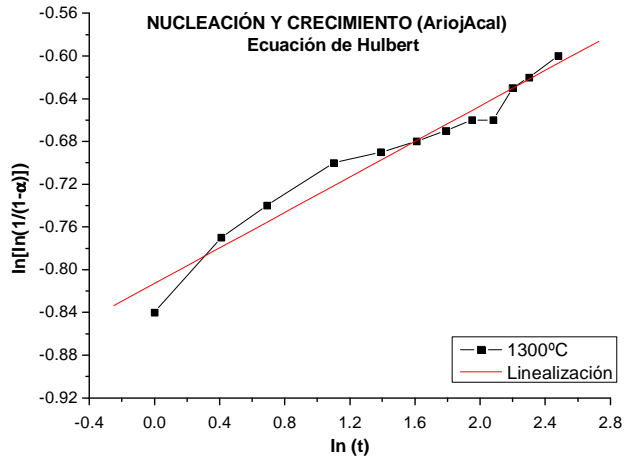

(a)

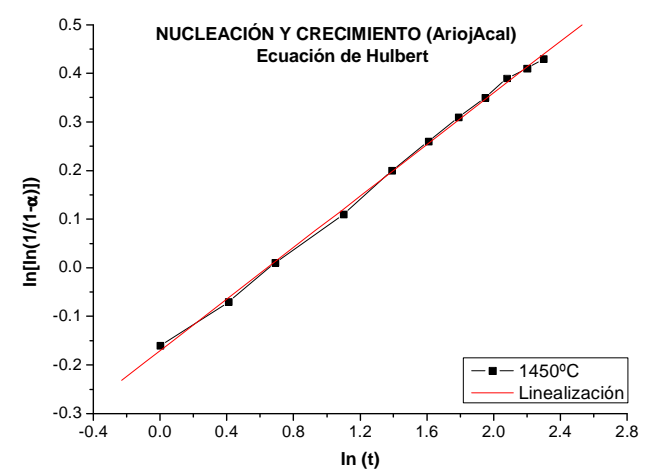

(c)

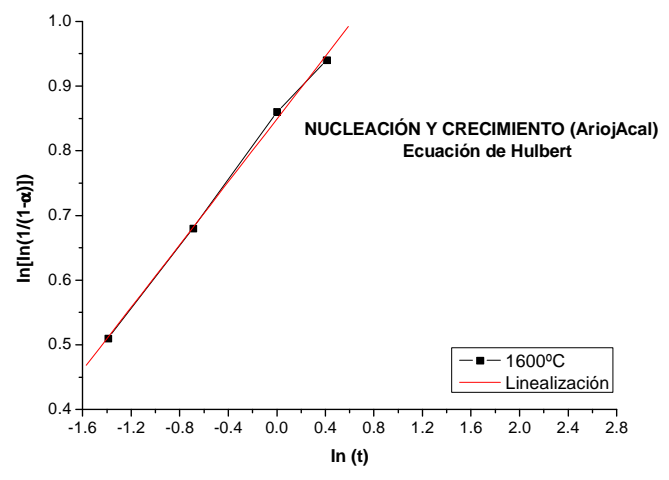

(e)

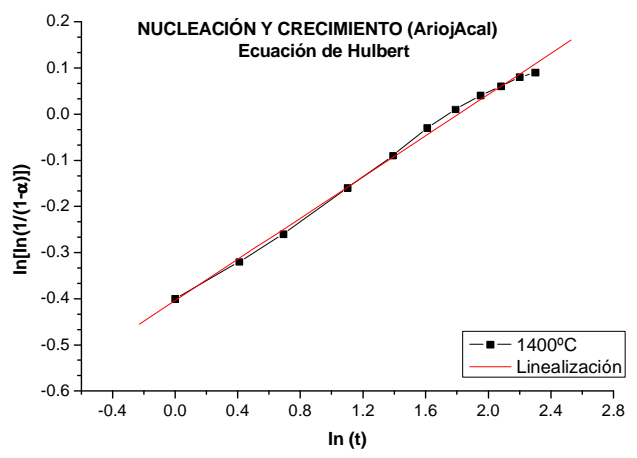

(b)

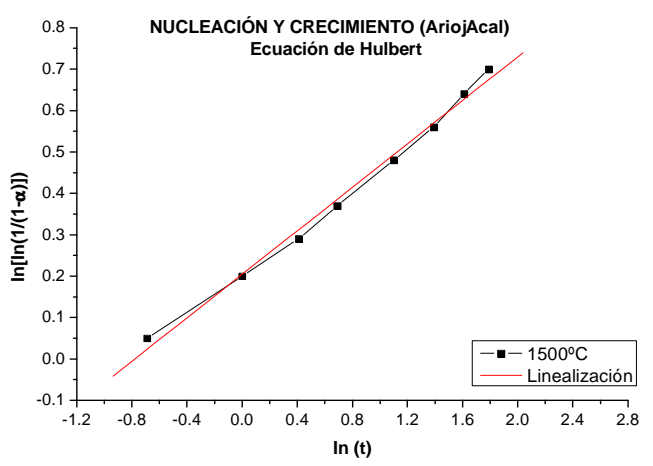

(d)

Figura 6.3. Modelo de Hulbert (nucleación y crecimiento) para la mezcla AriojAcal, a) $1300^{\circ} \mathrm{C}$; b) $1400^{\circ} \mathrm{C}$; c) $1450^{\circ} \mathrm{C}$; d) $1500^{\circ} \mathrm{C}$ y e) $1600^{\circ} \mathrm{C}$. 


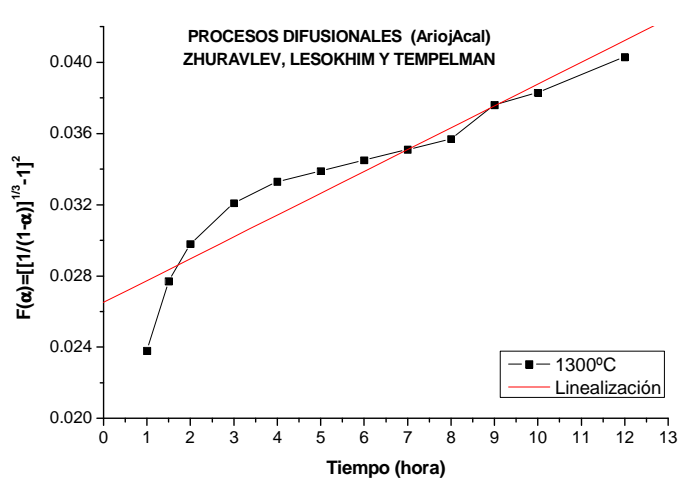

(a)

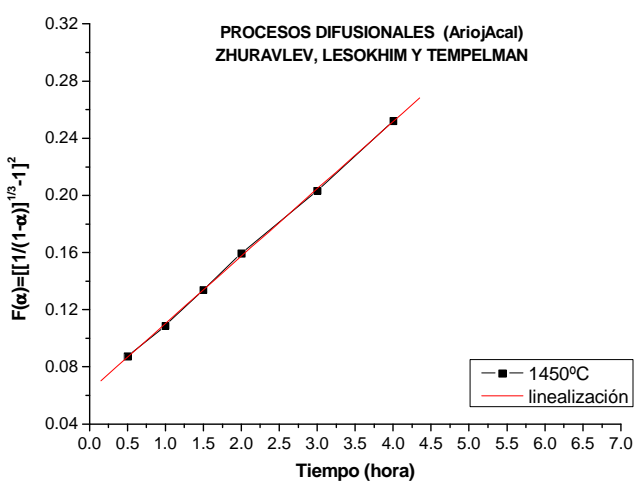

(c)

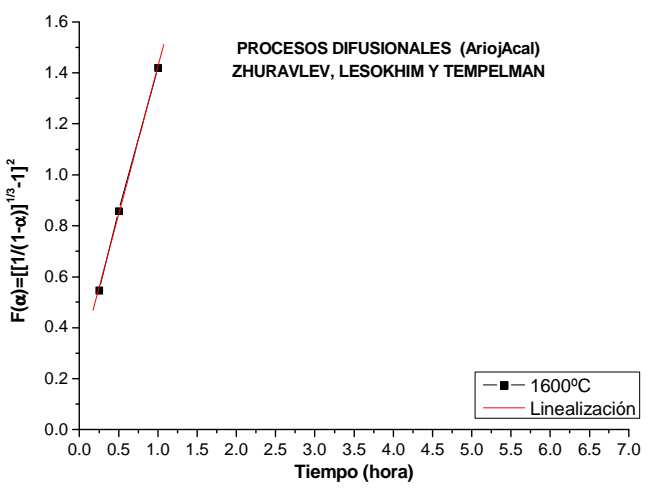

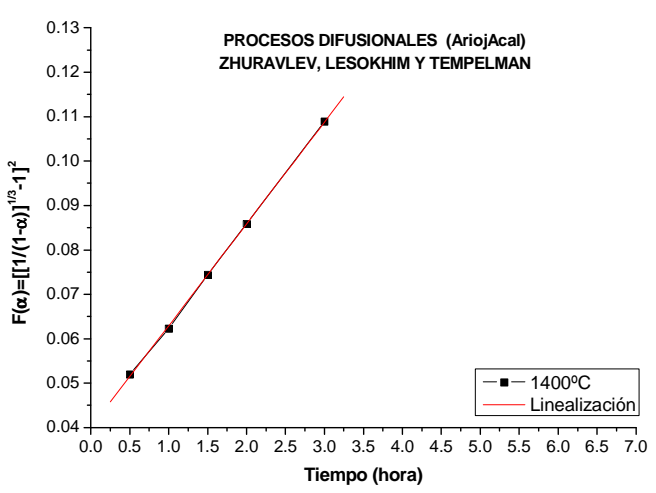

(b)

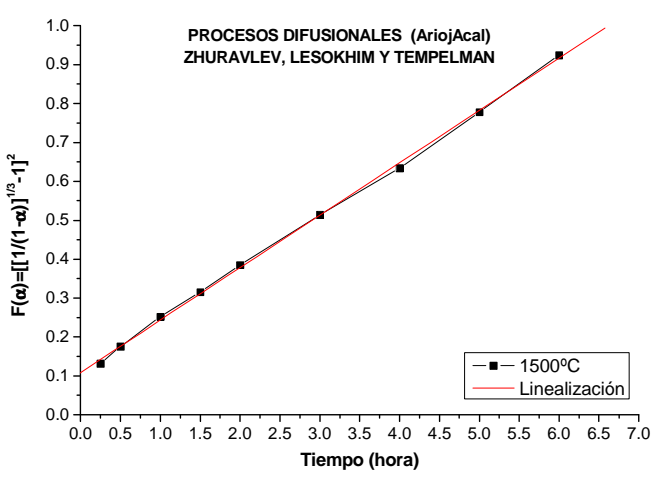

(d)

(e)

Figura 6.4. Modelo de Zhuravlev, Lesokhim y Tempelman (difusional) para la mezcla

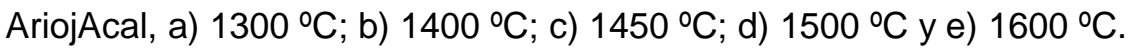


Los primeros y últimos puntos de conversión a algunas temperaturas (bajos y altos tiempos) no se consideraron debido a las oscilaciones presentadas en el análisis por cuantificación de mullita por técnica de DRX, mayoritariamente en el caso de la formación de mullita primaria generada por la arcilla La Rioja, y como ya se mencionó el ajuste de los modelos matemáticos en zonas extremas de conversión poseen en general desviaciones para cualquier sistema al que se apliquen.

Si bien la mullita primaria se forma a temperaturas inferiores a las de este estudio [Cáceres y Pereira, 1977; Liu et al.,1994; Rossini et al., 1970] y por ende los núcleos de mullita generada dentro de las partículas de arcilla ya existen es necesario que los nuevos núcleos mullita secundaria que se formarán a temperaturas superiores (este estudio) se depositen sobre la primaria y crezca sobre ellaoó que se formen nuevos en regiones distintas a los primeros.

Este mecanismo de por si justifica el ajuste del modelo de Hulbert desde el punto de vista del crecimiento cristalino, lo que no impide como ya se mencionó que en otros puntos de la masa en reacción donde hay alta concentración de alúmina se formen nuevos núcleos de mullita ya como secundaria, validando aquí también el modelo desde el punto de vista de la nucleación.

Por otro lado, si bien nuestro sistema posee una estequiometría más refractaria que la de la arcilla sola, se visualizó también aquí la presencia de fase vítrea (amorfa) aunque en mucha menor cantidad y de mayor viscosidad que en la arcilla sola, la cual actúa como barrera para el transporte de los nuevos gérmenes de mullita hacia los centros de crecimiento, sean estos de mullita primaria generada por la arcilla, como así también los núcleos supercríticos de mullita secundaria neta. [De Keyser, 1964; Pole y Taylor, 1935; Stanley y Brindley, 1969].

En las tablas 6.1 y 6.2 se muestran los valores del coeficiente exponencial $(\mathrm{m})$ y la constante cinética de velocidad de reacción (k) para cada temperatura y modelo. 
Tabla 6.1. Valores obtenidos de "m" (coeficiente exponencial) y "k" (constante cinética de velocidad de reacción) para cada temperatura. Modelo de Hulbert (nucleación y crecimiento) para la mezcla AriojAcal.

\begin{tabular}{|c|c|c|c|}
\hline Temperatura ( $\left.{ }^{\circ} \mathrm{C}\right)$ & "m" & In $\mathbf{k}$ & $\mathbf{k}\left(\mathbf{h}^{-1}\right)$ \\
\hline $\mathbf{1 4 0 0}$ & 0.22 & -1.81 & 0.16 \\
\hline $\mathbf{1 4 5 0}$ & 0.26 & -0.64 & 0.53 \\
\hline $\mathbf{1 5 0 0}$ & 0.26 & 0.78 & 2.18 \\
\hline $\mathbf{1 6 0 0}$ & 0.24 & 3.50 & 33.13 \\
\hline
\end{tabular}

Tabla 6.2. Valores obtenidos de "k" (constante cinética de velocidad de reacción) para cada temperatura. Modelo de Zhuravlev, Lesokhim y Tempelman (difusional) para la mezcla AriojAcal.

\begin{tabular}{|c|c|}
\hline Temperatura $\left({ }^{\circ} \mathrm{C}\right)$ & $\mathbf{k}\left(\mathbf{h}^{-1}\right)$ \\
\hline $\mathbf{1 4 0 0}$ & 0.02 \\
\hline $\mathbf{1 4 5 0}$ & 0.05 \\
\hline $\mathbf{1 5 0 0}$ & 0.13 \\
\hline $\mathbf{1 6 0 0}$ & 1.16 \\
\hline
\end{tabular}

Los valores de la constante cinética de la velocidad de reacción $(k)$ obtenidos en las figuras 6.3 y 6.4 , y mostrados en las tablas 6.1 y 6.2, como parte de las ordenadas al origen o de las pendientes según el caso, para cada temperatura, se utilizaron en la ecuación de Arrhenius para calcular la energía de activación del cada sistema, [Aglietti et al., 2000; Gatti et al., 2000; Menchi y Scian, 2005], de la siguiente forma:

$$
k=A e^{-E / R T}
$$

dónde:

$A=$ factor preexponencial o de colisión.

$\mathrm{E}=$ energía de activación molar.

$\mathrm{R}=$ constante universal de los gases.

$\mathrm{T}=$ temperatura absoluta.

$\mathrm{k}=$ constante de velocidad ya calculada. 
Aplicando In en ambos lados, en la ecuación anterior, tenemos:

$$
\ln k=\ln A-\frac{E}{R T}
$$

y graficando In k vs $1 / T$, se obtiene $E$ de la pendiente y $A$ del valor de la ordenada al origen. La figura 6.5 muestra la representación para el modelo por nucleación y crecimiento y la figura 6.6 representa el modelo difusional.

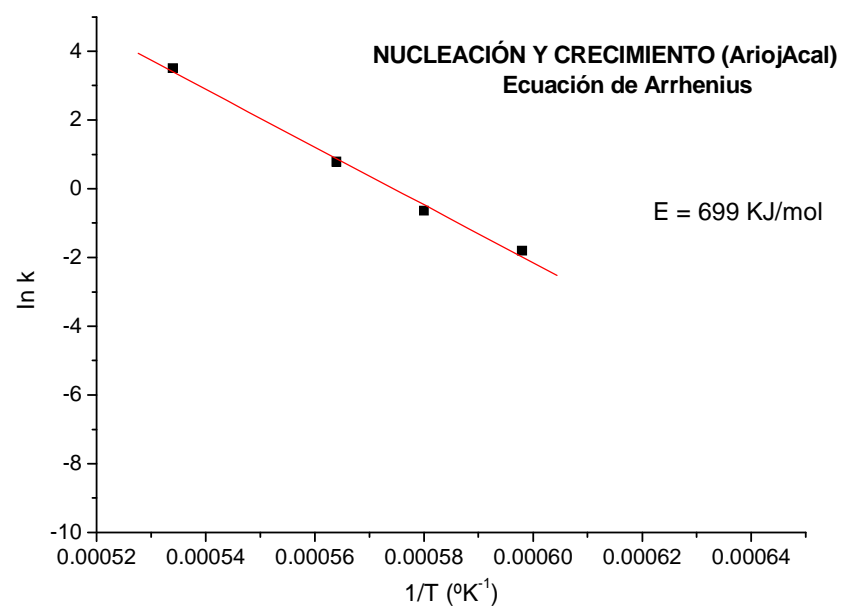

Figura 6.5. Representación de la Ec. de Arrhenius para las temperaturas y K calculadas con el modelo de Hulbert. Para la mezcla AriojAcal.

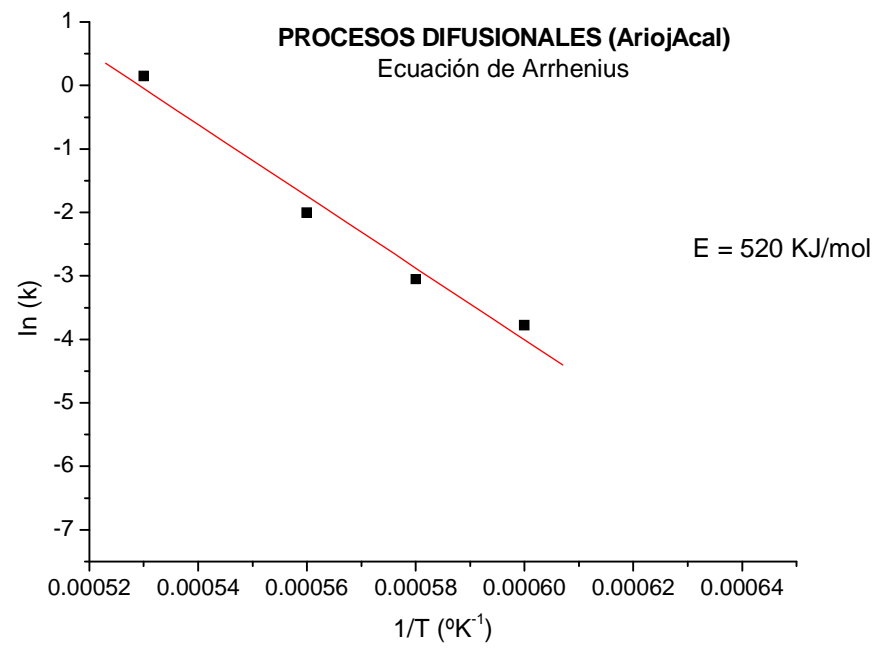

Figura 6.6. Representación de la Ec. de Arrhenius para las temperaturas y K calculadas con el modelo de Zhuravlev, Lesokhim y Tempelman. Para la mezcla AriojAcal. 
De las figuras 6.5 y 6.6, se obtuvieron los valores de energía de activación, encontrando para nucleación y crecimiento un valor de $699 \mathrm{KJ} / \mathrm{mol}$ y para el modelo difusional de Zhuravlev, Lesokhim y Tempelman fue de $520 \mathrm{KJ} / \mathrm{mol}$, estos son valores consistentes para reacciones que ocurren en el rango de temperaturas estudiadas.

Los dos modelos que ajustaron poseen dos particularidades diferentes desde el momento de su definición. El de difusión habla de la resistencia de transportar materiales hacia los centros de nucleación y crecimiento; y el de nucleación y crecimiento habla de la dificultad de que crezca mullita (aun habiendo ya núcleos) debido a que se van disolviendo y cristalizando simultáneamente (disolución precipitación) en parte en la masa vítrea. [Furusato y Mitsudomo, 1987; Liu et al.,1994; McGEE y Dodd, 1961].

La diferencia de las energías de activación observadas en ambos modelos mostró claramente que el proceso de transporte (difusión) ofrece una menor resistencia (menor energía de activación) que el de crecimiento ya que este último como ya se mencionó ni bien se acopla el material a un núcleo formado, parte se redisuelve, siendo más difícil llegar al objetivo de una conversión sin mayor resistencia.

Esto muestra que si bien hay dos mecanismos trabajando en forma simultánea el que ofrece menor resistencia es el de difusión.

De los resultados obtenidos en el estudio cinético para la mullita neta (AriojAcal), se determinó que $1550{ }^{\circ} \mathrm{C}$ durante 4 horas es una temper atura y tiempo apropiado para la formación máxima de mullita, por lo tanto las probetas elaboradas por tres métodos de conformado (prensado, colado y extrusión) se calcinarán a esa temperatura y tiempo.

\subsection{CONCLUSIONES PARCIALES}

En este trabajo no se evaluaron los mecanismos de cinética de reacción para la arcilla sola (Arioja). Se realizó solo a la mezcla con estequiometría $3 \mathrm{Al}_{2} \mathrm{O}_{3} \cdot 2 \mathrm{SiO}_{2}$ (AriojAcal), debido a que la mullitización primaria (arcilla) se generó completamente a $1300{ }^{\circ} \mathrm{C}$ durante las 3 primeras horas, por lo que el análisis encarado consiste prácticamente en la producción de mullita total y secundaria. 
Se tomaron los valores de las curvas conversión tiempo a diferentes temperaturas $\left(1300,1400,1450,1500\right.$, y $\left.1600^{\circ} \mathrm{C}\right)$ y se probaron los diferentes modelos cinéticos: control químico; nucleación y crecimiento (Hulbert) y procesos difusionales (Jander, Kroger -- Ziegler, Zhuravlev -Lesokhim - Tempelman, Ginstling - Brounshtein y Dunwald - Wagner).

Evaluados los modelos antes presentados ajustaron a rectas casi todas las temperaturas, excepto la de $1300^{\circ} \mathrm{C}$ a los modelos de Hulbert (nucleación y crecimiento) y Zhuravlev, Lesokhim yTempelman (control difusional). Por lo tanto no se consideró esta temperatura para incluirla en la evaluación cinética de modelados matemáticos.

Los modelos cinéticos funcionan realmente en valores de conversiones no extremas, por lo tanto no se consideraron para este estudio los primeros y últimos puntos de conversión a algunas temperaturas (bajos y altos tiempos) debido a las oscilaciones presentadas en el análisis por cuantificación de mullita por técnica de DRX.

$>\quad$ Los valores de energía de activación en el sistema mezcla AriojAcal, se obtuvieron por el modelo de nucleación y crecimiento con un valor de $699 \mathrm{KJ} / \mathrm{mol}$ y por el modelo difusional de Zhuravlev, Lesokhim y Tempelman fue de 520 $\mathrm{KJ} / \mathrm{mol}$, estos son valores consistentes para reacciones que ocurren en el rango de temperaturas estudiadas.

La diferencia de las energías de activación observadas en ambos modelos mostró que si bien hay dos mecanismos trabajando en forma simultánea el que ofrece menor resistencia es el de difusión, debido a que existen fenómenos de solubilización - cristalización de mullita ocurrentes en el tiempo.

\subsection{BIBLIOGRAFIA}

Aglietti E.F., Scian AN., Gatti W., Estudio de la cinetica de reacción de formación de Mullita, Actas del $X$ congreso Argentino e Internacional de Cerámica, Vidrio y Refractarios, San Martín - Buenos Aires - Argentina., pp. 263-270 (2000). 
$>$ Avrami M., Kinetics of Phase Change. I. General Theory. Journal of Chemical Physics 7 (12), pp. $1103-1112$ (1939).

$>$ Avrami M., Kinetics of Phase Change. II. Transformation-Time Relations for Random Distribution of Nuclei. Journal of Chemical Physics. 8 (2), pp. 212-224 (1940).

> Avrami M., Kinetics of Phase Change. III. Granulation, Phase Change, and Microstructure". Journal of Chemical Physics. 9 (2), pp. 177-184 (1941).

> Cáceres Carmen V., Pereira E., Formación de mullita por procesos no difusionales en el sistema bauxita - arcilla caolinítica, I estudio cinético, Rev. Latinoam. Ing. Quim. Apl. 7, pp. 119-133 (1977).

$>\quad$ Christian J., Phase transformations in physical metallurgy, R. Cahn, Ed. North Holland publishing Co., Amsterdam. (1965b).

$>$ Christian J., The theory of transformations in metals and alloys, Pergamon Press, N.Y., pp. 471-95 (1965a).

$>$ De Keyser W.L., Contributiou a Pétude du systeme Silice - Alumine. Bull Soc. Franc. Ceram. Janv. 62, pp. 27-33 (1964).

$>$ Dunwald H., y Wagner C., Journal of Physical Chemistry. (Leipzing). B24 (1), pp. 53-58 (1934).

$>$ Erofeev B.V., Generalized equation of chemical kinetics and its application in reaction involving solids, Compt. Rend. Acad. Sci. USSR, 52, pp.511-514 (1946).

$>$ Furusato I. y Mitsudomo T., Synthesis and Properties of Mullite from High Purity Kaolin, presented at the First International Workshop on Mullite, Tokyo, Japan, (1987).

$>$ Gatti W., Aglietti E.F., y Scian A.N., Estudio de la cinética de reacción de formación de mullita, Actas del $X$ Congreso Argentino e Internacional de Cerámica, Vidrio y Refractarios. V Congreso de Cerámica del Mercosur, Argentina, pp. 263-270 (2000).

$>\quad$ Ginstling A.M., Brounshtein B.I., Concemingthe Diffusion Kinetics of Reaction in Spherical Particles. Journal of Applied Chemistry. USSR., 23 (12), pp. 1327-38 (1950).

$>$ Hulbert S., Models of solid-state reactions in powder compacts: A review, Journal 
of the British Ceramic Society. 6 (1), pp. 11-20 (1969).

$>\quad$ Jander W., Reactions in the Solid State at High Temperature: 1, Z. Anorg. Allgem. Chem. 163 (1-2), pp. 1-30 (1927).

$>\quad$ Kingery W.D., Browen H. K., y Uhlmann D.R., Introduction to Ceramics, Jhon Wiley \& Sons, N.Y. 2da edición. 329 (1976).

$>$ Kroger C., y Ziegler G., Über die Geschwindigkeiten der zur Glasschmelze führender Reaktionen. II. Die Umsetzung von Natriumdisilikat mit Soda und Quarz mit Kalkstein. Glasstech. Ber., 26 (11), pp. 346-53 (1953).

> Kroger C., y Ziegler G., Über die Geschwindigkeiten der zur Glasschmelze führender Reaktionen. III. Reaktionsgeschwindigkeiten in quaternären System Na2O- CaO- SiO2- CO2. Glasstech. Ber., 27 (6), pp. 199-212 (1954).

$>\quad$ Le Bail A., Modelling the silica glass structure by the Rietveld method. Journal of Non-Crystalline Solids 183, pp. 39-42 (1995).

$>\quad$ Liu Kuo-Chung., Gareth Thornas., Caballero Angel., Moya Jose S, y De Aza Salvador., Time-Temperature-Transformation Curves for Kaolinite-- $\alpha$ Alúmina. Journal of the American Ceramic Society. 77 (6), pp. 1545 -1552 (1994).

> McGEE Thomas y Dodd M., Mechanism of secondary expansión of high alúmina refractaries containing calcined bauxite. Journal of the American Ceramic Society. 44 (6), pp. 277-283 (1961).

> Menchi A.M., y Scian A.N., Obtención de mullita nanoporosa por método sol-gel. Mecanismo de reacción, cinética de la reacción y control de tamaño de poro, Actas del Congreso Binacional SAM-CONAMET, Trabajo 304, Tópico 14, Argentina, pp. 1-6 (2005).

> Pole G.R., y Taylor N.W., Kinetics of Solid-Phase Reactions of Certain Carbonates with Mullite, Silica, and Alúmina, Journal of the American Ceramics Society. 18 (11), pp. 325-337 (1935).

$>$ Rietveld H. M., A profile refinement method for nuclear and magnetic structures, Journal of Applied Crystallography. 2, pp. 65-71 (1969).

$>$ Rosenstock Marta R., Pereira E., Cinética de la formación de mullita con mineralizadores. Lati. Am. Ing. Quim. y Quim. Apl 3, pp. 51-63 (1973).

$>$ Rossini Angel R., Cohen Arazi Salomón., Krenkel Teodoro G., Mullitización de mezclas de arcilla caolinítica e hidróxido de aluminio. Boletin de la sociedad 
Española de Cerámica, 9 (5), pp. 579-591 (1970).

$>\quad$ Serin B., y Ellickson R., Journal of Chemical Physics. 9, pp. $742-47$ (1941).

> Sharp J.H., Brindley G.W., y Narahari Achar B.N., Numerical Data for Some Commonly Used Solid State Reaction Equations, Journal of the American Ceramic Society. 49 (7), pp. 379-382 (1966).

$>$ Stanley W.G. y Brindley C.W. Development of noncrystalline material in subsolidus reactious between silica an alúmina. Journal of the American Ceramics Society. 52 (11), pp. 616-619 (1969).

> Testa R.H., Pereira E., y Quiroz R.W., Mullitization des bauxites. Materials Science and Engineering. 7, pp. 134-140 (1971b).

$>$ Zhuravlev V.F., Lesokhim I.G. y Tempellman R.G., Journal of Applied Chemistry USSR, 21 (9), pp. 887-902 (1948). 


\section{CAPITULO 7 CONFORMADO, TRATAMIENTO TÉRMICO Y CARACTERIZACIÓN DE MULLITA ESTEQUIOMÉTRICA \\ 3-2 $\left(3 \mathrm{Al}_{2} \mathrm{O}_{3} \cdot 2 \mathrm{SiO}_{2}\right)$}

$=0$.

Una de las principales características a tener en cuenta en la elaboración de un material cerámico, es el conformado de piezas, debido a que una excesiva o poca cantidad de agua utilizada en el conformado, podrá afectar la forma, dimensiones y propiedades del material elaborado independientemente del método a utilizar, ya sea prensado, colado o extrudado, además que dará lugar a distinto tiempo de secado y se modificarían las exigencias de la operación utilizada. [Mazdiyasni y Brown, 1972; Schneider 2008; Somiya y Hirata., 1991].

Como ejemplo de orientación, conocer el índice de plasticidad y sus límites (plástico y líquido), indicaría que por debajo del límite plástico se encuentra el porcentaje de humedad para el conformado por prensado; para elaborar probetas por el método de colado el porcentaje de humedad estaría por encima de límite líquido y si se encuentra en un rango entre el límite líquido y plástico correspondería al porcentaje de humedad para el conformado por extrusión, [Berna et al., 2003; Modesto y Bernardin, 2008; Worral, 1986].

Por lo general el material utilizado para conformar una pieza consiste de un polvo con agua y alguna combinación de aditivos que servirán para proporcionar la humedad 
correspondiente de acuerdo al tipo de conformado. Los aditivos deben ser compatibles con la química del material, y que se puedan eliminar durante la cocción a temperaturas inferiores a la de sinterización del material a obtener para que éste no interfiera con los resultados finales. Como se mencionó los distintos componentes de partida de un material (polvos, agua y aditivos) a procesar se determinarán obteniendo la consistencia adecuada para cada tipo de técnica de conformado (prensado, extrusión o colado).

En el presente trabajo se ha venido desarrollando el proceso de obtención y selección de materias primas para la elaboración de mullita de alta calidad utilizando mezclas con estequiometría 3-2 $\left(3 \mathrm{Al}_{2} \mathrm{O}_{3} \cdot 2 \mathrm{SiO}_{2}\right)$ a partir de las mejores arcillas preseleccionadas (Tincar Súper y La Rioja) y alúminas (calcinada e hidratada), las cuales se determinaron en el capítulo 4, (tabla 4.8). Respecto a la temperatura y tiempo de tratamiento a seguir en este estudio, éstos se establecieron en el capítulo 6, donde se concluyó que las probetas elaboradas por los tres métodos de conformado (prensado, colado y extrusión) se calcinarán a $1550 \stackrel{\circ}{\mathrm{C}}$ durante 4 horas, con una velocidad de calentamiento de $5{ }^{\circ} \mathrm{C}$ por minuto.

A las mezclas estequiométricas 3-2 de arcilla Tincar Súper más alúmina calcinada (AtinAcal) y arcilla La Rioja más alúmina calcinada (AriojAcal) se les realizó el ensayo de Índice de plasticidad, límite líquido y plástico siguiendo el procedimiento correspondiente (capitulo 3.4)

Tabla 7.1. Índice de plasticidad, límite líquido y plástico de las mezclas 3-2 (AtinAcal y AriojAcal).

\begin{tabular}{|c|c|c|c|}
\hline $\begin{array}{c}\text { Mezclas con estequiometría 3-2 } \\
\left(3 \mathrm{Al}_{2} \mathrm{O}_{3}-2 \mathrm{SiO}_{2}\right)\end{array}$ & $\begin{array}{c}\text { Límite } \\
\text { Líquido }\end{array}$ & $\begin{array}{c}\text { Límite } \\
\text { Plástico }\end{array}$ & $\begin{array}{c}\text { Índice de } \\
\text { Plasticidad }\end{array}$ \\
\hline AtinAcal & 22.1 & 20.5 & 1.6 \\
\hline AriojAcal & 23.3 & 22.8 & 0.5 \\
\hline
\end{tabular}

Se puede observar en la tabla 7.1 que la mezcla AtinAcal presenta un índice de plasticidad tres veces mayor con respecto a la mezcla AriojAcal, esto debido a que la arcilla La Rioja presenta una baja plasticidad respecto a la arcilla Tincar Súper, se observa a demás para ambos casos el índice es muy bajo, indicando esto que existe un rango de humedad muy estrecho para poder trabajar por extrudado, (tabla 4.3). 


\subsection{CONFORMADO POR EL MÉTODO DE PRENSADO UNIAXIAL}

El método de prensado consiste en la compactación y conformado simultáneos de un polvo cerámico o material granular. Se premezclan los polvos con ligantes o aditivos en proporciones adecuadas, con una cantidad apropiada de humedad, posteriormente se introduce el material en un molde rígido, aplicando una presión en una sola dirección (prensado uniaxial) por medio de un émbolo, o un pistón o un punzón rígido.

Las etapas generales para el conformado de piezas (probetas) por el método de prensado uniaxial, son mezclado; llenado de molde, compactación (conformado de la pieza), y extracción de la probeta del molde, (figura 7.1).
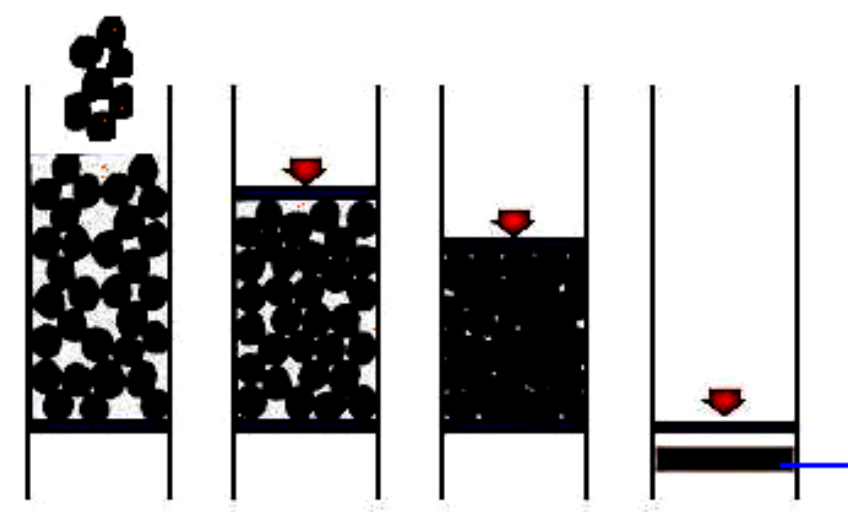

\section{PROBETA}

Figura 7.1 Representación esquemática del conformado por prensado uniaxial.

Durante el proceso de prensado uniaxial ocurre una deformación elástica y esta energía permanece almacenada hasta la extracción de la pieza, al mismo tiempo ocurre una deformación plástica cuyo efecto produce un incremento del área de contacto entre las partículas, (figura 7.1). Los polvos cerámicos deben tener una distribución granulométrica y de tamaño de partícula tal, que den lugar al menor número posible de huecos entre ellos después de la compactación mediante prensado, si es que se desea máxima densidad, [Salvado, 1964; Vercauteren et al., 1998].

Para conocer cuáles son las presiones más adecuadas para el desarrollo de este trabajo de tesis (obtención tecnológica de mullita), se elaboró un estudio aplicando diferentes presiones entre 10 a $250 \mathrm{MPa}$. La mezcla estequiométrica 3-2 de arcilla Tincar Súper más alúmina calcinada (AtinAcal), se compactó por prensado uniaxial con una humedad 
de $12.4 \%$ utilizando un compuesto orgánico (compuesto de alcohol cetilico, hidroxietil celulosa y cloruro de cetil amonio) como ayudante de prensado.

Se prepararon por esta vía probetas prismáticas de aproximadamente, $5.0 \times 0.8 \times 0.8$ $\mathrm{cm}^{3}$, a distintas presiones $(10,20,30,40,60,80,100,150,200$ y $250 \mathrm{MPa})$ en una prensa mecánica uniaxial. A cada probeta se le midió el valor de densidad en verde con el objetivo construir la curva presión vs densidad, tal como se observa en la figura 7.2.

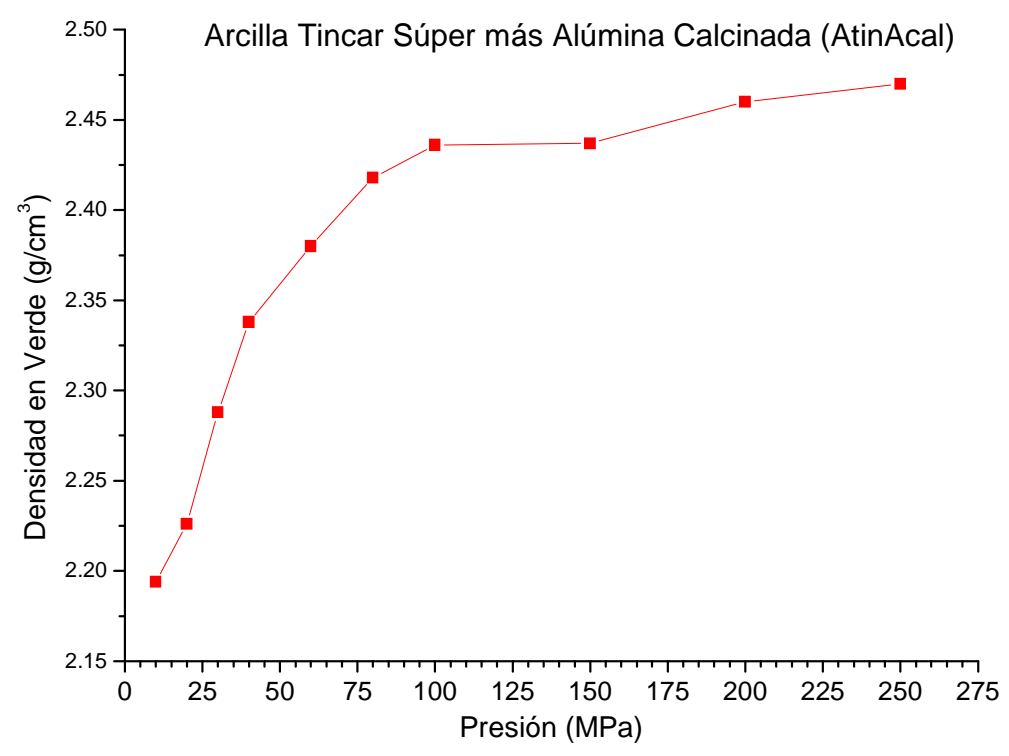

Figura 7.2. Curva de densidad en verde con respecto a la presión de prensado correspondiente a la mezcla estequiométrica 3-2 (arcilla Tincar Súper más alúmina calcinada).

Se puede observar en figura 7.2 que no existen grandes diferencian de densidad en verde por encima de los $100 \mathrm{MPa}$, debido a que las materias primas utilizadas no poseen alta plasticidad, y a medida que se incrementa la presión por encima de ese valor el aumento de densidad es mínimo, no siendo tan significativa en función del gasto de energía requerido. Esto no quiere decir que otros sistemas no requieran ser trabajados a presiones mayores.

Teniendo en cuenta los valores de presión con los que trabaja la mayoría de las industrias de materiales refractarios (entre 40 a $70 \mathrm{MPa}$ ), el desarrollo principal de este trabajo se realizó utilizando valores menores, cercanos y superiores a los que usa la industria, para luego poder comparar los resultados obtenidos (propiedades) con los 
adquiridos por otros métodos (colado y extrusión). De acuerdo a lo mencionado se tomaron tres presiones para continuar con este trabajo, las cuales fueron: 10, 40 y 100 MPa.

Por lo antedicho, no tiene sentido trabajar con presiones mayores a $100 \mathrm{MPa}$ ya que se saldrían de los valores normales de la industria para este tipo de materiales y aunque al aumentar la presión se obtendrían algunas densidades un poco mayores estas no justifican lo invertido como aumento de presión.

\subsection{CONFORMADO POR EL METODO DE COLADO}

La obtención de un cerámico uniforme y libre de defectos solo es posible si se controlan todas las etapas que intervienen en su fabricación. El colado en moldes de yeso es un método de conformado tradicional de la industria cerámica para la producción de piezas con formas complejas. Consiste en el vaciado de una suspensión acuosa en un molde permeable de yeso donde por capilaridad se absorbe buena parte del agua, la suspensión se consolida y cuando ha solidificado lo suficiente como para mantener la forma, se retira del molde, [Gutiérrez et al., 2000; Moreno, 2000; Temoche et al., 2003]. Posteriormente se seca y luego se sinteriza por calcinación.

Una barbotina cerámica es una suspensión que se prepara dispersando el material cerámico o su precursor en forma de polvo fino en un líquido adecuado que comúnmente es agua. Usualmente se requiere adicionar a la barbotina un dispersante para asegurar su estabilidad, [Cesarano et al., 1988a;1988b]. Para lograr una colada adecuada se requiere que la barbotina se encuentre en grado de defloculación óptimo que corresponde a la mínima viscosidad obtenida por adición de un dispersante, [Ferrari et al., 2000; Moreno et al., 1985; Moya et al., 1980; Tsetsekou et al., 2001].

Se efectuaron una serie de ensayos específicos para cada caso (mezcla estequiométrica 3-2 de arcilla - alúmina) y se verificó que satisfagan todas las especificaciones requeridas para el desarrollo del proceso de colado.

Para realizar el ensayo se utilizó un viscosímetro Brookfield LVT (figura 7.3), el principio de medida se basa en la rotación de un rotor cilíndrico que está sumergido en el fluido a medir y se determina el esfuerzo de torsión para mantener una velocidad de giro especificada. 


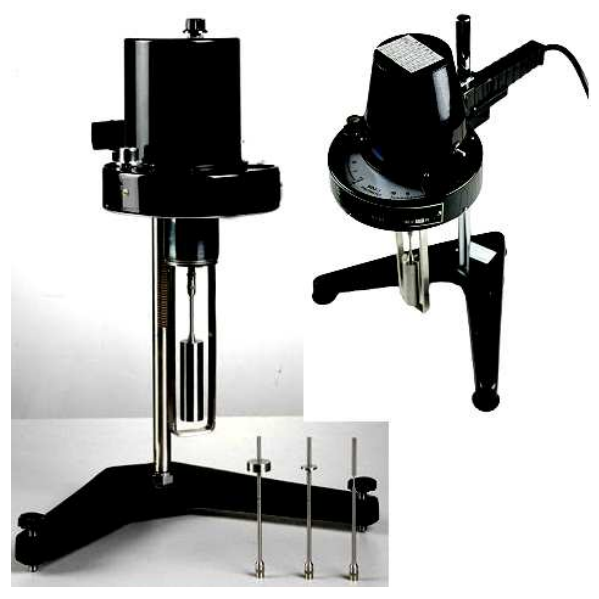

Figura 7.3. Viscosímetro Brookfield LVT.

Las suspensiones acuosas (78 y $80 \% \mathrm{p} / \mathrm{p}$ ) de las mezclas estequiométricas 3-2 de arcilla Tincar Súper más alúmina calcinada (AtinAcal) y arcilla La Rioja más alúmina calcinada (AriojAcal) respectivamente, se prepararon con contenido variable de dispersante (solución comercial de poliacrilato de amonio al $10 \%,\left(\mathrm{NH}_{4} \mathrm{PA}\right.$ - Dolapix)) a pH 9. Las dispersiones de las suspensiones se realizaron por aplicación de ultrasonido. Las mezclas (AtinAcal y AriojAcal) fueron sometidas a ensayo determinando así las curvas de viscosidad vs adición de dispersante (poliacrilato de amonio diluido al $10 \%$ ). Para ello se utilizó el viscosímetro Brookfield LVT, a velocidad de rotación fija, obteniendo así ciertos puntos de referencia; incluyendo el punto inicial de fluidez, punto inicial de viscosidad mínima, punto final de viscosidad mínima (donde empieza a aumentar) y punto medio de viscosidad entre las dos anteriores.

En la figura 7.4 se observan las variaciones de la viscosidad en función del contenido de dispersante agregado (\% respecto al sólido) para las mezclas estudiadas (AtinAcal y AriojAcal), observándose que a medida que la concentración del dispersante aumenta los valores de viscosidad decrecen hasta llegar a un mínimo. Se considera que la concentración de dispersante que corresponde al mínimo de viscosidad es la óptima. Adiciones mayores a la concentración óptima provocan un aumento leve de los valores de viscosidad. 


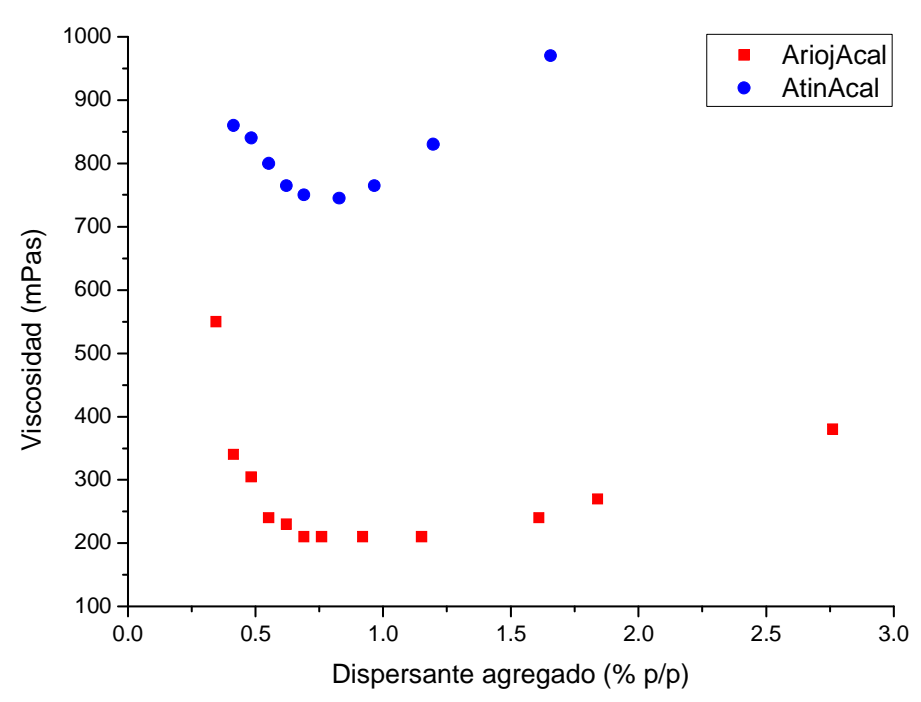

Figura 7.4. Viscosidad de la suspensión en función del contenido de dispersante (\% respecto del sólido), para las mezclas AtinAcal y AriojAcal.

La concentración óptima de dispersante varía entre 0.5 y $1.15 \%$ respecto del peso de sólido para las mezclas estudiadas. Con estas concentraciones se alcanza el máximo grado de dispersión de las partículas.

En la figura 7.4 se puede observar que la curva correspondiente a la mezcla AtinAcal presenta un valor mayor de viscosidad para prácticamente la misma cantidad de agua, esto debido al tamaño menor de partícula de la arcilla Tincar Súper con respecto a La Rioja, por lo que a aproximadamente igual concentración existirá un número mayor de partículas, las cuales al estar próximas interactuarán para generar una mayor viscosidad de la suspensión.

Posteriormente se realizaron suspensiones acuosas de las mezclas AtinAcal y AriojAcal que poseían un 78 y $80 \%$ p/p del sólido en agua destilada respectivamente, utilizando como dispersante poliacrilato de amonio diluido al $10 \%$. Se vertieron las mismas en moldes de yeso (tamaño de las probetas $6.0 \times 0.80 \times 0.80 \mathrm{~cm}^{3}$ ), dejándolas 1 y 3 días en el molde de yeso poroso que produce la eliminación del agua a través de sus poros; esto hace que la pasta se consolide y contraiga, pudiéndose a continuación extraer la pieza del molde, figura 7.5. 

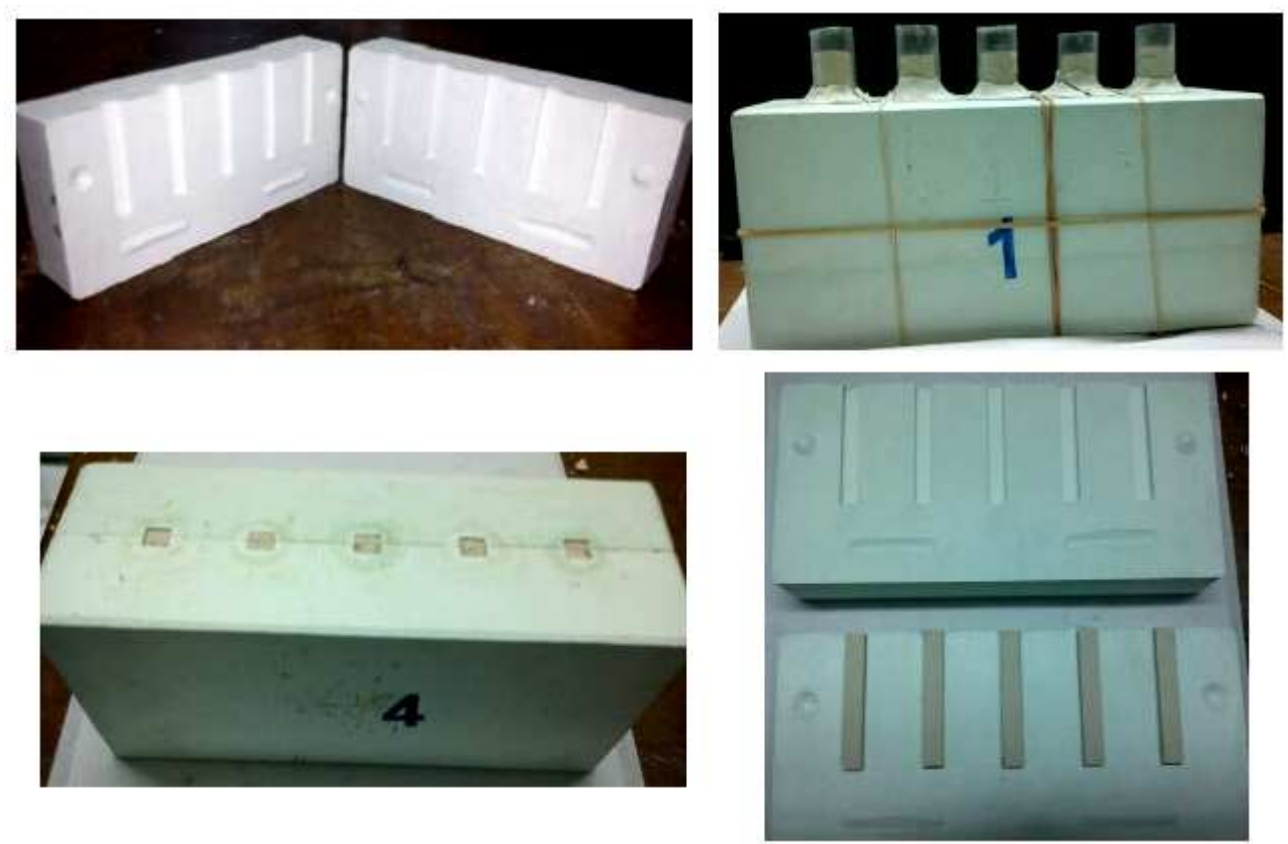

Figura 7.5. Procedimiento del conformado por el método de colado en moldes de yeso.

Las piezas extraídas se secaron a $110^{\circ} \mathrm{C}$ durante un día, luego se calcinaron a $1500{ }^{\circ} \mathrm{C}$ por 3 horas, con una rampa de calentamiento de $5^{\circ} \mathrm{C} / \mathrm{min}$. Las probetas obtenidas se caracterizaron a través de los valores de densidad de las piezas (método de Arquímedes), los resultados se muestran en la tabla 7.2.

Tabla 7.2. Densidad de las piezas (Arquímedes) de las mezclas AtinAcal y AriojAcal elaboradas por el método de colado dejándolas 1 y 3 días, calcinadas a $1500{ }^{\circ} \mathrm{C}$ durante 3 horas.

\begin{tabular}{|c|c|c|}
\hline $\begin{array}{c}\text { Mezclas con estequiometría } \\
3-2\left(3 \mathrm{Al}_{2} \mathrm{O}_{3} \cdot 2 \mathrm{SiO}_{2}\right)\end{array}$ & $\begin{array}{c}\text { Densidad de la pieza } \\
\text { (Arquímedes) } \\
\left(\mathrm{gr} / \mathrm{cm}^{3}\right) \\
1 \mathrm{día}\end{array}$ & $\begin{array}{c}\text { Densidad de la pieza } \\
\text { (Arquímedes) } \\
\text { (gr/ } \mathrm{cm}^{3} \text { ) } \\
3 \text { días }\end{array}$ \\
\hline AtinAcal & 1.94 & 1.95 \\
\hline AriojAcal & 1.98 & 1.98 \\
\hline
\end{tabular}

En la tabla 7.2, se puede observar que los valores de densidad para las dos mezclas no variaron al aumentar los días de secado en el molde, por lo tanto el conformado de las probetas por el método de colado se hicieron con un día de secado en el molde. 
Las mezclas estequiométricas 3-2 realizadas con arcilla (Tincar Súper y La Rioja) más alúmina hidratada, presentaron algunos problema al extraer las piezas del molde: formaban una capa fina en la superficie fácil de desmenuzarse, se pegaban al molde o se partían; esto debido al tamaño de la alúmina hidratada pasante malla 50 (300 $\mu \mathrm{m})$ y retenido el $98 \%$ en malla $200(75 \mu \mathrm{m})$.

Por lo tanto el agua necesaria para colar formaba una barbotina que al entrar en contacto con el molde se segregaba dejando la alúmina hidratada (gruesa) en el centro del cuerpo de la pieza, mientras que las partículas de la arcilla (finas) migraban hacia las paredes del molde junto con el agua.

Esta situación no permitió obtener piezas homogéneas aún con distintos tenores de agua, tiempos de permanencia en el molde y dispersantes, por tal motivo no se pudieron realizar probetas con alúmina hidratada por este método.

Tal vez se hubieran podido obtener probetas, modificando el tamaño de alúmina hidratada o trabajando con una distribución de tamaños de partículas, pero los resultados ya no serían comparativos con el método de prensado.

\subsection{CONFORMADO POR EL METODO DE EXTRUSIÓN}

Para realizar el conformado de precursores de piezas cerámicas por el método de extrusión, se suelen utilizar mezclas plásticas o semiplásticas con cierto contenido de arcillas, con adición de agua y pequeñas cantidades de aditivos lubricantes. En sistemas que no contienen arcilla, tales como óxidos puros, carburos y nitruros, es necesario añadir, en lugar de la arcilla, un material orgánico, mezclado con agua o con otro fluido, para proporcionar la plasticidad. Se requieren cantidades mayores o cercanas al $10 \%$ de aditivo orgánico para lograr la plasticidad adecuada para el conformado por extrusión, [Benbow et al., 1989].

En el caso de los sistemas arcilla - agua, durante el secado tiene lugar una contracción sustancial, que aumenta el riesgo de aparición de grietas. En el caso de sistemas con aditivos orgánicos, el problema mayor es la obtención de piezas en verde libre de defectos, y también la eliminación del material orgánico por calcinación, debido a que una eliminación demasiado rápida da lugar a agrietamientos, hinchamiento o distorsión geométrica, [Robinson, 1978].

La extrusión es una técnica de conformado, la cual consiste en producir una masa constituida por: polvo cerámico o precursor (material a estudio), mas líquido y aditivo 
(ligantes, plastificantes, dispersantes, defloculantes, lubricantes o surfactantes); posteriormente se amasa (en amasadora o mezcladora) dicha premezcla proporcionando a la misma una buena homogeneidad, maximizando la plasticidad y eliminando aire por el efecto de apriete de la pasta, [Benbow y Bridgwater, 1987].

Luego del proceso de mezclado - amasado, la pasta es introducida en una máquina (extrusora) consistente en una precámara de mezcla - empuje que conduce la masa hacía unas rejillas por las que pasa a una cámara de vacío, donde se produce la eliminación de burbujas de aire y aire disuelto en agua y en parte se elimina agua de humedad siendo luego esta pasta empujada por un tornillo sin fin hacia la boquilla de salida, en donde sufre durante el trayecto grandes esfuerzos de compresión y fricción, saliendo por la misma con el formato de diseño adecuado, [Benbow y Bridgwater, 1993]. De allí que la plasticidad es una característica importante que deben cumplir las pastas sometidas a este tipo de conformado. No está de más decir que el conformado por extrusión es una operación unitaria para ser utilizada en continuo.

Una de las variables más importantes a considerar es el porcentaje de humedad, ya que cuanto menos plástica sea la arcilla, mayor sensibilidad presentará a estos cambios de humedad. Una variación de uno, dos o tres por ciento de humedad en una arcilla plástica puede pasar desapercibida, en cambio, en una arcilla magra dará lugar a un cambio total de la consistencia y de las condiciones de flujo a través de la máquina extrusora. Por eso es importante realizar el ensayo de índice de plasticidad, límite líquido y plástico ya que para el conformado de probetas por el método de extrusión el límite plástico representaría la humedad mínima que la arcilla debería contener para poder ser moldeada y el límite líquido correspondería a la máxima humedad que la arcilla podría contener siendo todavía moldeable. Por encima de dicho porcentaje de humedad, la cohesión interna o atracción entre las partículas arcillosas, sería tan baja que la pieza recién moldeada no aguantaría su propio peso. La pieza extruida debe tener una resistencia adecuada para soportar su manejo sin desplomarse o deformarse.

Algunos de los defectos que pueden aparecer en el proceso de extrusión son [Benbow y Bridgwater, 1987; 1993]:

- Alabeo, distorsión, deformación: pueden ocurrir durante el secado o la cocción debido a la existencia de variaciones de densidad en la pieza cruda o durante la extrusión a causa de que el alineamiento o el diseño de la boquilla no son los adecuados, a una velocidad excesiva en el secado y/o calcinación. 
- Laminación: las laminaciones son grietas que, generalmente, forman un modelo o una orientación.

- El desgarramiento: consiste en la aparición de grietas superficiales que se forman cuando el material sale de la máquina de extrusión, estas grietas se extienden desde la superficie hacia el interior debido a las tensiones de contacto y fricción entre el material y la superficie de la boquilla. Mezclas demasiado secas con una cohesividad inadecuada sufrirán desgarramiento.

Otras grietas pueden deberse a un mezclado deficiente, contracciones diferenciales y restos parcialmente secos de una extrusión anterior (material reciclado). Existen otros defectos como agrietamiento, segregación, porosidad e inclusión.

Los defectos mencionados son macrodefectos que son observables a simple vista. También existen microdefectos tales como poros o inclusiones. Los poros resultan del aire atrapado no eliminado por el vacío, y de los aglomerados de polvo entre otros.

En el presente trabajo el conformado de las probetas por el método de extrusión se realizó utilizando una extrusora a vacío tipo estándar (marca UNICERAM, tipo MCV), con una presión en la línea de vacío de 162.08 hPa. , ver figura 7.6.
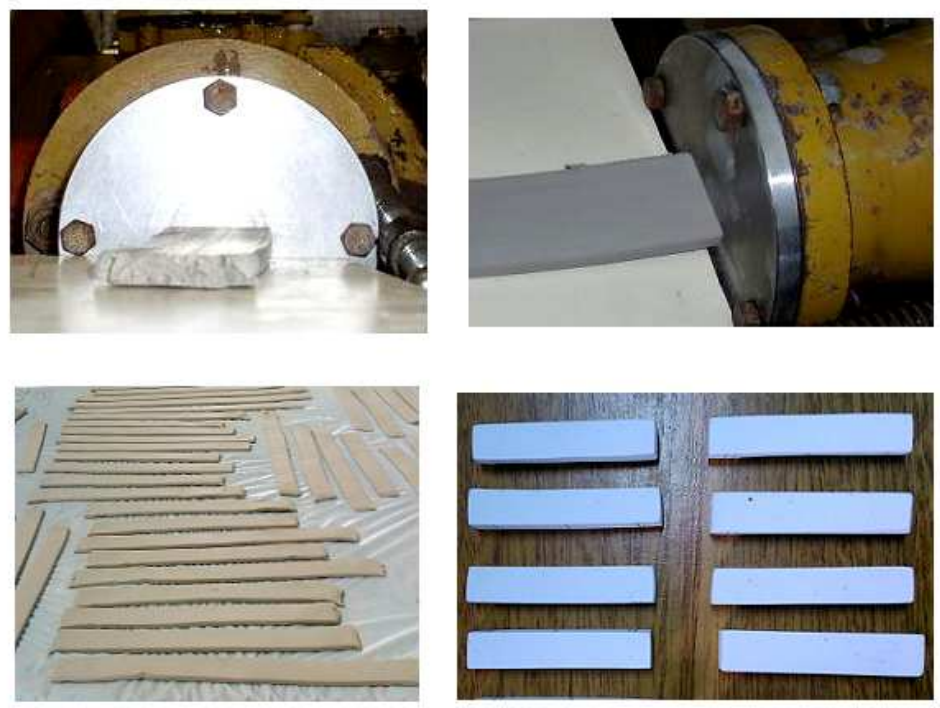

Figura 7.6. Procedimiento del conformado por el método de extrusión.

Las mezclas estequiométricas $3-2\left(3 \mathrm{Al}_{2} \mathrm{O}_{3} \cdot 2 \mathrm{SiO}_{2}\right)$ que fueron conformadas por este método fueron; arcilla Tincar Súper más alúmina calcinada (AtinAcal) y arcilla La Rioja más alúmina calcinada (AriojAcal), no realizándose ensayos para las mezclas 
conformadas con alúmina hidratada, debido al gran tamaño de partícula de ésta, haciendo prácticamente nula la plasticidad de la mezcla e imposibilitando la extrusión de la misma aún con el agregado de plastificantes.

Para conocer la cantidad de agua o porcentaje de humedad que debían tener las mezclas, fue necesario guiarse por los resultados obtenidos del índice de plasticidad, límite líquido y plástico (tabla 7.1)

Como se observó en la tabla 7.1 la mezcla AriojAcal presentó un índice de plasticidad bajo, debido a que la arcilla La Rioja es poco plástica, para mejorar su plasticidad se utilizó un plastificante (carboximetil celulosa al $2.5 \%$ ), el mismo plastificante se utilizó para la mezcla AtinAcal, con el fin de poder comparar las dos mezclas. Los porcentajes de humedad que se utilizaron fueron; para la AtinAcal del $21 \%$ y para AriojAcal fue de $23 \%$.

Se prepararon dos masas correspondientes a las dos mezclas en estudio, con su respectivo porcentaje de humedad; a posteriori se introdujeron independientemente una de la otra en la extrusora con el fin de no mezclarlas, dándole un conformado a las piezas en forma de cintas prismáticas (con un tamaño rectangular en la boquilla de $4.0 \mathrm{x}$ $0.8 \mathrm{~cm}$ ), posteriormente se cortaron de las cintas probetas de $5.3 \times 0.8 \times 0.8 \mathrm{~cm}^{3}$, éstas fueron secadas a $110^{\circ} \mathrm{C}$ y luego se calcinaron a $1550^{\circ} \mathrm{C}$ durante 4 horas, ver figura 7.6. Las probetas obtenidas se caracterizaron física y termomecánicamente.

7.4 Propiedades físicas y termomecánicas de mullita estequiométrica 3-2 $\left(3 \mathrm{Al}_{2} \mathrm{O}_{3} \cdot 2 \mathrm{SiO}_{2}\right)$ obtenida a partir de arcilla Tincar Súper más alúmina calcinada (AtinAcal) ó hidratada (AtinAhid), conformadas por los métodos de prensado, colado y extrudado.

\subsubsection{Caracterización de la mezcla AtinAcal conformada por el método de prensado (10, 40 y $100 \mathrm{MPa})$ y calcinadas a $1550 \stackrel{\circ}{\mathrm{C}}$ por 4 horas.}

Se elaboraron probetas por prensado uniaxial con formato prismático de $\sim 5.0 \times 0.8 \times 0.8$ $\mathrm{cm}^{3}$ a presiones de 10,40 y $100 \mathrm{MPa}$ con una humedad de $\sim 12.4 \%$, para la mezcla estequiométrica 3-2 de arcilla Tincar Súper más alúmina calcinada (AtinAcal) utilizando el aditivo de prensado ya mencionado, posteriormente las probetas se secaron a $110^{\circ} \mathrm{C}$ - 167 - 
y se calcinaron a $1550 \stackrel{\circ}{\mathrm{C}}$ durante 4 horas con una velocidad de calentamiento de $5 \stackrel{\circ}{ } \mathrm{C}$ por minuto, caracterizándolas física y termomecánicamente.

\subsubsection{Difractogramas de la mezcla AtinAcal.}

Para conocer las fases cristalinas presentes en la mezcla AtinAcal en cada una de las presiones estudiadas luego de la calcinación (1550 ํㅡ por 4 horas), se efectuó la caracterización por Difracción de Rayos X, ver figura 7.7.

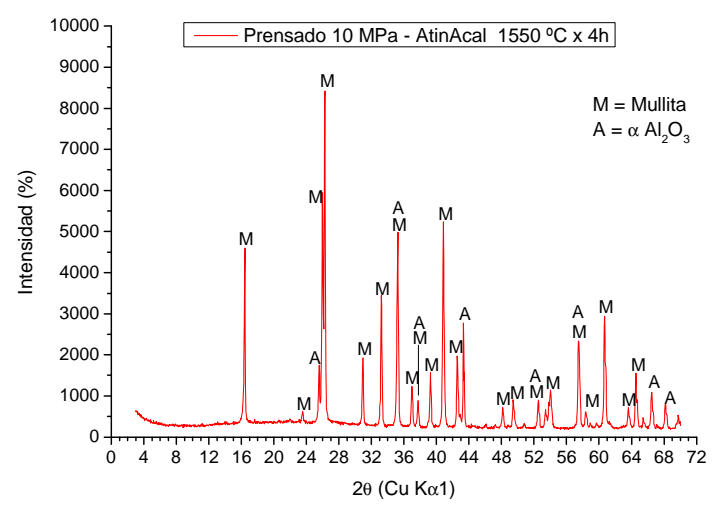

(a)

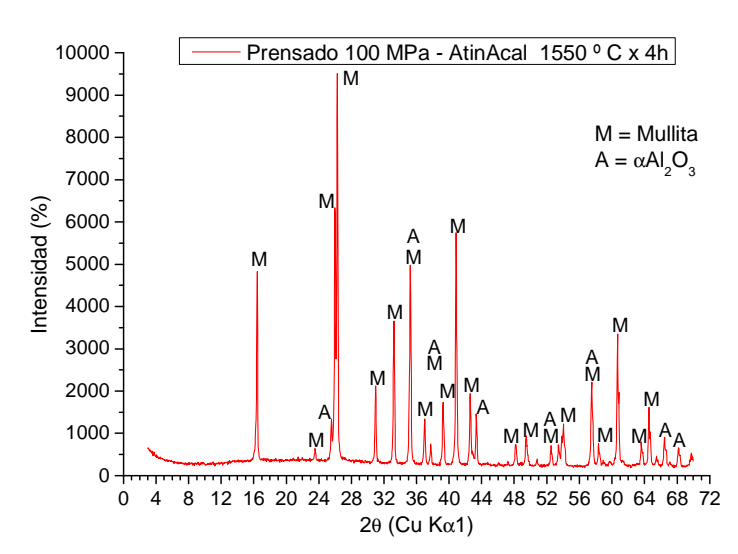

(c)

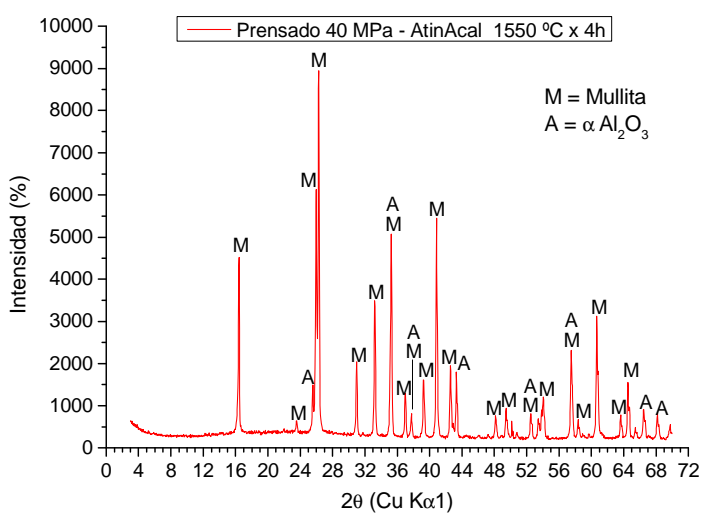

(b)

Figura 7.7. Difractogramas de la mezcla AtinAcal prensadas: a) $10 \mathrm{MPa}$, b) $40 \mathrm{MPa}$, y c) $100 \mathrm{MPa}$ y calcinadas a $1550 \stackrel{\circ}{\mathrm{C}}$ durante 4 horas. 
La figura 7.7 muestra los difractogramas de la mezcla AtinAcal conformada a tres presiones distintas (10, 40 y $100 \mathrm{MPa}$ ) calcinadas como se indicó, evidenciándose en todos los difractogramas la presencia de mullita (neta) como fase principal y una poca cantidad de fase $\alpha$-alúmina; se observa un leve aumento de la fase mullita y una disminución de la fase $\alpha$ - alúmina a medida que se aumenta la presión. [Angel y Prewitt, 1986; Villar et al., 2004].

\subsubsection{Propiedades físicas de la mezcla AtinAcal.}

Después de someter las probetas prismáticas a $1550{ }^{\circ} \mathrm{C}$ durante 4 horas, se procedió a evaluar distintas propiedades físicas. Utilizando el método de Arquímedes por inmersión en agua se obtuvieron valores del porcentaje de porosidad (abierta), densidad del material y densidad aparente en agua. El porcentaje de porosidad cerrada se calculó en base al valor teórico de la mullita $\left(3.17 \mathrm{~g} / \mathrm{cm}^{3}\right)$ dado que la cantidad de alúmina remanente es pequeña y además compensaría con la densidad de la fase amorfa, la cual siempre es menor que la de la mullita, también se midió el porcentaje de variación lineal respecto al conformado del material seco $\left(110^{\circ} \mathrm{C}\right)$. Los resultados obtenidos se muestran en la tabla 7.3.

Tabla 7.3. Propiedades físicas de las probetas obtenidas por el método de prensado para la mezcla AtinAcal calcinadas a $1550{ }^{\circ} \mathrm{C}$ durante 4 horas.

\begin{tabular}{|c|c|c|c|c|c|}
\hline PRESIÓN & $\begin{array}{c}\text { Porosidad } \\
\text { (Abierta) } \\
\%\end{array}$ & $\begin{array}{c}\text { Porosidad } \\
\text { (Cerrada) } \\
\%\end{array}$ & $\begin{array}{c}\text { Densidad de } \\
\text { la pieza } \\
\text { (Arquímedes) } \\
\mathbf{g} / \mathrm{cm}^{3}\end{array}$ & $\begin{array}{c}\text { Densidad } \\
\text { aparente en } \\
\text { agua (Del } \\
\text { sólido) } \\
\mathbf{g} / \mathrm{cm}^{3}\end{array}$ & $\begin{array}{c}\text { Variación } \\
\text { lineal respecto } \\
\text { al conformado } \\
\text { del material } \\
\text { seco a 110\%C } \\
\%\end{array}$ \\
\hline $\mathbf{1 0} \mathbf{~ M P a}$ & 38.7 & 2.2 & 1.90 & 3.10 & +3.0 \\
\hline $\mathbf{4 0} \mathbf{~ M P a}$ & 33.1 & 7.9 & 1.95 & 2.92 & +3.6 \\
\hline $\mathbf{1 0 0} \mathbf{~ M P a}$ & 30.8 & 8.5 & 2.01 & 2.90 & +4.0 \\
\hline
\end{tabular}

En la tabla 7.3 se observa, que el porcentaje de porosidad abierta va disminuyendo a medida que se aumenta la presión, mientras la porosidad cerrada muestra un comportamiento contrario, estos valores son consistentes ya que a mayor presión mayor 
contacto entre partículas, y a alta temperatura reaccionan - sinterizan formando poros cerrados en mayor cantidad que a baja presión. [Akhay et al., 1991; Schneider 2008].

De todas formas se observa que la porosidad abierta tiene un valor elevado aun prensando a alta presión. La figura 7.8 ilustra claramente este comportamiento.

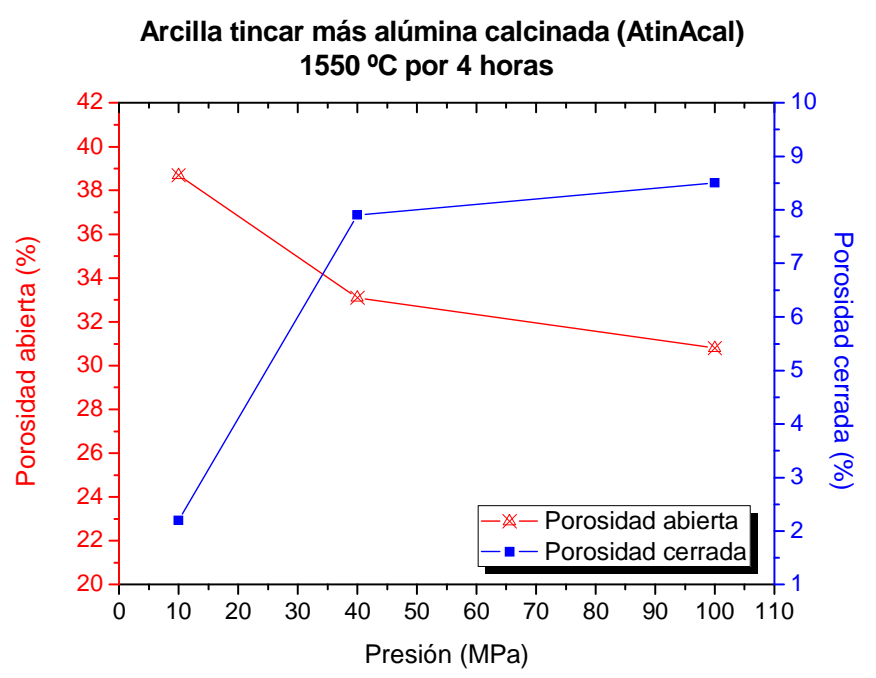

Figura 7.8. Porcentaje de porosidad abierta y cerrada de la mezcla estequiométrica AtinAcal, prensada a 10, 40 y $100 \mathrm{MPa}$ y calcinadas a $1550 \stackrel{\circ}{\mathrm{C}}$ durante 4 horas.

Respecto a los valores de densidad aparente en agua (densidad del sólido), se observó a $10 \mathrm{MPa}$ un valor muy cercano a la densidad teórica de la mullita $\left(3.17 \mathrm{~g} / \mathrm{cm}^{3}\right)$, indicando esto una baja cantidad de poros cerrados. A medida que se aumenta la presión el valor de la densidad del sólido se va alejando del valor teórico, debido a la mayor presencia de poros cerrados influyendo esto en un descenso de la densidad del sólido, (ver tabla 7.3). Los resultados obtenidos de densidad de la pieza presentaron un comportamiento contrario a la densidad aparente en agua. En la figura 7.9, se puede apreciar este comportamiento. 


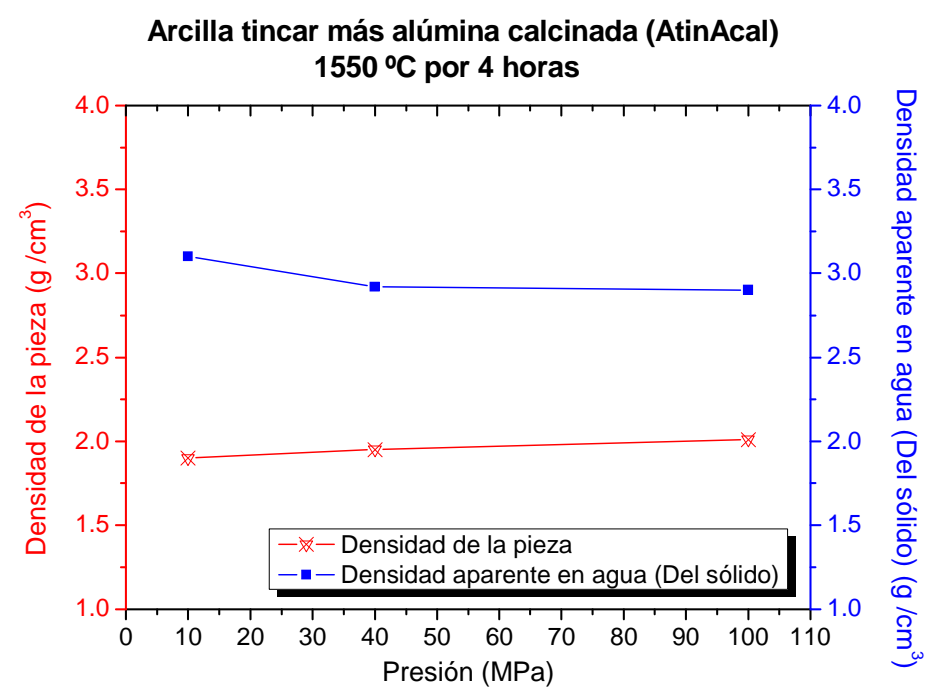

Figura 7.9. Densidad de la pieza y densidad aparente en agua de la mezcla AtinAcal, prensada a 10,40 y $100 \mathrm{MPa}$ y calcinadas a $1550{ }^{\circ} \mathrm{C}$ durante 4 horas.

La mezcla AtinAcal prensada a $100 \mathrm{MPa}$ presentó un porcentaje mayor de expansión lineal respecto al conformado del material seco a $110^{\circ} \mathrm{C}$ en comparación a las realizadas a menores presiones, ver tabla 7.3, esto debido a que las partículas están en mayor contacto y por lo tanto la reacción de mullitización secundaria con las partículas de $\alpha$-alúmina $\left(\mathrm{A}_{2} \mathrm{G}\right)$ la cual es expansiva, ocurre con mayor frecuencia en zonas de contacto directo, produciendo mayor expansión. De todos modos en forma simultánea se da la sinterización que genera contracción, por lo que existe una competencia entre ambos fenómenos a esta temperatura y tiempo.

\subsubsection{Distribución de tamaño de poro por intrusión de mercurio de la mezcla AtinAcal.}

Se aplicó la técnica de porosimetría por intrusión de mercurio a las probetas AtinAcal obtenidas por prensado a 10,40 y $100 \mathrm{MPa}$ y calcinadas a $1550 \stackrel{\circ}{\mathrm{C}}$ durante 4 horas, obteniéndose curvas de distribución de tamaño de poro (volumen acumulado de poros vs diámetro), ver figura 7.10 . 


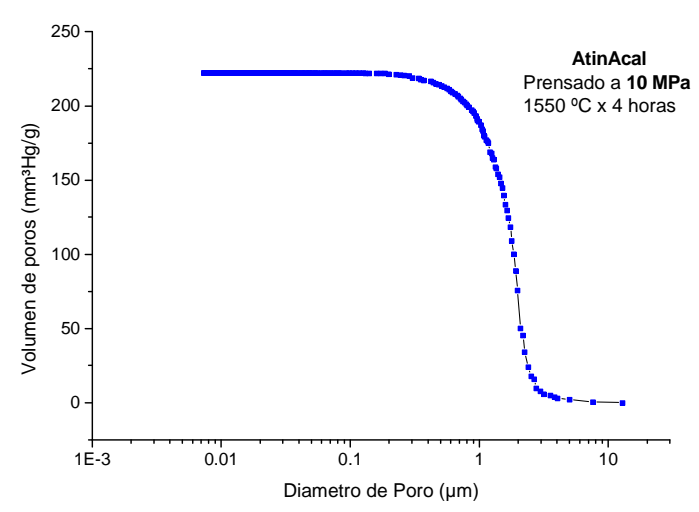

(a)

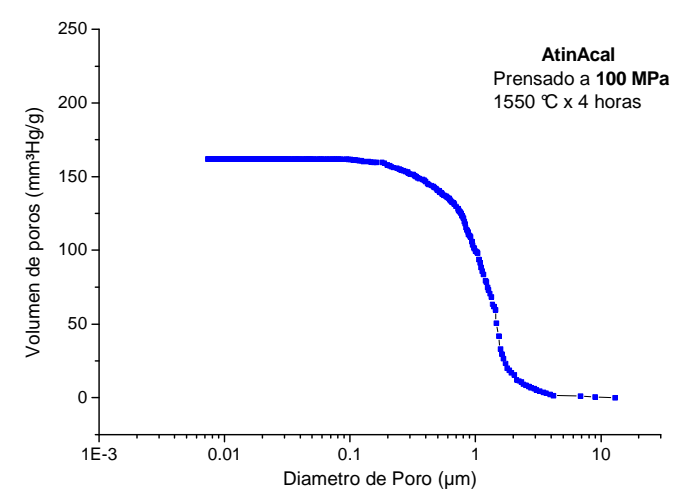

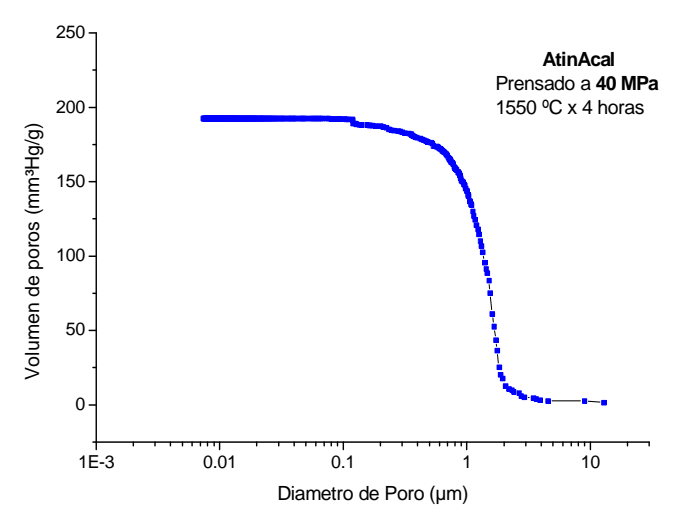

(b)

(c)

Figura 7.10. Curvas de distribución de tamaño de poros por intrusión de mercurio para la mezcla AtinAcal prensadas y calcinadas a $1550{ }^{\circ} \mathrm{C}$ durante 4 horas; a) $10 \mathrm{MPa}$; b) 40 MPa y c) $100 \mathrm{MPa}$.

En la figura 7.10 se observa que el volumen máximo de mercurio introducido (volumen de poros abiertos) en la muestra AtinAcal varió entre 222 y $162 \mathrm{~mm}^{3} \mathrm{Hg} / \mathrm{g}$ en función de la presión uniaxial, siendo mayor la penetración para presiones menores. [Lowell y Shields, 1991; Pospech y Schneider, 1989; Washburn, 1921].

En la figura 7.10 a (prensada a $10 \mathrm{MPa}$ ), se puede observar que prácticamente el desarrollo de poros abiertos se encuentra entre un diámetro de poros de 2.9 y $0.5 \mu \mathrm{m}$ y su volumen de poros total penetrado es de $222.4 \mathrm{~mm}^{3} \mathrm{Hg} / \mathrm{g}$, encontrándose que el diámetro de poro más frecuente se localiza en $1.92 \mu \mathrm{m}$, siendo una distribución muy estrecha. 
Los resultados de la distribución de diámetro de poros para la mezcla estequiométrica 32 (AtinAcal) prensada a $40 \mathrm{MPa}$ se muestran en la figura $7.10 \mathrm{~b}$, la porosidad total se encuentra prácticamente entre 2.7 y $0.5 \mu \mathrm{m}$, donde el diámetro más frecuente esta en $1.51 \mu \mathrm{m}$ y su volumen de poro penetrado esta en $176.2 \mathrm{~mm}^{3} \mathrm{Hg} / \mathrm{g}$.

La figura 7.10c muestra el sistema de prensado a $100 \mathrm{MPa}$. En este caso la curva expresa que los diámetros de poros se encuentran entre 3.4 y $0.3 \mu \mathrm{m}$, hallándose mayoritariamente en $1.43 \mu \mathrm{m}$, estando su volumen de poro total penetrado en 154.2 $\mathrm{mm}^{3} \mathrm{Hg} / \mathrm{g}$.

Todos los resultados de porosimetrías por intrusión de mercurio (figura 7.10) a las tres presiones mostraron tamaños de poros muy similares en el desarrollo total de poros abiertos, esta conducta se puede asociar al tamaño de granulometría de las materias primas utilizadas. No se observaron cambios sustanciales entre las presiones, pero si una disminución de porosidad abierta a medida que aumenta la presión, coincidiendo esto con lo observado en la porosidad medida por el método de Arquímedes, además de un ligero corrimiento del tamaño más frecuente hacia valores menores con el aumento de la presión de prensado.

\subsubsection{Microscopia electrónica de barrido de arcilla Tincar Súper y de la mezcla AtinAcal.}

Para conocer y diferenciar la microestructura de la mullita primaria generada por la arcilla Tincar Súper (Atincar) y la mullita neta generada por la reacción de una mezcla estequiométrica 3-2 de la arcilla más alúmina calcinada (AtinAcal), tabla 4.8, se procedió a observar piezas calcinadas ( $1550^{\circ} \mathrm{C}$ durante 4 horas) por microscopía electrónica de barrido (MEB).

Como se observó en el capítulo 5, estas muestras al ser calcinadas a altas temperaturas presentan la formación de fase vítrea o amorfa, además de mullita. Con el fin de eliminar esta fase de la superficie se realizó un etching químico con ácido fluorhídrico (HF) al 5 $\%$, durante 10 minutos. 


\subsection{Micrografía de la arcilla Tincar Súper (mullita primaria).}

Se elaboró una probeta de arcilla Tincar Súper (Atincar) por el método de prensado uniaxial a $100 \mathrm{MPa}$, se calcinó a $1550{ }^{\circ} \mathrm{C}$ durante 4 horas con una velocidad de calentamiento de $5 \stackrel{\circ}{\mathrm{C}}$ por minuto. Posteriormente se incluyó en resina y se pulió cómo se explicó en la sección 3.7. En la Figura 7.11 se muestra la fotografía y micrografías de la arcilla Tincar Súper prensada y calcinada a $1550{ }^{\circ} \mathrm{C}$ durante 4 horas, con y sin etching químico.

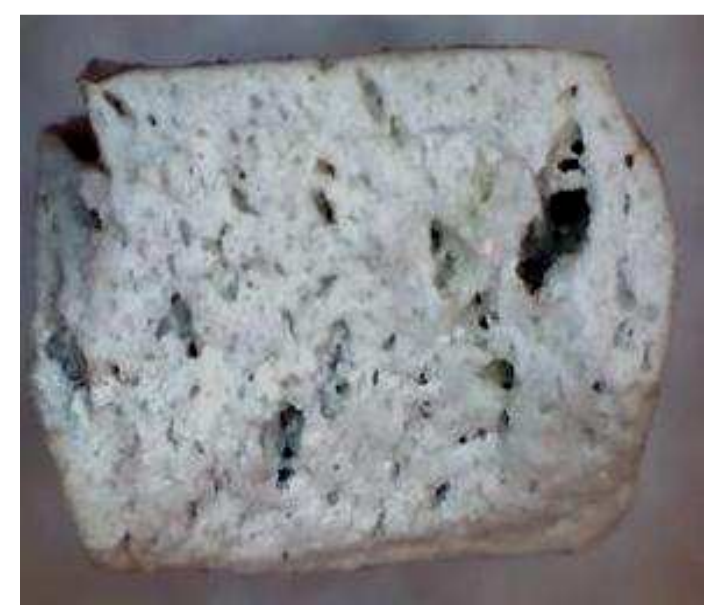

(a)

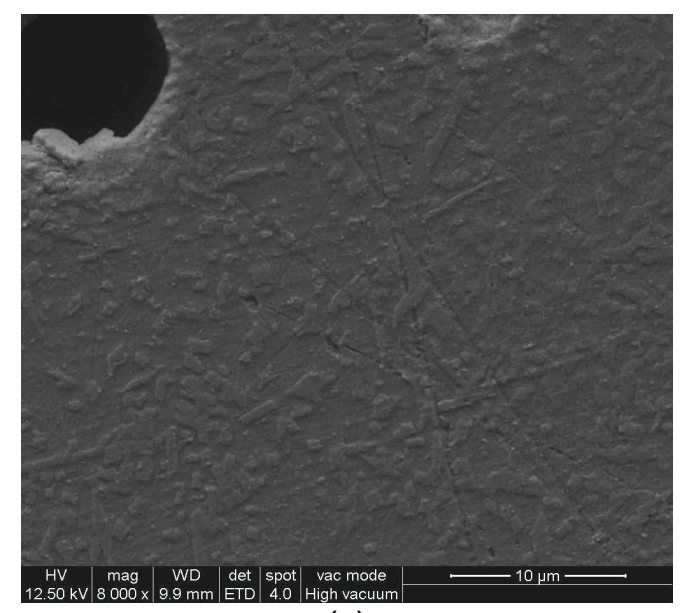

(c)

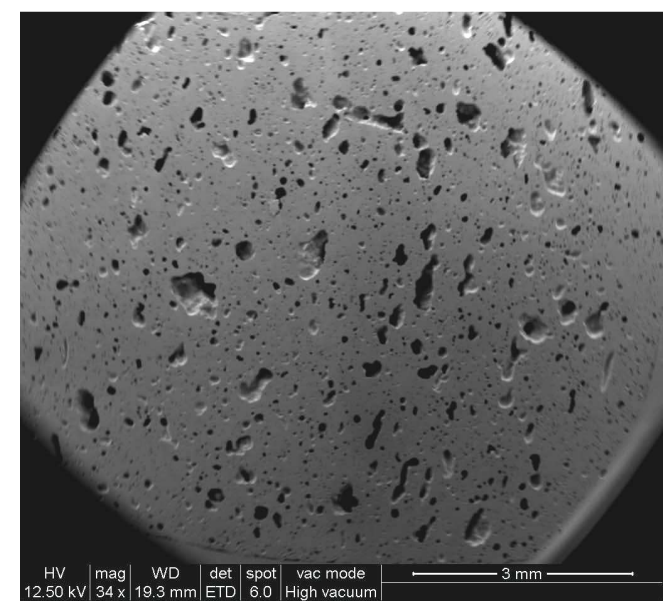

(b)

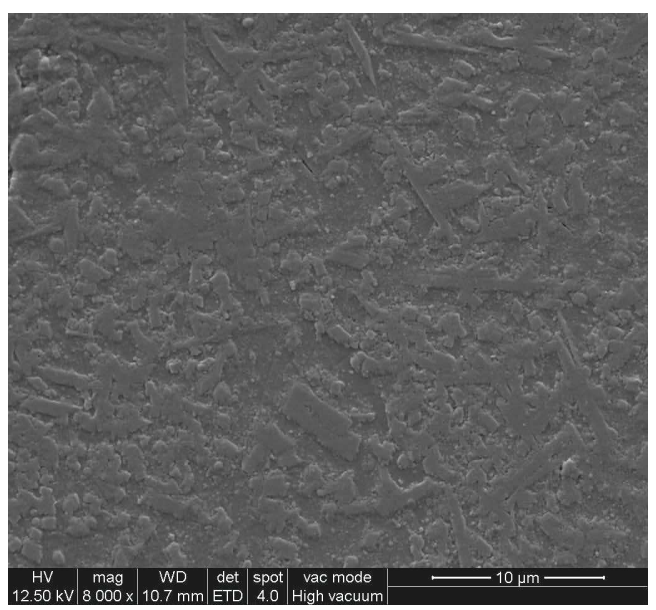

(d)

Figura 7.11. Fotografía, a), y micrografías por MEB de arcilla Tincar Súper prensada a $100 \mathrm{MPa}$ y calcinada $1550 \stackrel{\circ}{\mathrm{C}}$ durante 4 horas, observadas a: b) $34 \mathrm{x}$ c) $8000 \mathrm{x}$ y d) etching químico (HF 5\%) a 8000x. 
La figura 7.11a muestra una foto de la probeta calcinada como se indicó anteriormente. El aspecto hinchado de la misma es debido a que a una temperatura menor a la de 1550 ○C el sistema comenzó a vitrificar generando poros cerrados que al aumentar la temperatura hasta $1550 \stackrel{\circ}{\circ}$ produjo la expansión del aire ocluido en los mismos produciendo el hinchamiento observado.

La figura 7.11b, 34x, muestra la estructura macroporosa de la pieza en la cual si fueran poros abiertos estarían fuera del alcance de la técnica utilizada para la medición del tamaño de poro.

La figura 7.11c corresponde a la micrografía sin etching químico (8000x), donde se observa una superficie de formación de mullita (primaria) en forma de agujas y la presencia de la fase amorfa, mientras en la micrografía que se realizó el etching químico HF (5 \%) durante 10 minutos (figura 7.11d), se observa que se generó un sobre relieve de mullita (primaria), debido a que el HF eliminó la fase amorfa rica en sílice.

\subsection{Micrografías de la mezcla AtinAcal [(mullita neta (primaria más secundaria)].}

Se elaboraron probetas por el método de prensado a 10, 40 y $100 \mathrm{MPa}$, para la mezcla estequiométrica 3-2 de arcilla tincar Súper más alúmina calcinada (AtinAcal). Las mismas fueron calcinadas a $1550{ }^{\circ} \mathrm{C}$ durante 4 horas, y se prepararon como se explicó en la sección 3.7.

Las figuras 7.12, 7.13 y 7.14 muestran las micrografías mencionadas, mullita neta (AtinAcal), con y sin etching químico. 


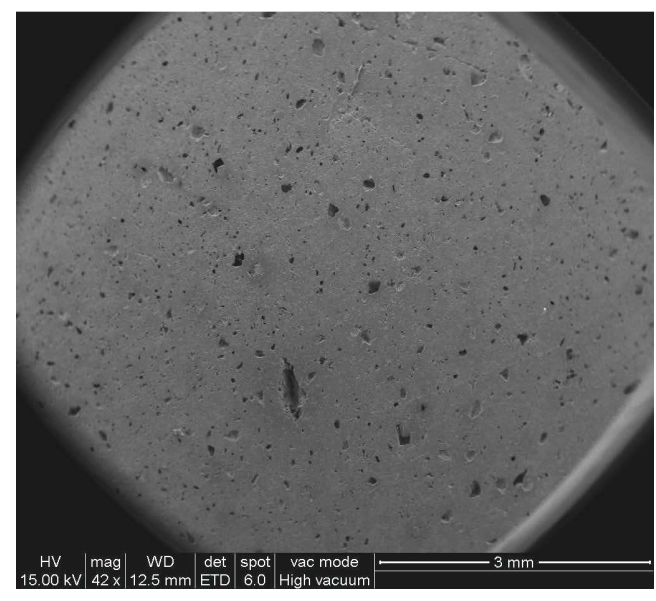

(a)

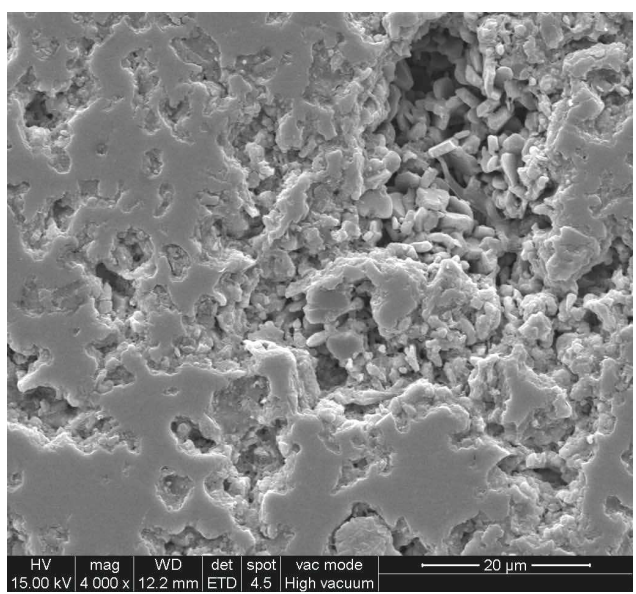

(c)

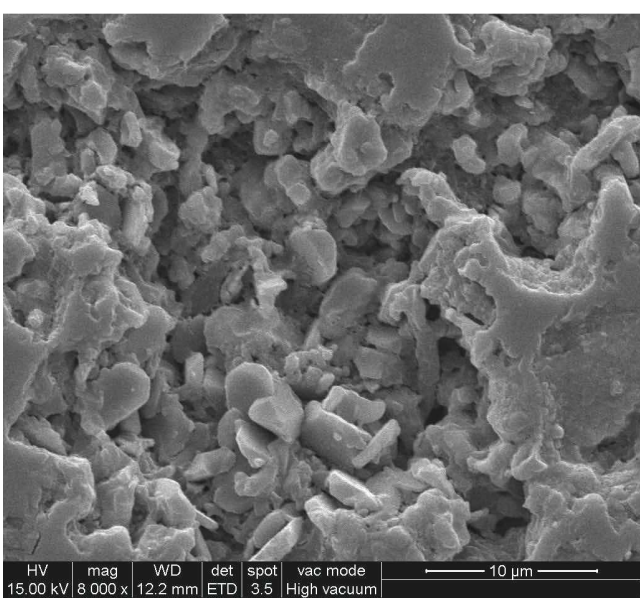

(b)

Figura 7.12 Micrografía de AtinAcal, prensada a $10 \mathrm{MPa}$ y calcinada a $1550 \stackrel{\circ}{\mathrm{C}}$ durante 4 horas; sin etching químico: a) 42x, b) $8000 x$, y c) con etching químico (HF 5\%) a 4000x. 


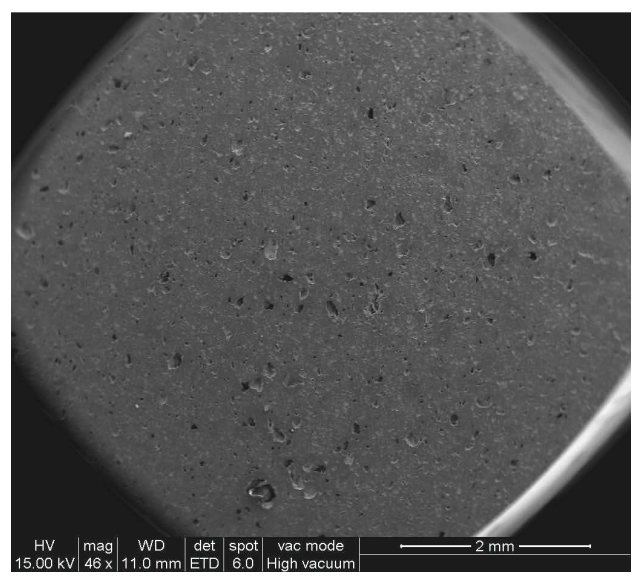

(a)

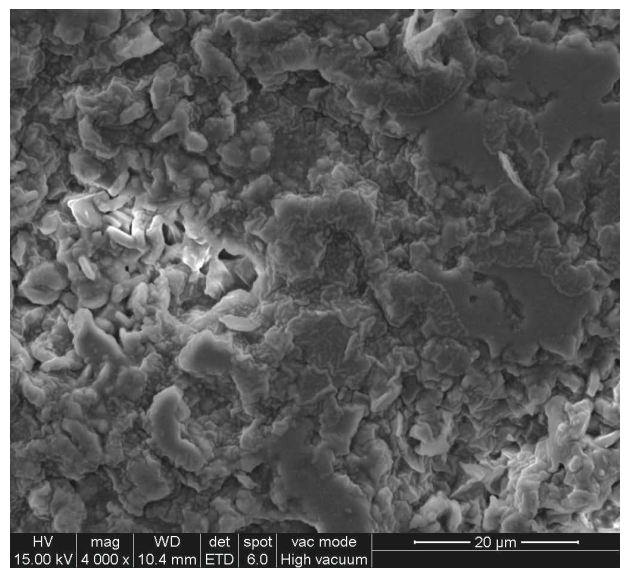

(c)

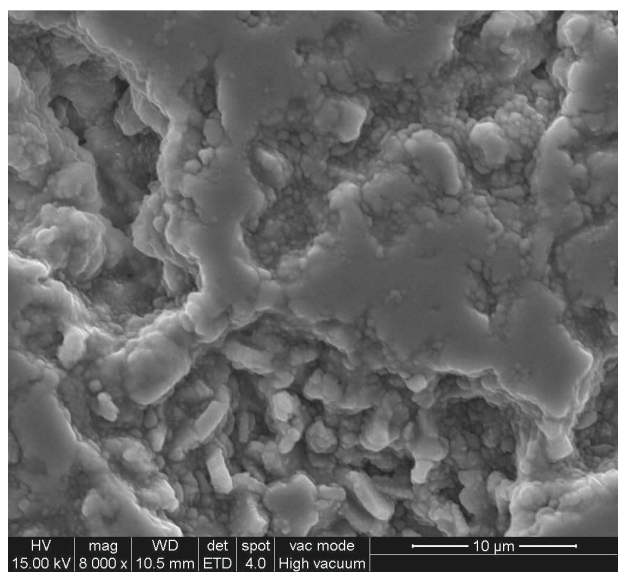

(b)

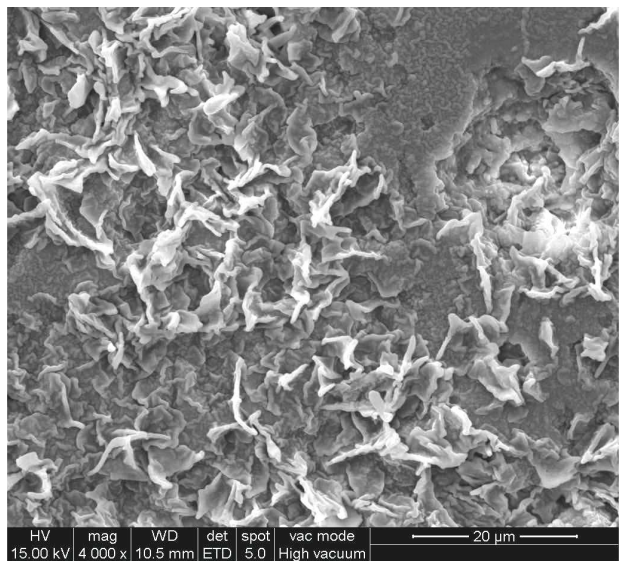

(d)

Figura 7.13 Micrografía de AtinAcal, prensada a $40 \mathrm{MPa}$ y calcinada a $1550{ }^{\circ} \mathrm{C}$ durante 4 horas: sin etching químico: a) 46x, b) 8000x; y con etching químico (HF 5\%): c) y d) 4000x. 


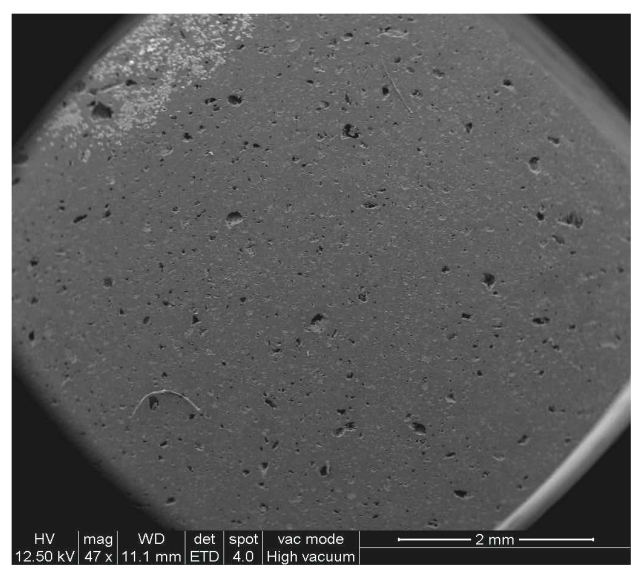

(a)

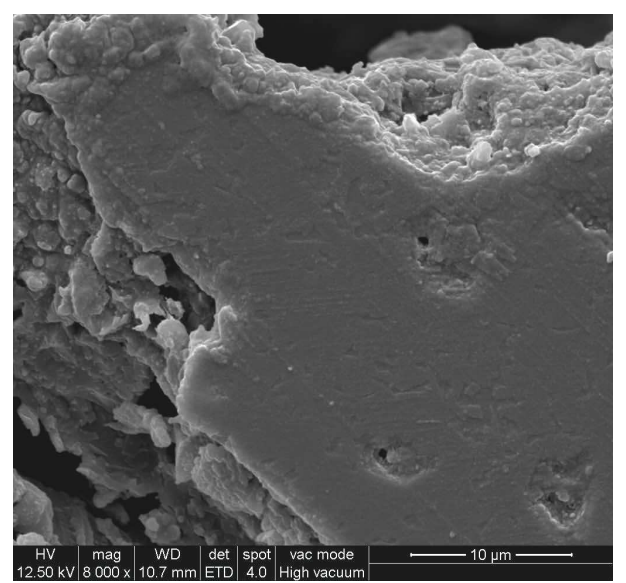

(c)

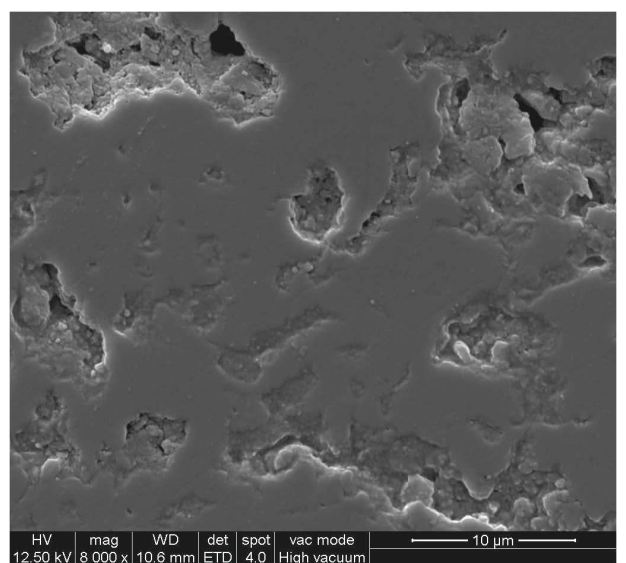

(b)

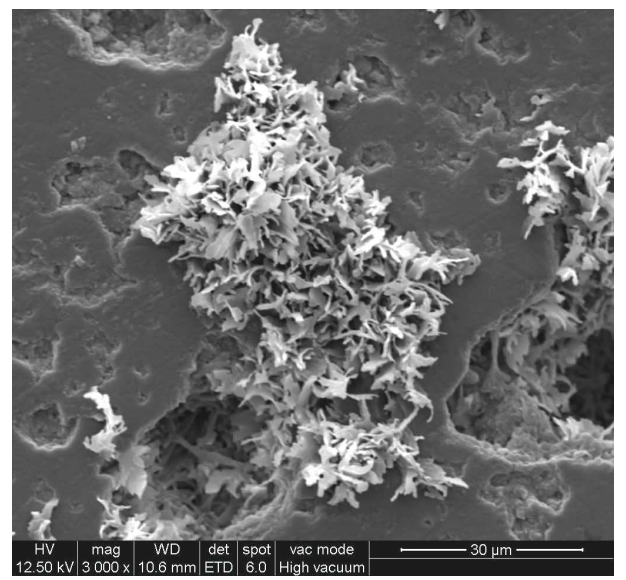

(d)

Figura 7.14 Micrografía de AtinAcal, prensada a $100 \mathrm{MPa}$ y calcinada a $1550{ }^{\circ} \mathrm{C}$ durante 4 horas: sin etching químico: a) 47x, b) 8000x; con etching químico (HF 5\%): c) 8000x, y d) $3000 x$.

En todas las micrografías sin ataque químico (figuras 7.12b, 7.13b, y 7.14b) se observó la formación acicular (agujas o bastones) de mullita, y zonas de puntas de bastón medio redondeadas que representaría la zona de sinterizado del material, no obteniendo un ordenamiento definido ni un tamaño homogéneo. [Goldstein et al., 2003; Jovani et al., 1979; Mesa, 2011]. Las muestras que sufrieron el ataque químico con ácido fluorhídrico al $5 \%$ durante 10 minutos (figuras $7.12 \mathrm{c}, 7.13 \mathrm{c}$, y 7.14c), mostraron que parte de la fase vítrea que está ligando a las agujas de mullita se ha destruido parcialmente con el ataque, observándose con más claridad en la de $40 \mathrm{MPa}$ (figura 7.13c). 
Las superficies vistas en microscopía electrónica de barrido corresponden a la superficie exterior de la mezcla en contacto con el molde de prensado, observándose que para presiones de 40 y $100 \mathrm{MPa}$ existe una fuerza mecánica o fricción intensa que orienta las laminitas de mezcla en un determinado sentido, esto no ocurrió a 10MPa. Este fenómeno se pudo observar al atacar y extraer la fase vítrea con ácido fluorhídrico al 5 $\%$ durante 10 minutos, dejando en descubierto la memoria laminar de la mezcla que se manifiesta como mullita en forma de láminas levantadas en sobre relieve (figuras $7.13 \mathrm{~d}$, y $7.14 d)$.

\subsubsection{Propiedades termomecánicas de la mezcla AtinAcal.}

Las caracterizaciones termomecánicas de la mezcla estequiométrica 3-2 (AtinAcal) conformadas por el método de prensado y calcinadas a $1550{ }^{\circ} \mathrm{C}$ durante 4 horas, se realizaron midiendo el módulo de rotura a la flexión (MOR1), módulo de elasticidad (E1), y módulo de rotura a la flexión y módulo de elasticidad luego de un choque térmico (MOR2 y E2), recordando que el choque térmico consistió en colocar las probetas en un horno a temperatura de $1000{ }^{\circ} \mathrm{C}$ en forma instantánea, manteniéndolas durante 20 minutos a esa temperatura para luego enfriarlas bruscamente en agua, los resultados obtenidos se muestran en la tabla 7.4.

En la tabla 7.4 se puede observar que el módulo de elasticidad (E1) y el módulo de rotura a la flexión (MOR1), presentaron un aumento en su valor a medida que se incrementaba la presión, probablemente debido a que al existir mayor cantidad de poro cerrado, con mantenimiento de la porosidad total, existe una mayor cantidad de sólido sinterizado y por tal motivo mayor resistencia a la flexión y mayor módulo de elasticidad. El módulo de rotura a la flexión después del choque térmico (MOR2) presentó una disminución con el aumento de la presión, mientras que el módulo elástico mostró lo contrario. [Aksel 2002; 2003; Ananthakumar et al., 2006; Torrecillas et al., 1999]. 
Tabla 7.4. Propiedades termomecánicas de las probetas obtenidas por el método de prensado para la mezcla AtinAcal calcinadas a $1550 \stackrel{\circ}{\mathrm{C}}$ durante 4 horas.

\begin{tabular}{|c|c|c|c|}
\hline & $10 \mathrm{MPa}$ & $40 \mathrm{MPa}$ & $100 \mathrm{MPa}$ \\
\hline $\begin{array}{c}\text { MÓDULO DE ELASTICIDAD } \\
\text { (E1) } \\
(\mathrm{GPa})\end{array}$ & 33.5 & 46.0 & 58.7 \\
\hline $\begin{array}{l}\text { MÓDULO DE ELASTICIDAD } \\
\text { Después de choque térmico } \\
\text { (E2) } \\
(\mathrm{GPa})\end{array}$ & 24.3 & 32.4 & 34.2 \\
\hline $\begin{array}{c}\text { RELACIÓN DE MÓDULOS } \\
\text { (E1/E2) }\end{array}$ & 1.4 & 1.4 & 1.7 \\
\hline $\begin{array}{l}\text { MÓDULO DE ROTURA A LA FLEXIÓN } \\
\text { (MOR1) } \\
(\mathrm{MPa})\end{array}$ & 37.2 & 39.8 & 47.6 \\
\hline $\begin{array}{l}\text { MÓDULO DE ROTURA A LA FLEXIÓN } \\
\text { Después de choque térmico } \\
\text { (MOR } 2) \\
\text { (MPa) }\end{array}$ & 6.5 & 3.5 & 2.4 \\
\hline $\begin{array}{c}\text { RELACIÓN DE MÓDULOS } \\
\text { (MOR1/MOR2) }\end{array}$ & 5.7 & 11.4 & 19.8 \\
\hline
\end{tabular}

La figura 7.15, representa los resultados de la tabla 7.4, observándose que el módulo de elasticidad después del choque térmico (E2), presenta un incremento de su valor a medida que aumenta la presión, lo que podría significar que después del choque térmico los poros cerrados se han fisurado pero el material sigue en contacto y por lo tanto se propagará la onda acústica de medición sobre el material, aunque con menor intensidad que la original (E1). [Ault y Ueltz,1953; Fenstermacher y Hummel, 1961].

En cambio los valores de MOR2 caen al aumentar la presión de prensado debido a que existe una mayor cantidad de poros cerrados que a bajas presiones, y estos al ser afectados por el choque térmico y fisurarse, aun estando en contacto el material a ambos lados de la fisura, la propagación de una fractura por esfuerzo mecánico (MOR2) ocurre fácilmente. 


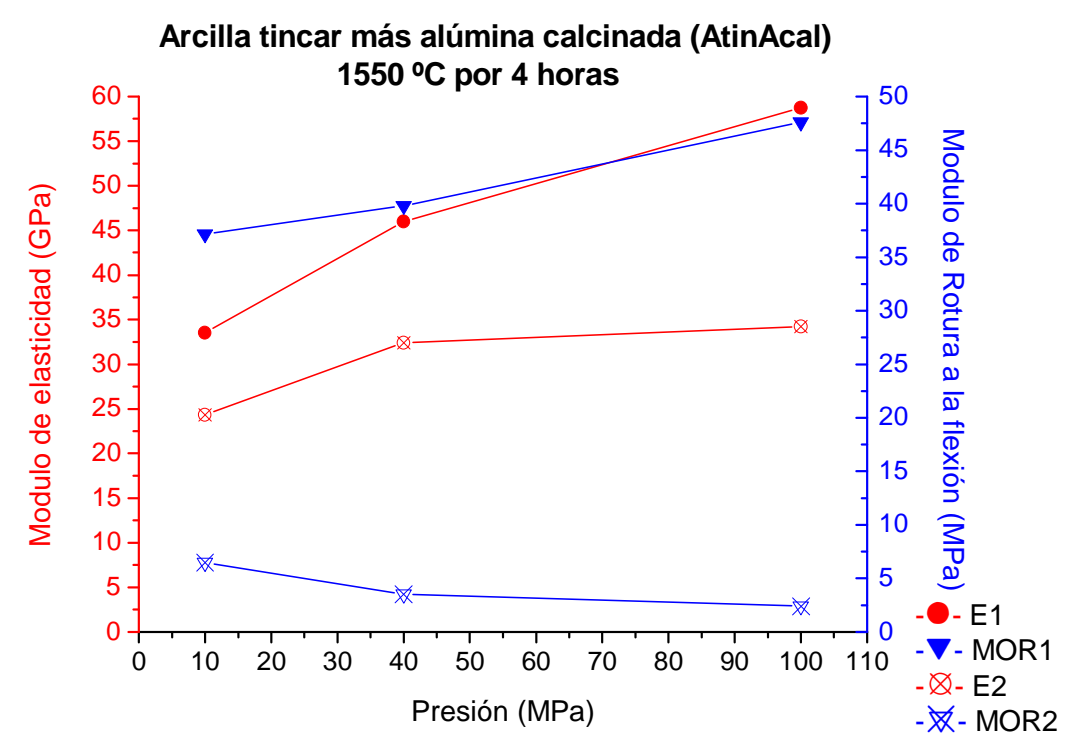

Figura 7.15. Módulo de elasticidad y módulo de rotura a la flexión antes (E1 y MOR1) y después del choque térmico (E2 y MOR2), para la muestra AtinAcal prensada a 10, 40 y $100 \mathrm{MPa}$, calcinadas a $1550 \stackrel{\circ}{\mathrm{C}}$ durante 4 horas.

Cabe reafirmar que los resultados de las propiedades termomecánicas de la muestra AtinAcal a las tres presiones (figura 7.15) mostraron valores del MOR2 y E2 bajos con respecto al MOR1 y E1, evidenciándose que el ensayo de choque térmico baja las propiedades mecánicas del material debido a las fracturas internas inducidas por el efecto térmico al que fue sometido.

\subsubsection{Caracterización física y termomecánica de la mezcla AtinAhid, conformada por prensado $(10,40$ y $100 \mathrm{MPa})$ y calcinadas a $1550 \stackrel{\circ}{\mathrm{C}}$ por 4 horas.}

\subsubsection{Difractogramas de la mezcla AtinAhid.}

Se conformaron probetas por prensado a 10, 40 y $100 \mathrm{MPa}$ con una humedad de $\sim 10$ $\%$, para la mezcla estequiométrica 3-2, de arcilla Tincar Súper más alúmina hidratada (AtinAhid) con un tamaño $5.0 \times 0.8 \times 0.8 \mathrm{~cm}^{3}$, las probetas fueron secadas a $110{ }^{\circ} \mathrm{C} \mathrm{y}$ calcinadas a $1550 \stackrel{\circ}{\mathrm{C}}$ durante 4 horas con una velocidad de calentamiento de $5 \stackrel{\circ}{ } \mathrm{C}$ por 
minuto, posteriormente se caracterizaron por Difracción de Rayos X, los difractogramas obtenidos se muestran en la figura 7.16.

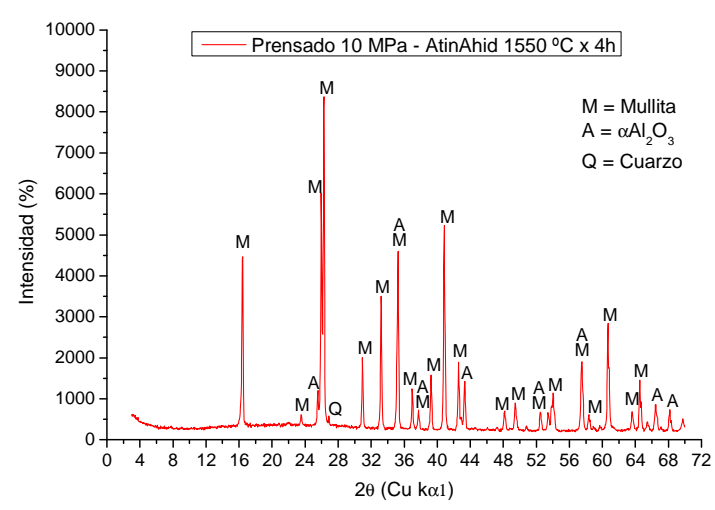

(a)

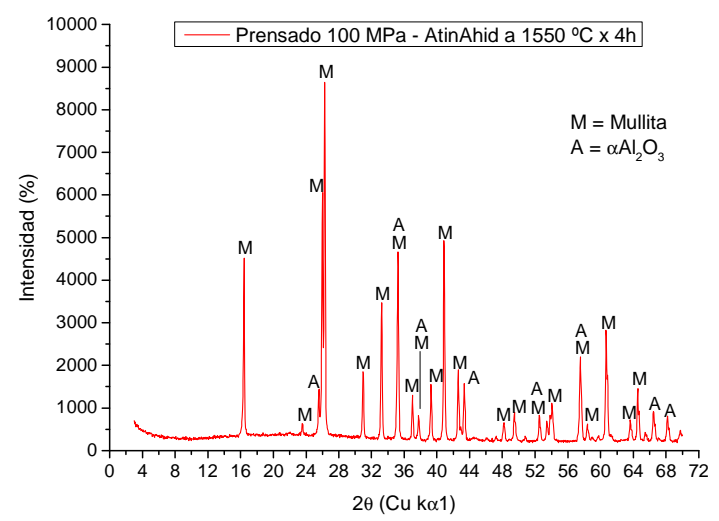

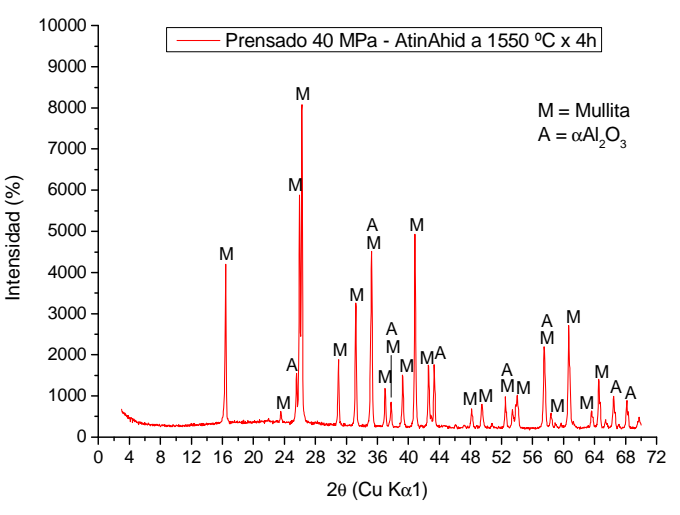

(b)

(c)

Figura 7.16. Difractogramas de la mezcla AtinAhid prensadas: a) $10 \mathrm{MPa}$, b) $40 \mathrm{MPa}, \mathrm{y}$ c) $100 \mathrm{MPa}$, calcinadas a $1550^{\circ} \mathrm{C}$ durante 4 horas.

En la figura 7.16, se muestran tres difractogramas correspondientes a la mezcla AtinAhid conformada por el método de prensado (10, 40 y $100 \mathrm{MPa})$ y calcinadas como se indicó anteriormente, evidenciando la presencia de mullita (neta) como fase principal y una poca cantidad de $\alpha$-alúmina, no observándose grandes modificaciones a medida que se aumenta la presión. Solo la figura $7.16 \mathrm{a}(10 \mathrm{MPa})$ mostró una muy pequeña cantidad de cuarzo que correspondería a la arcilla Tincar Súper.

También se notó en todos los difractogramas una leve banda centrada en $22^{\circ}$ de $2 \theta$, indicando esto la presencia de fase vítrea de la matriz silícea. [Klug y Alexander, 1974; McGEE y Dodd, 1961]. 


\subsubsection{Propiedades físicas de la mezcla AtinAhid.}

Las probetas elaboradas por el método de prensado (10, 40 y $100 \mathrm{MPa}$ ) y calcinadas a $1550 \stackrel{\circ}{C}$ durante 4 horas, se caracterizaron evaluando distintas propiedades físicas. Se calculó el porcentaje de variación lineal respecto al conformado del material seco (110 ${ }^{\circ}$ C) y se utilizó el método de Arquímedes por inmersión en agua para encontrar los valores del porcentaje de porosidad (abierta), densidad del material y densidad aparente en agua. El porcentaje de porosidad cerrada se calculó en base al valor teórico de la densidad de la mullita $\left(3.17 \mathrm{~g} / \mathrm{cm}^{3}\right)$. Los resultados obtenidos se muestran en la tabla 7.5 .

Tabla 7.5. Propiedades físicas de las probetas obtenidas por el método de prensado para la mezcla AtinAhid calcinadas a $1550 \stackrel{\circ}{ } \mathrm{C}$ durante 4 horas.

\begin{tabular}{|c|c|c|c|c|c|}
\hline PRESIÓN & $\begin{array}{c}\text { Porosidad } \\
\text { (Abierta) } \\
\%\end{array}$ & $\begin{array}{c}\text { Porosidad } \\
\text { (Cerrada) } \\
\%\end{array}$ & $\begin{array}{c}\text { Densidad de } \\
\text { la pieza } \\
\text { (Arquímedes) } \\
\mathbf{g} / \mathrm{cm}^{3}\end{array}$ & $\begin{array}{c}\text { Densidad } \\
\text { aparente } \\
\text { en agua } \\
\text { (Del sólido) } \\
\mathbf{g} / \mathrm{cm}^{3}\end{array}$ & $\begin{array}{c}\text { Variación lineal } \\
\text { respecto al } \\
\text { conformado del } \\
\text { material seco a } \\
110 \text { ' } \\
\%\end{array}$ \\
\hline $\mathbf{1 0} \mathbf{~ M P a}$ & 37.1 & 2.2 & 1.95 & 3.10 & -8.6 \\
\hline $\mathbf{4 0} \mathbf{~ M P a}$ & 32.6 & 2.5 & 2.08 & 3.09 & -8.7 \\
\hline $\mathbf{1 0 0} \mathbf{~ M P a}$ & 27.2 & 7.6 & 2.13 & 2.93 & -9.2 \\
\hline
\end{tabular}

En la tabla 7.5 se observa, que el porcentaje de porosidad abierta va disminuyendo, mientras la porosidad cerrada va creciendo a medida que se aumenta la presión, este comportamiento es lógico ya que a mayor presión mayor contacto entre partículas.

La figura 7.17 muestra el comportamiento del porcentaje de porosidad abierta y cerrada con respecto a la variación de la presión ejercida. [Furusato y Mitsudomo, 1987; Schneider 2008]. 


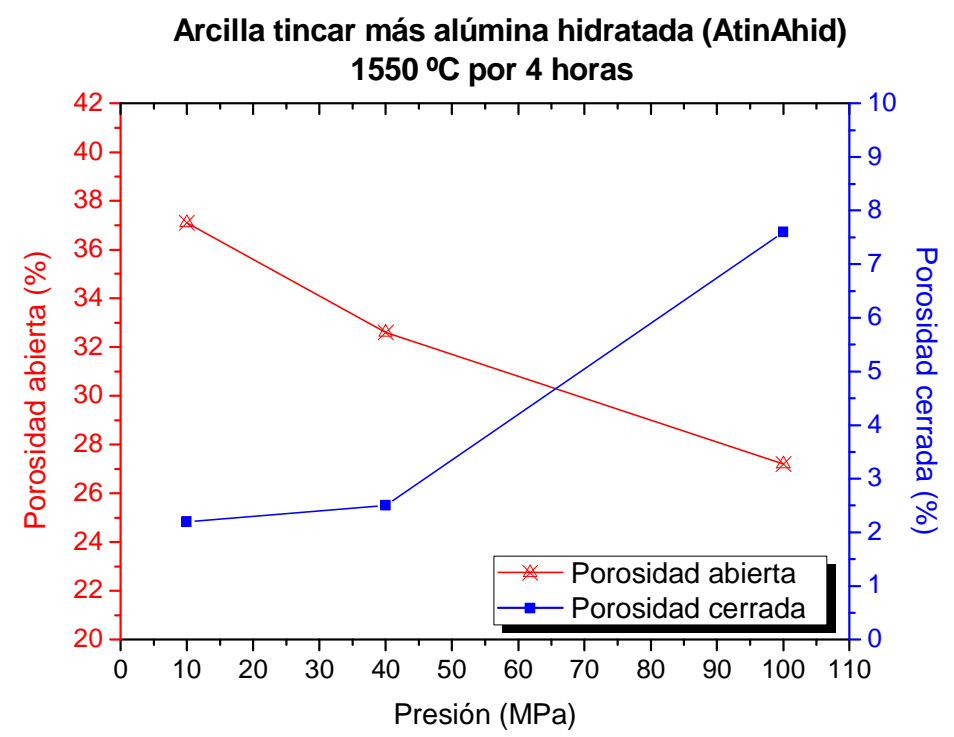

Figura 7.17. Porcentaje de porosidad abierta y cerrada de la mezcla estequiométrica AtinAhid, prensada a 10, 40 y $100 \mathrm{MPa}$ y calcinada a $1550 \stackrel{\circ}{\mathrm{C}}$ durante 4 horas.

Al comparar los porcentajes de porosidad de la mezcla AtinAcal (figura 7.8) con los de la mezcla AtinAhid (figura 7.17), se observó que los valores de porosidad abierta independientemente de la presión, son un poco menores para la AtinAhid, y respecto a los porcentajes de porosidad cerrada se manifestó una diferencia en los valores que fueron prensados a $40 \mathrm{MPa}$, notándose un aumento mayor para la AtinAcal.

En la figura 7.18, se puede apreciar la variación de la densidad de la pieza y la densidad aparente en agua con respecto a la presión uniaxial (10, 40 y $100 \mathrm{MPa}$ ) ejercida en el método de prensado y luego calcinadas a $1550 \stackrel{\circ}{ } \mathrm{C}$ durante 4 horas. Observándose que los valores de densidad aparente en agua (densidad del sólido), a presiones de 10 y 40 MPa presentaron un valor muy cercano a la densidad teórica de la mullita $\left(3.17 \mathrm{~g} / \mathrm{cm}^{3}\right)$, indicando esto una baja cantidad de poros cerrados, y a medida que se aumenta la presión a $100 \mathrm{MPa}$ el valor teórico se va alejando, eso reflejado por el aumento de los poros cerrados. Mientras la densidad de la pieza presentó un comportamiento contrario a la densidad aparente en agua. 


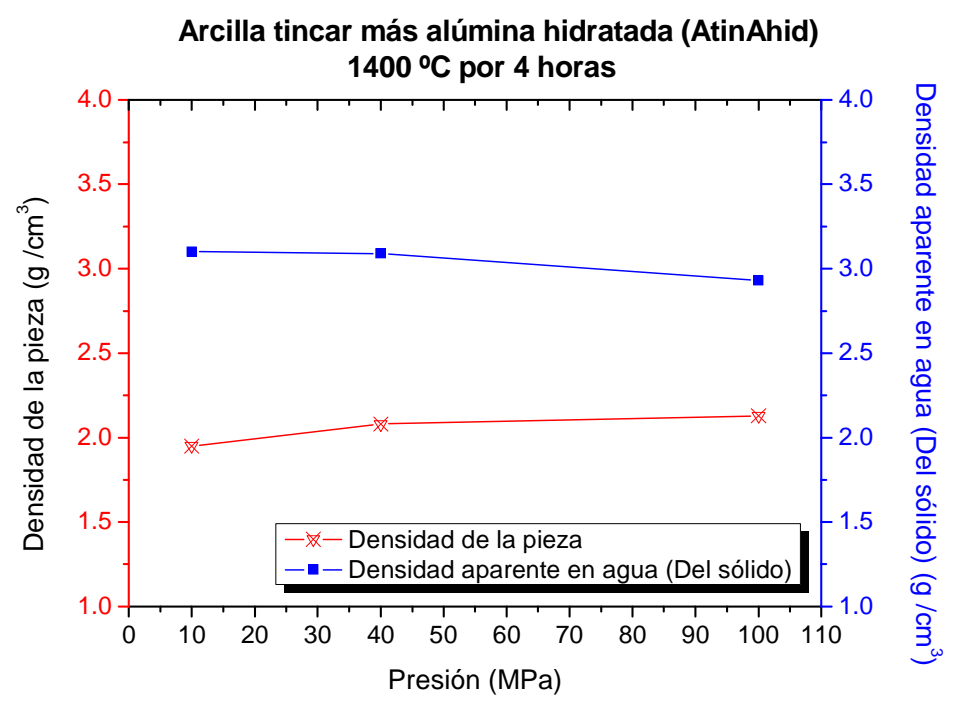

Figura 7.18. Densidad de la pieza y densidad aparente en agua de la mezcla estequiométrica AtinAhid, prensada a 10, 40 y $100 \mathrm{MPa}$ y calcinadas a $1550{ }^{\circ} \mathrm{C}$ durante 4 horas.

Comparando estos valores de densidad (tabla 7.5) con los de la mezcla AtinAcal (tabla 7.3) se apreció que la mezcla a AtinAhid mostró valores un poco más altos de densidad de la pieza y densidad aparente en agua (del sólido).

Respecto a la variación lineal, la contracción observada se explica debido a que a alta temperatura la sílice difunde hacia el interior de la alúmina porosa generada por la deshidratación del hidróxido de aluminio, generando mullita en el interior de la misma, el fenómeno expansivo de ésta es anulado porque es neutralizada por los huecos de los poros, por lo que el fenómeno observado es solo sinterización, evidenciándose esto en la variación lineal respecto al conformado, donde se presentó un valor alto de contracción, en comparación a la mezcla AtinAcal la cual había mostrado expansión, (tabla 7.3).

\subsubsection{Distribución de tamaño de poro por intrusión de mercurio de la mezcla AtinAhid.}

Se realizó el ensayo de porosimetría por intrusión de mercurio a la mezcla AtinAhid obtenida a una presión de $40 \mathrm{MPa}$ y calcinada a $1550 \stackrel{\circ}{\circ} \mathrm{C}$ durante 4 horas, en la figura 
7.19 se puede observar la curva de distribución de volumen acumulado de poros en función del diámetro de poro.

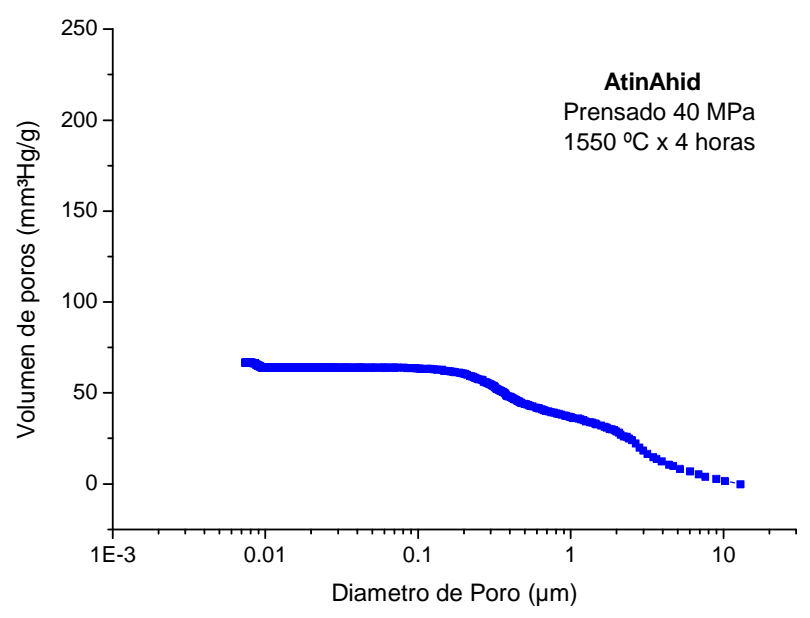

Figura 7.19. Curva de distribución de tamaño de poros por intrusión de mercurio para la mezcla AtinAhid prensada a $40 \mathrm{MPa}$ y calcinada $1550 \stackrel{\circ}{ } \mathrm{C}$ durante 4 horas.

Se puede observar en la figura 7.19 que la mezcla AtinAhid calcinada a la temperatura indicada, presenta una distribución de tamaño de poros amplia y bimodal, donde el diámetro de poro más frecuente está en $0.31 \mu \mathrm{m}$, posiblemente existan tamaños de poros más pequeños pero el equipo utilizado no los detectó. [Lowell y Shields, 1991; Pospech y Schneider, 1989; Washburn, 1921]. Se observó también que hay una existencia apreciable de poros en el intervalo de $12.8-2.9 \mu \mathrm{m}$, caso no observado en la mezcla AtinAcal.

La confrontación de estos resultados con la porosidad obtenida por el método de Arquímedes (tabla 7.5), corrobora además que la mezcla AtinAhid posee pequeños poros abiertos que el ensayo de porosidad por intrusión en mercurio no los detectó, por estar debajo de su límite de medición. Las porosidades abiertas por Arquímedes son semejantes.

Comparando las figuras $7.10 \mathrm{~b}$ y 7.19 correspondientes a la mezcla AtinAcal y AtinAhid prensadas a $40 \mathrm{MPa}$, se observó que la mezcla que contiene alúmina calcinada mostró una distribución de poros en un rango más estrecho, mientras la mezcla que contiene alúmina hidratada mostró una distribución amplia, observándose poros mayores a $3 \mu \mathrm{m}$ deduciendo de la porosidad abierta total que existen poros menores a $7 \mathrm{~nm}$, si bien la 
alúmina hidratada como materia prima mostró una gran reactividad, no mostraron los productos homogeneidad textural (distribución de tamaño de poros) como para justificar un estudio sistemático más profundo, quizás otro hubiera sido el caso si se hubiera utilizado alúmina hidratada de igual tamaño que la calcinada, pero no está disponible comercialmente como material standard. No se realizó una molienda sobre la alúmina hidratada comercial ya que el propósito de ésta tesis fue utilizar materias primas de disponibilidad comercial.

\subsubsection{Propiedades termomecánicas de la mezcla AtinAhid.}

Las probetas elaboradas de la mezcla AtinAhid por el método de prensado y calcinadas a $1550 \stackrel{\circ}{\mathrm{C}}$ durante 4 horas, fueron caracterizadas termomecánicamente a través del módulo de rotura a la flexión (MOR1), módulo de elasticidad (E1), módulo de rotura a la flexión y módulo de elasticidad luego de un choque térmico (MOR2 y E2). Los valores obtenidos se muestran en la tabla 7.6.

Se puede observar en la tabla 7.6 los resultados de Módulo de Rotura a la flexión en tres puntos (MOR1) y el módulo de elasticidad (E1) de las probetas no sometidas al choque térmico, las cuales presentaron un incremento de su valor a medida que se aumentaba la presión, debido a una mayor cantidad de sólido sinterizado.

Respecto a los valores de los Módulos de Rotura y Elasticidad después del choque térmico (MOR2 y E2), el sistema se comportó de la misma forma que el punto anterior (MOR1 y E1), aunque mostraron que el choque térmico afectó las propiedades termomecánicas notándose esto con la disminución en sus valores con respecto a MOR1 y E1. [Hamidouche et al., 2003; Schneider 2008]. 
Tabla 7.6. Propiedades termomecánicas de las probetas obtenidas por el método de prensado para la mezcla AtinAhid calcinadas a $1550 \stackrel{\circ}{\mathrm{C}}$ durante 4 horas.

\begin{tabular}{|c|c|c|c|}
\hline & $10 \mathrm{MPa}$ & $40 \mathrm{MPa}$ & $100 \mathrm{MPa}$ \\
\hline $\begin{array}{l}\text { MÓDULO DE ELASTICIDAD } \\
(\mathrm{E} 1) \\
(\mathrm{GPa})\end{array}$ & 17.7 & 30.5 & 38.0 \\
\hline $\begin{array}{l}\text { MÓDULO DE ELASTICIDAD } \\
\text { Después de choque térmico } \\
\text { (E2) } \\
(\mathrm{GPa})\end{array}$ & 11.3 & 21.5 & 28.9 \\
\hline $\begin{array}{c}\text { RELACIÓN DE MÓDULOS } \\
\text { (E1/E2) }\end{array}$ & 1.5 & 1.4 & 1.3 \\
\hline $\begin{array}{l}\text { MÓDULO DE ROTURA A LA FLEXIÓN } \\
\text { (MOR1) } \\
(\mathrm{MPa})\end{array}$ & 21.9 & 22.6 & 31.5 \\
\hline $\begin{array}{l}\text { MÓDULO DE ROTURA A LA FLEXIÓN } \\
\text { Después de choque térmico } \\
\text { (MOR 2) } \\
(\mathrm{MPa})\end{array}$ & 10.1 & 11.9 & 13.0 \\
\hline $\begin{array}{l}\text { RELACIÓN DE MÓDULOS } \\
\text { (MOR1/MOR2) }\end{array}$ & 2.1 & 1.9 & 2.3 \\
\hline
\end{tabular}

La figura 7.20, representa los resultados de la tabla 7.6, evidenciándose de una mejor forma los cambios de las propiedades termomecánicas antes y después del choque térmico. 


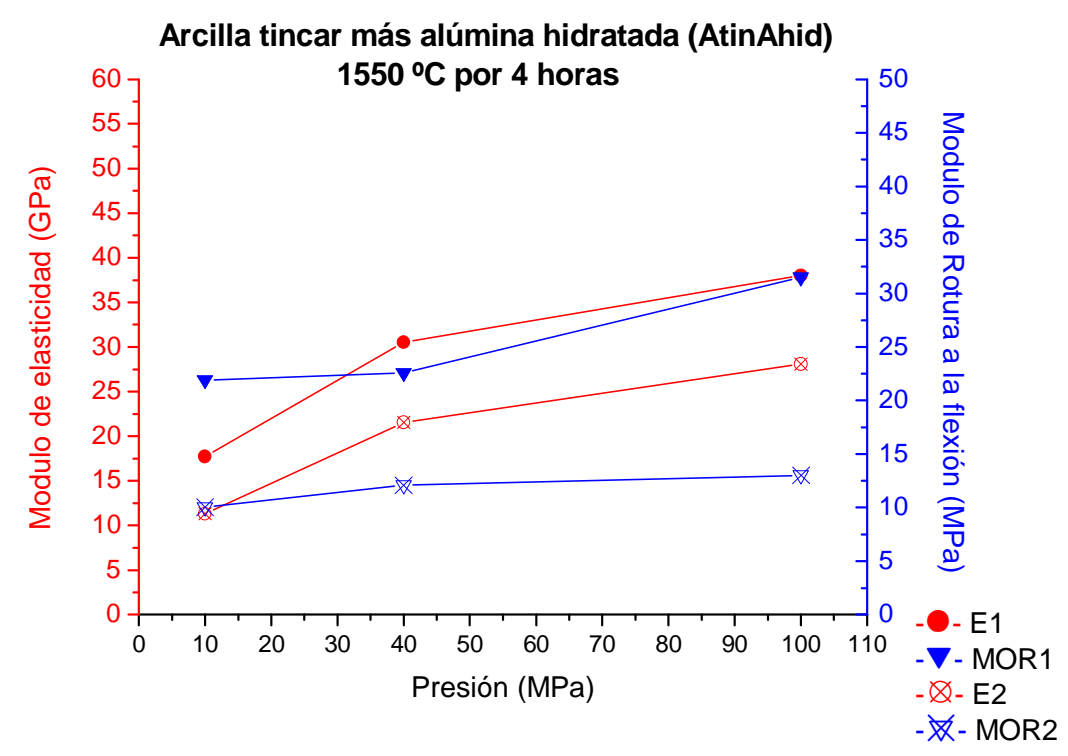

Figura 7.20. Módulo de elasticidad y módulo de rotura a la flexión antes (E1 y MOR1) y después del choque térmico (E2 y MOR2), para la muestra AtinAhid prensada a 10, 40 y $100 \mathrm{MPa}$, calcinadas a $1550 \stackrel{\circ}{\mathrm{C}}$ durante 4 horas.

Comparando los resultados de las propiedades termomecánicas de la mezcla estequiométrica 3-2 de arcilla Tincar Súper más alúmina calcinada (AtinAcal) con la de alúmina hidratada (AtinAhid), se observaron que los resultados de MOR1 y E1 fueron mayores para la mezcla con alúmina calcinada (AtinAcal) respecto a la mezcla con alúmina hidratada (AtinAhid), esto debido a que la alúmina hidratada contiene núcleos cerrados no conectados con el exterior donde en su interior hay un sistema poroso de alúmina no totalmente sinterizado y por ende de baja resistencia mecánica, originando que la fractura se propague fácilmente dentro de dichos núcleos, y sea absorbida por ellos haciendo mayor su resistencia a la propagación de la fractura (ver sección 4.2.2).

Respecto al Módulo de Rotura a la flexión después del choque térmico (MOR2), se pudo observar que la mezcla con alúmina hidratada (AtinAhid) presentó una mayor resistencia a la flexión que la AtinAcal, debido a que la alúmina hidratada generó poros cerrados conteniendo alúmina porosa que sirven como centros de absorción y neutralización de esa energía de fractura, y poros abiertos muy pequeños no detectados por la técnica de mercurio que impiden la propagación de la misma en mayor intensidad que para la mezcla con alúmina calcinada. Se puede observar también el mejor desempeño en el choque térmico en la mezcla con alúmina hidratada, en la relación de módulos. 


\subsubsection{Caracterización de la mezcla AtinAcal, conformada por el método de colado y calcinada a $1550 \stackrel{\circ}{\circ}$ durante 4 horas.}

Se estudió el conformado de piezas por el método de colado en moldes de yeso de suspensiones acuosas a partir de una mezcla esteqiométrica $3 \mathrm{Al}_{2} \mathrm{O}_{3} \cdot 2 \mathrm{SiO}_{2}$ utilizando arcilla Tincar Súper y alúmina calcinada (AtinAcal), tabla 4.8.

La elaboración de las probetas por colado en moldes de yeso (tamaño de las probetas $6.0 \times 0.80 \times 0.80 \mathrm{~cm}^{3}$ ), consistió en el vertido de la suspensión mezcla AtinAcal en un molde de yeso poroso que produce la eliminación del agua a través de sus poros, esto hace que la pasta se consolide y contraiga pudiéndose a continuación extraer la pieza del molde después de 24 horas. La suspensión acuosa poseía un 78 \%p/p de sólidos en agua destilada, utilizándose como dispersante una solución de poliacrilato de amonio diluido al $10 \%$

Luego de desmoldadas las probetas se secaron a $110^{\circ} \mathrm{C}$ y posteriormente se calcinaron a $1550{ }^{\circ} \mathrm{C}$ durante 4 horas con una rampa de calentamiento de $5 \mathrm{C} / \mathrm{min}$. La caracterización de las probetas calcinadas se realizó por: Difracción de Rayos X (DRX), densidad, y porosidad por el método de Arquímedes, variación lineal respecto al conformado del material seco $\left(110{ }^{\circ} \mathrm{C}\right)$, microscopía electrónica de barrido (MEB), módulo de rotura a la flexión (MOR1), módulo de elasticidad (E1), módulo de rotura a la flexión y módulo de elasticidad luego de un choque térmico (MOR2 y E2).

\subsubsection{Difractograma de la mezcla AtinAcal.}

La figura 7.21 muestra el difractograma de Rayos $X$ de la mezcla AtinAcal elaborada por el método de colado y calcinada a $1550 \stackrel{\circ}{\circ}$ durante 4 horas. 


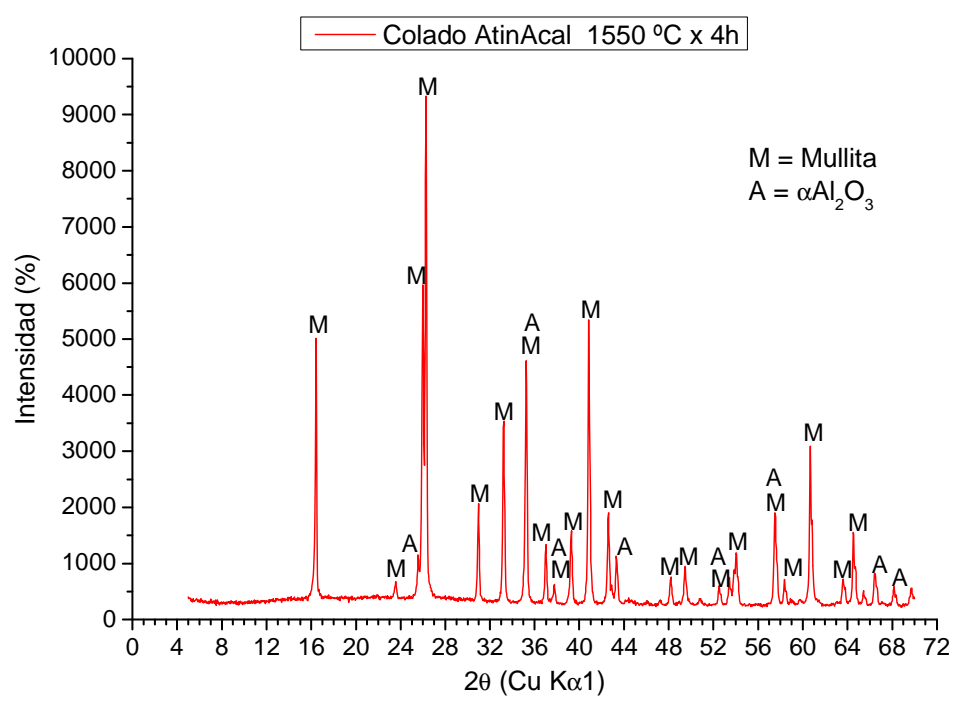

Figura 7.21. Difractograma de la mezcla AtinAcal conformada por el método de colado y calcinada a $1550 \stackrel{\circ}{\circ}$ durante 4 horas.

En el difractograma de la figura 7.21 se observa la presencia de dos fases: mullita (neta) como fase principal y mayoritaria, siendo la otra fase $\alpha$-alúmina en muy pequeña cantidad. [Pankratz et al., 1963; Shigeo y Rustum, 1962].

\subsubsection{Propiedades físicas de la mezcla AtinAcal.}

Las probetas obtenidas por el método de colado y calcinadas a $1550{ }^{\circ} \mathrm{C}$ durante 4 horas, se caracterizaron midiendo el porcentaje de variación lineal respecto al conformado del material seco a $110 \stackrel{\circ}{\circ}$ y utilizando el método de Arquímedes por inmersión en agua, se obtuvieron valores de densidad del material, densidad aparente en agua y el porcentaje de porosidad (abierta), mientras el porcentaje de porosidad cerrada se calculó en base al valor teórico de la mullita $\left(3.17 \mathrm{~g} / \mathrm{cm}^{3}\right)$. La tabla 7.7, muestra los resultados obtenidos.

Se observa en la tabla 7.7 que el valor de la densidad del sólido es menor al valor teórico de mullita $\left(3.17 \mathrm{~g} / \mathrm{cm}^{3}\right)$, debido a la cantidad de poros cerrados. 
Tabla 7.7 Propiedades físicas de la mezcla AtinAcal obtenida por el método de colado y calcinadas a $1550{ }^{\circ} \mathrm{C}$ durante 4 horas.

\begin{tabular}{|c|c|}
\cline { 2 - 2 } \multicolumn{1}{c|}{} & $\begin{array}{c}\text { Arcilla Tincar + Alúmina Calcinada } \\
\text { (AtinAcal) }\end{array}$ \\
\hline $\begin{array}{c}\text { POROSIDAD (Abierta) } \\
\%\end{array}$ & 37.3 \\
\hline $\begin{array}{c}\text { POROSIDAD (Cerrada) } \\
\text { \%/cm }\end{array}$ & 7.6 \\
\hline $\begin{array}{c}\text { DENSIDAD DE LA PIEZA (Arquímedes) } \\
\text { (Del sólido) } \\
\text { g/cm }\end{array}$ & 1.84 \\
\hline DENSIDAD APARENTE EN AGUA & 2.93 \\
\hline $\begin{array}{c}\text { VARIACIÓN LINEAL respecto al conformado } \\
\text { del material seco a 110 }{ }^{\circ} \text { C }\end{array}$ & +2.5 \\
\hline
\end{tabular}

Comparando los resultados de las propiedades físicas obtenidas por el método de colado (tabla 7.7) con el método de prensado a 10, 40 y $100 \mathrm{MPa}$ (tabla 7.3), se observó que; los valores del porcentaje de porosidad abierta, densidad de la pieza y la variación lineal respecto al conformaron se asemejan a los resultados obtenidos a una presión de $10 \mathrm{MPa}$, mientras los valores de porosidad cerrada y densidad aparente en agua se asemejan a los mostrados a una presión de $40 \mathrm{MPa}$.

Por lo tanto los resultados de las propiedades físicas obtenidas por el método de colado (tabla 7.7) se encuentran en términos comparativos en un rango de prensado de 10 a 40 MPa.

\subsubsection{Distribución de tamaño de poro por intrusión de mercurio de la mezcla AtinAcal.}

La curva de distribución de tamaño de poros, volumen de poros acumulado, en función del diámetro de poro para la mezcla AtinAcal obtenida por el método de colado y calcinada a $1550 \stackrel{\circ}{ } \mathrm{C}$ durante 4 horas, se obtuvo a partir de la técnica de porosimetría por intrusión de mercurio, ver figura 7.22. 


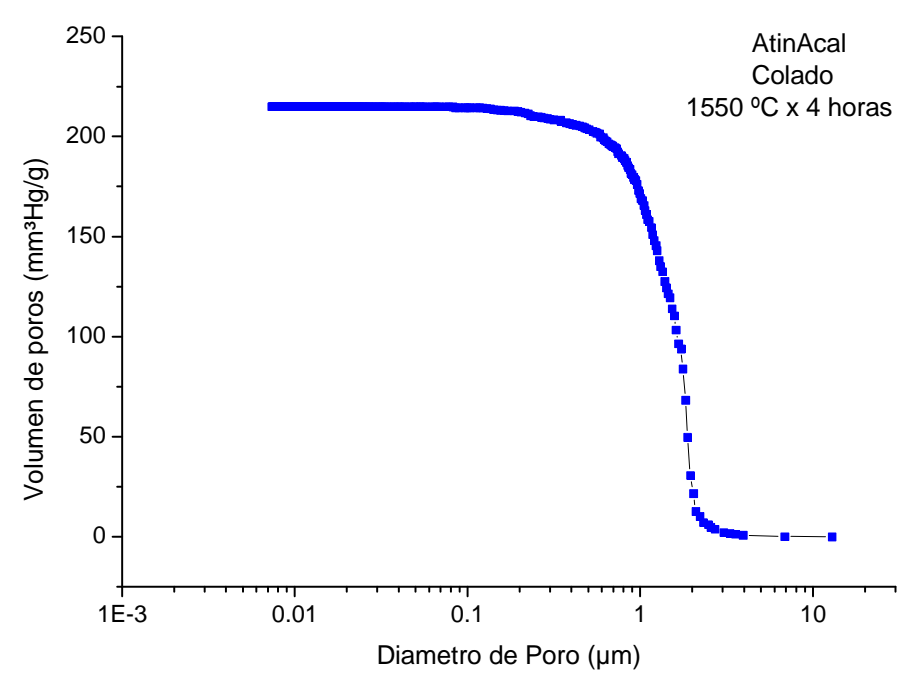

Figura 7.22. Curva de distribución de tamaño de poros por intrusión de mercurio (volumen de poro acumulado vs diámetro de poro) para la mezcla AtinAcal obtenida por el método de colado calcinada a $1550 \stackrel{\circ}{\mathrm{C}}$ durante 4 horas.

La figura 7.22 muestra la curva de distribución de tamaño de poros (abiertos) para la mezcla AtinAcal obtenida por el método de colado y calcinada como se indicó, donde se puede observar que prácticamente el desarrollo de poros abiertos se encuentra entre un diámetro de poros de 2.7 y $0.6 \mu \mathrm{m}$ y su volumen de poros total penetrado es 215 $\mathrm{mm}^{3} \mathrm{Hg} / \mathrm{g}$, encontrándose que el diámetro de poro más frecuente se localiza en $1.8 \mu \mathrm{m}$.

Comparando estos resultados con los obtenidos por el método de prensado (figura 7.10) se concluye que el diámetro más frecuente es similar a la prensada a $10 \mathrm{MPa}$, al igual que el máximo volumen de poros.

\subsubsection{Micrografías de la mezcla AtinAcal (mullita neta).}

El análisis de microscopía electrónica de barrido (MEB) se realizó para la mezcla AtinAcal conformada por el método de colado y calcinada a la temperatura que se indicó anteriormente, la cual fue incluida y pulida, como se indicó en la sección 3.7. A la mitad de la muestra se le realizó un etching químico con ácido fluorhídrico al $5 \%$, durante 10 minutos, con el objetivo de eliminar la fase vítrea generada en el sistema. Las micrografías se muestran en la figura 7.23. 
Las micrografías de la figura 7.23 corresponden a la superficie de contacto entre el exterior de la mezcla y el molde de colado (yeso), observándose en la micrografía sin etching químico (figura 7.23 a y b) la formación de cristales de mullita de forma acicular y la presencia de sinterizado del material, no habiendo un ordenamiento específico, ni un tamaño homogéneo y para las que sufrieron el etching químico (HF al $5 \%$ ) durante 10 minutos (figura 7.23 c y7.23d) revelaron que parte de la fase vítrea que está ligando a la mullita se ha destruido parcialmente con el ataque, aunque su visualización es dificultosa.

Comparando los resultados de microscopía electrónica de barrido de la mezcla AtinAcal conformada por el método de prensado (figuras $7.12,7.13$ y 7.14) con el de colado (figura 7.23) después de realizado el ataque químico con ácido fluorhídrico al $5 \%$ durante 10 minutos, se concluyó que el sistema acuoso (método de colado) es muy similar al prensado a $10 \mathrm{MPa}$, esto debido a que los dos sistemas no presentaron una fuerza mecánica o fricción intensa que oriente las laminitas del material de la superficie en un determinado sentido, no dejando en descubierto la memoria laminar de la mezcla que se manifestó como mullita en forma de láminas levantadas en sobre relieve como se observó en casos de alta presión de prensado (40 y $100 \mathrm{MPa}$ ), (figuras $7.13 \mathrm{~d}$ y $7.14 \mathrm{~d}$ ). 


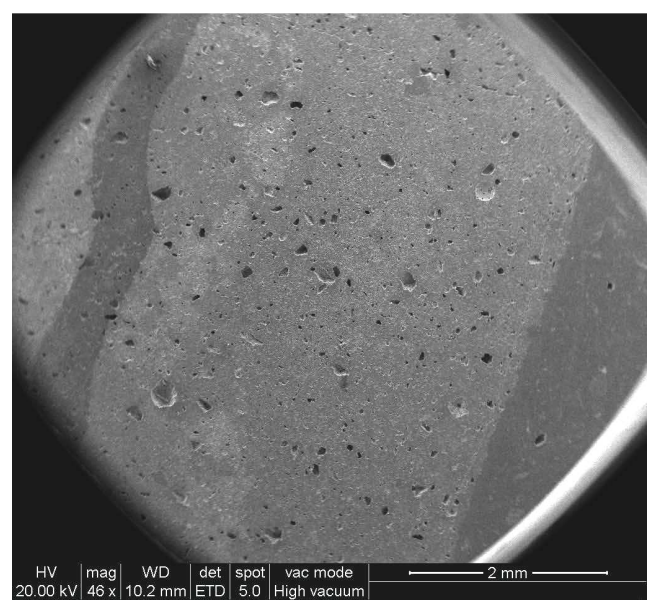

(a)

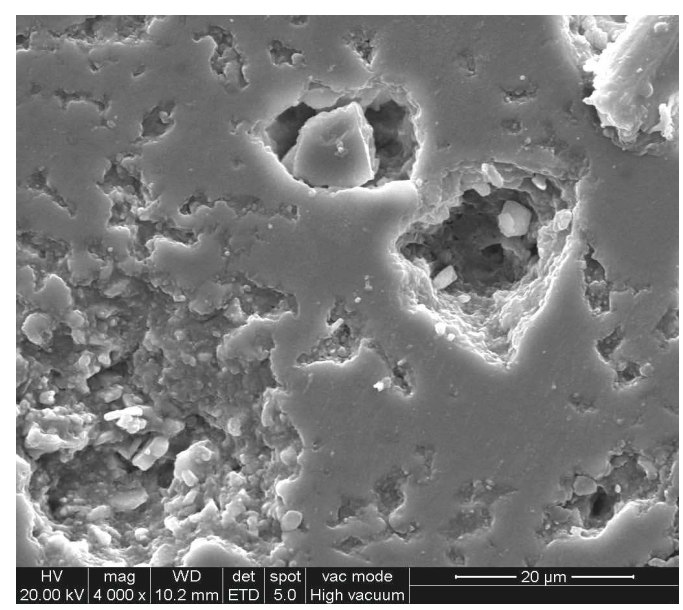

(c)

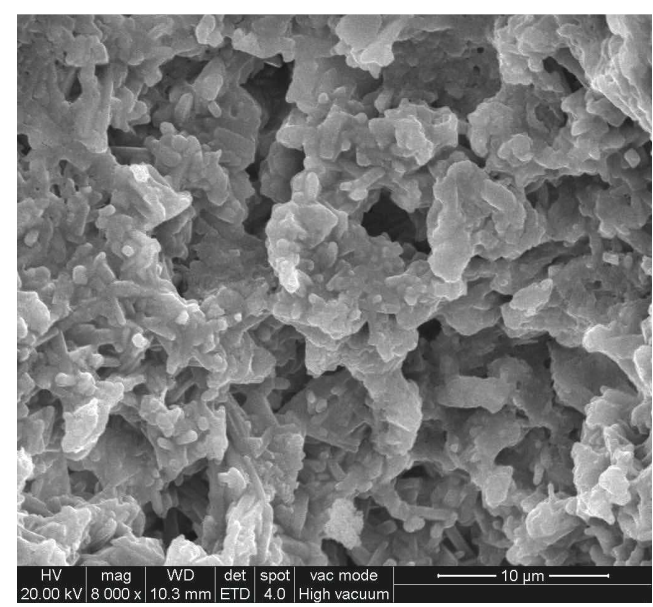

(b)

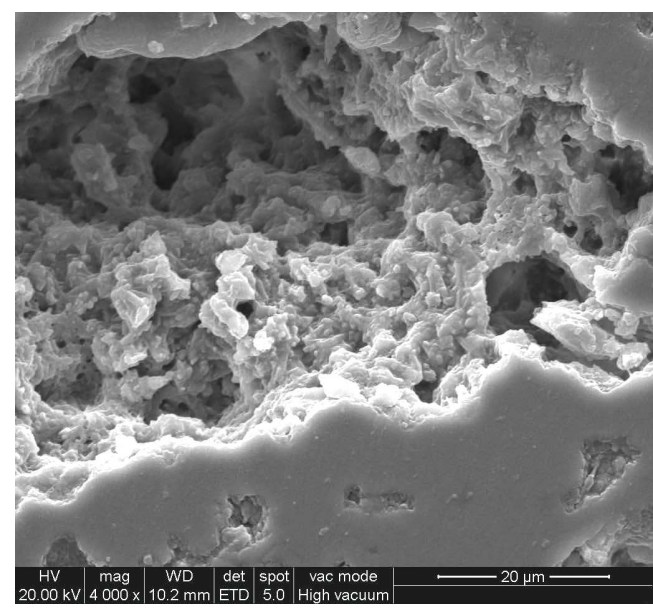

(d)

Figura 7.23. Micrografía de AtinAcal, obtenida por el método de colado y calcinada a $1550 \stackrel{\circ}{\circ}$ durante 4 horas; sin etching químico: a) 46x, b) $8000 x$, y con etching químico (HF 5\%), c) y d) 4000x.

\subsubsection{Propiedades termomecánicas de la mezcla AtinAcal.}

Las probetas obtenidas de mezcla estequiométrica 3-2 de arcilla Tincar Súper mas alúmina calcinada (AtinAcal) conformadas por el método de colado y calcinadas a 1550 ○C durante 4 horas se caracterizaron utilizando el módulo de rotura a la flexión y módulo 
de elasticidad antes (MOR1 y E1) y después (MOR2 y E2) del choque térmico anteriormente mencionado. Los valores calculados se muestran en la tabla 7.8.

Tabla 7.8. Propiedades termomecánicas de la mezcla AtinAcal obtenidas por el método de colado y calcinadas a $1550^{\circ} \mathrm{C}$ durante 4 horas.

\begin{tabular}{|c|c|}
\hline & $\begin{array}{l}\text { Arcilla tincar + Alúmina Calcinada } \\
\qquad \text { (AtinAcal) }\end{array}$ \\
\hline $\begin{array}{l}\text { MÓDULO DE ELASTICIDAD } \\
\text { (E1) } \\
(\mathrm{GPa})\end{array}$ & 44.3 \\
\hline $\begin{array}{l}\text { MÓDULO DE ELASTICIDAD } \\
\text { Después de choque térmico } \\
\text { (E2) } \\
\text { (GPa) }\end{array}$ & 7.5 \\
\hline $\begin{array}{l}\text { RELACIÓN DE MÓDULOS } \\
\text { (E1/E2) }\end{array}$ & 5.9 \\
\hline $\begin{array}{l}\text { MÓDULO DE ROTURA A LA FLEXIÓN } \\
\text { (MOR1) } \\
\text { (MPa) }\end{array}$ & 45.7 \\
\hline $\begin{array}{l}\text { MÓDULO DE ROTURA A LA FLEXIÓN } \\
\text { Después de choque térmico } \\
\text { (MOR 2) } \\
\text { (MPa) }\end{array}$ & 9.6 \\
\hline $\begin{array}{l}\text { RELACIÓN DE MÓDULOS } \\
\text { (MOR1/MOR2) }\end{array}$ & 4.8 \\
\hline
\end{tabular}

En la tabla 7.8 se puede observar que el choque térmico realizado produce una disminución en las propiedades termomecánicas del módulo de elasticidad (E2) y módulo de rotura (MOR2) con respecto a E1 y MOR1. [Absi y Glandus, 2004; Aksel y Warren, 2003].

Comparando los resultados obtenidos por el método de colado (tabla7.8) y de prensado a distintas presiones (tabla7.4), se observó que no presentan una similitud coherente de sus propiedades termomecánicas. 


\subsubsection{Caracterización de la mezcla AtinAcal, conformada por el método de extrusión y calcinada a $1550 \stackrel{\circ}{\circ}$ durante 4 horas.}

Se estudió el conformado de piezas elaboradas por el método de extrusión aplicando un vacío de $162.08 \mathrm{hPa}$, para la mezcla estequiométrica 3-2 de arcilla Tincar Súper más alúmina calcinada (AtinAcal), elaborando primero una masa de la mezcla en estudio con un porcentaje de humedad del $21 \%$ (agua más carboximetil celulosa al $2.5 \%$ ). Para obtener una buena homegenizacion se utilizó una mezcladora industrial (Macotest), a posteriori a la masa se la dejó bien sellada en bolsa plástica durante 1 día para conseguir una buena maduración y homogenización de humedad. Después del tiempo transcurrido la masa fue introducida en la extrusora, obteniendo tiras largas, que posteriormente fueron cortadas a un tamaño de $\sim 5.3 \times 0.8 \times 0.8 \mathrm{~cm}^{3}$, secadas a $110 \mathrm{C}$ y calcinadas a $1550^{\circ} \mathrm{C}$ durante 4 horas (figura 7.6). Las probetas fueron caracterizadas utilizando: Difracción de Rayos X (DRX), densidad, y porosidad por el método de Arquímedes, porosimetría por intrusión de mercurio, microscopía electrónica de barrido (MEB), variación lineal respecto al conformado del material seco (110), módulo de rotura a la flexión (MOR1), módulo de elasticidad (E1), módulo de rotura a la flexión y módulo de elasticidad luego de un choque térmico (MOR2 y E2).

\subsubsection{Difractograma de la mezcla AtinAcal.}

La probeta de la mezcla AtinAcal obtenida por el método de extrusion y calcinada a $1550{ }^{\circ} \mathrm{C}$ durante 4 horas fue caracterizada por DRX, con el fin de conocer las fases cristalinas presentes en el sistema, la figura 7.24 muestra el difractograma obtenido. 


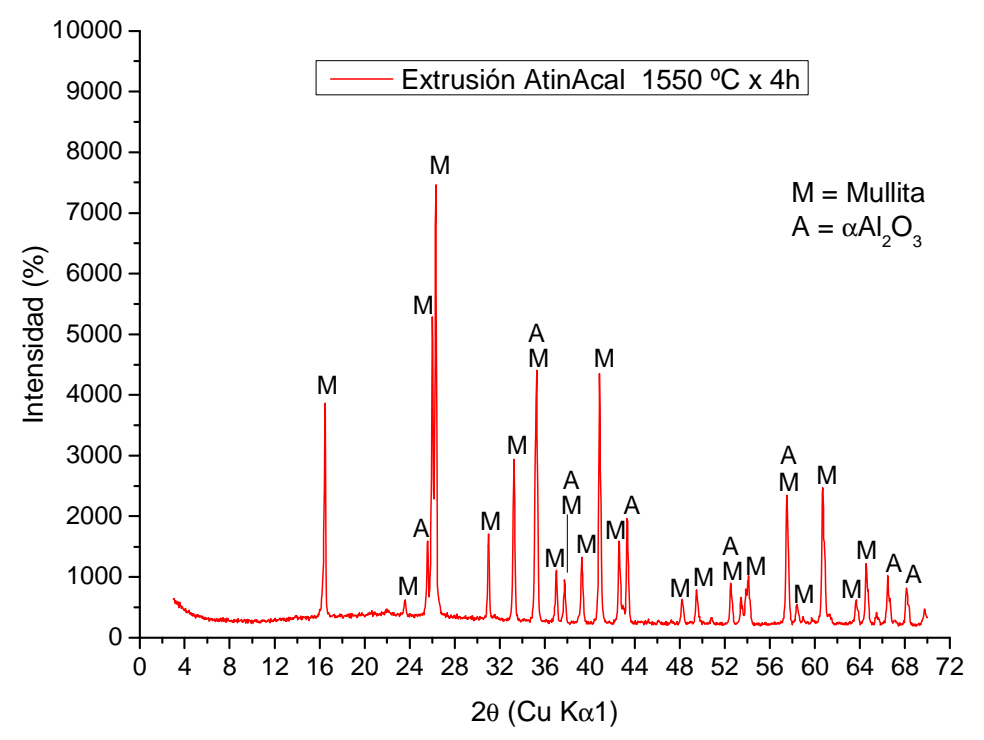

Figura 7.24. Difractograma de la mezcla AtinAcal conformada por el método de extrusión, calcinada a $1550^{\circ} \mathrm{C}$ durante 4 horas.

El difractograma de la figura 7.24 muestra que la mullita (neta) es la fase principal y mayoritaria, encontrándose también $\alpha$-alúmina en pequeña cantidad. Se observa una leve banda centrada en $22^{\circ}$ de $2 \theta$, indicando esto la presencia de fase vítrea de matriz silícea.

\subsubsection{Propiedades físicas de la mezcla AtinAcal.}

Las probetas obtenidas por extrusión y calcinadas a $1550{ }^{\circ} \mathrm{C}$ durante 4 horas, se caracterizaron, utilizando el método de Arquímedes por inmersión en agua obteniendo valores del porcentaje de porosidad (abierta), densidad del material y densidad aparente en agua. El porcentaje de porosidad cerrada se calculó en base al valor teórico de la mullita $\left(3.17 \mathrm{~g} / \mathrm{cm}^{3}\right)$, además se midió el porcentaje de variación lineal respecto al conformado del material seco a $110^{\circ} \mathrm{C}$. Los valores obtenidos se muestran en la tabla 7.9 .

En la tabla 7.9 se puede observar que el valor de densidad aparente en agua (sólido) es menor al valor teórico de la mullita $3.17 \mathrm{~g} / \mathrm{cm} 3$, esto debido al porcentaje de poros cerrados generados en el sistema. 
Tabla 7.9. Propiedades físicas de la mezcla AtinAcal obtenida por el método de extrusión y calcinada a $1550 \stackrel{\circ}{\mathrm{C}}$ durante 4 horas.

\begin{tabular}{|c|c|}
\hline & $\begin{array}{l}\text { Arcilla Tincar + Alúmina Calcinada } \\
\qquad(\text { AtinAcal) }\end{array}$ \\
\hline $\begin{array}{c}\text { POROSIDAD (Abierta) } \\
\%\end{array}$ & 34.7 \\
\hline $\begin{array}{c}\text { POROSIDAD (Cerrada) } \\
\%\end{array}$ & 6.6 \\
\hline $\begin{array}{l}\text { DENSIDAD DE LA PIEZA (Arquímedes) } \\
\qquad \mathrm{g} / \mathrm{cm}^{3}\end{array}$ & 1.93 \\
\hline $\begin{array}{c}\text { DENSIDAD APARENTE EN AGUA } \\
\text { (Del sólido) } \\
\mathrm{g} / \mathrm{cm}^{3}\end{array}$ & 2.96 \\
\hline $\begin{array}{l}\text { VARIACIÓN LINEAL respecto al conformado } \\
\text { del material seco }\left(110^{\circ} \mathrm{C}\right) \\
\%\end{array}$ & +1.3 \\
\hline
\end{tabular}

Confrontando los resultados obtenidos (tabla 7.9) con los del método de prensado a 10 , 40 y $100 \mathrm{MPa}$ (tabla 7.3) se puede concluir que las propiedades físicas como porosidad (abierta y cerrada) y densidad (pieza y sólido) del método de extrusión son similares a las obtenidas a una presión de $40 \mathrm{MPa}$. [Penty et al., 1972]. Mientras el valor de la variación lineal respecto al conformado mostró un valor menor de expansión en comparación a las 3 presiones.

\subsubsection{Distribución de tamaño de poro por intrusión de mercurio de la mezcla AtinAcal.}

A las probetas AtinAcal obtenidas por el método de extrusión y calcinada a $1550{ }^{\circ} \mathrm{C}$ durante 4 horas, se les determinó la distribución de tamaño de poro por porosimetría por intrusión de mercurio, obteniendo la curva de distribución de tamaño de poro (volumen acumulado de poro vs diámetro), ver figura 7.25. 


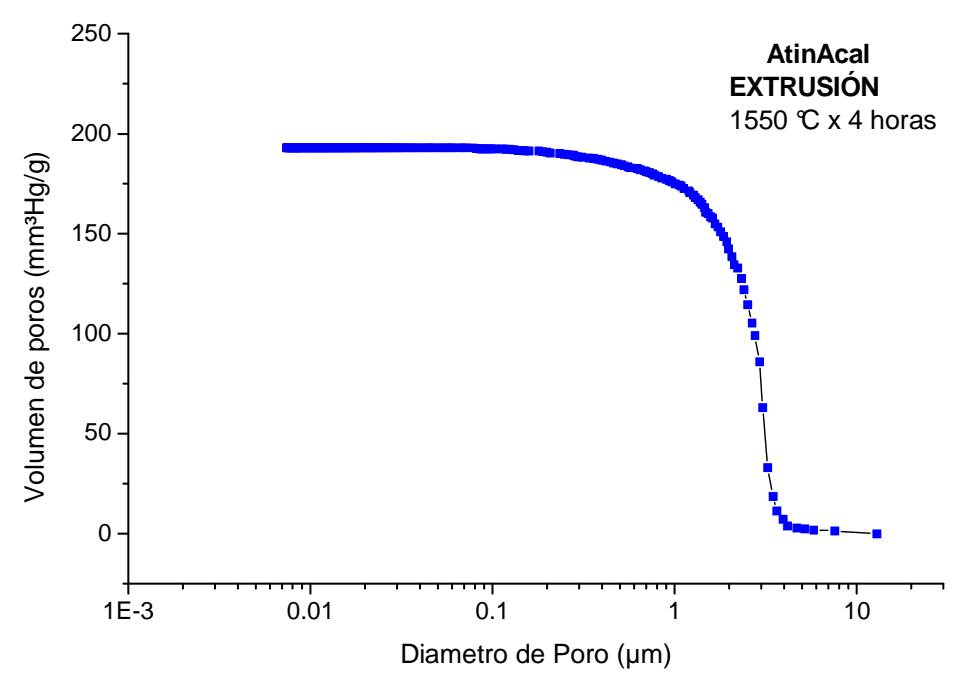

Figura 7.25. Curva de distribución de tamaño de poros por intrusión de mercurio para la mezcla AtinAcal obtenida por el método de extrusión calcinada a $1550 \stackrel{\circ}{\mathrm{C}}$ durante 4 horas.

En la figura 7.25 se puede observar la curva de distribución de tamaño de poros monomodal (abiertos) encontrándose prácticamente su desarrollo entre un diámetro de 3.9 y $0,9 \mu \mathrm{m}$, y su volumen total de poros penetrados es de $193 \mathrm{~mm}^{3} \mathrm{Hg} / \mathrm{g}$, estando su diámetro de poros más frecuente de $2,9 \mu \mathrm{m}$, siendo este dato ligeramente superior a los obtenidos por el método de prensado.

\subsubsection{Microscopia electrónica de barrido de la mezcla AtinAcal.}

El análisis de microscopía electrónica de barrido se realizó para la mezcla AtinAcal conformada por el método de extrusión y calcinada a $1550 \stackrel{\circ}{\mathrm{C}}$ durante 4 horas, posteriormente se incluyó la misma en resina y se pulió como se indicó en la sección 3.7. A la mitad de la muestra se le efectúo un etching químico con ácido fluorhídrico al 5 $\%$, durante 10 minutos, con el fin de eliminar la fase vítrea formada en el sistema. La figura 7.26 muestra las micrografías mencionadas antes y después del etching químico. 


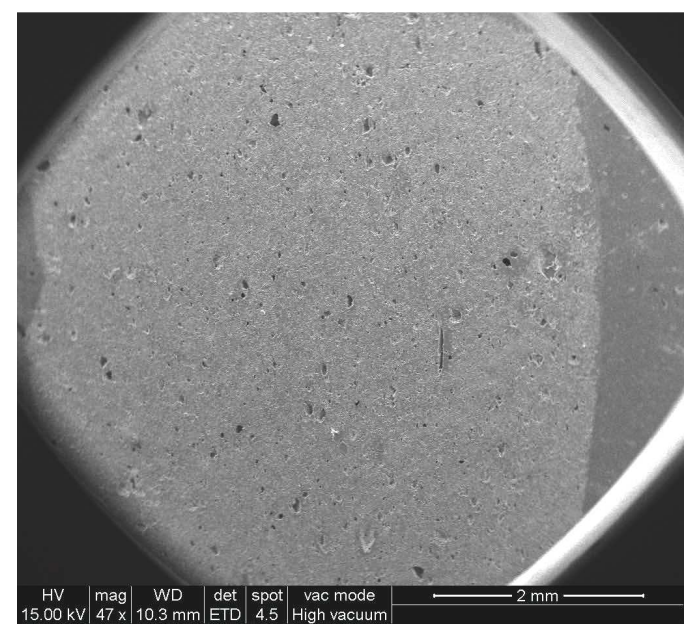

(a)

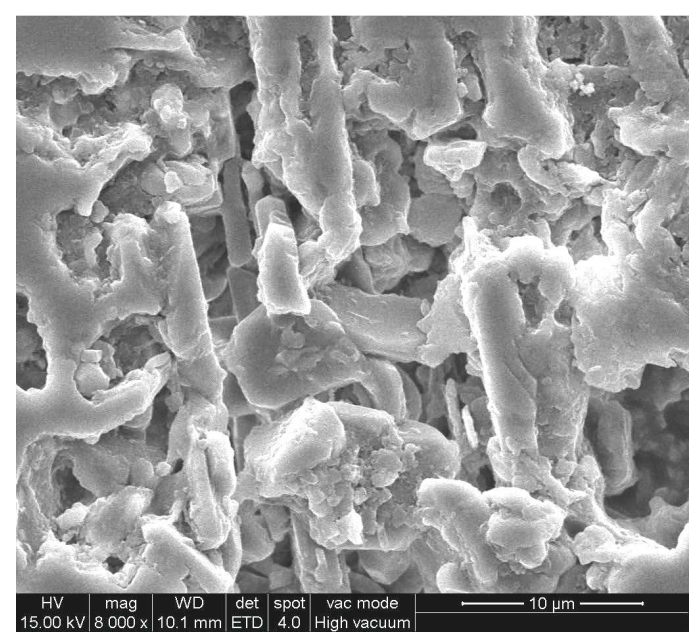

(c)

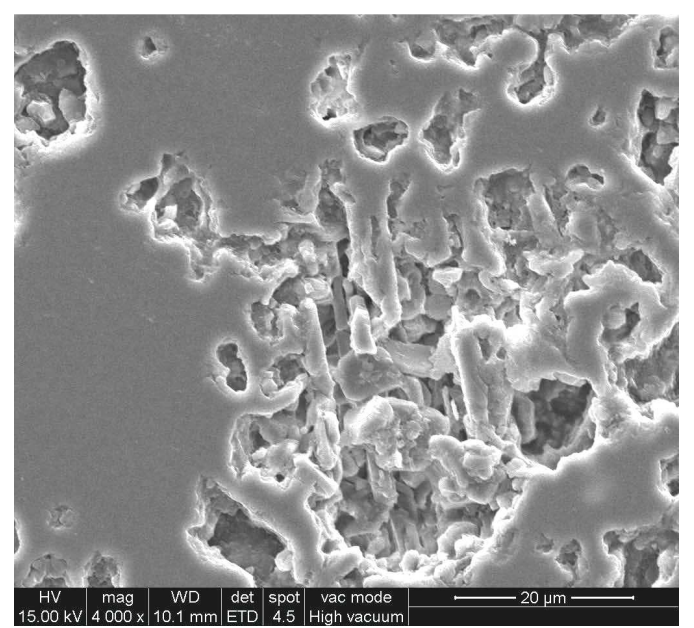

(b)

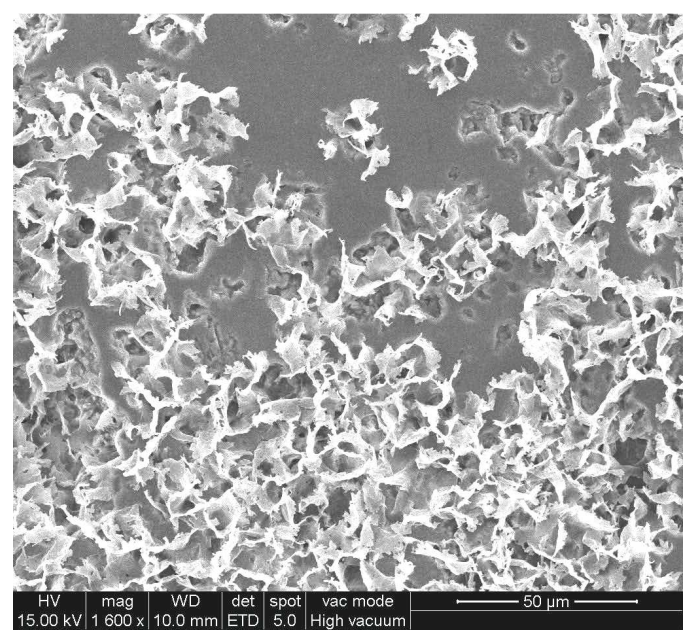

(d) 


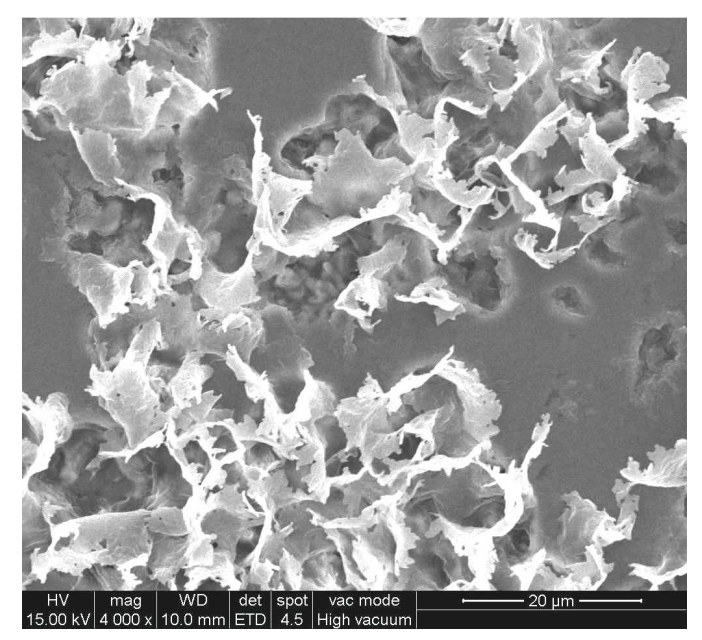

(e)

Figura 7.26 Micrografía de AtinAcal, obtenida por el método de extrusión y calcinada a $1550{ }^{\circ} \mathrm{C}$ durante 4 horas; sin etching químico: a) 47x, b) 4000x, c) 8000x, y con etching químico (HF 5\%), d) 1600x y e) 4000x.

En las micrografías sin ataque químico (figuras 7.26b, 7.26c) se observaron la formación acicular (agujas o bastones) de mullita neta, y unas zonas de punta de bastón medio redondeadas que constituiría la zona de sinterizado del material, no alcanzando un ordenamiento definido, ni un tamaño homogéneo. [Douy, 2006; Ester et al., 2005; Goldstein et al., 2003].

Y para las micrografías que sufrieron el etching químico (HF al $5 \%$ ) durante 10 minutos (figura $7.26 \mathrm{~d}$ y $7.26 \mathrm{e}$ ) revelaron que parte de la fase vítrea que está ligando a la mullita se ha destruido parcialmente con el ataque, notándose igualmente que en las superficies vistas por microscopía de barrido para prensado que corresponden a la superficie en contacto con el exterior, mientras a que en el método de extrusión existe una compresión y fricción por desplazamiento del material en estudio. Esto se reveló como mullita en forma de láminas levantadas en sobre relieve, este fenómeno también se observó en el método de prensado a 40 y $100 \mathrm{MPa}$ en la zona superficial pero con mucha menor intensidad. 


\subsubsection{Propiedades termomecánicas de la mezcla AtinAcal.}

Las caracterizaciones termomecánicas de la mezcla estequiométrica 3-2 de arcilla Tincar Súper y alúmina Calcinada (AtinAcal) conformadas por el método de extrusión y calcinadas a la temperatura que se indicó anteriormente, se caracterizaron calculando el módulo de rotura a la flexión (MOR1), módulo de elasticidad (E1), módulo de rotura a la flexión y módulo de elasticidad luego de un choque térmico anteriormente mencionado (MOR2 y E2). Los valores calculados se muestran en la tabla 7.10.

Tabla 7.10. Propiedades termomecánicas de la mezcla AtinAcal obtenidas por el método de extrusión y calcinada a $1550 \stackrel{\circ}{\mathrm{C}}$ durante 4 horas.

\begin{tabular}{|c|c|}
\hline & $\begin{array}{c}\text { Arcilla Tincar + Alúmina Calcinada } \\
\text { (AtinAcal) }\end{array}$ \\
\hline $\begin{array}{c}\text { MÓDULO DE ELASTICIDAD } \\
\text { (E1) } \\
\text { (GPa) }\end{array}$ & 36.4 \\
\hline $\begin{array}{l}\text { MÓDULO DE ELASTICIDAD } \\
\text { Después de choque térmico } \\
\text { (E2) } \\
(\mathrm{GPa})\end{array}$ & 24.1 \\
\hline $\begin{array}{l}\text { RELACIÓN DE MÓDULOS } \\
\text { (E1/E2) }\end{array}$ & 1.5 \\
\hline $\begin{array}{c}\text { MÓDULO DE ROTURA A LA FLEXIÓN } \\
\text { (MOR1) } \\
\text { (MPa) }\end{array}$ & 65.1 \\
\hline $\begin{array}{c}\text { MÓDULO DE ROTURA A LA FLEXIÓN } \\
\text { Después de choque térmico } \\
\text { (MOR 2) } \\
\text { (MPa) }\end{array}$ & 11.3 \\
\hline $\begin{array}{l}\text { RELACIÓN DE MÓDULOS } \\
\text { (MOR1/MOR2) }\end{array}$ & 5.7 \\
\hline
\end{tabular}

En la tabla 7.10 se puede observar que el choque térmico realizado ocasiona una disminución en las propiedades termomecánicas del módulo de elasticidad (E2) y 
módulo de rotura (MOR2) con respecto a E1 y MOR1. [Christaras et al., 1994; Cotterel et al., 1995].

Contrastando los resultados obtenidos del método de extrusión (tabla 7.10) con el método de prensado (tabla7.4), se observó que no presentaron una similitud general para correlacionar los dos métodos de conformado, debido a que los módulos de elasticidad E1 y E2 presentaron una aproximación con los valores prensados a $10 \mathrm{MPa}$, mientras los valores de módulo de rotura a la flexión en tres puntos antes y después del choque térmico, presentaron valores mayores a los obtenidos a $100 \mathrm{MPa}$.

De todas formas la relación de módulos de elasticidad puede considerarse similar al de prensado a $100 \mathrm{MPa}$ y la relación de módulos de rotura a la flexión semejante a la de prensado a $10 \mathrm{MPa}$.

Esta información concluye en que desde el punto de vista de los módulos de elasticidad y módulos de rotura no se puede establecer una correlación del método de extrusión con los de prensado.

7.5 Propiedades físicas y termomecánicas de mullita estequiométrica 3-2 $\left(3 \mathrm{Al}_{2} \mathrm{O}_{3} \cdot 2 \mathrm{SiO}_{2}\right)$ obtenida a partir de arcilla La Rioja más alúmina calcinada (AriojAcal) ó hidratada (AriojAhid), conformadas por el método de prensado, colado y extrudado.

\subsubsection{Caracterización de la mezcla AriojAcal, conformada por el método de prensado $(10,40$ y $100 \mathrm{MPa})$ y calcinadas a $1550 \stackrel{\circ}{ } \mathrm{C}$ durante 4 horas.}

Se conformaron probetas por el método de prensado uniaxial a 10, 40 y $100 \mathrm{MPa}$ con formato prismático de aproximadamente $5.0 \times 0.8 \times 0.8 \mathrm{~cm}^{3}$, con una humedad de $\sim 11.6 \%$, para la mezcla estequiométrica 3-2 de arcilla La Rioja más alúmina calcinada (AriojAcal), las probetas fueron secadas a $110 \stackrel{\circ}{\circ}$ y calcinadas a $1550 \stackrel{\circ}{\mathrm{C}}$ durante 4 horas con una velocidad de calentamiento de $5 \stackrel{\circ}{\circ}$ por minuto, caracterizándolas física y termomecánicamente. 


\subsubsection{Difractogramas de la mezcla AriojAcal.}

Las probetas obtenidas por el método de prensado a 10, 40 y $100 \mathrm{MPa}$ de la mezcla AriojAcal y calcinadas a $1550 \stackrel{\circ}{\circ}$ durante 4 horas, se caracterizaron por Difracción de Rayos X, la figura 7.27 muestra los difractogramas obtenidos.

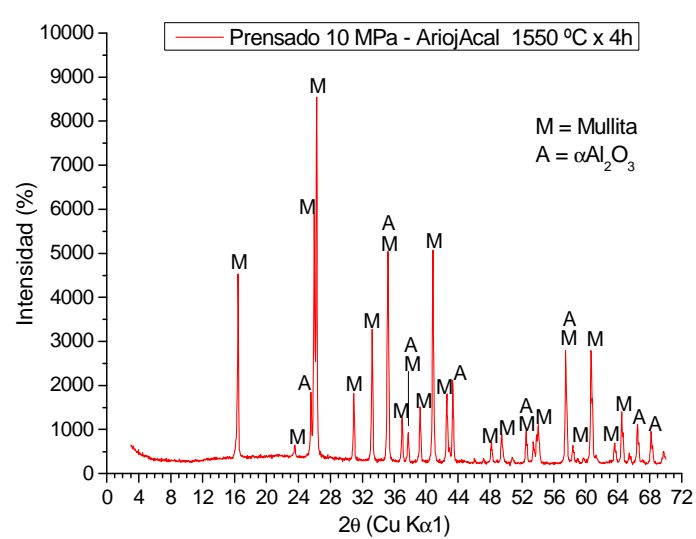

(a)

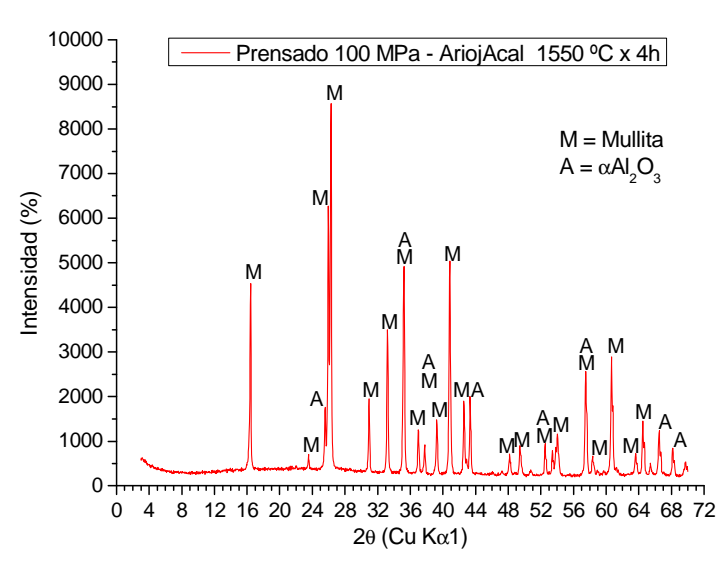

(c)

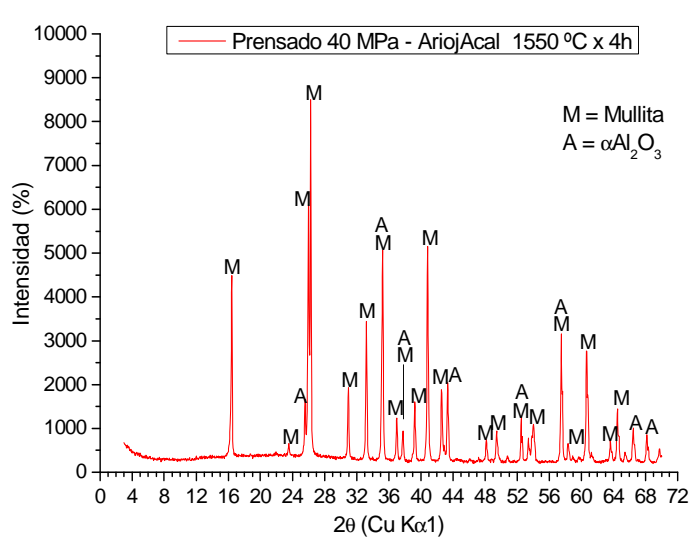

(b)

Figura 7.27. Difractogramas de la mezcla AriojAcal prensadas: a) $10 \mathrm{MPa}$, b) $40 \mathrm{MPa}, \mathrm{y}$ c) $100 \mathrm{MPa}$, y calcinadas a $1550 \stackrel{\circ}{\mathrm{C}}$ durante 4 horas. 
La figura 7.27 muestra los difractogramas de la mezcla AriojAcal conformada a tres presiones distintas (10, 40 y $100 \mathrm{MPa})$ y calcinadas como se indicó anteriormente, observándose en todos los casos la presencia de mullita neta como fase principal y mayoritaria y una poca cantidad de $\alpha$-alúmina, no presentando modificaciones apreciables a medida que se aumenta la presión.

\subsubsection{Propiedades físicas de la mezcla AriojAcal.}

Las caracterizaciones físicas de la mezcla estequiométrica 3-2 (AriojAcal) conformadas por prensado a 10, 40 y $100 \mathrm{MPa}$ y calcinadas a $1550{ }^{\circ} \mathrm{C}$ durante 4 horas, se realizaron midiendo el porcentaje de variación lineal respecto al conformado del material seco (110 ${ }^{\circ}$ C) y utilizando el método de Arquímedes por inmersión en agua obteniendo valores del porcentaje de porosidad (abierta), densidad del material y densidad aparente en agua, mientras que el porcentaje de porosidad cerrada se calculó en base al valor teórico de la mullita $\left(3.17 \mathrm{~g} / \mathrm{cm}^{3}\right)$. Los resultados adquiridos se muestran en la tabla 7.11.

Tabla 7.11. Propiedades físicas de las probetas conformadas por el método de prensado para la mezcla AriojAcal calcinadas a $1550 \stackrel{\circ}{C}$ durante 4 horas.

\begin{tabular}{|c|c|c|c|c|c|}
\hline PRESIÓN & $\begin{array}{c}\text { Porosidad } \\
\text { (Abierta) } \\
\%\end{array}$ & $\begin{array}{c}\text { Porosidad } \\
\text { (Cerrada) } \\
\%\end{array}$ & $\begin{array}{c}\text { Densidad de } \\
\text { la pieza } \\
\text { (Arquímedes) } \\
\mathbf{g} / \mathrm{cm}^{3}\end{array}$ & $\begin{array}{c}\text { Densidad } \\
\text { aparente en } \\
\text { agua (Del } \\
\text { sólido) } \\
\mathbf{g} / \mathrm{cm}^{3}\end{array}$ & $\begin{array}{c}\text { Variación } \\
\text { lineal } \\
\text { respecto al } \\
\text { conformado } \\
\text { del material } \\
\text { seco a 110C } \\
\%\end{array}$ \\
\hline $\mathbf{1 0} \mathbf{~ M P a}$ & 38.3 & 0.6 & 1.94 & 3.15 & -0.2 \\
\hline $\mathbf{4 0} \mathbf{~ M P a}$ & 34.2 & 0.9 & 2.06 & 3.14 & +0.2 \\
\hline $\mathbf{1 0 0} \mathbf{~ M P a}$ & 31.1 & 1.6 & 2.15 & 3.12 & +0.5 \\
\hline
\end{tabular}

La tabla 7.11 muestra que el porcentaje de porosidad abierta va disminuyendo, mientras la porosidad cerrada va aumentando a medida que se incrementa la presión, este comportamiento es lógico ya que a mayor presión mayor contacto entre partículas, y a alta temperatura reaccionan - sinterizan formando más poros cerrados que a baja presión. 
La figura 7.28 muestra el comportamiento del porcentaje de porosidad abierta y cerrada con relación a la variación de la presión ejercida, observándose que la porosidad abierta tiene un valor elevado aún prensando a alta presión (100 MPa).

Arcilla La Rioja más alúmina calcinada (AriojAcal) $1550 \stackrel{\circ}{\circ}$ por 4 horas

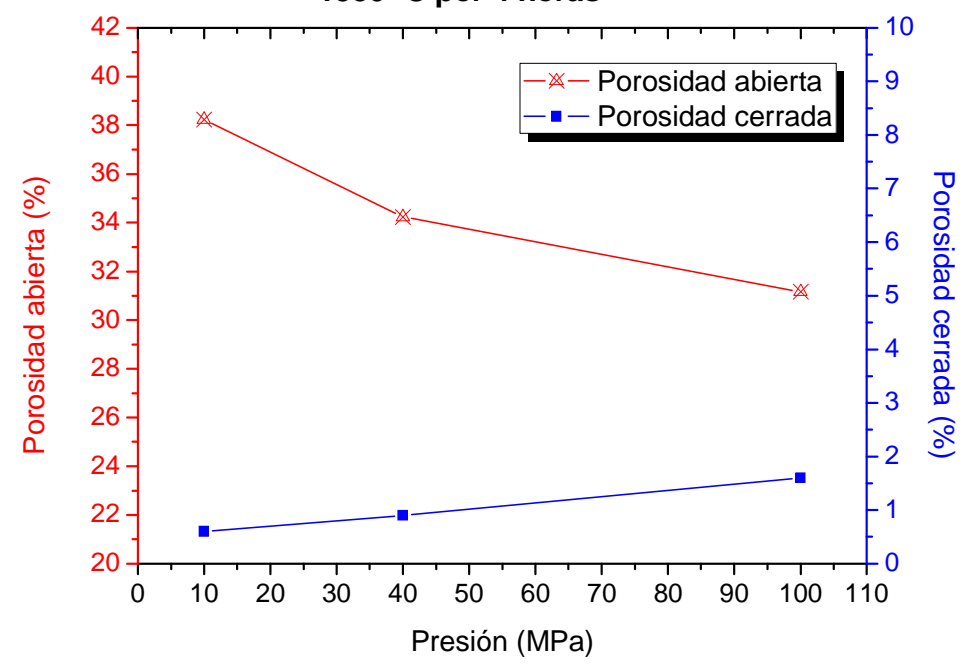

Figura 7.28. Porcentaje de porosidad abierta y cerrada de la mezcla estequiométrica AriojAcal, prensada a 10,40 y $100 \mathrm{MPa}$ y calcinadas a $1550{ }^{\circ} \mathrm{C}$ durante 4 horas.

En la figura 7.29, se observa la variación de la densidad de las piezas y la del sólido (densidad aparente en agua) con respecto a la presión ejercida en el conformado por prensado (10, 40 y $100 \mathrm{MPa}$ ) luego de calcinadas a $1550 \stackrel{\circ}{\mathrm{C}}$ durante 4 horas. 


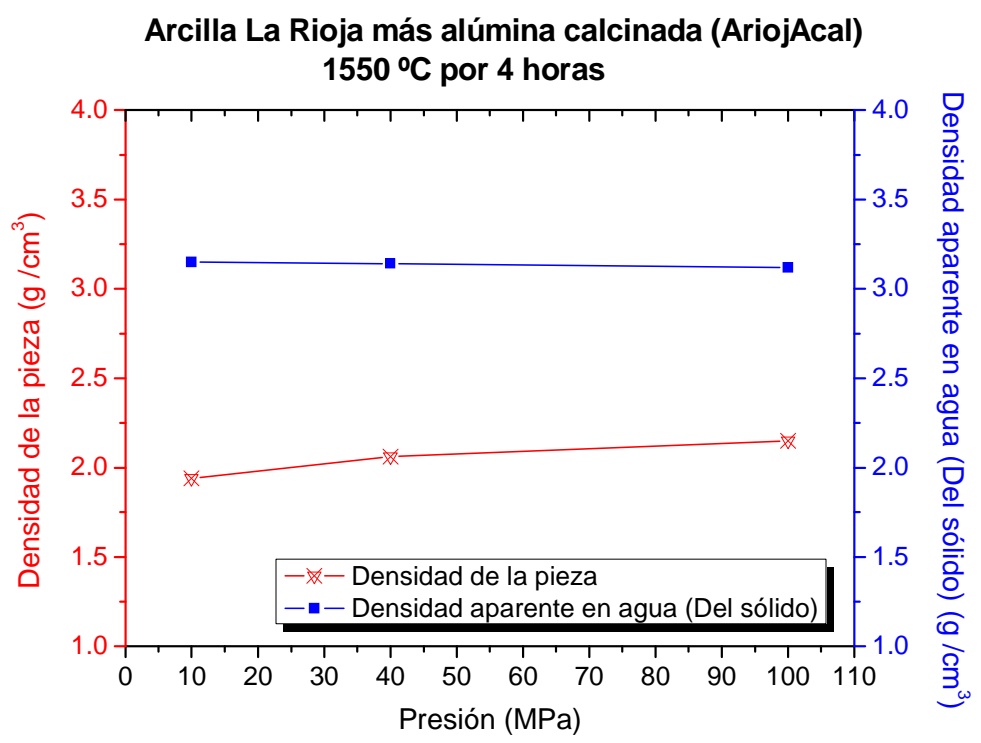

Figura 7.29. Densidad de la pieza y densidad aparente en agua de la mezcla AriojAcal, prensada a 10,40 y $100 \mathrm{MPa}$ y calcinadas a $1550 \stackrel{\circ}{\mathrm{C}}$ durante 4 horas.

Se observa en la figura 7.29, que los valores de densidad aparente en agua en las tres presiones, presentaron un valor muy cercano a la densidad teórica de la mullita (3.17 $\mathrm{g} / \mathrm{cm}^{3}$ ), y por lo tanto un bajo porcentaje de porosidad cerrada, aún a $100 \mathrm{MPa}$, esto debido a la alta refractariedad de la arcilla. Mientras la densidad de la pieza presentó solo un leve aumento por la misma razón recién explicada.

En la tabla 7.11 se pueden apreciar los porcentajes de la variación lineal respecto al conformado del material seco a $110^{\circ} \mathrm{C}$, notándose que a una presión de $10 \mathrm{MPa}$ el material presentó una pequeña contracción, en cambio a $40 \mathrm{MPa}$ una pequeña expansión y a medida que se aumentó la presión a $100 \mathrm{MPa}$ se elevó el valor de expansión. La explicación de este fenómeno tiene dos justificaciones, una es la mullitización secundaria, la cual es expansiva y la otra la sinterización y como las probetas fueron sometidas a $1550{ }^{\circ} \mathrm{C}$ durante 4 horas estos dos fenómenos entran en competencia ya que actúan simultáneamente.

A $10 \mathrm{MPa}$ de presión de prensado, el material reaccionante posee una muy alta porosidad inicial, lo que permite que la misma absorba la mayor parte del fenómeno expansivo de la formación de mullita secundaria, ya que parte de los bastones de mullita que se van formando lo hacen hacia el interior de los poros y no empujando el material para producir la expansión, quedando entonces como más relevante el fenómeno de sinterización de la mullita formada, lo que produce la contracción resultante observada. 
En cambio ya a $40 \mathrm{MPa}$ el sistema se revierte, la porosidad abierta es menor que el primer caso y comienza a pesar más la expansión (que es ahora absorbida en menor magnitud por los poros) que la sinterización, observándose como resultante una ligera expansión. Para $100 \mathrm{MPa}$ el fenómeno recién descripto se ve magnificado por una nueva reducción de la porosidad y la expansión resultante es aún mayor que para el caso de prensado a $40 \mathrm{MPa}$.

\subsubsection{Distribución de tamaño de poro por intrusión de mercurio de la mezcla AriojAcal.}

A las probetas AriojAcal obtenidas por prensado (10, 40 y $100 \mathrm{MPa}$ ) y calcinadas a 1550 ${ }^{\circ} \mathrm{C}$ durante 4 horas, se les determinó la distribución de tamaño de poro utilizando la técnica de porosimetría por intrusión de mercurio, obteniéndose curvas de volumen acumulado de poros vs diámetro de poro, ver figura 7.30.

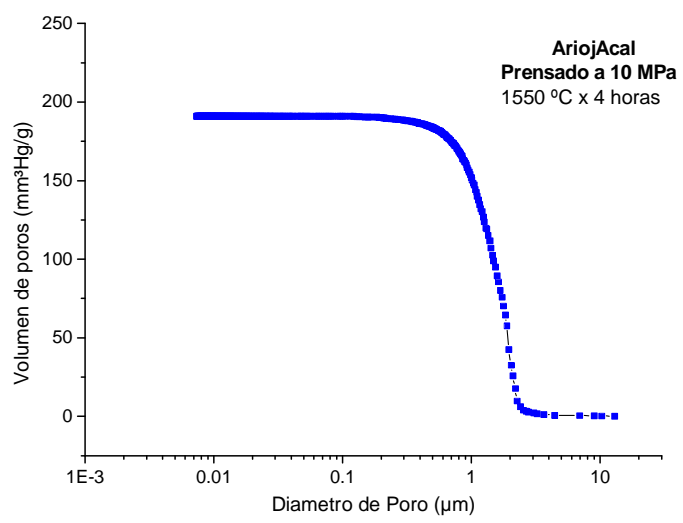

(a)

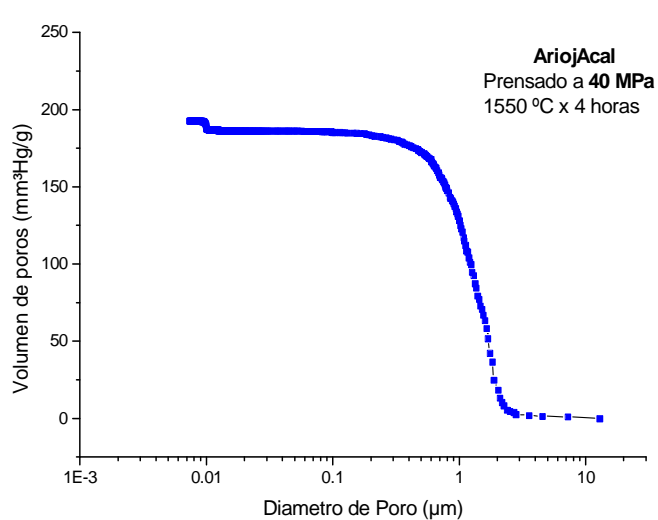

(b) 


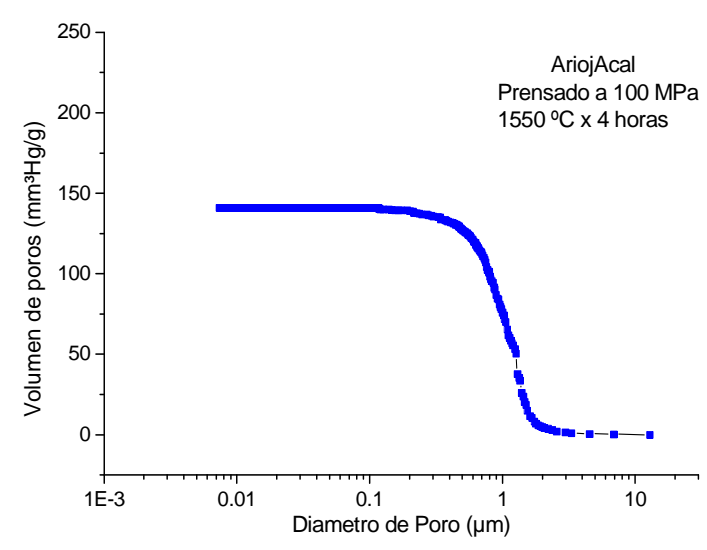

(c)

Figura 7.30. Curvas de distribución de tamaño de poros por intrusión de mercurio para la mezcla AriojAcal prensadas y calcinadas a $1550{ }^{\circ} \mathrm{C}$ durante 4 horas; a) $10 \mathrm{MPa}$; b) 40 MPa y c) $100 \mathrm{MPa}$.

La figura 7.30 muestra las curvas de distribución de tamaño de poros (abiertos), notándose que el volumen total de mercurio introducido en las muestras AriojAcal varió entre 191 y $141 \mathrm{~mm}^{3} \mathrm{Hg} / \mathrm{g}$ con respecto a la presión de prensado, siendo mayor la penetración para presiones menores.

La figura 7.30a muestra el comportamiento del sistema prensado a $10 \mathrm{MPa}$, en este caso la curva expresa que casi todos los poros poseen diámetros comprendidos entre 2.5 y $0.2 \mu \mathrm{m}$, hallándose mayoritariamente en $1.82 \mu \mathrm{m}$, siendo el volumen total penetrado de $191 \mathrm{~mm}^{3} \mathrm{Hg} / \mathrm{g}$ (hasta el límite inferior de diámetro detectado por el equipo). En la figura 7.30b (prensada a $40 \mathrm{MPa}$ ), se puede observar que prácticamente el desarrollo de poros abiertos se encuentra entre un diámetro de poros de 2.5 y $0.5 \mu \mathrm{m}$ y su volumen de poros total penetrado es de $192 \mathrm{~mm}^{3} \mathrm{Hg} / \mathrm{g}$, encontrándose que el diámetro de poro más frecuente se localiza en $1.91 \mu \mathrm{m}$.

Los resultados de la distribución de diámetro de poros para la mezcla estequiométrica 32 (AtinAcal) prensada a $100 \mathrm{MPa}$ se muestran en la figura $7.30 \mathrm{c}$, la porosidad total se encuentra prácticamente entre 2.1 y $0.4 \mu \mathrm{m}$, donde el diámetro más frecuente está en $1.26 \mu \mathrm{m}$ y su volumen de poros total penetrado es de $141 \mathrm{~mm}^{3} \mathrm{Hg} / \mathrm{g}$.

Las tres presiones mostraron tamaños de poros dentro de un rango lógico y con rango estrecho en el desarrollo total de poros abiertos, este comportamiento se puede relacionar con la granulometría de las materias primas utilizadas. También se observó una disminución de poros abiertos a medida que se incrementó la presión, habiéndose 
observado también esto con los valores de porosidad medida por el método de Arquímedes.

\subsubsection{Microscopia electrónica de barrido de arcilla La Rioja y de la mezcla AriojAcal.}

Se prepararon muestras para ser observadas por microscopía electrónica de barrido (MEB), tal como se indicó en la sección 3.7, para la arcilla La Rioja sola (Arioja) y mezcla estequiométrica 3-2 de la arcilla más alúmina calcinada (AriojAcal), tratadas térmicamente a $1550{ }^{\circ} \mathrm{C}$ durante 4 horas con una velocidad de calentamiento de $5{ }^{\circ} \mathrm{C}$ por minuto, con el fin de conocer y diferenciar la microestructura de la mullita primaria (arcilla) y la mullita neta (mezcla).

Estas muestras al ser calcinadas a altas temperaturas presentaron la formación de fase vítrea o amorfa (mucho más la arcilla sola que la mezcla), esto se observó en el capítulo 5. Para eliminar esta fase y realizar una buena observación en el microscopio se efectuó un etching químico con ácido fluorhídrico (HF) al $5 \%$, durante 10 minutos sobre la mitad de la pieza.

\subsection{Micrografía de la arcilla La Rioja (mullita primaria).}

El análisis por microscopía electrónica de barrido (MEB) se realizó para la arcilla La Rioja (Arioja), conformada por el método de prensado uniaxial a $100 \mathrm{MPa}$, y calcinada a la temperatura que se indicó anteriormente, posteriormente se incluyó en resina y se pulió, como se explicó en la sección 3.7.

En la figura 7.31 se muestra la fotografía y micrografías de la arcilla La Rioja prensada y calcinada a $1550{ }^{\circ} \mathrm{C}$ durante 4 horas, con y sin etching químico. 


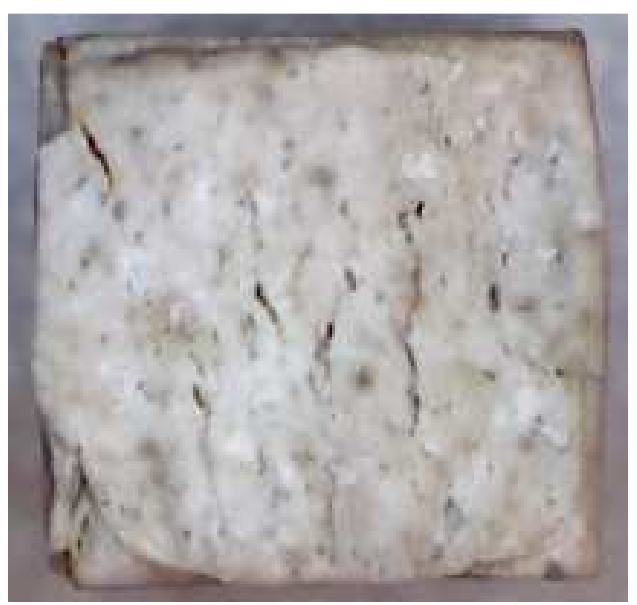

(a)

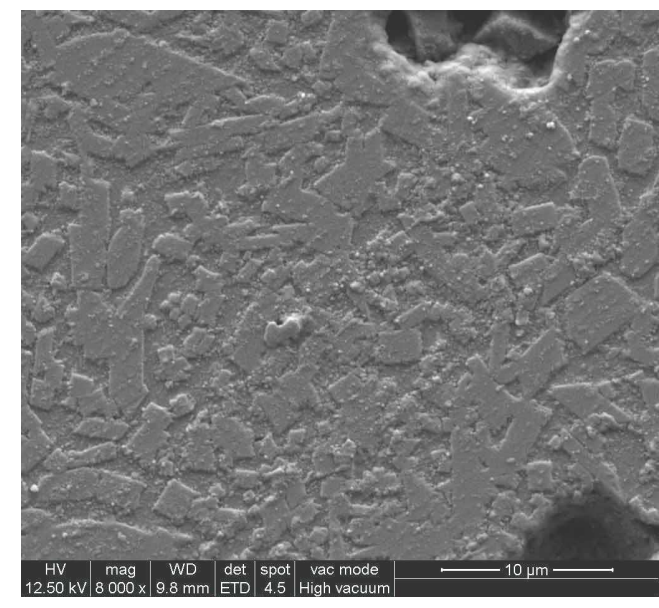

(c)

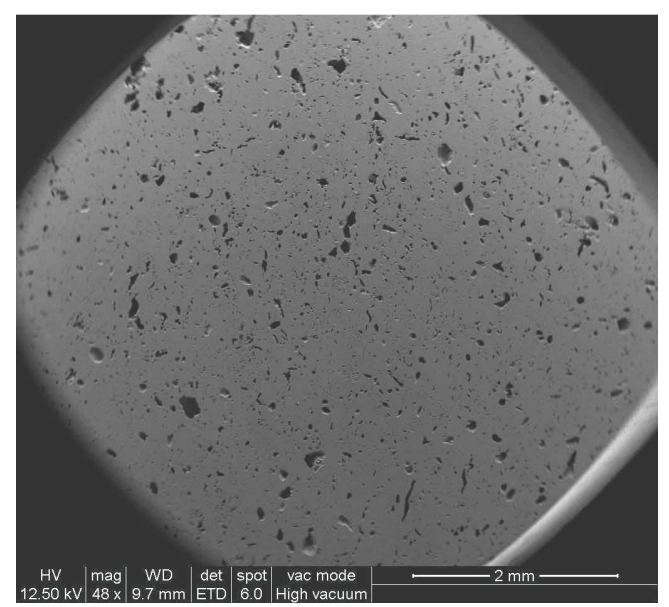

(b)

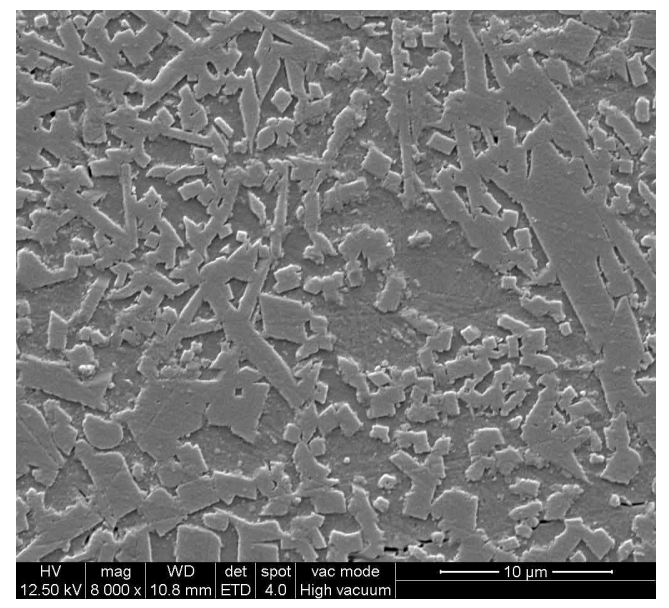

(d)

Figura 7.31. Fotografía, a), y micrografías por MEB de arcilla La Rioja prensada a 100 MPa y calcinada $1550{ }^{\circ} \mathrm{C}$ durante 4 horas, observada a: b) $48 \times \mathrm{c}$ ) $8000 \mathrm{x}$ y d) etching químico (HF 5\%) a 8000x.

La figura 7.31a muestra una foto de la arcilla La Rioja calcinada como se indicó anteriormente, observándose en ella algunas fracturas en el interior de la probeta y un leve hinchamiento de la pieza la cual resulto baja en comparación a la arcilla Tincar Súper (figura 7.11a). Este comportamiento es debido a que la arcilla La Rioja es más caolinítca y más refractaria, por lo tanto generaría menor fase vítrea y por ende menos 
poros cerrados a una temperatura menor de $1550{ }^{\circ} \mathrm{C}$, no observándose los efectos de deformación expansiva por hinchamiento vistos en la arcilla Tincar Súper.

La micrografía sin etching químico (8000x) se muestra en la figura 7.31c, donde se observa una superficie de formación de mullita (primaria) y la presencia de la fase amorfa (el leve bajo relieve observado es debido a que en el proceso de pulido el vidrio (fase amorfa) es erosionado más fácilmente que la mullita), y para la micrografía con etching químico (ácido fluorhídrico al $5 \%$ durante 10 minutos), figura $7.31 \mathrm{~d}$, se observa un sobre relieve de mullita (primaria) más nítido que la figura 7.31c, debido a que el ácido fluorhídrico eliminó la fase amorfa rica en sílice.

\subsection{Micrografías de la mezcla AriojAcal [mullita neta (primaria más secundaria)].}

Se elaboraron probetas por prensado a 10, 40 y $100 \mathrm{MPa}$, para la mezcla estequiométrica $3 \mathrm{Al}_{2} \mathrm{O}_{3} \cdot 2 \mathrm{SiO}_{2}$ de arcilla La Rioja más alúmina calcinada (AriojAcal), tabla 4.8. Las mismas fueron tratadas térmicamente a $1550 \stackrel{\circ}{\circ} \mathrm{C}$ durante 4 horas, posteriormente se prepararon como se explicó en la sección 3.7.

Las superficies vistas en microscopía electrónica de barrido, corresponden a la superficie en contacto exterior de la mezcla con el molde de prensado. Las figuras 7.32, 7.33 y 7.34 muestran las micrografías mencionadas, mullita neta (AriojAcal), con y sin etching químico.

Las micrografías observadas a las tres presiones sin ataque químico (figuras 7.32b, 7.33b y 7.34b) mostraron la formación de bastones de mullita y zonas de punta de bastón redondeados que mostrarían la zona de sinterizado del material, sin un ordenamiento definido ni un tamaño homogéneo. [Elssner et al., 1999; Liu et al., 1991; Obadia y Broussaud, 1998].

Las figuras $7.32 \mathrm{c}, 7.33 \mathrm{c}$ y $7.34 \mathrm{c}$ corresponden a las micrografías de las muestras que fueron atacadas químicamente con ácido fluorhídrico al $5 \%$ durante 10 minutos, observándose que parte de la fase vítrea que estaba ligada a los bastones de mullita se ha destruido parcialmente con el ataque. En la figura 7.32c se puede apreciar que el etching químico afectó los bordes de los bastones de mullita. 


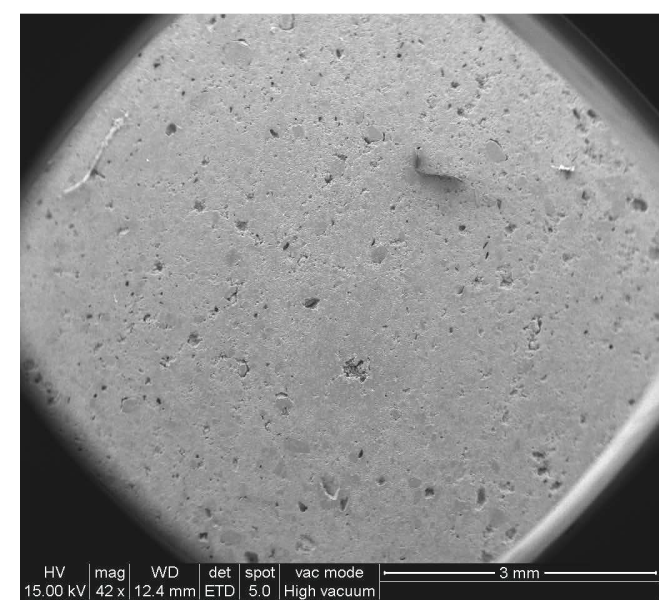

(a)

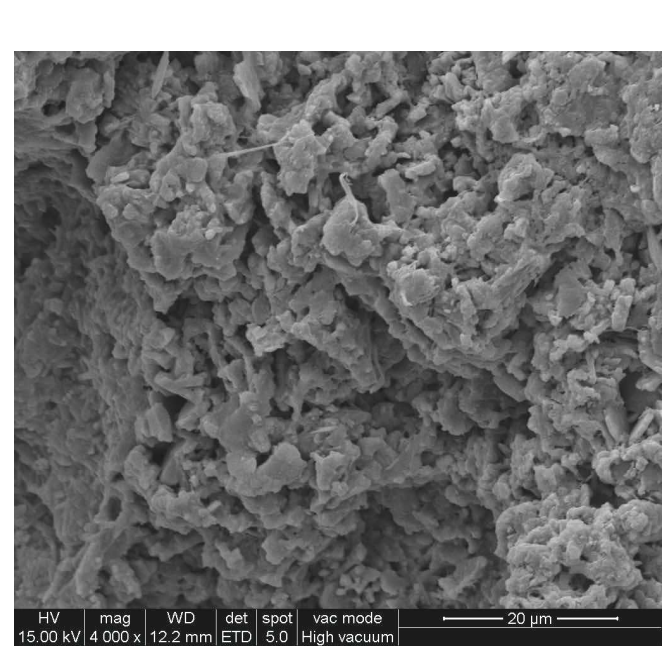

(c)

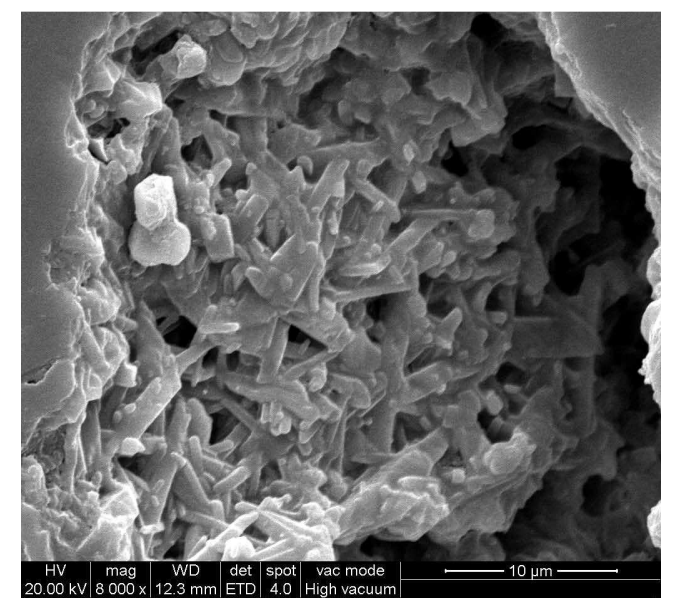

(b)

Figura 7.32 Micrografía de AriojAcal, prensada a $10 \mathrm{MPa}$ y calcinada a $1550{ }^{\circ} \mathrm{C}$ durante 4 horas; sin etching químico: a) 42x, b) $8000 x$, y c) con etching químico (HF 5\%) a 4000x.

La mezcla AriojAcal prensada a $100 \mathrm{MPa}$ (figura 7.34) presentó el mismo comportamiento observado en la mezcla AtinAcal prensada a 40 y $100 \mathrm{MPa}$ (figuras $7.13 d$ y $7.14 d$ ), notándose que la fase vítrea atacada con el etching químico deja en descubierto la memoria laminar de la mezcla que se manifiesta como mullita en forma de láminas levantadas en sobre relieve (figura 7.34c). Ese comportamiento no se observó a presiones de 10 y 40 MPa debido a que la arcilla La Rioja es poco plástica, 
más gruesa y más dura, y por lo tanto le cuesta más orientarse a bajas presiones, en la interfase con el metal del molde, de allá que a bajas presiones no se observó dicho efecto.

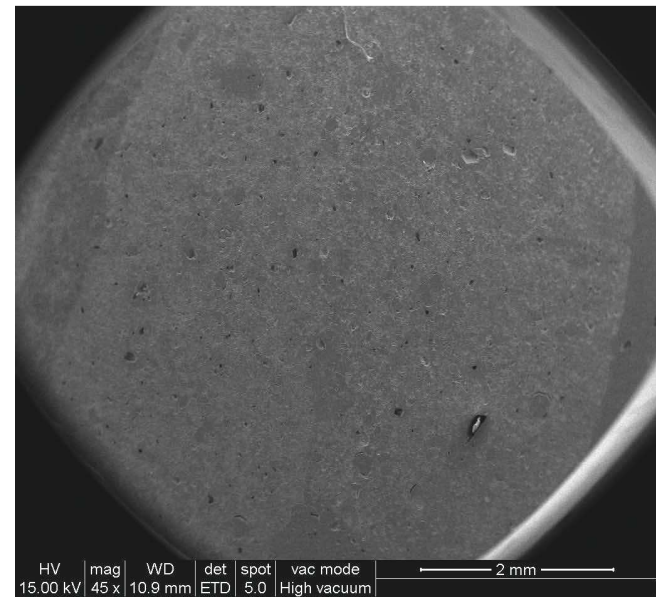

(a)

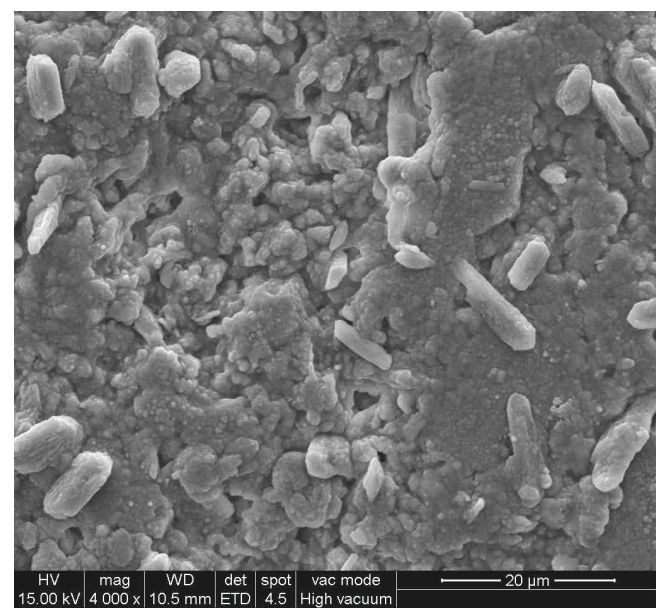

(c)

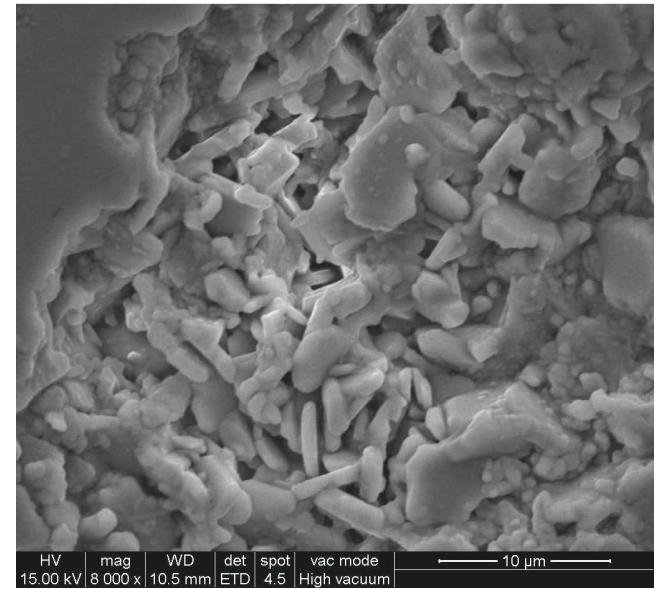

(b)

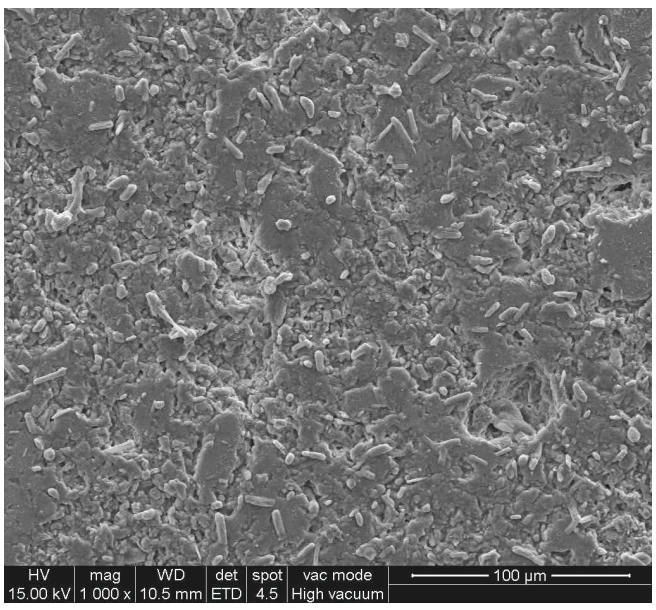

(d)

Figura 7.33 Micrografía de AriojAcal, prensada a $40 \mathrm{MPa}$ y calcinada a $1550 \stackrel{\circ}{\mathrm{C}}$ durante 4 horas: sin etching químico: a) 45x, b) 8000x; y con etching químico (HF 5\%): c) 4000x, y d) 1000x. 


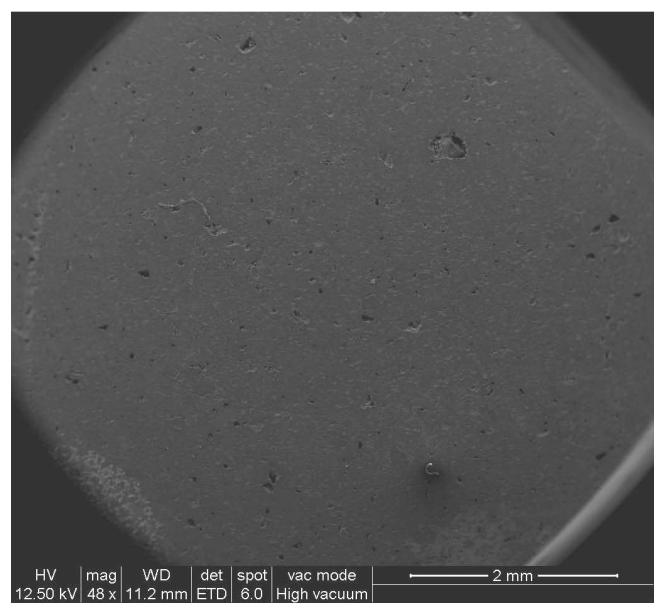

(a)

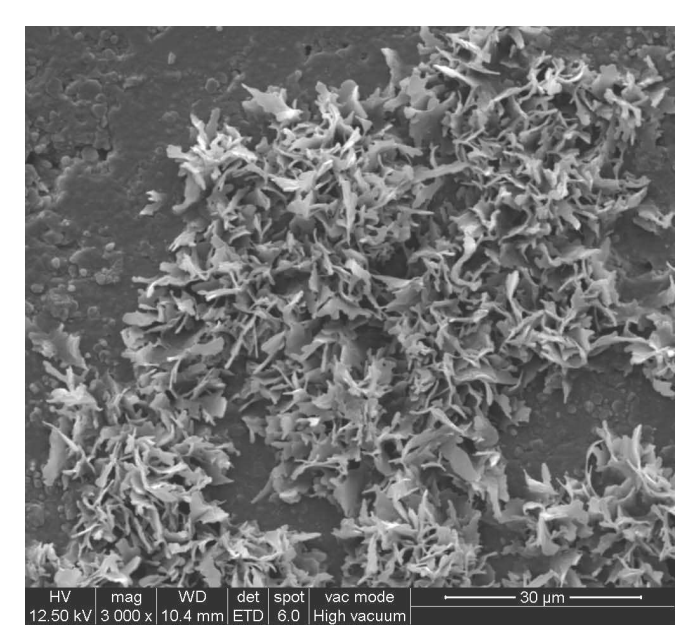

(c)

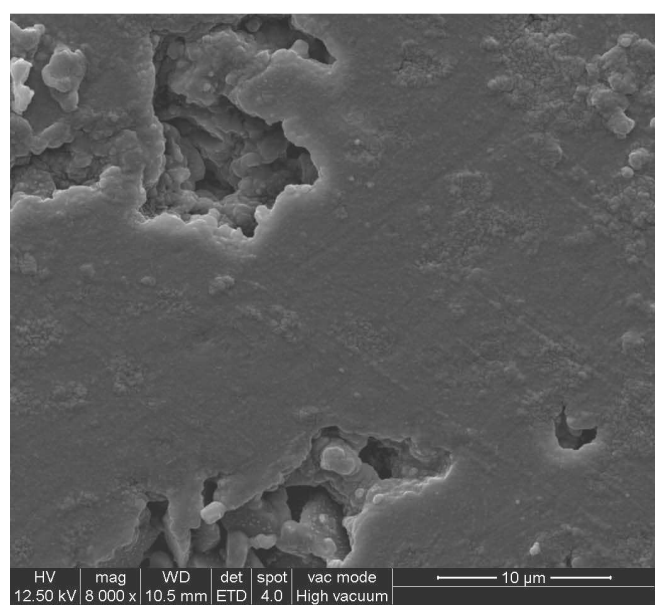

(b)

Figura 7.34 Micrografía de AriojAcal, prensada a $100 \mathrm{MPa}$ y calcinada a $1550 \stackrel{\circ}{\mathrm{C}}$ durante 4 horas: sin etching químico: a) 48x, b) 8000x; con etching químico (HF 5\%): c) $3000 x$.

\subsubsection{Propiedades termomecánicas de la mezcla AriojAcal.}

Las probetas obtenidas por el método de prensado a 10, 40 y $100 \mathrm{MPa}$ de la mezcla AriojAcal y calcinadas a $1550{ }^{\circ} \mathrm{C}$ durante 4 horas se caracterizaron utilizando el módulo de rotura a la flexión y módulo de elasticidad antes y después del choque térmico 
(MOR1, E1, MOR2 y E2 respectivamente). El choque térmico consistió en colocar las probetas en un horno a temperatura de $1000{ }^{\circ} \mathrm{C}$ en forma instantánea, manteniéndolas durante 20 minutos a esa temperatura para luego enfriarlas bruscamente en agua. Los valores medidos se muestran en la tabla 7.12

Tabla 7.12. Propiedades termomecánicas de las probetas obtenidas por el método de prensado para la mezcla AriojAcal calcinadas a $1550 \stackrel{\circ}{ } \mathrm{C}$ durante 4 horas.

\begin{tabular}{|c|c|c|c|}
\hline & $10 \mathrm{MPa}$ & $40 \mathrm{MPa}$ & $100 \mathrm{MPa}$ \\
\hline $\begin{array}{c}\text { MÓDULO DE ELASTICIDAD } \\
\text { (E1) } \\
(\mathrm{GPa})\end{array}$ & 24.3 & 37.9 & 56.7 \\
\hline $\begin{array}{l}\text { MÓDULO DE ELASTICIDAD } \\
\text { Después de choque térmico } \\
\text { (E2) } \\
(\mathrm{GPa})\end{array}$ & 19.1 & 29.7 & 42.9 \\
\hline $\begin{array}{c}\text { RELACIÓN DE MÓDULOS } \\
\text { (E1/E2) }\end{array}$ & 1.3 & 1.3 & 1.3 \\
\hline $\begin{array}{l}\text { MÓDULO DE ROTURA A LA FLEXIÓN } \\
\text { (MOR1) } \\
\text { (MPa) }\end{array}$ & 32.4 & 36.7 & 48.3 \\
\hline $\begin{array}{l}\text { MÓDULO DE ROTURA A LA FLEXIÓN } \\
\text { Después de choque térmico } \\
\text { (MOR 2) } \\
\text { (MPa) }\end{array}$ & 4.1 & 2.4 & 1.7 \\
\hline $\begin{array}{l}\text { RELACIÓN DE MÓDULOS } \\
\text { (MOR1/MOR2) }\end{array}$ & 7.9 & 15.3 & 28.4 \\
\hline
\end{tabular}

Se puede observar en la tabla 7.12 que el módulo de elasticidad (E1) y el módulo de rotura a la flexión en tres puntos (MOR1), presentaron un aumento en su valor a medida que se incrementaba la presión, debido a una mayor cantidad de sólido sinterizado y por tal motivo mayor resistencia a la flexión y mayor módulo de elasticidad.

La figura 7.35, representa los resultados de la tabla 7.12, evidenciándose de mejor forma los cambios de las propiedades termomecánicas antes y después del choque térmico. 


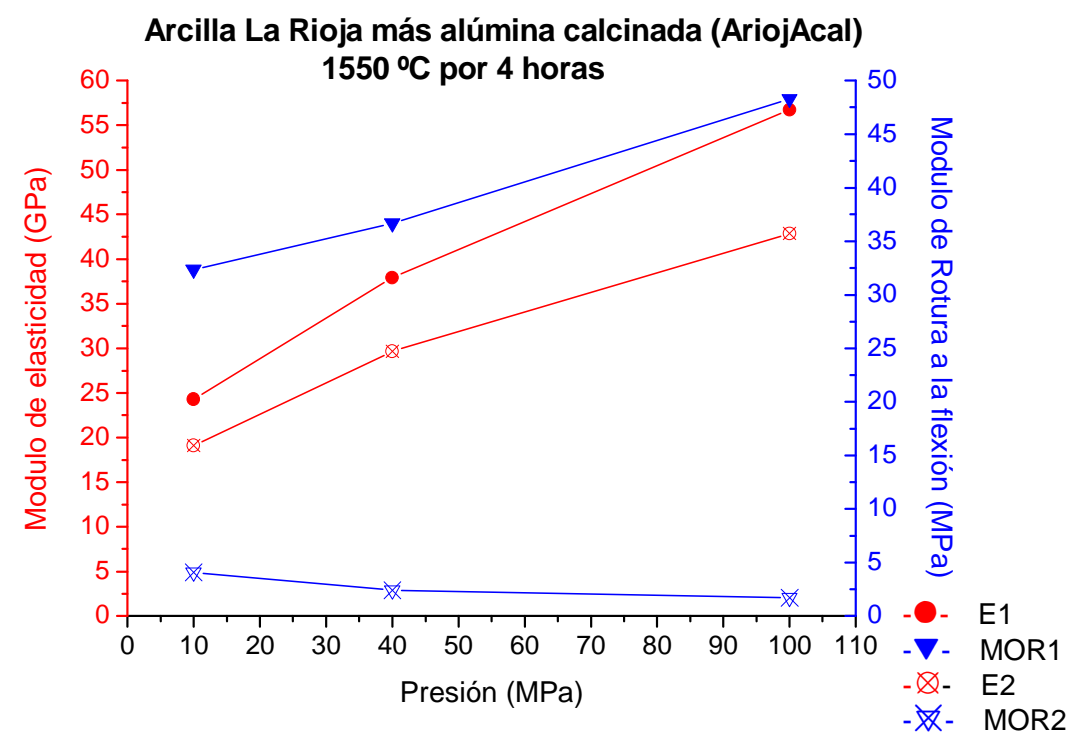

Figura 7.35 Módulo de elasticidad y módulo de rotura a la flexión antes (E1 y MOR1) y después del choque térmico (E2 y MOR2), para la muestra AriojAcal prensada a 10, 40 y $100 \mathrm{MPa}$, calcinadas a $1550^{\circ} \mathrm{C}$ durante 4 horas.

En la figura 7.35 se puede observar que en el Módulo de Rotura a la flexión luego del choque térmico (MOR 2) los valores disminuyen al aumentar la presión de prensado, debido a que existe más cantidad de poros cerrados que a bajas presiones, y estos al ser afectados por el choque térmico y fisurarse, aun estando en contacto el material en ambos lados de la fisura, generan fácilmente la propagación de una fractura por esfuerzo mecánico (MOR2). El módulo de elasticidad (E2) en cambio presentó un aumento en su valor a medida que se incrementó la presión, lo que podría corroborar que después del choque térmico los poros cerrados se han fisurado pero el material sigue en contacto y por lo tanto la onda de medición se propaga igual sobre el material, aunque con menor intensidad que la original (E1). [Becher, 1981; Rendtorff y Aglietti, 2010]. 


\subsubsection{Caracterización física y termomecánica de la AriojAhid y calcinadas a 1550 ㅇ por 4 horas.}

\subsubsection{Difractogramas de la mezcla AriojAhid.}

Se elaboraron probetas por prensado uniaxial con formato prismático de $5.0 \times 0.8 \times 0.8$ $\mathrm{cm}^{3}$, a presiones de 10, 40 y $100 \mathrm{MPa}$ con una humedad de $\sim 9.9 \%$, para la mezcla estequiométrica 3-2, de arcilla La Rioja más alúmina hidratada (AriojAhid), las probetas fueron secadas a $110{ }^{\circ} \mathrm{C}$ y calcinadas a $1550{ }^{\circ} \mathrm{C}$ durante 4 horas con una velocidad de calentamiento de $5 \stackrel{\circ}{\circ}$ por minuto, posteriormente se caracterizaron por Difracción de Rayos X, los difractogramas obtenidos se muestran en la figura 7.36.

En la figura 7.36, se observan los difractogramas correspondientes a la mezcla AriojAhid conformada a tres presiones distintas (10,40 y $100 \mathrm{MPa})$ y calcinadas como se indicó anteriormente, mostrando la presencia de mullita (neta) como fase principal y una cantidad considerable de $\alpha$-alúmina. No se observan grandes modificaciones en las fases a medida que se aumenta la presión. Se observa una leve banda centrada en $22^{\circ}$ de $2 \theta$, indicando esto la presencia de fase vítrea de matriz silícea de mayor intensidad que en el caso en que se utilizó alúmina calcinada, e incluso que con arcilla Tincar Súper.

Comparando los difractogramas obtenidos por el método de prensado de la mezcla estequiométrica 3-2 de arcilla La Rioja más alúmina calcinada (AriojAcal), figura 7.27, con la de alúmina hidratada (AriojAhid), figura 7.36, se observó que la mezcla con alúmina calcinada (AriojAcal) presentó mayor intensidad de la fase mullita, y por lo tanto menos $\alpha$ - alúmina, indicando en este caso una menor conversión en iguales condiciones temperatura - tiempo. 


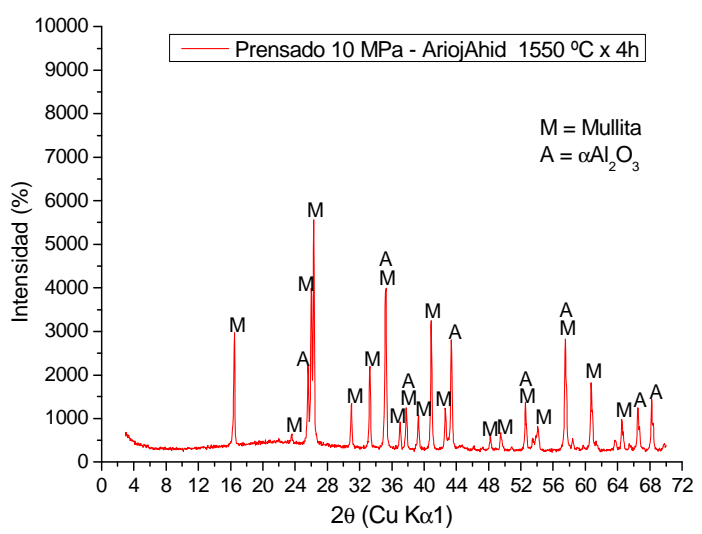

(a)

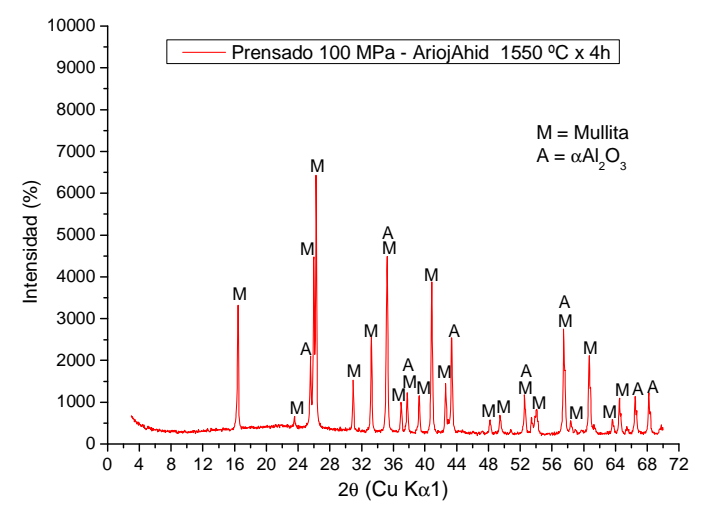

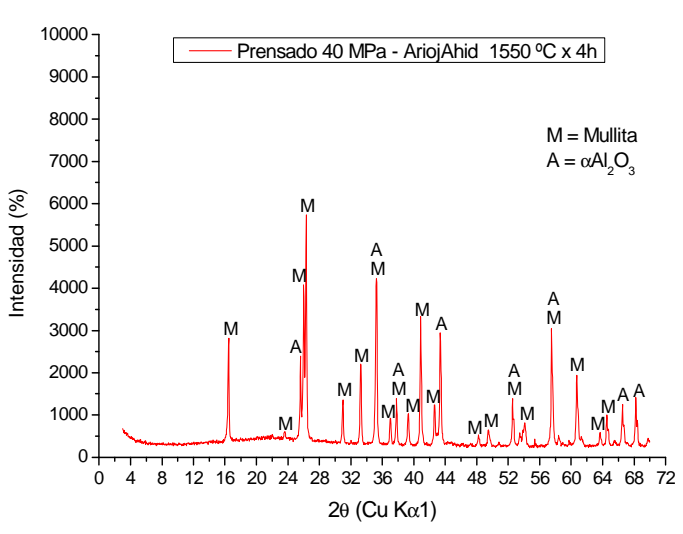

(b)

(c)

Figura 7.36. Difractogramas de la mezcla AriojAhid prensadas: a) $10 \mathrm{MPa}$, b) $40 \mathrm{MPa}, \mathrm{y}$ c) $100 \mathrm{MPa}$ calcinadas a $1550 \stackrel{\circ}{\mathrm{C}}$ durante 4 horas.

\subsubsection{Propiedades físicas de la mezcla AtinAhid.}

Las probetas obtenidas por prensado $\left(10,40\right.$ y $100 \mathrm{MPa}$ ) y calcinadas a $1550{ }^{\circ} \mathrm{C}$ durante 4 horas, se caracterizaron utilizando el método de Arquímedes por inmersión en agua obteniendo valores del porcentaje de porosidad (abierta), densidad del material y densidad aparente en agua. El porcentaje de porosidad cerrada se calculó en base al valor teórico de la mullita $\left(3.17 \mathrm{~g} / \mathrm{cm}^{3}\right)$, también se midió el porcentaje de variación lineal respecto al conformado del material seco $\left(\begin{array}{lll}110^{\circ} & \mathrm{C}\end{array}\right)$. Los resultados obtenidos se observan en la tabla 7.13 . 
Tabla 7.13. Propiedades físicas de las probetas obtenidas por el método de prensado para la mezcla AriojAhid calcinadas a $1550 \stackrel{\circ}{\circ}$ durante 4 horas.

\begin{tabular}{|c|c|c|c|c|c|}
\hline PRESIÓN & $\begin{array}{c}\text { Porosidad } \\
\text { (Abierta) } \\
\%\end{array}$ & $\begin{array}{c}\text { Porosidad } \\
\text { (Cerrada) } \\
\%\end{array}$ & $\begin{array}{c}\text { Densidad de } \\
\text { la pieza } \\
\text { (Arquímedes) } \\
\mathrm{g} / \mathrm{cm}^{3}\end{array}$ & $\begin{array}{c}\text { Densidad } \\
\text { aparente } \\
\text { en agua } \\
\text { (Del } \\
\text { sólido) } \\
\mathrm{g} / \mathrm{cm}^{3}\end{array}$ & $\begin{array}{c}\text { Variación } \\
\text { lineal respecto } \\
\text { al conformado } \\
\text { del material } \\
\text { seco a } 110 \\
\%\end{array}$ \\
\hline $\mathbf{1 0} \mathbf{~ M P a}$ & 31.7 & 1.3 & 2.13 & 3.13 & -9.8 \\
\hline $\mathbf{4 0} \mathbf{~ M P a}$ & 28.8 & 1.6 & 2.22 & 3.12 & -9.7 \\
\hline $\mathbf{1 0 0} \mathbf{~ M P a}$ & 27.7 & 2.5 & 2.23 & 3.09 & -8.8 \\
\hline
\end{tabular}

La tabla 7.13 muestra que el porcentaje de porosidad abierta va disminuyendo, mientras el porcentaje de porosidad cerrada va aumentando a medida que se incrementa la presión, este comportamiento es correcto debido a que a mayor presión mayor contacto entre partículas y al ser tratadas térmicamente a $1550 \stackrel{\circ}{\circ}$ durante 4 horas reaccionan y sinterizan formando poros cerrados en mayor cantidad que a baja presión, debido a que la sílice difunde hacia el interior de la alúmina propagada por la deshidratación del hidróxido de aluminio generando mullita en el interior de la misma, por lo tanto el fenómeno expansivo de ésta es anulado porque es neutralizado por los huecos de los poros, esto se puede observar en el porcentaje de variación lineal respecto al conformado, donde se presentó un comportamiento de contracción en todos los casos, mientras en la mezcla AriojAcal presentó expansión. En la figura 7.37 se observa claramente este comportamiento. 


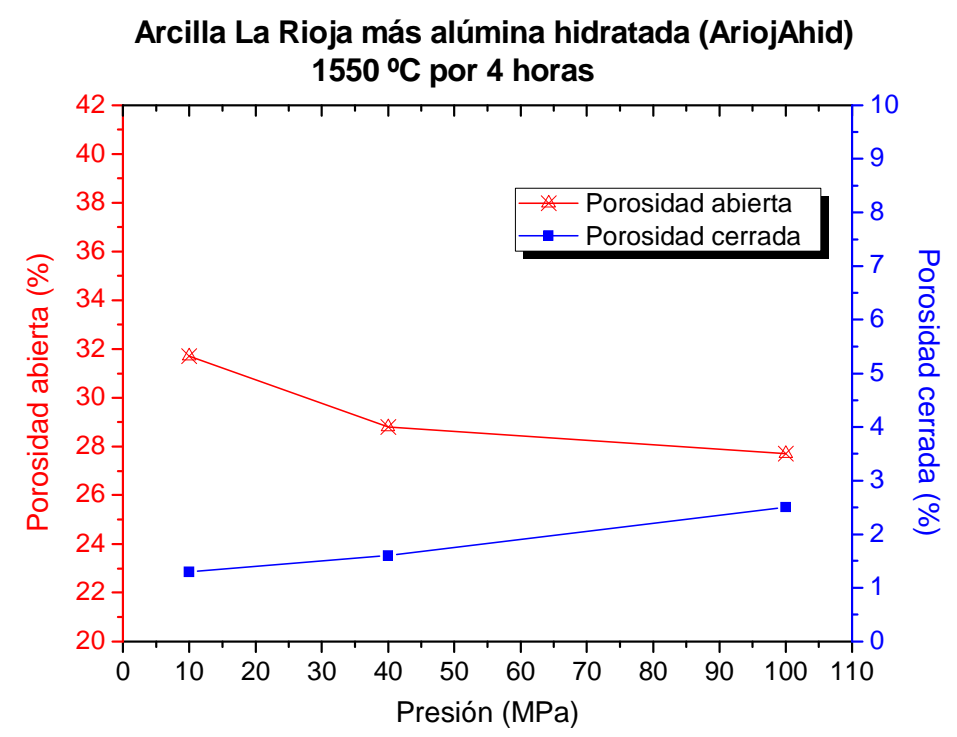

Figura 7.37. Porcentaje de porosidad abierta y cerrada de la mezcla estequiométrica AriojAhid, prensada a 10,40 y $100 \mathrm{MPa}$ y calcinada a $1550 \stackrel{\circ}{\circ}$ durante 4 horas.

Al comparar los porcentajes obtenidos de la mezcla AriojAhid (figura 7.37) con los de la mezcla AriojAcal (figura 7.28), se pudo apreciar que los valores de porosidad abierta independientemente de la presión ejercida son mayores para la AriojAcal, siendo su porosidad cerrada mayor en AriojAhid que en la AriojAcal.

La figura 7.38 muestra las variaciones de las densidades de la pieza y la del sólido (densidad aparente en agua) con respecto a la variación de la presión uniaxial (10, 40 y $100 \mathrm{MPa}$ ) ejercida en el conformado de piezas por el método de prensado y posteriormente calcinadas a $1550 \stackrel{\circ}{\mathrm{C}}$ durante 4 horas.

En la figura 7.38 se observa que todos valores de densidad aparente en agua (sólido) presentaron valores muy cercanos al valor de la densidad teórica de la mullita (3.17 $\mathrm{g} / \mathrm{cm}^{3}$ ), aunque a medida que se aumentaba la presión se iba alejando de este valor, indicando un aumento de poros cerrados. Mientras la densidad de la pieza presentó un pequeño aumento a medida que se incrementó la presión. 


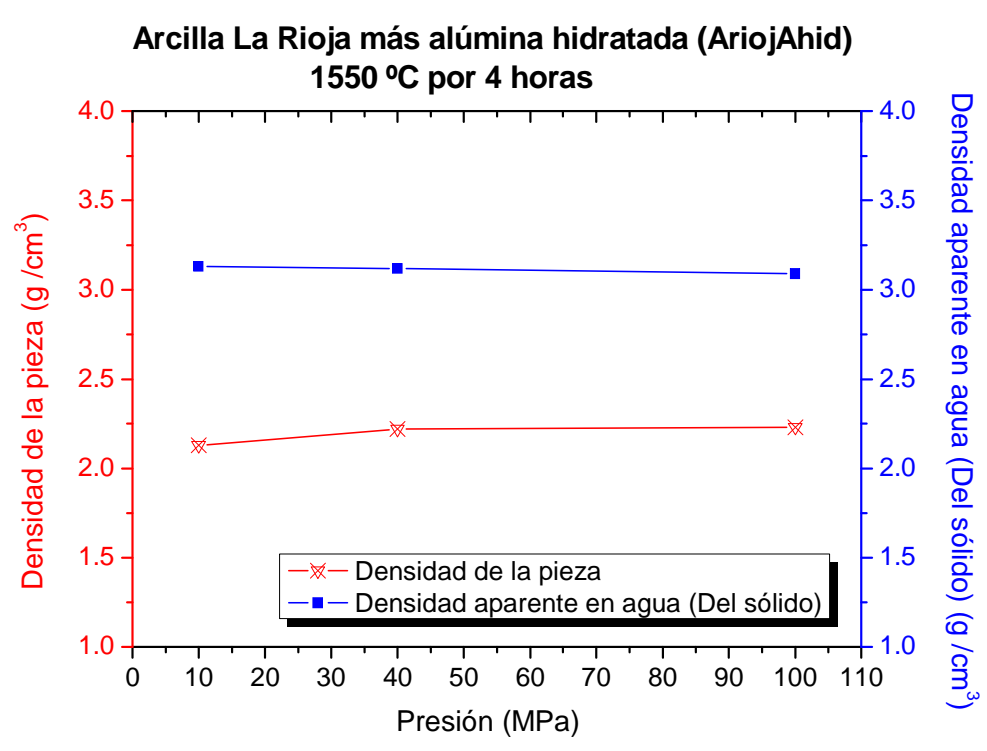

Figura 7.38. Densidad de la pieza y densidad aparente en agua de la mezcla estequiométrica AriojAhid, prensada a 10, 40 y $100 \mathrm{MPa}$ y calcinada a $1550 \stackrel{\circ}{\circ}$ durante 4 horas.

Confrontando los resultados obtenidos de las densidades de la pieza y del sólido entre las mezcla AriojAcal (tabla 7.11) y AriojAhid (tabla 7.13), se obtuvo que la densidad de la pieza fue un poco mayor para la mezcla con alúmina hidratada, y con respecto a la densidad del sólido la mezcla con alúmina calcinada (AriojAcal prensada a 10 y $40 \mathrm{MPa}$ ) presentó un valor mayor, siendo cercano a la densidad teórica de la mullita, debido a la menor cantidad de poro cerrado.

\subsubsection{Distribución de tamaño de poro por intrusión de mercurio de la mezcla AriojAhid.}

El ensayo de porosimetría por intrusión de mercurio se realizó para la mezcla estequiométrica 3-2 de arcilla La Rioja más alúmina hidratada, conformada por el método de prensado a $40 \mathrm{MPa}$ y calcinada a $1550 \stackrel{\circ}{ } \mathrm{C}$ durante 4 horas. La figura 7.39 muestra la curva de distribución de volumen acumulado de poros con respecto al diámetro de poro. 


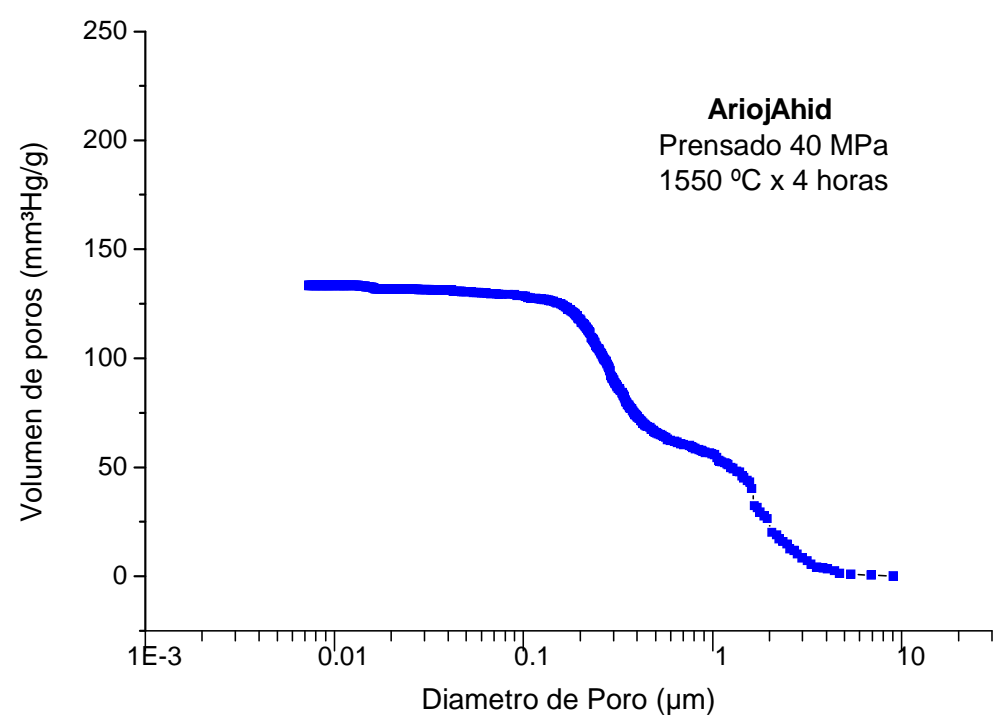

Figura 7.39. Curva de distribución de tamaño de poros por intrusión de mercurio para la mezcla AriojAhid prensada a $40 \mathrm{MPa}$ y calcinada $1550 \stackrel{\circ}{\circ}$ durante 4 horas.

Se observa en la mezcla AriojAhid (figura 7.39) un sistema bimodal de poros abiertos (diámetros más frecuentes: 0.25 y $1.61 \mu \mathrm{m}$ ) al igual que la mezcla AtinAhid (figura 7.19), siendo la medida de tamaño menor causada por la porosidad interna de la alúmina hidratada reaccionada, y la mayor generada por la arcilla con la alúmina hidratada en la matriz de la mezcla.

La bimodalidad es más notoria en la mezcla que contiene arcilla La Rioja quizás debido a la diferencia con el tamaño de partícula de la arcilla Tincar Súper.

En este caso el volumen total de poro penetrado hasta la presión de trabajo (133 $\left.\mathrm{mm}^{3} \mathrm{Hg} / \mathrm{g}\right)$ fue mayor al de la mezcla AtinAhid $\left(72 \mathrm{~mm}^{3} \mathrm{Hg} / \mathrm{g}\right)$ por la misma razón recién expuesta.

\subsubsection{Propiedades termomecánicas de la mezcla AriojAhid.}

Las probetas conformadas por prensado a 10, 40 y $100 \mathrm{MPa}$ de la mezcla AriojAhid y calcinadas a 1550 ㅇ C durante 4 horas, se caracterizaron termomecánicamente, calculando el módulo de rotura a la flexión en tres puntos (MOR1), módulo de elasticidad (E1), módulo de rotura a la flexión y módulo de elasticidad luego de un choque térmico anteriormente mencionado (MOR2 y E2). Los valores calculados se muestran en la tabla 7.14 . 
Tabla 7.14. Propiedades termomecánicas de las probetas obtenidas por prensado para la mezcla AriojAhid calcinadas a $1550 \stackrel{\circ}{\mathrm{C}}$ durante 4 horas.

\begin{tabular}{|c|c|c|c|}
\hline & $10 \mathrm{MPa}$ & $40 \mathrm{MPa}$ & $100 \mathrm{MPa}$ \\
\hline $\begin{array}{c}\text { MÓDULO DE ELASTICIDAD } \\
\text { (E1) } \\
\text { (GPa) }\end{array}$ & 32.3 & 34.2 & 36.6 \\
\hline $\begin{array}{l}\text { MÓDULO DE ELASTICIDAD } \\
\text { Después de choque térmico } \\
\text { (E2) } \\
(\mathrm{GPa})\end{array}$ & 26.9 & 29.5 & 31.5 \\
\hline $\begin{array}{c}\text { RELACIÓN DE MÓDULOS } \\
\text { (E1/E2) }\end{array}$ & 1.2 & 1.2 & 1.2 \\
\hline $\begin{array}{l}\text { MÓDULO DE ROTURA A LA FLEXIÓN } \\
\text { (MOR1) } \\
\text { (MPa) }\end{array}$ & 24.3 & 30.2 & 32.1 \\
\hline $\begin{array}{l}\text { MÓDULO DE ROTURA A LA FLEXIÓN } \\
\text { Después de choque térmico } \\
\text { (MOR } 2) \\
(\mathrm{MPa})\end{array}$ & 11.8 & 13.8 & 20.2 \\
\hline $\begin{array}{l}\text { RELACIÓN DE MÓDULOS } \\
\text { (MOR1/MOR2) }\end{array}$ & 2.1 & 2.2 & 1.6 \\
\hline
\end{tabular}

En la tabla 7.14 se puede observar que el módulo de elasticidad (E1) y módulo de rotura a la flexión en tres puntos (MOR1), presentaron un aumento de su valor a medida que se incrementaba la presión, esto debido a una mayor cantidad de sólido sinterizado.

Se puede apreciar también que las propiedades termomecánicas después del choque térmico (E2 y MOR2) se vieron afectadas debido a la disminución de sus valores con respeto a $\mathrm{E} 1$ y MOR1, pero en el caso del MOR2 la disminución no fue drástica como en los valores de la mezcla AriojAcal.

La figura 7.40 muestra los resultados de las propiedades termomecánicas de las piezas antes y después del choque térmico (tabla 7.14). 


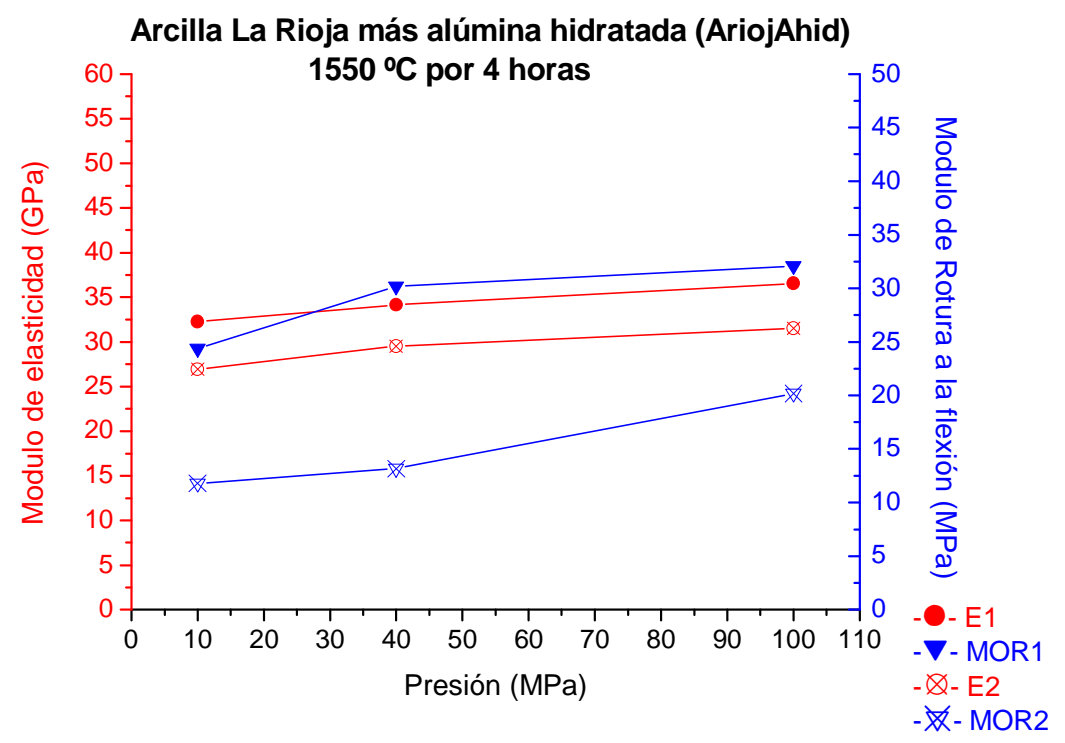

Figura 7.40. Módulo de elasticidad y módulo de rotura a la flexión antes (E1 y MOR1) y después del choque térmico (E2 y MOR2), para la muestra AriojAhid prensada a 10, 40 y $100 \mathrm{MPa}$, calcinadas a $1550 \stackrel{\circ}{\mathrm{C}}$ durante 4 horas.

Comparando los resultados obtenidos en la mezcla AriojAhid (figura 7.40) con los de la mezcla AriojAcal (figura 7.35) se observaron que los resultados de MOR1 y E1 fueron mayores para la mezcla con alúmina calcinada (AriojAcal), a excepción de la probeta prensada a $10 \mathrm{MPa}$ que presentó un valor contrario. La alúmina hidratada contiene núcleos cerrados no conectados con el exterior donde en su interior hay un sistema poroso de alúmina no totalmente sinterizado y por lo tanto una baja resistencia mecánica, causando que la energía de fractura inducida no se propague fácilmente en la pieza sino que se absorba dentro de dichos núcleos no debilitando drásticamente a la pieza.

Los módulos de rotura a la flexión antes y después del choque térmico (MOR1 y MOR2) de la mezcla AriojAhid presentaron un incremento en el valor a medida que se aumentaba la presión.

Comparando la relación de módulos de rotura de la mezclas con alúmina hidratada (AriojAhid) y calcinada (AriojAcal), se observó que la mezcla AriojAhid presentó un valor muy bajo, lo que la convierte en muy potable para ser utilizada donde se requiera resistencia al choque térmico más que resistencia mecánica, aunque los valores de esta última propiedad también son buenos. 


\subsubsection{Caracterización de la mezcla AriojAcal, conformada por el método de colado y calcinada a $1550 \stackrel{\circ}{C}$ durante 4 horas.}

Se realizaron suspensiones acuosas a partir de una mezcla estequiométrica $3 \mathrm{Al}_{2} \mathrm{O}_{3} \cdot 2 \mathrm{SiO}_{2}$ utilizando arcilla La Rioja y alúmina calcinada (AriojAcal), con un $80 \% \mathrm{p} / \mathrm{p}$ de sólidos utilizando como dispersante poliacrilato de amonio diluido al $10 \%$.

La suspensión preparada se vertió en moldes de yeso con capacidad para moldear probetas de tamaño $6.0 \times 0.8 \times 0.8 \mathrm{~cm}^{3}$. El material se dejó durante 24 hs en los moldes de yeso. Luego de desmoldadas, las probetas se secaron a $110{ }^{\circ} \mathrm{C}$ y posteriormente se calcinaron a $1550{ }^{\complement} \mathrm{C}$ durante 4 horas. Las piezas ob tenidas se caracterizaron física y termomecánicamente.

\subsubsection{Difractograma de la mezcla AriojAcal.}

Para conocer las fases cristalinas presentes en la mezcla AriojAcal conformada por el método de colado y calcinada a 1550 ` durante 4 ho ras, se efectuó la caracterización por Difracción de Rayos X, ver figura 7.41.

En el difractograma de la figura 7.41 se observa la presencia de dos fases, mullita (neta) como fase principal y mayoritaria, siendo la otra fase $\alpha$-alúmina en muy poca cantidad.

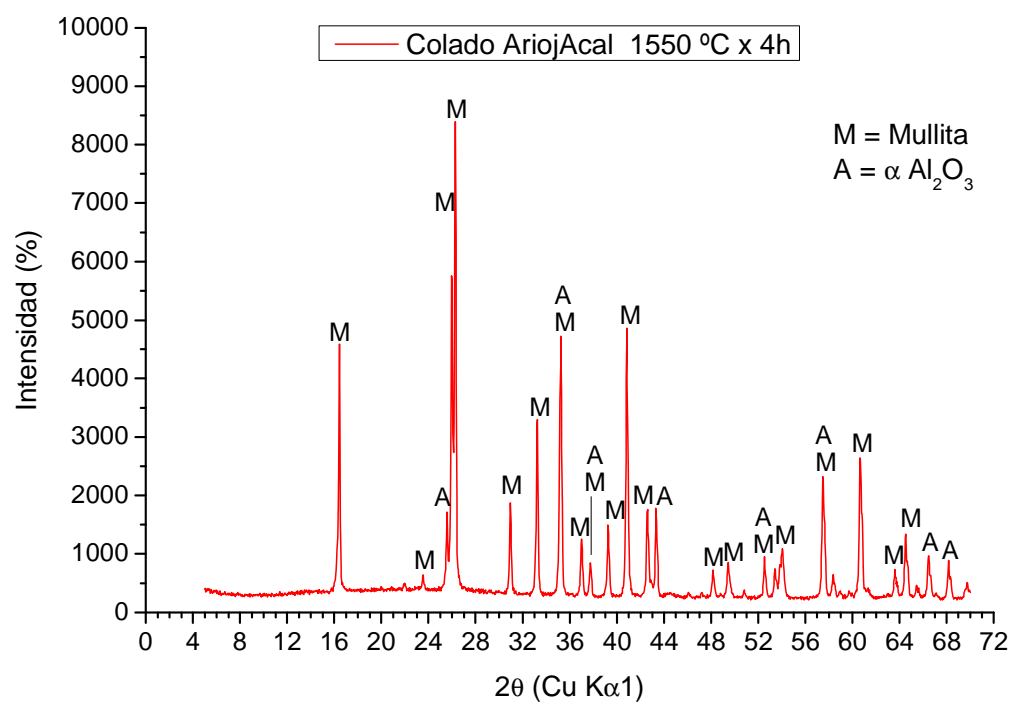

Figura 7.41. Difractograma de la mezcla AriojAcal conformada por el método de colado y calcinada a $1550^{\circ} \mathrm{C}$ durante 4 horas. 


\subsubsection{Propiedades físicas de la mezcla AriojAcal.}

Las probetas elaboradas por el método de colado y calcinadas a la temperatura que se indicó anteriormente, se caracterizaron evaluando diferentes propiedades físicas. Se utilizó el método de Arquímedes por inmersión en agua para encontrar los valores del porcentaje de porosidad (abierta), densidad del material y densidad aparente en agua. El porcentaje de porosidad cerrada se calculó en base al valor teórico de densidad de la mullita $\left(3.17 \mathrm{~g} / \mathrm{cm}^{3}\right)$, también se calculó el porcentaje de variación lineal respecto al conformado del material seco $\left(110^{\circ} \mathrm{C}\right)$. Los resultados obtenidos se muestran en la tabla 7.15 .

En la tabla 7.15 se puede observar que el valor de la densidad del sólido (aparente en agua) es un poco menor al valor teórico de mullita $\left(3.17 \mathrm{~g} / \mathrm{cm}^{3}\right)$, esto debido a la cantidad de poros cerrados.

Tabla 7.15 Propiedades físicas de la mezcla AriojAcal obtenida por el método de colado y calcinada a $1550^{\circ} \mathrm{C}$ durante 4 horas.

\begin{tabular}{|c|c|}
\cline { 2 - 2 } \multicolumn{1}{c|}{} & $\begin{array}{c}\text { Arcilla Rioja + Alúmina Calcinada } \\
\text { (AriojAcal) }\end{array}$ \\
\hline POROSIDAD (Abierta) & 37.6 \\
\hline $\begin{array}{c}\text { POROSIDAD (Cerrada) } \\
\text { \% }\end{array}$ & 2.5 \\
\hline $\begin{array}{c}\text { DENSIDAD DE LA PIEZA (Arquímedes) } \\
\text { (c) } \\
\text { (Del sólido) } \\
\text { g/cm }\end{array}$ & 1.93 \\
\hline $\begin{array}{c}\text { DENSIDAD APARENTE EN AGUA } \\
\text { \% }\end{array}$ & 3.09 \\
\hline $\begin{array}{c}\text { VARIACIÓN LINEAL respecto al } \\
\text { conformado del material seco a 110 }\end{array}$ & -0.2 \\
\hline
\end{tabular}

Confrontando los resultados de las propiedades físicas obtenidas por el método de colado (tabla 7.15) con el método de prensado a 10, 40 y $100 \mathrm{MPa}$ (tabla 7.11), se observó que: los valores del porcentaje de porosidad abierta, densidad de la pieza y la variación lineal respecto al conformado del material seco $\left(110^{\circ} \mathrm{C}\right)$ son similares a los 
resultados obtenidos a una presión de $10 \mathrm{MPa}$, mientras los valores de porosidad cerrada y densidad aparente en agua se asemejan a presiones mayores de $100 \mathrm{MPa}$, probablemente debido al alto porcentaje de porosidad cerrada inducido por el alto contacto entre partículas.

\subsubsection{Distribución de tamaño de poro por intrusión de mercurio de la mezcla AriojAcal.}

La curva de distribución de volumen acumulado de poros en función del diámetro de poro para la mezcla AriojAcal obtenida por el método de colado y calcinada a $1550 \stackrel{\circ}{ } \mathrm{C}$ durante 4 horas, se obtuvo a partir de la técnica de porosimetría por intrusión de mercurio, ver figura 7.42 .

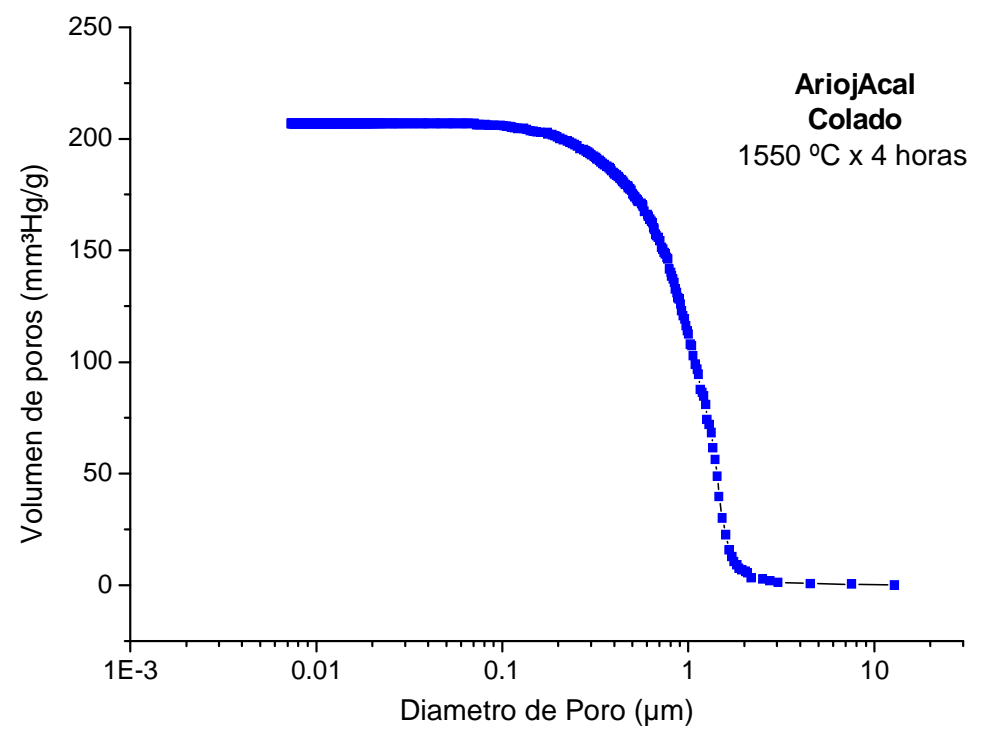

Figura 7.42. Curva de distribución de tamaño de poros por intrusión de mercurio para la mezcla AriojAcal obtenida por el método de colado calcinada a $1550 \stackrel{\circ}{\mathrm{C}}$ durante 4 horas.

La figura 7.42 muestra la curva de distribución de tamaño de poros monomodal (abiertos) encontrándose prácticamente su desarrollo entre un diámetro de 2.5 y 0,2 $\mu \mathrm{m}$, y su volumen total de poros penetrados de $207 \mathrm{~mm}^{3} / \mathrm{g}$ de material; su diámetro de poro más frecuente se situó en $1,43 \mu \mathrm{m}$. 


\subsubsection{Micrografías de la mezcla AriojAcal (mullita neta).}

A una fracción de la probeta de la mezcla AriojAcal conformada por el método de colado y calcinada a $1550{ }^{\circ} \mathrm{C}$ durante 4 horas, se la incluyó en resina y se pulió como se indicó en la sección 3.7. A la mitad de la probeta incluida se le efectúo un etching químico con ácido fluorhídrico al $5 \%$, durante 10 minutos, con el objetivo de eliminar la fase vítrea formada en el sistema, posteriormente a la muestra preparada se le realizó una caracterización por microscopía electrónica de barrido. La figura 7.43 muestra las micrografías mencionadas con y sin etching químico.

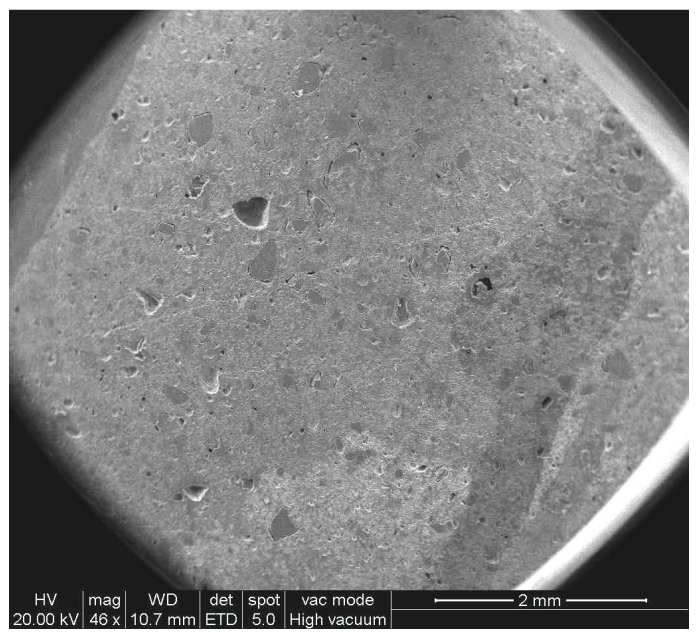

(a)

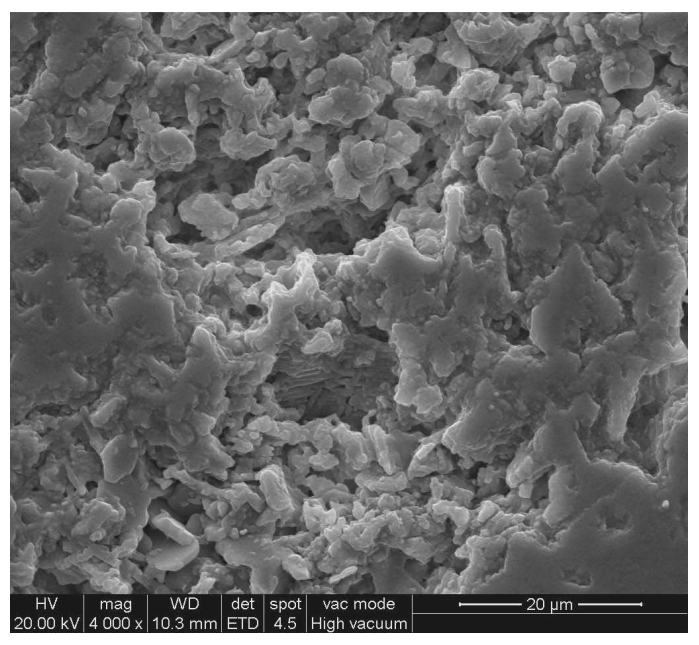

(c)

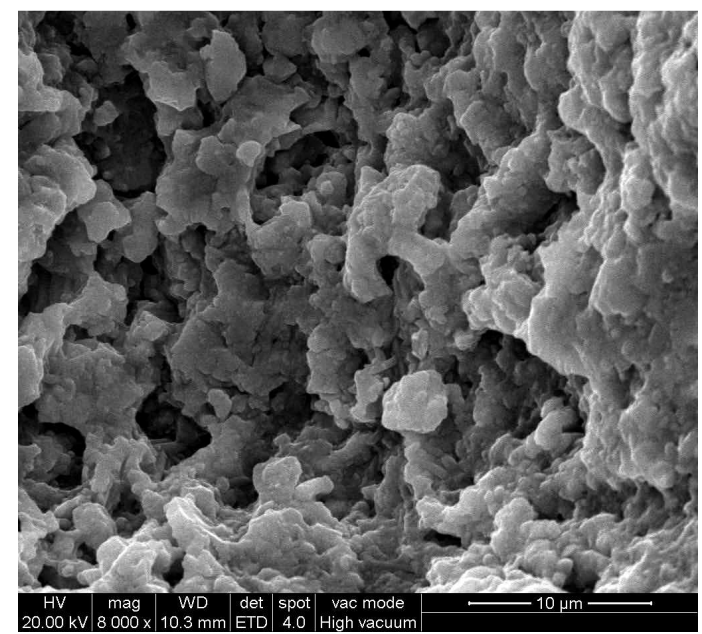

(b)

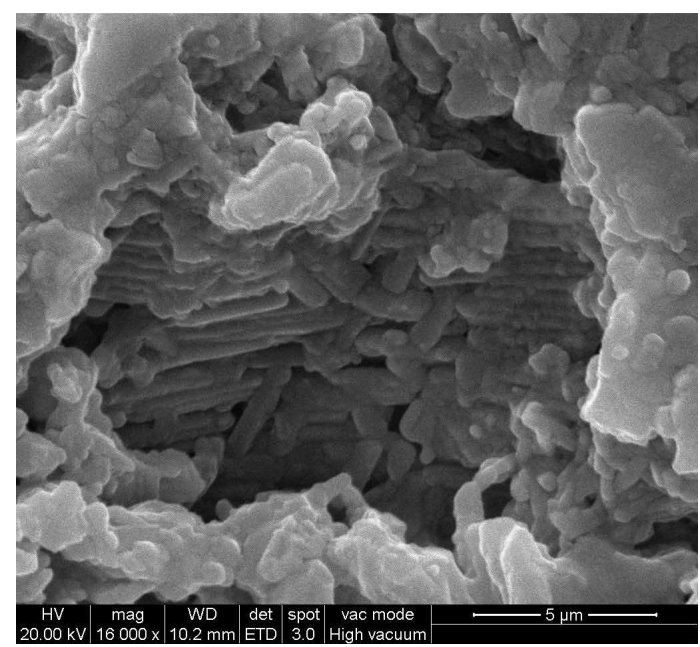

(d)

Figura 7.43 Micrografía de AriojAcal, obtenida por el método de colado y calcinada a $1550 \stackrel{\circ}{\circ}$ durante 4 horas; sin etching químico: a) 46x, b) $8000 x$, y con etching químico (HF 5\%), c) 4000x, y d) 16000x. 
Todas las micrografías observadas por MEB conciernen a la superficie en contacto entre el exterior de la mezcla AriojAcal y el molde de yeso (método por colado), observándose en la figura 7.43b la micrografía sin etching químico, notándose la formación de cristales de mullita en forma no acicular y en zonas de puntas de bastón medio redondeadas que representarían la zona de sinterizado del material, no obteniendo un tamaño homogéneo, ni un ordenamiento definido.

Y para las micrografías que sufrieron el etching químico (HF al $5 \%$ ) durante 10 minutos (figura $7.43 \mathrm{c}$ y $7.43 \mathrm{~d}$ ) revelaron que parte de la fase vítrea que está ligando a la mullita se ha destruido parcialmente con el ataque, notándose con claridad los bastones de mullita (neta).

\subsubsection{Propiedades termomecánicas de la mezcla AriojAcal.}

Las probetas elaboradas por el método de colado para la mezcla AriojAcal y posteriormente calcinadas a $1550{ }^{\circ} \mathrm{C}$ durante 4 horas, fueron caracterizadas utilizando distintos ensayos termomécanicos, tales como: módulo de rotura a la flexión y módulo de elasticidad antes (MOR1 y E1) y después del choque térmico anteriormente mencionado (MOR2 y E2). Los valores calculados se muestran en la tabla 7.16.

La tabla 7.16 muestra que el choque térmico realizado produjo una disminución en los valores de las propiedades termomecánicas, aunque presentan una buena relación de módulos que la hacen apta para servicios donde se requieren buena resistencia al choque térmico. [Anderson y Rowcliffe 1998; Evans, 1975; Tomba, 1994].

Comparando los valores obtenidos por el método de colado (tabla 7.16), con los del método de prensado (tabla 7.12) para la mezcla AriojAcal calcinadas a $1550{ }^{\circ} \mathrm{C}$ durante 4 horas, se observó que los módulos de elasticidad E1 y E2 presentaron una similitud con los valores prensados a $40 \mathrm{MPa}$, aunque los valores de módulo de rotura a la flexión corresponderían a valores cercanos a los prensados a $10 \mathrm{MPa}$.

El mejor comportamiento al choque térmico del sistema colado frente a los prensados es justificado por el menor valor del MOR1 frente aún prensado de $10 \mathrm{MPa}$ (esto se da macroscópicamente en todos los sistemas refractarios comerciales de igual composición química y mineralógica. En este caso las porosidades y su distribución de poro son semejantes a un prensado a $10 \mathrm{MPa}$, no observándose otras diferencias con las -231 - 
técnicas utilizadas. Quizás haciendo un análisis más profundo de sus microestructuras (ejemplo: tamaño de grano) podría explicarse ésta diferencia.

Tabla 7.16. Propiedades termomecánicas de la mezcla AriojAcal obtenidas por el método de colado y calcinadas a $1550{ }^{\circ} \mathrm{C}$ durante 4 horas.

\begin{tabular}{|c|c|}
\hline & $\begin{array}{c}\text { Arcilla Rioja + Alúmina Calcinada } \\
\text { (AriojAcal) }\end{array}$ \\
\hline $\begin{array}{c}\text { MÓDULO DE ELASTICIDAD } \\
\text { (E1) } \\
(\mathrm{GPa})\end{array}$ & 33.8 \\
\hline $\begin{array}{l}\text { MÓDULO DE ELASTICIDAD } \\
\text { Después de choque térmico } \\
\text { (E2) } \\
(\mathrm{GPa})\end{array}$ & 25.1 \\
\hline $\begin{array}{l}\text { RELACIÓN DE MÓDULOS } \\
\text { (E1/E2) }\end{array}$ & 1.3 \\
\hline $\begin{array}{l}\text { MÓDULO DE ROTURA A LA FLEXIÓN } \\
\text { (MOR1) } \\
\text { (MPa) }\end{array}$ & 25.9 \\
\hline $\begin{array}{c}\text { MÓDULO DE ROTURA A LA FLEXIÓN } \\
\text { Después de choque térmico } \\
\text { (MOR 2) } \\
\text { (MPa) }\end{array}$ & 10.5 \\
\hline $\begin{array}{l}\text { RELACIÓN DE MÓDULOS } \\
\text { (MOR1/MOR2) }\end{array}$ & 2.5 \\
\hline
\end{tabular}

7.5.4 Caracterización de la mezcla AriojAcal, conformada por el método de extrusión y calcinada a $1550 \stackrel{\circ}{C}$ durante 4 horas.

Se confeccionaron probetas con estequiometría 3-2 por el método de extrusión aplicando vacío, con una presión absoluta sobre la pasta en extrusión de $162.08 \mathrm{hPa}$. La masa de la mezcla estequiométrica 3-2 de arcilla La Rioja más alúmina calcinada (AriojAcal) se confeccionó con un porcentaje de humedad del 23 \% (agua más carboximetil celulosa al $2.5 \%$ ), tal como se explicó en la sección 7.3. La extrusión se 
realizó con boquilla de salida para generar cintas de $0.8 \mathrm{~cm}$ de espesor. Las cintas eran cortadas en longitudes del orden de los $30-40 \mathrm{~cm}$ ni bien salían de la extrusora. De dichas cintas se cortaron probetas de $\sim 5.3 \times 0.8 \times 0.8 \mathrm{~cm}^{3}$, las cuales fueron secadas a $110^{\circ} \mathrm{C}$ y calcinadas a $1550{ }^{\circ} \mathrm{C}$ durante 4 horas, post eriormente se caracterizaron utilizando: Difracción de Rayos X, densidad y porosidad por el método de Arquímedes, porosimetría por intrusión de mercurio, microscopía electrónica de barrido (MEB), variación lineal respecto al conformado del material seco $\left(110^{\circ} \mathrm{C}\right)$, módulo de rotura a la flexión y módulo de elasticidad antes (MOR1 y E1) y después del choque térmico mencionado anteriormente (MOR2 y E2).

\subsubsection{Difractograma de la mezcla AriojAcal.}

La figura 7.44 muestra el difractograma de Rayos $\mathrm{X}$ de la mezcla estequiométrica 3-2 (AriojAcal) conformada por el método de extrusión y calcinada a $1550 \stackrel{\circ}{\mathrm{C}}$ durante 4 horas. En la figura 7.44, se evidencian la presencia de mullita (neta) como fase principal y una poca cantidad de $\alpha$-alúmina aun sin reaccionar.

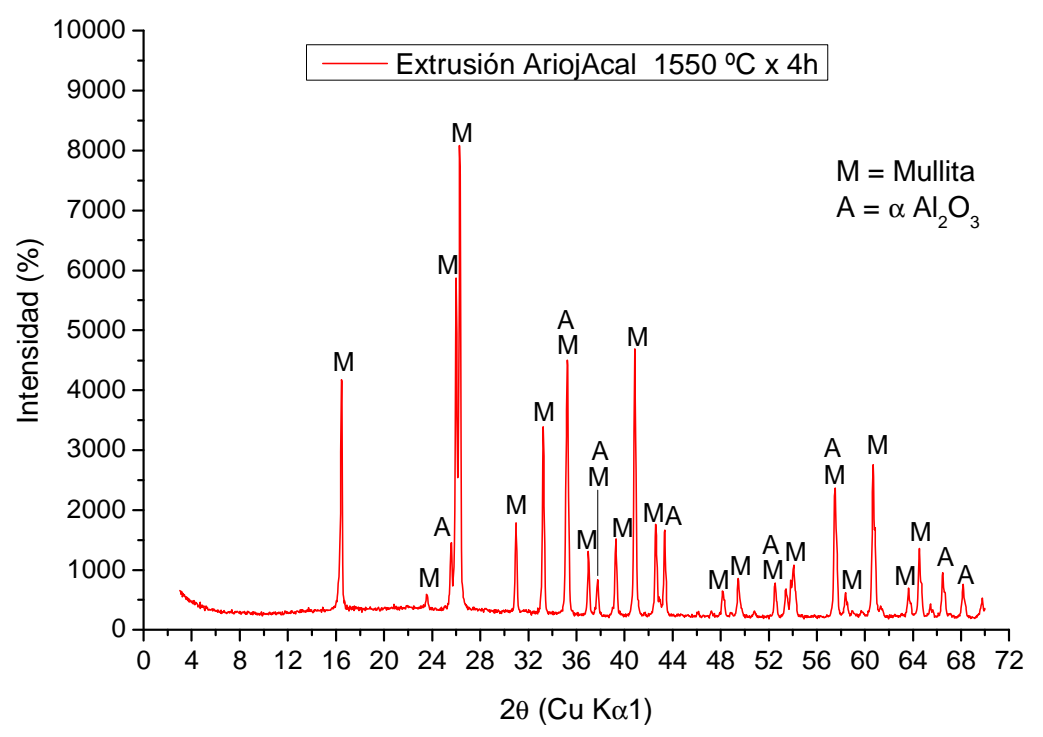

Figura 7.44. Difractograma de la mezcla AriojAcal conformada por el método de extrusión, calcinada a $1550^{\circ} \mathrm{C}$ durante 4 horas. 


\subsubsection{Propiedades físicas de la mezcla AriojAcal.}

Después de someter las probetas obtenidas por el método de extrusión y calcinadas a $1550 \stackrel{\circ}{\circ}$ durante 4 horas, se procedió a caracterizarlas utilizando el método de Arquímedes por inmersión en agua donde se obtuvieron valores del porcentaje de porosidad (abierta), densidad del material y densidad aparente en agua. El porcentaje de porosidad cerrada se calculó en base al valor teórico de la mullita $\left(3.17 \mathrm{~g} / \mathrm{cm}^{3}\right)$, también se midió el porcentaje de variación lineal respecto al conformado del material seco $\left(110^{\circ} \mathrm{C}\right)$. La tabla 7.17 , muestra los resultados obtenidos.

En la tabla 7.17 se observan los resultados de las propiedades físicas de la mezcla AriojAcal, calcinada a la temperatura ya mencionada, encontrando que el valor de la densidad del sólido (densidad aparente en agua) es relativamente igual al valor teórico de la mullita $3.17 \mathrm{~g} / \mathrm{cm}^{3}$.

Tabla 7.17. Propiedades físicas de la mezcla AriojAcal obtenida por el método de extrusión y calcinada a $1550 \stackrel{\circ}{\mathrm{C}}$ durante 4 horas.

\begin{tabular}{|c|c|}
\hline & $\begin{array}{c}\text { Arcilla Rioja + Alúmina Calcinada } \\
\text { (AriojAcal) }\end{array}$ \\
\hline $\begin{array}{c}\text { POROSIDAD (Abierta) } \\
\%\end{array}$ & 36.6 \\
\hline $\begin{array}{c}\text { POROSIDAD (Cerrada) } \\
\%\end{array}$ & 0.6 \\
\hline $\begin{array}{l}\text { DENSIDAD DE LA PIEZA (Arquímedes) } \\
\qquad \mathrm{g} / \mathrm{cm}^{3}\end{array}$ & 1.99 \\
\hline $\begin{array}{c}\text { DENSIDAD APARENTE EN AGUA } \\
\text { (Del sólido) } \\
\mathrm{g} / \mathrm{cm}^{3}\end{array}$ & 3.15 \\
\hline $\begin{array}{c}\text { VARIACIÓN LINEAL respecto al } \\
\text { conformado del material seco a } 110 \stackrel{\circ}{\circ} \text {. } \\
\%\end{array}$ & -1.6 \\
\hline
\end{tabular}

Confrontando los resultados obtenidos (tabla 7.17) con los del método de prensado a 10,40 y $100 \mathrm{MPa}$ (tabla 7.11) se observó que las propiedades físicas como porosidad (abierta y cerrada) y densidad (pieza y sólido) del método de extrusión son semejantes a 
las obtenidas a presiones entre 10 y $40 \mathrm{MPa}$. Mientras el valor de la variación lineal respecto al conformado mostró un valor menor a la prensada a $10 \mathrm{MPa}$.

\subsubsection{Distribución de tamaño de poro por intrusión de mercurio de la mezcla AriojAcal.}

Se realizó el ensayo de porosimetría por intrusión de mercurio a la mezcla AriojAcal conformada por el método de extrusión y calcinada a $1550 \stackrel{\circ}{\mathrm{C}}$ durante 4 horas, en la figura 7.45 se puede observar la curva de distribución de volumen acumulado de poros en función del diámetro de poro.

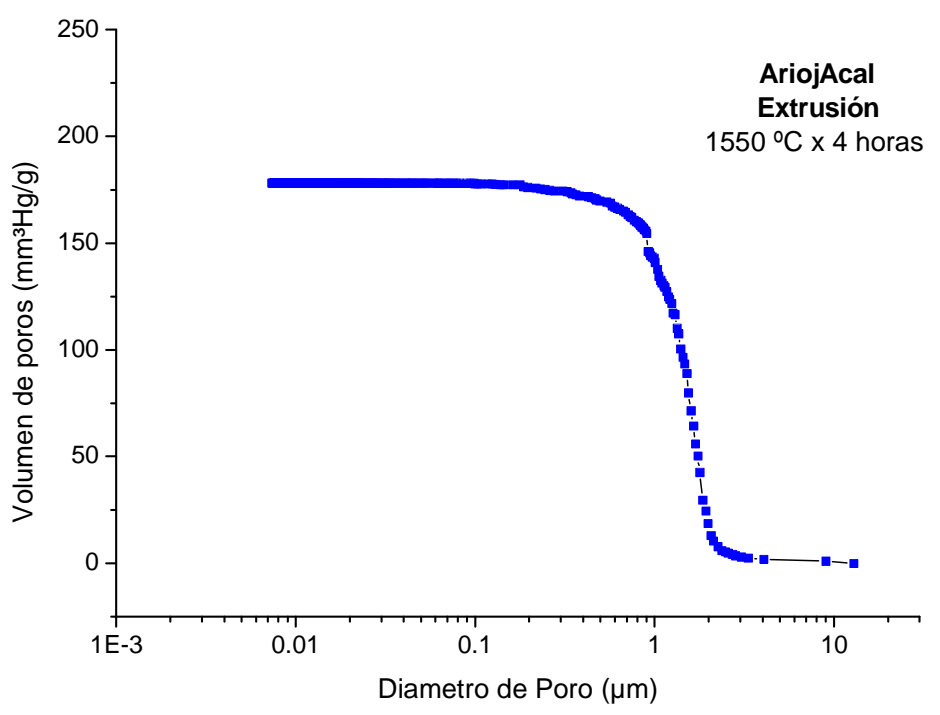

Figura 7.45. Curva de distribución de tamaño de poros por intrusión de mercurio para la mezcla AriojAcal conformada por el método de extrusión calcinada a $1550{ }^{\circ} \mathrm{C}$ durante 4 horas.

Los resultados de la distribución de diámetro de poros para la mezcla estequiométrica 32 (AriojAcal) conformada por el método de extrusión y calcinada como se indicó anteriormente, se muestran en la figura 7.45 , encontrándose que la porosidad total se halla prácticamente cubierta por los poros de tamaños entre 2.7 y $0.6 \mu \mathrm{m}$, donde el diámetro más frecuente esta en $1.52 \mu \mathrm{m}$ y su volumen de poros total penetrado es de $178,2 \mathrm{~mm}^{3} \mathrm{Hg} / \mathrm{g}$. 


\subsubsection{Microscopia electrónica de barrido de la mezcla AriojAcal.}

La mezcla AriojAcal conformada por el método de extrusión y calcinada a $1550{ }^{\circ} \mathrm{C}$ durante 4 horas fue también caracterizada por microscopía electrónica de barrido. Un trozo de la probeta fue incluida en resina y pulida, como se indicó en la sección 3.7; a la mitad de esta probeta se le realizó un etching químico con ácido fluorhídrico al $5 \%$, durante 10 minutos, con el fin de eliminar la fase vítrea generada en el sistema. Las micrografías obtenidas se muestran en la figura 7.46.

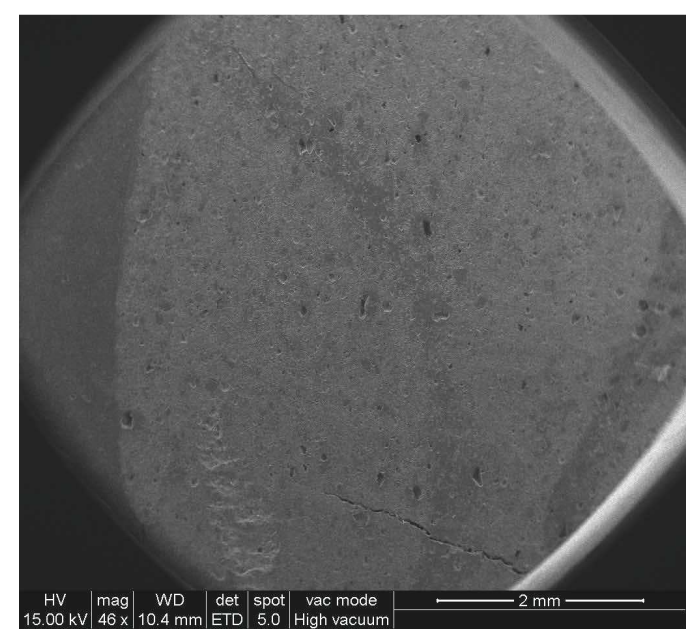

(a)

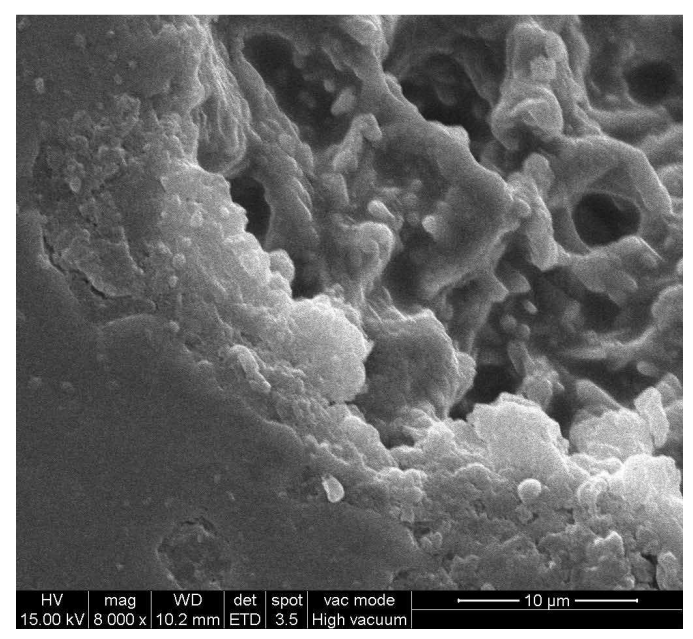

(c)

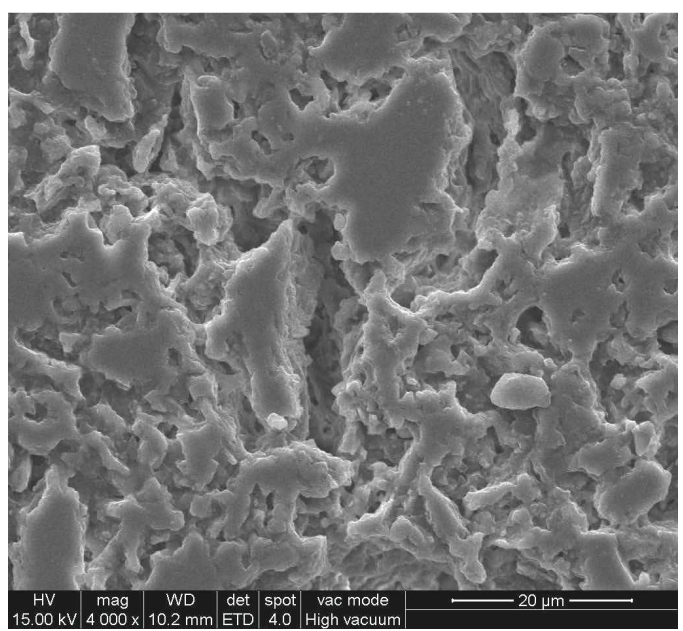

(b)

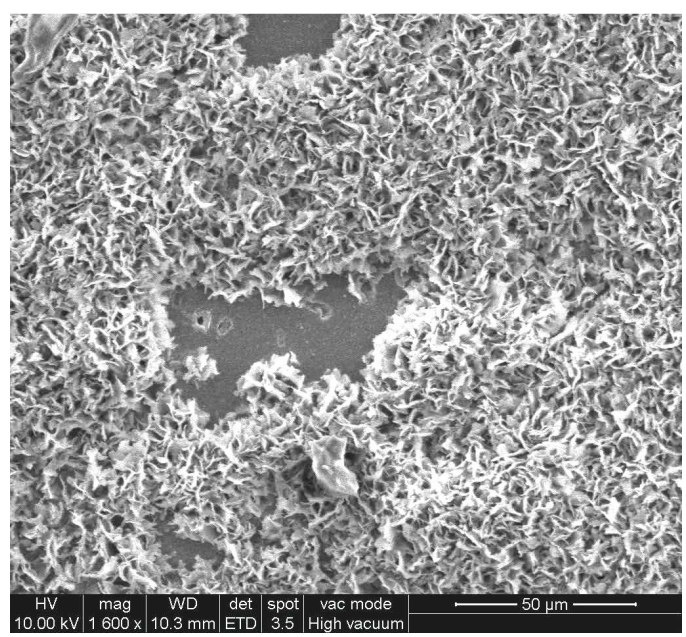

(d) 


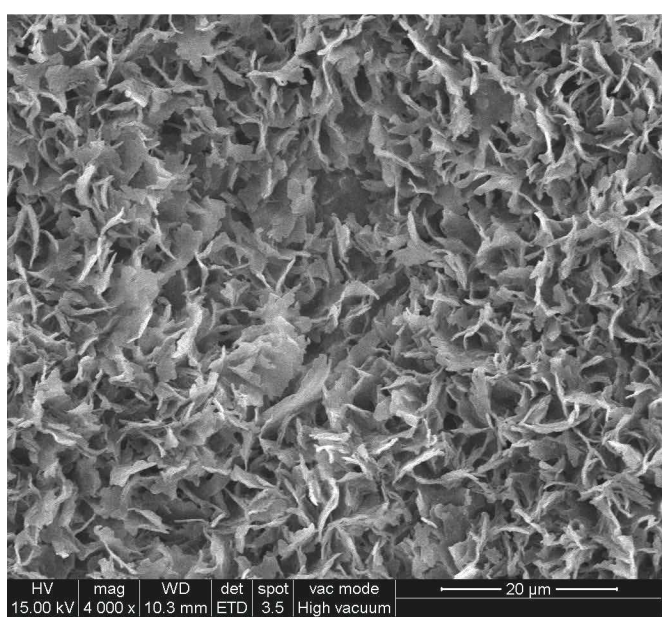

(e)

Figura 7.46 Micrografía de AriojAcal, obtenida por el método de extrusión y calcinada a $1550{ }^{\circ} \mathrm{C}$ durante 4 horas; sin etching químico: a) 46x, b) 4000x, c) 8000x, y con etching químico (HF 5\%), d) 1600x y e) 4000x.

En las figuras $7.46 \mathrm{~b}$ y $7.46 \mathrm{c}$ que corresponden a las micrografías sin ataque químico para la mezcla AriojAcal se puede observar que no presentan un ordenamiento definido, ni un tamaño homogéneo de bastones de mullita y las zonas de puntas de bastones representarían la zona de sinterizado del material.

Las micrografías de las figuras $7.46 \mathrm{~d}$ y 7.46 e muestran la reacción del ataque químico sobre la fase vítrea que está ligado a la mullita cristalina, notándose que se ha destruido casi toda la fase vítrea con el etching químico (ácido fluorhídrico al $5 \%$, durante 10 minutos), revelándose la fase cristalina como mullita en forma de láminas levantadas en sobre relieve. El efecto laminar observado es debido a que la superficie en contacto con el exterior en el método de extrusión en la parte superior e inferior de la probeta corresponden a la zona de contacto de la boquilla, soportando una compresión y fricción por desplazamiento del material (AriojAcal), orientándose en esa zona la formación de mullita tipo laminar en lugar de la formación de bastones. Este comportamiento se observó también en el método de prensado a 40 y $100 \mathrm{MPa}$ en las zonas de compactación del cabezal del molde. 


\subsubsection{Propiedades termomecánicas de la mezcla AriojAcal.}

El análisis de las propiedades termomecánicas para la mezcla estequiométrica 3-2 (AriojAcal) conformada por el método de extrusión y posteriormente calcinada a $1550{ }^{\circ} \mathrm{C}$ durante 4 horas se realizó midiendo el módulo de elasticidad y módulo de rotura a la flexión (E1 y MOR1) antes y después del choque térmico (E2 y MOR2) ya mencionado anteriormente; los resultados obtenidos se muestran en la tabla 7.18.

La tabla 7.18 muestra que el choque térmico realizado causó una disminución en las propiedades termomecánicas (E2 y MOR2) con respecto a E1 y MOR1.

Tabla 7.18. Propiedades termomecánicas de la mezcla AriojAcal conformada por el método de extrusión y calcinada a $1550 \stackrel{\circ}{\mathrm{C}}$ durante 4 horas.

\begin{tabular}{|c|c|}
\hline & $\begin{array}{c}\text { Arcilla Rioja + Alúmina Calcinada } \\
\text { (AriojAcal) }\end{array}$ \\
\hline $\begin{array}{c}\text { MÓDULO DE ELASTICIDAD } \\
\text { (E1) } \\
\text { (GPa) }\end{array}$ & 26.7 \\
\hline $\begin{array}{l}\text { MÓDULO DE ELASTICIDAD } \\
\text { Después de choque térmico } \\
\text { (E2) } \\
\text { (GPa) }\end{array}$ & 18.0 \\
\hline $\begin{array}{l}\text { RELACIÓN DE MÓDULOS } \\
\text { (E1/E2) }\end{array}$ & 1.5 \\
\hline $\begin{array}{l}\text { MÓDULO DE ROTURA A LA FLEXIÓN } \\
\text { (MOR1) } \\
\text { (MPa) }\end{array}$ & 37.2 \\
\hline $\begin{array}{l}\text { MÓDULO DE ROTURA A LA FLEXIÓN } \\
\text { Después de choque térmico } \\
\text { (MOR 2) } \\
\text { (MPa) }\end{array}$ & 9.4 \\
\hline $\begin{array}{l}\text { RELACIÓN DE MÓDULOS } \\
\text { (MOR1/MOR2) }\end{array}$ & 3.9 \\
\hline
\end{tabular}

Comparando los resultados obtenidos para la mezcla AriojAcal conformada por el método de extrusión (tabla 7.18) con el método de prensado a 10, 40 y $100 \mathrm{MPa}$ (tabla 
7.12) se puede concluir que las propiedades termomécanicas se asemejan a un prensado de $10 \mathrm{MPa}$, aunque la relación de módulos de rotura a la flexión es mejor en el conformado por extrusión que en el de prensado. Si bien el valor de relación de módulos (MOR1/MOR2) es elevado desde el punto de vista de la resistencia al choque térmico, debe notarse que el valor del MOR2 es muy bueno, poseyendo valores similares a los valores normales de módulos de rotura a la flexión de ladrillos refractarios silicoaluminosos comerciales, considerando que esa resistencia se obtuvo luego de que la pieza fuera sometida a un choque térmico violento por lo tanto el valor de la relación de módulos pasa a segundo plano en la evaluación del material.

En las secciones anteriores se mostraron las caracterizaciones de mullitas obtenidas a partir de una mezcla estequiométrica 3-2 de arcilla Tincar Súper más alúmina calcinada (AtinAcal) y arcilla La Rioja más alúmina calcinada (AriojAcal), obtenidas por tres diferentes métodos de conformado: prensado (10, 40 y $100 \mathrm{MPa}$ ), colado y extrusión.

Comparando los resultados obtenidos por el método de prensado a 10, 40 y $100 \mathrm{MPa}$, con el método de colado y extrudado (secciones 7.41 y 7.51 ), se pudo generalizar para las mezclas estequiométricas 3-2 conformadas con arcilla y alúmina calcinada (AtinAcal y AriojAcal) que; el método de colado (secciones 7.43 y 7.53) correspondería a una probeta prensada a $10 \mathrm{MPa}$, aunque los valores oscilan entre 10 y $40 \mathrm{MPa}$ con mayor incidencia en los valores de $10 \mathrm{MPa}$, mientras que el método de extrusión (secciones 7.44 y 7.54 ) se relacionaría a un prensado de $40 \mathrm{MPa}$.

\subsection{Caracterización por dilatometria de mullitas 3-2 obtenidas por distintos métodos de conformado de mezclas estequimétricas $3 \mathrm{Al}_{2} \mathrm{O}_{3} \cdot 2 \mathrm{SiO}_{2}$ de dos arcillas distintas más alúmina calcinada (AtinAcal y AriojAcal).}

La caracterización por dilatometría se realizó para las mezclas AtinAcal y AriojAcal, conformadas por el método de colado, extrudado y prensado a $100 \mathrm{MPa}$, calcinadas a $1550{ }^{\circ} \mathrm{C}$ durante 4 horas. A las probetas ya calcinad as se les midió el coeficiente de dilatación térmica tal como se indicó en la sección 3.8, las curvas que representan el porcentaje de la variación de la longitud en función de la temperatura, se muestran en las figuras 7.47 y 7.48 . 


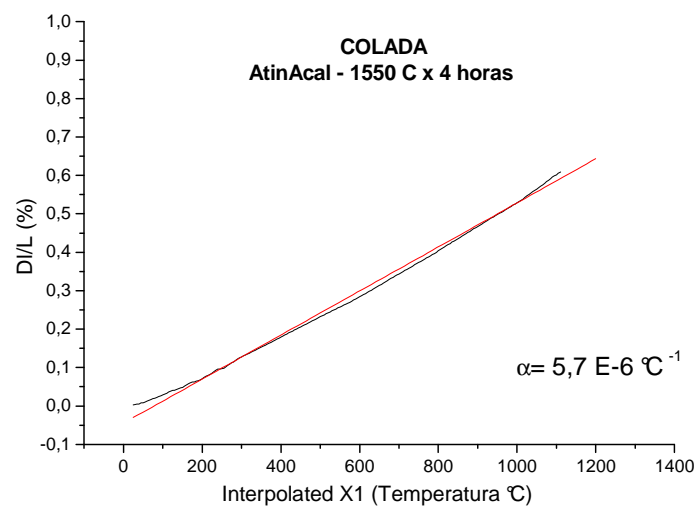

(a)

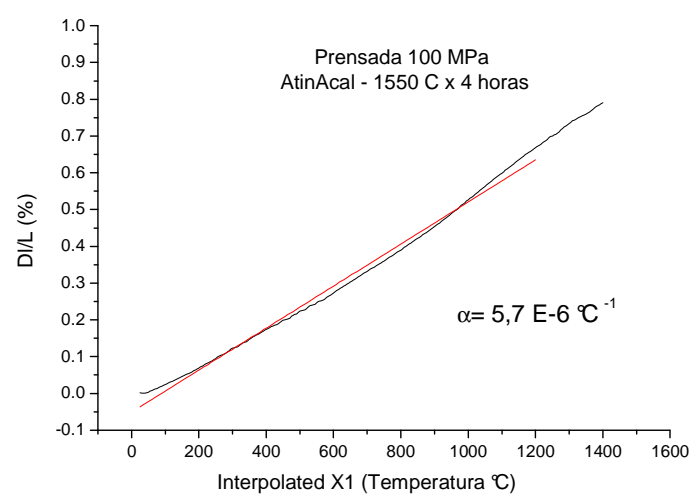

(c)

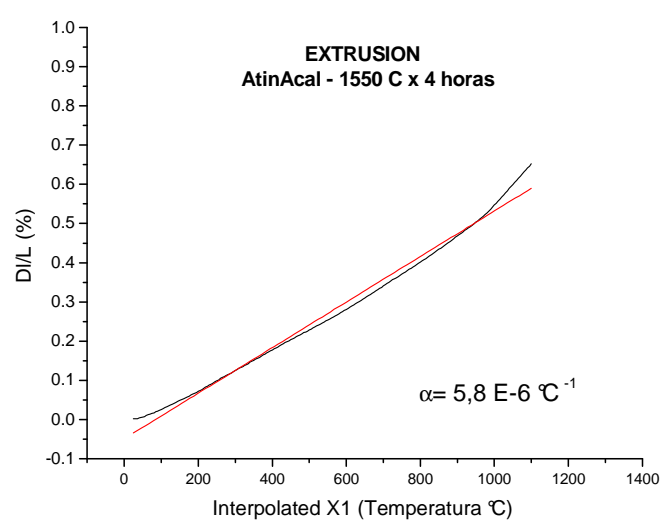

(b)

Figura 7.47. Curvas de dilatometría de la mezcla AtinAcal calcinadas a $1550{ }^{\circ} \mathrm{C}$ durante 4 horas conformadas por; a) colado; b) extrusión; c) prensado a $100 \mathrm{MPa}$. 


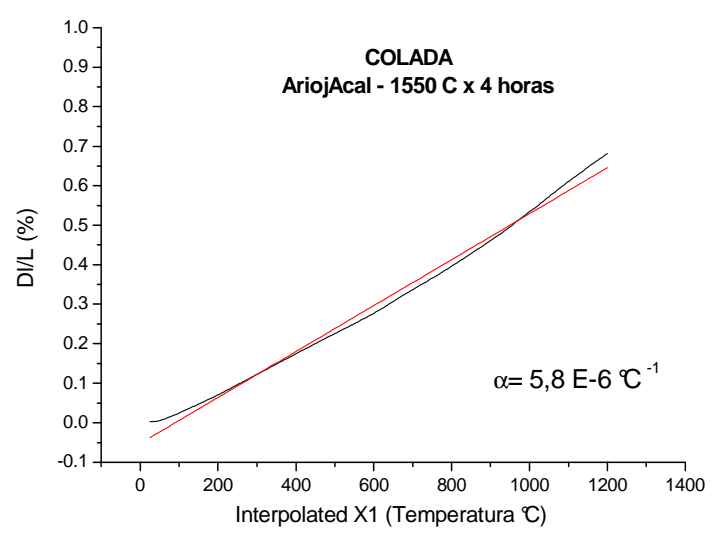

(a)

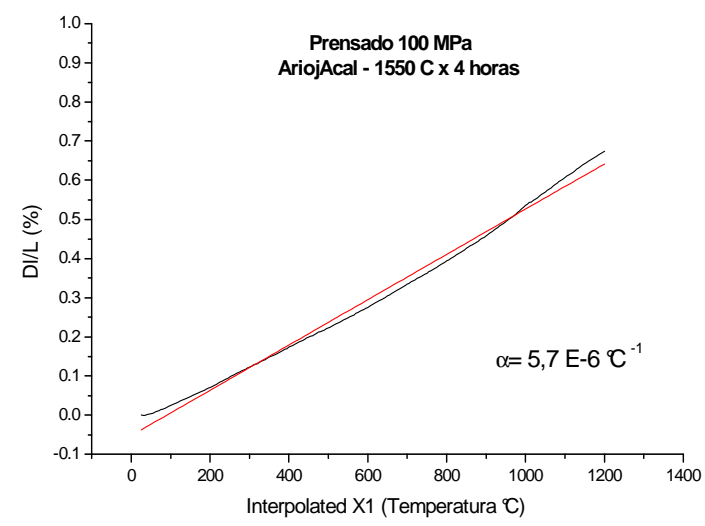

(c)

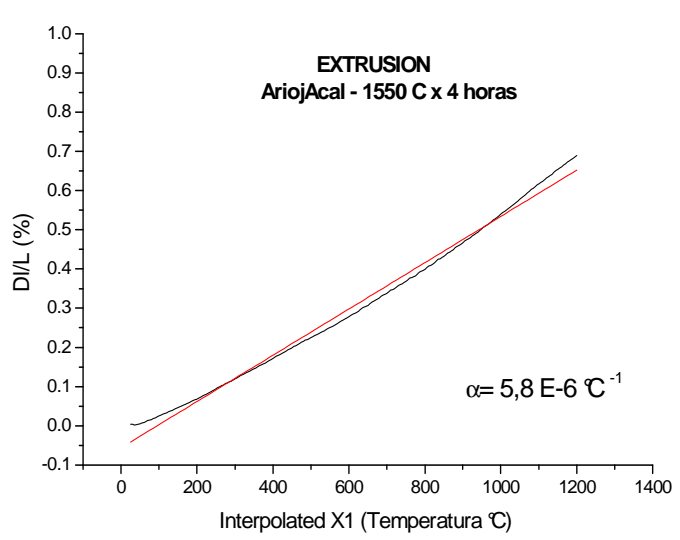

(b)

Figura 7.48. Curvas de dilatometría de la mezcla AriojAcal calcinadas a $1550{ }^{\circ} \mathrm{C}$ durante 4 horas conformadas por; a) colado; b) extrusión; c) prensado a $100 \mathrm{MPa}$.

En las figuras 7.47 y 7.48 , se pueden observar que los valor del coeficiente de dilatación $(\alpha)$ para las probetas elaboradas por los tres métodos de conformado mencionados (colado, extrusión y prensado a $100 \mathrm{MPa}$ ) presentaron valores casi iguales, esto debido a que las probetas caracterizadas en este caso por dilatometría eran de mullita (AtinAcal y AriojAcal calcinada a $1550^{\circ} \mathrm{C}$ durante 4 horas) y sus propiedades intrínsecas son del material y no de la textura del mismo. 
La diferencia entre el valor teórico de dilatación de la mullita $\left(5.210^{-6} \mathrm{C}^{-1}\right)$, y el experimental obtenido $\left(\sim 5.710^{-6} \mathrm{C}^{-1}\right)$, es debido a la presencia de alúmina que todavía quedó presente en el sistema y por lo tanto contribuye a aumentar en algo el valor sobre dato teórico, además de diferencias asociadas a la técnica experimental respecto al valor teórico.

\subsection{CONCLUSIONES PARCIALES}

La mullita de alta gama obtenida en este capítulo, fue elaborada utilizando mezclas estequiométricas 3-2 $\left(3 \mathrm{Al}_{2} \mathrm{O}_{3} \cdot 2 \mathrm{SiO}_{2}\right)$ a partir de las mejores arcillas preseleccionadas (Tincar Súper y La Rioja) y alúminas (calcinada e hidratada), conformadas por tres métodos: prensado (10, 40 y $100 \mathrm{MPa})$, colado y extrusión, y calcinadas a $1550{ }^{\circ} \mathrm{C}$ durante 4 horas, con una velocidad de calentamiento de $5 \stackrel{\circ}{ } \mathrm{C}$ por minuto.

Se encontró que el índice de plasticidad de la mezcla AtinAcal fue tres veces mayor con respecto a la mezcla AriojAcal, esto debido a que la arcilla La Rioja presentó una baja plasticidad respecto a la arcilla Tincar Súper. En ambos casos el índice fue muy bajo por lo tanto existió un rango de humedad muy estrecho para el conformado por extrusión.

No se pudieron elaborar probetas por el método de colado y extrusión con las mezclas AtinAhid y AriojAhid (arcilla Tincar Súper y La Rioja más alúmina hidratada respectivamente), ya que presentaron algunos problemas el extraer las piezas en el molde (colado) debido a que el tamaño de la alúmina era "grande" para su conformado (extrudado).

Todas las mezclas y conformados presentaron difractogramas de rayos $\mathrm{X}$ similares, donde se evidenció la presencia de mullita neta como fase principal y mayoritaria, y una poca cantidad de $\alpha$-alúmina, también se observó una leve banda centrada en $22^{\circ}$ de $2 \theta$ indicando la presencia de fase vítrea de la matriz silícea. 
Se observó en los difractogramas obtenidos a las tres presiones un leve aumento en la fase mullita y una disminución de la fase $\alpha$-alúmina a medida que se aumenta la presión, esto para la mezcla AtinAcal, y en las mezclas AtinAhid, AriojAcal y AriojAhid no se observaron grandes modificaciones.

Se encontró en todas las mezclas conformadas por el método de prensado (10, 40 y $100 \mathrm{MPa}$ ) que el porcentaje de porosidad abierta (Arquímedes) va disminuyendo, mientras la porosidad cerrada va creciendo a medida que se aumenta la presión, ya que a mayor presión mayor contacto entre partículas. Se observó también que los valores de porosidad abierta independientemente de la presión, son un poco menores para las mezclas con alúmina hidratada (AtinAhid y AriojAhid) con respecto a los de alúmina calcinada (AtinAcal y AriojAcal).

Los resultados de porosidad abierta (Arquímedes) para las mezclas AtinAcal y AriojAcal conformadas por el método de colado se asemejan a las obtenidas a una presión de $\sim 10 \mathrm{MPa}$, y por el método de extrusión a $\sim 40 \mathrm{MPa}$.

Las mezclas estequiométricas 3-2 que presentaron una densidad aparente en agua (densidad del sólido) similar o cercana al valor teórico de la mullita (3.17 $\mathrm{g} / \mathrm{cm}^{3}$ ), fueron:

- La mezcla AtinAcal prensada a $10 \mathrm{MPa}$ y en la mezcla AtinAhid a 10 y 40 MPa.

- Todas las mezclas realizadas con arcilla La Rioja y alúmina calcinada e hidratada (AriojAcal y AriojAhid) conformadas por los tres métodos (prensado; 10, 40 y $100 \mathrm{MPa}$, colado y extrusión), esto debido a la alta refractariedad de la arcilla.

En la mezcla AtinAcal se observó un crecimiento en el porcentaje de expansión lineal respecto al conformado a $110^{\circ} \circ \mathrm{C}$ a medida que se aumentaba la presión, esto debido a que las partículas van teniendo un mayor contacto entre ellas, generando así una reacción de mullitización secundaria de mucho contacto con las partículas de alúmina calcinada, la cual es expansiva. 
La mezcla AriojAcal a una presión de $10 \mathrm{MPa}$ presentó una pequeña contracción lineal respecto al conformado a $110^{\circ}{ }^{\circ} \mathrm{C}$, debido a que el material reaccionante posee una alta porosidad inicial, la cual permite que los bastones de mullita que se van formando lo hagan hacia el interior de los poros y no empujando el material para producir la expansión, en cambio a $40 \mathrm{MPa}$ se presentó una pequeña expansión y a medida que se aumentó la presión a 100 MPa creció un poco el valor de expansión que ahora es absorbida en menor magnitud por los poros.

En cambio las mezclas realizadas con alúmina hidratada (AtinAhid y AriojAhid) obtenidas por el método de prensado (10,40 y $100 \mathrm{MPa}$ ) mostraron un alto valor de contracción en comparación a las obtenidas con alúmina calcinada (AtinAcal y AriojAcal), debido a que a alta temperatura la sílice difunde hacia el interior de la alúmina porosa generada por la deshidratación del hidróxido de aluminio, generando mullita en el interior de la misma, contribuyendo más el fenómeno de sinterizado que el de expansión.

La variación lineal respecto al conformado a $110^{\circ}{ }^{\circ} \mathrm{C}$ para las mezclas AtinAcal y AriojAcal obtenidas por el método de colado, presentaron valores semejantes a un prensado de $10 \mathrm{MPa}$ y los valores por el método de extrusión presentaron una menor expansión en comparación a las tres presiones.

Las mezclas AtinAcal y AriojAcal conformadas por los métodos de prensado, colado y extrudado, presentaron un sistema monomodal de poros abiertos, no observándose grandes diferencias en el desarrollo total de poros, este comportamiento se relacionó con la granulometría de las materias primas utilizadas, también se observaron pequeños cambios en los poros abiertos a medida que se incrementaba la presión. En cambio las mezclas AtinAhid y AriojAhid prensadas a $40 \mathrm{MPa}$ presentaron un sistema bimodal y una distribución de tamaño de poros amplia, la bimodalidad es más notoria en la mezcla que contiene arcilla La Rioja.

Se observó por microscopía electrónica de barrido la formación de mullita primaria en forma de bastones y la presencia de la fase amorfa presentes en las arcillas Tincar Súper y La Rioja calcinadas a 1550 C durante 4 horas. Se eliminó la fase amorfa utilizando un etching químico con ácido fluorhídrico (HF) al $5 \%$ 
durante 10 minutos, notándose posteriormente un sobre relieve de mullita (primaria).

Las micrografías observadas en todas las mezclas y en los tres métodos de conformado (prensado; 10, 40 y $100 \mathrm{MPa}$, colado y extrudado) correspondieron a la superficie en contacto con el exterior de la mezcla con el molde. Se observó en todos los casos la formación de cristales de mullita en forma acicular (agujas o bastones) y zonas de puntas de bastón medio redondeadas que representaría la zona de sinterizado del material, no habiendo un ordenamiento definido ni un tamaño homogéneo.

Se observaron diferencias en las superficies vistas por microscopía electrónica de barrido después de haber atacado y extraído la fase vítrea con HF al $5 \%$ durante 10 minutos, entre los tres conformados (prensado; 10, 40 y $100 \mathrm{MPa}$, colado y extrudado), encontrando que:

- Las probetas conformadas por el método de prensado presentaron una fuerza mecánica o fricción intensa que orientó las láminas de mezcla en un determinado sentido, dejando en descubierto la memoria laminar de la mezcla (AtinAcal y AriojAcal) que se manifiestó en la micrografía como mullita (neta) en forma de láminas levantadas en sobre relieve. Esto se observó a 40 y $100 \mathrm{MPa}$ para la mezcla AtinAcal y en la mezcla AriojAcal se presentó solo $100 \mathrm{MPa}$ debido a que la arcilla La Rioja es poco plástica, más gruesa y más dura y por lo tanto le cuesta más orientarse a bajas presiones.

- El método por colado en las mezclas AtinAcal y AriojAcal presentaron un comportamiento similar al prensado a $10 \mathrm{MPa}$, esto debido a que los dos sistemas no presentaron una fuerza mecánica o fricción intensa que orientara las laminitas del material en un determinado sentido.

- Las mezclas AtinAcal y AriojAcal presentaron en el método por extrusión una compresión y fricción por desplazamiento del material en estudio, esto observado como mullita en forma de láminas levantadas en sobre relieve, pero con mucha más intensidad que las prensadas a 40 y $100 \mathrm{MPa}$. 
Se observó en el módulo de rotura a la flexión (MOR1) y en el módulo de elasticidad dinámico (E1) antes del choque térmico que las mezclas AtinAcal, AtinAhid, AriojAcal y AriojAhid conformadas por el método de prensado (10, $40 \mathrm{y}$ $100 \mathrm{MPa}$ ) presentaron un incremento en su valor a medida que se aumentaba la presión, debido a una mayor cantidad de sólido sinterizado. Los resultados fueron mayores para las mezclas con alúmina calcinada (AtinAcal y AriojAcal) respecto a las mezclas con alúmina hidratada (AtinAhid y AriojAhid), esto debido a que la alúmina hidratada contiene núcleos cerrados no conectados con el exterior originando que la fractura inducida se propague fácilmente dentro de dichos núcleos sin ofrecer resistencia.

$>\quad$ Se observó que el choque térmico realizado en todas las mezclas y conformados produjeron una disminución en las propiedades termomecánicas del módulo de elasticidad dinámico (E2) y módulo de rotura a la flexión (MOR2) con respecto a E1 y MOR1.

Todas las mezclas conformadas por el método de prensado obtuvieron un incremento del valor del módulo de elasticidad dinámico después del choque térmico (E2) con respecto al aumento de la presión, esto debido a que el choque térmico produjo fisuras en los poros cerrados pero el material seguía en contacto y por lo tanto se propagó la onda acústica de medición sobre el material.

En cambio los valores de módulo de rotura después de choque térmico (MOR2) cayeron al aumentar la presión de prensado debido a que existió una mayor cantidad de poros cerrados que a bajas presiones y estos al ser afectados por el choque térmico y fisurarse, aun estando en contacto el material a ambos lados de la fisura, la propagación de una fractura por esfuerzo mecánico ocurre fácilmente.

Contrastando los resultados de las propiedades termomecánicas del método de prensado con las obtenidas por el método de colado y extrudado, se concluyó que no presentaron una buena similitud general para correlacionar con los métodos de conformado. 
$>\quad$ Comparando la relación de módulos de rotura de las mezclas con alúmina hidratada (AriojAhid) y calcinada (AriojAcal), se observó que la mezcla AriojAhid presentó un valor muy bajo, la cual la hace buena para ser utilizada donde se requiera resistencia al choque térmico más que resistencia mecánica.

$>\quad$ Comparando los resultados obtenidos en las mezclas estequiométricas 3-2 conformada con arcilla y alúmina calcinada (AtinAcal y AriojAcal) por el método de prensado a 10, 40 y $100 \mathrm{MPa}$, con el método de colado y extrudado, se llegó a la conclusión de que:

- El método por colado corresponde a una probeta prensada a $10 \mathrm{MPa}$, aunque los valores oscilaban entre 10 y $40 \mathrm{MPa}$ con mayor incidencia hacia los valores de $10 \mathrm{MPa}$.

- El método por extrusión se relacionó con un prensado a 40 MPa.

$>\quad$ Se encontró que el valor del coeficiente de dilatación presentó valores casi iguales en las mezclas (AtinAcal y AriojAcal) conformadas por el método de colado, extrusión y prensado a $100 \mathrm{MPa}$, debido a que el análisis estudiado fue a la mullita (probetas calcinadas a $1550{ }^{\circ} \mathrm{C}$ durante 4 horas) y sus propiedades intrínsecas son del material y no de la textura del mismo.

\subsection{BIBLIOGRAFIA}

> Absi J., Glandus J.C., Improved method for severe thermal shocks testing of ceramics by water-quenching, Journal of The European Ceramics Society. 24, pp. 2835-2838 (2004).

> Aksay A.I., Dabbs D.M., Sarikaya M., Mullite for structural, electronic and optical, applications, Journal of the American Ceramics Society. 74 (10), pp. 2343-2358. (1991)

$>$ Aksel C., The effect of mullite on the mechanical properties and thermal shock behaviour of alúmina-mullite refractory materials, Ceramics International. 29, pp. 183-188 (2003). 
> Aksel C., The influence of Zircon on the mechanical properties and thermal shock behaviour of slip-cast alúmina-mullite refractories, Materials Letters. 57, pp. 992997 (2002).

> Aksel C., Warren P.D., Thermal shock parameters [R, $\mathrm{R}^{\prime \prime \prime}$ and $\left.\mathrm{R}^{\prime \prime \prime \prime}\right]$ of magnesia - spinel composites, Journal of the European Ceramic Society. 23, pp. 301-308 (2003).

> Ananthakumar S., Jayasankar M., Warrier K.G.K., Microstructural, mechanical and thermal characterisation of sol-gel-derived aluminium titanate-mullite ceramic composites, Acta Mater. 54 (11), pp. 2965-2973 (2006).

> Anderson T., Rowcliffe D.J., Thermal cycling of indented ceramic materials, Journal of The European Ceramics Society. 18, pp. 2065-2071(1998).

> Angel R.J., Prewitt C.T., Crystal structure of mullite: a re-examination of the average structure. Am. Miner. 71, pp.1476-1482 (1986).

> Ault N.N, Ueltz H.F.G., Sonic analysis for solid bodies, Journal of the American Ceramic Society. 36 (6), pp. 199-203 (1953).

$>$ Becher P.F., Effect of water bath temperature on the thermal shock of $\mathrm{Al}_{2} \mathrm{O}_{3}$, Journal of the American Ceramics Society. 64, pp. C17-C18. (1981).

> Benbow J.J., and Bridgwater J., The cutting of paste extrudates. Chemical Engineering Science, 48 (17), pp. 3088-3091(1993).

> Benbow J.J., Lawson T.A., Oxley E.W, Bridgwater J., Prediction of paste extrusion pressure, Ceramic Bulletin., 68 (10), pp. 1821-1824 (1989).

> Benbow J.J., y Bridgwater J., The influence of formulation on extrudate structure and strength. Chemical Engineering Science. 42 (4), pp.753-766 (1987).

> Bernal I., Cabezas H., Espitia C., Mojica J., y Quintero J., Análisis próximo de arcillas para cerámica. Revista. Académica Colombiana de Ciencias exactas y naturales. 27, pp. 569-578 (2003).

$>\quad$ Cesarano J., Aksay I.A., Bleier A., Satability of aqueous $\alpha-\mathrm{Al} 2 \mathrm{O} 3$ suspensions satabilized with poly (methacrylic acid) polyelectrolytes. Journal of the American Ceramics Society., 4, pp. 250-255 (1988a).

$>$ Cesarano J., Aksay I.A., Processing of highly concentrated aqueous $\alpha$-alúmina suspensions stabilizet with polyelectrolytes. Journal of the American Ceramics Society.,12, pp. 1062-1067 (1988b). 
> Christaras B., Auger F., Mosse E., Determination of the módulo of elasticity of rocks. Comparison of the ultrasonic velocity and mechanical resonance frequency methods with direct static methods. Materials and Structures. 27 (4), pp. 222-228 (1994).

> Cotterel B., Sze W.O., Caidong Q., Thermal shock and size effects in castable refractories, Journal of the American Ceramics Society. 78 (8), pp. 2056-2064 (1995).

$>$ Douy A., Crystallisation of amorphous spray-dried precursors in the Al2O3-SiO2 system. Journal of the European Ceramic Society. 26, pp. 1447-1454 (2006).

> Elssner G., Hoven H., Kiessler G., Wellner P. Ceramics and Ceramic composites: Materialogrphic preparation, - Elsevier (1999).

> Esther Ruiz de Sola., Francisco Estevan., Francisco Jose Torres., Javier Alarcón., Effect of thermal treatment on the structural evolution of 3:2 and 2:1 mullite monophasic gels. Journal of Non - Crystalline solids. 351 (14-15), pp. 1202-1209 (2005).

D Evans A.G., Thermal shock fracture in ceramics materials, Proceedings of the British Ceramic Society. 25, pp. 217-235 (1975).

$>\quad$ Fenstermacher J.E., Hummel F.A., High - Temperature Mechanical Properties of Ceramic Materials: IV, Journal of the American Ceramic Society. 44 (6), pp. 284289 (1961).

> Ferrari B., Moreno R., Lange F.F., Comportamiento coloidal de un caolín deshidratado, Boletín de la Sociedad Española de Cerámica y Vidrio. 39 (2), pp. 229-235 (2000).

> Fischer R.X., Schneider H., The mullite - type family of crystal structures. H. Schneider, S. Komarneni (Eds.), Mullite, Wiley-VCH, Weinheim, pp. 1-46 (2005)

> Furusato I., Mitsudomo T., Synthesis and Properties of Mullite from High Purity Kaolin; presented at the First International Workshop on Mullite, Tokyo, Japan (1987).

> Goldstein J., Newbury D.E., Joy D.C., Lyman C.E., Echlin P., Lifshin E., Sawyer L.C., Michael J.R., Scanning Electron Microscopy and X-ray Microanalysis, 3rd edition, Springer, pp. 271-296 (2003). 
> Gutiérrez C., Sánchez Herencia J., Moreno R., Suspensiones, Reología, Reometría, Porcelana sanitaria, Plasticidad, Punto de fluidez, Suspensions, Rheology, Rheometry, Sanitary porcelain, Plasticity, Yield stress, Boletín de la Sociedad Española de Cerámica y Vidrio. 39 (1), pp. 105-117 (2000).

> Hamidouche M., Bouaouadja N., Olagnon C. y Fantozzi G., Thermal shock behaviour of mullite ceramic, Ceramics International. 29 (6), pp. 599-609 (2003).

> Jovani M., Alonso J.J., Manglano J.J., Estudio por microscopía electrónica de barrido (S.E.M.) de pastas cerámicas refractarias y de la mullita en ellas formada. Bol. Soc. Esp. Ceram. V. 18 (2), pp. 85-92 (1979).

> Kanraki S., Tabata H., Kumazawa T., y Ohta S., Sintering and Mechano chemical Properties of Stoichiornetric Mullite, Journal of the American Ceramics Society., 68 (1) C-6-C-7 (1985).

> Klug H.P., y Alexander L.E., X-ray diffraction procedures for polycrystalline and amorphous materials. John Wiley \& Sons, New York. (1974) pp. 716

> Liu Kuo-Chung., Gareth Thornas., Caballero Angel., Moya Jose S, y De Aza Salvador., Microstructure and Microanalysis of Mullite Processed by Reaction Sintering of Kaolinite - Alúmina Mixtures: in Ceramics Today-Tomorrow's Ceramics. Edited by P. Vincenzini. Elsevier Science Publishers, London, U.K., pp. 177-86.Ç (1991).

> Lohre W., Urban H., Morphology of Mullite, Berichte der Deutschen Keramischen Gesellschaft. 37 (6), pp. 249-251 (1960).

$>\quad$ Lowell S., Shields J.E., Powder Surface Area and Porosity, 3rd ed., Chapman and Hall, New York, pp.87-96 (1991).

> Mari E. A., Los materiales cerámicos: Un enfoque unificador sobre las cerámicas tradicionales y avanzadas, los vidrios, los cementos, los refractarios y otros materiales inorgánicos no metálicos, Librería Editorial Alsina, Buenos Aires. pp.82 (1998).

> Mazdiyasni K.S., Brown L.M., Sintesis and mechanical properties of stoichiometric aluminum silicate (mullite), Journal of the American Ceramic Society. 55 (11), pp. 548-552 (1972).

> McGEE Thomas y Dodd M., Mechanism of secondary expansión of high alúmina refractaries containing calcined bauxite. Journal of the American Ceramic Society. 44 (6) (1961) pp. 277-283. 
> Mesa Toro Carlos Mario., Estudio de la producción de agregados mullíticos para la industria refractaria, Tesis doctoral, Universidad Nacional de Colombia, Medellin, Colombia, pp. 26-31 (2011).

> Modesto C., Bernardin A.M. Determination of clay plasticity. Indentation method versus Pfefferkorn method, Applied Clay Science. 40, pp. 15-19 (2008).

$>$ Moreno R., Moya J.S., y Requena J., Colaje de óxidos cerámicos, I: Fundamentos, Boletín de la Sociedad Española de Cerámica y Vidrio. 24 (3), pp. 165-171 (1985).

$>\quad$ Moreno R., Tendencias en el conformado de suspensiones cerámicas, Boletín de la Sociedad Española de Cerámica y Vidrio. 39 (5), pp. 601-608 (2000).

$>$ Moya J.S., Rubio J., y Pask J.A., Electrophorec -tic Behaviour of Silica - Bearing Alúmina Surfaces. American Ceramic Society Bulletin. 59 (12) pp. 198-120 (1980).

$>$ Obadia S., Broussaud D., Microstructural Developments in $\mathrm{Al}_{2} \mathrm{O}_{3}-\mathrm{SiO}_{2}$ Sintered Ceramics for High Temperature Application," Science of Ceramics. 14, ed. D. Taylor. Institute of Ceramics, UK, pp. 431-436 (1998).

> Pankratz L.B., Weller W.W., y Kelley K., Low - Low - temperature heat capacity and high - temperature heat content of mullite U.S. Dept. of the Interior. Bureau of Mines, Rep. Inyest. 6287, pp. 7 (1963)

> Pask J.A., Zhang X.W., y Tomsia A.P., Effect of sol-gel mixing on mullite microstructure and phase equilibria in the $\mathrm{Al}_{2} \mathrm{O}_{3}-\mathrm{SiO}_{2}$ system. Journal of the American Ceramic Society. 70 (10), pp. 704-707 (1987).

$>$ Penty R.A, Hasselman D.P.H., y Spriggs R. M., Young's Modulus of High Density Polycrystalline Mullite, Journal of the American Ceramics Society., 55 (3) (1972) pp.169-70.

> Pospech R., Schneider P., Powder Particle Sizes from Mercury Porosimetry, Powder Technol. 59, pp. 163 (1989).

> Rendtorff Nicolás., Aglietti Esteban., Mechanical and thermal shock behavior of refractory materials for glass feeders, Materials Science and Engineering. 527 (16-17) pp. 3840-3847, (2010).

$>$ Robinson G.C., Extrusion defects, Ceramic Processing before firing, Wiley - 
Interscience, New York, pp. 391-407 (1978).

> Sanchez Conde C., La mullita y su identificación en materiales cerámicos. Boletín de la Sociedad Española de Cerámica y Vidrio. 5 (1) (1996) pp. 79-106.

> Salvador de Aza Pendás., Defectos de prensado, Boletín de la Sociedad Española de Cerámica y Vidrio. 3 (4), pp.395-416 (1964).

> Schneider H., Okada K., Pask J.A., Mullite and Mullite Ceramics. John Wiley \& Sons, Chichester. (1994) pp. 266.

> Schneider H., Schreuer J., Hildmann, B., Structure and properties of mullite-A review. Journal of the European Ceramic Society. 28 (2) (2008) pp 329-344.

$>$ Shigeo Aramaki., y Rustum Roy., Revised Phase Diagram for the System $\mathrm{Al}_{2} \mathrm{O}_{3}$ $2 \mathrm{SiO}_{2}$, Journal of the American Ceramics Society. 45 (5), pp. 229-42 (1962)

> Somiya S., Hirata Y., Mullite powder technology and applications in Japan. Ceram. Bull. 70 (10), pp. 1624-1632 (1991).

> Temoche F., Garrido L.B., Aglietti E.F., Estabilización y Procesamiento de suspensiones concentradas de mullita-zirconia, Jornadas SAM-CONAMET., pp. 09-20 (2003).

> Tomba Martínez A.G., Choque térmico en materiales cerámicos: Cerámica y cristal. 113, pp. 25-31 (1994).

> Torrecillas R., Calderon J.M., Moya J., Reece M.J., Davies C.K.L., Olagnon C., Fantozzi G., Suitability of mullite for high temperature applications, Journal of the European Ceramic Society. 19 (13-14), pp. 2519-2527 (1999).

> Torrecillas R., Calderon J.M., Moya J., Reece M.J., Davies C.K.L., Olagnon C., Fantozzi G., Suitability of mullite for high temperature applications, Journal of the European Ceramic Society. 19 (13-14), pp. 2519-2527 (1999).

$>$ Tsetsekou Athena., Agrafiotis Christos., Milias Aggelos., Optimization of the rheological properties of alúmina slurries for ceramic processing applications Part I: Slip-casting, Journal of the European Ceramic Society. 21, pp. 363-373 (2001).

> Vercauteren S., Keyzer K., Vansant E.F., Luyten J., Leysen R., Porous Ceramic Membranes: Preparation, Transport Properties and Applications, Journal of Porous Materials., 5, pp. 241- 258 (1998).

> Villar Castro, M.P., Gago-Duport L., Garcia R., Comportamiento de mullitas a alta temperatura: estudio mediante difracción de rayos $\mathrm{X}$. Boletín de la Sociedad 
Española de Cerámica y Vidrio. 43 (2), pp. 135-137 (2004).

> Washburn E. W., The Dynamics of Capillary Flow, Physical Review 17, pp. 273 (1921).

$>$ Worral W.E., Clay and ceramic raw materials. Elsevier applied science publishers. London. pp. 147 -166 (1986). 


\section{CAPITULO 8}

\section{ELABORACIÓN, CARACTERIZACIÓN Y COMPARACIÓN DE HORMIGONES REFRACTARIOS DE ULTRA BAJO CEMENTO UTILIZANDO COMO AGREGADOS GRANOS DE MULLITA (COMERCIAL Y EXPERIMENTAL)}

Los hormigones refractarios son elaborados mezclando distintos tipos de agregados que soportan altas temperaturas con un ligante apropiado. Usualmente y para servicios extremos se suelen utilizar cementos aluminosos mezclados con granos de alúmina, donde durante su etapa de servicio pueden ser sometidos a temperaturas que pueden alcanzar los $1900^{\circ} \mathrm{C}$ y soportar esfuerzos de abrasión, erosión, acción de ácidos, entre otros. [Krause, 1987; Lee y Moore, 1998; Lee et al., 2001; Lewis, 1991].

Los hormigones refractarios requieren de buenas propiedades termomecánicas a alta temperatura siendo que un alto porcentaje de cemento afecta sus propiedades. De hecho una gran cantidad de $\mathrm{CaO}$ baja la temperatura de fusión del sistema si se trata de mezclas silicoaluminosas. [Parr et al., 2003; Puig, 2002]. Por otra parte a temperaturas muy altas la formación de $\mathrm{CA}_{6}\left(\mathrm{CaO} .6 \mathrm{Al}_{2} \mathrm{O}_{3}\right)$ en sistemas con muy alta alúmina es expansiva y esto afecta en gran medida las propiedades mecánicas de las piezas acabadas. [Rivas et al., 2003; Yongting et al., 2003]. 
Por estas razones los hormigones refractarios han ido disminuyendo el contenido de cemento de sus dosificaciones, desde porcentajes que oscilaban entre 15 y $25 \%$, hasta dosificaciones actuales que presentan valores que oscilan entre 3 y $0,5 \%$ de cemento e incluso se han elaborado dosificaciones sin cemento. Esto se ha logrado con el empleo de materiales reactivos con tamaños de partículas inferiores a las del cemento, unido a un tratamiento térmico que consigue deshacer el enlace hidráulico que le brinda el cemento para formar un enlace cerámico con lo que se consiguen mayores prestaciones y mayor vida útil.

Los hormigones refractarios son clasificados de acuerdo al contenido de cemento de sus dosificaciones. Los hormigones refractarios convencionales son los que poseen entre 15 y $25 \%$ de cemento (con respecto al peso total del hormigón). [Parr, 1997; Scrivener, 1998]. Estos hormigones han sido utilizados por varios años y hasta la década de los 80 del pasado siglo eran los únicos hormigones refractarios hidráulicos utilizados. [Lee y Moore, 1998].

A finales de la década de los 70 y principios de los 80 del siglo $\mathrm{XX}$, se desarrollaron hormigones refractarios que poseían contenidos de cemento entre 5 y $8 \%$, denominándolos hormigones con bajo contenido de cemento, estos hormigones se apoyan en el uso de partículas finas que actúan como rellenos reactivos (micro-sílice y alúmina reactiva principalmente) para lograr un empaquetamiento de partículas más efectivo. [Parr et al. 2001; 2004]. Aditivos fluidificantes son necesarios para dispersar las partículas finas y lograr una buena homogenización del hormigón aún con bajos contenidos de agua, la disminución del contenido de agua presenta como beneficio la posibilidad de lograr un proceso de secado de mayor facilidad y con menor riesgo. [Ahari et al., 2003; Bier et al., 1995; Bier y Parr, 1996; Evangelista et al., 2000; Hundere y Myhre, 1997; Myhre y Hundere, 1997a; 1997b; Parr et al., 2002].

A finales de la década de los 80 y principios de los 90 se produjeron nuevas mejoras en la tecnología relacionada al desarrollo y fabricación de los hormigones refractarios, situado a niveles aún más bajo los porcentajes de cemento, ubicándolos en intervalos de 2 a 4 por ciento. Estos nuevos productos son conocidos como hormigones refractarios con muy bajo contenido de cemento o ultra bajo cemento. [Kiedl et al., 1976; Parr et al., 1997; 2007; Scrivener, 1998].

Para lograr alta resistencia mecánica debido a la reducción de la cantidad de cemento es necesario mejorar la compactación del material, actualmente el uso de las curvas de - 255 - 
distribución de tamaño de partícula son una herramienta útil en la formulación de productos refractarios. Los modelos de distribución de tamaño de partícula han sido usados por muchos años en la industria, pero en una escala limitada, principalmente para las fracciones más gruesas de la distribución. Nuevas tecnologías de medición del tamaño de partículas han hecho posible analizar las fracciones de tamaño submicrónico, y se ha encontrado que estas son igualmente importantes, sino más, que las distribuciones de las fracciones más gruesas. [Scian y Aglietti, 1998].

Muchos autores han trabajado sobre sistemas de distribución de tamaño de partículas con el objeto de lograr máximos empaquetamientos, y por ende una mayor densidad en los materiales elaborados por compactación y/o vibrado.

Las curvas de distribución granulométrica para máximo empaquetamiento más utilizadas son las conocidas como Furnas, Andreassen y Alfred. [Andreasen y Andersen, 1930; Funk et al., 1982; Furnas, 193; Scian y Aglietti, 1998]. Todas ellas poseen características similares y son por lo tanto correlacionables entre sí.

Los trabajos que más han trascendido hasta la fecha, y que se usaron como base para posteriores desarrollos utilizan la base de Andreassen, [Andreasen y Andersen, 1930], actualmente las curvas de tamaño de distribución de Andreasen siguen siendo las más utilizadas para obtener compactación máxima debido a su simplicidad. [Scian y Aglietti, 1998].

El método desarrollado por Andreasen en 1930 se basa en la optimización de los compactos. La ecuación establecida por Andreasen logra compacidad máxima de una distribución continua de tamaño de partículas [Andreasen y Andersen, 1930]:

$$
C \%=100\left(\frac{D}{D l}\right)^{n}
$$

Dónde:

- $\mathrm{C} \%=$ Volumen en \% del tamaño $\mathrm{D}$ en la mezcla.

- $\quad \mathrm{DI}=$ Tamaño máximo en la mezcla.

- $\mathrm{n}=$ Módulo de la distribución, puede tomar valores entre 0 y 1 .

Cuando el módulo de distribución ( $n$ ) toma valores cercanos a 0.35 se obtienen máximos valores de densidad para los compactados, con $n>0.35$ se obtienen buenos empaquetamientos en gruesos, pero con serias deficiencias en la trabajabilidad (falta de 
finos), mientras que con $n<0.35$ se observa buena trabajabilidad, pero con bajos valores de densidad (exceso de finos). [Scian y Aglietti, 1998].

El modelo de Andreassen no introduce ningún factor relacionado con la forma del grano y supone partículas esféricas [Andreasen y Andersen, 1930; Scian y Aglietti, 1998]. La principal objeción que ha encontrado la ecuación de Andreasen es que el modelo supone tamaños de partículas de diámetro mínimo tendiente a cero, en reducción infinita.

En este trabajo se utilizaron las curvas granulométricas desarrolladas en el Centro de Tecnología de Recurso Minerales y Cerámica (CETMIC) cc-n variable [Scian y Aglietti, 1998] denominadas módulo de distribución variable ( $n=v a r i a b l e)$, este modelo consiste en variar el coeficiente " $n$ " del modelo de Andreasen en forma continua para los diferentes rangos de tamaños de partículas, figura 8.1, la distribución granulométrica así obtenida cumple con el requerimiento de máximo empaquetamiento y máxima trabajalidad simultáneas.

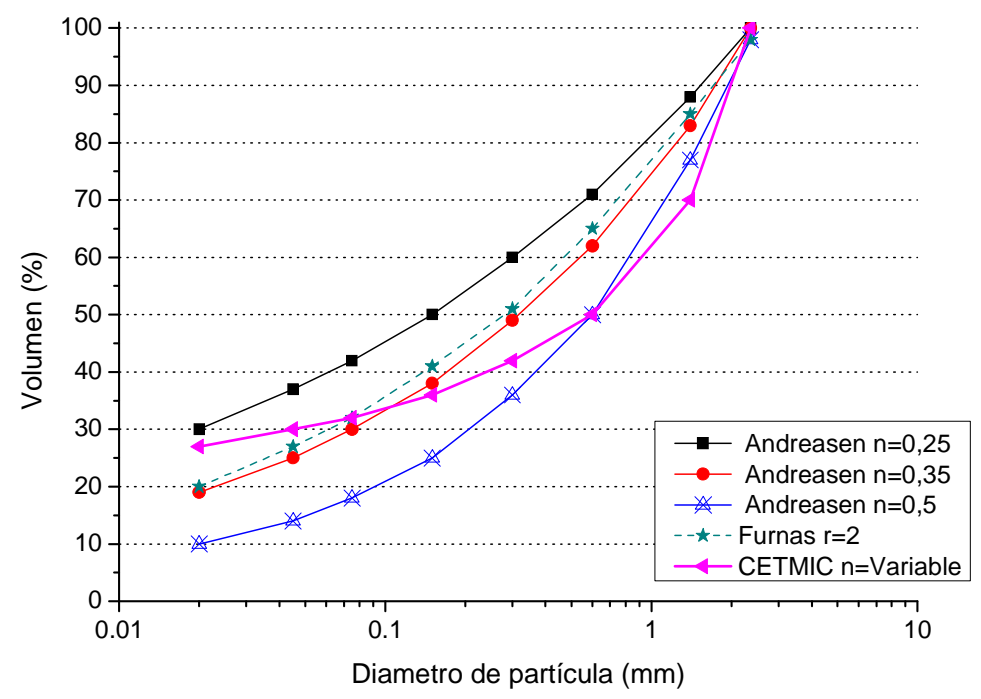

Figura 8.1 Curvas de distribución de tamaño según la ecuación de Andreasen para diferentes valores fijos de $\mathrm{n}$ y $\mathrm{n}$ variable. [Scian y Aglietti, 1998].

El conocimiento desarrollado en este trabajo fue de gran importancia para la elaboración de una pequeña producción a escala en banco, con el objeto de obtener por molienda "granos de mullita" y a partir de curvas granulométricas continuas de máximo 
empaquetamiento desarrolladas en el CETMIC, elaborar algunos prototipos mulliticos de alta calidad (mullita desarrollada en este estudio) y comparar esta mullita con una comercial (Mulcoa 70). En el capítulo anterior se desarrolló la elaboración y caracterización de la mullita experimental (sección 7.4.4) a utilizar en la formación del hormigón y en la sección siguiente se mostrará la caracterización de la mullita comercial (Mulcoa 70).

La elaboración de los hormigones refractarios se realizó a partir de una mullita comercial (Mulcoa 70) y una experimental (AtinAcal conformada por extrusión y calcinada a 1550 ${ }^{\circ}$ C). Para ambos hormigones se utilizaron curvas granulométricas con módulo de distribución variable. Este estudio se efectuó con el fin de diferenciar y conocer las propiedades físicas y termomecánicas de los hormigones elaborados, a pesar de que existe una diferencia en la porosidad (textura) entre las dos mullitas utilizadas, pero no en su composición mineralógica global, como se verá mas adelante.

\subsection{CARACTERIZACIÓN DE UNA MULLITA COMERCIAL (MULCOA 70)}

Antes de elaborar los hormigones refractarios, es importante conocer las propiedades físicas de la materia prima principal (mullita). En el capítulo anterior se realizó la caracterización física y termomecánica a la mulita experimental desarrollada a partir de una mezcla estequiométrica 3-2 utilizando arcilla Tincar Súper y alúmina calcinada (AtinAcal) conformada por el método de extrusión y calcinada a $1550 \stackrel{\circ}{\circ}$, presentando una buena conversión de mullita, y aceptables propiedades físicas y termomecánicas.

Consecuentemente también se realizó un estudio a la mullita comercial, Ilamada Mulcoa 70, caracterizándola solo físicamente, debido a que el material venia en forma de granos (piedra pequeña) y por lo tanto realizar un análisis termomecánico sería más complejo ya que las piezas (mullita) no tenían una forma, ni un tamaño definido y no cumplirían con las normas requeridas para dichos ensayos.

La composición química de la Mulcoa 70 se tomó de la ficha técnica suministrada por el proveedor comercial, ver tabla 8.1. 
Tabla 8.1. Análisis químico por ficha técnica suministrada por el proveedor de la Mulcoa 70.

\begin{tabular}{|c|c|}
\cline { 2 - 2 } \multicolumn{1}{c|}{} & Mulcoa 70 \\
\hline $\mathrm{SiO}_{2}$ & 26.8 \\
\hline $\mathrm{Al}_{2} \mathrm{O}_{3}$ & 68.8 \\
\hline $\mathrm{Na}_{2} \mathrm{O}$ & 0.07 \\
\hline $\mathrm{K}_{2} \mathrm{O}$ & 0.05 \\
\hline $\mathrm{CaO}$ & 0.06 \\
\hline $\mathrm{Fe}_{2} \mathrm{O}_{3}$ & 1.22 \\
\hline $\mathrm{MgO}_{2}$ & 0.07 \\
\hline $\mathrm{TiO}_{2}$ & 2.82 \\
\hline $\mathbf{P}_{2} \mathrm{O}_{5}$ & 0.11 \\
\hline
\end{tabular}

El análisis de la Mulcoa 70 se desarrolló para corroborar las propiedades de esta mullita y conocer que fases cristalinas existen aparte de mullita, que porcentaje de porosidad abierta presenta, ver su morfología y comparar el valor de la densidad del sólido con la densidad teórica de la mullita.

\subsubsection{Difractograma de la mullita comercial (Mulcoa 70)}

Con el fin de conocer las fases cristalinas presentes en la mullita comercial (Mulcoa 70) se utilizó la técnica de Difracción de Rayos X, los difractogramas obtenidos se muestran en la figura 8.2. 


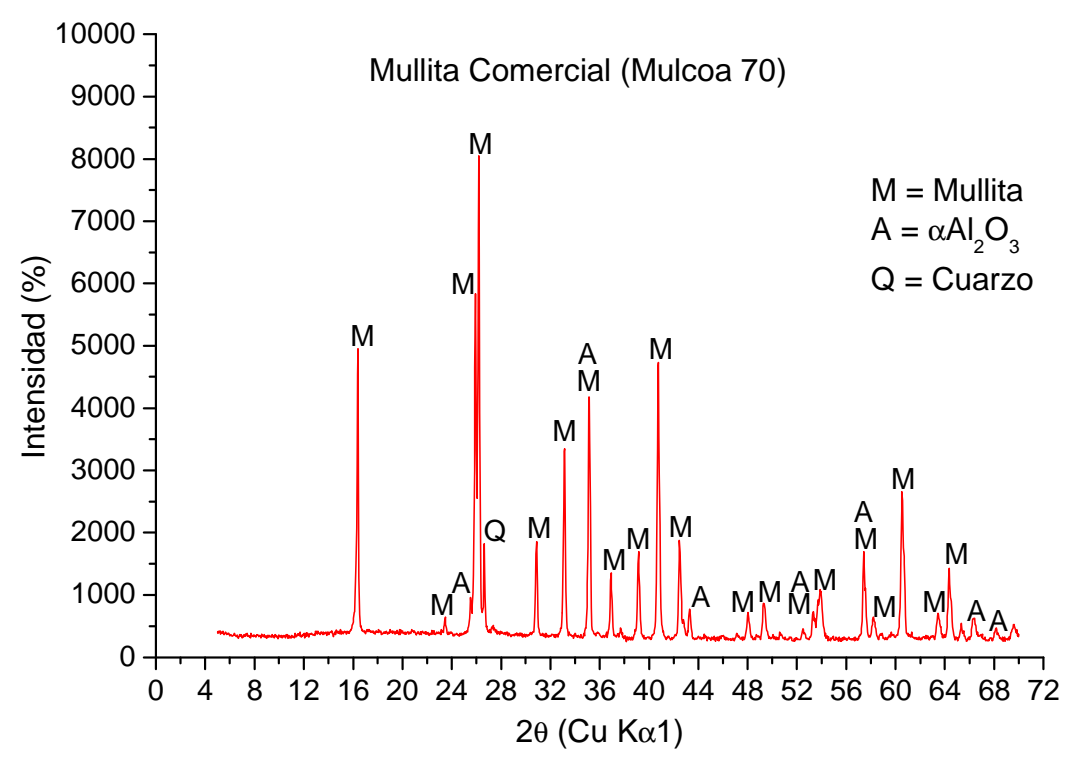

Figura 8.2. Difractograma de mullita comercial (Mulcoa 70).

En el difractograma de la figura 8.2 se observa la presencia de mullita neta como fase principal y mayoritaria, $\alpha$-alúmina en muy poca cantidad y un pequeño pico de cuarzo, que correspondería a la materia prima arcillosa que no alcanzó a reaccionar en la sinterización. [Pankratz et al., 1963; Testa y Pereira, 1971; Villar et al., 2004].

\subsubsection{Propiedades físicas de la mullita comercial (Mulcoa 70)}

Se utilizó el método de Arquímedes por inmersión en agua para encontrar los valores del porcentaje de porosidad (abierta), densidad del material y densidad aparente en agua (del sólido). La tabla 8.2, muestra los resultados obtenidos.

En la tabla 8.2 se puede observar que el valor de porosidad abierta es relativamente bajo, debido a la cantidad de impurezas o fundentes presentes (esto observado por el color de la Mulcoa 70, color marrón grisáceo) y a que fue obtenida posiblemente a alta temperatura, aunque se desconoce la misma y el modo de calcinación.

Respecto al resultado de la densidad aparente en agua (sólido), la Mulcoa 70 presentó un valor un poco lejos con respecto al valor teórico de la mullita $\left(3.17 \mathrm{~g} / \mathrm{cm}^{3}\right)$, esto puede deberse a la presencia de poros cerrados generados en el sistema. [Kanraki et al., 1985; Myhre y Hundere, 1997; Ohira et al., 1996; Penty et al., 1972]. 
Tabla 8.2. Propiedades físicas de la Mulcoa 70.

\begin{tabular}{|c|c|}
\hline $\begin{array}{c}\text { PRESIÓN } \\
\text { POROSIDAD (Abierta) } \\
\%\end{array}$ & $\begin{array}{c}\text { MULLITA COMERCIAL } \\
\text { (MULCOA 70) }\end{array}$ \\
\hline $\begin{array}{c}\text { DENSIDAD DE LOS GRANOS } \\
\text { (Arquímedes) } \\
\text { g/cm }\end{array}$ & 2.4 \\
\hline $\begin{array}{c}\text { DENSIDAD APARENTE EN AGUA } \\
\text { (Del sólido) } \\
\text { g/cm }\end{array}$ & 2.91 \\
\hline
\end{tabular}

\subsubsection{Micrografía de la mullita comercial (Mulcoa 70)}

Para conocer la microestructura de la mullita comercial llamada Mulcoa 70, se la incluyó en resina y se pulió la pieza como se indicó en la sección 3.7, posteriormente se procedió a observarla por microscopía electrónica de barrido (MEB). La figura 8.3 muestra la micrografía mencionada.

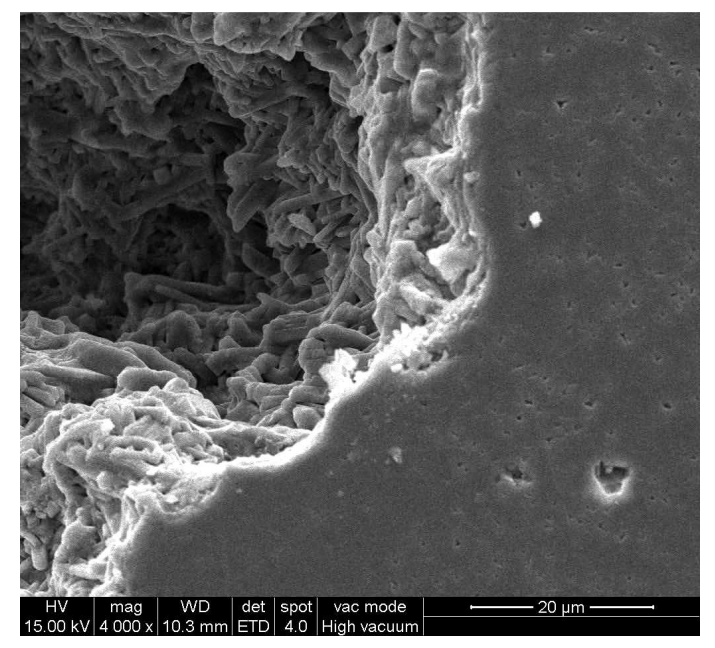

(a)

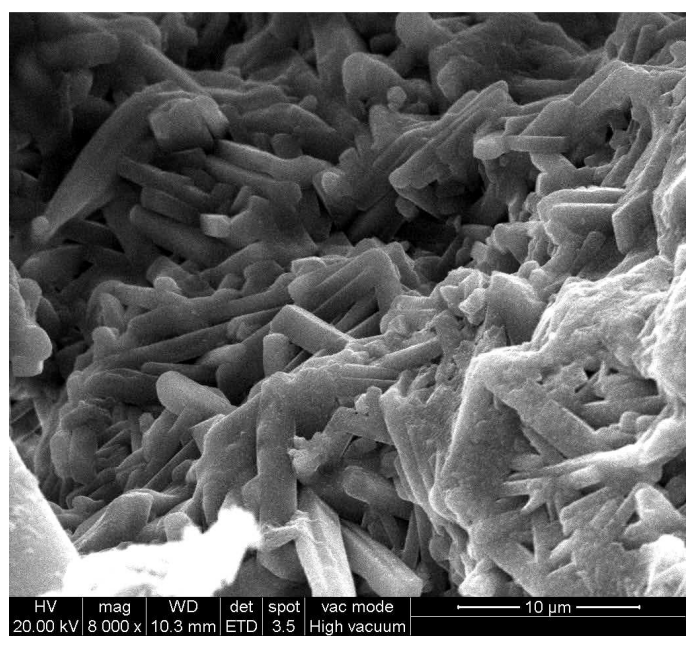

(b)

Figura 8.3. Micrografía de Mulcoa 70; a) 4000x, y b) 8000x. 
En la figura 8.3 se observa claramente la formación acicular (agujas o bastones) de mullita neta, no presentando un ordenamiento definido ni un tamaño homogéneo. [Jovani et al., 1979].

\subsection{ELABORACIÓN DE DOS HORMIGONES REFRACTARIOS DE ULTRA BAJO CEMENTO, uno utilizando granos de mullita comercial (Mulcoa 70) y el otro con granos de mullita experimental (AtinAcal, $1550{ }^{\circ} \mathrm{C}$ durante 4 horas).}

Se elaboraron dos variedades de hormigones de ultra bajo cemento $(3 \%$ de cemento aluminoso), uno de ellos utilizando granos de mullita comercial con Mulcoa 70 y el otro con una de las mullitas experimentales desarrolladas en este trabajo, a partir de una mezcla estequiométrica 3-2 utilizando arcilla Tincar Súper más alúmina calcinada, conformada por el método de extrusión y calcinada a $1550 \stackrel{\circ}{\mathrm{C}}$ durante 4 horas (sección 7.4.4), la cual fue posteriormente molida y tamizada para obtener "granos de mullita".

Para la elaboración de ambos hormigones se utilizaron curvas granulométricas con módulo de distribución cc-n variable [Scian y Aglietti, 1998] con distintos tamaños de granos de mullita, $10 \%$ de alúmina calcinada $\left(d_{50}=5 \mu \mathrm{m}\right), 5 \%$ de micro-sílice $\left(d_{50}=0.5 \mu \mathrm{m}\right)$, y un $0.2 \%$ de tripolifosfato de sodio (TSPP) como dispersante, variando únicamente el porcentaje de agua debido a la mayor porosidad de la mullita experimental. En la tabla 8.3 se puede observar la composición y granulometría utilizada.

En sistemas industriales se controla la distribución de tamaño de partícula mayores a malla 325 por razones económicas (sobre todo en éstas mezclas) se trabajó como lo muestra la tabla 8.3 , pero si se sabe que: en estos casos las mullitas $<325(44 \mu \mathrm{m})$ no poseen altos porcentajes de tamaños inferiores a $10-20 \mu \mathrm{m}$, la alúmina $A_{2} G$ posee $d_{50}=5 \mu \mathrm{m}$ y la microsílice $d_{50}=0.5 \mu \mathrm{m}$. Esta combinación, junto al gel generado por el cemento a edades tempranas hace que las partículas más pequeñas vayan llenando los huecos alejados por los más grandes, formando así la matiz del sistema. 
Tabla 8.3. Composición y granulometría utilizadas para elaborar hormigones de mullita comercial con Mulcoa 70 o experimental con AtinAcal calcinada a $1550 \stackrel{\circ}{\mathrm{C}}$ durante 4 horas.

\begin{tabular}{|c|c|c|}
\hline MATERIAL & $\begin{array}{c}\text { GRANULOMETRİA } \\
\text { \# malla }\end{array}$ & $\begin{array}{c}\text { PORCENTAJE } \\
\%\end{array}$ \\
\hline Mullita & $-6+8$ & 24 \\
\hline Mullita & $-8+14$ & 16 \\
\hline Mullita & $-14+30$ & 14 \\
\hline Mullita & $-30+50$ & 7 \\
\hline Mullita & $-50+140$ & 5 \\
\hline Mullita & $-140+325$ & 5 \\
\hline Mullita & -325 & 11 \\
\hline Alúmina calcinada & -325 & 5 \\
\hline Micro-sílice & -325 & 3 \\
\hline Cemento aluminoso, $70 \%$ & -325 & 0.2 \\
\hline Al ${ }_{2} \mathbf{O}_{3}$ & & \\
\hline TSPP & --- & \\
\hline
\end{tabular}

Los valores de los porcentajes fueron obtenidos de la curva granulométrica cc-n variable [Scian y Aglietti, 1998] desarrollada en el Centro de Tecnología de Recursos Minerales y Cerámica (CETMIC) con inicio de pasante malla 6 (muchos de los hormigones y mezclas refractarias parten de malla 6 en sus formulaciones). En las figuras $8.4 a$ y $8.5 a$ se observan los materiales utilizados y los hormigones elaborados. 


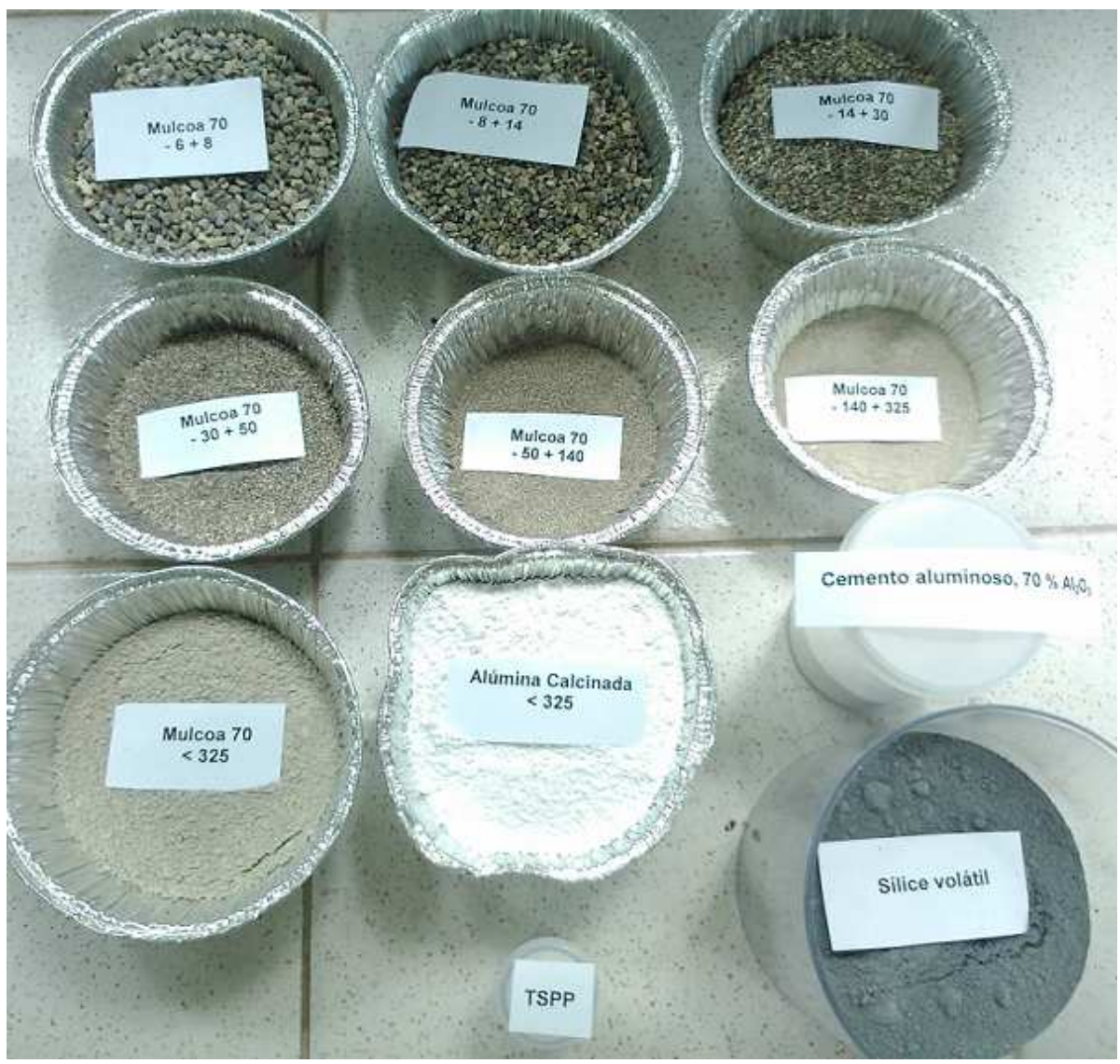

(a)
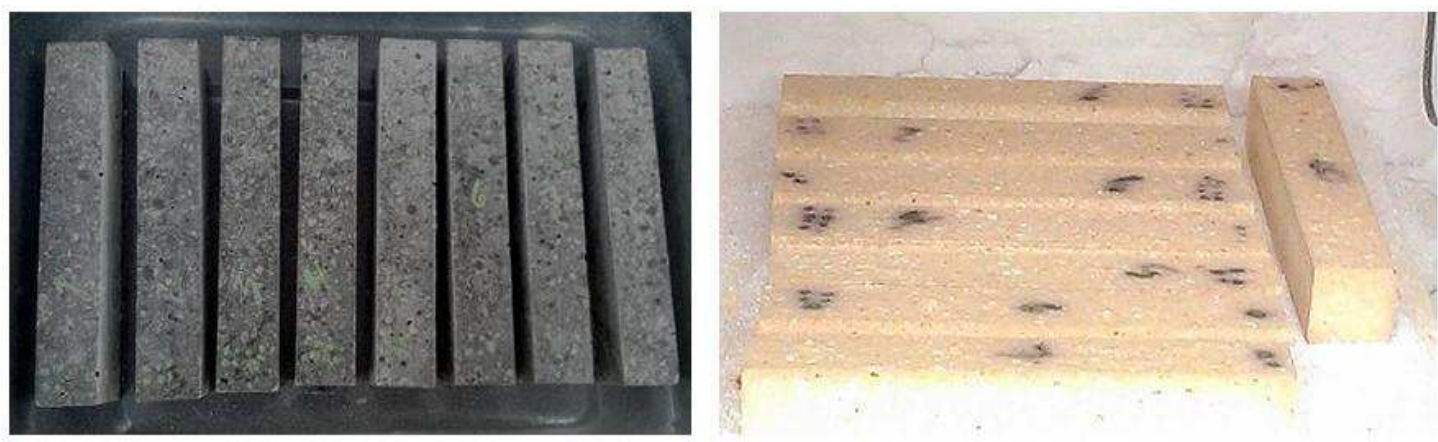

(b)

Figura 8.4. Hormigón comercial (con Mulcoa 70); a) Granulometría utilizada, b) hormigones antes y después de la calcinación a $1400 \stackrel{\circ}{C}$ durante 5 horas. 


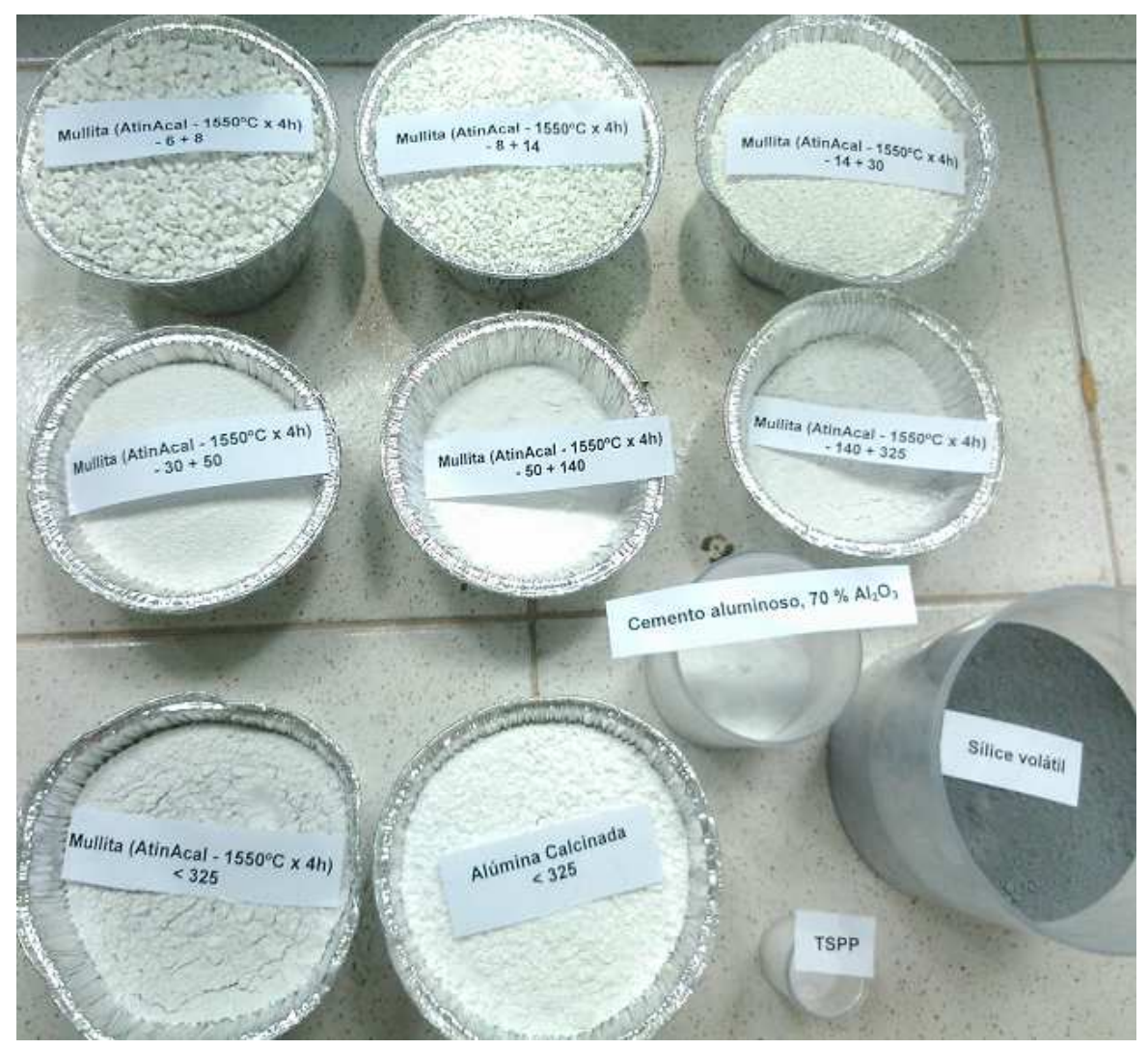

(a)
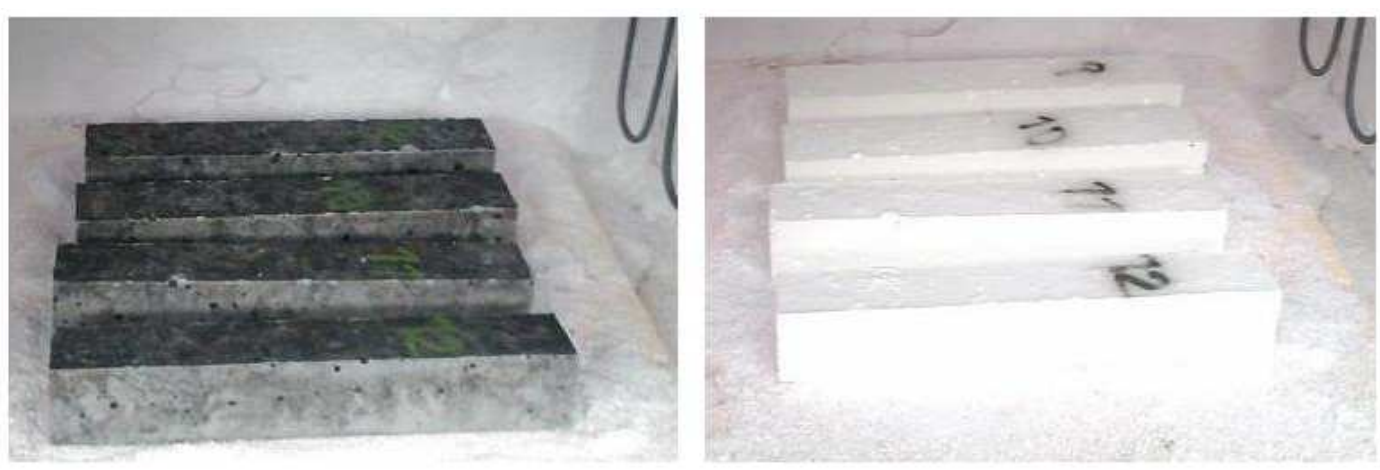

(b)

Figura 8.5. Hormigón experimental (con AtinAcal a $1550 \stackrel{\circ}{\circ}$ durante 4 horas); a) Granulometría utilizada, b) hormigones antes y después de la calcinación a $1400{ }^{\circ} \mathrm{C}$ durante 5 horas. 
Para la elaboración de los hormigones se utilizó un mezclador de alta velocidad empleándose los requerimientos de agua necesaria para su conformado por vibración, para el hormigón con Mulcoa 70 se usó un 7.3 \% de agua mientras que para la mullita experimental (AtinAcal a $1550 \stackrel{\circ}{\circ}$ durante 4 horas) fue de $17.3 \%$. Esta cantidad debe ser medida con cierta precisión debido a que un exceso de agua reduce significativamente la resistencia mecánica de las piezas terminadas. La mayor cantidad de agua requerida por la mezcla que poseía granos de mullita AtinAcal fue debida a la gran diferencia de porosidad abierta que poseían estos granos respecto a los de Mulcoa 70 (34.7\% contra $4.4 \%$ ) lo que hizo que exista un mucho mayor requerimiento de agua utilizado en el llenado de poros, ya que el necesario para el fraguado y vibración es semejante para ambos al tener igual granulometría y componentes.

Los materiales fueron moldeados por vibración en moldes metálicos $(2.5 \times 2.5 \times 15 \mathrm{~cm})$. Las probetas se dejaron secar a temperatura ambiente durante 1 día, y a $110{ }^{\circ} \mathrm{C}$ durante dos días, luego se trataron térmicamente a $1400{ }^{\circ} \mathrm{C}$ durante 5 horas. En las figuras $8.4 \mathrm{~b}$ y $8.5 \mathrm{~b}$ se observan los hormigones elaborados antes y después del tratamiento térmico.

\subsubsection{Propiedades físicas de los hormigones refractarios de ultra bajo cemento (mullita comercial y experimental).}

Las probetas calcinadas así obtenidas fueron caracterizadas utilizando el método de Arquímedes por inmersión en agua donde se obtuvieron valores del porcentaje de porosidad (abierta), densidad del material y densidad aparente en agua, también se midió el porcentaje de variación lineal respecto al conformado del material seco a 110 ${ }^{\circ} \mathrm{C}$. La tabla 8.4, muestra los resultados promedio de 6 probetas.

En la tabla 8.4 se puede observar que existe una diferencia de porosidad abierta entre los dos hormigones, y que el hormigón con mullita comercial presentó un menor valor, esto debido a que la mullita experimental (AtinAcal a $1550{ }^{\circ} \mathrm{C}$ durante 4 horas) es más porosa, como se pudo observar en la tabla 7.9.

Si se compara los valores de las porosidades de mullita sola (tabla 7.9 y 8.2) con la generada en los hormigones (tabla 8.4), se vio que la porosidad de la mullita experimental disminuyó debido a que el cemento cuando se hidrata forma un sistema sol gel que penetra en los poros de la mullita que cuando se calcina posiblemente entra a sellarlos, y al utilizar más porcentaje de agua hace que fluya más y entren más fácil. [Odegard et al., 1998; 2000]. Mientras la mullita comercial presentó un valor de porosidad mayor que los granos solos, indicando que la porosidad es sola de los 
hormigones más no de la Mulcoa 70 (porosidad de la matriz y sólido con el cemento), por eso es mayor el valor con respecto al material solo.

Los valores de las densidades de la pieza y del sólido, son menores en el hormigón elaborado con mullita experimental debido a que el gel cementiceo tapó el poro y lo sinterizó, convirtiéndose el poro abierto en cerrado. [Norton, 1949; Odegard et al., 2000]. Los porcentajes de variación lineal respecto al conformado del material seco a $110^{\circ} \mathrm{C}$, para los dos hormigones presentaron valores similares.

Tabla 8.4. Caracterización física de los hormigones (comercial y experimental) calcinados a $1400 \stackrel{\circ}{\mathrm{C}}$ durante 5 horas.

\begin{tabular}{|c|c|c|}
\hline & $\begin{array}{l}\text { CON MULLITA } \\
\text { COMERCIAL } \\
\text { (MULCOA 70) }\end{array}$ & $\begin{array}{c}\text { CON MULLITA } \\
\text { EXPERIMENTAL } \\
\text { (AtinAcal a } 1550^{\circ} \mathrm{C} \times \text { 4h) }\end{array}$ \\
\hline $\begin{array}{c}\text { POROSIDAD (Abierta) } \\
\%\end{array}$ & 17.5 & 31.8 \\
\hline $\begin{array}{c}\text { DENSIDAD DE LA PIEZA } \\
\text { (Arquímedes) } \\
\text { g/cm }{ }^{3}\end{array}$ & 2.45 & 1.94 \\
\hline $\begin{array}{c}\text { DENSIDAD APARENTE EN } \\
\text { AGUA (Del sólido) } \\
\text { g/cm } \\
\end{array}$ & 2.96 & 2.84 \\
\hline $\begin{array}{c}\text { VARIACIÓN LINEAL } \\
\text { respecto al conformado del } \\
\text { material seco a } 110 \text { ㅇ } \\
\%\end{array}$ & +0.2 & +0.2 \\
\hline
\end{tabular}

\subsubsection{Propiedades termomecánicas de los hormigones refractarios de ultra bajo cemento (mullita comercial y experimental)}

Los hormigones obtenidos y calcinados a $1400{ }^{\circ} \mathrm{C}$ durante 5 horas se caracterizaron utilizando el módulo de rotura a la flexión y módulo de elasticidad dinámico (MOR1, E1) antes y después del choque térmico (MOR2 y E2), el cual consistió en colocar las 
probetas en un horno a temperatura de $1000{ }^{\circ} \mathrm{C}$ en forma instantánea, manteniéndolas durante 20 minutos a esa temperatura, siendo posteriormente enfriados bruscamente en agua. Los resultados se muestran en la tabla 8.5. Todos los datos son el resultado del valor promedio de 6 probetas.

Tabla 8.5. Propiedades termomecánicas de los hormigones (comercial y experimental) calcinados a $1400 \stackrel{\circ}{\mathrm{C}}$ durante 5 horas.

\begin{tabular}{|c|c|c|}
\cline { 2 - 3 } \multicolumn{1}{c|}{} & $\begin{array}{c}\text { CON MULLITA } \\
\text { COMERCIAL } \\
\text { (MULCOA 70) }\end{array}$ & $\begin{array}{c}\text { CON MULLITA } \\
\text { EXPERIMENTAL } \\
\text { (AtinAcal a 1550 으 x 4h) }\end{array}$ \\
\hline $\begin{array}{c}\text { MÓDULO DE ELASTICIDAD } \\
\text { (E1) } \\
\text { (GPa) }\end{array}$ & 57.6 & 37.6 \\
\hline $\begin{array}{c}\text { MÓDULO DE ELASTICIDAD } \\
\text { Después de choque térmico } \\
\text { (E2) } \\
\text { (GPa) }\end{array}$ & 30.9 & 16.6 \\
\hline $\begin{array}{c}\text { RELACIÓN DE MÓDULOS } \\
\text { (E1/E2) }\end{array}$ & 1.8 & \\
\hline $\begin{array}{c}\text { MÓDULO DE ROTURA A LA } \\
\text { FLEXIÓN (MOR1) } \\
\text { (MPa) }\end{array}$ & 26.7 & 23.3 \\
\hline $\begin{array}{c}\text { MÓDULO DE ROTURA A LA } \\
\text { FLEXIÓN }\end{array}$ & 15.2 & \\
\hline $\begin{array}{c}\text { Después de choque térmico } \\
\text { (MOR 2) } \\
\text { (MPa) }\end{array}$ & & \\
\hline $\begin{array}{c}\text { RELACIÓN DE MÓDULOS } \\
\text { (MOR1/MOR2) }\end{array}$ & 1.8 & \\
\hline
\end{tabular}

La tabla 8.5 muestra que el choque térmico realizado causó una disminución en las propiedades termomecánicas E2 y MOR2 con respecto a E1 y MOR1, debido al daño que produjo el choque térmico violento en la estructura interna de los hormigones. [Becher y Lewis, 1980; Cotterell et al., 1995; Myhre, 2008; Nakayama y Ishizuka, 1966]. 
También se puede observar que los resultados obtenidos para el hormigón con Mulcoa 70 presentaron valores mayores con respecto al hormigón experimental, justificándose esto con la menor cantidad de poros presentes en el hormigón con mullita comercial.

En los valores obtenidos en la relación de módulos se pudo ver que el módulo de rotura a la flexión y el módulo de elasticidad antes y después del choque térmico, conservaron la misma relación en ambos materiales (1.8 y 2.3 para Mulcoa 70 y para la experimental respectivamente). La diferencia entre 1.8 y 2.3 no es significativa a la hora de evaluar las bondades al choque térmico, ya que valores entre 1.6 y 2.4 en módulo de rotura a la flexión son consideradas buenas para este tipo de casos.

De acuerdo a lo observado en la mullita comercial (Mulcoa 70) y la experimental (AtinAcal a $1550{ }^{\circ} \mathrm{C}$ durante 4 horas) por cualquier método de conformado, queda claro que para esta mullita experimental de alta pureza se requerirían para su elaboración temperaturas de calcinación superiores a 1550 C y el uso de hornos rotativos, si se desea disminuir la porosidad del sistema, ya que las fases y morfología presentes en el material experimental son comparables y aun mejores que las de Mulcoa 70 dado que poseen menor cantidad de impurezas (tabla 8.1).

Cuando se realizó el estudio cinético en este trabajo (capítulo 6) utilizando arcilla La Rioja y mezcla estequimétrica 3-2, a una temperatura de $1600{ }^{\circ} \mathrm{C}$ durante 5 horas la mullita obtenida tenía porosidades de $\sim 25 \%$, confirmando esto lo mencionado en el párrafo anterior (de usar temperatura mayor) para obtener una menor porosidad por aumento de temperatura, y además, de usar horno rotatorio esto contribuiría a reducirla drásticamente.

No se utilizó mayor temperatura que $1550{ }^{\circ} \mathrm{C}$ en la producción masiva (método de prensado, extrusión y colado) por dos razones:

Primero, porque la conversión a mullita durante 4 horas era similar a la obtenida a 1600 oC durante 5 horas y segundo por las cantidades de probetas calcinadas para este trabajo, de haberlas realizado a $1600{ }^{\circ} \mathrm{C}$ a 5 horas hubiera exigido de sobremanera el equipo térmico disminuyendo su vida útil. 


\subsection{CONCLUSIONES PARCIALES}

Se pudo corroborar por difracción de rayos X que la mullita comercial, Mulcoa 70, presentó a la mullita como fase principal y mayoritaria, también se encontró una poca cantidad de $\alpha$-alúmina y un pequeño pico de cuarzo.

La Mulcoa 70 presentó un porcentaje de porosidad abierta (Arquímedes) bajo, debido posiblemente a la cantidad de impurezas o fundentes presentes, presentando también un valor de la densidad aparente en agua (sólido) lejos con respecto al valor teórico de la mullita $\left(3.17 \mathrm{~g} / \mathrm{cm}^{3}\right)$. Por microscopía electrónica de barrido se observó claramente la formación de bastones de mullita, no presentando un ordenamiento definido ni un tamaño homogéneo.

Se compararon dos hormigones de ultra bajo cemento $(3 \%$ de cemento aluminoso), elaborados a partir de granos de mullita, uno de ellos utilizando granos de mullita comercial Mulcoa 70 y el otro granos de mullita experimental desarrollada en este trabajo de tesis (mezcla estequiométrica 3-2 utilizando arcilla Tincar Súper más alúmina calcinada, conformada por el método de extrusión y calcinada a $1550 \stackrel{\circ}{ } \mathrm{C}$ durante 4 horas).

Los porcentajes utilizados para la elaboración de los hormigones fueron obtenidos de la curva granulométrica cc-n variable, desarrollada en el CETMIC (Centro de Tecnología de Recursos Minerales y Cerámica), con inicio de pasante malla 6 y finalización pasante malla 325 .

La cantidad de agua que se requirió para la elaboración de los hormigones fueron: para el hormigón con Mulcoa 70 un $7.3 \%$, mientras que para la mullita experimental (AtinAcal a $1550 \stackrel{\circ}{ } \mathrm{C}$ durante 4 horas) $17.3 \%$. Esta discrepancia en la cantidad de agua se debió a la gran diferencia en la porosidad abierta que poseían estos granos.

Las dos versiones de hormigones de ultra bajo cemento elaborados fueron calcinadas a $1400 \stackrel{\circ}{\mathrm{C}}$ durante 5 horas, encontrando en sus propiedades físicas y termomecánicas lo siguiente: 
- El hormigón elaborado con mullita comercial presentó un menor valor de porosidad abierta (Arquímedes) esto es debido a que la mullita experimental (AtinAcal a $1550{ }^{\complement} \mathrm{C}$ durante 4 horas) fue más porosa .

- Se encontró que el valor de la densidad del sólido fue menor en el hormigón elaborado con mullita experimental debido a que el gel cementiceo tapó los poros y sinterizó a alta temperatura.

- Los dos hormigones presentaron valores similares en el porcentaje de variación lineal respecto al conformado del material seco a $110^{\circ} \mathrm{C}$.

- El choque térmico realizado causó en ambos materiales una disminución en las propiedades termomecánicas E2 y MOR2 con respecto a E1 y MOR1, pero en ambos casos las propiedades termomecánicas residuales son consideradas aptas para condiciones de servicio normales.

- Se puedo observar que el hormigón elaborado con Mulcoa 70 presentó valores mayores en sus propiedades termomecánicas con respecto al hormigón experimental, esto debido a la poca cantidad de poros presentes en el hormigón con mullita comercial.

- Se encontraron buenas relaciones de módulos (de rotura a la flexión y de elasticidad antes y después del choque térmico) en ambos hormigones, conservando la misma relación en ambos materiales (1.8 y 2.3 para Mulcoa 70 y para la experimental respectivamente).

\subsection{BIBLIOGRAFIA}

$>\quad$ Ahari K., Sharp J., y Lee W., Hydration of refractory oxides in castable bond systems-II: alúmina-silica and magnesia-silica mixtures. Journal of the European Ceramic Society, (2003). 
$>\quad$ Andreasen A.H.M., y Andersen J., Ueber die Beziehung zwischen Kornabstufung und Zwischenraum in Produkten aus losen Koernern (mit einigen Experimenten), Kolloid - Z. 50, pp.217-228 (1930).

> Becher P.F., Lewis D., Carman K.R, y Gonzalez A.C., Thermal Shock Resistance of Ceramics: Size and Geometry Effects in Quench Tests, American Ceramic Society Bulletin., 59, 54245 (1980).

$>\quad$ Bier T., Mathieu A., Espinosa B., et al., Admixtures and their Interactions With High Range Calcium Alúminates Cement. UNITECR congress, Japón, (1995).

$>\quad$ Bier T., y Parr C., Admixtures with Calcium Alúminates Cements and CAC Based Castables. 28th Annual SA Ceramic Society Symposium, Johanesburgo, (1996).

> Cotterell B., Ong S.W., Qin C., Thermal shock and size effects in castable refractories, Journal of the American Ceramic Society 78 (8), pp. 2056-2064 (1995).

$>\quad$ Evangelista P., Parr C., y. Revais C, Optimization of alúminate cements with $70 \%$ and $80 \%$ of alúmina based castables, Refractories Applications, (2000).

$>\quad$ Funk J.E., Dinger D.R y Funk J.E., Control parameters for a 75 Wt\% Coal Water Slurry: Co - Al, Proceedings of the 4th International symposium of Coal slurry combustion, Orlando FL. 4, pp. 10-12 (1982).

$>\quad$ Furnas C.C., Industrial \& Engineering Chemistry. 23, pp. 1052- 1058 (1931).

$>\quad$ Hundere A., y Myhre B., Substitution of Reactive Alúmina with Microsilica in Low Cement and Ultra Low Cement Castables. Part II: The Effect of Temperature on Hot Properties. UNITECR '97, New Orleans, (1997).

> Jovani M., Alonso J.J., Manglano J.J., Estudio por microscopía electrónica de barrido (S.E.M.) de pastas cerámicas refractarias y de la mullita en ellas formada. Boletín de la Sociedad Española de Cerámica y Vidrio. V. 18 (2), pp. 85-92 (1979).

$>\quad$ Kanraki S., Tabata H., Kumazawa T., y Ohta S., Sintering and Mechanochemical Properties of Stoichiornetric Mullite, Journal of the American Ceramics Society., 68 (1) C-6-C-7 (1985).

$>\quad$ Kiedl J.P., Jost V., y Clavaud B., Low lime content hydraulic cements and castables made from them, Fr. Pat. \# 76.22344 (1976).

$>\quad$ Krause C., Refractories: The Hidden industry, American Ceramic Society, (1987). 
$>\quad$ Lee W.E., and Moore R.E., Evolution of in Situ Refractories in the 20th Century, Journal of the American Ceramic Society. 81 (6) (1998).

$>\quad$ Lee W.E., Vieira W., Zhang S., Ghanbari Ahari K., Sarpoolaky H., y Parr C., Castable Refractory Concrete, Internacional Materials Reviews. 46 (3) pp. 145167 (2001).

$>$ Lewis G., Applications for Tradicional Ceramic, Refractories, Engineered Materials Handbook, pp. 895- 918 (1991).

$>$ Myhre B., What does it take to make a mullite bond?, Ceramic Forum International. (2008).

> Myhre B., y Hundere A., Mullite bonded castables, American Ceramic Society 99th Annual meeting in Cincinnati, Ohio, 1997.

$>\quad$ Myhre B., y Hundere A., Mullite bonded castables, American Ceramic Society 99th Annual meeting in Cincinnati, Ohio, (1997b).

$>\quad$ Myhre B., y. Hundere A, Substitution of Reactive Alúmina with Microsilica in Low Cement and Ultra Low Cement Castable. Part I: Properties Related to Installation and Demoulding. UNITECR '97, New Orleans, (1997a).

> Nakayama J., Ishizuka M., Experimental Evidence for Thermal Shock Damage Resistance, American Ceramic Society Bulletin., 45, 66669 (1966).

$>\quad$ Norton F.H., Refractories, McGraw-Hill Book Co., Inc., New York, Ceram. Abstr. pp. $492-93$ (1949).

$>\quad$ Odegard C., Feldborg H., y Myhre B., Mullite formation in refractory castables, in India International Refractories Congress, Ranchi, (2000).

$>\quad$ Odegard C., Myhre B, Hundere A., et al., Mullite-bonded castable with andalusite as aggregate, 41th International Colloquium on Refractories, Aachen, (1998).

> Ohira H., Ismai M.G.M.U.I., Yamamoto Y., Akiba T., Sōrniya Shigeyuki., Mechanical properties of high purity mullite at elevated temperaturas. Journal of the European Ceramic Society. 16 (2), pp. 225-229 (1996).

$>\quad$ Pankratz L.B., Weller W.W., y Kelley K., Low - Low-temperature heat capacity and high-temperature heat content of mullite U.S. Dept. of the Interior. Bureau of Mines, Rep. Inyest. 6287, pp. 7 (1963).

$>\quad$ Parr C., Bier T., Mathieu A., et al., Monolíticos con Cemento de Alúminato Cálcico $-273-$ 
(CAC) para aplicaciones especiales. L. Alúminates, (1997)

> Parr C., Bier T., Mathieu A., et al., Monolíticos con Cemento de Alúminato Cálcico (CAC) para aplicaciones especiales. L. Alúminates, (1997).

$>\quad$ Parr C., Bin L., Alt C., et al., Interactions between Silica Fume and CAC and Methods to Optimise Castable Placing Properties, in TARJ Conference on Raw Materials, Japón, (2007).

> Parr C., Bin L., Valdelievre B., et al., The Advantage of the Calcium Calcium Alúminates Cements Containing Castables for Steel Ladle Applications. XXXII ALAFAR meeting, Antigua, (2004).

$>$ Parr C., Fryda H., y Roesky R., Out of the mould and into the fire - a new perspectiveon the optimization of deflocculated castables. UNITECR, Cancun, (2001).

$>$ Parr C., Valdelievre B., y Wohrmeyer C., Applications of calcium alúminates cement to dense low water demand refractory castables, Refractories Applications and News. 7 (3) (2002).

$>\quad$ Parr C., Wohrmeyer C., y S.-T. W., The use of calcium alúminates cements in monolithic refractories for steel applications, in Prague International conference of Refractories, Prague. (2003).

$>$ Penty R.A, Hasselman D.P.H., y Spriggs R. M., Young's Modulus of High Density Polycrystalline Mullite, Journal of the American Ceramics Society. 55 (3), pp.169-70 (1972).

$>$ Puig J., Cemento de Alúminato de calcio: origen, producción y aplicaciones," Cemento y Hormigón. 73 (836), pp. 4-14 (2002).

$>$ Rivas J., De Aza A., Turrillas X., et al., "Hidratación de los cementos de alúminatos de calcio (Parte I)," Boletín de la Sociedad Española de Cerámica y Vidrio. 42 (2003).

$>$ Scian A.N., y Aglietti E.F., Development of a New Particle Size Distribution: Variable CCM, Refractories Applications. American Ceramic Society Refractory Ceramics Division. 3 (3) pp 4-7. (1998)

$>$ Scrivener K.L., Capmas A., Calcium alúminates cements, Lea's Chemistry of cement and concrete, P.C. Hewlett. Londres, pp. 710-778 (1998).

$>\quad$ Testa R.H., y Pereira E., Reacciones de mullitización en el sistema bauxita - 
arcilla. Rev. Lati. Am. Ing. Quim. y Quim. Apl 1, pp. 45-55 (1971).

$>\quad$ Villar Castro, M.P., Gago-Duport, L., Garcia, R., Comportamiento de mullitas a alta temperatura: estudio mediante difracción de rayos X. Boletín de la Sociedad Española de Cerámica y Vidrio. 43 (2), pp. 135-137 (2004).

$>$ Yongting W., Valdelievre B., Parr C., et al., The Use of Calcium Alúminates Cements in Monolithic Refractories for Tundish Applications, in 4th International conference on Refractories, Dalian, (2003). 


\section{CAPITULO 9}

CONCLUSIONES GENERALES

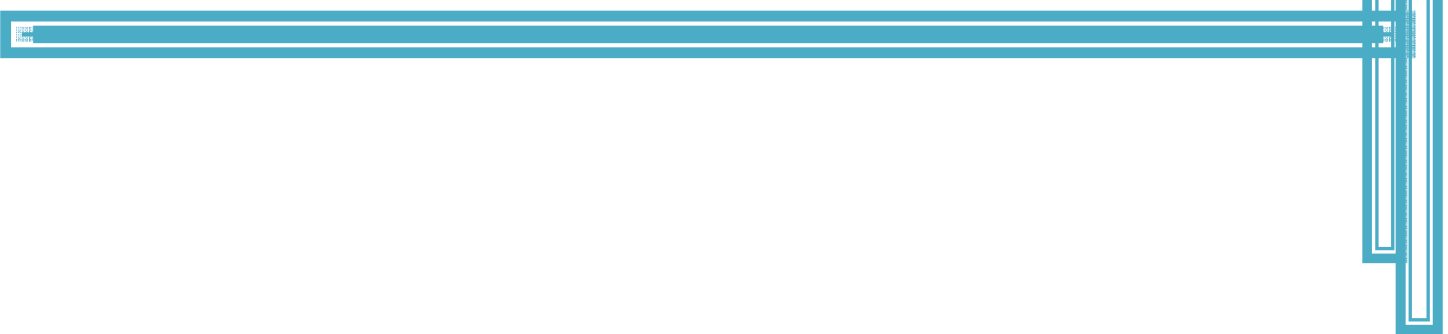

$>\quad$ Se analizaron cinco materias primas arcillosas nacionales (arcillas/caolines), con diferente granulometría, procedentes de diferente origen geológico y provenientes de diferentes regiones del país (Patagonia y NOA), seleccionándose dos arcillas caoliníticas, una por su alto tenor de caolinita (La Rioja) y la otra por su amplia disponibilidad comercial al momento de la elaboración de este trabajo (Tincar Súper), esta última con cierto tenor de cuarzo ( 55). Por otro lado se seleccionaron y caracterizaron dos fuentes distintas de alúminas comerciales (calcinada e hidratada) con el objeto de complementar la estequiometría $3 \mathrm{Al}_{2} \mathrm{O}_{3} \cdot 2 \mathrm{SiO}_{2}$ de la mullita.

Con las dos arcillas y alúminas mencionadas en el ídem anterior se realizaron 4 mezclas distintas con estequiometría $3 \mathrm{Al}_{2} \mathrm{O}_{3} \cdot 2 \mathrm{SiO}_{2}$, para continuar el estudio de conformado y producción de mullita sintética de alta gama ( $91 \%$ de mullita cristalina y $\sim 9 \%$ fase amorfa).

Para el seguimiento cuantitativo y estudio cinético de la reacción de formación de mullita, se seleccionó la arcilla La Rioja por su alto tenor de caolinita $(96,7 \%)$, tamaño malla pasante 200, y como fuente de óxido de aluminio, alúmina calcinada pasante malla 325 , para asegurar una buena reactividad. 
Se realizaron tratamientos térmicos entre 1300 y $1600{ }^{\circ} \mathrm{C}$ a distintos tiempos, tanto a la arcilla sola (Arioja), como a la mezcla estequiométrica 3-2 (AriojAcal).

Sobre las muestras anteriores se cuantificaron fases cristalinas y amorfas utilizando el método de Rietveld aplicando el modelo de Le Bail, como el mejor método de cuantificación de entre tres evaluados.

Con los datos obtenidos cuantitativamente se evaluó el porcentaje de mulita neta (mezcla AriojAcal) y el de mullita primaria (procedente de la arcilla, Arioja). Por diferencia de ambos se calculó el porcentaje de mullita secundaria (proveniente de la sílice no mullitizada liberada por la arcilla y reaccionada con la alúmina calcinada).

Se evaluaron distintos modelos matemáticos para reacciones en estado sólido sobre las curvas conversión tiempo de mullita neta a distintas temperaturas, concluyendo que el modelo de Hulbet (nucleación y crecimiento) y el modelo de Zhuravlev, Lesokhim y Tempelman (difusional) fueron los que mejor ajustaron, evaluándose las constantes cinéticas y la energía de activación en cada caso.

$>\quad$ De los datos del estudio cinético realizado se concluyó que $1550{ }^{\circ} \mathrm{C}$ y 4 horas de tratamiento eran suficientes para la conversión máxima a mullita, aún presentando un $\sim 10 \%$ de fase vítrea, similar a lo observado en mullitas comerciales de alta calidad. De todas formas no se obtuvieron resultados óptimos en lo referente a la porosidad.

Se realizaron tres tipos de conformados para cada uno de las mezclas estequiométricas con arcillas (Tincar Súper y La Rioja) y alúminas (calcinada e hidratada), por:

- Prensado a 10, 40 y $100 \mathrm{MPa}$.

- Colado en moldes de yeso.

- Extrudado.

No se realizaron probetas por el método de colado y extrudado con las mezclas que poseían alúmina hidratada (AtinAhid y AriojAhid) debido a su alto tamaño de partícula que dificultaba el conformado de piezas discretas para su evaluación. 
Las preformas fueron calcinadas a $1550{ }^{\circ} \mathrm{C}$ durante 4 horas. Evaluándose las siguientes propiedades:

- Fases cristalinas por Difracción de Rayos X.

- Porcentaje de porosidad (abierta) por Arquímedes y distribución de tamaño de poros por intrusión de mercurio.

- Densidad de la pieza.

- Densidad aparente en agua (sólido)

- Variación lineal respecto al conformado del material seco $\left(110^{\circ} \mathrm{C}\right)$.

- Microscopía Electrónica de Barrido sin y con etching químico (ácido fluorhídrico al $5 \%$, durante 10 minutos).

- Módulo de Rotura a la Flexión en tres puntos antes y después del choque térmico (MOR1 y MOR2 respectivamente).

- Módulo de Elasticidad dinámico $(E)$ antes y después del choque térmico (E1 y E2 respectivamente).

- Dilatometría.

Todas las mezclas con cualquier tipo de conformado presentaron difractogramas de rayos $X$ similares, donde se evidenció la presencia de mullita como fase principal y mayoritaria, y una poca cantidad de $\alpha$-alúmina, también se observó una leve banda centrada en $22^{\circ}$ de $2 \theta$ indicando la presencia de fase vítrea de la matriz silícea.

Se observó por Microscopía Electrónica de Barrido que todas las muestras analizadas presentaron una cristalización de la mullita en forma de bastones.

$>\quad$ Se encontró en todas las mezclas por prensado (10, 40 y $100 \mathrm{MPa}$ ) que el porcentaje de porosidad abierta disminuye con el aumento de presión, mientras la porosidad cerrada crece.

En términos generales se mostró que las propiedades fisicoquímicas y termomecánicas obtenidas utilizando mezclas con alúmina calcinada (AtinAcal y AriojAcal) conformadas por el método de colado se asemejaban a las obtenidas por prensado a $10 \mathrm{MPa}$, mientras que por el método de extrusión se asimilaban a las prensadas a $40 \mathrm{MPa}$. 
Cuando se utilizó mezclas con alúmina hidratada (AtinAhid y AriojAhid) en el conformado por prensado, se observó una gran diferencia en la variación lineal con respecto a las conformadas con alúmina calcinada (AtinAcal y AriojAcal), encontrándose una gran contracción para los primeros y una leve expansión para los segundos.

Las curvas de dilatometría realizadas sobre probetas conformadas por los distintos métodos (prensado, colado y extrusión) y calcinadas a $1550{ }^{\circ} \mathrm{C}$ durante 4 horas mostraron valores de coeficiente de expansión lineal similares, dado a que esta propiedad es intrínseca de la mullita y no depende de su textura.

$>\quad$ Se seleccionó el método de extrusión para producir mullita en escala, debido a que es el método más usado industrialmente para el conformado de precursores de mullita, cuando el objetivo que se tiene es producir granos de mullita.

Se extrudaron 20 kilos de precursores AtinAcal y se calcinaron a $1550 \stackrel{\circ}{ } \mathrm{C}$ durante 4 horas, obteniéndose posteriormente por molienda granos de mullita desde malla pasante 6 hasta pasante malla 325 .

$>\quad$ Los hormigones refractarios de ultra bajo cemento confeccionados con granos de mullita comercial (Mulcoa 70) y con granos producidos mediante el escalado mencionado (mullita experimental), fueron calcinados a $1400 \stackrel{\circ}{\mathrm{C}}$ durante 5 horas, evaluándose sus propiedades fisicoquímicas y termomecánicas concluyendo que las diferencias observadas corresponden solamente a las diferencias en la porosidad de los granos y no a la composición del material mullitico.

$>\quad$ Se concluye que se puede obtener mullita sintética de alta gama utilizando arcillas nacionales refractarias de alto tenor en caolinítica mezclándolas con alúminas de alta pureza.

Los métodos de conformados de las mezclas precursores pueden ser: prensado, extrudado ó colado.

$>\quad$ Con las granulometrías y materias primas utilizadas, una calcinación a $1550 \stackrel{\circ}{ } \mathrm{C}$ en un horno batch durante 4 horas es suficiente para lograr máxima conversión - 279 - 
de mullita, aunque para lograr mullita de baja porosidad se requeriría un horno rotativo y mayor temperatura de calcinación.

$>\quad$ Se demostró que una producción a escala banco es posible en laboratorio, ya que se produjeron granos en cantidad suficiente para permitir elaborar probetas normalizadas de hormigones refractarios de ultra bajo cemento y evaluar sus propiedades. 


\section{APÉNDICE I}

\section{TARJETAS CRISTALOGRÁFICAS DE LAS FASES CRISTALINAS PRESENTES EN LOS MATERIALES ESTUDIADOS}

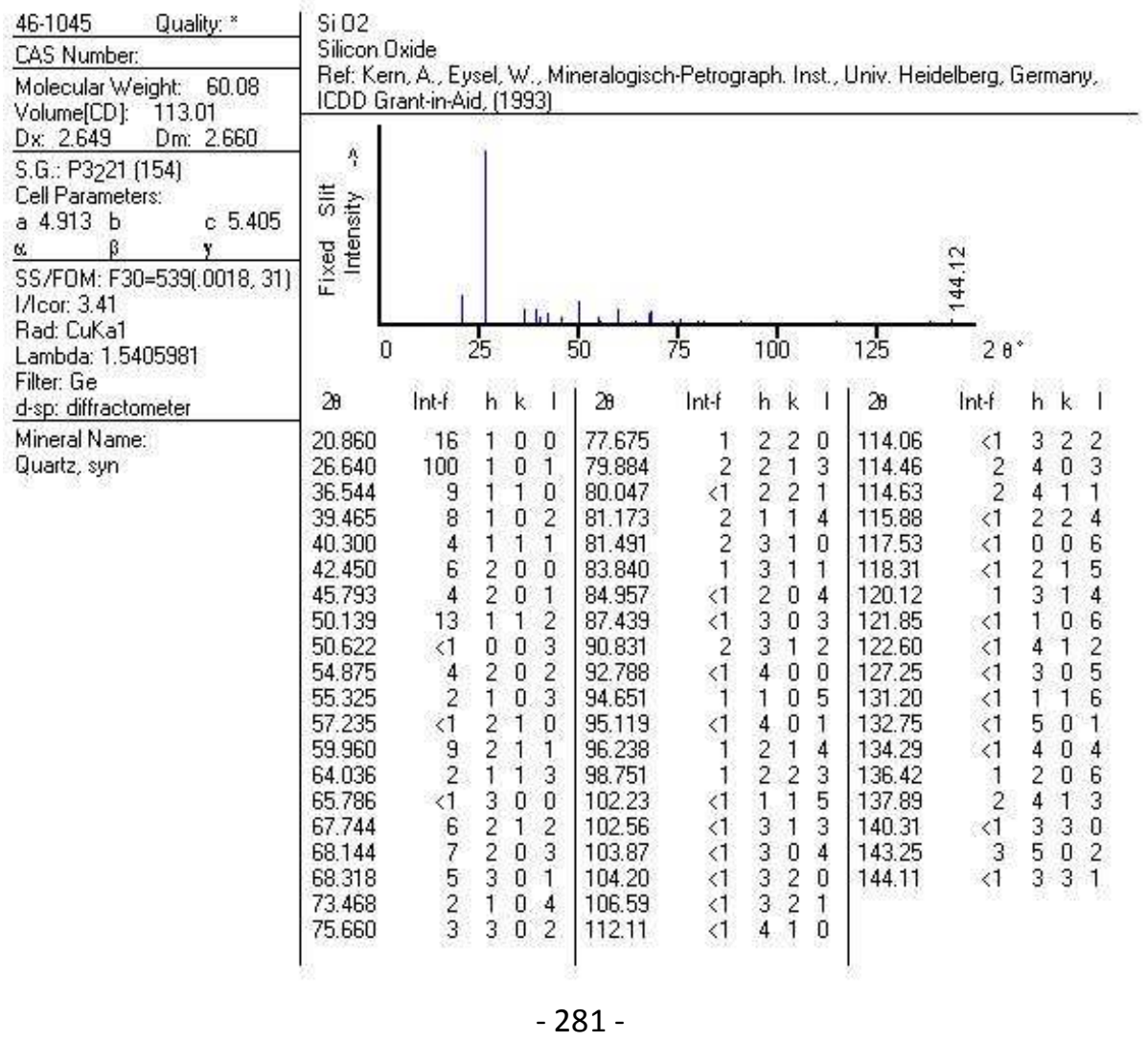




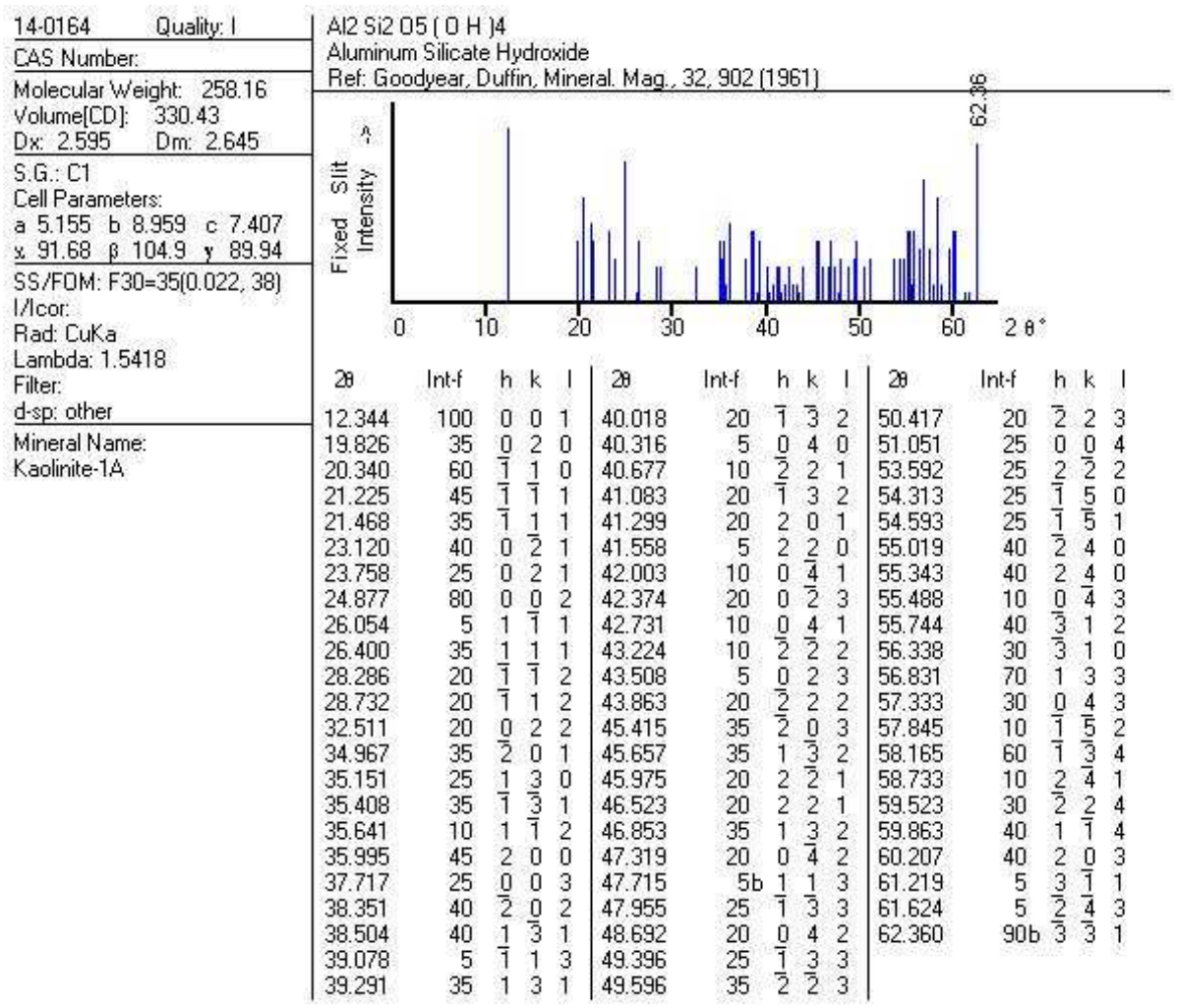

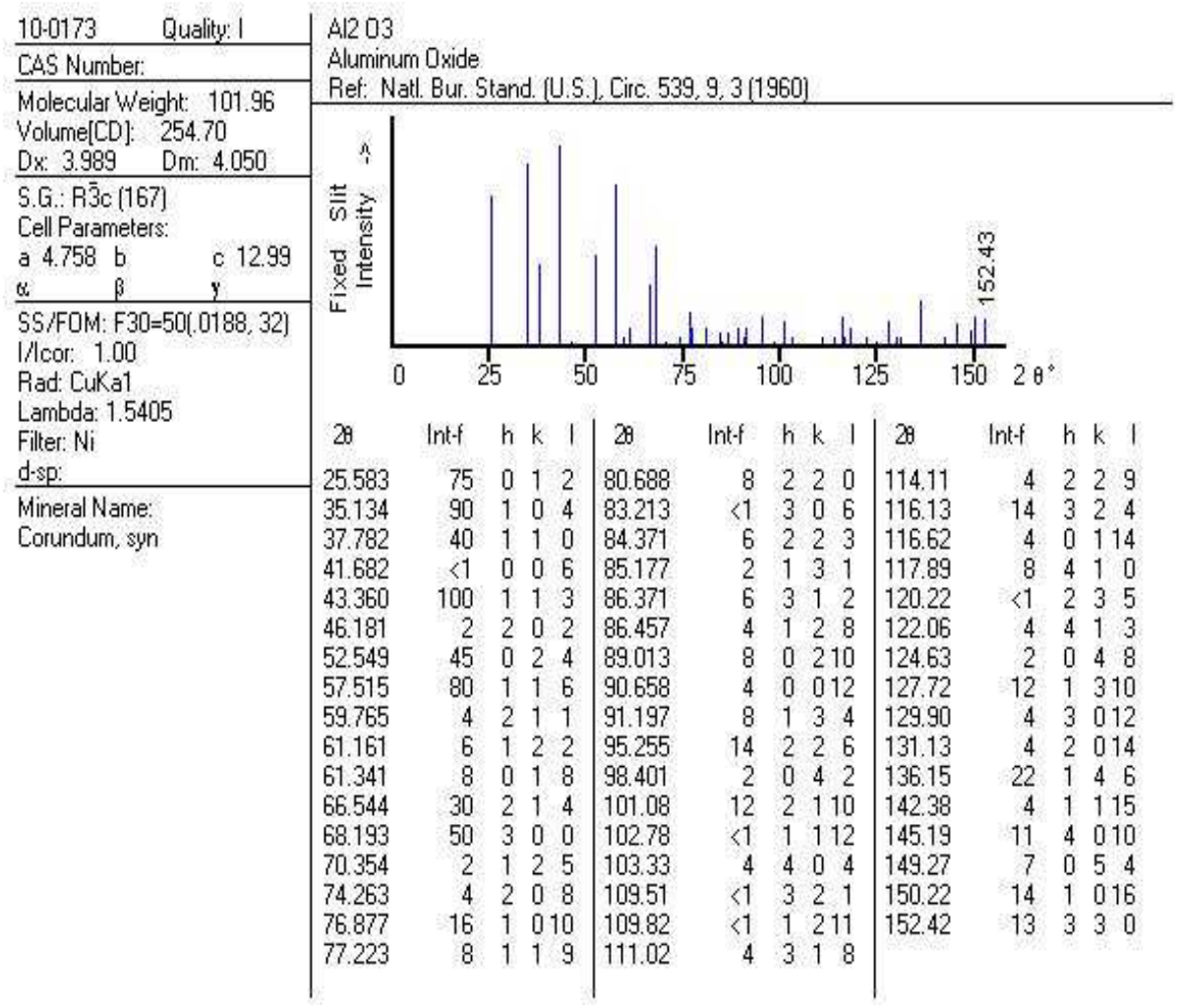




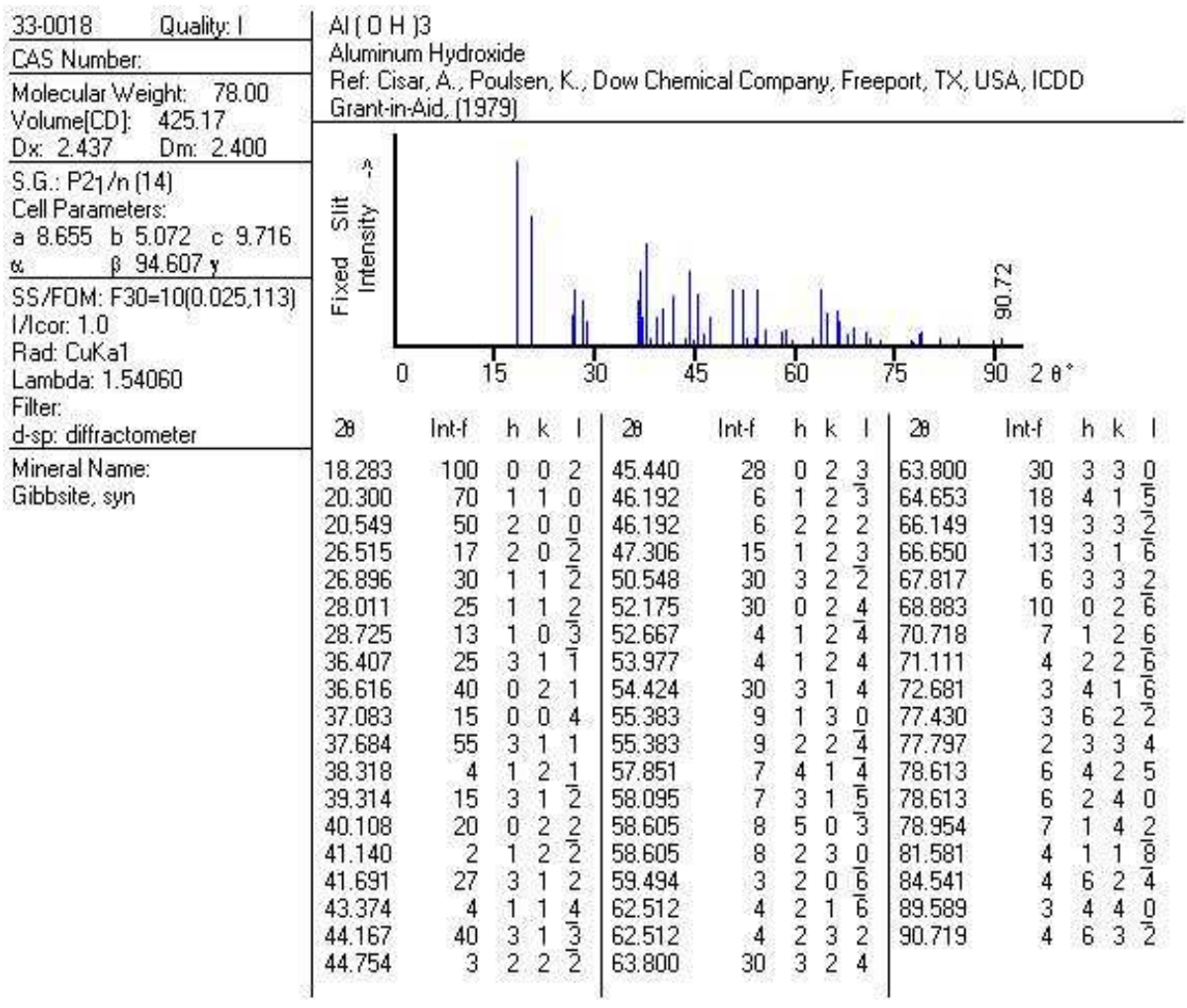

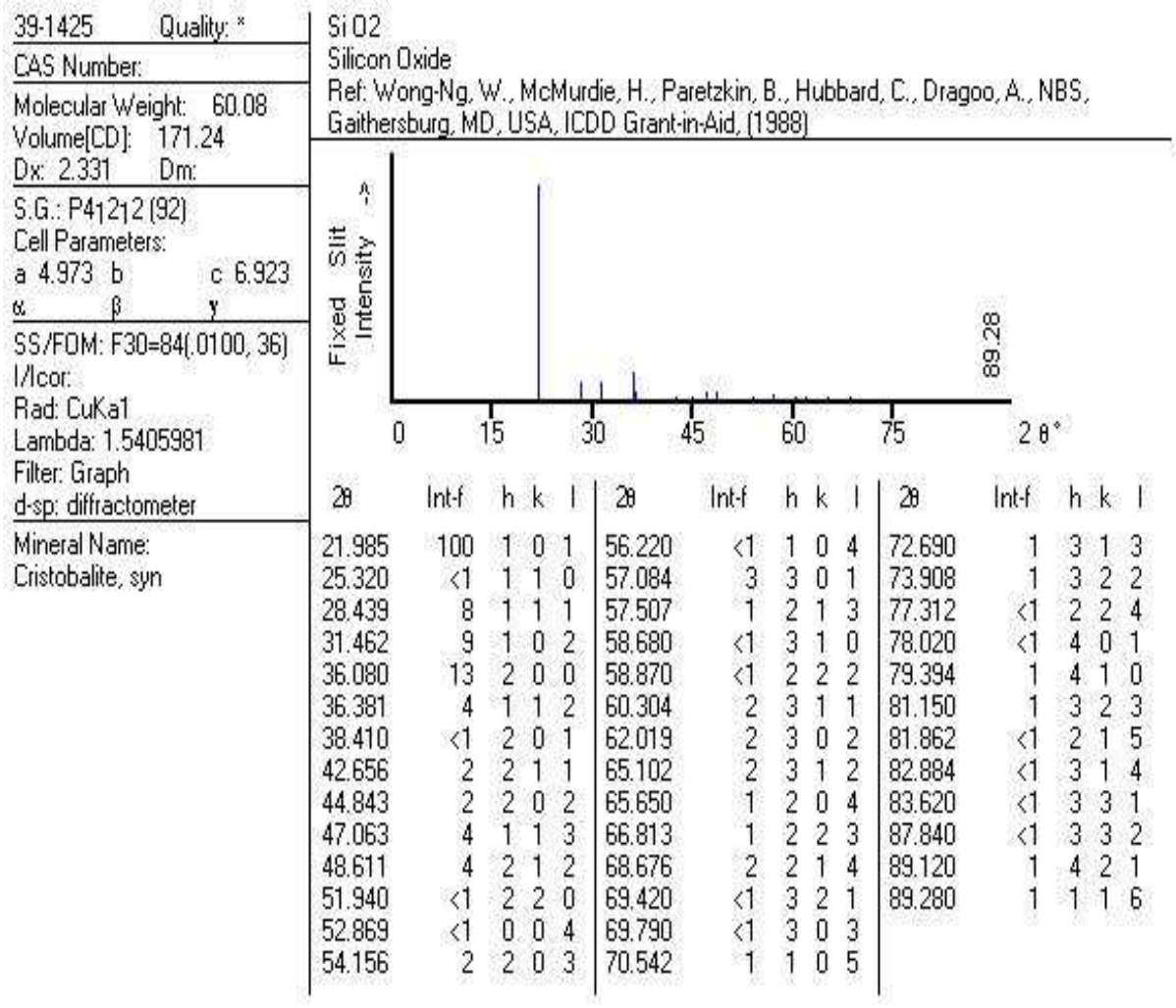




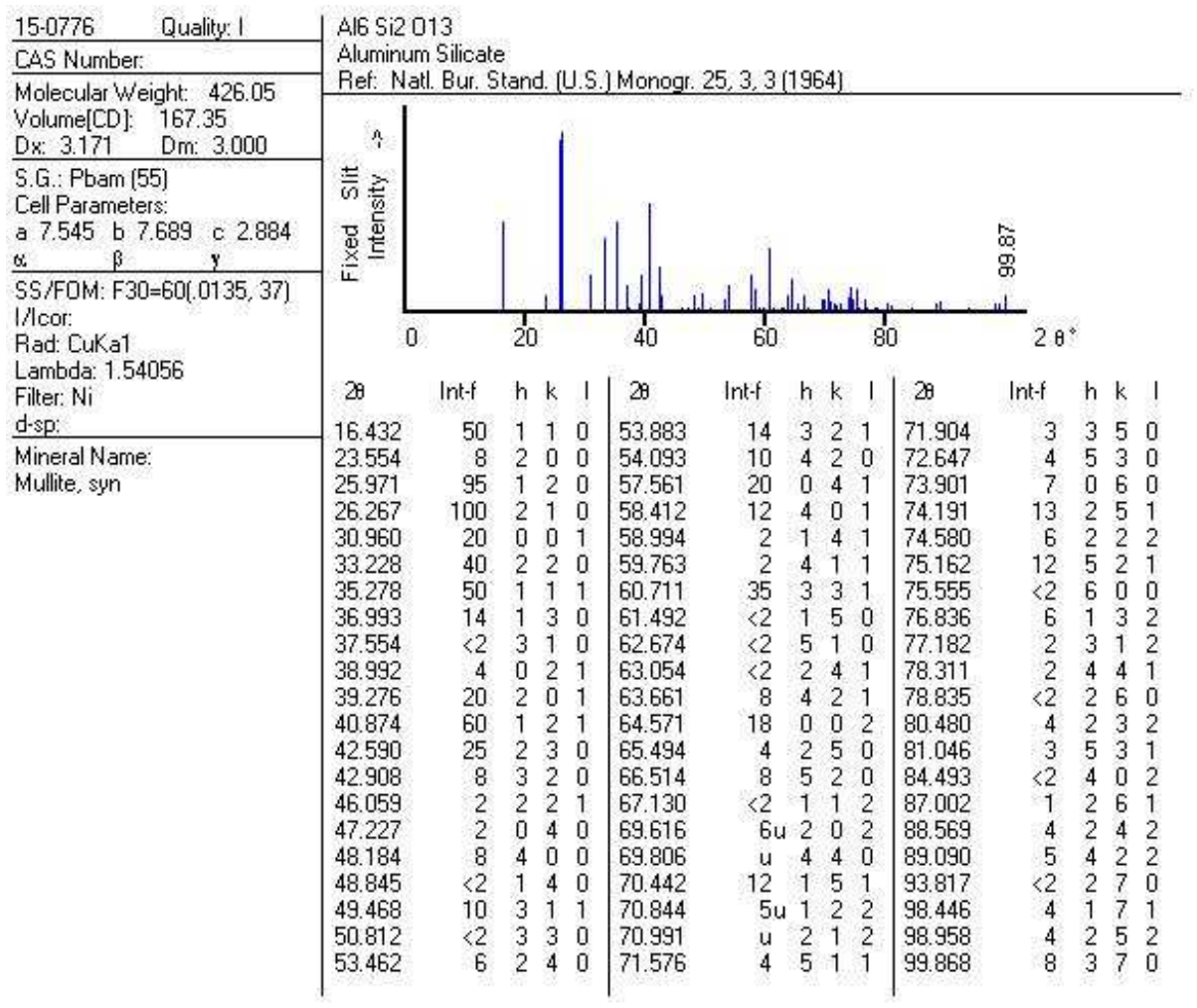




\section{APÉNDICE II}

ÍNDICE DE SIGLAS Y ABREVIATURAS

\begin{tabular}{|c|c|}
\hline ATD & Análisis Térmico Diferencial \\
\hline Atincar & Arcilla Tincar Súper \\
\hline AtinAcal & $\begin{array}{l}\text { Mezcla estequiométrica 3-2 de arcilla Tincar Súper más alúmina } \\
\text { calcinada. }\end{array}$ \\
\hline AtinAhid & $\begin{array}{l}\text { Mezcla estequiométrica 3-2 de arcilla Tincar Súper más alúmina } \\
\text { hidratada. }\end{array}$ \\
\hline Arioja & Arcilla La Rioja \\
\hline AriojAcal & Mezcla estequiométrica 3-2 de arcilla La Rioja más alúmina calcinada. \\
\hline AriojAhid & Mezcla estequiométrica 3-2 de arcilla La Rioja más alúmina hidratada. \\
\hline Cc80Acal & Mezcla estequiométrica 3-2 de caolín C80 mas alúmina calcinada. \\
\hline Cc80Ahid & Mezcla estequiométrica 3-2 de caolín C80 mas alúmina hidratada. \\
\hline CPE & Cono Pirométrico Equivalente. \\
\hline DRX & Difracción de Rayos X \\
\hline E1 & Módulo de Elasticidad Dinámico sin choque térmico \\
\hline E2 & Módulo de Elasticidad Dinámico después del choque térmico \\
\hline IP & Índice de Plasticidad \\
\hline LL & Límite Líquido \\
\hline LP & Límite Plásticoํㅜ \\
\hline MEB & Microscopía Electrónica de Barrido. \\
\hline MOR1 & Módulo de Rotura a la Flexión sin choque térmico \\
\hline MOR2 & Módulo de Rotura a la Flexión después del choque térmico \\
\hline $\mathbf{p} / \mathbf{p}$ & Porcentaje en peso \\
\hline SEM & Scanning Electron Microscopy \\
\hline TG & Termogravimetría \\
\hline 3-2 & $3 \mathrm{Al}_{2} \mathrm{O}_{3} \cdot 2 \mathrm{SiO}_{2}$ \\
\hline
\end{tabular}


"Solo conseguirás llegar al final de tu camino si obedeces tu ritmo personal. Puede que tardes más que otros o tengas que avanzar solo, pero es necesario respetar tu propio rítmo. Cuando percibas esto, quizá to apliques a todo lo que tienes que hacer en la vida". Paulo Coelho. 